UNIVERSIDADE DE SÃO PAULO

INSTITUTO DE GEOCIÊNCIAS

\title{
PROCESSOS DE ACRESÇÃO E RETRABALHAMENTO CONTINENTAL NO EMBASAMENTO DO ORÓGENO BRASÍLIA MERIDIONAL
}

\author{
Caue Rodrigues Cioffi
}

Orientador: Prof. Dr. Mario da Costa Campos Neto

\section{TESE DE DOUTORAMENTO}

Programa de Pós-graduação em Mineralogia e Petrologia

São Paulo

2016 
Autorizo a reprodução e divulgação total ou parcial deste trabalho, por qualquer meio convencional ou eletrônico, para fins de estudo e pesquisa, desde que citada a fonte.

Ficha catalográfica preparada pelo Serviço de Biblioteca e Documentação do Instituto de Geociências da Universidade de São Paulo

Cioffi, Caue Rodrigues

Processos de acresção e retrabalhamento continental no embasamento do Orógeno Brasília meridional. - São Paulo, 2016.

198 p. : il.

Tese (Doutorado) : IGc/USP

Orient.: Campos Neto, Mario da Costa

1. Orógeno Brasília 2. Acresção crustal 3. Paleoproterozóico 4. Complexo Pouso Alegre 5. Complexos arqueanos I. Título 
Para Brenda e Manuela,

por todos momentos vividos ao longo desse trabalho. 


\section{Agradecimentos}

A FAPESP pelo financiamento dessa pesquisa através do projeto de auxílio a pesquisa (2013/13530-8) e das bolsas de doutorado no pais (2012/24933-3) e estágio de pesquisa no exterior (2014/05881-8). A CAPES pela bolsa no primeiro ano do doutorado. Ao orientador dessa tese, professor Mario da Costa Campos Neto, tanto pelo suporte durante o desenvolvimento desse projeto, quanto por todos os anos de trabalho conjunto no Orógeno Brasília meridional. Ao professor Andreas Möller, supervisor do estágio de pesquisa no exterior, por todo o apoio durante a estadia na Universidade do Kansas e por todo conhecimento transmitido. Agradecimentos especiais são concedidos a Brenda Rocha por todo companheirismo e pela participação direta nessa pesquisa. Ao professor Renato Moraes e ao geólogo Rafael Bittencourt Lima pelo apoio nos trabalhos de campo. Ao Vasco Loios pelo suporte durante a separação mineral. À Josh Feldman e Heather Shinogle pela ajuda na obtenção das imagens de catodoluminescência e elétrons retroespalhados. À Maggie Sochko e Solange Souza pelo auxílio com as análises de LA-ICP-MS. Ao Marcos Mansueto e Leandro de Moraes pelo apoio durante as análises de microssonda eletrônica. A minha família, em especial meus pais (Marisa e Paulo) e minha irmã (Barbara), por todo o apoio durante essa jornada acadêmica. Por fim, gostaria de agradecer o Instituto de Geociências - USP, incluindo professores, funcionários e alunos, por toda a minha formação em geologia. 


\section{RESUMO}

O Orógeno Brasília meridional é interpretado como resultado da colisão ediacarana entre a margem ativa da placa Paranapanema e a margem passiva do paleocontinente São Francisco. Os processos colisionais geraram uma pilha de nappes sub-horizontais com cunha orogênica mergulhando para sudoeste e transporte tectônico para leste-nordeste. Ortognaisses migmatíticos, arqueanos a paleoproterozóicos, que representam o embasamento do orógeno, afloram em uma janela tectônica, de orientação nordeste-sudoeste com pelo menos 350 quilômetros de extensão por aproximadamente 15 a 75 quilômetros de largura, que divide os dois lobos da Nappe Socorro Guaxupé. Esses ortognaisses, que são o objeto de estudo dessa tese, podem ser divididos em dois domínios tectônicos principais: (1) um domínio paleoproterozóico representado pelo Complexo Pouso Alegre e (2) um domínio arqueano representado pelos complexos Amparo, Serra Negra, Heliodora e Minduri.

O Complexo Pouso Alegre é constituído predominantemente por ortognaisses migmatíticos, de composição tonalítica a granodiorítica, com idades de cristalização dos protólitos ígneos entre 2,15 e 2,08 Ga e assinaturas isotópicas de neodímio e háfnio juvenis. As assinaturas geoquímicas indicam ambientes de arco continental ou arco oceânico evoluído como possíveis contextos tectônicos. No presente trabalho, o Complexo Pouso Alegre é interpretado como a continuação orogênica do sistema de arcos do Cinturão Mineiro. O Complexo Pouso Alegre em conjunto com as suítes juvenis do Cinturão Mineiro representa um importante evento de geração de crosta continental, na borda sul do paleocontinente São Francisco, entre 2,35 e 2,08 Ga, durante um período considerado, globalmente, de baixa preservação de rochas juvenis. Portanto, os dados apresentados nessa tese reforçam a ideia de que o registro global de rochas juvenis e consequentemente modelos de preservação da crosta continental e aglomeração dos supercontinentes estão enviesados devido à baixa amostragem na América do Sul.

Os complexos arqueanos do embasamento do Orógeno Brasília meridional investigados nessa tese apresentam um período bem definido de magmatismo do tipo TTG entre 2,96 e 3,00 Ga. Magmatismo granítico a aproximadamente 2,76 Ga marca a transição entre magmatismo do tipo TTG e magmatismo granítico de alto potássio na área de estudo. As idades obtidas para o magmatismo meso-arqueano estão dentro do hiato de idades, sugerido na literatura, para a crosta arqueana da porção sul do cráton do São Francisco e indica que esses complexos são exóticos ao cráton do São Francisco. Esses complexos estão separados da crosta arqueana do cráton do São Francisco pelo sistema de arcos paleoproterozóicos, representado pelo Complexo Pouso Alegre e Cinturão Mineiro. Esses complexos arqueanos são interpretados como microntinentes acrescionados a borda sul do cráton do São Francisco, provavelmente durante o Paleoproterozóico, após o desenvolvimento das suítes do Complexo Pouso Alegre.

Os eventos colisionais neoproterozóicos foram responsáveis por importante deformação e metamorfismo em fácies anfibolito superior com fusão parcial associada. A presença de leucossomas tonalíticos com hornblenda peritética evidencia processos de fusão parcial com influxo de água. Condições máximas de metamorfismo obtidas para o Complexo Pouso Alegre por termobarometria THERMOCALC average $P$-T são de aproximadamente $670^{\circ} \mathrm{C}$ e $9.5 \mathrm{kbar}$. Esses dados são corroborados por termometria $\mathrm{Zr}$ na titanita que fornece temperaturas médias de $700^{\circ} \mathrm{C}$ para uma pressão estimada de 9 kbar. Geocronologia U-Pb em zircão e titanita estabelece condições máximas de metamorfismo entre aproximadamente 620 e $616 \mathrm{Ma}$. Bordas recristalizadas de cristais de titanita e leucogranitos intrusivos apresentam idade de $607 \mathrm{Ma}$, que é interpretada como a idade da descompressão pós-pico metamórfico, associada a exumação do Complexo Pouso Alegre. 


\begin{abstract}
The Southern Brasilia Orogen has been interpreted as the result of the Ediacaran collision between the active margin of the Paranapanema plate and the passive margin of the São Francisco paleocontinent. The collision generated a pile of sub-horizontal nappes with a southwest-dipping tectonic wedge and tectonic transport towards the east-northeast. Archean and Paleoproterozoic migmatitic orthogneisses, that represent the orogen basement, occur in a NE-SW trending tectonic window between the two domains of the Socorro Guaxupé Nappe. This window is approximately $350 \mathrm{~km}$ long and $15-75 \mathrm{~km}$ wide. These orthogneisses can be divided into two main tectonic domains: (1) a Paleoproterozoic domain represented by the Pouso Alegre Complex and (2) an Archean domain that comprises the Amparo, Serra Negra, Heliodora and Minduri complexes.
\end{abstract}

The Pouso Alegre Complex is comprised mainly of migmatitic orthogneisses of tonalitic to granodioritic composition with igneous crystallization ages from 2.15 to $2.08 \mathrm{Ga}$ and juvenile isotopic signatures ( $\mathrm{Nd}-\mathrm{Hf})$. The geochemical signatures suggest a continental arc margin or an evolved accreted oceanic arc as the favored tectonic setting for the Pouso Alegre Complex. The Pouso Alegre Complex is interpreted as the orogenic counterpart of the Mineiro Belt arc system. The Pouso Alegre Complex and the juvenile suites of the Mineiro Belt represent a major continental crust generation event at the southern edge of the São Francisco paleocontinent, between 2.35 and $2.08 \mathrm{Ga}$, during a period considered to have relatively low preservation rates of juvenile rocks on a global scale. Therefore, the data presented in this thesis supports the idea that there is a bias in the juvenile rock record and consequently in the crust preservation models because of the small dataset for South America.

The Archean complexes in the basement of the southern Brasilia Orogen show a well-defined period of TTG-type magmatism between 2.96 and $3.00 \mathrm{Ga}$. An additional period of Neoarchean high-K granitoid magmatism at ca. $2.76 \mathrm{Ga}$ is interpreted to mark the transition from TTG-type to high-K granitoid magmatism in the area. The Mesoarchean igneous crystallization ages presented in this study lie within the southern São Francisco craton "magmatic gap" and suggest that these Archean complexes are exotic to the Archean crust of the São Francisco craton. These complexes are separated from the São Francisco craton Archean crust by the Paleoproterozoic Pouso Alegre Complex / Mineiro Belt arc system. These Archean complexes are interpreted as Archean microcontinents that were accreted to the southern São Francisco paleocontinent. The timing of accretion is not well constrained but most likely occurring during the Paleoproterozoic after development of the Pouso Alegre Complex arc-related suites.

The Neoproterozoic collisional events were responsible for intense deformation and metamorphism in upper amphibolite facies associated with partial melting. The presence of tonalitic leucosomes with peritectic hornblende suggests the occurrence of water-fluxed melting reactions. Maximum P-T conditions of $\mathrm{ca} .670^{\circ} \mathrm{C}$ and $9.5 \mathrm{kbar}$ were obtained by THERMOCALC average P-T thermobarometry for the Pouso Alegre Complex. These results are in good agreement with the average temperatures obtained by $\mathrm{Zr}$-in-titanite thermometry of $\mathrm{ca} .700^{\circ} \mathrm{C}$. Zircon and titanite U-Pb geochronology constrain the age of the upper amphibolite facies metamorphism between 620 and $616 \mathrm{Ma}$. Titanite recrystallized rims and intrusive leucogranites have ages of ca. $607 \mathrm{Ma}$ that are interpreted as the age of the post-metamorphic peak decompression related to the exhumation of the Pouso Alegre Complex. 


\section{Sumário}

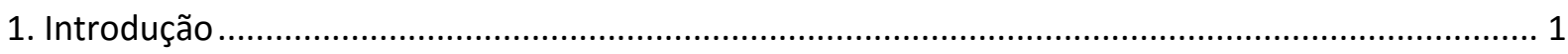

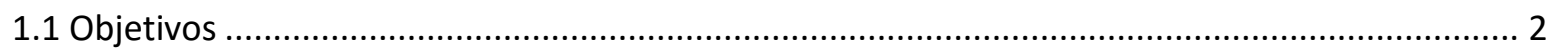

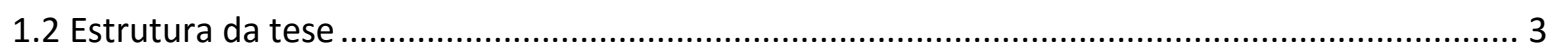

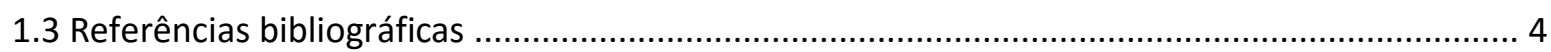

2. Revisão bibliográfica sobre a temática abordada e ferramentas utilizadas ...............................6 6

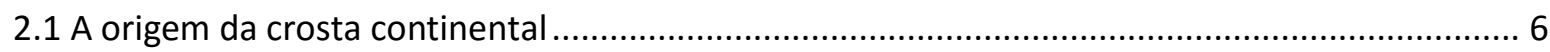

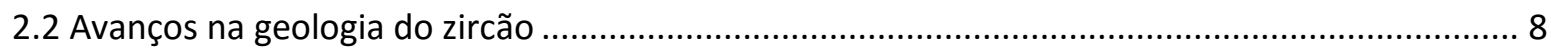

2.3 Isótopos de neodímio e háfnio aplicados a estudos sobre origem e evolução crustal ............. 10

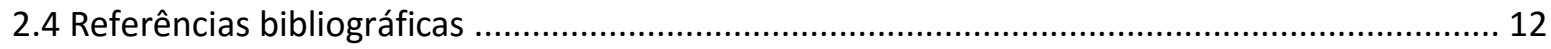

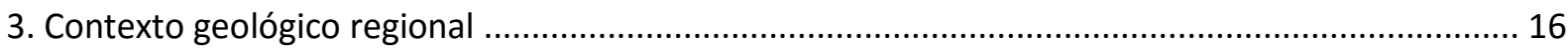

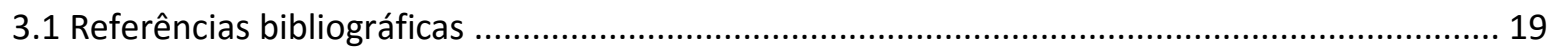

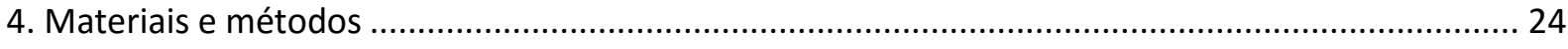

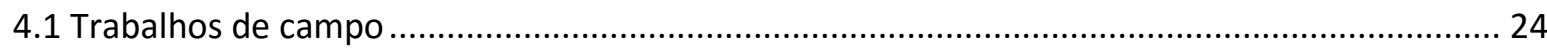

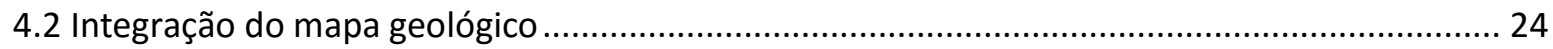

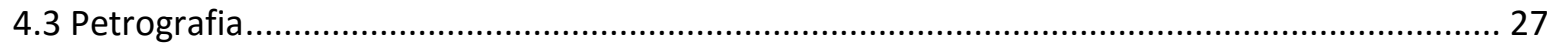

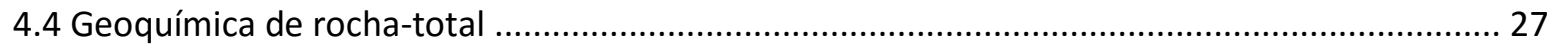

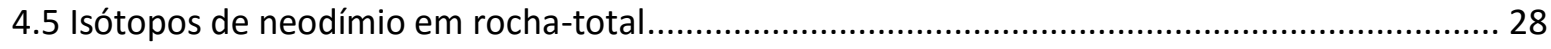

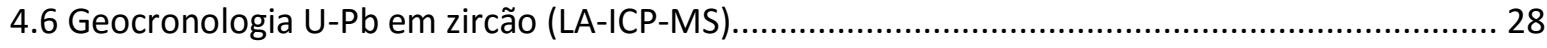

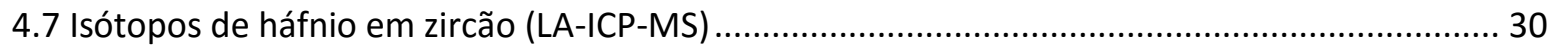

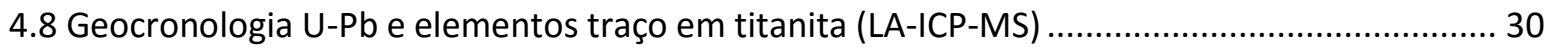

4.9 Análises minerais por microssonda eletrônica ............................................................ 31

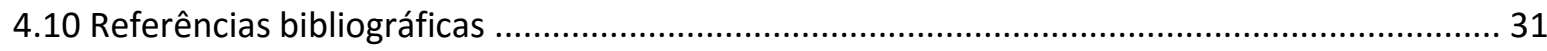

5. O Complexo Pouso Alegre: eventos paleoproterozóicos de geração de crosta continental no embasamento do Orógeno Brasília meridional ........................................................................ 34

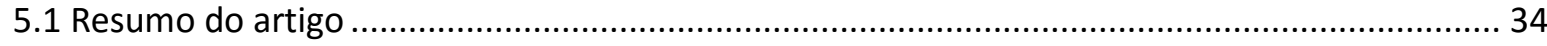

6. Os complexos arqueanos: microcontinentes acrescionados ao paleocontinente São Francisco..... 36

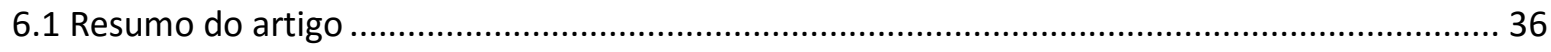

7. O retrabalhamento neoproterozóico do Complexo Pouso Alegre .............................................. 38

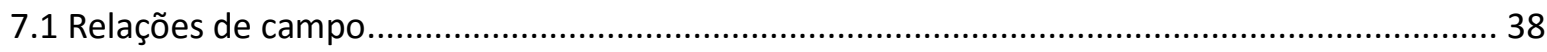

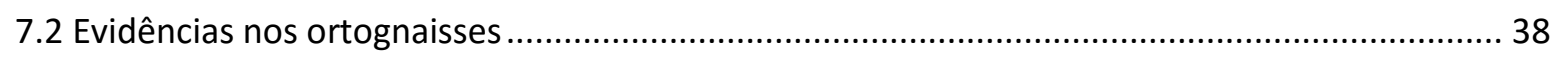

7.2.1 Descrição das amostras de ortognaisses analisadas ................................................ 41

7.2.1.1 Amostras 1D e 1E (ortognaisses tonalíticos) .................................................... 41

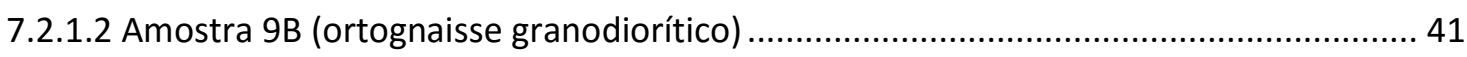

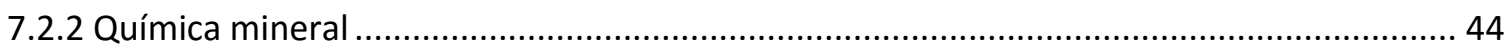

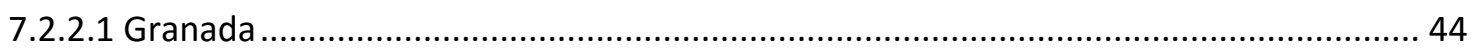




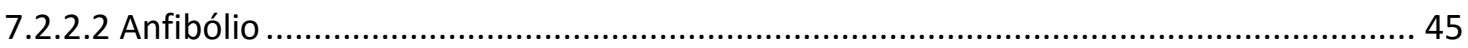

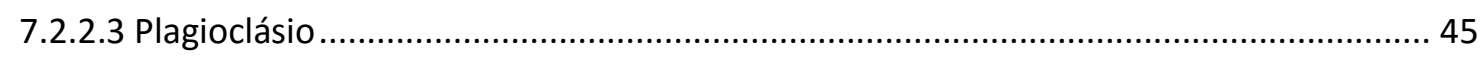

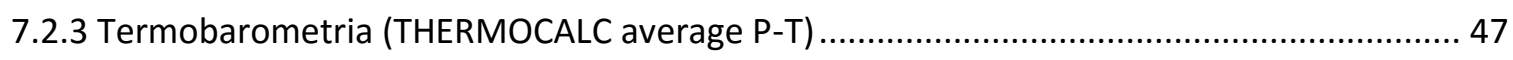

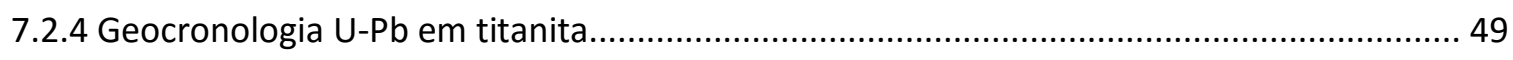

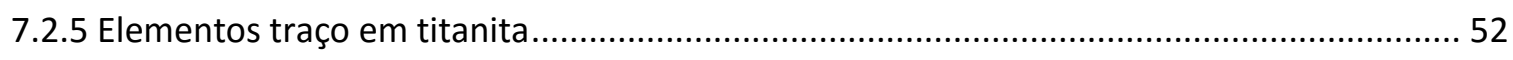

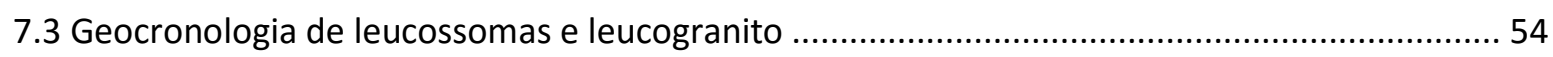

7.4 Idade e condições P-T do metamorfismo no Complexo Pouso Alegre ....................................55

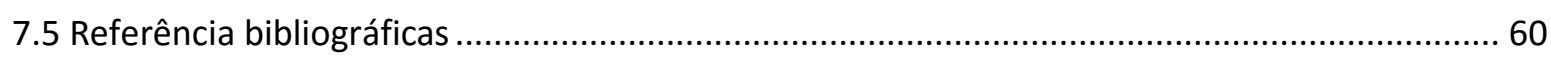

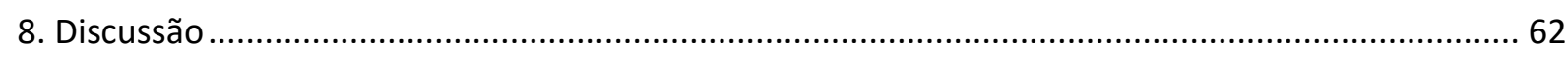

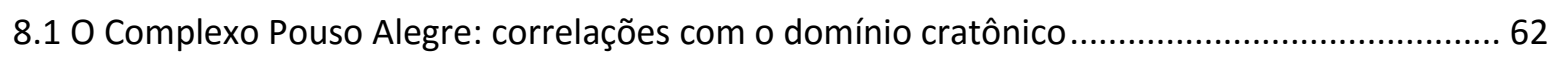

8.2 Eventos de geração crustal paleoproterozóicos e suas implicações para modelos de

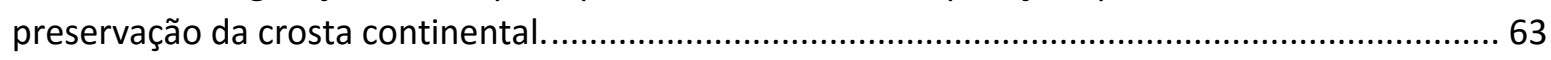

8.3 Ambientes tectônicos do Complexo Pouso Alegre .................................................................6. 64

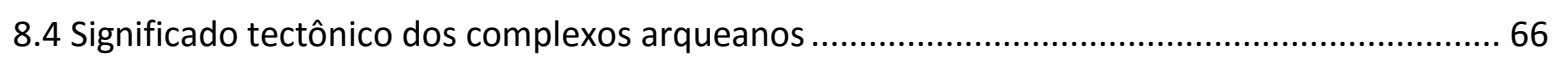

8.50 retrabalhamento neoproterozóico do Complexo Pouso Alegre: implicações para a evolução

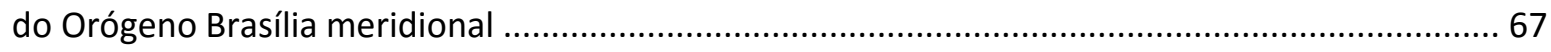

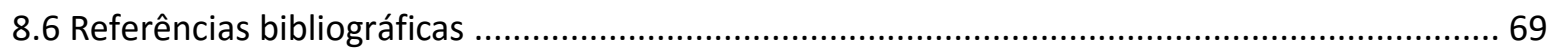

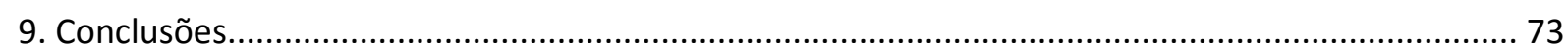

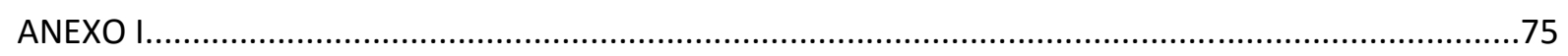

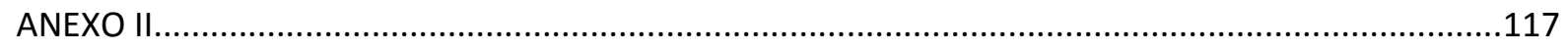

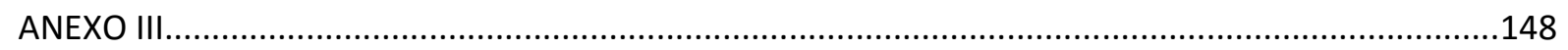

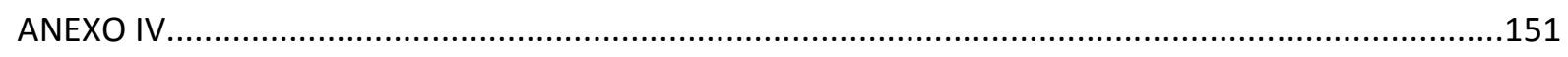

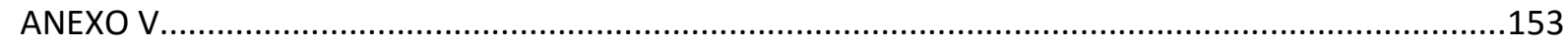

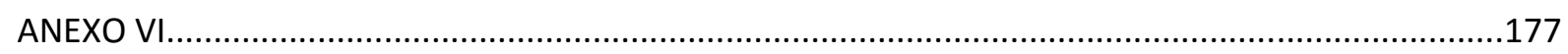

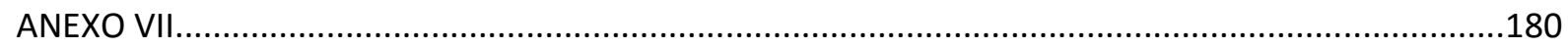

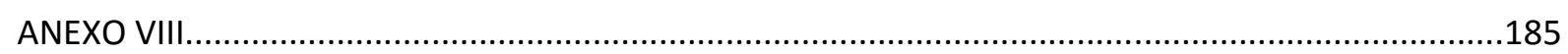

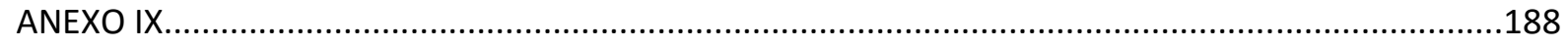




\section{Introdução}

A presente tese é resultado de um estudo integrado de geocronologia, geoquímica isotópica, geoquímica elemental e química mineral em rochas ortoderivadas que constituem o embasamento do Orógeno Brasília meridional. Essas rochas são principalmente ortognaisses migmatíticos, arqueanos a paleoproterozóicos, que afloram em uma janela estrutural, de orientação nordeste-sudoeste com pelo menos 350 quilômetros de extensão, entre os estados de São Paulo e Minas Gerais. Apesar da proximidade com grandes centros urbanos do sudeste brasileiro, o embasamento arqueano a paleoproterozóico do Orógeno Brasília meridional é extremamente carente de estudos geocronológicos e geoquímicos, especialmente estudos com aplicação de técnicas $\mathrm{U}-\mathrm{Pb}$ in-situ, como laser ablation (LA)-ICP-MS. Praticamente todos os dados apresentados na literatura para as rochas ortoderivadas do embasamento do Orógeno Brasília meridional foram gerados através de técnicas que envolvem a dissolução das amostras (ID-TIMS) (Fetter et al., 2001; Campos Neto et al., 2011). Portanto, a presente tese representa o primeiro estudo sistemático do embasamento do Orógeno Brasília meridional utilizando-se uma combinação de técnicas U-Pb in-situ (LA-ICP-MS), geoquímica isotópica ( $\mathrm{Nd}$ e Hf) e geoquímica elemental.

Essa abordagem integrada permitiu o entendimento de uma história prolongada, do Arqueano ao Neoproterozóico, associada ao crescimento e retrabalhamento do paleocontinente São Francisco. Essa história inclui os processos de crescimento do paleocontinente São Francisco durante o Paleoproterozóico e o retrabalhamento do mesmo durante os eventos orogênicos neoproterozóicos. O crescimento paleoproterozóico ocorreu através de geração de nova crosta continental em ambientes de arco instalados nas bordas do paleocontinente São Francisco e através de acresção de microcontinentes mais antigos. O retrabalhamento neoproterozóico, resultado da colisão entre o paleocontinente São Francisco e a placa Paranapanema (Brito Neves et al., 1999; Campos Neto, 2000; Trouw et al., 2000), foi responsável por intensa deformação e metamorfismo em fácies anfibolito superior e obliteração de grande parte das relações geológicas originais.

Ênfase é dada aos processos de geração de crosta continental paleoproterozóicos registrados no embasamento do Orógeno Brasília meridional. Essas suítes apresentam idades de cristalização entre 2,15 e 2,08 Ga, associadas a assinaturas isotópicas juvenis e indicam um importante período de geração de crosta continental. Diversas suítes juvenis com idades entre 2,35 e 2,13 Ga ocorrem na extremidade sul do cráton do São Francisco na região do Cinturão Mineiro (e.g. Noce et al., 2000; Teixeira et al., 2000, 2015; Ávila et al., 2010; Seixas et al., 2012, 2013). Essas suítes foram interpretadas como relacionadas a acresção de arcos oceânicos e arcos continentais a borda sul do paleocontinente São Francisco durante o Paleoproterozóico. Na presente tese, o embasamento paleoproterozóico do 
Orógeno Brasília meridional é interpretado como a continuação orogênica desse sistema de arcos. Portanto, o presente trabalho amplia consideravelmente a área e o intervalo de tempo dos eventos paleoproterozóicos de geração de crosta continental na borda sul do paleocontinente São Francisco. Esse período é considerado como de baixa preservação de rochas juvenis em escala global (e.g. Condie, 1998, 2000; Hawkesworth et al., 2009, 2013; Condie \& Aster, 2010), porém é aparentemente um período de alta geração e preservação de crosta continental na América do Sul e no oeste da África (e.g. Abouchami et al., 1990; Teixeira et al., 2015). Essas evidências sugerem que os modelos de preservação da crosta continental e consequentemente da aglomeração dos supercontinentes (e.g. Hawkesworth et al., 2009, 2013; Condie \& Aster, 2010) estão provavelmente enviesados devido à baixa amostragem na América do Sul e oeste da África.

\subsection{Objetivos}

- Datação dos eventos magmáticos, arqueanos a paleoproterozóicos, registrados nas rochas do embasamento do Orógeno Brasília meridional, através de análises U-Pb LA-ICP-MS em cristais de zircão, principalmente em núcleos preservados.

- Caracterização geoquímica e isotópica ( $\mathrm{Nd}$ em rocha-total; Hf em zircão) dos ortognaisses migmatíticos do embasamento do Orógeno Brasília meridional.

- Determinação da idade de retrabalhamento dessas rochas durante a orogenia neoproterozóica, através de análises U-Pb LA-ICP-MS em zircão, principalmente bordas recristalizadas e zircões provenientes de leucossomas e leucogranitos.

- Determinação das idades do evento metamórfico Neoproterozóico através de análises U-Pb LA-ICPMS em cristais de titanita.

- Caracterização das condições P-T as quais o embasamento foi submetido durante o retrabalhamento neoproterozóico, através termobarometria THERMOCALC average $P$-T e termometria Zr na titanita.

- Estabelecimento de um modelo de evolução tectônica, do Arqueano ao Neoproterozóico, para as rochas do embasamento do Orógeno Brasília meridional, através da combinação de dados de geoquímica elemental, U-Pb (zircão e titanita), Lu-Hf (zircão) e Sm-Nd (rocha-total). 


\subsection{Estrutura da tese}

Capítulo 1 (Introdução): apresenta a introdução da tese, justificativas, objetivos e forma de organização da mesma.

Capítulo 2 (Revisão bibliográfica sobre a temática abordada e ferramentas utilizadas): nesse capítulo são apresentados ao leitor os principais modelos sobre o crescimento da crosta continental ao longo do tempo e as principais ferramentas utilizadas na construção desses modelos.

Capítulo 3 (Contexto geológico regional): esse capítulo versa sobre o contexto geológico da área de estudo, no caso, o Orógeno Brasília meridional e a porção sul do cráton do São Francisco.

Capítulo 4 (Materiais e métodos): nesse capítulo são enumerados os métodos utilizados durante o desenvolvimento dessa pesquisa, incluindo detalhes sobre os procedimentos analíticos realizados.

Capítulo 5 (O Complexo Pouso Alegre: Eventos paleoproterozóicos de geração de crosta continental no embasamento do Orógeno Brasília meridional): esse capítulo apresenta novos dados de geocronologia $\mathrm{U}-\mathrm{Pb}$ em zircão, geoquímica elemental e isotópica ( $\mathrm{Nd}-\mathrm{Hf}$ ) para as rochas paleoproterozóicas com assinaturas isotópicas juvenis presentes no embasamento do Orógeno Brasília meridional. Os dados, interpretações e conclusões referentes a esse capítulo são apresentados de maneira integral no artigo em anexo (ANEXO I) (Paleoproterozoic continental crust generation events at 2.15 and $2.08 \mathrm{Ga}$ in the basement of the southern Brasilia Orogen, SE Brazil). Esse artigo foi publicado no periódico científico Precambrian Research.

Capítulo 6 (Os complexos arqueanos: microcontinentes acrescionados ao paleocontinente São Francisco): nesse capítulo são apresentados novos dados de geocronologia U-Pb em zircão, geoquímica elemental e isotópica ( $\mathrm{Nd}-\mathrm{Hf}$ ) para os complexos arqueanos do embasamento do Orógeno Brasília meridional. Os dados, interpretações e conclusões referentes a esse capítulo são apresentados de maneira integral no artigo em anexo (ANEXO II) (Tectonic significance of the Meso- to Neoarchean complexes in the basement of the southern Brasilia Orogen). Esse artigo foi submetido para publicação no periódico científico Precambrian Research.

Capítulo 7 (O retrabalhamento Neoproterozóico do Complexo Pouso Alegre): nesse capítulo são apresentados novos dados de geocronologia U-Pb em zircão e titanita e dados de termobarometria que são utilizados na tentativa de definição da idade e condições P-T do metamorfismo do embasamento durante os eventos colisionais neoproterozóicos.

Capítulo 8 (Discussão): discussão integrada dos resultados obtidos nessa tese e apresentados nos capítulos 5, 6 e 7.

Capítulo 9 (Conclusões): apresenta as conclusões e considerações finais da presente tese. 


\subsection{Referências bibliográficas}

Abouchami, W., Boher, M., Michard, A., Albarède, F., 1990. A major 2.1Ga event of mafic magmatism in West Africa - an early stage of crustal accretion. Journal of Geophysical Research: Solid Earth 95, 17605-17629.

Ávila, C.A., Teixeira, W., Cordani, U.G., Moura, C.A.V., Pereira, R.M., 2010. Rhyacian (2.23-2.20 Ga) juvenile accretion in the Southern São Francisco craton, Brazil: Geochemical and isotopic evidence from the Serrinha magmatic suite, Mineiro belt. Journal of South American Earth Sciences 29, 464-482.

Brito Neves, B.B., Campos Neto, M.C., Fuck, R.A., 1999. From Rodinia to western Gondwana: an approach to the Brasiliano-pan African cycle and orogenic collage. Episodes 22, 155-166.

Campos Neto, M.C., 2000. Orogenic Systems from southwestern Gondwana: an approach to Brasiliano-Pan African Cycle and orogenic collage in southeastern Brazil. In: Cordani, U.G., Milani, E.J., Thomaz Filho, A., Campos, D.A. (Eds.), Tectonic Evolution of South America. 31th International Geological Congress. Rio de Janeiro, Brazil, pp. 335-365.

Campos Neto, M.C., Basei, M.A.S., Janasi, V.A., Moraes, R., 2011. Orogen migration and tectonic setting of the Andrelândia Nappe System: An Ediacaran western Gondwana collage, south São Francisco craton. Journal of South American Earth Sciences 32, 393-406.

Condie, K.C., 1998. Episodic continental growth and supercontinents: a mantle avalanche connection? Earth and Planetary Sciences Letters 163, 97-108.

Condie, K.C., 2000. Episodic crustal growth models: afterthoughts and extensions. Tectonophysics 322, 153-162.

Condie, K.C., Aster, R.C., 2010. Episodic zircon age spectra of orogenic granitoids: The supercontinent connection and continental growth. Precambrian Research 180, 227-236.

Hawkesworth, C., Cawood, P.A., Kemp, T., Storey, C.D., Dhuime, B., 2009. A matter of preservation. Science $323,49-50$.

Hawkesworth, C., Cawood, P.A., Dhuime, B., 2013. Continental growth and the crustal record. Tectonophysics 609, 651-660.

Noce, C.M., Teixeira, W., Quéméneur, J.J.G., Martins, V.T.S., Bolzachini, E., 2000. Isotopic signatures of Paleoproterozoic granitoids from the Southern São Francisco Craton and implications for the evolution of the Transamazonian Orogeny. Journal of South American Earth Sciences 13, 225-239. 
Seixas, L.A.R., David, J., Stevenson, R., 2012. Geochemistry, Nd isotopes and U-Pb geochronology of a 2350 Ma TTG suite, Minas Gerais, Brazil: Implications for the crustal evolution of the southern São Francisco craton. Precambrian Research 196-197, 61-80.

Seixas, L.A.R., Bardintzeff, J-M., Stevenson, R., Bonin, B., 2013. Petrology of the high - Mg tonalites and dioritic enclaves of the ca. 2130 Ma Alto Maranhão suite: Evidence for a major juvenile crustal addition event during the Rhyacian orogenesis, Mineiro Belt, southeast Brazil. Precambrian Research 238, 1841.

Teixeira, W., Sabatè, P., Barbosa, J., Noce, C.M., Carneiro, M.A., 2000. Archean and Paleoproterozoic evolution of the São Francisco Craton, Brazil. In: Cordani, U.G., Milani, E.J., Thomaz Filho, A., Campos, D.A. (Eds.), Tectonic Evolution of South America. 31th International Geological Congress. Rio de Janeiro, Brazil, pp. 101-137.

Teixeira, W., Ávila, C.A., Dussin, I.A., Corrêa Neto, A.V., Bongiolo, E.M., Santos, J.O., Barbosa, N.S., 2015. A juvenile accretion episode $(2.35-2.32 \mathrm{Ga})$ in the Mineiro Belt and its role to the Minas accretionary orogeny: Zircon U-Pb-Hf and geochemical evidences. Precambrian Research 256, 148-169.

Trouw, R.A.J., Heilbron, M., Ribeiro, A., Paciullo, F., Valeriano, C.M., Almeida, J.C.H., Tupinambá, M., Andreis, R.R., 2000. The central segment of Ribeira belt. In: Cordani, U.G., Milani, E.J., Thomaz Filho, A., Campos, D.A. (Eds.), Tectonic Evolution of South America. 31th International Geological Congress. Rio de Janeiro, Brazil, pp. 287-310. 


\section{Revisão bibliográfica sobre a temática abordada e ferramentas utilizadas}

\subsection{A origem da crosta continental}

Evidências geoquímicas e geocronológicas indicam que a crosta continental não é produto dos processos iniciais de acresção do planeta Terra e foi gerada posteriormente. É amplamente aceito que a crosta continental foi extraída do manto terrestre e que ao contrário da crosta oceânica, ela dificilmente é reciclada no manto devido sua baixa densidade. Uma exceção é a reciclagem de produtos de erosão da crosta continental na forma de sedimentos. Os principais locais de geração recente de crosta continental são as margens destrutivas de placas tectônicas. No modelo generalizado (MacDonald et al., 2000), o anfibólio formado a partir da hidratação do fundo oceânico, na camada superior da placa em subducção, começa a desidratar a aproximadamente 50-60km de profundidade, liberando água na cunha mantélica. Essa hidratação resulta na formação de anfibólio nos peridotitos mantélicos. Esses anfibólio-peridotitos são então subductados junto com a placa oceânica até a profundidade de aproximadamente $110 \mathrm{~km}$, onde ocorre a quebra do anfibólio, liberando água para a cunha astenosférica, iniciando assim a fusão parcial. Nesse modelo, a principal fonte do magmatismo de arco é a cunha mantélica, porém outras fontes podem contribuir em maior ou menor proporção. Entre essas fontes podemos citar: a fase fluída, a placa em subducção e os sedimentos subductados. A fusão da placa em subducção é considerada por alguns autores (ex. Martin, 1999) como o processo gerador de adakitos, que seriam os correlatos modernos dos magmas do tipo TTG.

A definição de uma curva apropriada do crescimento da crosta continental (Fig. 2.1) vem sendo alvo de controvérsias nos últimos quarenta anos. Em 1969 Hurley \& Handy propuseram, com base na distribuição de idades das rochas crustais, que os continentes cresceram progressivamente com o tempo. Outra linha de pensamento foi exposta por Armstrong (1968) que sugere que todo o volume presente de crosta continental foi gerado próximo ao início da história do planeta e vem desde então sendo reciclado e recriado através da subducção de sedimentos. Compilações mais recentes defendem o crescimento progressivo da crosta continental (ex. Belousova et al., 2010; Dhuime et al., 2012). A estimativa do volume de crosta continental de diferentes idades seria o caminho obvio para a definição de um modelo apropriado de crescimento crustal, porém essa estimativa não é tão simples por duas razões. A primeira é que não podemos assumir que as idades dos continentes são as mesmas em superfície e em profundidade (Corfu, 1987) e a segunda é que o retrabalhamento da crosta antiga fará com que as idades observadas sejam mais novas do que são na realidade. $\mathrm{O}$ segundo problema tem sido contornado por estudos recentes através da utilização de métodos isotópicos robustos, como por exemplo, a associação de idades $\mathrm{U}-\mathrm{Pb}$ e idades modelo $\mathrm{Nd}$ e $\mathrm{Hf}$. 
Não existe registro no planeta Terra da existência de grandes volumes de crosta félsica associados ao início da história do planeta. Tarney e Jones (1994) alegam que seria difícil a geração de um grande volume de crosta, em um curto período de tempo, como o proposto na teoria de Armstrong (1968). Além disso, é extremamente rara a ocorrência de zircões do início do Arqueano (Nutman, 2001), sugerindo que a crosta félsica não era abundante durante esse período. Estudos isotópicos nos sistemas U-Th-Pb (Kramers \& Tolstikhin, 1997) e modelos baseados na evolução do Neodímio (Nagler \& Kramers, 1998) chegaram à conclusão de que no máximo $10 \%$ da massa crustal, existente atualmente, poderia ter existido em 4,4Ga. Todas essas evidências sustentam a teoria de crescimento progressivo da crosta continental. A variação dessa teoria defendida por Condie $(1998,2000)$ sugere um crescimento progressivo episódico da crosta continental. $\mathrm{O}$ autor defende que a distribuição das idades U-Pb das rochas crustais juvenis é episódica, com picos principais em 2,7, 1,9 e 1,2Ga, que representariam atividades de plumas mantélicas ativadas por avalanches de material subductado no manto. Outros autores como Stein \& Hofmann (1994) e Albarède (1998) também defendem a atuação de superplumas mantélicas na geração episódica de crosta continental.

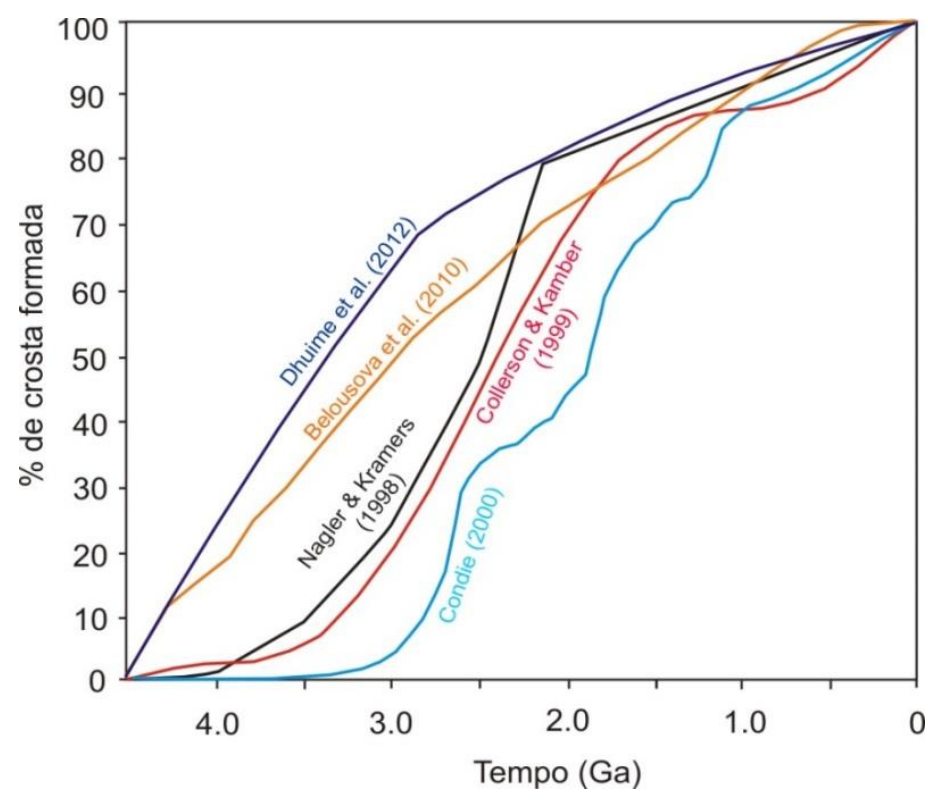

Figura 2.1. Curvas de crescimento da crosta continental baseadas na evolução do Nd no manto (Nagler \& Kramers, 1998), idades U-Pb de rochas crustais juvenis (Condie, 2000), razões Nb/U do manto empobrecido (Collerson \& Kamber, 1999), Isótopos de Háfnio em zircão (Belousova et al. 2010) e Isótopos de Háfnio e Oxigênio em zircão (Dhuime et al. 2012).

Estudos recentes baseados em isótopos de oxigênio e/ou háfnio (Belousova et al., 2010; Dhuime et al., 2012), sugerem um crescimento contínuo da crosta continental e estimam que de 60 a $75 \%$ da crosta continental foi extraída do manto no Arqueano, sendo que após esse período processos 
de retrabalhamento crustal predominaram. Para explicar como uma crosta continental com crescimento contínuo poderia gerar um registro episódico de rochas juvenis, Hawkesworth (2009, 2013) evocaram modelos de preservação crustal. Esses modelos alegam que a periocidade do registro de rochas juvenis é reflexo da variação de potencial de preservação de rochas em diferentes ambientes tectônicos, sendo que um maior potencial de preservação pode estar associado a aglomeração de supercontinentes. Para esses modelos, os períodos entre os picos do registro juvenil são considerados períodos de baixa preservação de crosta juvenil e não necessariamente períodos de baixa geração de rochas juvenis com sugerido por Condie $(1998,2000)$.

Em todas as curvas apresentadas na figura 2.1, o período pré-2,0Ga é o de maior taxa de crescimento da crosta continental, sendo atribuído a esse período a geração de aproximadamente $80 \%$ da crosta continental existente no planeta atualmente. Portanto, a aplicação de métodos isotópicos no estudo de rochas magmáticas, arqueanas a paleoproterozóicas, pode fornecer importantes informações sobre a origem e evolução da crosta continental. $O$ advento de técnicas de análise isotópicas in-situ (ex. Microssonda iônica, LA-ICP-MS) gerou um grande avanço na geocronologia do zircão e com isso no entendimento dos processos de geração e evolução crustal. As idades U-Pb obtidas nos diferentes domínios dos cristais de zircão podem ser relacionadas a diferentes eventos geológicos. A natureza desses eventos, sejam eles de geração crustal a partir de uma fonte mantélica ou de diferenciação crustal a partir de uma crosta mais antiga, pode ser definida através da associação das idades U-Pb com dados isotópicos de Háfnio em zircão e de Neodímio em rocha total.

\subsection{Avanços na geologia do zircão}

Os avanços nas técnicas de análise isotópica in-situ, como a microssonda iônica e LA-ICP-MS, proporcionaram uma verdadeira revolução na geocronologia do zircão. Essas técnicas possibilitam a análise das diferentes porções de cristais individuais de zircão e consequentemente o reconhecimento de núcleos herdados, sobrecrescimentos mais jovens e zonas de alteração (ex. Gerdes \& Zeh, 2006). A alta resolução espacial dessas técnicas permite o estudo de cristais de zircão com estruturas internas complexas (Corfu et al., 2003) e, portanto, permite a investigação de rochas com história geológica policíclica.

Uma das grandes vantagens do zircão é sua capacidade de preservação durante eventos magmáticos, metamórficos e erosionais que destruiriam a maioria dos minerais. Os eventos de formação de zircão têm a tendência a preservar-se como zonas estruturais distintas em grãos de zircão pré-existentes. Devido a essa característica, normalmente o zircão é constituído por zonas distintas, cada uma preservando um período particular de formação ou consumo (Corfu et al., 2003). A melhor 
resolução das estruturas internas dos grãos de zircão é obtida por imagens de catodoluminescência e de elétrons retroespalhados. Os diferentes padrões de estruturas internas podem ser associados a diferentes eventos geológicos da história da rocha. Como por exemplo, padrões internos com zoneamento concêntrico são normalmente associados a eventos de cristalização magmática, enquanto que bordas recristalizadas podem ser associadas a eventos metamórficos de média a alta temperatura. O valor dessas informações é muito maior quando associadas a dados de geoquímica elemental e isotópica dos diferentes domínios dos cristais.

Devido aos altos teores de Urânio e sua ocorrência generalizada em rochas crustais, o zircão tornou-se o principal mineral utilizado para datações no sistema U-Pb. Outro fator importante na escolha do zircão como geocronômetro são suas altas temperaturas de fechamento do sistema U-Pb, que permitem que o sistema permaneça fechado, mesmo em eventos de alto grau metamórfico com fusão parcial associada. As primeiras datações precisas do sistema U-Pb em zircão foram realizadas por ID-TIMS (Isotope Dilution Thermal lonization Mass Spectrometry) na década de 1950 (Tilton et al., 1955; Wetherhill, 1956). Com a evolução da técnica ao longo do tempo, tornou-se possível a determinação das composições isotópicas de $\mathrm{U}$ e $\mathrm{Pb}$ em quantidades cada vez menores de zircão. $\mathrm{Na}$ década de 1980 pesquisadores da Australian National University desenvolveram o SHRIMP (Sensitive High Resolution Ion Microprobe) e aplicaram a técnica pela primeira vez na geocronologia do zircão (Compston et al., 1984). A técnica permitiu a determinação das razões isotópicas em pequenas porções de cristais individuais e mostrou-se uma ferramenta poderosa para a datação de zircões com estruturas internas complexas. Datações in-situ por microssonda iônica são capazes de atingir precisão analítica apenas uma ordem de magnitude inferior às datações por ID-TIMS. Os grandes obstáculos para o uso da microssonda iônica são o alto custo do equipamento e a escassez desse tipo de instrumento em laboratórios de geocronologia pelo mundo.

Na década de 1990 surgiram as técnicas de LA-ICP-MS (Laser Ablation Inductively Coupled Plasma) que rapidamente tornaram-se importantes ferramentas analíticas para determinação de elementos traços em amostras geológicas (Jackson et al., 1992). Desde a metade da década de 1990, a técnica tem sido aplicada amplamente na datação U-Pb em zircão (ex. Hirata \& Nesbitt, 1995; Li et al., 2001; Tiepolo et al., 2003; Tiepolo, 2003; Frei \& Gerdes, 2009; Gerdes \& Zeh, 2009). A precisão e acurácia da técnica são semelhantes e em alguns casos até mesmo superiores aos obtidos por microssonda iônica (Gerdes \& Zeh, 2006). O uso crescente das técnicas de LA-ICP-MS provém do fato de ser a técnica de datação U-Pb mais rápida, com custos mais baixos e com maior disponibilidade em laboratórios de geocronologia pelo mundo (Jackson et al., 2004).

Além dos altos conteúdos de urânio, o zircão também é hospedeiro de frações significativas dos conteúdos totais de Th, Hf e elementos terras raras (Bea, 1996; O'Hara et al., 2001). Nos últimos anos ocorreu um interesse crescente na composição do zircão, especialmente elementos traço, na 
tentativa de se compreender melhor o significado de múltiplas idades obtidas por análises U-Pb insitu. Interpretações petrogenéticas podem ser obtidas através de dados geoquímicos de zircão, como por exemplo, segundo Hoskin \& Ireland (2000), zircões com afinidade mantélica diferenciam-se de zircões crustais por apresentarem conteúdos totais de elementos terras raras mais baixos e padrões menos fracionados. Os mesmos autores não indentificaram diferenças significativas nos padrões de elementos terras raras, dentro do grupo das rochas crustais, apesar da ampla variedade de litotipos. Outra característica importante do zircão é que sua estrutura cristalina pode acomodar uma quantidade significativa de háfnio (>1\% wt), porém apenas quantidades mínimas de lutécio ( $1 \mathrm{ppm})$. Portanto, as composições isotópicas iniciais de Háfnio do magma, no momento de cristalização do zircão, podem ser obtidas com grande precisão através de técnicas LA-ICP-MS.

\subsection{Isótopos de neodímio e háfnio aplicados a estudos sobre origem e evolução crustal}

Como discutido anteriormente, uma das questões fundamentais para o entendimento da origem e evolução da crosta terrestre, é a definição das idades de formação crustal. Essas idades representam o momento em que rochas crustais foram extraídas de materiais mais densos e primitivos provenientes do manto terrestre. Essas idades, diferentemente das idades de cristalização ou metamorfismo, são cruciais para a compreensão sobre o crescimento da massa dos continentes ao longo do tempo. O sistema isotópico $\mathrm{Sm} / \mathrm{Nd}$ é particularmente apropriado para a definição de idades de extração do manto, pois o principal fracionamento entre Sm e Nd ocorre durante a extração do magma a partir de fontes mantélicas, sendo que processos crustais, incluindo metamorfismo de alto grau e fusão parcial, geralmente tem pouca influência sobre o sistema (DePaolo, 1988).

Uma das principais aplicações do método $\mathrm{Sm} / \mathrm{Nd}$ em rocha total nos estudos sobre evolução crustal é o cálculo de idades modelo de extração mantélica. DePaolo \& Wasserburg (1976) em um trabalho pioneiro sobre isótopos de Neodímio em rochas terrestres desenvolveram uma notação onde as razões iniciais de ${ }^{143} \mathrm{Nd} /{ }^{144} \mathrm{Nd}$ podem ser representadas em relação a sua divergência com a curva de evolução do reservatório CHUR (chondritic uniform reservoir) e denominaram a notação de $\varepsilon_{N d}$. Matematicamente essa notação é definida como:

$$
\in N d(t)=\left(\frac{\left(\frac{143 N d}{144 N d}\right) \operatorname{amostra}(t)}{\left(\frac{143 N d}{144 N d}\right) \operatorname{CHUR}(t)}-1\right) \times 10^{4}
$$


DePaolo \& Wasserburg (1979) alegaram que a crosta seria derivada de reservatórios mantélicos com $\varepsilon_{\mathrm{Nd}}=0$ e esse modelo foi utilizado para o cálculo de idades de extração mantélicas denominadas TCHur. DePaolo (1981), em um trabalho com rochas do embasamento proterozóico do Colorado Front Range, sugeriu que rochas crustais seriam na verdade provenientes de um reservatório mantélico empobrecido em elementos imcompatíveis e com $\varepsilon_{\mathrm{Nd}}>0$. Nesse trabalho, o autor propõe uma curva para a evolução do Neodímio no manto empobrecido (Fig. 2.2) e define as idades modelo de extração do manto empobrecido (T $\left.T_{D M}\right)$. Uma importante alternativa ao modelo de DePaolo (1981) foi proposta por Goldstein et al. (1984). O modelo de Goldstein et al. (1984) assume um empobrecimento linear do manto de $\varepsilon_{\mathrm{Nd}}=0$ em 4560Ma a $\varepsilon_{\mathrm{Nd}}=+10$ atualmente (composição MORB) (Fig. 2.2). Os autores denominaram as idades modelo de extração mantélicas obtidas pelo modelo de $T_{C R}$ (crustal residence). No entanto, segundo Dickin (2005), o modelo de Goldstein et al. (1984) não é o mais apropriado para o cálculo de idades de extração crustal de rochas geradas em ambientes tectônicos de arco magmático, pois as mesmas apresentam assinaturas de neodímio menos empobrecidas do que rochas provenientes de dorsais oceânicas.

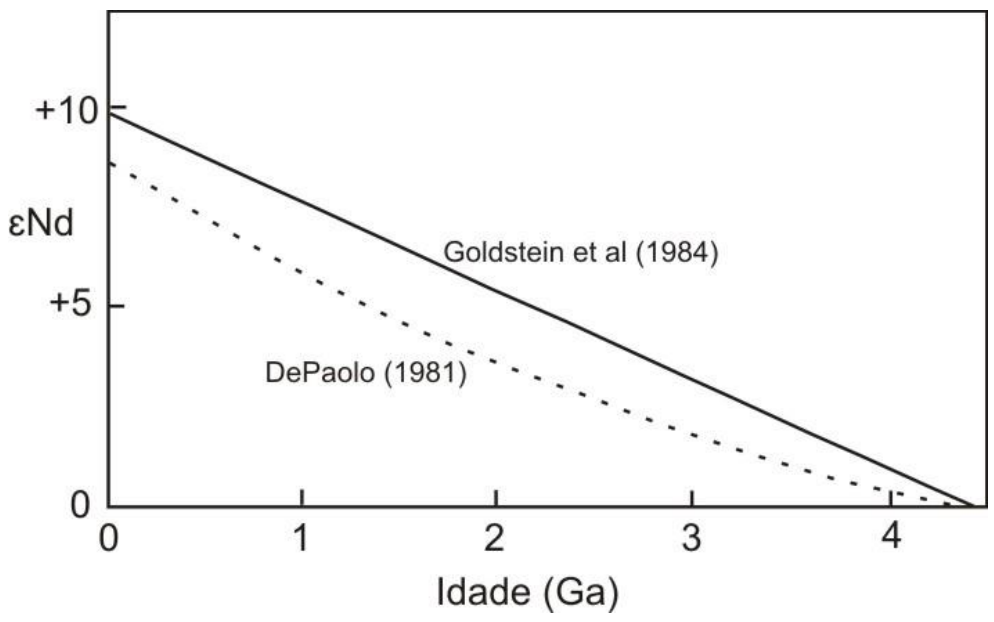

Figura 2.2. Diagrama $\varepsilon_{N d}$ Vs tempo, com os dois modelos mais populares de evolução do Neodímio no manto empobrecido. Linha cheia: Goldstein et al. (1984); Linha pontilhada: DePaolo (1981).

O mapeamento de terrenos gnáissicos de embasamento através de idades modelo de neodímio é um importante recurso na definição de províncias crustais. Porém, os resultados obtidos devem ser confirmados através de outros métodos geocronológicos. Normalmente, as idades modelo de neodímio definem a idade mais antiga do terreno e as idades mínimas são definidas pela datação $\mathrm{U}-\mathrm{Pb}$ de rochas intrusivas. Quanto menor for a diferença entre as idades modelo de neodímio e as idades U-Pb da cristalização ígnea, maior é a certeza de que as idades modelo de neodímio realmente representam uma idade de formação crustal. 
Outra importante ferramenta na definição de idades de formação crustal é o sistema isotópico Lu/Hf. O sistema pode ser utilizado como traçador de processos geoquímicos de diferenciação do planeta (crosta e manto), devido ao fato do fracionamento entre Lu e Hf ocorrer principalmente durante a geração magmática. Como citado anteriormente o zircão apresenta uma maior afinidade com háfnio comparado ao lutécio, portanto as razões Lu/Hf nos zircões é invariavelmente baixa ( 0.002). A razão ${ }^{176} \mathrm{Lu} /{ }^{177} \mathrm{Hf}$ no zircão é geralmente menor que 0.0005 , o que significa que mudanças das razões ${ }^{176} \mathrm{Hf} /{ }^{177} \mathrm{Hf}$ como resultado do decaimento do ${ }^{176} \mathrm{Lu}$ são praticamente desprezíveis. Portanto, o zircão efetivamente preserva as razões iniciais ${ }^{176} \mathrm{Hf} /{ }^{177} \mathrm{Hf}$ de suas fontes no momento de sua cristalização. Essas razões podem ser utilizadas no cálculo de idades modelo (manto primitivo ou manto empobrecido) e sendo as idades de cristalização conhecidas a partir de técnicas de datação U$\mathrm{Pb}$, na determinação do valor de $\varepsilon \mathrm{Hf}$ inicial. Valores positivos de $\varepsilon \mathrm{Hf}$ inicial são indicativos de derivação mantélica, enquanto que valores fracamente positivos ou negativos podem indicar contribuição crustal. Portanto, a composição isotópica de háfnio no zircão pode ser utilizada como traçador geoquímico da mesma maneira que isótopos de neodímio são utilizados em amostras de rocha total.

Na realidade, o háfnio é um traçador mais sensível do que neodímio, uma vez que a as razões Lu/Hf no manto empobrecido aumentaram, em relação ao material não fracionado, em uma taxa duas vezes maior do que as razões Sm/Nd (Patchett \& Tatsumoto, 1980). Além disso, estudos como o de Hoskin \& Black (2000) demonstraram que o zircão pode perder U, Th e Pb radiogênico durante eventos metamórficos e mesmo assim reter suas concentrações iniciais de lutécio e háfnio. Portanto, a metodologia Lu-Hf em zircão apresenta-se como um traçador geoquímico mais robusto do que as metodologias $\mathrm{Sm} / \mathrm{Nd}$ em rocha total, uma vez que em certas circunstâncias é reconhecido que o sistema Sm/Nd pode ser afetado por episódios de metamorfismo (ex. Gruau et al. 1996). Essas características tornam o método Lu/Hf uma potente ferramenta para estudos sobre diferenciação terrestre e evolução crustal (Vervoort et al., 1996; Amelin et al., 1999, 2000; Hawkesworth \& Kemp, 2006; Kemp et al., 2006; Belousova et al., 2010; Dhuime et al., 2012).

\subsection{Referências bibliográficas}

Albarede, F., 1998. The growth of the continental crust. Tectonophysics 296, 1-14.

Amelin, Y., Lee, D-C., Halliday, A.N., Pidgeon, R.T., 1999. Nature of the Earth's earliest crust formation from hafnium isotopes in single detrital zircons. Natuire 399, 252-255.

Amelin, Y., Lee, D-C., Halliday, A.N., 2000. Early-middle Archean crustal evolution deduced from Lu-Hf and U-Pb isotopic studies of single zircon grains. Geochimica et Cosmochimica Acta 64, 4205-4225. 
Armstrong, R.L., 1968. A model for the evolution of strontium and lead isotopes in a dynamics Earth. Rev. Geophys. 6, 175-199.

Bea, F. 1996. Residence of REE, Y, Th and U in granites and crustal protoliths: Implications for the chemistry of crustal melts. Journal of Petrology 37, 521-552.

Belousova, E.A., Kostitsyn, Y.A., Griffin, W.L., Begg, G.C., O’Reilly, S.Y., Pearson, N.J., 2010. The growth of the continental crust: Constraints from zircon Hf-iotope data. Lithos 119, 457-466.

Collerson, K.D., Kamber, B., 1999. Evolution of the continents and the atmosphere inferred from Th-U$\mathrm{Nb}$ systematics of the depleted mantle. Science 283, 1519-1522.

Compston, W., Williams, I.S., Meyer, C., 1984. U-Pb geochronology of zircons from lunar breccia 73217 using a sensitive high mass-resolution ion microprobe. Proc. $14^{\text {th }}$ Lunar and Planet. Sci. Conf., J.Geophys.Res. 89, B525-534.

Condie, K.C., 1998. Episodic continental growth and supercontinents: a mantle avalanche connection. Earth and Planetary Science Letters 163, 97-108.

Condie, K.C., 2000. Episodic continental growth models: afterthoughts and extensions. Tectonophysics $322,153-162$.

Corfu, F., 1987. Inverse age stratification in the Archean crust of the Superior Province: evidence for infra- and subcrustal accretion from high resolution U-Pb zircon and monazites ages. Precambrian Research 36, 259-275.

Corfu, F., Hanchar, J.M., Hoskin, P.W.O., Kinny, P., 2003. Atlas of Zircon Textures. In: Hanchar, J.M. \& Hoskin, P.W.O. (eds). Zircon. Reviews in Mineralogy and Geochemistry 53, 469-500.

DePaolo, 1981. Neodymium isotopes in the Colorado Front Range and crust - mantle evolution in the Proterozoic. Nature 291, 193-197.

DePaolo, D.J., Wasserburg, G.J., 1976. Nd isotopic variations and petrogenetic models. Geophys. Res. Lett. 3, 249-252.

DePaolo, D.J., Wasserburg, G.J., 1979. Sm-Nd age of the Stillwater complex and the mantle evolution curve for neodymium. Geochimica et Cosmochimica Acta 43, 999-1008.

Dhuime, B., Hawkesworth, C.J., Cawood, P.A., Storey, C.D., 2012. A change in the geodynamics of Continental Growth 3 Billion Years Ago. Science, 1334-1336.

Dickin, A.P., 2005. Radiogenic Isotope Geology. Cambridge University Press. 
Frei, D., Gerdes, A., 2009. Precise and accurate in situ U-Pb dating of zircon with high sample throughput by automated LA-SF-ICP-MS. Chemical Geology 261, 261-270.

Gerdes, A., Zeh, A., 2006. Combined U-Pb and Hf isotope LA-(MC-)ICP-MS analyses of detrital zircons: Comparison with SHRIMP and new constraints for the provenance and age of an Armorican metasediment in Central Germany. Earth and Planetary Science Letters 249, 47-61.

Gerdes, A., Zeh, A., 2009. Zircon formation versus zircon alteration - New insights from combined Lu$\mathrm{Hf}$ in-situ LA-ICP-MS analyses, and consequences for the interpretation of Archean zircon from the Central Zone of the Limpopo Belt. Chemical Geology 261, 230-243.

Goldstein, S.L., O'Nions, R.K., Hamilton, P.J., 1984. A Sm-Nd isotopic study of atmospheric dusts and particulates from major river systems. Earth and Planetary Sciences Letters 70, 221-236.

Gruau, G., Rosing, M., Bridgwater, D., Gill, R.C.O., 1996. Resetting of Sm-Nd systematics during metamorphism of $>3.7-G a$ rocks: implications for isotopic models of early Earth differentiation. Chemical Geology 133, 225-240.

Hawkesworth, C.J., Kemp, A.I.S., 2006. Using hafnium and oxygen isotopes to unravel the record of crustal evolution. Chemical Geology 226, 144-162.

Hawkesworth, C.J., Cawood, P.A., Kemp, A.I.S., Storey, C., Dhuime, B., 2009. Geochemistry: A matter of preservation. Science $323,49-50$.

Hawkesworth, C., Cawood, P.A., Dhuime, B., 2013. Continental growth and the crustal record. Tectonophysics 609, 651-660.

Hirata, T., Nesbitt, R. W., 1995. U-Pb isotope geochronology of zircon: evaluation of the laser probeinductively coupled plasma-mass spectrometry technique. Geochimica et Cosmochimica Acta 59, 2491-2500.

Hoskin, P.W.O., Black, L.P., 2000. Metamorphic zircon formation by solid-state recrystallization of protolith igneous zircon. Journal of Metamorphic Geology 18, 423-439.

Hoskin, P.W.O., Ireland, T.R., 2000. Rare earth element chemistry of zircon and its use as a provenance indicator. Geology 28, 627-630.

Hurley, P.M., Rand, J.R., 1969. Pre-drift continental nucleii. Science 164, 1229-1242.

Jackson, S.E., Norman, J. P., Griffin, W.L., Belousova, E. A., 2004. The application of laser ablationinductively coupled plasma-mass spectrometry to in situ U-Pb zircon geochronology. Chemical Geology 211, 47-69. 
Kemp, A.I.S., Hawkesworth, C.J., Paterson, B.A., Kinny, P., 2006. Episodic growth of the Gondwana supercontinent from hafnium and oxygen isotopes in zircon. Nature 439, 580-583.

Kramers, J.D., Tolstikhin, I.N., 1997. Two terrestrial lead isotopes paradoxes, forward transport modelling, core formation and the history of the continental crust. Chemical Geology 139, 75-110.

Li, X.-H., Liang, X., Sun, M., Guan, H., Malpaas, J. G., 2001. Precise ${ }^{206} \mathrm{~Pb} /{ }^{238} \mathrm{U}$ age determination on zircons by laser ablation microprobe-inductively coupled plasma-mass spectrometry using continuous linear ablation. Chemical Geology 175, 209-219.

Macdonald, R., Hawkesworth, C.J., Heath, E., 2000. The lesser Antilles volcanic chain: a study in arc magmatism. Earth Science Reviews 49, 1-76.

Martin, H., 1999. Adakitic magmas: modern analogues of Archean granitóides. Lithos 46, 411-429.

Nagler, T.F., Kramers, J.D., 1998. Nd isotopic evolution of the upper mantle during the Precambrian: models, data and the uncertainty of both. Precambrian Research 91, 233-252.

Nutman, A.P., 2001. On the scarcity of >3900 Ma detrital zircons in >3500 Ma metasediments.

Patchett, P.J., Tatsumoto, M., 1980. Hafnium isotope variations in oceanic basalts. Geophysical Research Letters 7, 1077-1080.

Stein, M., Hofmann, A.W., Mantle plumes and episodic crustal growth. Nature 372, 63-68.

Tarney, J., Jones, C., 1994. Trace element geochemistry of orogenic igneous rocks and crustal growth models. Journal of the Geological Society of London 151, 855-868.

Tiepolo, M., 2003. In situ Pb geochronology of zircon with laser ablation-inductively coupled plasmasector field mass spectrometry. Chemical Geology 199, 159-177.

Tiepolo, M., Bottazzi, P., Palenzona, M., Vannucci, R., 2003. A laser probre coupled with ICP-double focusing sector-field mass spectrometer for in situ analysis of geological samples and U-Pb dating of zircon. Canadian Mineralogist 41, 259-272.

Tilton, G.R., Patterson, C., Brown, H., Inghram, M., Hayden, R., Hess, D., Larsen, E., 1955. Isotopic composition and distribution of lead, uranium and thorium in a Precambrian Granite. Geological Society of America Bulletin 66, 1131-1148.

Vervoort, J.D., Patchett, P.J., Gehrels, G.E., Nutman, A.P., 1996. Constraints on early Earth differentiation from hafnium and neodymium isotopes. Nature 379, 624-627.

Wetherill, G.W., 1956. Discordant uranium-lead ages. Trans. Amer. Geophys. Union 37, 320-32 


\section{Contexto geológico regional}

As rochas investigadas nessa pesquisa estão localizadas na extensão meridional do Orógeno Brasília (Fuck et al., 1994; Dardenne, 2000), interpretado como resultado da colisão ediacarana, entre a margem passiva do paleocontinente São Francisco a leste e a margem ativa da placa Paranapanema a oeste (Brito Neves et al., 1999; Campos Neto, 2000; Trouw et al., 2000). Os processos colisionais geraram uma pilha de nappes sub-horizontais do tipo thick-skinned, com cunha orogênica mergulhando para sul-sudoeste e deslocamento horizontal de pelo menos $150 \mathrm{~km}$, no sentido lestenordeste nas nappes superiores e no sentido norte-nordeste nas nappes inferiores. Dois domínios tectônicos principais são identificados nesse sistema de nappes (Fig. 3.1): (1) um domínio relacionado a margem ativa da placa Paranapanema, constituído por uma unidade relacionada ao arco magmático (Nappe Socorro-Guaxupé) (e.g. Campos Neto \& Caby, 2000; Janasi, 2002) e unidades metassedimentares relacionadas ao prisma acrescionário e bacias de ante-arco (Sistema de Nappes Andrelândia) (e.g. Campos Neto et al., 2010, 2011); (2) um domínio de margem passiva relacionado ao paleocontinente São Francisco, constituído por ortognaisses do embasamento (e.g. Fetter et al., 2001; Peternel et al., 2005; Cioffi et al., 2016) e rochas metassedimentares da margem passiva (Complexo São Vicente e as nappes Carrancas e Lima Duarte) (e.g. Trouw et al., 2008; Rocha, 2011; Westin \& Campos Neto, 2013; Westin et al., 2016).

Segundo Campos Neto et al. $(2004,2011)$ essas nappes registram diacronicamente a migração da pilha orogênica em sentido ao cráton, com idades mais antigas nos alóctones superiores a oeste e idades mais novas nos alóctones inferiores a leste. O metamorfismo de fácies granulito da Nappe Socorro-Guaxupé foi datado em $625 \pm 5$ Ma (Campos Neto et al., 2004; Rocha et al., 2016). Idades U$\mathrm{Pb}$ (ID-TIMS) em monazita proveniente de rochas metassedimentares do Sistema de Nappes Andrelândia variam entre 618 Ma (nappes superiores) e 612 Ma (nappes inferiores) (Campos Neto et al., 2010, 2011). Idades U-Pb (ID-TIMS) em monazita relacionadas ao metamorfismo de fácies anfibolito da Nappe Carrancas estão entre 590-575 Ma (Valeriano et al., 2004; Campos Neto et al., 2011) e migmatitos metatexíticos da Nappe Lima Duarte apresentam idades U-Pb em monazita de aproximadamente 575Ma (Machado et al., 1996; Campos Neto et al., 2011). Para alguns autores (e.g. Trouw et al., 1994, 2000, 2013; Ribeiro et al., 1995; Peternel et al., 2005; Heilbron et al., 2008; Zuquim et al., 2011) parte desse sistema de nappes foi afetada pela tectônica relacionada ao cinturão Ribeira e os mesmos consideram a área como uma zona de interferência entre a Faixa Brasília e a Faixa Ribeira. Para esses autores a fase de deformação $D_{3}$ associada às lineações de orientação NW-SE seria relacionada à colisão do cinturão Ribeira no período entre 590 e $550 \mathrm{Ma}$. No presente trabalho essa hipótese não é assumida e toda tectônica neoproterozóica da região é associada à evolução do Orógeno Brasília. 


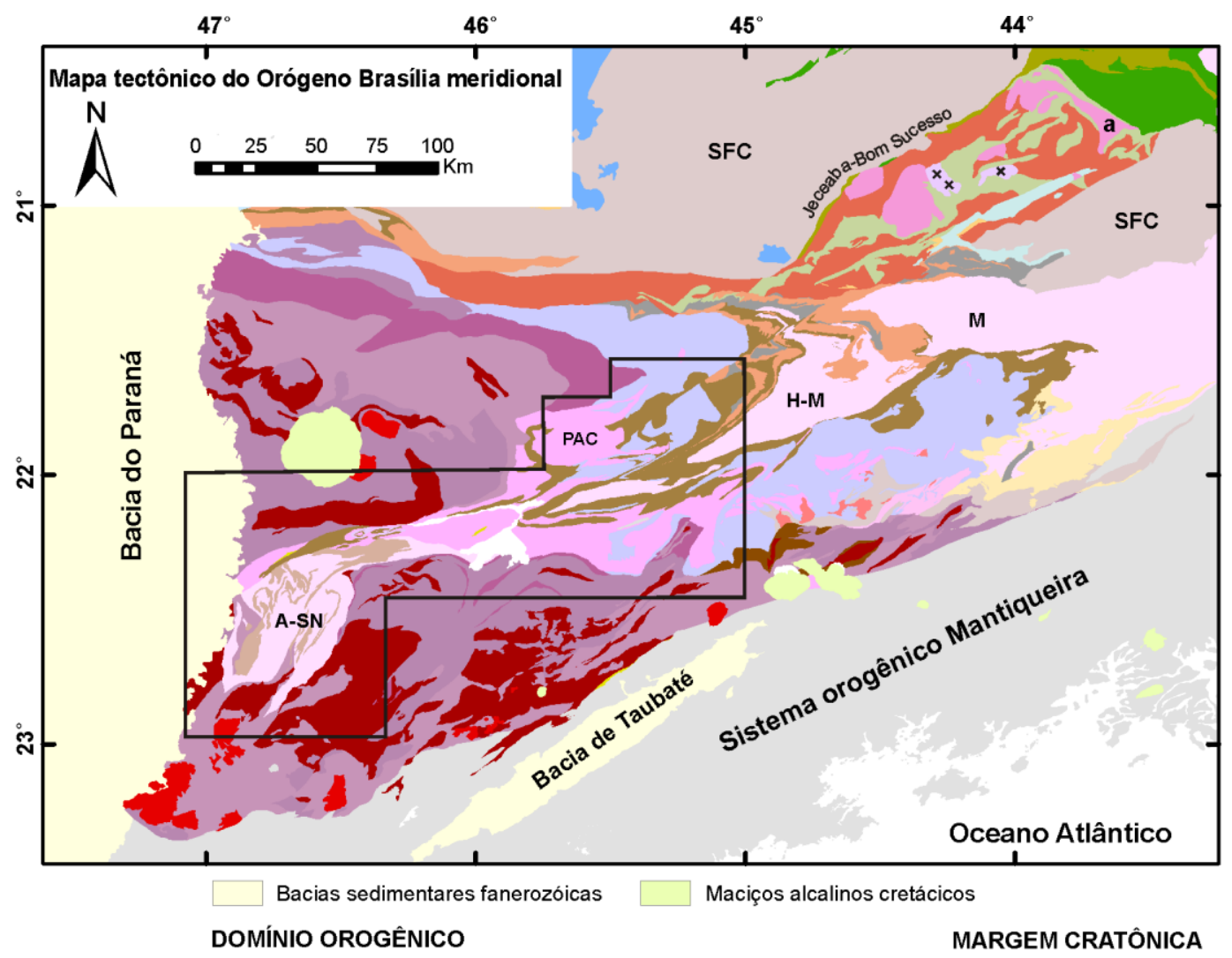

Domínio de margem ativa
Prisma acrescionário neoproterozóico
e bacias de ante-arco
Leucogranitos
Sistema de Nappes Andrelândia
Migmatitos Alagoa e Rio Preto
Domínio de arco neoproterozóico
Nappe Socorro - Guaxupé
Granitóides pós-tectônicos
Granitóides orogênicos
Ortognaisses metatexíticos
Paragnaisses metatexíticos
Ortognaisses diatexíticos
Granulitos

\begin{tabular}{|c|c|}
\hline \multicolumn{2}{|c|}{ Domínio de margem passiva } \\
\hline \multicolumn{2}{|c|}{ Idade desconhecida - Grupo Itapira } \\
\hline \multicolumn{2}{|c|}{ Sequência flysch neoproterozóica } \\
\hline \multicolumn{2}{|c|}{ Nappes psamo-pelíticas neoproterozóicas } \\
\hline Carrancas & Lima Duarte \\
\hline \multicolumn{2}{|c|}{ Mesoproterozóico } \\
\hline \multicolumn{2}{|c|}{ Sequências São João del Rei e Carandai } \\
\hline \multicolumn{2}{|c|}{$\begin{array}{l}\text { Paleoproterozóico } \\
\text { Immature metasedimentary sequence } \\
\text { São Vicente Complex }\end{array}$} \\
\hline \multicolumn{2}{|c|}{$\begin{array}{l}\text { Orhogneisses - Pouso Alegre Complex } \\
\text { (PAC) }\end{array}$} \\
\hline \multicolumn{2}{|l|}{ Arqueano } \\
\hline \multicolumn{2}{|c|}{$\begin{array}{l}\text { Ortognaisses e migmatitos } \\
\text { (A-SN Amparo-Serra Negra, } \\
\text {-M Heliodora-Minduri, M Mantiqueira) }\end{array}$} \\
\hline
\end{tabular}

MARGEM CRATÔNICA

Plataforma carbonática neoproterozóica Paleoproterozóico (Riaciano-Sideriano) Cinturão Mineiro

Suites igneas de 2,13-2,17 Ga (a - Alto Maranhão suite)

Sequências supracrustais de 2,2-2,35 Ga

$\times$ × Suítes ígneas de $2.35 \mathrm{Ga}$ (Lagoa Dourada e Resende da Costa)

Undivided granitoids

Paleoproterozóico

Supergrupo Minas

Arqueano

Supergrupo Rio das Velhas

Complexos granito-gnássicos (SFC)

Figura 3.1. Mapa tectônico do Orógeno Brasília meridional com localização da área de estudo.

Ortognaisses migmatíticos arqueanos a paleoproterozóicos que representam o embasamento desse sistema de nappes afloram em uma janela tectônica, de aproximadamente 350 quilômetros de extensão por aproximadamente 15 a 75 quilômetros de largura, que divide os dois lobos da Nappe Socorro-Guaxupé. A orientação dessa faixa varia de NE-SW na porção oeste para ENE-WSW em direção a leste. Esses ortognaisses estão intercalados com sequências supracrustais e foram intensamente afetados por processos de deformação e metamorfismo relacionados ao evento neoproterozóico. Trabalhos pioneiros (ex. Hasui \& Oliveira, 1984; Vasconcelos, 1988; Campos Neto, 1991; Perrota, 1991) denominaram essa faixa como Faixa Alto Rio Grande. No presente trabalho esse termo não é utilizado, 
em favor de uma abordagem mais integrada, onde toda a região juntamente com a Nappe SocorroGuaxupé representa o sistema de nappes da extensão sul do Orógeno Brasília (Campos Neto \& Caby, 1999, 2000; Trouw et al., 2000; Campos Neto et al., 2004, 2010, 2011). Sendo que, os ortognaisses arqueanos a paleoproterozóicos presentes nessa faixa são considerados rochas do embasamento do sistema de nappes e provavelmente representam a borda sul do paleocontinente São Francisco retrabalhada durante a orogênese neoproterozóica.

Na porção oeste dessa faixa (Fig. 3.1) afloram, no núcleo de uma grande estrutura antiformal, os migmatitos arqueanos dos complexos Amparo e Serra-Negra (Ebert, 1968; Basei et al., 1986). Essas rochas são predominantemente hornblenda-biotita- e biotita-gnaisses migmatíticos, de composição tonalítica a granítica, com taxas de fusão e estruturas migmatíticas variadas. Esses migmatitos estão intercalados com sequências meta-vulcanosedimentares que são atribuídas ao Grupo Itapira (Ebert, 1968, 1971). Datações U-Pb em zircão (SHRIMP e ID-TIMS) indicam idades entre 2,8 e 3,0 Ga para a cristalização dos protólitos ígneos dos migmatitos (Tassinari \& Nutman, 2001; Fetter et al., 2001). Zircões provenientes de neossoma granítico de migmatito do Complexo Amparo forneceram idades de aproximadamente 2,0 Ga (Tassinari \& Nutman, 2001). Bordas de cristais de zircão foram datadas, pelos mesmos autores, em aproximadamente $600 \mathrm{Ma}$, sugerindo o retrabalhamento dessa crosta antiga em pelo menos dois eventos tectono-termais desde o Arqueano.

$\mathrm{Na}$ porção central e oriental dessa faixa, predominam ortognaisses migmatíticos paleoproterozóicos, de afinidade cálcio-alcalina e assinaturas isotópicas juvenis, intercalados com sequências metassedimentares relacionadas à margem passiva (Sistema de nappes Carrancas e Complexo São Vicente) e à margem ativa (Sistema de Nappes Andrelândia) do orógeno neoproterozóico (Fig. 3.1). Na presente tese são agrupados sob a denominação de Complexo Pouso Alegre uma ampla gama de ortognaisses migmatíticos paleoproterozóicos com assinaturas isotópicas juvenis e composições variando de tonalito a granito, que haviam sido previamente incluídos nos Complexos Amparo e São Gonçalo do Sapucaí (ex. Vasconcelos, 1988; Perrota, 1991; Campos Neto, 1991). No presente trabalho o termo Complexo São Gonçalo do Sapucaí não é utilizado e a denominação Complexo Amparo é utilizada exclusivamente para rochas de idade arqueana. O termo Suíte Serra de São Gonçalo (Perrota, 1991) foi mantido para denominar uma unidade do Complexo Pouso Alegre, caracterizada por rochas de composição granítica e estrutura porfiroclástica, que tem como exposição típica os afloramentos da Serra de São Gonçalo a noroeste de São Gonçalo do SapucaíMG. Dados U-Pb em zircão apresentados na literatura sugerem idades de cristalização dos protólitos ígneos do Complexo Pouso Alegre entre 2,16 e 2,08 Ga (ID-TIMS - Fetter et al., 2001; Peternel et al., 2005; Campos Neto et al., 2011) (microssonda iônica - Zuquim et al., 2011). Dados de isótopos de neodímio fornecem idades modelo $\mathrm{T}_{\mathrm{DM}}$ entre 2,51 e 2,14 Ga, associados com valores de $\varepsilon_{\mathrm{Nd}_{(\mathrm{t})}}$ entre 0.95 e +3.18 (Fetter et al., 2001; Campos Neto et al., 2011). Esses dados prévios sugerem a ocorrência 
de significativos eventos paleoproterozóicos de geração de crosta continental no Complexo Pouso Alegre.

$\mathrm{Na}$ extremidade sul do cráton do São Francisco ocorrem, alinhadas ao longo de um cinturão de orientação nordeste-sudoeste, as suítes ígneas paleoproterozóicas e rochas metassedimentares associadas ao Cinturão Mineiro. Essas rochas são interpretadas como resultado de uma sucessiva acresção de arcos oceânicos e arcos continentais a borda sul do paleocontinente São Francisco durante o Paleoproterozóico (Teixeira et al., 2000, 2008, 2015; Noce et al., 2000; Ávila et al., 2010, 2014; Seixas et al., 2012, 2013; Barbosa et al., 2015). O limite entre as rochas do Cinturão Mineiro e as unidades arqueanas do cráton do São Francisco é definido pelo lineamento Jeceaba-Bom Sucesso (Campos \& Carneiro, 2008) (Fig. 1). As suítes ígneas incluem plútons não deformados de composição gabróica a granítica e ortognaisses de composição throndjhemítica a granítica. As idades das suítes variam entre 2,35 e 2,10 Ga (Noce et al., 2000; Teixeira et al., 2000, 2008; Ávila et al., 2010; Seixas et al., 2012, 2013; Barbosa et al., 2015) e diversos corpos de rochas juvenis foram identificados entre essas suítes. As suítes juvenis mais antigas descritas até o momento são a Suíte TTG Lagoa Dourada (Seixas et al., 2012) e os Ortognaisses Resende da Costa (Teixeira et al., 2015), que apresentam idades de cristalização de 2,35 Ga e idades modelo $T_{D M}$ entre 2,3 e 2,5 Ga. O episódio mais novo de magmatismo juvenil reconhecido no Cinturão Mineiro é representado pelos tonalitos e dioritos da Suíte Alto Maranhão que apresentam idades de cristalização de aproximadamente 2,13 Ga e idades modelo $T_{D M}$ entre 2,3 e 2,4 Ga. Portanto, o contexto geológico associado as idades e assinaturas isotópicas, sugerem uma conexão entre as rochas do Cinturão Mineiro no domínio cratônico e o Complexo Pouso Alegre no domínio orogênico.

\subsection{Referências bibliográficas}

Ávila, C.A., Teixeira, W., Cordani, U.G., Moura, C.A.V., Pereira, R.M., 2010. Rhyacian (2.23-2.20 Ga) juvenile accretion in the Southern São Francisco craton, Brazil: Geochemical and isotopic evidence from the Serrinha magmatic suite, Mineiro belt. Journal of South American Earth Sciences 29, 464-482.

Ávila, C.A., Teixeira, W., Bongiolo, E.M., Dussin, I.A., Vieira, T.A.T., 2014. Rhyacian evolution of subvolcanic and metasedimentary rocks of the Southern segment of the Mineiro belt, São Francisco Craton, Brazil. Precambrian Research 243, 221-251.

Barbosa, N.S, Teixeira, W., Ávila, C.A., Montecinos, P.M., Bongiolo, E.M., 2015. 2.17-2.10 Ga plutonic episodes in the Mineiro belt, São Francisco Craton, Brazil: U-Pb ages, geochemical constraints and tectonics. Precambrian Research 270, 204-225. 
Basei, M.A.S., Campos Neto, M.C., Bergmann, M., Figueiredo, M.C.H., 1986. Geologia da Folha Amparo (SP), 1:50.000. Relatório Final, Convênio IG-USP/PRÓ-MINÉRIO, v.1, 109p.

Brito Neves, B.B., Campos Neto, M.C., Fuck, R.A., 1999. From Rodinia to Western Gondwana: an approach to the Brasiliano-Pan African Cycle and orogenic collage. Episodes 22, 155-166.

Campos, J.C.S., Carneiro, M.A., 2008. Neoarchean and Paleoproterozoic granitoids marginal to the Jeceaba-Bom Sucesso lineament (SE border of the southern São Francisco craton): Genesis and tectonic evolution. Journal of South American Earth Sciences 26, 463-484.

Campos Neto, M. C. - 1991 - A porção ocidental da Faixa Alto rio Grande - ensaio de Evolução Tectônica. Tese de Doutoramento - Universidade de São Paulo, 210p.

Campos Neto, M.C., 2000. Orogenic Systems from southwestern Gondwana: an approach to Brasiliano-Pan African Cycle and orogenic collage in southeastern Brazil. In: Cordani, U.G., Milani, E.J., Thomaz Filho, A., Campos, D.A. (Eds.), Tectonic Evolution of South America. 31th International Geological Congress. Rio de Janeiro, Brazil, pp. 335-365.

Campos Neto, M.C., Caby, R., 1999. Neoproterozoic high-pressure metamorphism and tectonic constraint from the nappe system south of the São Francisco Craton, southeast Brazil. Precambrian Research 97, 3-26.

Campos Neto, M.C., Caby, R., 2000. Lower crust extrusion and terrane accretion in the Neoproterozoic nappes of southeast Brazil. Tectonics 19, 669-687.

Campos Neto, M.C., Basei, M.A.S, Vlach, S.F., Caby, R., Szabó, G.A.J., Vasconcelos, P. 2004. Migração de Orógenos e Superposição de Orogêneses: Um Esboço da Colagem Brasiliana no Sul do Cráton do São Francisco, SE - Brasil. Geologia USP. Série científica 4, 13-40.

Campos Neto, M.C., Cioffi, C.R., Moraes, R., Motta, R.G., Siga Jr., O., Basei, M.A.S., 2010. Structural and metamorphic control on the exhumation of high-P granulites: The Carvalhos Klippe example, from the oriental Andrelândia Nappe System, southern portion of the Brasília Orogen, Brazil. Precambrian Research 180, 125-142.

Campos Neto, M.C., Basei, M.A.S., Janasi, V.A., Moraes, R., 2011. Orogen migration and tectonic setting of the Andrelândia Nappe System: An Ediacaran western Gondwana collage, south São Francisco craton. Journal of South American Earth Sciences 32, 393-406.

Cioffi, C.R., Campos Neto, M.C., Möller, A., Rocha, B.C., 2016. Paleoproterozoic continental crust generation events at 2.15 and $2.08 \mathrm{Ga}$ in the basement of the southern Brasília Orogen, SE Brazil. Precambrian Research 275, 176-196. 
Dardenne, M.A., 2000. The Brasília Fold Belt. In: Cordani, U.G., Milani, E.J., Thomaz Filho, A., Campos, D.A. (Eds.) Tectonic Evolution of South America. 31th International Geological Congress. Rio de Janeiro, Brazil, pp.231-263.

Ebert, H., 1968. Ocorrências da fácies granulítica no sul do estado de Minas Gerais e em áreas adjacentes, em dependência da estrutura orogênica: hipóteses sobre sua origem. Anais da Acadêmia Brasileira de Ciências 40, 215-229.

Fetter, A.H., Hackspacker, P.C., Ebert, H.D., Dantas, E.L., Costa, A.C.D., 2001. New Sm/Nd and U/Pb geochronological constraints on the Archean to Neoproterozoic evolution of the Amparo basement complex of the central Ribeira belt, southeastern Brazil. 3rd South American Symposium on Isotope Geology (Extended Abstracts, CD-ROM).

Fuck, R.A., Pimentel, M.M., Silva, L.J.H.D., 1994. Compartimentação tectônica da porção oriental da Província Tocantins. In: Congresso Brasileiro de Geologia, vol.38. Balneário Camboriú, SBG, pp. 215216.

Hasui, Y., Oliveira, M.A.F., 1984. Província Mantiqueira setor central. In: Almeida \& Hasui (Coords.) O Pré-Cambriano do Brasil, Edgar Blücher, 308-344.

Heilbron, M., Valeriano, C.M., Tassinari, C.C.G., Almeida, J.C.H., Tupinambá, M., Siga Jr, O., Trouw, R.A.J., 2008. Correlation of Neoproterozoic terranes between the Ribeira Belt, SE Brazil and its African counterpart: comparative tectonic evolution and open questions. In: Pankhurst, R.J., Trouw, R.A.J., Brito Neves, B.B., de Wit, M. (Eds.), West Gondwana Pre-Cenozoic Correlations across the South Atlantic Region, Journal Geological Society of London, Special Publication, vol.294, pp. 211-232.

Janasi, V., 2002. Elemental and Sr-Nd isotope geochemistry of two Neoproterozoic mangerite suites in SE Brazil: implications for the origin of the mangerite-charnockite-granite series. Precambrian Research $119,301-327$.

Machado, N., Valladares, C., Heilbron, M., Valeriano, C.M., 1996. U-Pb geochronology of central Ribeira belt (Brazil) and implications for the evolution of the Brazilian Orogeny. Precambrian Research 70, 347361.

Noce, C.M., Teixeira, W., Quéméneur, J.J.G., Martins, V.T.S., Bolzachini, E., 2000. Isotopic signatures of Paleoproterozoic granitoids from the Southern São Francisco Craton and implications for the evolution of the Transamazonian Orogeny. Journal of South American Earth Sciences 13, 225-239.

Perrota, M.M., 1991. A Faixa Alto Rio Grande na região de São Gonçalo do Sapucaí, MG. Dissertação de Mestrado, IGc-USP, 158p. 
Peternel, R., 2005. A zona de superposição entre as Faixas Brasília e Ribeira na região entre Caxambu e Pedralva, sul de Minas Gerais. Unpublished PhD Thesis. Instituto de Geociências - UFRJ, (257pp.).

Ribeiro, A., Trouw, R.A.J., Andreis, R.R., Paciullo, F.V.P., Valença, J.G., 1995. Evolução das bacias proterozóicas e o termo-tectonismo brasiliano na margem sul do cráton do São Francisco. Revista Brasileira de Geociências 25, 235-248.

Rocha, B.C. 2011. Evolução metamórfica dos metassedimentos da Nappe Lima Duarte e rochas associadas do Complexo Mantiqueira. Unpublished Master's dissertation, IGc-USP, (201pp.).

Rocha, B.C., Moraes, R., Möller, A., Cioffi, C.R., Jercinovic, M.J., Timing of anatexis and melt crystallization in the Socorro-Guaxupé Nappe, SE Brazil: Insights from trace element compositions of zircon, monazite and garnet coupled to U-Pb geochronology. Lithos (2016), hhtp://dx.doi.org/10.1016/j.lithos.2016.05.020.

Seixas, L.A.R., David, J., Stevenson, R., 2012. Geochemistry, Nd isotopes and U-Pb geochronology of a 2350 Ma TTG suite, Minas Gerais, Brazil: Implications for the crustal evolution of the southern São Francisco craton. Precambrian Research 196-197, 61-80.

Seixas, L.A.R., Bardintzeff, J-M., Stevenson, R., Bonin, B., 2013. Petrology of the high $-M g$ tonalites and dioritic enclaves of the ca. 2130 Ma Alto Maranhão suite: Evidence for a major juvenile crustal addition event during the Rhyacian orogenesis, Mineiro Belt, southeast Brazil. Precambrian Research 238, 1841.

Tassinari, C.C.G., Nutman, A.P., 2001. Archean and Proterozoic multiple tectonothermal events recorded by gneisses in the Amparo region, São Paulo state, Brazil. 3rd South American Symposium on Isotope Geology (Extended Abstracts, CD-ROM).

Teixeira, W., Sabatè, P., Barbosa, J., Noce, C.M., Carneiro, M.A., 2000. Archean and Paleoproterozoic evolution of the São Francisco Craton, Brazil. In: Cordani, U.G., Milani, E.J., Thomaz Filho, A., Campos, D.A. (Eds.), Tectonic Evolution of South America. 31th International Geological Congress. Rio de Janeiro, Brazil, pp. 101-137.

Teixeira, W., Ávila, C.A., Nunes, L.C., 2008. Nd-Sr isotopic geochemistry and U-Pb geochronology of the Fé Granitic Gneiss and Lajeado Granodiorite: Implications for Paleoproterozoic evolution of the Mineiro Belt, Southern São Francisco Craton, Brazil. Geologia USP série científica 8, 53-74.

Teixeira, W., Ávila, C.A., Dussin, I.A., Corrêa Neto, A.V., Bongiolo, E.M., Santos, J.O., Barbosa, N.S., 2015. A juvenile accretion episode (2.35-2.32 Ga) in the Mineiro Belt and its role to the Minas accretionary orogeny: Zircon U-Pb-Hf and geochemical evidences. Precambrian Research 256, 148-169. 
Trouw, R.A.J., Paciullo, F.V.P., Ribeiro, A., 1994. A Faixa Alto Rio Grande reinterpretada como zona de interferência entre a Faixa Brasília e a Faixa Ribeira. In: SBG, Congresso Brasileiro de Geologia, 1994, pp. 234-235

Trouw, R.A.J., Heilbron, M., Ribeiro, A., Paciullo, F., Valeriano, C.M., Almeida, J.C.H., Tupinambá, M., Andreis, R.R., 2000. The central segment of Ribeira belt. In: Cordani, U.G., Milani, E.J., Thomaz Filho, A., Campos, D.A. (Eds.), Tectonic Evolution of South America. 31th International Geological Congress. Rio de Janeiro, Brazil, pp. 287-310.

Trouw, R.A.J., Nunes, R.P.M., Castro, E.M.O., Trouw, C.C., Matos, G.C., 2008. Nota explicativa das Folhas Varginha (SF.23-V-D-VI) e Itajubá (SF.23-Y-B-III). Programa Geologia do Brasil. Contrato CPRMUFRJ N067/PR/05. (99pp).

Trouw, R.A.J., Peternel, R., Ribeiro, A., Heilbron, M., Vinagre, R., Duffles, P., Trouw, C.C., Fontainha, M., Kussama, H.H., 2013. A new interpretation for the interference zone between the southern Brasília belt and the central Ribeira belt, SE Brazil. Journal of South American Earth Sciences 48, 43-57.

Valeriano, C.M., Machado, N., Simonetti, A., Valladares, C.S., Seer, H.J., Simões, L.S.A., 2004. U-Pb geochronology of the Southern Brasília belt (SE-Brazil): sedimentary provenance, Neoproterozoic orogeny, and assembly of West Gondwana. Precambrian Research 130, 27-55.

Vasconcelos, A.C.B.C., 1988. O Grupo Andrelândia na região de Ouro Fino, MG. Dissertação de mestrado, IGc-USP, 199p.

Westin, A., Campos Neto, M.C., 2013. Provenance and tectonic setting of the external nappe of the Southern Brasília Orogen. Journal of South American Earth Sciences 48, 220-239.

Westin, A., Campos Neto, M.C., Hawkesworth, C., Cawood, P., Dhuime, B., Delavault, H., A Paleoproterozoic intra-arc basin associated with a juvenile source in the southern Brasilia Orogen: using $\mathrm{U}-\mathrm{Pb}$ ages and $\mathrm{Hf}-\mathrm{Nd}$ isotopic analyses in provenance studies of complexes areas. Precambrian Research 276, 178-193.

Zuquim, M.P.S., Trouw, R.A.J., Trouw, C.C., Tohver, E., 2011. Structural evolution and U-Pb SHRIMP zircon ages of the Neoproterozoic Maria da Fé shear zone, central Ribeira Belt - SE Brazil. Journal of South American Earth Sciences 31, 199-213. 


\section{Materiais e métodos}

\subsection{Trabalhos de campo}

Foram realizadas quatro etapas de trabalho de campo visando à compreensão das relações entre os litotipos estudados e amostragem dos mesmos. As etapas de campo foram realizadas nos períodos de: novembro/2012; fevereiro/2013; novembro/2013; março/2014. A primeira etapa realizada em novembro de 2012 teve como objetivo principal o reconhecimento de campo e amostragem de rochas da região de Amparo-SP (pontos AMP-01 a AMP-20). A segunda etapa realizada em fevereiro de 2013 foi dedicada principalmente à região de Pouso Alegre-MG e São Gonçalo do Sapucaí-MG (pontos CAU-01 a CAU-23). A terceira etapa realizada em novembro de 2013 teve como objetivo principal a apresentação da área de estudo para o professor Andreas Möller, da Universidade do Kansas - EUA, que foi orientador de estágio de pesquisa no exterior (BEPE-Fapesp), desenvolvido pelo autor dessa tese no período ente agosto de 2014 a agosto de 2015. Nesse trabalho de campo foram apresentados ao professor Möller pedreiras na região de Pouso Alegre-MG e Amparo-SP, onde já haviam sido coletadas amostras e onde as relações de campo características da área de estudo podem ser visualizadas. A última etapa de campo realizada em março de 2014 teve como objetivo o reconhecimento e amostragem nas regiões de São Lourenço-MG, Heliodora-MG e Silvianópolis-MG (pontos CAU-24 a CAU-67). Os afloramentos onde foram coletadas as amostras para petrografia, geoquímica de rocha-total, geoquímica isotópica e geocronologia estão discriminados na tabela 4.1 e localizados na Figura 4.1.

\subsection{Integração do mapa geológico}

O mapa geológico apresentado nessa tese (Fig. 4.1), foi integrado a partir dos seguintes mapas: Carta Geológica da Folha Campinas 1:250.000 (SF.23-Y-A) (Morais et al., 1999 (Org.)); Carta Geológica da Folha Guaratinguetá 1:250.000 (SF.23-Y-B) (Morais et al., 1999 (Org.)); Geologia da Folha Varginha 1:100.000 (SF.23 V-D-VI) (Trouw et al., 2008); Geologia da Folha Itajubá 1:100.000 (SF.23-Y-B-III) (Trouw et al., 2008); mapa geológico apresentado na tese de doutoramento de Campos Neto (1991); mapa geológico apresentado na tese de doutoramento de Peternel (2005) e mapa geológico apresentado na dissertação de mestrado de Perrota (1991). 
Tabela 4.1 Sumário das amostras analisadas.

\begin{tabular}{|c|c|c|c|c|c|c|}
\hline Ponto & Petrografia & Geoquímica - RT & Isótopos Nd - RT & U-Pb zircão & $\begin{array}{l}\text { Isótopos Hf } \\
\text { zircão }\end{array}$ & U-Pb titanita \\
\hline AMP-02 & $x$ & & & & & \\
\hline AMP-04 & $x$ & & & & & \\
\hline AMP-05 & $x$ & & & & & \\
\hline AMP-09 & $x$ & $x$ & $x$ & $x$ & $\mathrm{x}$ & \\
\hline AMP-13 & $x$ & & & & & \\
\hline AMP-14 & $x$ & & & & & \\
\hline AMP-16 & $x$ & & & & & \\
\hline AMP-17 & $\mathrm{x}$ & & & & & \\
\hline AMP-18 & $\mathrm{X}$ & & & & & \\
\hline AMP-20 & $x$ & & & & & \\
\hline CAU-1 & $x$ & $\mathrm{X}$ & $x$ & $x$ & $x$ & $x$ \\
\hline CAU-2 & $\mathrm{X}$ & & & & & \\
\hline CAU-6 & $\mathrm{X}$ & $\mathrm{x}$ & $x$ & $x$ & $x$ & \\
\hline CAU-7 & $X$ & $\mathrm{X}$ & $X$ & $\mathrm{X}$ & $\mathrm{X}$ & \\
\hline CAU-9 & $x$ & $x$ & $x$ & $x$ & & $x$ \\
\hline CAU-13 & $\mathrm{X}$ & & & & & \\
\hline CAU-16 & $x$ & & & & & \\
\hline CAU-19 & $\mathrm{X}$ & & & & & \\
\hline CAU-20 & $x$ & $x$ & $x$ & $x$ & $\mathrm{x}$ & \\
\hline CAU-22 & $\mathrm{X}$ & $\mathrm{X}$ & $\mathrm{X}$ & $\mathrm{X}$ & $x$ & \\
\hline CAU-23 & $\mathrm{X}$ & $\mathrm{x}$ & $\mathrm{X}$ & $\mathrm{X}$ & & \\
\hline CAU-24 & $\mathrm{X}$ & $\mathrm{x}$ & $x$ & $\mathrm{X}$ & & \\
\hline CAU-26 & $\mathrm{X}$ & $\mathrm{X}$ & $\mathrm{X}$ & $\mathrm{X}$ & & \\
\hline CAU-28 & $X$ & $X$ & $\mathrm{X}$ & & & \\
\hline CAU-37 & $X$ & $\mathrm{X}$ & $X$ & $\mathrm{X}$ & $\mathrm{X}$ & \\
\hline CAU-43 & $\mathrm{X}$ & & & & & \\
\hline CAU-45 & $x$ & & & & & \\
\hline CAU-46 & $\mathrm{X}$ & & & & & \\
\hline CAU-48 & $x$ & $x$ & $x$ & $x$ & & \\
\hline CAU-51 & $x$ & $\mathrm{X}$ & $x$ & & & \\
\hline CAU-53 & $x$ & & & & & \\
\hline CAU-61 & $\mathrm{X}$ & & & & & \\
\hline
\end{tabular}




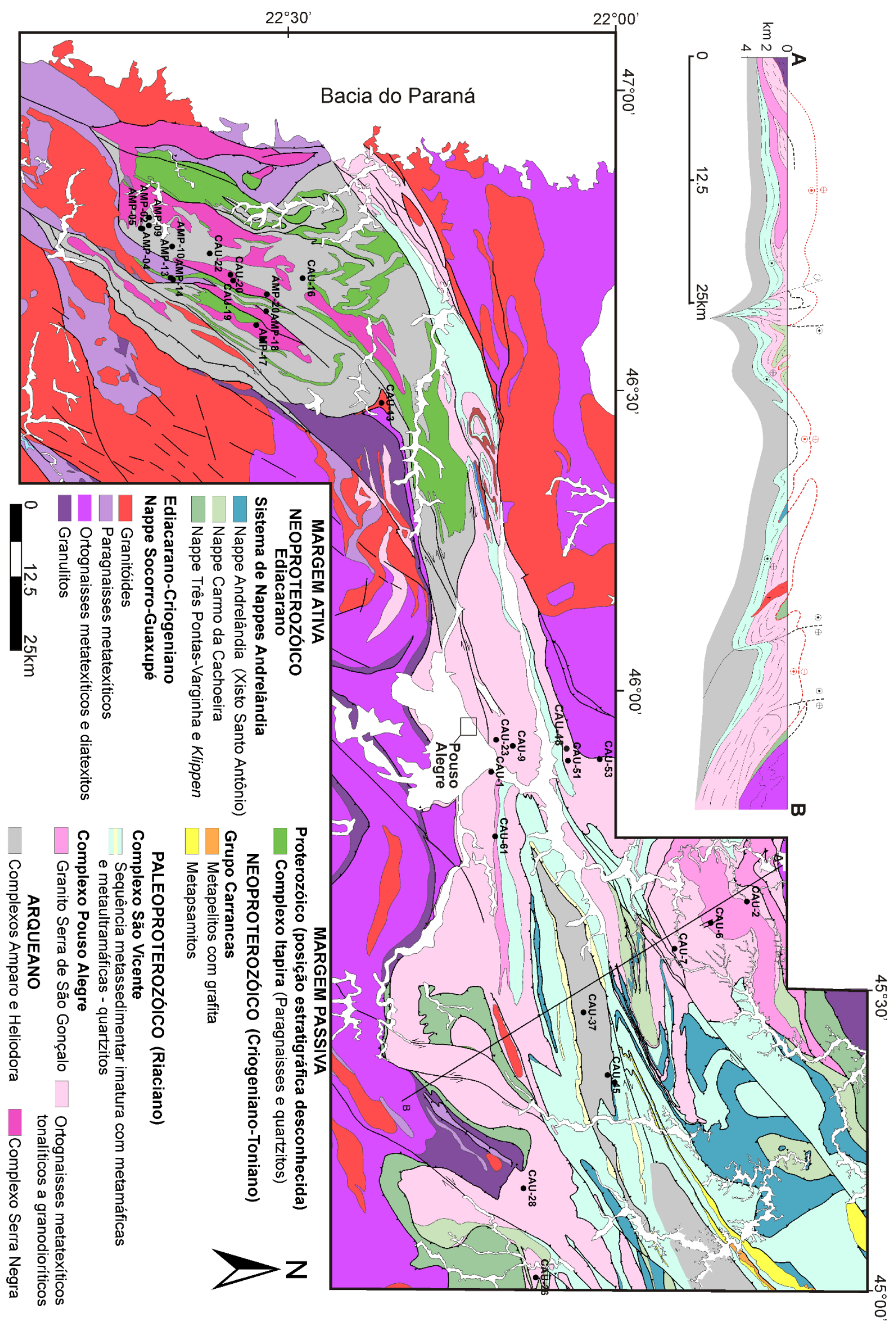

Figura 4.1 Mapa geológico da área de estudo com localização dos pontos amostrados. 


\subsection{Petrografia}

Durante o desenvolvimento desse projeto de pesquisa foram confeccionadas cem seções delgadas provenientes de trinta e três afloramentos. As seções delgadas foram analisadas através de microscópio óptico de luz transmitida, modelo Axioplan, da marca Zeiss. Essas análises tiveram como objetivo o estabelecimento das associações minerais, assim como as relações texturais nos diferentes litotipos amostrados. Essas informações foram utilizadas em conjunto com o restante dos dados obtidos na definição de um modelo petrogenético para as rochas estudadas.

\subsection{Geoquímica de rocha-total}

A preparação das amostras de rocha-total, para análises de geoquímica elemental e isotópica, foi realizada no Laboratório de Tratamento de Amostras (LTA) do NAP Geonalítica-USP, seguindo as seguintes etapas: 1) lavagem das amostras e retirada de porções alteradas da rocha; 2) fragmentação das amostras com marreta; 3 ) segunda etapa de lavagem e secagem, a fim de reduzir eventuais riscos de contaminação a partir da marreta; 4) fragmentação das amostras utilizando o britador com mandíbulas de aço; 5) quarteamento das amostras utilizando o quarteador Jones para a retirada de aproximadamente $100 \mathrm{~g}$ de amostra representativa; 6) fragmentação das amostras utilizando prensa hidráulica, na fração grânulo; 7) pulverização das amostras utilizando moinho com anéis de ágata até atingir fração inferior a 200 mesh; 8) pesagem de 7,5g de amostra; 9) micronização utilizando micronizadores de ágata; 10) secagem em estufa por 48hs; 11) pesagem de $7 \mathrm{~g}$ de amostra; 12) homogeneização manual da amostra com $20 \%$ de parafina em saco plástico; 13) confecção das pastilhas de pó prensado para análise dos elementos menores utilizando prensa hidráulica. As etapas de preparação das pastilhas vítreas para análise dos elementos maiores, realizadas no Laboratório de Química e ICP-MS do NAP Geonalítica-USP, foram as seguintes: 1) secagem em estufa por 24hs; 2) pesagem de $1 \mathrm{~g}$ de amostra; 3) pesagem de $9 \mathrm{~g}$ de fundente (meta/tetraborato de lítio); 4) homogeneização da amostra com o fundente em frasco de vidro; 5) fusão do material a $1200^{\circ} \mathrm{C}$ por 15 min para confecção das pastilhas vítreas.

No total, foram determinadas as concentrações de elementos maiores e menores em vinte e nove amostras, através de espectrometria de fluorescência de raios-X. Catorze análises foram realizadas no Laboratório de Fluorescência de Raios-X (FRX) do NAP Geoanalítica-USP, utilizando um equipamento automático Phillips, modelo PW2400, seguindo os procedimentos descritos por Mori et al. (1999). Quinze amostras foram analisadas no ACME laboratories, Vancouver-Canada, após fusão das amostras com meta/tetraborato de lítio. As análises químicas para a determinação dos elementos traço, incluindo os elementos terras-raras, de vinte e cinco amostras, foram realizados no Laboratório 
de Química e ICP-AES/MS do NAP Geonalítica-USP. Essas análises foram realizadas por espectrometria de massa com plasma induzido acoplado (Inductively Coupled Plasma-Mass Spectrometry) (ICP-MS), utilizando-se um ICP-MS do tipo quadrupolo, modelo ELAN 6100DRC, da marca PerkinElmer/Sciex. Antes da realização das análises, as amostras foram dissolvidas por ataque ácido $\left(\mathrm{HF}+\mathrm{HNO}_{3}\right)$, durante cinco dias, em bombas do tipo Parr, aquecidas a $200^{\circ} \mathrm{C}$ (para maiores detalhes sobre os procedimentos analíticos consultar Navarro et al., 2002 e 2008). Os resultados das análises de geoquímica de rochatotal são apresentados no ANEXO III.

\subsection{Isótopos de neodímio em rocha-total}

Alíquotas de dezenove amostras foram separadas para realização de análises das composições isotópicas de neodímio. Dez análises foram realizadas no Centro de Pesquisas Geocronológicas da Universidade de São Paulo (CPGeo-USP) utilizando-se um ICP-MS multicoletor, modelo Neptune, da marca Thermo Scientific. As mesmas amostras pulverizadas utilizadas para as análises de geoquímica elemental foram dissolvidas em ácido e posteriormente o neodímio foi separado em colunas iônicas, seguindo os procedimentos descritos em Sato (1995). Durante o período das análises, o padrão JNdi (Serviço Geológico do Japão; Tanaka et al., 2000; ${ }^{143} \mathrm{Nd} /{ }^{144} \mathrm{Nd}=0,512115 \pm 0,000007$ ) forneceu uma razão média ${ }^{143} \mathrm{Nd} /{ }^{144} \mathrm{Nd}$ de $0,512102 \pm 0,000006(1 \sigma)$. As composições isotópicas de neodímio de seis amostras foram determinadas por espectrometria de massa por ionização térmica utilizando-se um espectrômetro Finnigan MAT 262 no laboratório de geocronologia da Universidade de Brasília. Essas análises seguiram os procedimentos analíticos descritos em Gioia \& Pimentel (2000). Incertezas para razões ${ }^{143} \mathrm{Nd} /{ }^{144} \mathrm{Nd}$ dessas amostras são consideradas menores do que $\pm 0,005 \%$, baseado em repetidas análises dos materiais de referência BHVO-1 e BCR-1 (USGS). As razões isotópicas de neodímio de todas as amostras foram normalizadas para uma razão ${ }^{146} \mathrm{Nd} /{ }^{144} \mathrm{Nd}=0,7219$. As razões ${ }^{147} \mathrm{Sm} /{ }^{144} \mathrm{Nd}$ foram calculadas a partir das concentrações determinadas por ICP-MS. Os resultados das análises de isótopos de neodímio em rocha-total são apresentadas no ANEXO IV.

\subsection{Geocronologia U-Pb em zircão (LA-ICP-MS)}

Análises geocronológicas U-Pb in-situ foram realizadas em grãos de zircão de dezenove amostras através da metodologia LA-ICP-MS (laser ablation - inductively coupled plasma - mass spectrometry). Os grãos de zircão foram separados das amostras moídas através de processos padrão de separação de minerais pesados. Esses processos incluíram primeiramente a moagem das amostras em moinho de disco e peneiragem gradual até a obtenção de três frações, com as seguintes 
granulometrias: $60-100 \mu \mathrm{m} ; 100-250 \mu \mathrm{m}$ e $<250 \mu \mathrm{m}$. Em seguida, os concentrados de minerais pesados foram obtidos através do processamento em uma mesa separadora do tipo Wilfley. Os minerais magnéticos foram removidos do concentrado de minerais pesados através do uso de um imã de mão e de um separador magnético do tipo Frantz. Após a separação dos minerais magnéticos, os minerais pouco densos restantes foram removidos através do processamento em líquidos densos (bromofórmio e iodeto de metileno). Os zircões foram selecionados do concentrado de minerais pesados através do uso de uma lupa binocular e em seguida foram embutidos em mounts de resina epoxy e polidos até a metade da largura dos grãos para exposição das porções internas. As estruturas internas dos cristais de zircão foram investigadas com imagens de catodoluminescência $(\mathrm{CL})$, obtidas com microscópio eletrônico de varredura (MEV). As imagens de catodoluminescência serviram como guia para o posicionamento das análises U-Pb.

Catorze amostras foram analisadas no departamento de geologia da Universidade do Kansas utilizando-se um ICP-MS ELEMENT2 acoplado a um sistema de ablação a laser do tipo excimer 193nm, modelo Analyte.G2, da marca Photon Machines. Para essas análises foram utilizados spots circulares com diâmetro de $20 \mu \mathrm{m}$. O laser foi configurado para operar com fluência de $2,2 \mathrm{Jcm}^{-2}$ a uma taxa de repetição de $10 \mathrm{~Hz}$. O material resultante da ablação foi transportado para dentro do ICP-MS através de gás hélio. Fracionamento elemental, fracionamento downhole e calibração, foram realizados através da análise sistemática do padrão de referência primário GJ1 (Jackson et al., 2004). A redução dos dados foi realizada através do esquema de redução de dados VizualAge (Petrus \& Kamber, 2012) utilizando-se o programa IOLITE 2.5 (Paton et al., 2011). Durante as análises o padrão secundário Plesovice (Sláma et al., 2008) forneceu uma idade média ${ }^{206} \mathrm{~Pb} /{ }^{238} \mathrm{U}=339,6 \pm 0,6 \mathrm{Ma}(\mathrm{n}=119$; MSWD=2,2), dentro da margem de $1 \%$, em relação ao resultado de $337,13 \pm 0,37$ Ma obtido por IDTIMS (Sláma et al., 2008). Cinco amostras foram analisadas no CPGeo-USP utilizando-se um ICP-MS multicoletor, modelo Neptune, da marca Thermo Scientific, acoplado a um sistema de ablação a laser excimer 193nm, modelo Analyte, da marca Photon Machines. Para essas análises foram utilizados spots circulares de $32 \mu \mathrm{m}$ a uma taxa de repetição de $6 \mathrm{~Hz}$ e o material resultante da ablação foi transportado em gás hélio. O material de referência GJ1 foi utilizado como padrão primário e as correções foram realizadas com uma tabela excel in-house. Os dados dessas cinco amostras foram corrigidos para chumbo comum baseado no ${ }^{204} \mathrm{~Pb}$ e no modelo de Stacey \& Kramers (1975). Diagramas concordia, idades concordia e médias ponderadas foram calculadas através do programa Isoplot (Ludwig, 2003). Os resultados das análises U-Pb são apresentados no ANEXO V. 


\subsection{Isótopos de háfnio em zircão (LA-ICP-MS)}

Análises in-situ de isótopos de háfnio em zircão foram realizadas em sete amostras, utilizandose um ICP-MS multicoletor Thermo Scientific Neptune acoplado a um sistema de ablação a laser, da marca Photon Machines, modelo Analyte.193 nm no CPGeo-USP. As análises foram realizadas nos mesmos domínios internos dos cristais previamente datados pela técnica U-Pb. Foram utilizados spot circulares de $47 \mu \mathrm{m}$ de diâmetro, tempo de ablação de 60 segundos, taxa de repetição de $7 \mathrm{~Hz}$ e o material resultante da ablação foi transportado para dentro do ICP-MS em gás hélio. Os isótopos ${ }^{172} \mathrm{Yb}$, ${ }^{173} \mathrm{Yb},{ }^{175} \mathrm{Lu},{ }^{177} \mathrm{Hf},{ }^{178} \mathrm{Hf},{ }^{179} \mathrm{Hf},{ }^{180} \mathrm{Hf}$ and ${ }^{176}(\mathrm{Hf}+\mathrm{Yb}+\mathrm{Lu})$ foram analisados simultaneamente. As razões ${ }^{176} \mathrm{Hf} /{ }^{177} \mathrm{Hf}$ foram normalizadas para ${ }^{179} \mathrm{Hf} /{ }^{177} \mathrm{Hf}=0,7325$. O cálculo da razão ${ }^{176} \mathrm{Lu} /{ }^{177} \mathrm{Hf}$ foi baseado na razão ${ }^{176} \mathrm{Lu} /{ }^{175} \mathrm{Lu}=0,02669$. Correções das razões $\mathrm{Lu}$-Hf para fracionamento de massa foram realizadas aplicando-se as variações do material de referência GJ1. Os cálculos dos valores de $\varepsilon \mathrm{Hf}$ foram realizados baseados em uma constante de decaimento do ${ }^{176} \mathrm{Lu}=1,867 \times 10^{-11} \mathrm{a}^{-1}$ (Söderlund et al., 2004) e razões ${ }^{176} \mathrm{Hf} /{ }^{177} \mathrm{Hf}$ e ${ }^{176} \mathrm{Lu} /{ }^{177} \mathrm{Hf}$ para o condrito, nos dias atuais, igual a 0,282772 e 0,0332, respectivamente (Blichert-Toft and Albarède, 1997). Idades modelo duplo estágio foram calculadas assumindo-se o valor médio crustal para a razão ${ }^{176} \mathrm{Lu} /{ }^{177} \mathrm{Hf}=0,015$ (e.g., Griffin et al., 2002; Goodge and Vervoort, 2006). As razões ${ }^{176} \mathrm{Hf} /{ }^{177} \mathrm{Hf}=0,283225$ e ${ }^{176} \mathrm{Lu} /{ }^{177} \mathrm{Hf}=0,038512$ (Vervoort and BlichertToft, 1997) foram adotadas para o manto depletado. Os resultados das análises de isótopos de háfnio em zircão são apresentados no ANEXO VI.

\subsection{Geocronologia U-Pb e elementos traço em titanita (LA-ICP-MS)}

Análises geocronológicas U-Pb in-situ foram realizadas em cristais de titanita de três amostras através da metodologia LA-ICP-MS (laser ablation - inductively coupled plasma - mass spectrometry). Essas análises foram realizadas em seções delgadas, no departamento de geologia da Universidade do Kansas, utilizando-se um ICP-MS ELEMENT2 acoplado a um sistema de ablação a laser do tipo excimer 193nm, modelo Analyte.G2, da marca Photon Machines. Antes da realização das análises, os cristais de titanita tiveram suas estruturas internas investigadas através de imagens de elétrons retroespalhados, obtidas com um microscópio eletrônico de varredura FEIQuanta 600F no laboratório de microscopia (MAI) da Universidade do Kansas. Essas imagens foram o guia para a posicionamento dos spots analíticos. As análises U-Pb foram realizadas em spots circulares com diâmetro de $35 \mu \mathrm{m}$. $\mathrm{O}$ laser foi configurado para operar com fluência $4,0 \mathrm{Jcm}^{-2}$ e taxa de repetição de $10 \mathrm{~Hz}$. 0 material resultante da ablação foi carregado para dentro do ICP-MS através de gás hélio. Fracionamento elemental, fracionamento downhole e calibração, foram corrigidos através da análise sistemática ao longo do material de referência BLR-1 (Aleinikoff et al., 2007). A redução dos dados foi realizada 
através do esquema de redução de dados VizualAge (Petrus \& Kamber, 2012) utilizando-se o programa IOLITE 2.5 (Paton et al., 2011). Durante as análises, o padrão secundário P8 (Möller et al., 2000) forneceu uma idade relacionada ao intercepto inferior no diagrama Tera-Wasserburg de $614 \pm 10 \mathrm{Ma}$, dentro da margem de erro, da idade obtida por ID-TIMS. As análises de elementos traço em titanita também foram realizadas por LA-ICP-MS, nas mesmas seções delgadas datadas pela metodologia U$\mathrm{Pb}$. Para essas análises foram utilizados spots circulares com diâmetro de $25 \mu \mathrm{m}$. O laser foi configurado para operar com fluência $3,0 \mathrm{Jcm}^{-2}$ a uma taxa de repetição de $10 \mathrm{~Hz}$. Calibração externa foi realizada relativamente ao material de referência NIST-612, utilizando-se as concentrações apresentadas no banco de dados GeoRem, atualizadas em dezembro de 2009. As concentrações médias de silício para as titanitas de cada amostra, obtidas através de análises por microssonda eletrônica, foram utilizados como padrões internos. O material de referência BLR-1 (Aleinikoff et al., 2007) foi analisado como padrão secundário para verificação da acurácia e reprodutibilidade dos dados. Os resultados das análises U-Pb em titanita são apresentados no ANEXO VII e as análises de elementos traço no ANEXO VIII.

\subsection{Análises minerais por microssonda eletrônica}

Mapas composicionais e análises quantitativas (WDS) foram realizadas através de uma microssonda eletrônica da marca JEOL, modelo JXA-FE-8530, com canhão eletrônico suportado por Field Emission (FE), no NAP Geonalítica-USP. Análises quantitativas foram realizadas com feixe de elétrons focado a 15 kV e 20 nA. Foram realizadas análises quantitativas de granada, anfibólio, feldspato e titanita. Granada, anfibólio e titanita foram analisados com spots de $5 \mu \mathrm{m}$ de diâmetro e o feldspato foi analisado com spots de $10 \mu \mathrm{m}$. Mapas composicionais foram coletados a $15 \mathrm{kV}$ com corrente de 250 nA e tempo de permanência de 40 ms. A distribuição catiônica dos minerais foi recalculada com o software AX (http://www.esc.cam.ac.uk/research/research-groups/holland/ax). Resultados representativos das análises minerais por microssonda eletrônica são apresentados no ANEXO IX.

\subsection{Referências bibliográficas}

Aleinikoff, J.N., Wintsch, R.P., Tollo, R.P., Unruh, D.N., Fanning, C.M., Schmitz, M.D., 2007. Ages and origins of rocks of Killingworth dome, South-central Connecticut: Implications for the tectonic evolution of southern New England. American Journal of Science 307, 63-118. 
Blichert-Toft, J., Albarède, F., 1997. The Lu-Hf isotope geochemistry of chondrites and the evolution of the mantle-crust system. Earth and Planetary Science Letters 148, 243-258.

Campos Neto, M. C. - 1991 - A porção ocidental da Faixa Alto rio Grande - ensaio de Evolução Tectônica. Tese de Doutoramento - Universidade de São Paulo, 210p.

Gioia, S.M.C.L., Pimentel, M.M., 2000. The Sm-Nd method in the geochronology laboratory of the University of Brasília. Anais da Academia Brasileira de Ciências 72, 219-245.

Goodge, J.W., Vervoort, J.D., 2006. Origin of Mesoproterozoic A-type granites in Laurentia: $\mathrm{Hf}$ isotope evidence. Earth and Planetary Science Letters 243, 711-731.

Griffin, W.L., Wang, X., Jackson, S.E., Pearson, N.J., O’Reilly, S.Y., Xu, X., Zhou, X., 2002. Zircon chemistry and magma mixing, SE China: In-situ analysis of $\mathrm{Hf}$ isotopes, Tonglu and Pingtan igneous complexes. Lithos 61, 237-169.

Jackson, S.E., Pearson, N.J., Griffin, W.L., Belousova, E.A., 2004. The application of laser ablationinductively coupled plasma-mass spectrometry to in-situ U-Pb zircon geochronology. Chemical Geology 211, 47-69.

Ludwig, K.R., 2003. Isoplot/Ex 3.00: A geochronological toolkit for Microsoft Excel. Berkeley Geochronology Center Special Publication, 4.

Morais, S.N., 1999a. Programa Levantamentos Geológicos Básicos do Brasil: Integração Geológica da Folha Campinas . (Escala) 1:250.000 SF-23-Y-A. Estados de São Paulo e Minas Gerais (Nota Explicativa) - São Paulo - CPRM (26pp.).

Morais, S.N., 1999b. Programa Levantamentos Geológicos Básicos do Brasil: Integração Geológica da Folha Guaratinguetá. (Escala) 1:250.000 SF-23-Y-B. Estados de São Paulo e Minas Gerais (Nota Explicativa) - São Paulo - CPRM (28pp.).

Mori, P.E., Reeves, S., Correia, C.T., Haukka, M., 1999. Development of fused glass disc XRF facility and comparisson with the pressed poder pellet technique at Instituto de Geociências, Universidadade de São Paulo. Revista Brasileira de Geociências 29, 441-446.

Navarro, M.S., Ulbrich, H.H.G.J., Andrade, S., Janasi, V.A., 2002. An adaptation of ICP-OES routine determination techniques for the analysis of rare-earth elements by chromatographic separation en geologic materials: test with reference material and granitic rock. Journal of Alloys and Compounds $344,40-45$.

Navarro, M.S., Andrade, S., Ulbrich, H., Gomes, C.B., Girardi, V.A.V., 2008. The direct determination of rare Earth elements in basaltic and related rocks using ICP-MS: Testisng the efficiency of microwave oven sample decomposition procedures. Geostandards and Geoanalytical Research 32, 167-180. 
Paton, C., Hellstrom, J., Paul, B., Woodhead, J., Hergt, J., 2011. Iolite:Freeware for the visualisation and processing of mass spectrometry data. Journal of Analytical Atomic Spectrometry 26, 2508-2518.

Perrota, M.M., 1991. A Faixa Alto Rio Grande na região de São Gonçalo do Sapucaí, MG. Unpublished Master's dissertation, IGc-USP, (158pp.).

Petrus, J.A., Kamber, B.S., 2012. VizualAge: A Novel Approach to Laser Ablation ICP-MS U-Pb Geochronology Data Reduction. Geostandards and Geoanalytical Research 36, 247-270.

Peternel, R., 2005. A zona de superposição entre as Faixas Brasília e Ribeira na região entre Caxambu e Pedralva, sul de Minas Gerais. Unpublished PhD Thesis. Instituto de Geociências - UFRJ, (257pp.).

Sláma, J., Košler, J., Condon, D.J., Crowley, J.L., Gerdes, A., Hanchar, J.M., Horstwood, S.A., Morris, G.A., Nasdala, L., Norberg, N., Schaltegger, U., Schoene, B., Tubrett, M.N., Whitehouse, M.J., 2008. Plešovice zircon - A new natural reference material for $\mathrm{U}-\mathrm{Pb}$ and $\mathrm{Hf}$ isotopic microanalysis. Chemical Geology 249, 1-35.

Söderlund, U., Patchett, P.J., Vervoort, J.D., Isachsen, C.E., 2004. The ${ }^{176}$ Lu decay constant determined by $\mathrm{Lu}-\mathrm{Hf}$ and $\mathrm{U}-\mathrm{Pb}$ isotope systematics of Precambrian mafic intrusions. Earth and Planetary Sciences Letters 219, 311-324.

Stacey, J.S., Kramers, J.D., 1975. Approximation of terrestrial lead isotope evolution by two-stage model. Earth and Planetary Science Letters 26, 207-221.

Tanaka, T; Togashi, S., Kamioka, H., Amakawa, H., Kagami, H., Hamamoto, T., Yuhara, M., Orihashi, Y., Yoneda, S., Shimizu, H., Kunimaru, T., Takahashi, K., Yanagi, T., Nakano, T., Fujimaki, H., Shinjo, R., Asahara, Y., Tanimizu, M., Dragusanu, C., 2000. JNdi-1: a neodymium isotopic reference in consistency with LaJolla neodymium. Chemical Geology 168, 279-281.

Trouw, R.A.J., Nunes, R.P.M., Castro, E.M.O., Trouw, C.C., Matos, G.C., 2008. Nota explicativa das Folhas Varginha (SF.23-V-D-VI) e Itajubá (SF.23-Y-B-III). Programa Geologia do Brasil. Contrato CPRMUFRJ N067/PR/05. (99pp).

Vervoort, J.D., Blichert-Toft, J., 1999. Evolution of the depleted mantle: Hf isotopic evidence from juvenile rocks through time. Geochimica et Cosmochimica Acta 63, 533-556. 


\section{O Complexo Pouso Alegre: eventos paleoproterozóicos de geração de crosta continental no embasamento do Orógeno Brasília meridional}

Neste capítulo são apresentados novos dados de geocronologia U-Pb em zircão, geoquímica elemental e isotópica ( $\mathrm{Nd}-\mathrm{Hf}$ ) dos ortognaisses do Complexo Pouso Alegre, que constituem o embasamento paleoproterozóico do Orógeno Brasília meridional. Os dados e interpretações são apresentados na íntegra no artigo "Paleoproterozoic continental crust generation events at 2.15 and $2.08 \mathrm{Ga}$ in the basement of the Southern Brasilia Orogen, SE Brazil” (ANEXO I). Portanto, a leitura do mesmo é imprescindível para compreensão da discussão e conclusões apresentadas nessa tese. Esse artigo foi publicado no periódico científico Precambrian Research.

\subsection{Resumo do artigo}

Novos dados U-Pb em zircão (LA-ICP-MS) combinados com isótopos de $\mathrm{Nd-Hf}$ e geoquímica elemental fornecem informações sobre a idade e ambientes tectônicos de eventos de geração de crosta continental no embasamento paleoproterozóico do Orógeno Brasília meridional. O embasamento paleoproterozóico, denominado Complexo Pouso Alegre, é constituído predominantemente por ortognaisses metatexíticos, de composição tonalítica a granodiorítica com lentes e/ou boudins de rochas metamáficas associadas. Corpos de granito porfiroclástico ocorrem subordinadamente. Foram reconhecidos dois grupos de idades de cristalização bem definidos a 2,14 - 2,15 Ga (6 amostras; média ponderada de 2146,7 $\pm 6,7 \mathrm{Ma}$ ) e 2,07 - 2,08 Ga (5 amostras; média ponderada de 2078,7 $\pm 6,7 \mathrm{Ma}$ ). Grãos de zircão herdados são praticamente ausentes. Dados de isótopos de neodímio em rocha-total apresentam assinaturas juvenis com idades modelo $\mathrm{T}_{\mathrm{DM}}$ entre 2,16 e 2,37 $\mathrm{Ga}$ associadas a valores positivos de $\varepsilon \mathrm{Nd}_{(\mathrm{t})}$ entre +1.9 e +8.7 . Análises de geoquímica de rocha-total apresentam uma ampla variação nos conteúdos de $\mathrm{SiO}_{2}$ entre 52 e 76\%, sendo os litotipos félsicos mais abundantes. As amostras analisadas apresentam altas concentrações de $\mathrm{Rb}, \mathrm{Ba}$, Th, $\mathrm{U}$ e baixas razões $\mathrm{Nb} / \mathrm{La}$, que são características de magmas de zonas de subducção, sendo que a maioria das amostras apresenta afinidades de arco continental. As assinaturas geoquímicas associadas a predominância de litotipos félsicos sugerem margens continentais ou arcos oceânicos evoluídos como prováveis ambientes tectônicos para geração do Complexo Pouso Alegre. O Complexo Pouso Alegre é interpretado como a porção mais meridional e mais nova de um sistema de arcos instalado na borda sul do cráton do São Francisco durante o Paleoproterozóico. Essa parte do complexo de arcos foi profundamente retrabalhada pelos eventos colisionais relacionados ao Orógeno Brasília meridional e seu análogo cratônico é o Cinturão Mineiro, na porção sul do cráton do São Francisco. O Complexo Pouso Alegre e 
as suítes juvenis do Cinturão Mineiro representam um importante evento de geração de crosta continental entre 2.35 e $2.08 \mathrm{Ga}$. Esse período não é reconhecido por extensiva geração e preservação de crosta continental em escala global. Porém, esse parece ser um importante período de geração e preservação de crosta continental na borda sul do paleocontinente São Francisco. 


\section{Os complexos arqueanos: microcontinentes acrescionados ao paleocontinente São}

Francisco

Neste capítulo são apresentados novos dados de geocronologia U-Pb em zircão, geoquímica elemental e isotópica (Nd-Hf) dos complexos Amparo, Serra Negra e Heliodra-Minduri, que constituem - embasamento arqueano do Orógeno Brasília meridional. Os dados e interpretações são apresentados na íntegra no artigo "Tectonic significance of the Meso- to Neoarchean complexes in the basement of the southern Brasilia Orogen" (ANEXO II). Portanto, a leitura do mesmo é imprescindível para compreensão da discussão e conclusões apresentadas nessa tese. Esse artigo foi submetido para publicação no periódico científico Precambrian Research.

\subsection{Resumo do artigo}

A maior parte das evidências sobre o crescimento do paleocontinente São Francisco estão escondidas dentro dos orógenos que circundam o cráton do São Francisco. Os complexos de embasamento dentro desses orógenos podem fornecer informações valiosas sobre os processos de crescimento continental. Esse estudo investiga os complexos meso- a neoarqueanos do embasamento do Orógeno Brasília meridional através de uma combinação de geocronologia e isótopos de háfnio em zircão, assim como, geoquímica e isótopos de neodímio em rocha-total. Esses novos dados são utilizados para discutir a evolução arqueana desses complexos e seus papéis na aglomeração do paleocontinente São Francisco. Um período bem definido de magmatismo do tipo TTG foi identificado entre 2,96 e 3,00 Ga. Essas amostras fornecem valores de $\varepsilon \mathrm{Hf}_{(\mathrm{t})}$ predominantemente positivos entre $-0,4$ e $+4,7$ associados a idades modelo duplo estágio entre 3,2 e 3,4 Ga. Esses resultados sugerem fontes juvenis com participação de crosta ligeiramente mais antiga que corroboram com as heranças em zircão a aproximadamente 3,19 Ga. Um período adicional de magmatismo granítico neoarqueano a aproximadamente $2,76 \mathrm{Ga}$ é interpretado como produto da transição neoarqueana entre magmatismo do tipo TTG e magmatismo granítico de alto potássio. Esse magmatismo neoarqueano é associado a assinaturas isotópicas menos radiogênicas, com valores negativos de $\varepsilon \mathrm{Hf}_{(t)}$, entre $-0,6$ e $-7,1$, e $\varepsilon \mathrm{Nd}_{(t)}=$ $-2,5$. No entanto, as fontes desse magmatismo granítico continuam indefinidas.

Os complexos arqueanos investigados estão separados da crosta arqueana da porção sul do cráton do São Francisco pelo sistema de arcos composto pelo Complexo Pouso Alegre e Cinturão Mineiro. Dados publicados da crosta arqueana na porção sul do cráton do São Francisco apresentam idades de cristalização entre 3,22 e 2,72 Ga, com um hiato entre aproximadamente 3,20 e 2,93 Ga. Portanto, os 
dados apresentados nesse trabalho indicam que os complexos arqueanos no embasamento do Orógeno Brasília meridional são exóticos ao cráton do São Francisco, porque eles apresentam idades de cristalização dentro do hiato magmático. Baseado no contexto geológico e dados geocronológicos, é proposto que os complexos arqueanos no embasamento do Orógeno Brasília meridional são microcontinentes arqueanos que foram acrescionados ao paleocontinente São Francisco. A idade da acresção não é bem definida, porém provavelmente ocorreu durante o Paleoproterozóico, após 2,08Ga. 


\section{O retrabalhamento neoproterozóico do Complexo Pouso Alegre}

\subsection{Relações de campo}

O Complexo Pouso Alegre é constituído predominantemente por ortognaisses de composição tonalítica a granodiorítica com bandamento composicional paralelo a foliação gnáissica (Figs. 7.1a, b) e paralelo a leucossomas estromáticos com espessura entre aproximadamente $1 \mathrm{~mm}$ e $10 \mathrm{~cm}$ (Figs. 7.1a-f). O bandamento composicional, em grande parte herdado dos protólitos ígneos, é resultado de reorientação e paralelização de contatos preexistentes durante o desenvolvimento da foliação. Rochas máficas ocorrem como boudins, com espessura entre $10 \mathrm{~cm}$ e $10 \mathrm{~m}$, orientados paralelamente a foliação (Figs. 7.1c e 7.2c). Acumulação de fundido em zonas surreicas de boudins é uma estrutura comum (Fig. 7.1c) e sugere que a fusão parcial foi contemporânea a deformação em um regime com importante extensão paralela a foliação. Leucossomas estromáticos estão frequentemente dobrados em dobras apertadas com plano axial paralelo a foliação principal (Figs. 7.1d, e), sendo comum a ocorrência de porfiroblastos de anfibólio \pm biotita associados a leucossomas (Fig. 7.1f).

Diques de leucogranito de granulação grossa a muito grossa, com espessura entre 2 e $50 \mathrm{~cm}$, são abundantes em afloramentos nos arredores de Pouso Alegre - MG. Esses diques apresentam orientações diversas, localmente concordantes com a foliação dos gnaisses migmatíticos e também cortando a mesma em um arranjo em rede (Fig. 7.2). Nas regiões mais deformadas a orientação geral dos diques tende a paralelizar-se com a foliação principal (Fig. 7.2). Nessas regiões a diversidade de orientações pretéritas dos diques é destacada pela presença de diques estirados com orientação paralela a foliação e diques dobrados com orientação perpendicular a foliação. Localmente o mesmo dique está estirado em uma porção e dobrado em outra, indicando que o mesmo não se encontrava homogeneamente orientado em relação ao campo de esforço (Figs. 7.2e, f). Em alguns diques observase um ramo principal discordante da foliação e ramos secundários de menor dimensão concordantes com a foliação (Fig. 7.2d). O predomínio é de leucogranitos (IC-2-3\%) grossos a muito grossos (Figs. 7.3a, b) com megacristais de plagioclásio e K-feldspato pertítico em meio a matriz quartzo-feldspática recristalizada.

\subsection{Evidências nos ortognaisses}

Com o intuito de investigar as condições P-T-t às quais o Complexo Pouso Alegre foi submetido durante o retrabalhamento Neoproterozóico, três amostras de ortognaisses foram selecionadas para análises de química mineral em fases principais (granada, anfibólio e feldspato), análises U-Pb em titanita e análises de elementos traço em titanita. O critério principal para seleção das amostras foi a presença mútua de granada e titanita. A amostras estão localizadas na Figura 4.1 (capítulo 4 Materiais e métodos). 

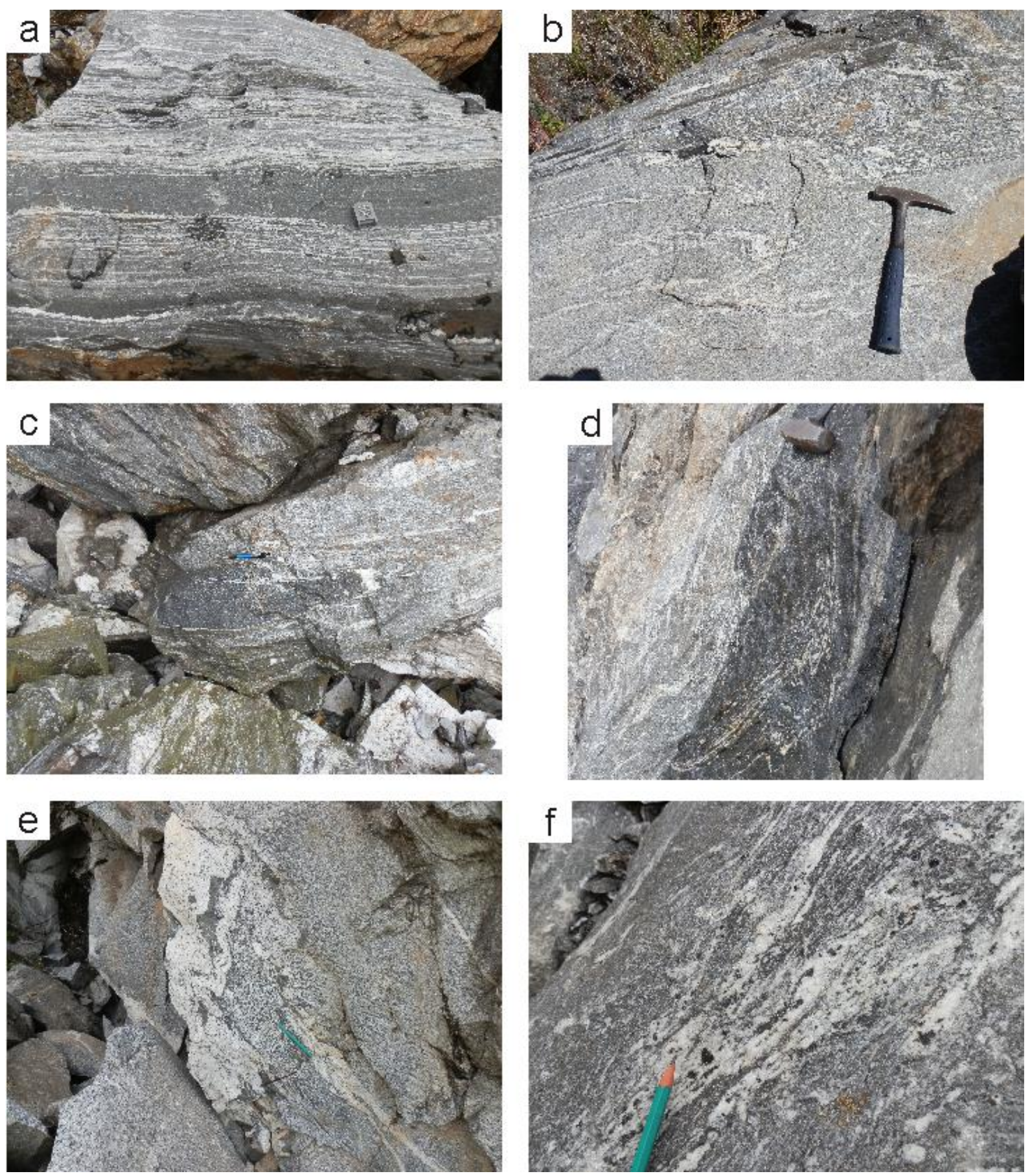

Figura 7.1. (a,b) Bandamento composicional paralelo a leucossomas estromáticos;. (c) Boudin de rocha máfica com espessura entre aproximadamente 10 e $15 \mathrm{~cm}$ orientado paralelamente a foliação principal - notar acumulação de fundido no boudin neck; $(\mathrm{d}, \mathrm{e})$ Leucossomas com espessura entre aproximadamente $<1 \mathrm{~cm}$ a até $15 \mathrm{~cm}$ dobrados em dobras apertadas com foliação principal paralela aos planos axiais das dobras; (f) Cristais de anfibólio de até aproximadamente $1 \mathrm{~cm}$ associados a leucossomas. 

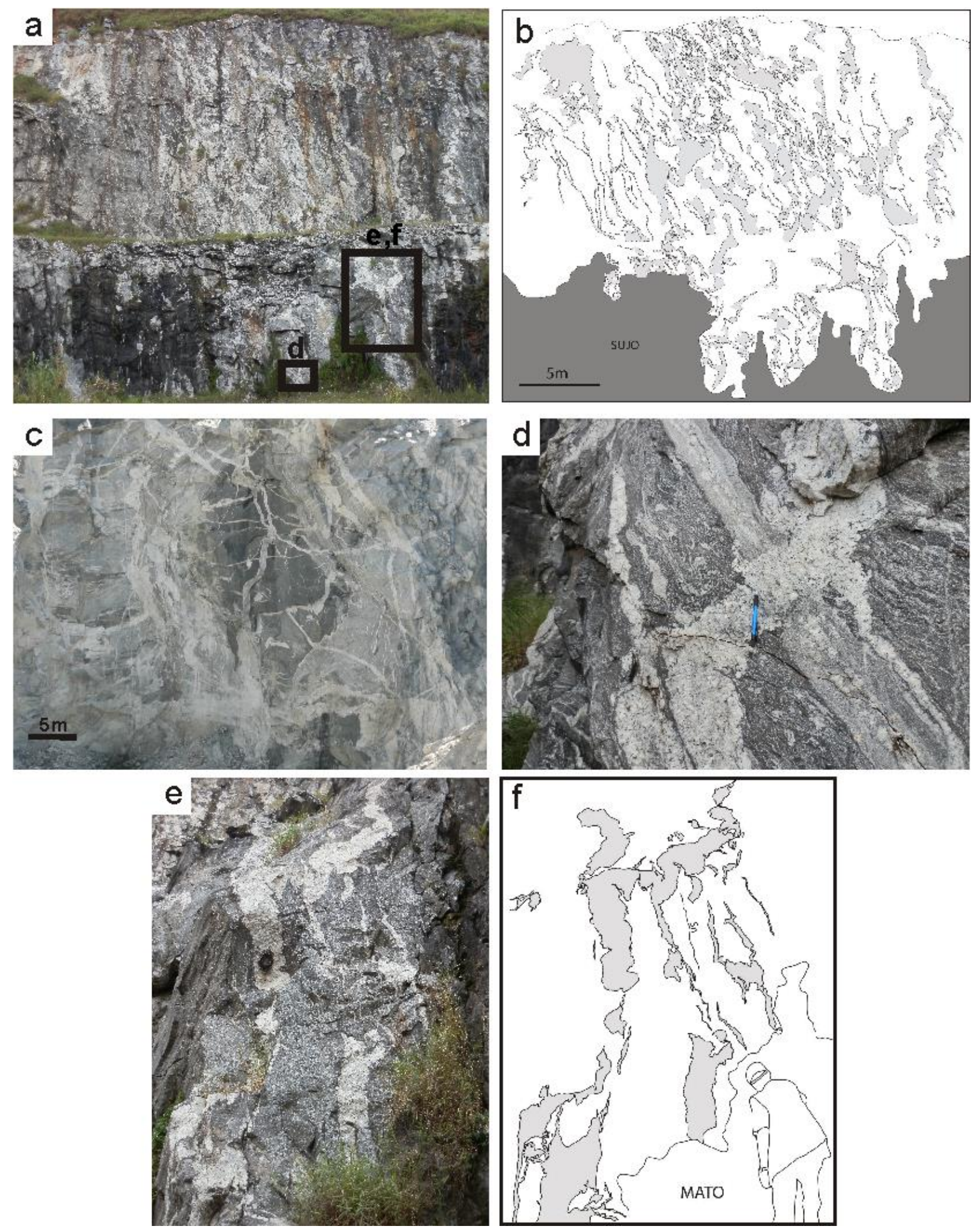

Figura 7.2. (a,b) Injeções de leucogranito paralelizadas com a foliação principal em zonas de maior deformação

- (a) foto com áreas das figuras d-f demarcadas e (b) croqui com injeções de leucogranito destacadas em cinza;

(c) Boudin decamétrico de rocha máfica em meio a biotita gnaisses migmatíticos, sendo que todo conjunto está cortado por vários diques de leucogranito de orientações diversas; (d) Dique de leucogranito com orientação geral discordante da foliação principal e ramificações paralelas a foliação; $(e, f)$ Dique de leucogranito em parte dobrado e em parte separado em boudins - (a) foto e (b) croqui. 

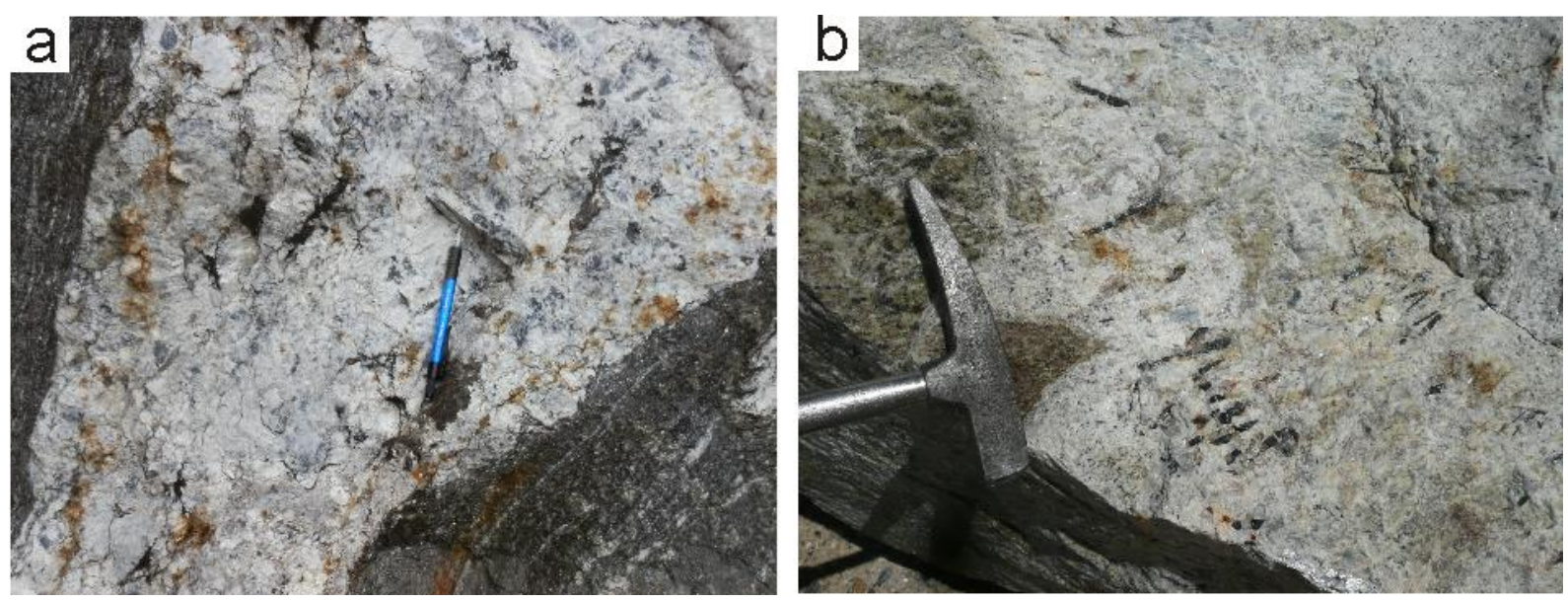

Figura 7.3. (a) Dique de leucogranito grosso a muito grosso paralelo à foliação do biotita-hornblenda gnaisse; (b) Cristais prismáticos de turmalina de até aproximadamente $5 \mathrm{~cm}$ associados a leucogranito grosso

\subsubsection{Descrição das amostras de ortognaisses analisadas}

\subsubsection{Amostras 1D e 1E (ortognaisses tonalíticos)}

As amostras 1D e 1E são biotita-hornblenda gnaisses com granada e zoisita de composição tonalítica, coloração cinza escuro e índice de cor entre 15 e 20\%. Essas amostras apresentam estrutura foliada e textura predominantemente granoblástica inequigranular média com cristais de hornblenda de até aproximadamente $7 \mathrm{~mm}$ homogeneamente distribuídos, orientados na direção da foliação e parcialmente substituídos por biotita (Figs. 7.4a, b). Zoisita ocorre na forma de agregados de cristais submilimétricos associados aos leitos ricos em biotita (Fig. 7.4c). Granada ocorre como cristais submilimétricos, localmente inclusos em hornblenda (Fig. 7.4d) e também como cristais poiquiloblásticos de até aproximadamente $5 \mathrm{~mm}$ de diâmetro, ricos em inclusões de quartzo, plagioclásio, biotita e hornblenda (Figs. 7.4 e, f). Plagioclásio ocorre como grãos de até $3 \mathrm{~mm}$ com textura granoblástica. Quartzo está em grande parte recristalizado em granulação fina. Grãos maiores de até aproximadamente $3 \mathrm{~mm}$, são alongados na direção da foliação e apresentam forte extinção ondulante. Minerais acessórios frequentes incluem titanita, apatita, opacos, clorita e zircão.

\subsubsection{Amostra 9B (ortognaisse granodiorítico)}

A amostra 9B é um hornblenda-biotita gnaisse de composição granodiorítica, coloração cinza claro e índice de cor entre 10 e 12\%. A amostra apresenta estrutura foliada/bandada com intercalação de leitos de 2 a $10 \mathrm{~mm}$ de espessura com textura predominantemente nematolepidoblástica fina-

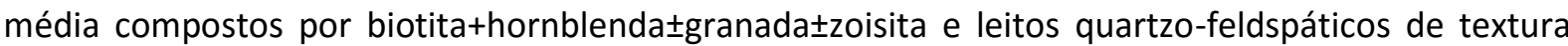
granoblástica fina-média e espessura entre 1 e 4mm (Figs. 7.5a, b). Hornblenda ocorre como cristais de até aproximadamente $2 \mathrm{~mm}$, orientados na direção da foliação e parcialmente substituídos por 
biotita (Fig. 7.5c). Granada ocorre como cristais de até aproximadamente $2 \mathrm{~mm}$, livre de inclusões, associados aos leitos ricos em hornblenda e biotita (Figs. 7.5a, b). Epidoto/zoisita ocorrem como agregados de cristais anédricos a subeuédricos associados aos leitos ricos em biotita (Fig. 7.5d). Plagioclásio, microclínio e quartzo ocorrem em textura granoblástica fina-média e é comum a ocorrência de mesopertita associada a leitos de leucosoma. Localmente, ocorrem núcleos de alanita em cristais subeuédricos de epidoto/zoisita (Figs. 7.5e, f). Minerais acessórios frequentes incluem: titanita, apatita, opacos e zircão.
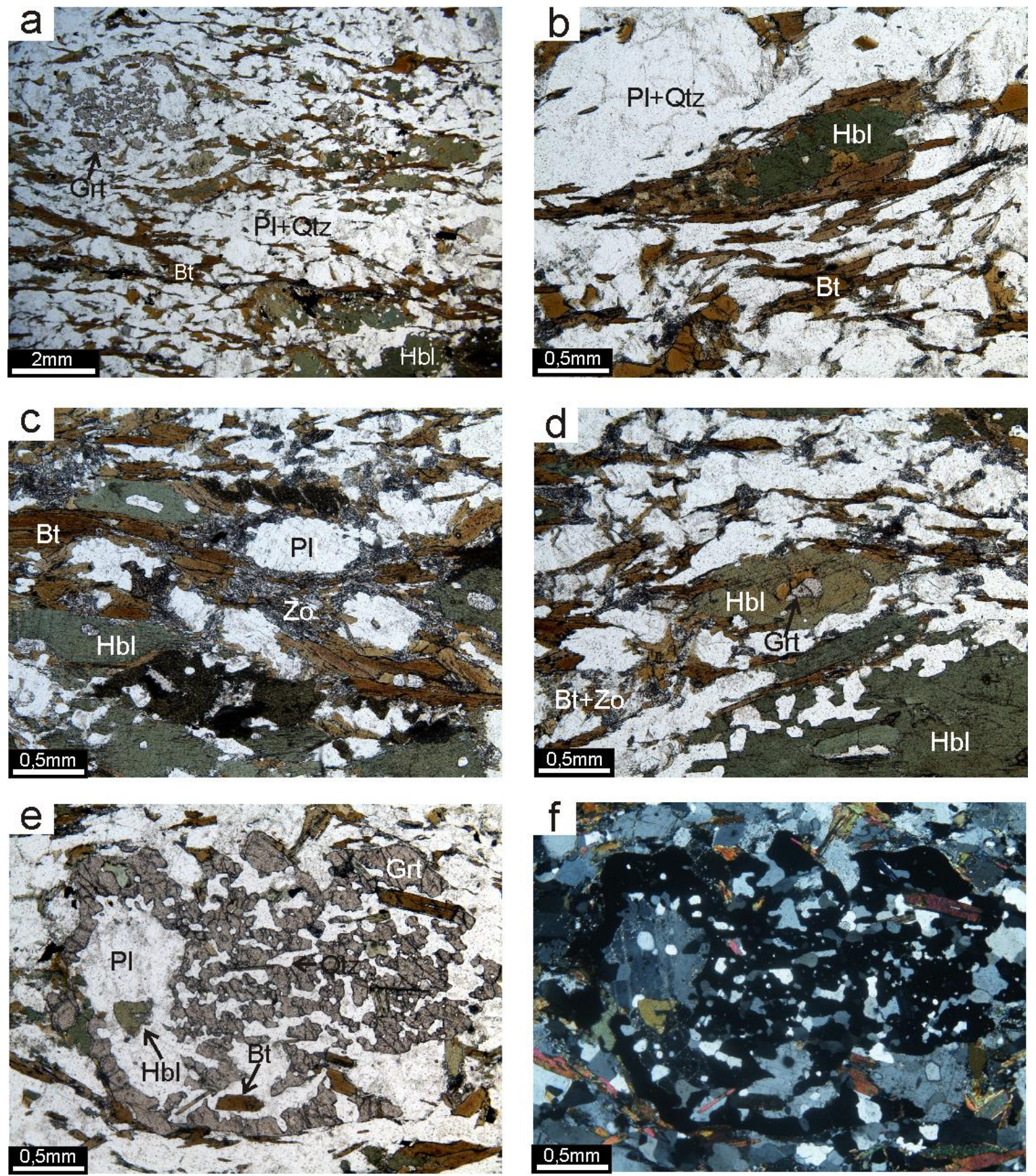

Figura 7.4. Fotomicrografias amostras $1 \mathrm{D}$ e $1 \mathrm{E}$ (ortognaisses tonalíticos). (a) Textura nematogranoblástica inequigranular média com cristais de hornblenda parcialmente substituídos por biotita - Nicóis descruzados; (b) Cristal de hornblenda parcialmente substituído por biotita - Nicóis descruzados; (c) Agregados de zoisota associados a leitos ricos em biotita - Nicóis descruzados (d) Cristal de granada incluso em hornblenda - Nicóis 
descruzados; (e) Porfiroblasto poiquiloblástico de granada com inclusões de plagioclásio, quartzo, hornblenda e biotita - Nicóis descruzados; (f) idem a figura 4e com nicóis cruzados.
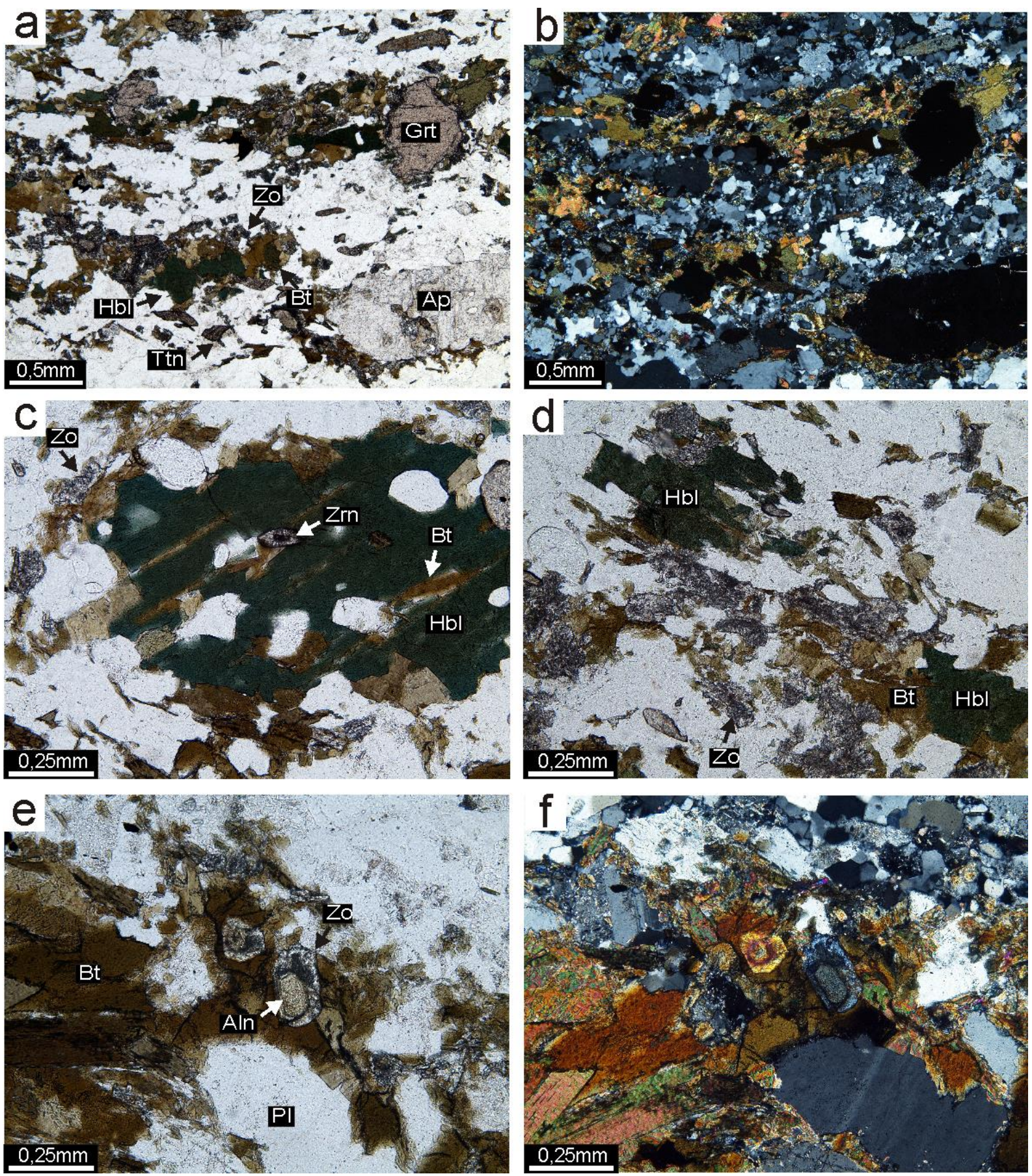

Figura 7.5. Fotomicrografias amostra 9B (ortognaisse granodiorítico) (a,b) Intercalação de leitos lepidonemablásticos ricos em biotita + hornblenda \pm granada e leitos granoblásticos constituídos por plagioclásio, microclínio e quartzo - (a) Nicóis descruzados e (b) Nicóis cruzados; (c) Cristal de hornblenda parcialmente substituído por biotita - Nicóis descruzados; (d) Agregados de zoisita associados a biotita - Nicóis 
descruzados; (e,f) Cristais subeuédricos de alanita com bordas substituídas por epidoto/zoisita - (e) Nicóis descruzados e (f) Nicóis cruzados.

\subsubsection{Química mineral}

Visando a realização de cálculos termobarométricos, as composições de granada, anfibólio e plagioclásio das três amostras descritas no item anterior (1D, 1E e 9B) foram determinadas por microssonda eletrônica no núcleo de apoio a pesquisa geoanalítica da Universidade de São Paulo (NAP GEOANALÍTICA-USP). As composições de biotita não foram consideradas nos cálculos termobarométricos, pois a mesma é produto de reações retrometamórficas e encontra-se em claro desequilíbrio textural com o anfibólio (Figs. 7.4 e 7.5). Os procedimentos analíticos são descritos no capítulo 4 (Materiais e métodos).

\subsubsection{Granada}

Nas amostras de gnaisses tonalíticos (1D e 1E) todos os cristais de granada analisados são ricos em almandina $\left(X_{\mathrm{alm}}=0,50-0,60\right.$. Cristais maiores do que $500 \mu \mathrm{m}$ tendem a apresentar núcleos mais ricos em almandina $\left(X_{\mathrm{alm}}=0,55-0,60\right)$ e bordas externas com conteúdos mais baixos $\left(X_{\mathrm{alm}}=0,50\right)$ (Fig. 7.6). Os teores de grossulária são relativamente elevados em todos os cristais de granada analisados, com valores de $X_{\text {grs }}$ entre 0,30 e 0,33 nos núcleos dos cristais e ligeiramente mais baixos, entre 0,28 e 0,30, nas bordas. A queda nos conteúdos de almandina e grossulária nas bordas dos cristais é diretamente associada a um aumento nos teores de espessartita. Os núcleos dos cristais apresentam baixos conteúdos de espessartita $\left(X_{\mathrm{sps}}=0,04-0,06\right)$. Em regiões da borda externa dos cristais, com espessura variando entre aproximadamente $50-150 \mu \mathrm{m}$, ocorre um aumento expressivo nos conteúdos de espessartita com valores de $\mathrm{X}_{\text {sps }}$ entre 0,15-0,17 (Fig. 7.6). Cristais menores do que 500 $\mu m$ tendem a ser ricos em espessartita (Fig. 7.7) com valores de $X_{\text {sps }}$ entre aproximadamente 0,10 e 0,15 . Os conteúdos de piropo são baixos em todos os cristais analisados, com valores de $X_{\text {prp }}$ entre 0,06 e 0,07 nos núcleos dos cristais e levemente mais baixos, em torno de 0,05 , nas bordas externas.

Os cristais de granada do gnaisse granodiorítico (amostra 9B) também apresentam altos conteúdos de almandina $\left(X_{\mathrm{alm}}=0,53-0,59\right)$ e grossulária $\left(X_{\mathrm{grs}}=0,34-0,45\right)$. Alguns cristais apresentam núcleo mais rico em grossulária, com valores de $X_{\text {grs }}$ entre 0,40 e 0,45, e bordas com valores um pouco mais baixos, em torno de 0,36-0,39 (Fig. 7.6d). A queda nos conteúdos de grossulária em direção às bordas dos cristais é diretamente associada a um aumento nos conteúdos de almandina ( $X_{\text {alm }}$ núcleos $=0,53-0,56 ; X_{\text {alm }}$ bordas $=0,57-0,59$ ) e piropo ( $X_{\text {prp }}$ núcleos $=0,01-0,02 ; X_{\text {prp }}$ bordas $\left.=0,03-0,04\right)$. Os conteúdos de espessartita não apresentam variações expressivas ao longo dos cristais e são geralmente baixos $\left(X_{\text {sps }}=0,01-0,02\right)$, sendo a única exceção um pequeno cristal, incluso em anfibólio, 
de aproximadamente $100 \mu \mathrm{m}$ de diâmetro. Nesse cristal os conteúdos de espessartita são consideravelmente mais altos $\left(X_{\text {sps }}=0,11-0,13\right)$. Esses conteúdos mais altos de espessartita estão associados a conteúdos relativamente mais baixos de grossulária $\left(X_{\mathrm{grs}}=0,31-0,33\right)$ e almandina $\left(\mathrm{X}_{\mathrm{alm}}\right.$ $=0,52-0,55)$.

\subsubsection{Anfibólio}

Todo o anfibólio presente nas amostras de gnaisses tonalíticos (amostras 1D e 1E) é classificado como anfibólio cálcico $\left(\mathrm{Ca}^{(\mathrm{B})} \geq 1,5\right)$ e apresenta valores de $\mathrm{Na}+\mathrm{K}^{(\mathrm{A})}$ abaixo de 0,5. É possível a distinção de dois trends composicionais (Fig. 7.8a). A primeira população é constituída por cristais de anfibólio presentes em bandas sem granada da amostra 1E (Fig. 7.8). Esses cristais apresentam os conteúdos mais elevados de silício ( $\mathrm{Si}=6,40-6,76 \mathrm{apfu}$ ) e maiores razões $\mathrm{Mg} /\left(\mathrm{Mg}+\mathrm{Fe}^{2+}\right)$, em geral acima de 0,5. Segundo o esquema proposto por Leake et al. (1997), são classificados principalmente como magnésio-hornblenda e tschermakita, com poucas análises plotando no campo da ferrotschermakita (Fig. 7.8). A segunda população é constituída por cristais de bandas com granada das amostras 1E e 1D. Essa população apresenta valores mais baixos de silício ( $\mathrm{Si}=6,10-6,55 \mathrm{apfu}$ ) e razões $\mathrm{Mg} /\left(\mathrm{Mg}_{\mathrm{Fe}}{ }^{2+}\right)$ abaixo de 0,5 , sendo classificados predominantemente como ferro-tschermakita, com apenas uma análise plotando no campo da ferro-hornblenda (Fig. 7.8).

O anfibólio da amostra de gnaisse granodiorítico (9B) também é classificado como anfibólio cálcico $\left(C \mathrm{C}^{(\mathrm{B})} \geq 1,5\right)$, porém se diferencia do anfibólio presente nas amostras de gnaisses tonalíticos por apresentar valores de $\mathrm{Na}+\mathrm{K}^{(\mathrm{A})} \geq 0,5$. A composição do anfibólio nessa amostra é bastante homogênea (Fig. 7.8), com pequenas variações nos conteúdos de silício ( $\mathrm{Si}=5,89-6,01$ ) e baixas razões $\mathrm{Mg} /$ $\left(\mathrm{Mg} \mathrm{Fe}^{2+}\right)$, que variam entre 0,21 e 0,24. De acordo com o esquema proposto por Leake et al. (1997), devido as maiores concentrações de ${ }^{\mathrm{V}} \mathrm{Al}$ em relação a $\mathrm{Fe}^{3+}$, o presente anfibólio é classificado como hastingsita (Fig. 7.8).

\subsubsection{Plagioclásio}

O plagioclásio presente nas amostras de gnaisses tonalíticos (1D e 1E) apresenta conteúdos de anortita entre 29 e 39\%, sendo classificado predominantemente como andesina. Não foi observada uma correlação direta entre as variações nos teores de anortita e o contexto textural dos grãos. Em geral, os grãos de plagioclásio analisados não apresentam zoneamento composicional expressivo. Alguns grãos apresentam um leve aumento nos conteúdos de anortita, em torno de 2 a $4 \%$, do núcleo para as bordas. $\mathrm{Na}$ amostra de gnaisse granodiorítico (9B), o plagioclásio apresenta teores de anortita um pouco mais baixos $\left(X_{a n}=0,26-0,27\right)$ e menor variação composicional quando comparado às amostras de gnaisses tonalíticos, sendo em sua totalidade classificado como oligoclásio. 

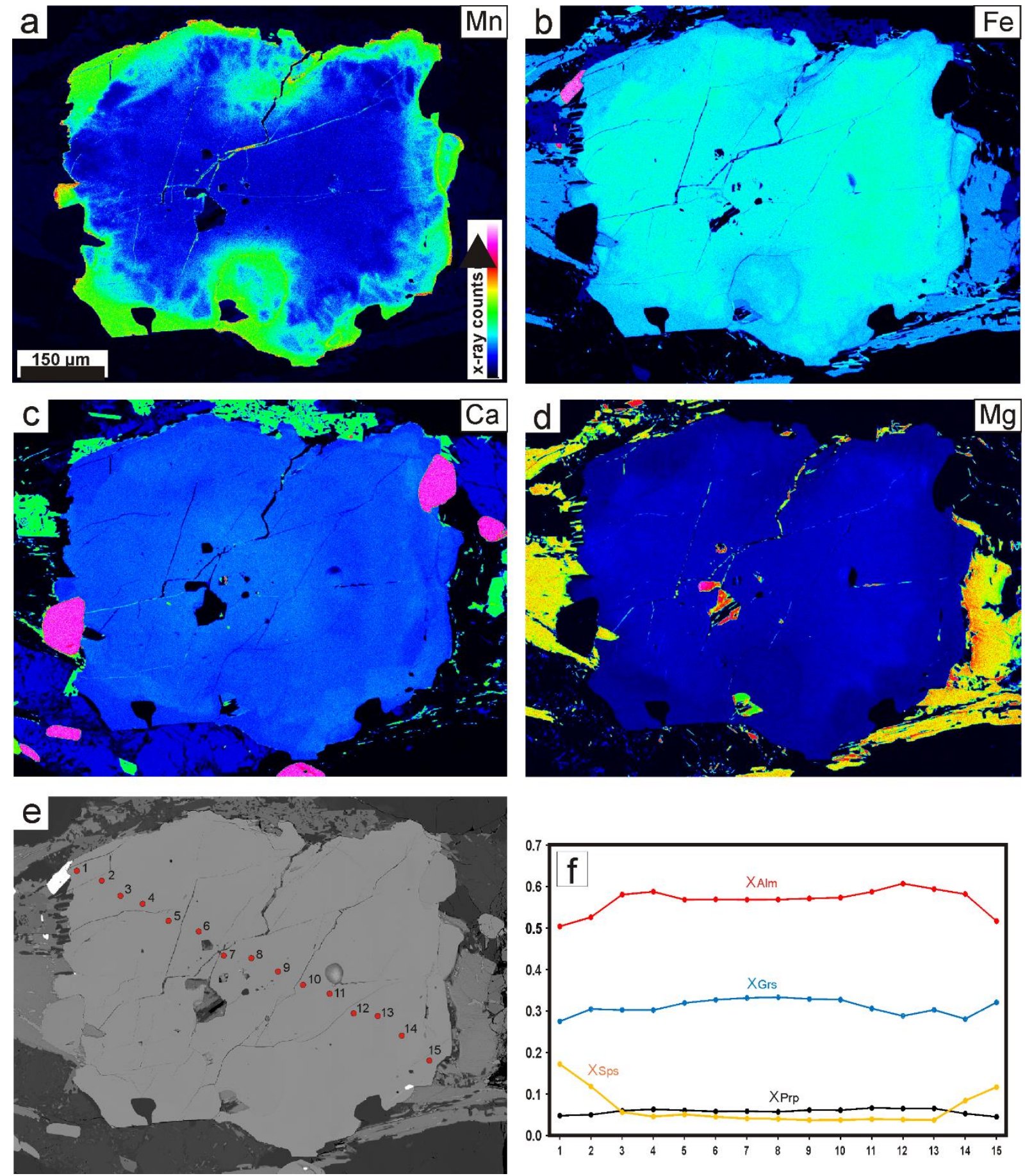

Figura 7.6. (a-d) Mapas composicionais ( $x$-ray) de cristal de granada da amostra $1 E$ (gnaisse tonalítico) - (a) manganês, (b) ferro, (c) cálcio, (d) magnésio; (e) Imagem de elétrons retroespalhados do mesmo cristal de granada com localização das análises quantitativas; (f) Perfil composicional ao longo do cristal. 

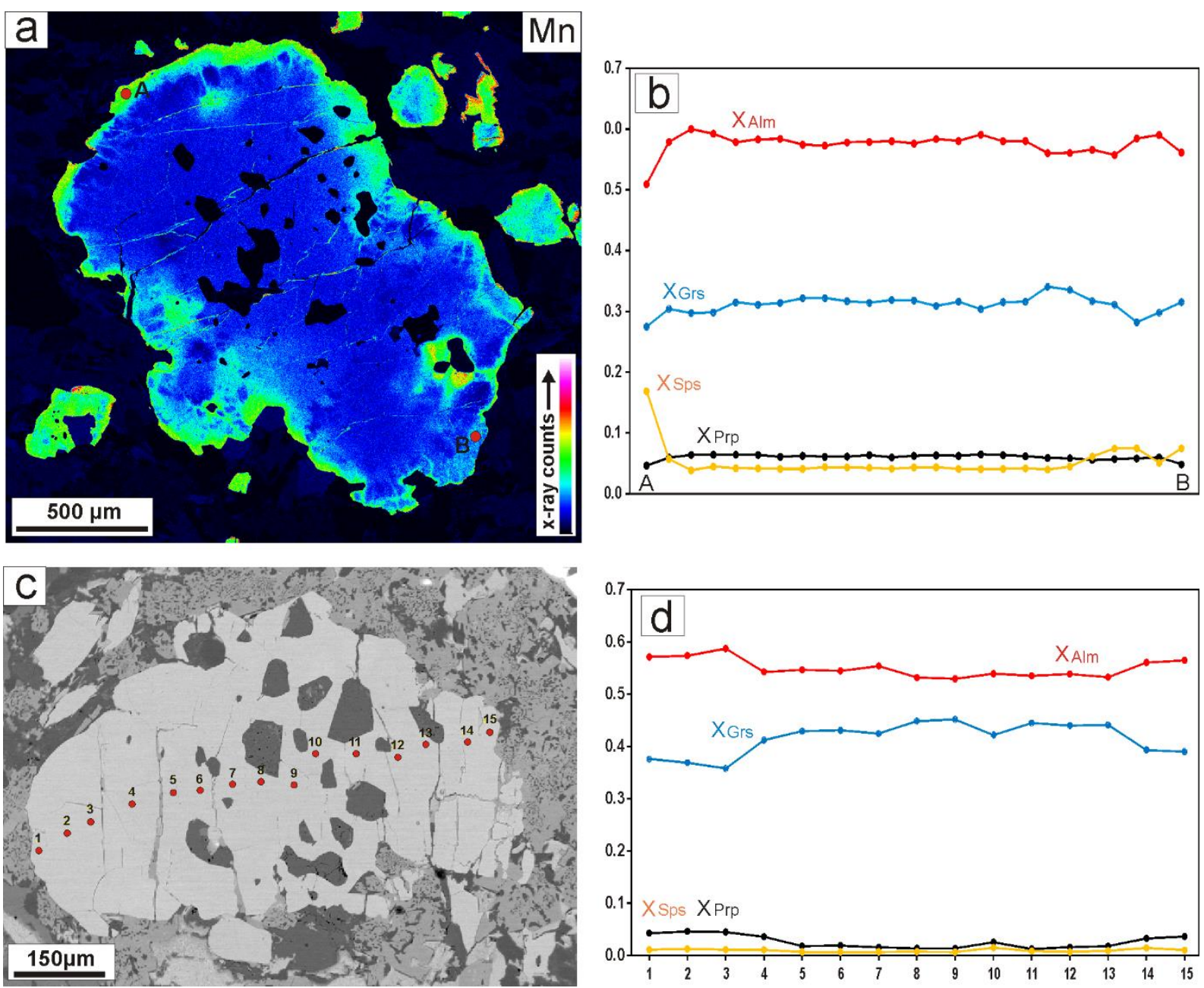

Figura 7.7. (a) Mapa composicional com concentrações de manganês de cristal de granada da amostra 1E (gnaisse tonalítico); (b) perfil composicional ao longo do cristal da figura 7a; (c) Imagem de elétrons retroespalhados de cristal de granada da amostra 9B (gnaisse granodiorítico) com localização das análises quantitativas; (d) Perfil composicional ao longo do cristal da figura 7c.

\subsubsection{Termobarometria (THERMOCALC average P-T)}

Formulas minerais e atividades de membros finais foram obtidas através do software AX desenvolvido por Tim Holland (http://www.esc.cam.ac.uk/research/research-groups/researchprojects/tim-hollands-software-pages/ax). Pressões e temperaturas foram calculadas com o programa THERMOCALC (Powell and Holland, 1998), versão 3.33, no modo average P-T. Foram considerados para os cálculos as composições de granada, anfibólio e plagioclásio, sendo que quartzo e $\mathrm{H}_{2} \mathrm{O}$ foram consideradas fases em excesso. Para todos os cálculos apresentados o membro final pargasita foi excluído, devido a inconsistência de sua atividade com o restante dos dados, o que leva a resultados com grandes incertezas e altos valores de sigfit. 


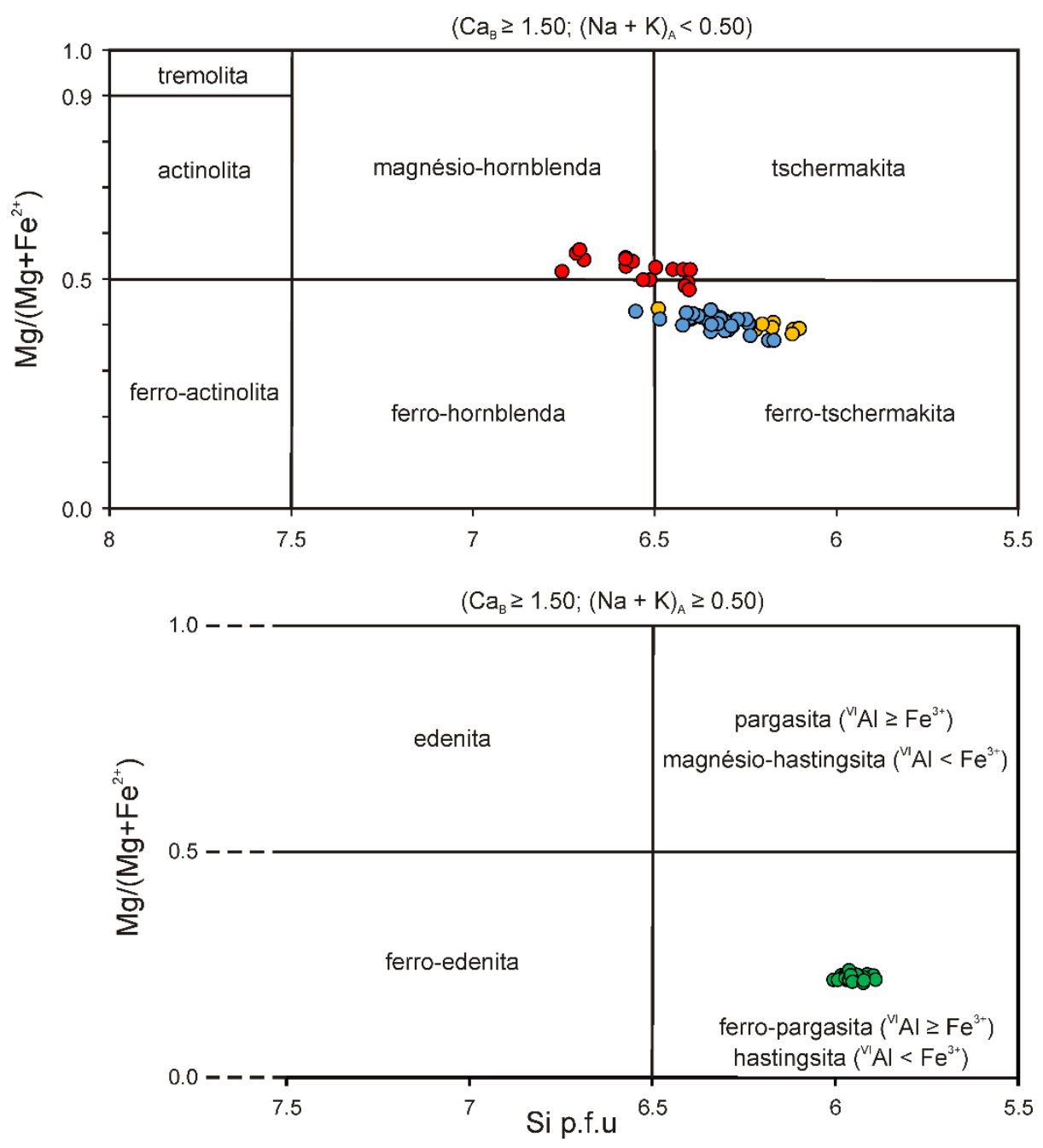

Figura 7.8. Diagramas de classificação de anfibólio segundo Leake et al. (1997). Símbolos vermelhos: amostra 1E - bandas sem granada; símbolos amarelos: amostra 1E - bandas com granada; símbolos azuis: amostra 1D; símbolos verdes: amostra 9B.

Como descrito no item 7.1.2 (química mineral), os cristais de granada das amostras de gnaisses tonalíticos (1D e 1E) apresentam um enriquecimento considerável nos conteúdos de espessartita em suas bordas externas (Figs. 7.6a,f e 7.7a,b), fato provavelmente relacionado a reabsorção de parte dos cristais durante reações retrogressivas do tipo net-transfer. Portanto, essas porções dos cristais não estavam em estabilidade com a assembleia de pico metamórfico e não são adequadas para o cálculo das condições máximas de metamorfismo. As composições pobres em espessartita dos núcleos dos cristais foram utilizadas para tais cálculos. $\mathrm{O}$ anfibólio presente nessas amostras apresenta dois trends composicionais distintos (Fig. 7.8). Foram calculadas pressões e temperaturas associando-se composições do núcleo da granada e plagioclásio (andesina - $X_{a n}=0,33$ ) às duas composições de anfibólio. Quando utilizado o anfibólio ferro-tschermakita, obtêm-se temperatura de $667 \pm 97{ }^{\circ} \mathrm{C} \mathrm{e}$ pressão de 9,4 \pm 1,4 kbar (corr=0,692; sigfit=1,17). Se a composição mais rica em magnésio (magnésiohornblenda) é utilizada, obtêm-se temperatura de $558 \pm 67^{\circ} \mathrm{C}$ e pressão de $8,3 \pm 1,0 \mathrm{kbar}$ (corr=0,641; 
sigfit=0,43). O resultado obtido com o anfibólio ferro-tschermakita é considerado mais próximo da realidade, uma vez que esse anfibólio ocorre nas bandas com granada e, portanto, no mesmo contexto textural, sendo provável que sua composição esteja em equilíbrio com a granada. O anfibólio mais rico em magnésio ocorre em bandas sem granada que provavelmente correspondem a outro domínio composicional.

$\mathrm{Na}$ amostra de gnaisse granodiorítico foram calculadas pressões e temperaturas com as diferentes composições dos porfiroblastos de granada (Figs. 7.7c, d). As composições de anfibólio e plagioclásio dessa amostra não apresentam variações significativas (Fig. 7.8). Utilizando-se a composição do núcleo dos porfiroblastos de granada obteve-se temperatura de $536 \pm 113^{\circ} \mathrm{C}$ e pressão de $8,7 \pm 1,4 \mathrm{kbar}$ (corr=0,871; sigfit=0,26). Com a composição da borda interna obtêm-se temperatura de $615 \pm 112{ }^{\circ} \mathrm{C}$ e pressão de $9,5 \pm 1,4$ kbar (corr=0,834; sigfit=0,47). Com a composição da borda externa mais pobre em grossulária e mais rica em piropo e almandina obtêm-se temperatura de 881 $\pm 185{ }^{\circ} \mathrm{C}$ e pressão de $11,8 \pm 2,1 \mathrm{kbar}$ (corr=0,856; sigfit=0,96). Os resultados obtidos com as composições das bordas externas dos cristais apresentam as maiores incertezas e podem estar relacionados a desequilíbrio entre a composição da granada e as demais fases utilizadas nos cálculos. Portanto, os resultados obtidos com as composições das bordas internas dos cristais de granada são considerados as estimativas mais confiáveis das condições de pico metamórfico e estão dentro da margem de erro dos resultados obtidos nas amostras de gnaisses tonalíticos.

\subsubsection{Geocronologia U-Pb em titanita}

As análises U-Pb em titanita foram realizadas in-situ em seções delgadas por LA-ICP-MS. Foram utilizados spots circulares com diâmetro de $35 \mu \mathrm{m}$ (detalhes dos procedimentos analíticos estão apresentados no capítulo 4 - Materiais e métodos). As estruturas internas dos grãos de titanita foram investigadas com imagens de elétrons retroespalhados, obtidas com microscópio eletrônico de varredura. Essas imagens foram utilizadas como guia para a determinação da localização dos pontos analíticos. Grande parte dos grãos analisados apresenta, nas imagens de elétrons retroespalhados, zoneamento concêntrico irregular, aparentemente resultado de recristalização incompleta dos grãos. Nas amostras de gnaisses tonalíticos (1D e 1E) o zoneamento dos grãos é geralmente complexo (Figs. 7.9a-d), dificultando a definição dos núcleos e bordas dos cristais. Na amostra de gnaisse granodiorítico (9B) o zoneamento é menos complexo, sendo mais fácil a distinção entre núcleos de coloração cinza escuro e bordas mais claras (Figs. 7.9e, f).

As análises U-Pb não corrigidas para chumbo comum são apresentadas em diagramas TeraWasserburg (1972) (Fig. 7.10). Assume-se que projeções em direção a razões ${ }^{207} \mathrm{~Pb} /{ }^{206} \mathrm{~Pb}$ mais elevadas são resultado de maiores proporções de chumbo comum. Amostras com grande dispersão nas 
proporções de chumbo comum permitem uma regressão dos dados, onde o intercepto superior representa a composição do chumbo comum e o intercepto inferior a idade de (re)cristalização da titanita.
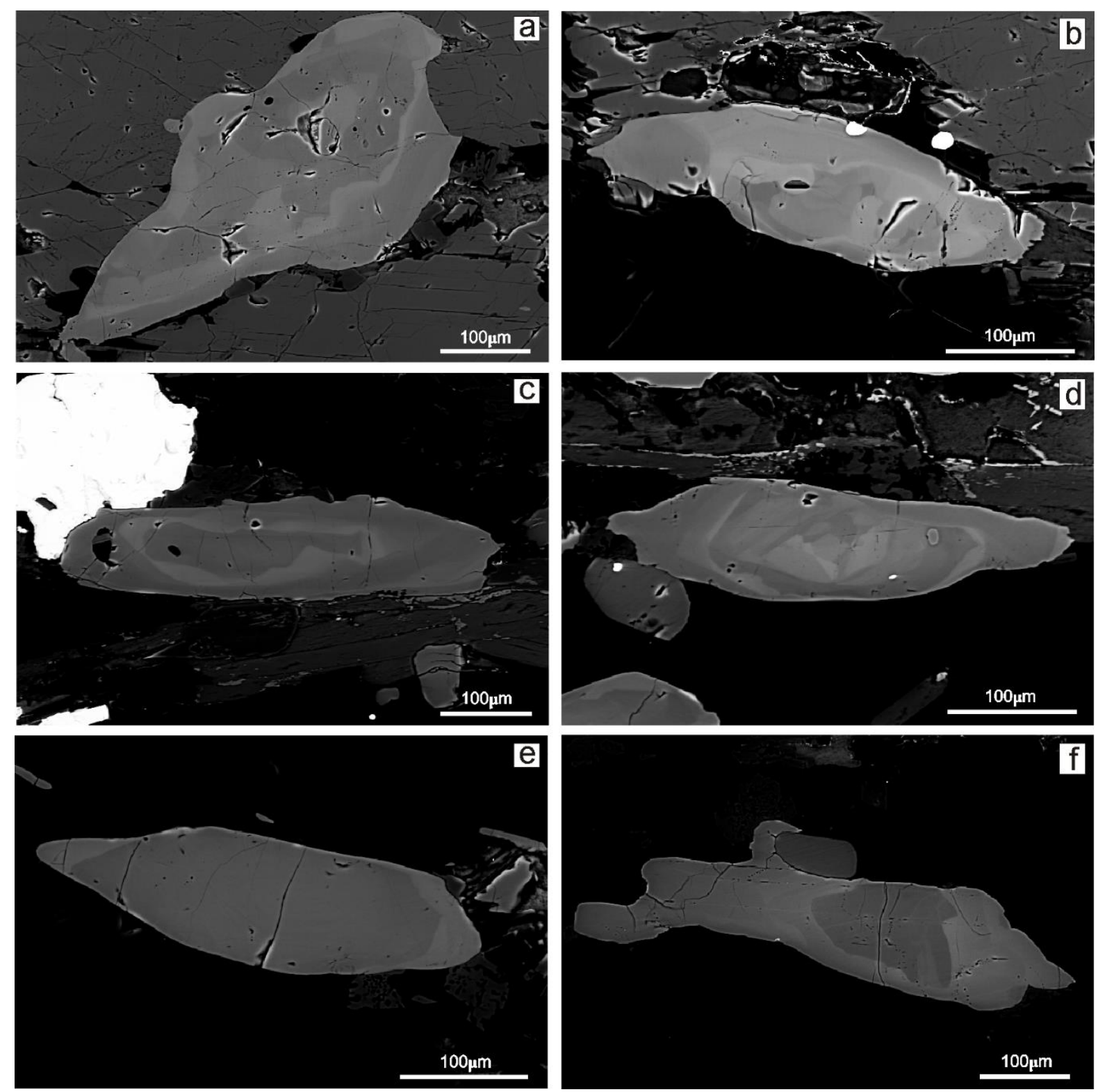

Figura 7.9. Imagens de elétrons retroespalhados de grãos de titanita representativos. (a, b) amostra 1D, (c, d) amostra 1E, (e, f) amostra 9B.

Foram analisados entre aproximadamente 40 a 50 spots por amostra totalizando 139 pontos analisados. Apenas duas análises da amostra $1 \mathrm{E}$ apresentam resultados paleoproterozóicos concordantes (Fig. 7.10b). Todas as análises restantes pertencem a populações neoproterozóicas. Nas amostras 1D e 1E (Figs. 7.10a, b) o espalhamento das análises não permite uma diferenciação clara 
entre idades dos domínios internos e bordas neoproterozóicos. Na amostra 1D a regressão incluindo domínios internos e bordas dos cristais define um intercepto inferior a 628.4 $\pm 6.6 \mathrm{Ma}$ (MSWD=7,6; n=39) (Fig. 7.10a). Na amostra 1E, excluindo-se três análises com componente paleoproterozóico, o restante das análises define um intercepto inferior a 620,6 \pm 6,4 Ma (MSWD=4,5; n=43) (Fig. 7.10b). Considerando-se apenas os dados obtidos nos núcleos dos cristais dessa amostra define-se um intercepto inferior a 622,8 $\pm 8,8 \mathrm{Ma}$ (MSWD=2,5; $\mathrm{n}=25$ ). A amostra 9B apresenta a melhor correlação entre as razões isotópicas e permite a distinção entre idades dos núcleos e das bordas dos cristais. Nessa amostra considerando-se apenas as análises dos núcleos dos cristais define-se um intercepto inferior a 618,3 $\pm 6,3 \mathrm{Ma}$ (MSWD=2,0; $\mathrm{n}=43$ ) (Fig. 7.10c). As análises das bordas dos cristais definem um intercepto inferior a 606,7 $\pm 5,7 \mathrm{Ma}$ (MSWD=0,54; $\mathrm{n=11}$ ) (Fig. 7.10d).
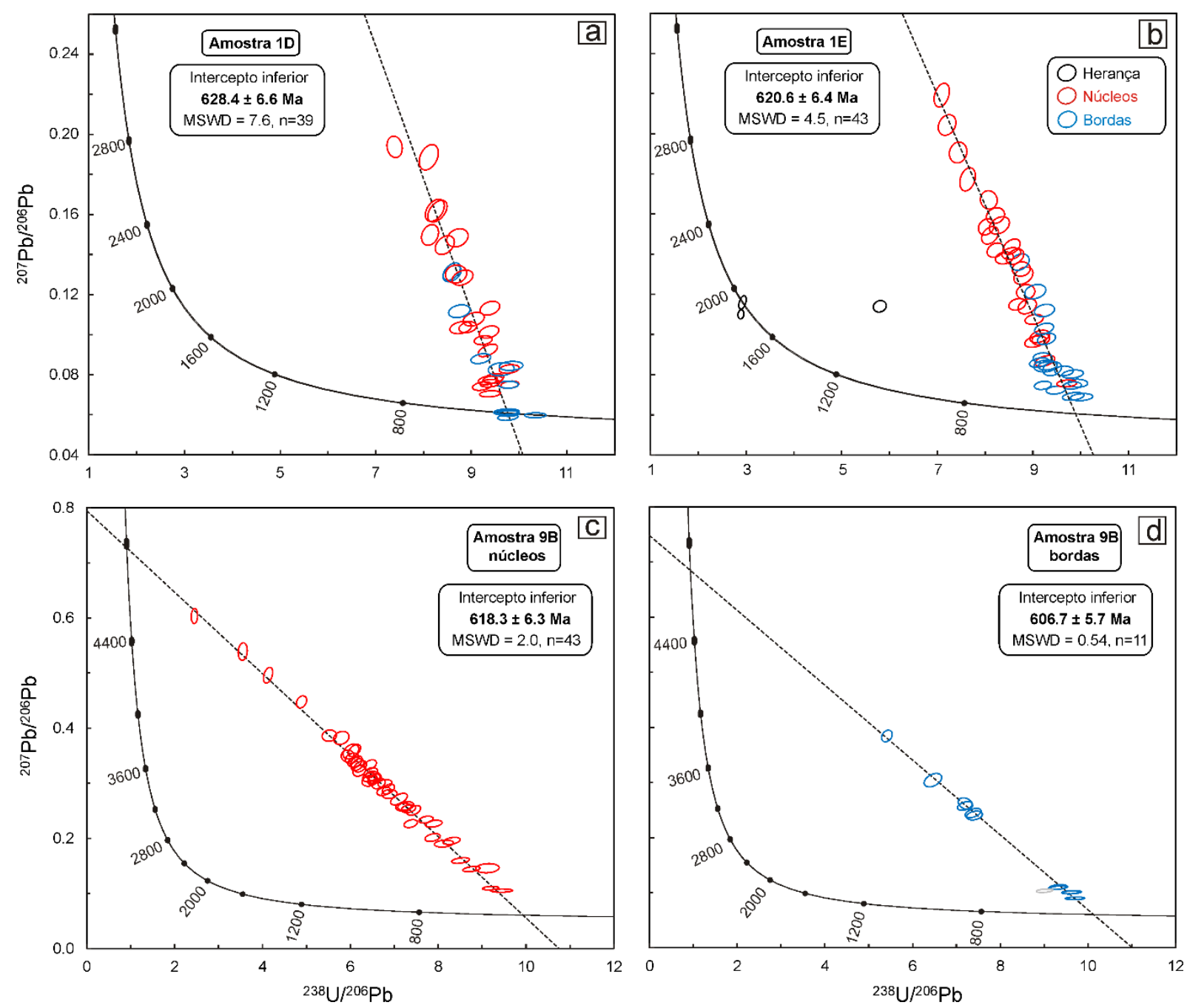

Figura 7.10. Diagramas Tera-Wasserburg para as titanitas analisadas. (a) amostra 1D - intercepto inferior a 628,6 \pm 6,6 $\mathrm{Ma}$ (MSWD=7,6, n=39), (b) amostra $1 \mathrm{E}$ - intercepto inferior a 620,6 $\pm 6,4 \mathrm{Ma}$ (MSWD=4,5, n=43), (c) amostra $9 B$ núcleos - intercepto inferior a 618,3 $\pm 6,3 \mathrm{Ma}(M S W D=2,0, n=43)$, (d) amostra 9B bordas - intercepto inferior a $606,7 \pm 5,7 \mathrm{Ma}(M S W D=0,54, \mathrm{n}=11$ ). 


\subsubsection{Elementos traço em titanita}

As concentrações de elementos traço, incluindo elementos terras raras (ETR) e zircônio, foram determinadas por LA-ICP-MS nos mesmos cristais datados pelo método U-Pb (detalhes sobre procedimentos analíticos no capítulo 4 - Materiais e métodos). Um dos principais objetivos dessas análises foi a aplicação do geotermômetro Zr em titanita (Hayden et al., 2008). Para a aplicação do método, além das concentrações de zircônio é necessário a determinação de pressão, $a \mathrm{SiO}_{2}$ e $a \mathrm{TiO}_{2}$. Para os cálculos foi considerada a pressão aproximada de 9kbar obtida por termobarometria THERMOCALC average $P-T$. Devido a presença de quartzo foi considerado $a \mathrm{SiO}_{2}=1$. A ausência de rutilo nas amostras analisadas determina que a $a \mathrm{TiO}_{2}$ seja menor que 1 , sendo que valor de 0,5 foi escolhido por representar um limite inferior plausível de $a \mathrm{TiO}_{2}$ em rochas crustais (Hayden \& Watson, 2007; Ferry $\&$ Watson, 2007).
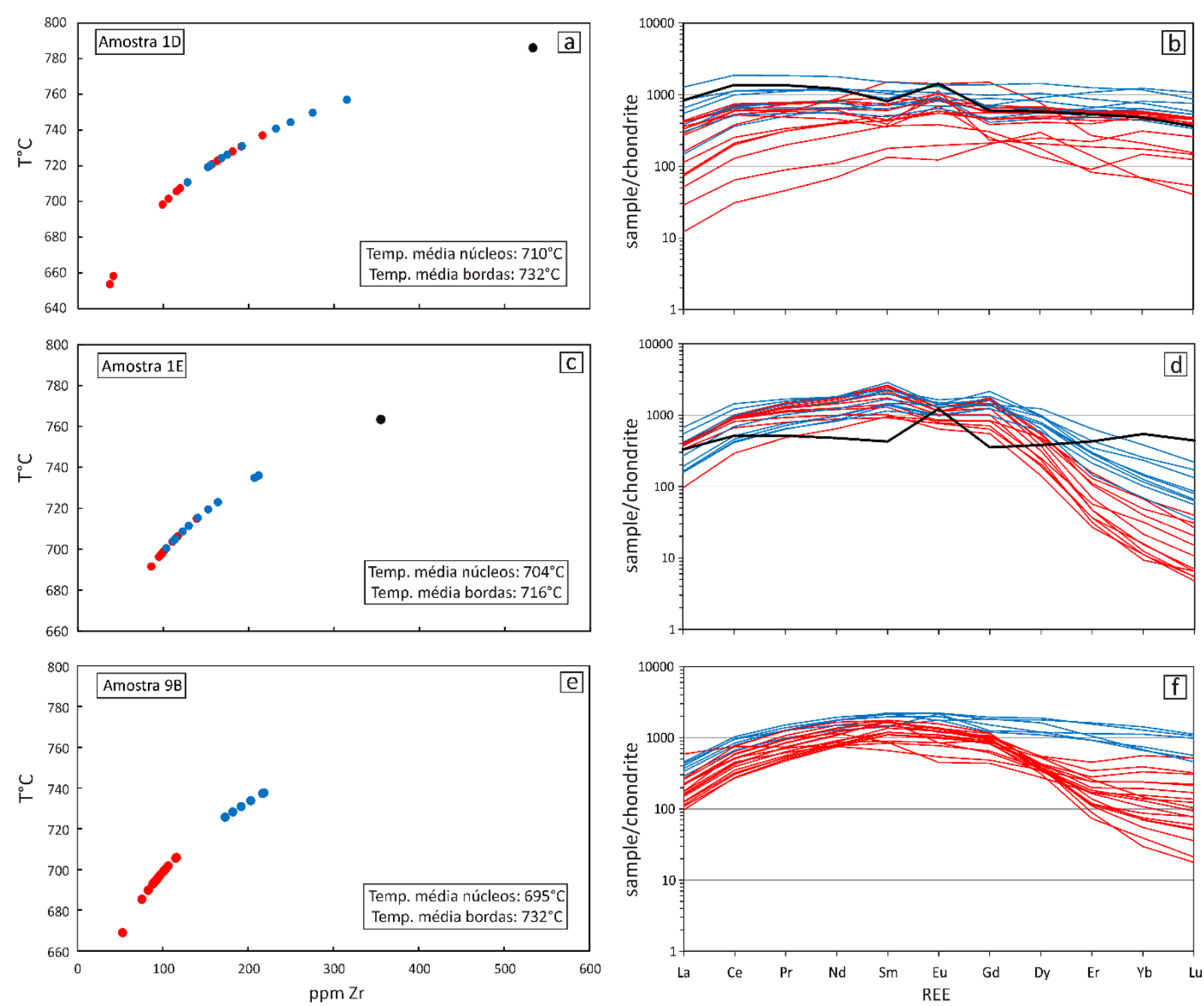

Figura 7.11. (a, c, e) Diagramas temperatura $\left({ }^{\circ} \mathrm{C}\right)$ vs concentrações de zircônio $(\mathrm{ppm})$ para as amostras 1D, 1E e 9B, respectivamente. As temperaturas foram calculadas segundo o método proposto por Hayden et al. (2008) para pressões estimadas de $9 \mathrm{kbar}$ e $\mathrm{aTiO}_{2}=0.5$. (b, d, f) Padrões de elementos terras raras normalizados para o condrito de Boynton (1983) para as amostras 1D, 1E e 9B, respectivamente. Mesma simbologia da Figura 7.10. 
Nas três amostras analisadas as bordas dos cristais de titanita tendem a ser mais enriquecidas em zircônio do que os domínios internos (Figs. 7.11a, c, e), sendo essa tendência melhor definida na amostra 9B (Fig. 7.11e). Essa tendência é acompanhada por um sistemático enriquecimento em elementos terras raras, especialmente elementos terras raras pesados, nas bordas dos cristais (Figs. $7.11 b, d, f)$. As exceções são duas análises em núcleos, uma na amostra 1D e outra na amostra 1E, que apresentam conteúdos de zircônio bastante superiores as demais análises (Figs. 7.11a, c) associados a padrões de elementos terras raras planos com anomalia positiva de európio bem definida (Figs. 7.11b, d). O domínio rico em zircônio da amostra $1 E$ é relacionado a um dos raros núcleos paleoproterozóicos herdados (Figs. 7.10b e 7.11c) e, portanto, essas concentrações mais elevadas de zircônio são interpretadas como heranças magmáticas.

As temperaturas calculadas com as composições dos núcleos dos cristais de titanita da amostra 1D variam entre 654 e $737^{\circ} \mathrm{C}$ com média de $710^{\circ} \mathrm{C}(\mathrm{n}=14$ ) (Fig. 7.11a). Utilizando-se as composições das bordas dos cristais dessa amostra obtêm-se valores entre 711 e $757^{\circ} \mathrm{C}$ com média de $732^{\circ} \mathrm{C}(n=10)$ (Fig. 7.11a). As temperaturas calculadas com as composições dos núcleos dos cristais da amostra $1 \mathrm{E}$ variam entre $692 \mathrm{e} 723^{\circ} \mathrm{C}$ com média de $704^{\circ} \mathrm{C}(\mathrm{n}=12)$ e as temperaturas calculadas com as bordas dos cristais dessa amostra estão entre 700 e $736^{\circ} \mathrm{C}$ com média de $716^{\circ} \mathrm{C}(\mathrm{n}=10)$ (Fig. 7.11C). As composições dos núcleos dos cristais da amostra $9 \mathrm{~B}$ resultam em temperaturas entre 669 e $706^{\circ} \mathrm{C}$ com média de $695^{\circ} \mathrm{C}(\mathrm{n}=19$ ) e as composições das bordas dos cristais dessa amostra resultam em temperaturas entre 726 e $738^{\circ} \mathrm{C}$ com média de $732^{\circ} \mathrm{C}$ ( $n=6$ ) (Fig. 7.11e). Nota-se que temperaturas médias obtidas com as composições das bordas dos cristais são ligeiramente mais elevadas do que as temperaturas obtidas com as composições dos núcleos dos cristais considerando-se que ambos domínios foram gerados em mesma condição de pressão. Essa diferença é de $12^{\circ} \mathrm{C}$ na amostra $1 \mathrm{E}$ e chega a $27^{\circ} \mathrm{C}$ na amostra $9 \mathrm{~B}$ (Figs. 7.11a, c, e).

O sistemático aumento nos conteúdos de elementos terras raras pesados nas bordas dos cristais de titanita sugerem que os mesmos foram gerados a partir do consumo de minerais ricos em elementos terras raras pesados. Nesse caso o principal candidato seria a granada, sendo que a química dos cristais de granada das amostras $1 \mathrm{D}$ e $1 \mathrm{E}$, com bordas enriquecidas em manganês, sugere reabsorção da granada durante reações retrometamórficas (vide seção 7.2.2 - química mineral). Portanto, existe uma aparente contradição entre os padrões de elementos terras raras que sugerem crescimento das bordas dos cristais de titanita através do consumo de granada durante reações retrometamórficas e os conteúdos de zircônio na titanita que sugerem que as bordas dos cristais foram cristalizadas em temperaturas mais altas do que os núcleos. Devido a dependência de pressão inerente ao termômetro Zr na titanita, uma solução para esse problema é considerar que as bordas foram geradas em pressões mais baixas e, portanto, os maiores conteúdos de zircônio nas bordas dos cristais podem ser resultado de descompressão e não necessariamente de aumento de temperatura. 
Portanto, as temperaturas obtidas nos núcleos dos cristais são provavelmente as melhores estimativas para as condições máximas de temperatura.

\subsection{Geocronologia de leucossomas e leucogranito}

Foram selecionadas duas amostras de leucossoma tonalíticos e uma amostra de leucogranito para realização de análises U-Pb em zircão. A amostras estão localizadas na Figura 4.1 (capítulo 4 - Materiais e métodos). Os leucossomas tonalíticos apresentam estrutura foliada e textura predominantemente granoblástica inequigranular fina a média. Cristais de plagioclásio de até $5 \mathrm{~mm}$ estão orientados na direção da foliação em meio a matriz quartzo-feldspática recristalizada de granulação fina. Leitos lepidoblásticos esparsos, de espessura submilimétrica, compostos por biotita + epidoto/zoisita \pm alanita \pm mica branca fina marcam a foliação, envolvendo porfiroclastos de plagioclásio e aglomerados quartzo-feldspáticos recristalizados. Minerais acessórios comuns nos leucossomas tonalíticos são: opacos, zircão, granada e microclínio. Os zircões do leucossoma 7B dividem-se em duas populações, uma paleoproterozóica e outra neoproterozóica (Fig. 7.13). Os zircões paleoproterozóicos apresentam alta luminescência e estruturas internas do tipo zoneamento oscilatório e/ou zoneamento setorial nas imagens de catodoluminescência (Fig. 7.12). Esses zircões são caracterizados por razões Th/U entre 0,10 e 0,45 e pela ausência de núcleos herdados mais antigos. Alguns desses grãos paleoproterozóicos apresentam bordas com texturas de recristalização incompleta (ex. grão 35.1 - Fig. 7.12). Considerando-se apenas os domínios paleoproterozóicos (Figs. 7.13 a, b) define-se um intercepto superior a $2119 \pm 26 \mathrm{Ma}(\mathrm{n}=10 ; \mathrm{MSWD}=2,3)$. Essa datação é considerada a idade de cristalização do protólito ígneo. Os domínios neoproterozóicos ocorrem como bordas bem desenvolvidas em cristais com núcleos aparentemente reabsorvidos e metamícticos (Fig. 7.12) e também como cristais sem núcleos herdados, escuros e com zoneamento do tipo setorial (Fig. 7.12). Essa população é caracterizada por baixas razões Th/U que variam entre $<0,01$ e 0,02. Nos diagramas concordia (Figs. 7.13 a, c, d) observa-se um espalhamento das análises neoproterozóicas em direção a uma componente de chumbo comum (Fig. 7.13c). Considerando-se apenas as análises com discordância menor ou igual $1 \%$, obtêm-se a idade concordia de 616,3 $\pm 1,6$ Ma ( $n=38 ; M S W D=1,16$; probabilidade=0,16) (Fig. 7.13d). Essa datação é considerada a idade de cristalização do leucossoma.

Na amostra do leucossoma 9C os zircões também se dividem em duas populações, uma associada ao protólito paleoproterozóico e outra neoproterozóica, associada a cristalização do leucossoma (Fig. 7.15). Uma série de análises ocorrem espalhadas entre esses dois domínios e provavelmente são resultado de perda de chumbo e/ou idades de mistura (Fig. 7.15a). Os domínios paleoproterozóicos ocorrem como núcleos com zoneamento oscilatório em cristais com bordas neoproterozóicas e 
também como cristais com zoneamento oscilatório sem bordas neoproterozóicas (Fig. 7.14). Os domínios neoproterozóicos ocorrem como bordas bem desenvolvidas com zoneamento oscilatório e/ou setorial (Fig. 7.14). Diversos cristais com bordas neoproterozóicas apresentam núcleos escuros e/ou com texturas cáoticas em imagens de catodoluminescência. Esses núcleos são altamente discordantes com forte perda de chumbo no evento Neoproterozóico (ex. Fig. 7.14 - grão 81). Considerando-se as dezoito análises paleoproterozóicas mais concordantes, com razões Th/U entre 0,20 e 0,66, define-se um intercepto superior em $2084 \pm 13 \mathrm{Ma}$ (MSWD=2,6) (Fig. 7.15b), interpretado como idade de cristalização do protólito ígneo. A população neoproterozóica apresenta baixas razões Th/U, entre <0,01 e 0,04, e um forte espalhamento em direção a perda recente de chumbo (Fig. 7.15c). Considerando-se apenas as análises neoproterozóicas com discordância menor ou igual a 1\% obtêmse uma idade concordia de 615,3 $\pm 2,3 \mathrm{Ma}$ ( $\mathrm{n}=18 ; \mathrm{MSWD}=1,12$; probabilidade=0,28) (Fig. 7.15d), que é idêntica, dentro da margem de erro, a idade obtida no leucossoma 7B.

A amostra de leucogranito analisada (1-0) apresenta estrutura foliada e textura granoblástica inequigranular grossa com megacristais de plagioclásio e feldspato potássico de até aproximadamente $3 \mathrm{~cm}$ em meio a matriz quartzo-feldspática, recristalizada, de granulação fina a muito-fina. Granada é mineral acessório frequente e ocorre como cristais submilimétricos, subeuédricos a euédricos, normalmente concentrados em trilhas. Em geral, os cristais de granada são livres de inclusões, porém localmente ocorrem inclusões de turmalina. Ocorrem também como minerais acessórios: zoisita, zircão e clorita. Os zircões dessa amostra são completamente escuros nas imagens de catodoluminescência, resultado dos altos teores de urânio nos cristais que variam entre aproximadamente 1870 e $6820 \mathrm{ppm}$. As razões Th/U são baixas entre aproximadamente 0,01 e 0,02. Os trinta pontos analisados nessa amostra definem um intercepto superior em $607 \pm 5,7 \mathrm{Ma}$ (MSWD=0,58) interpretado como idade de cristalização do leucogranito.

\subsection{Idade e condições P-T do metamorfismo no Complexo Pouso Alegre}

O estudo integrado de relações de campo, relações texturais, composições químicas minerais e geocronologia U-Pb em zircão e titanita permitiu a definição das condições $\mathrm{P}-\mathrm{T}$ e idade do metamorfismo Neoproterozóico no Complexo Pouco Alegre. A presença de leucossomas tonalíticos frequentemente associados a anfibólio peritético (Fig. 7.1f) e ausência de minerais anidros, sugere fusão parcial em presença de fluidos. Estudos experimentais (Conrad et al., 1988; Patiño Douce \& Harris, 1998) demonstram que fusão parcial em presença de fluidos tendem a gerar fundidos de composição tonalítica a throndjhemítica ao contrário de composições graníticas, normalmente geradas por reações de fusão parcial por desidratação. O estudo experimental de Gardien et al. (2000) 
corrobora com a hipótese de fusão em presença de fluidos, pois demonstra a necessidade de adição de pelo menos 2 a 4 wt\% de água para a estabilização de hornblenda no fundido em biotita gnaisses.

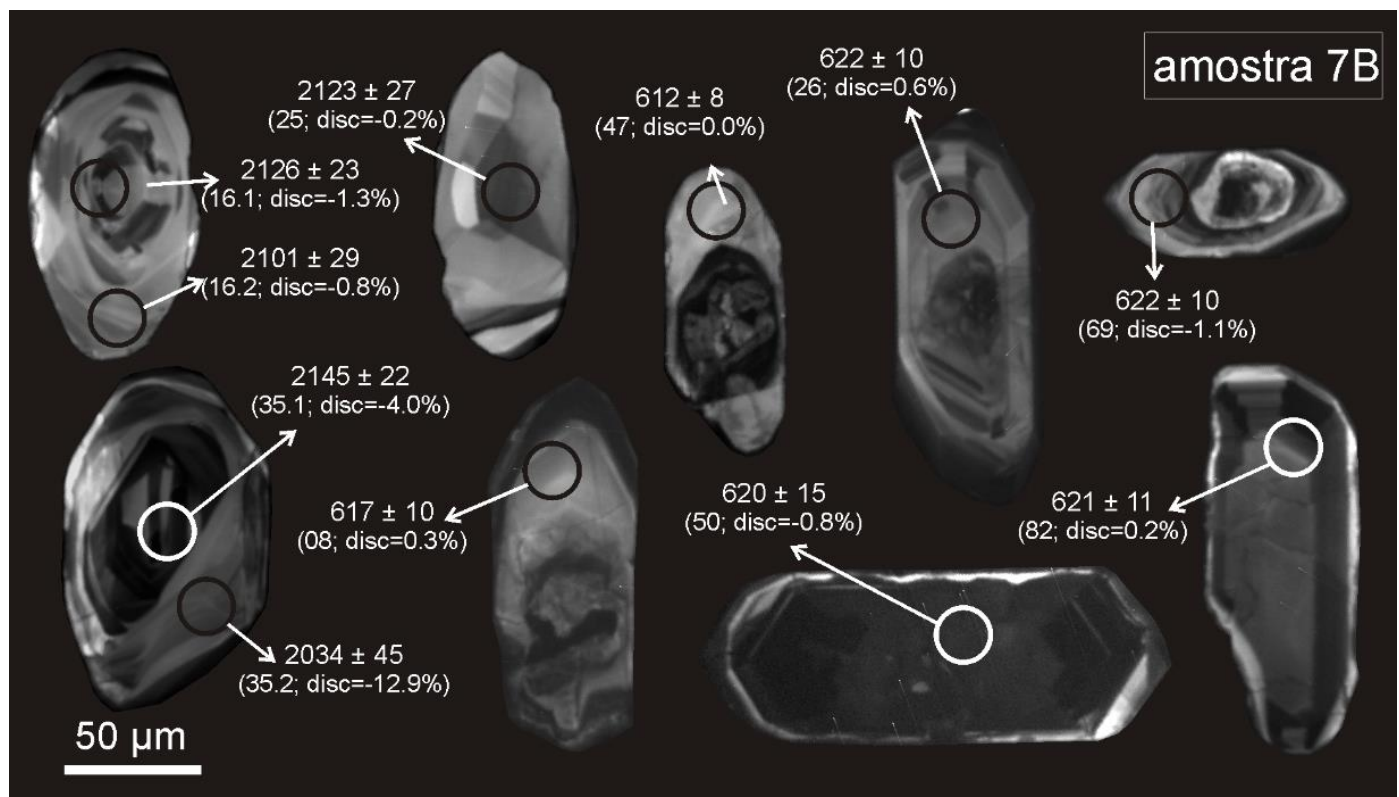

Figura 7.12. Imagens de catodoluminescência de grãos representativos da amostra de leucossoma 7B
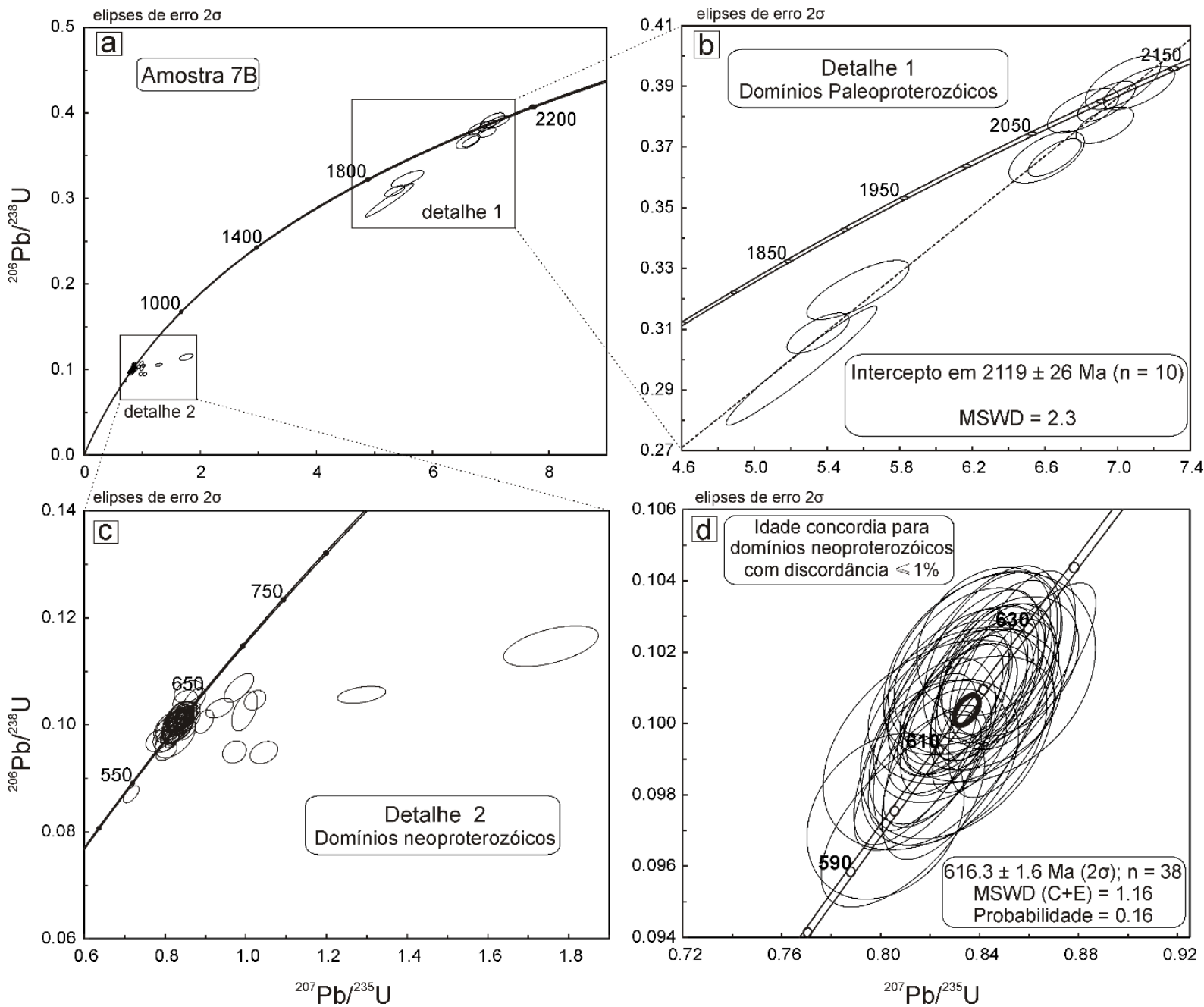

Figura 7.13. Diagramas concórdia para as análises de zircão do leucossoma 7B. 


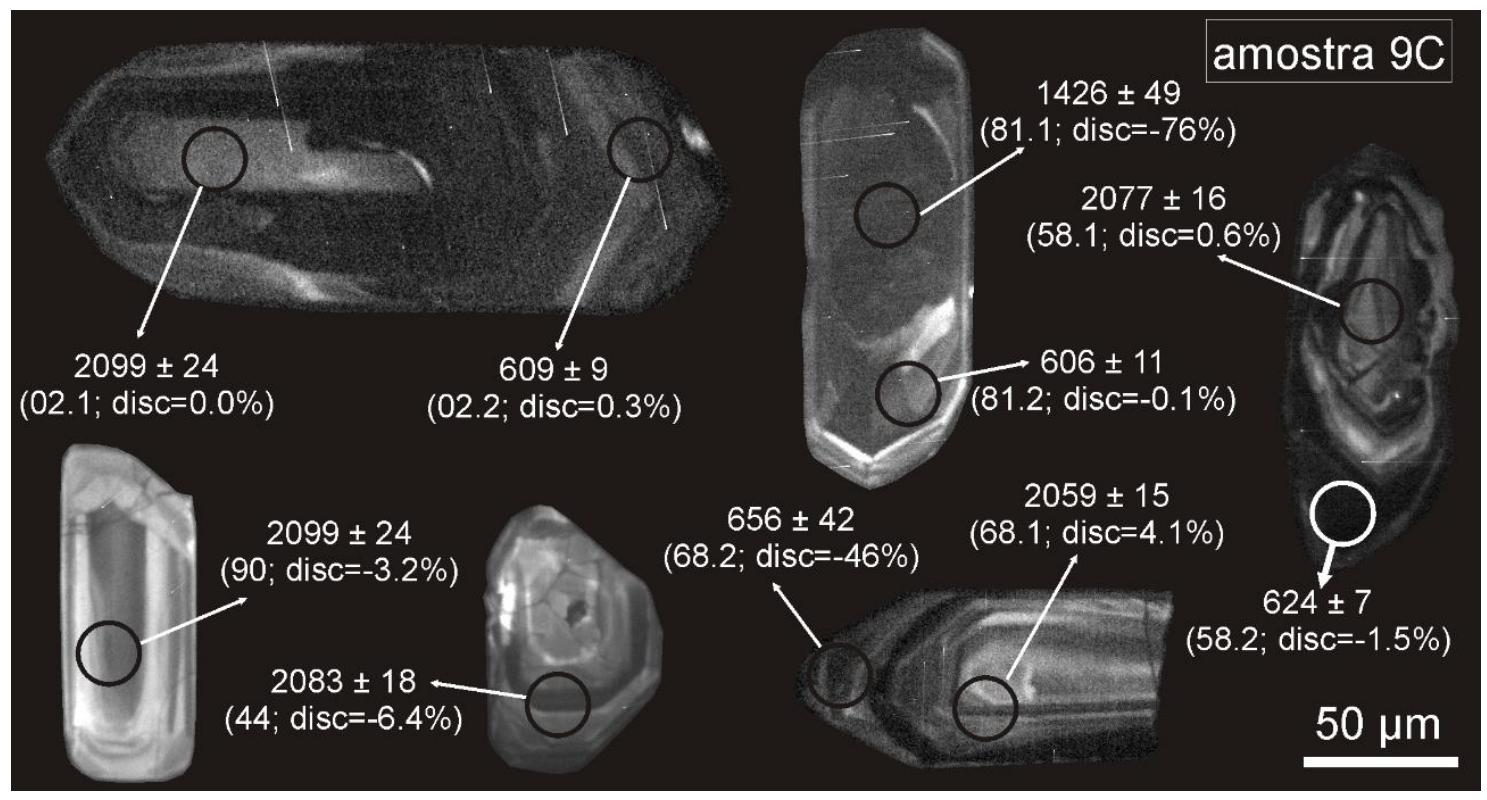

Figura 7.14. Imagens de catodoluminescência de grãos representativos da amostra de leucossoma 9C.
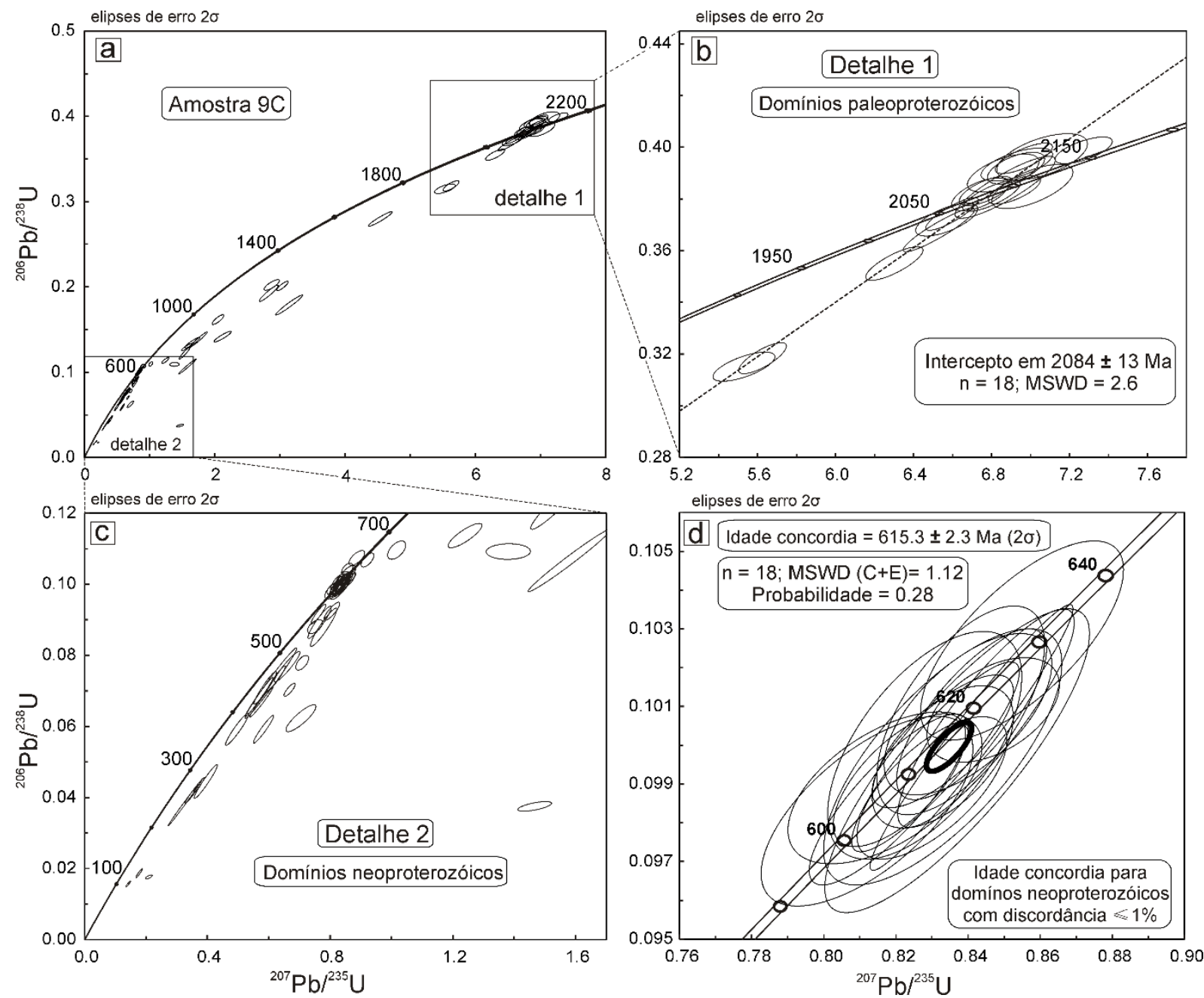

Figura 7.15. Diagramas concórdia para as análises de zircão do leucossoma 9C. 


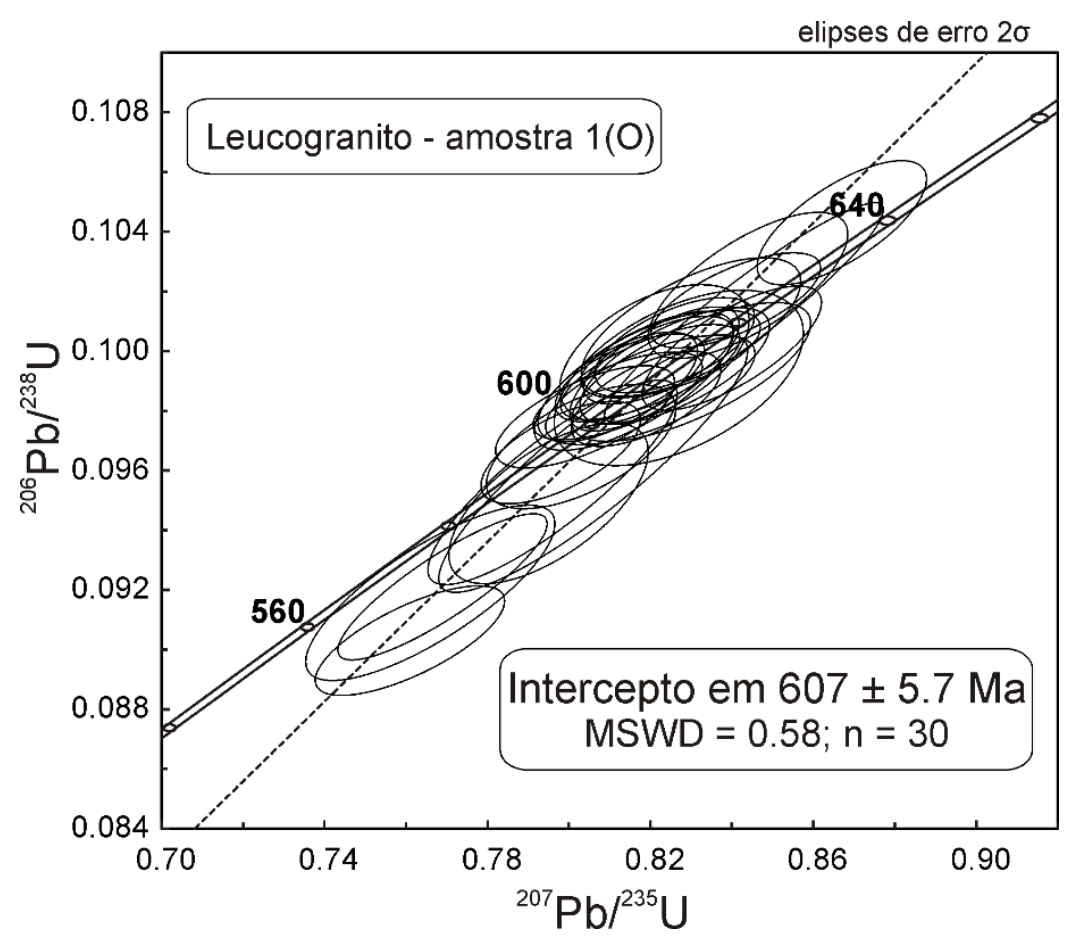

Figura 7.16. Diagrama concórdia para as análises de zircão do leucogranito 1(0).

As reações de fusão parcial em presença de $\mathrm{H}_{2} \mathrm{O}$ determinadas experimentalmente apresentam correlações negativas entre aumento de pressão e temperatura e ocorrem em temperaturas entre aproximadamente 600 e $650{ }^{\circ} \mathrm{C}$ a $10 \mathrm{kbar}$ e em temperaturas entre aproximadamente 650 e $700{ }^{\circ} \mathrm{C}$ a $3 \mathrm{Kbar}$ (Fig. 7.17). Portanto, as posições dessas reações estabelecem temperaturas mínimas de aproximadamente $600^{\circ} \mathrm{C}$ para o metamorfismo do Complexo Pouso Alegre. Termobarometria THERMOCALC average $P-T$, baseada nas composições das fases minerais principais (granada, anfibólio, plagioclásio), define condições máximas aproximadas para o metamorfismo a temperatura de $670 \pm 100^{\circ} \mathrm{C}$ e pressão de $9,4 \pm 1,4 \mathrm{kbar}$ (Fig. 7.17). Resultados de termometria zircônio na titanita (núcleos) estão entre 654 e $734^{\circ} \mathrm{C}$ assumindo-se pressão de 9 kbar e, portanto, coincidem dentro da margem de erro com os resultados obtidos por termobarometria THERMOCALC average $P$ $T$ e atestam a confiabilidade dos mesmos (Fig. 7.17).

A idade do metamorfismo foi estabelecida através de geocronologia U-Pb em titanita presente nos ortognaisses e zircão proveniente de leucossomas e leucogranito. Nos ortognaisses tonalíticos (1D e 1E) as análises de núcleos e bordas dos cristais de titanita apresentam um grande espalhamento não sendo possível a distinção entre as idades dos núcleos e bordas dos cristais (Figs. 7.10a, b). Nessas amostras as idades obtidas para o intercepto inferior no diagrama Tera-Wasserburg estão entre 620 e $628 \mathrm{Ma}$. No ortognaisse granodiorítico a correlação entre as razões ${ }^{207} \mathrm{~Pb} /{ }^{206} \mathrm{~Pb}$ e ${ }^{238} \mathrm{U} /{ }^{206} \mathrm{~Pb}$ é melhor definida sendo possível a distinção entre idades dos núcleos e das bordas dos cristais de titanita (Figs. 
7.10c, d). Os núcleos dos cristais dessa amostra definem um intercepto inferior no diagrama TeraWasserburg a $618 \pm 6 \mathrm{Ma}$ (Fig. 7.10c). Essas datações são interpretadas como idades de (re)cristalização da titanita durante o metamorfismo de fácies anfibolito superior. Excluindo-se a idade mais antiga, obtida na amostra 1D, que apresenta o maior MSWD entre as amostras analisadas, as idades obtidas para a (re)cristalização das titanitas são, dentro da margem de erro, idênticas as idades obtidas para cristalização dos leucossomas tonalíticos entre 615 e 616 Ma (Fig. 7.18). Considerandose as idades obtidas nas titanitas da amostra $1 \mathrm{E}$ (domínios internos + bordas) e 9B (núcleos), juntamente com as idades obtidas em zircão dos leucossomas tonalíticos, obtêm-se uma média ponderada de 616,2 \pm 1,3 Ma (MSWD=0,99; probabilidade=0,40; $n=4$ ) interpretada como a melhor estimativa da idade do metamorfismo de fácies anfibolito superior associado a fusão parcial no Complexo Pouso Alegre.

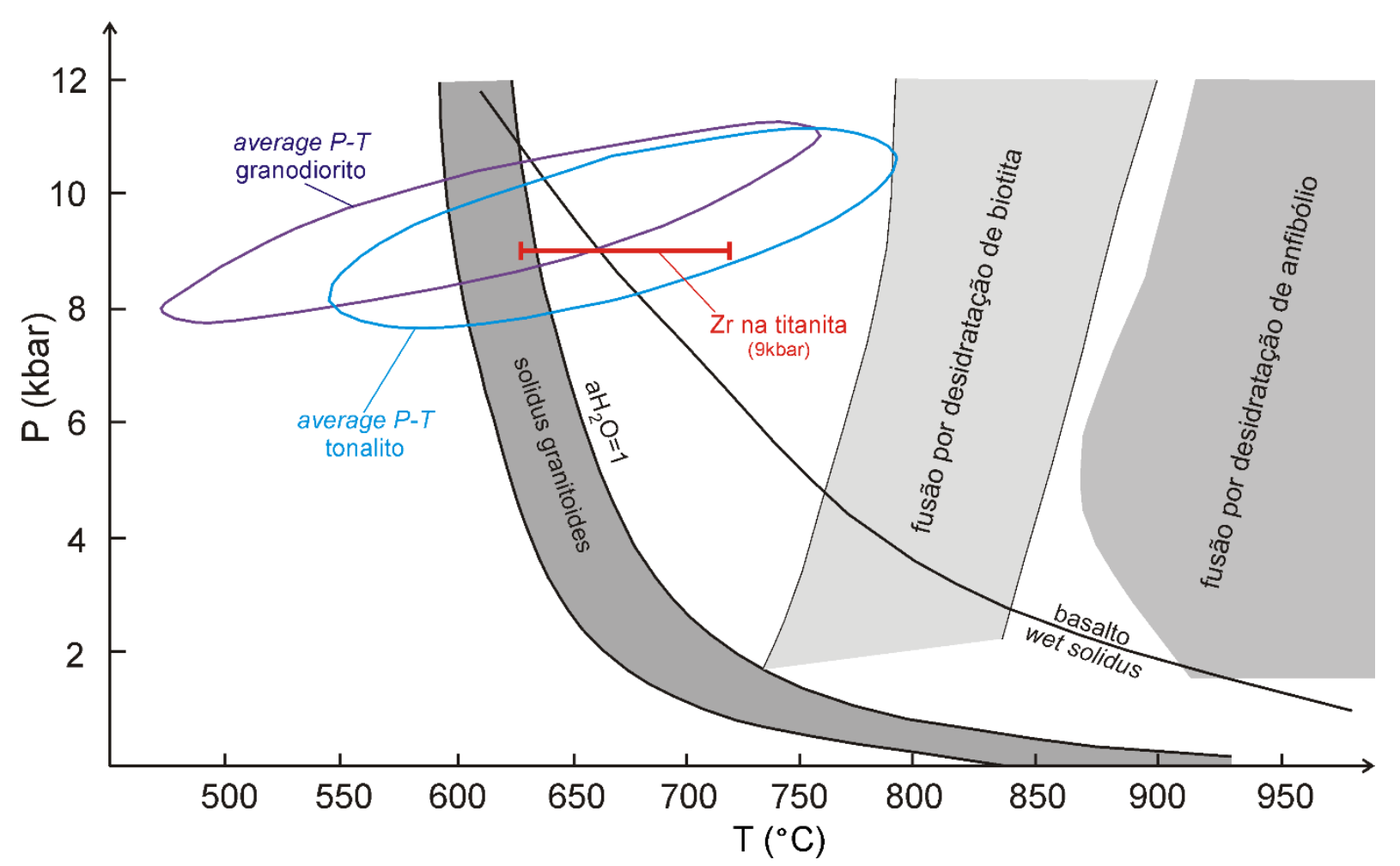

Figura 7.17. Diagrama pressão (kbar) vs. temperatura $\left({ }^{\circ} \mathrm{C}\right)$ com compilação das reações de fusão com presença de água e reações de fusão por desidratação extraída de Weinberg \& Hasalová (2015). As elipses azul e roxa representam os resultados obtidos através de termobarometria THERMOCALC average P-T para as amostras de ortognaisses tonalíticos e granodiorítico, respectivamente. A barra vermelha representa as temperaturas obtidas pelo método zircônio na titanita para os núcleos dos cristais a pressão de 9 kbar.

As análises nas bordas dos cristais de titanita do ortognaisse granodiorítico 9B definem um intercepto inferior no diagrama Tera-Wasserburg em 606,7 \pm 5,7 Ma. Essas bordas são enriquecidas 
em elementos terras raras pesados (Fig. 7.11f), o que sugerem que as mesmas foram geradas a partir do consumo de granada durante reações retrometamórficas. Portanto, essa datação é interpretada como a idade da descompressão durante o metamorfismo retrógrado. Essa idade é idêntica, dentro da margem de erro, a idade de cristalização de $607 \pm 5,7$ Ma obtida no leucogranito 1(O) (Fig. 7.18). Como discutido na seção relações de campo, as relações de corte indicam que os diques de leucogranito grosso são posteriores aos leucossomas estromáticos (Figs. 7.2c, d). Esses diques encontram-se deformados o que indica a continuidade do processo de deformação após a intrusão dos diques. As relações estruturais associadas a idade $\mathrm{U}-\mathrm{Pb}$ sugerem que os diques de leucogranito foram intrudidos durante o processo de exumação do Complexo Pouso Alegre em condições de temperatura abaixo do solidus, pois no momento das intrusões todo o fundido gerado no metamorfismo progressivo já estava cristalizado. Essas idades demostram a continuidade da deformação associada a exumação no Orógeno Brasília Meridional até pelo menos 607 Ma. Essa interpretação está de acordo com o recente trabalho de Rocha et al. (2016), que indica um evento prolongado de metamorfismo na Nappe Socorro-Guaxupé, com eventos principais de cristalização de fundido a aproximadamente 615 e $608 \mathrm{Ma}$ e crescimento de monazita associada a quebra retrógrada de granada a aproximadamente 600Ma.

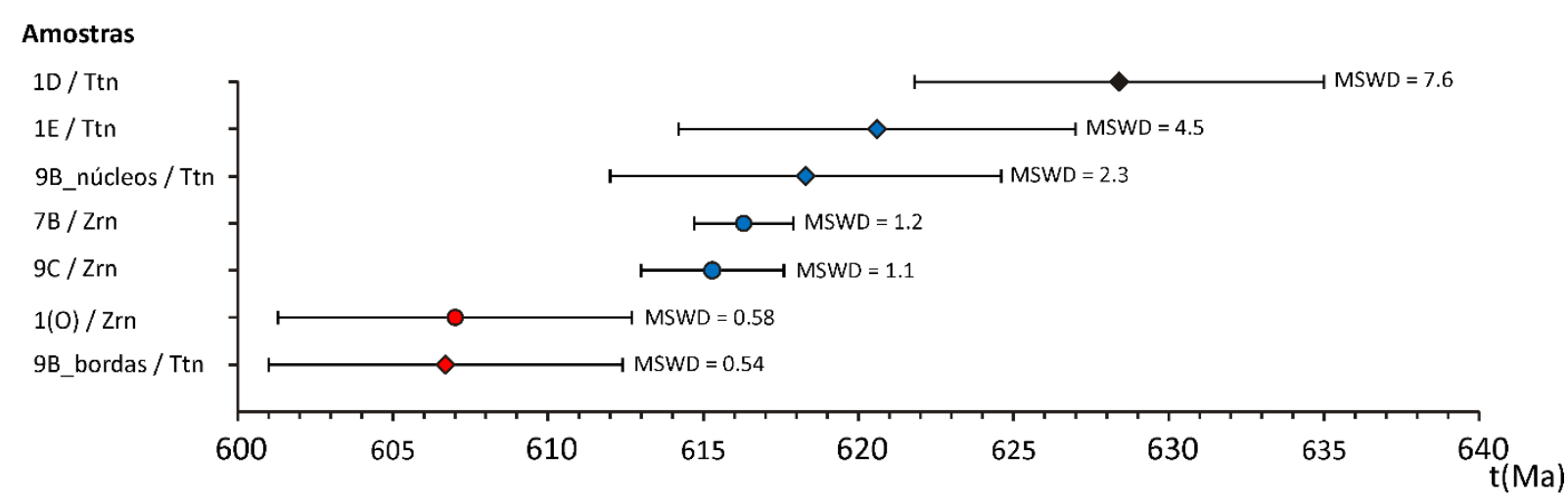

Figura 7.18. Compilação das idades U-Pb relacionadas ao evento metamórfico Neoproterozóico.

\subsection{Referência bibliográficas}

Conrad, W.K., Nicholls, I.A., Wall, V.J., 1988. Water-saturated and -undersaturated melting of metaluminous and peraluminous crustal compositions at 10 kbar: Evidence for the origin of silicic magmas in the Taupo volcanic zone, New Zealand, and other occurrences. Journal of Petrology 29, 765-803. 
Ferry, J.M., Watson, E.B., 2007. New thermodynamic models and revised calibrations for the Ti-inzircon and Zr-in-rutile thermometers). Contributions to mineralogy and petrology 154, 429-437.

Gardien, V., Thompson, A.B., Ulmer, P., 2000. Melting of biotite + plagioclase + quartz gneisses: the role of $\mathrm{H}_{2} \mathrm{O}$ in the stability of amphibole. Journal of Petrology 41, 651-666.

Hayden, L.A., Watson, E.B., 2007. Rutile saturation in hydrous siliceous melts and its bearing on Tithermometry of quartz and zircon. Earth and Planetary Sciences Letters 258, 561-568.

Hayden, L.A., Watson, E.B., Wark, D.A., 2008. A thermobarometer for sphene (titanite). Contributions to mineralogy and petrology $155,529-540$.

Leake, B.E., Wooley, A.R., Arps, C.E.S., Birch, W.D., Gilbert, M.C., Grice, J.D., Hawthorne, F.C., Kato, A., Kisch, H.J., Krivovichev, V.G., Linthout, K., Laird, L., Mandarino, J.A., Maresch, W.V., Nickel, E.H., Schumacher, J.C., Smith, D.C., Stephenson, N.C.N., Ungaretti, L., Whittaker, E.J.W., Youzhi, G., 1997. The Canadian Mineralogist 35, 219-246.

Patiño Douce, A.E., Harris, N., 1998. Experimental constraints on Hymalaian anataxis. Journal of Petrology 39, 689-710.

Powell, R., Holland, T.J.B., 1988. An internally consistent dataset with uncertainties and correlations: 3. Applications to geobarometry, worked examples and a computer program. Journal of metamorphic geology 6, 173-204.

Rocha, B.C., Moraes, R., Möller, A., Cioffi, C.R., Jercinovic, M.J., Timing of anatexis and melt crystallization in the Socorro-Guaxupé Nappe, SE Brazil: Insights from trace element compositions of zircon, monazite and garnet coupled to U-Pb geochronology. Lithos (2016), hhtp://dx.doi.org/10.1016/j.lithos.2016.05.020.

Tera, F., Wasserburg, G.J., 1972. U-Th-Pb systematics in three Apollo 14 basalts and the problem of initial Pb in lunar rocks. Earth and Planetary Sciences Letters 14, 281-304.

Weinberg, R.F., Hasalova, P., 2015. Water-fluxed melting of the continental crust: A review. Lithos 212$215,158-188$. 


\section{Discussão}

\subsection{O Complexo Pouso Alegre: correlações com o domínio cratônico}

A posição da sutura neoproterozóica entre as placas do São Francisco e Paranapanema é uma questão ainda em debate nos dias de hoje. Alguns autores (e.g. Campos Neto et al., 2010, 2011) consideram o Sistema de Nappes Andrelândia como sedimentos da margem ativa, associados ao prisma acrescionário e bacias de ante-arco. Portanto, para os mesmos, a zona de sutura está situada abaixo do Sistema de Nappes Andrelânia. Outros autores (e.g. Trouw et al., 2013), correlacionam o Sistema de Nappes Andrelândia com os sedimentos da margem passiva e, portanto, localizam a zona de sutura acima do Sistema de Nappes Andrelândia. Em ambos os modelos, o Complexo Pouso Alegre ${ }^{1}$ representa parte do assoalho sobre a qual as nappes neoproterozóicas foram transportadas e, portanto, parte da placa do São Francisco intensamente retrabalhada durante a orogenia neoproterozóica. Os eventos neoproterozóicos foram responsáveis por importante transporte tectônico no sentido leste-nordeste. Como resultado, parte do Complexo Pouso Alegre está sobreposto a rochas supracrustais do Complexo São Vicente (Westin et al., 2016) e aos complexos arqueanos. Escamas tectônicas do Complexo Pouso Alegre encontram-se imbricadas com metassedimentos do Sistema de Nappes Andrelândia.

Os dados geocronológicos apresentados nessa tese indicam que o Complexo Pouso Alegre compreende duas suítes magmáticas paleoproterozóicas, sendo uma gerada a 2,15 Ga e a outra a 2,08 Ga. Zircões herdados são extremamente raros e ambas as suítes apresentam assinaturas isotópicas de neodímio e háfnio juvenis. Na porção sul do cráton do São Francisco, na área denominada como Cinturão Mineiro, são reconhecidas suítes magmáticas com assinaturas isotópicas juvenis e idades entre 2,35 e 2,10 Ga (e.g. Ávila et al., 2010; Seixas et al., 2012, 2013; Teixeira et al., 2015; Barbosa et al., 2015), interpretadas como uma sucessão de processos de acresção de arcos oceânicos e arcos continentais a borda sul do paleocontinente São Francisco durante o Paleoproterozóico. Baseado nos dados isotópicos associados ao contexto geológico, o Complexo Pouso Alegre é interpretado como a porção mais meridional e mais nova desse sistema de arcos do Paleoproterozóico, instalado na borda

1 O termo Complexo Pouso Alegre é utilizado nessa tese para designar as suítes paleoproterozóicas (2,15-2,08 Ga) com assinaturas isotópicas juvenis que ocorrem no embasamento do Orógeno Brasília meridional. Parte dessas suítes estava anteriormente sob outras nomenclaturas e parte era tratada como embasamento indiferenciado. Esse termo foi sugerido ao longo do desenvolvimento do presente projeto de pesquisa e utilizado pela primeira vez na literatura em um artigo resultado dessa tese (Cioffi et al., 2016). 
sul do paleocontinente São Francisco e intensamente retrabalhado durante o desenvolvimento do Orógeno Brasília meridional.

\subsection{Eventos de geração crustal paleoproterozóicos e suas implicações para modelos de preservação da crosta continental.}

Os dados apresentados nessa tese, em conjunto com dados prévios (Fetter et al., 2001; Campos Neto et al., 2011), sugerem importantes eventos paleoproterozóicos de geração de crosta continental no Complexo Pouso Alegre, parte do embasamento do Orógeno Brasília meridional. A partir dos dados apresentados nessa tese, foram reconhecidos dois grupos de idades de cristalização a $2078,7 \pm 6,7 \mathrm{Ma}$ e $2146,7 \pm 6,6 \mathrm{Ma}$ (média ponderada para os grupos; $n=6$ e $n=5$, respectivamente). Essas amostras estão associadas a valores de $\varepsilon \mathrm{Nd}_{(\mathrm{t})}$ positivos e idades modelo $\mathrm{T}_{\mathrm{DM}}$ entre 2,16 e 2,37 Ga. Os dados de isótopos de háfnio obtidos para três dessas amostras apresentam valores de $\varepsilon \mathrm{Hf}_{(t)}$ positivos entre $+1,9$ e $+8,7$. Esses dados, associados a ausência de zircões herdados mais antigos, são forte evidência do caráter juvenil das amostras analisadas.

Os dados e interpretações apresentados no presente trabalho aumentam consideravelmente a área e o intervalo de tempo dos eventos paleoproterozóicos de geração de crosta continental na borda sul do paleocontinente São Francisco. O volume de material continental juvenil é ainda maior quando levado em consideração as rochas metassedimentares do Complexo São Vicente. Essas rochas apresentam proveniência de fontes paleoproterozóicas juvenis e foram interpretadas por Westin et al. (2016) como produtos de erosão do Complexo Pouso Alegre. Como discutido no item anterior, no presente trabalho o Complexo Pouso Alegre é considerado como sendo a continuação do Cinturão Mineiro retrabalhado, durante o Neoproterozóico, no desenvolvimento do Orógeno Brasília meridional. Portanto, as rochas do Complexo Pouso Alegre, juntamente com as suítes juvenis do Cinturão Mineiro, representam um importante evento paleoproterozóico de geração de crosta continental, com idades de cristalização entre 2,35 e 2,08 Ga e idades modelo $\mathrm{T}_{\mathrm{DM}}$ entre 2,5 e 2,2 Ga. Esse intervalo de tempo é reconhecido por baixa geração e preservação de rochas juvenis em escala global, porém é aparentemente um importante período de geração e preservação de crosta continental na América do Sul e no oeste da África (Abouchami et al., 1990; Teixeira et al., 2015).

Estudos recentes sobre o crescimento da crosta continental, baseados em isótopos de háfnio e oxigênio (e.g. Belousova et al., 2010; Dhuime et al., 2012), sugerem que a crosta continental teve um crescimento contínuo e que de 60 a $75 \%$ do volume da crosta continental foi extraído do manto durante o Arqueano. Após esse período, os processos de retrabalhamento crustal teriam predominado. Esses modelos aparentemente contrastam com o registro global das rochas juvenis que 
apresentam concentrações episódicas de idades U-Pb, com picos principais a 2,7, 1,9 e 1,2 Ga (Condie, 1998; Condie \& Aster, 2010). Modelos de preservação crustal (Hawkesworth et al., 2009, 2013) são utilizados para explicar como uma crosta continental com crescimento contínuo pode gerar um registro episódico de idades de rochas juvenis. Segundo esses modelos, rochas geradas entre os picos de idades do registro juvenil são consideradas como possuindo baixo potencial de preservação. Para esses modelos, os picos de idades do registro juvenil representam períodos de aglomeração de supercontinentes que favoreceriam a preservação de rochas juvenis (e.g. Hawkesworth et al., 2009, 2013; Condie \& Aster, 2010).

Modelos confiáveis de preservação crustal dependem de modelos acurados do registro global de idades de rochas juvenis. Uma amostragem não representativa do registro de rochas juvenis pode levar a modelos de preservação da crosta continental distorcidos e consequentemente a interpretações errôneas sobre os períodos de aglomeração dos supercontinentes. As rochas juvenis investigadas nessa tese apresentam idades de cristalização entre 2,15 e 2,08 Ga. Esse período está situado entre dois importantes picos do registro geológico juvenil a 2,7 e 1,9 Ga. Portanto, essas rochas foram geradas em um período considerado como de baixa preservação de rochas juvenis em escala global. No entanto, esse parece ser um importante período de geração de crosta continental na borda sul do paleocontinente São Francisco. Portanto, a presente tese sugere que o registro global de idades de rochas juvenis está enviesado, devido a defasagem de dados provenientes da América do Sul e África, em comparação com os outros continentes. Esse estudo também enfatiza a necessidade de reconhecimento de rochas juvenis retrabalhadas para o estabelecimento de modelos confiáveis de geração e preservação da crosta continental.

\subsection{Ambientes tectônicos do Complexo Pouso Alegre}

A compreensão sobre os ambientes e processos de geração da crosta continental durante o Paleoproterozóico é fundamental para a definição do início da tectônica de placas moderna. Aparentemente, uma grande mudança nos ambientes de geração crustal ocorreu na transição entre o Arqueano e o Paleoproterozóico. Durante o Arqueano, arcos e platôs oceânicos eram provavelmente os principais ambientes de geração de crosta continental (Nair \& Chacko, 2008; Condie \& Kröner, 2013). Após o Arqueano, a crosta oceânica tornou-se mais fina e subductável, tornando improvável a acresção de arcos oceânicos a margens continentais. Como resultado, ocorreu uma mudança nos ambientes de geração de crosta no final do Arqueano, que passaram de arcos e platôs oceânicos para arcos continentais (Condie \& Kröner, 2013). 
No caso do Complexo Pouso Alegre a ausência de relações primárias preservadas entre os diferentes litotipos faz com que as assinaturas geoquímicas sejam as principais ferramentas na definição dos ambientes tectônicos. A maioria dos litotipos do Complexo Pouso Alegre apresenta evidências de fusão parcial, porém a quantidade gerada e principalmente extraída de fundido aparentemente não foi expressiva. Esse fato é indicado pela frequente presença de estrutura estromática e também bolsões de leucossoma. Texturas ígneas, herdadas dos protólitos, como no caso da textura porfiroclástica do granito Serra de São Gonçalo, também são indicativas de baixas taxas de fusão. Essas hipóteses são reforçadas pela ausência de fases minerais anidras e pelas temperaturas máximas obtidas por termobarometria em torno de $700^{\circ} \mathrm{C}$ que impediriam geração expressiva de fundido. Portanto, as composições dos litotipos do Complexo Pouso Alegre não são consideradas residuais nas escalas das amostras e podem ser utilizadas como aproximações confiáveis das composições dos protólitos na tentativa de definição dos ambientes tectônicos.

As assinaturas geoquímicas de elementos maiores das amostras do Complexo Pouso Alegre, incluindo o caráter cálcio-alcalino, são características de batólitos gerados em ambientes relacionados a subducção. As rochas do Complexo Pouso Alegre apresentam altas concentrações de Rb, Ba, Th, U e baixas razões $\mathrm{Nb} / \mathrm{La}$, que são características de magmas de zonas de subducção e são relacionadas a um enriquecimento em elementos móveis, atribuídos ao influxo de fluidos provenientes da placa em subducção na cunha mantélica (Rudnick \& Fountain, 1995; Plank, 2005). Os diagramas discriminantes tectônicos (Pearce et al., 1984; Verma et al., 2013) também indicam ambientes relacionados a subducção para a maioria das amostras analisadas, fato esse reforçado pelas assinaturas isotópicas juvenis de neodímio e háfnio.

Após a definição do ambiente relacionado a subducção, é necessário diferenciar entre um ambiente oceânico ou continental. No Complexo Pouso Alegre ocorre um predomínio de rochas félsicas, sendo que grandes volumes de rocha félsica são comuns em arcos continentais e ocorrem em menor proporção em arcos oceânicos. O enriquecimento em elementos imcompatíveis observado nas amostras granodioríticas e graníticas do Complexo Pouso Alegre está consideravelmente acima dos campos dos arcos oceânicos e assemelham-se a arcos continentais. Além disso, a maioria das amostras cai dentro dos campos de arcos continentais dos diagramas discriminantes baseados em elementos traço imóveis de Verma et al. (2013). Todas essas características são evidências de assinaturas de arcos continentais nas amostras do Complexo Pouso Alegre.

Um fato que dificulta a diferenciação entre arcos oceânicos e continentais é a possibilidade de arcos oceânicos serem acrescionados a margens continentais e evoluírem para arcos continentais após a acresção (e.g. Draut et al., 2002, 2009; Condie \& Kröner, 2013). O modelo envolve o espessamento do arco durante a acresção, criando as condições necessárias para que a base do arco acrescionado seja fundida e gere batólitos com assinaturas de arcos continentais. Assumindo-se esse modelo, o 
Complexo Pouso Alegre pode ter sido gerado em um arco continental instalado na borda sul do paleocontinente São Francisco ou em um arco oceânico acrescionado e evoluído. No segundo cenário os magmas félsicos com assinatura de arcos continentais foram gerados provavelmente após a acresção.

A suíte mais nova de 2,08 Ga é composta por granodioritos e granitos enquanto que composições mais primitivas como tonalitos, predominam na suíte mais antiga de 2,15 Ga. Em relação a elementos maiores, a suíte mais recente é enriquecida em $\mathrm{K}_{2} \mathrm{O}, \mathrm{TiO}_{2}, \mathrm{P}_{2} \mathrm{O}_{5}$ e empobrecida em $\mathrm{CaO}$, $\mathrm{MgO}$ e $\mathrm{FeO}_{\mathrm{t}}$ em relação a suíte mais antiga. Quanto a concentrações de elementos traço, a suíte mais recente é enriquecida $\mathrm{Rb}, \mathrm{Zr}$, Nb, Ba, ETRL, Th e apresenta maiores razões $\mathrm{Gd} / \mathrm{Yb}$. Os valores médios de $\varepsilon \mathrm{Nd}_{(\mathrm{t})}$ e $\varepsilon \mathrm{Hf}_{(t)}$ da suíte mais recente são ligeiramente mais baixos do que os da suíte mais antiga. Todas essas características são similares as utilizadas na diferenciação entre os batólitos orientais e ocidentais do Peninsular Ranges na cordilheira norte-americana (e.g. Lee et al., 2008), sendo os batólitos ocidentais relacionados a um arco oceânico acrescionado e os batólitos orientais relacionados a fase de arco continental. A maior dificuldade para aplicação do modelo dos batólitos do Peninsular Ranges no Complexo Pouso Alegre é a ausência de evidências paleogeográficas preservadas. Os batólitos do Peninsular Ranges são claramente divididos em domínios geográficos distintos. Portanto, outros processos como retrabalhamento da suíte mais antiga na geração da suíte mais recente não podem ser descartados. Porém, esse processo parece bastante improvável, uma vez que a suíte mais recente não apresenta herança de zircões provenientes da suíte mais antiga.

\subsection{Significado tectônico dos complexos arqueanos}

O embasamento do Orógeno Brasília meridional pode ser dividido em dois domínios tectônicos principais: (1) um domínio de arco magmático paleoproterozóico composto pelos ortognaisses do Complexo Pouso Alegre e por rochas metassedimentares do Complexo São Vicente (e.g. Cioffi et al., 2016; Westin et al., 2016) e (2) um domínio arqueano composto pelos complexos Amparo, Serra Negra, Heliodora-Minduri e Mantiqueira (e.g. Fetter et al., 2001; Tassinari \& Nutman, 2001; Peternel, 2005). Como apresentado nos itens anteriores dessa discussão, a presente tese assume que o Complexo Pouso Alegre é a continuação do Cinturão Mineiro dentro do Orógeno Brasília meridional. Se essa premissa for verdadeira, os complexos arqueanos do embasamento do Orógeno Brasília meridional estão separados da crosta arqueana do Cráton do São Francisco por esse sistema de arcos paleoproterozóico com pelo menos 350 quilômetros de extensão.

Os dados U-Pb apresentados nessa tese indicam magmatismo meso-arqueano do tipo TTG entre 2,96 e 3,00 Ga nos complexos Amparo, Serra Negra e Heliodora. Dados publicados na literatura 
sugerem quatro períodos principais de magmatismo na crosta arqueana na porção sul do Cráton do São Francisco (Teixeira et al., 2000; Lana et al., 2013; Farina et al., 2015): (1) Evento magmático Santa Barbara (ca. 3230-3200 Ma); (2) Rio das Velhas I (2930-2850 Ma); (3) Rio das Velhas II (2800-2760 Ma) e (4) Mamona (ca. 2760-2680 Ma). Portanto, os dados geocronológicos apresentados nessa tese, indicam que os Complexos arqueanos do embasamento do Orógeno Brasília meridional são exóticos a crosta arqueana da porção sul do cráton do São Francisco, uma vez que as idades de cristalização ígnea dos mesmos estão dentro do hiato magmático da porção sul do cráton do São Francisco.

Baseado no contexto geológico e dados geocronológicos, os complexos Arqueanos do embasamento do Orógeno Brasília meridional são interpretados como microcontinentes acrescionados a borda sul do paleocontinente São Francisco. A idade do evento de acresção não é bem definida, porém é considerada mais nova do que as suítes do Complexo Pouso Alegre geradas entre 2,15 e 2,08 Ga. A única evidência direta sobre a idade de acresção são três análises levemente discordantes na amostra de granito neo-arqueano, que fornecem uma média ponderada de $2028 \pm 33$ $\mathrm{Ma}$, dentro da margem de erro das idades paleoproterozóicas obtidas em um neossoma do Complexo Amparo por Tassinari \& Nutman (2001).

A evolução pré-acresção é marcada por magmatismo meso-arqueano do tipo TTG a 2,96-3,00 Ga, seguido por magmatismo granítico a 2,76 Ga, que marca a transição neo-arqueana de magmatismo do tipo TTG para magmatismo granítico de alto potássio na área de estudo. As assinaturas isotópicas de háfnio e neodímio sugerem que o magmatismo do tipo TTG é essencialmente juvenil com a participação de crosta ligeiramente mais antiga. Essas evidências são suportadas pela idade dos zircões herdados de ca. 3,19 Ga. O magmatismo granítico neo-arqueano apresenta assinaturas isotópicas de háfnio e neodímio menos radiogênicas, fato esse que pode sugerir o retrabalhamento das suítes TTG como principal mecanismo para geração da suíte neo-arqueana. No entanto, como discutido por Laurent \& Zeh (2015), assinaturas isotópicas de háfnio de populações de zircão arqueanas podem fornecer informações ambíguas em relação as suas fontes. Portanto, sem um melhor entendimento a respeito da herança nos zircões dessa suíte, o envolvimento de crosta mais antiga do que 3,0 Ga ou até mesmo de material juvenil, não podem ser descartados.

\subsection{O retrabalhamento neoproterozóico do Complexo Pouso Alegre: implicações para a evolução do Orógeno Brasília meridional}

O Complexo Pouso Alegre apresenta evidências de intenso retrabalhamento durante os eventos orogênicos neoproterozóicos. Esses eventos foram responsáveis por metamorfismo em fácies anfibolito superior associado a intensa deformação em estado dúctil e transporte tectônico no sentido 
leste-nordeste. Na trajetória progressiva do metamorfismo, reações de fusão parcial na presença de $\mathrm{H}_{2} \mathrm{O}$ foram responsáveis pela geração de leucossomas tonalíticos, muitas vezes com hornblenda peritética associada. As condições máximas de metamorfismo, estabelecidas através de termobarometria THERMOCALC average P-T (Powell \& Holland, 1998), são de aproximadamente $670^{\circ} \mathrm{C}$ e 9,5 kbar. Esses dados são corroborados pelos dados obtidas através de termometria baseada nos conteúdos de zircônio nos cristais de titanita (Hayden et al., 2008), que forneceram temperaturas médias ao redor de $700^{\circ} \mathrm{C}$ para uma pressão assumida de $9 \mathrm{kbar}$.

A idade do metamorfismo no Complexo Pouso Alegre foi determinada através de análises U$\mathrm{Pb}$ em titanita proveniente dos ortognaisses e em zircão proveniente de leucossomas e leucogranitos. Os cristais de titanita das amostras de ortognaisses tonalíticos apresentam estruturas internas complexas e não foi possível a distinção entre idades de núcleos e bordas dos cristais. Nessas amostras os resultados obtidos variam entre 628 e 620 Ma e são interpretados como idade de (re)cristalização dos cristais de titanita no evento metamórfico de fácies anfibolito superior. Na amostra de ortognaisse granodiorítico as estruturas internas dos cristais de titanita são menos complexas e foi possível uma distinção entre idades dos núcleos e bordas dos cristais. Nessa amostra, os núcleos forneceram idade de aproximadamente $618 \mathrm{Ma}$ e as bordas de $607 \mathrm{Ma}$. Essas bordas são enriquecidas em elementos terras raras pesados e, portanto, foram interpretadas como relacionadas ao consumo de granada, provavelmente durante a descompressão associada a exumação do Complexo Pouso Alegre.

Os grãos de zircão das duas amostras de leucossomas tonalíticos analisados dividem-se em duas populações principais. A primeira relacionada as heranças paleoproterozóicas e a segunda aos domínios gerados durante o evento metamórfico neoproterozóico. Parte das análises do domínio neoproterozóico apresentam evidências de perda de chumbo recente, sendo que se considerando apenas as análises com discordância menor que 1\%, obtêm-se idades concordia entre 615 e 616 Ma, que são interpretadas como idades de cristalização dos leucossomas. Essas idades são idênticas, dentro da margem de erro, as idades mais novas obtidas nos núcleos dos cristais de titanita e são consideradas as melhores estimativas da idade do metamorfismo de fácies anfibolito superior.

Diques de leucogranito grosso intrudiram o Complexo Pouso Alegre e aparentemente são posteriores aos leucossomas estromáticos. Esses diques estão intensamente deformados, fato esse que confirma a continuidade da deformação após a intrusão dos diques. As análises U-Pb em zircões da amostra de leucogranito grosso, resultaram em idade de cristalização de aproximadamente 607 Ma, idêntica dentro da margem de erro, a idade obtida nas bordas dos cristais de titanita da amostra de ortognaisses granodiorítico. Essa idade é interpretada como a idade das intrusões dos diques, durante o processo de exumação do Complexo Pouso Alegre. Portanto, as idades obtidas nessa tese indicam que os processos de deformação, em condições dúcteis, associados a exumação do Orógeno Brasília meridional, perduraram até pelo menos $607 \mathrm{Ma}$. Esses dados corroboram com o recente 
trabalho de Rocha et al. (2016) que sugere um evento prolongado de metamorfismo na Nappe Socorro-Guaxupé, com pico metamórfico em fácies granulito a aproximadamente 630-625 Ma, eventos principais de cristalização do fundido a 615 e 608 Ma, e geração de monazita associada ao consumo de granada durante a trajetória retrógrada a ca. $600 \mathrm{Ma}$.

\subsection{Referências bibliográficas}

Abouchami, W., Boher, M., Michard, A., Albarède, F., 1990. A major 2.1Ga event of mafic magmatism in West Africa - an early stage of crustal accretion. Journal of Geophysical Research: Solid Earth 95, $17605-17629$

Ávila, C.A., Teixeira, W., Cordani, U.G., Moura, C.A.V., Pereira, R.M., 2010. Rhyacian (2.23-2.20 Ga) juvenile accretion in the Southern São Francisco craton, Brazil: Geochemical and isotopic evidence from the Serrinha magmatic suite, Mineiro belt. Journal of South American Earth Sciences 29, 464-482.

Barbosa, N.S, Teixeira, W., Ávila, C.A., Montecinos, P.M., Bongiolo, E.M., 2015. 2.17 - 2.10 Ga plutonic episodes in the Mineiro belt, São Francisco Craton, Brazil: U-Pb ages, geochemical constraints and tectonics. Precambrian Research 270, 204-225.

Belousova, E.A., Kostitsyn, Y.A., Griffin, W.L., Begg, G.C., O’Reilly, S.Y., Pearson, N.J., 2010. The growth of continental crust: Constraints from zircon Hf-isotopes data. Lithos 119, 457-466.

Campos Neto, M.C., Cioffi, C.R., Moraes, R., Motta, R.G., Siga Jr., O., Basei, M.A.S., 2010. Structural and metamorphic control on the exhumation of high-P granulites: The Carvalhos Klippe example, from the oriental Andrelândia Nappe System, southern portion of the Brasília Orogen, Brazil. Precambrian Research 180, 125-142.

Campos Neto, M.C., Basei, M.A.S., Janasi, V.A., Moraes, R., 2011. Orogen migration and tectonic setting of the Andrelândia Nappe System: An Ediacaran western Gondwana collage, south São Francisco craton. Journal of South American Earth Sciences 32, 393-406.

Cioffi, C.R., Campos Neto, M.C., Möller, A., Rocha, B.C., 2016. Paleoproterozoic continental crust generation events at 2.15 and $2.08 \mathrm{Ga}$ in the basement of the southern Brasília Orogen, SE Brazil. Precambrian Research 275, 176-196.

Condie, K.C., 1998. Episodic continental growth and supercontinents: a mantle avalanche connection? Earth and Planetary Sciences Letters 163, 97-108.

Condie, K.C., Aster, R.C., 2010. Episodic zircon age spectra of orogenic granitoids: The supercontinent connection and continental growth. Precambrian Research 180, 227-236. 
Condie, K.C., Kröner, A., 2013. The building blocks of continental crust: Evidence for a major change in the tectonic setting of continental growth at the end of the Archean. Gondwana Research 23, 394-402.

Dhuime, B., Hawkesworth, C., Cawood, P.A., Storey, C.D., 2012. A change in the geodynamic of Continental Growth 3 Billion Years Ago. Science 335, 1334-1336.

Draut, A.E., Clift, P.D., Hannigan, R.E., Layne, G., Shimizu, N., 2002. A model for continental crust genesis by arc accretion: rare earth element evidence from the Irish Caledonides. Earth and Planetary Science Letters 203, 861-877.

Draut, A.E., Clift, P.D., Amato, J.M., Blusztajn, J., Schouten, H., 2009. Arc-continent collision and the formation of continental crust: a new geochemical and isotopic record from the Ordovician Tyrone Igneous Complex, Ireland. Journal of the Geological Society of London 166, 485-500.

Farina, F., Capucine, A., Lana, C., 2015. The Neoarchean transition between medium- and high-K granitoids: Clues from the southern São Francisco Craton (Brazil). Precambrian Research 266, 375-394.

Fetter, A.H., Hackspacker, P.C., Ebert, H.D., Dantas, E.L., Costa, A.C.D., 2001. New Sm/Nd and U/Pb geochronological constraints on the Archean to Neoproterozoic evolution of the Amparo basement complex of the central Ribeira belt, southeastern Brazil. 3rd South American Symposium on Isotope Geology (Extended Abstracts, CD-ROM).

Hayden, L.A., Watson, E.B., Wark, D.A., 2008. A thermobarometer for sphene (titanite). Contributions to mineralogy and petrology $155,529-540$.

Hawkesworth, C., Cawood, P.A., Kemp, T., Storey, C.D., Dhuime, B., 2009. A matter of preservation. Science 323, 49-50.

Hawkesworth, C., Cawood, P.A., Dhuime, B., 2013. Continental growth and the crustal record. Tectonophysics 609, 651-660.

Lana, C., Alkmin, F.F., Armstrong, R., Scholz, R., Romano, R., Nalini Jr., H.A., 2013. The ancestry and magmatic evolution of the Archaean TTG rocks of the Quadrilátero Ferrífero province, southeast Brazil. Precambrian Research 231, 157-173.

Laurent, O., Zeh, A., 2015. A linear Hf isotope-age array despite different granitoid sources and complex Archean geodynamics: Example from the Pietersburg block (South Africa). Earth and Planetary Science Letters $430,326-338$.

Nair, R., Chacko, T., 2008. Role of oceanic plateaus in the initiation of subduction and origin of continental crust. Geology 36, 583-586. 
Pearce, J.A., Harris, N.B.W., Tindle, A.G., 1984. Trace element discrimination diagrams for the tectonic interpretation of granitic rocks. Journal of Petrology 25, 956-983.

Peternel, R., 2005. A zona de superposição entre as Faixas Brasília e Ribeira na região entre Caxambu e Pedralva, sul de Minas Gerais. Unpublished PhD Thesis. Instituto de Geociências - UFRJ, (257pp.).

Plank, T., 2005. Constraints from thorium/lanthanum on sediment recycling at subduction zones and the evolution of the continents. Journal of Petrology 46, 921-944.

Powell, R., Holland, T.J.B., 1988. An internally consistent dataset with uncertainties and correlations: 3. Applications to geobarometry, worked examples and a computer program. Journal of metamorphic geology 6, 173-204.

Rocha, B.C., Moraes, R., Möller, A., Cioffi, C.R., Jercinovic, M.J., Timing of anatexis and melt crystallization in the Socorro-Guaxupé Nappe, SE Brazil: Insights from trace element compositions of zircon, monazite and garnet coupled to U-Pb geochronology. Lithos (2016), hhtp://dx.doi.org/10.1016/j.lithos.2016.05.020.

Rudnick, R.L., Fountain, D.M., 1995. Nature and compostion of the continental crust: a lower crustal perspective. Reviews of Geophysics 33, 267-309.

Seixas, L.A.R., David, J., Stevenson, R., 2012. Geochemistry, Nd isotopes and U-Pb geochronology of a 2350 Ma TTG suite, Minas Gerais, Brazil: Implications for the crustal evolution of the southern São Francisco craton. Precambrian Research 196-197, 61-80.

Seixas, L.A.R., Bardintzeff, J-M., Stevenson, R., Bonin, B., 2013. Petrology of the high -Mg tonalites and dioritic enclaves of the ca. $2130 \mathrm{Ma}$ Alto Maranhão suite: Evidence for a major juvenile crustal addition event during the Rhyacian orogenesis, Mineiro Belt, southeast Brazil. Precambrian Research 238, 1841.

Tassinari, C.C.G., Nutman, A.P., 2001. Archean and Proterozoic multiple tectonothermal events recorded by gneisses in the Amparo region, São Paulo state, Brazil. 3rd South American Symposium on Isotope Geology (Extended Abstracts, CD-ROM).

Teixeira, W., Sabatè, P., Barbosa, J., Noce, C.M., Carneiro, M.A., 2000. Archean and Paleoproterozoic evolution of the São Francisco Craton, Brazil. In: Cordani, U.G., Milani, E.J., Thomaz Filho, A., Campos, D.A. (Eds.), Tectonic Evolution of South America. 31th International Geological Congress. Rio de Janeiro, Brazil, pp. 101-137.

Teixeira, W., Ávila, C.A., Dussin, I.A., Corrêa Neto, A.V., Bongiolo, E.M., Santos, J.O., Barbosa, N.S., 2015. A juvenile accretion episode (2.35-2.32 Ga) in the Mineiro Belt and its role to the Minas accretionary orogeny: Zircon U-Pb-Hf and geochemical evidences. Precambrian Research 256, 148-169. 
Trouw, R.A.J., Peternel, R., Ribeiro, A., Heilbron, M., Vinagre, R., Duffles, P., Trouw, C.C., Fontainha, M., Kussama, H.H., 2013. A new interpretation for the interference zone between the southern Brasília belt and the central Ribeira belt, SE Brazil. Journal of South American Earth Sciences 48, 43-57.

Verma, S.P., Pandarinath, K., Verma, S.K., Agrawal, S., 2013. Fifteen new discriminant-function-based multi-dimension robust diagrams for acid rocks and their applications to Precambrian rocks. Lithos 168-169, 113-123.

Westin, A., Campos Neto, M.C., Hawkesworth, C., Cawood, P., Dhuime, B., Delavault, H., A Paleoproterozoic intra-arc basin associated with a juvenile source in the southern Brasília Orogen: using U-Pb ages and Hf-Nd isotopic analyses in provenance studies of complexes areas. Precambrian Research 276, 178-193. 


\section{Conclusões}

Uma das principais conclusões dessa tese é que grande parte da história do crescimento paleoproterozóico do paleocontinente São Francisco está escondida nos orógenos neoproterozóicos marginais, que contornam o cráton do São Francisco. Portanto, a investigação do embasamento desses orógenos pode fornecer informações importantes sobre a aglomeração do paleocontinente São Francisco e consequentemente da história dos supercontinentes. No embasamento do Orógeno Brasília meridional, foco dessa pesquisa, foram identificados dois domínios tectônicos principais: (1) um domínio de arco magmático paleoproterozóico representado pelo Complexo Pouso Alegre e (2) um domínio arqueano representado pelos complexos Amparo, Serra Negra, Heliodora-Minduri e Mantiqueira.

Os ortognaisses do Complexo Pouso Alegre registram episódios de geração de crosta continental com idades de cristalização entre 2,15 e 2,08 Ga. As suítes do Complexo Pouso Alegre apresentam assinaturas de geoquímicas relacionadas a ambientes de subducção, sendo que grande parte das amostras apresenta assinaturas geoquímicas de arco continental. A predominância de rochas félsicas e as assinaturas geoquímicas sugerem um ambiente de arco continental ou de arco oceânico acrescionado e evoluído como possíveis cenários tectônicos para geração do Complexo Pouso Alegre. O Complexo Pouso Alegre é interpretado como a continuação do Cinturão Mineiro intensamente retrabalhada durante o desenvolvimento do Orógeno Brasília meridional. Portanto, o mesmo é interpretado como a porção mais meridional e mais nova desse sistema de arcos paleoproterozóicos instalado na borda sul do paleocontinente São Francisco.

O Complexo Pouso Alegre e as suítes juvenis do Cinturão Mineiro representam um importante evento de geração de crosta continental com idades de cristalização entre 2,35 e 2,08 Ga e idades modelo $T_{D M}$ entre 2,5 e 2,2 Ga. Essas suítes indicam importante preservação de crosta continental juvenil na borda sul do paleocontinente São Francisco durante um período considerado globalmente como de baixa preservação. Portanto, os dados apresentados nessa tese, em conjunto com dados da literatura, indicam que o registro global de rochas juvenis está provavelmente enviesado pela baixa amostragem na América do Sul e oeste da África. Outro aspecto importante ressaltado nessa tese é a importância do reconhecimento e investigação de rochas juvenis retrabalhadas para definição de modelos acurados de preservação da crosta continental e consequentemente da aglomeração dos supercontinentes.

Os complexos arqueanos Amparo, Serra Negra e Heliodora-Minduri registram magmatismo meso-arqueano do tipo TTG entre 2,96 e 3,00 Ga. O magmatismo granítico neo-arqueano a 2,76 Ga, identificado no Complexo Amparo, é interpretado como registro da transição neo-arqueana entre 
magmatismo do tipo TTG e magmatismo granítico de alto potássio na área de estudo, ressaltando a noção de que esse é, globalmente, um importante período de mudança nos ambientes de magmatismo e estilos tectônicos. Seguindo a linha de raciocínio de que o Complexo Pouso Alegre é a continuação orogênica do Cinturão Mineiro, os complexos arqueanos do embasamento do Orógeno Brasília meridional estão separados da crosta arqueana do cráton do São Francisco por esse sistema de arcos paleoproterozóico. As idades obtidas nesse trabalho para o magmatismo meso-arqueano estão dentro do hiato de idades, apresentado na literatura, para a crosta arqueana da porção sul do cráton do São Francisco. Portanto, os complexos arqueanos do embasamento do Orógeno Brasília meridional são considerados exóticos ao cráton do São Francisco e são interpretados como microcontinentes acrescionados a borda sul do paleocontinente São Francisco após o desenvolvimento do Complexo Pouso Alegre entre 2,15 e 2,08 Ga. A idade exata da acresção não é bem definida, sendo a única evidência direta algumas análises com baixa discordância de uma amostra neo-arqueana, que forneceram resultados de aproximadamente 2,03 Ga. Os dados e intepretações apresentados nessa tese, sustentam que estudos focados na idade desse hipotético evento acrescionário paleoproterozóico seriam de grande valor para a compreensão da geologia regional e são, portanto, altamente encorajados.

As conclusões finais dessa tese dizem respeito as condições e idade do metamorfismo sofrido pelo Complexo Pouso Alegre durante o retrabalhamento Neoproterozóico. A presença de leucossomas tonalíticos frequentemente associados a hornblenda peritética sugere reações de fusão parcial com influxo de água e estabelece temperaturas mínimas para o metamorfismo ao redor de 600 a $650^{\circ} \mathrm{C}$. Cálculos termobarométricos, baseados nas composições de fases principais, realizados com THERMOCALC average $P$ - $T$, estabelecem condições máximas de metamorfismo a aproximadamente $670^{\circ} \mathrm{C}$ e 9,5 kbar. Esses dados são corroborados por dados obtidos por termometria baseada nos conteúdos de zircônio na titanita que indicam temperaturas médias ao redor de $700^{\circ} \mathrm{C}$. Núcleos de cristais de titanita fornecem idades entre 620 e $618 \mathrm{Ma}$, consideradas idades de (re)cristalização dos cristais de titanita durante o evento metamórfico de fácies anfibolito superior. Essas idades são idênticas, dentro da margem de erro, as idades de cristalização obtidas para os leucossomas tonalíticos entre 616 e 615 Ma. Bordas de titanita ricas em elementos terras raras pesados são interpretadas como associadas ao consumo de granada durante a descompressão associada a exumação do Complexo Pouso Alegre e fornecem idade de aproximadamente $607 \mathrm{Ma}$. Leucogranitos grossos que intrudiram o Complexo Pouso Alegre apresentam idade idêntica de $607 \mathrm{Ma}$ e são interpretados como resultado de fusão de níveis inferiores devido a descompressão associada a exumação. Esses diques estão fortemente deformados e, portanto, atestam a continuidade dos processos de deformação dúctil associados a exumação do Orógeno Brasília meridional até pelo menos $607 \mathrm{Ma}$. 


\section{ANEXO I \\ (Paleoproterozoic continental crust generation events at 2.15 and $2.08 \mathrm{Ga}$ in the basement of the southern Brasilia Orogen, SE Brazil)}


ANEXO I

Artigo publicado na revista Precambrian Research

\section{Paleoproterozoic continental crust generation events at 2.15 and $2.08 \mathrm{Ga}$ in the basement of the southern Brasília Orogen, SE Brazil}

Caue Rodrigues Cioffi ${ }^{1,2,}{ }^{*}$, Mario da Costa Campos Neto ${ }^{1}$, Andreas Möller ${ }^{2}$, Brenda Chung Rocha $^{1,2}$

${ }^{1}$ Instituto de Geociências, Universidade de São Paulo, SP, Brazil

${ }^{2}$ Department of Geology, The University of Kansas, Lawrence, KS, USA

*Corresponding author.E-mail addresses: cauecioffi@usp.br; caue.cioffi@yahoo.com.br

\section{Abstract}

New zircon U-Pb LA-ICP-MS data combined with $\mathrm{Nd}$-Hf isotopes and whole-rock geochemistry provide constraints on timing and tectonic setting of Paleoproterozoic continental crust generation events in the basement of the Neoproterozoic southern Brasilia Orogen, SE Brazil. The Paleoproterozoic basement, designated as the Pouso Alegre Complex, comprises mainly metatexitic tonalitic to granodioritic orthogneisses with lenses and boudins of metamafic rocks. Minor porphyroclastic granite bodies also occur. Two well-defined crystallization ages groups were recognized at $2.14-2.15 \mathrm{Ga}$ (6 samples; weighted average of $2146.7 \pm 6.6 \mathrm{Ma}$ ) and $2.07-2.08 \mathrm{Ga}$ (5 samples; weighted average of $2078.7 \pm 6.7 \mathrm{Ma}$ ). Inheritance of older zircon grains is almost absent. Whole-rock $\mathrm{Nd}$ data show juvenile signatures with $T_{D M}$ ages between 2.16 and $2.37 \mathrm{Ga}$ associated with positive $\varepsilon N d_{(t)}$ values from +0.16 to +2.85 . Zircon $\mathrm{Hf}$ LA-ICP-MS analysis yields positive $\varepsilon \mathrm{Hf}_{(t)}$ values from +1.9 to +8.7 . Whole-rock geochemical analyses show a wide range of $\mathrm{SiO}_{2}$ contents from 52 to 76 wt\% with felsic types predominating over mafic ones. The analyzed samples show high concentrations of $\mathrm{Rb}, \mathrm{Ba}, \mathrm{Th}, \mathrm{U}$ and 
low $\mathrm{Nb} /$ La ratios, which are characteristics of subduction zone magmas and most of the samples show continental arc affinities. The geochemical signatures associated with the predominance of felsic rocks suggest a continental arc margin or an evolved accreted oceanic arc as the favored tectonic setting for the Pouso Alegre Complex. The Pouso Alegre Complex is interpreted as the southernmost and youngest recognized part of an arc complex emplaced at the southern edge of the São Francisco paleocontinent during the Paleoproterozoic. This part of the arc complex was deeply reworked by the collisional events related to the Neoproterozoic southern Brasília Orogen and its cratonic counterpart is the Mineiro Belt at the southern São Francisco craton. The Pouso Alegre Complex and the juvenile suites of the Mineiro Belt represent a major Paleoproterozoic continental crust generation event between 2.35 and $2.08 \mathrm{Ga}$. This time period has not been recognized for extensive continental crust generation and preservation globally. However, it appears to be a major period of continental crust generation and preservation at the southern edge of the São Francisco paleo-continent.

Keywords: Paleoproterozoic; Crust generation; Juvenile crust; Pouso Alegre Complex; Brasília Orogen

\section{Introduction}

Juvenile crustal rocks represent additions from the mantle and therefore can provide important clues about crust generation processes. Juvenile rocks generated close to the ArcheanProterozoic boundary are of particular interest, as this period seems to mark a change in crustal growth processes (e.g., Taylor and McLennan, 1985; Jayananda et al., 2000; Hawkesworth et al., 2010; Condie and Kröner, 2013; Kamber, 2015). During the Archean, oceanic plateaus and oceanic arcs were important sites of crust generation. After the late Archean, with changes in the style of plate tectonics, continental arcs most likely became the main sites of crust generation (Condie and Kröner, 2013).

One important observation in the juvenile rock record is the occurrence of major episodic $U$ $\mathrm{Pb}$ age peaks at 2.7, 1.9 and 1.2 Ga, documented by Condie $(1998,2000)$ and Condie and Aster $(2010)$. Recent crustal growth models based on $\mathrm{Hf}$ and $\mathrm{O}$ isotopes suggest continuous growth of the continental crust over time (Belousova et al., 2010; Dhuime et al., 2012). Crust preservation models (Hawkesworth et al., 2009; 2013) have been used to explain how a continuously growing continental crust could generate an episodic record of juvenile rocks. According to these models, rocks generated between those age peaks are considered as having relatively low preservation potential. The peaks of juvenile crust preservation have been associated with supercontinent assemblages (e.g., Hawkesworth et al., 2009, 2013; Condie and Aster, 2010). 
In this article, Paleoproterozoic (2.15-2.08 Ga) juvenile orthogneisses of the Pouso Alegre Complex in the basement of the Neoproterozoic southern Brasília Orogen are investigated. These rocks were generated in a time period that has been recognized for low preservation of juvenile rocks on a global scale. Previous U-Pb geochronological data from the Pouso Alegre Complex are scarce, but the ID-TIMS data indicated zircon ages of 2.16-2.08 Ga (Table 1), with strong overprints by Neoproterozoic orogenic events. This contribution is the first systematic study of the Pouso Alegre Complex rocks using a combination of U-Pb zircon in-situ techniques (LA-ICP-MS), zircon Hf isotopes and whole-rock geochemistry. The data refine the ages and documents the juvenile character of Paleoproterozoic crust generation events in the basement of the southern Brasilia Orogen (Fetter et al., 2001; Campos Neto et al., 2011), to better define their extent and their possible tectonic settings.

\section{Geological Setting}

The southern part of the Brasilia Orogen (Dardenne, 2000) (Fig. 1) has been interpreted as the result of the Neoproterozoic collision between the passive margin of the São Francisco paleo-continent and the active margin of the Paranapanema plate (Brito Neves et al., 1999; Campos Neto, 2000; Trouw et al., 2000). The collision generated a pile of sub-horizontal nappes with a southwest-dipping tectonic wedge, and transport towards the east-northeast. Rocks from three different tectonic settings are recognized within these nappes (from WSW to ENE): (1) a magmatic arc domain, which was developed at the active continental margin of the Paranapanema plate (the Socorro-Guaxupé Nappe), (2) a subducted metasedimentary sequence (the Andrelândia Nappe System) and (3) a passive continental margin domain related to the São Francisco paleocontinent (the São Vicente Complex; the Carrancas and Lima Duarte Nappes) (Campos Neto and Caby, 1999, 2000; Trouw et al., 2000, 2013; Campos Neto et al., 2010, 2011) (Fig. 2).

The southern Brasilia Orogen nappe system records the migration of the orogenic front towards the cratonic area, with older ages recorded by the upper nappes in the west and younger ages recorded by the lower nappes in the east. The ages of collision-related metamorphism are: $c a .635-$ $625 \mathrm{Ma}$ in the Socorro-Guaxupé Nappe; ca. 645 - $610 \mathrm{Ma}$ in the Andrelândia Nappe System; and ca. $590 \mathrm{Ma}$ in the Carrancas and Lima Duarte Nappe Systems (Campos Neto et al., 2004, 2010, 2011; Valeriano et al., 2004; Martins et al., 2009; Reno et al., 2009). 


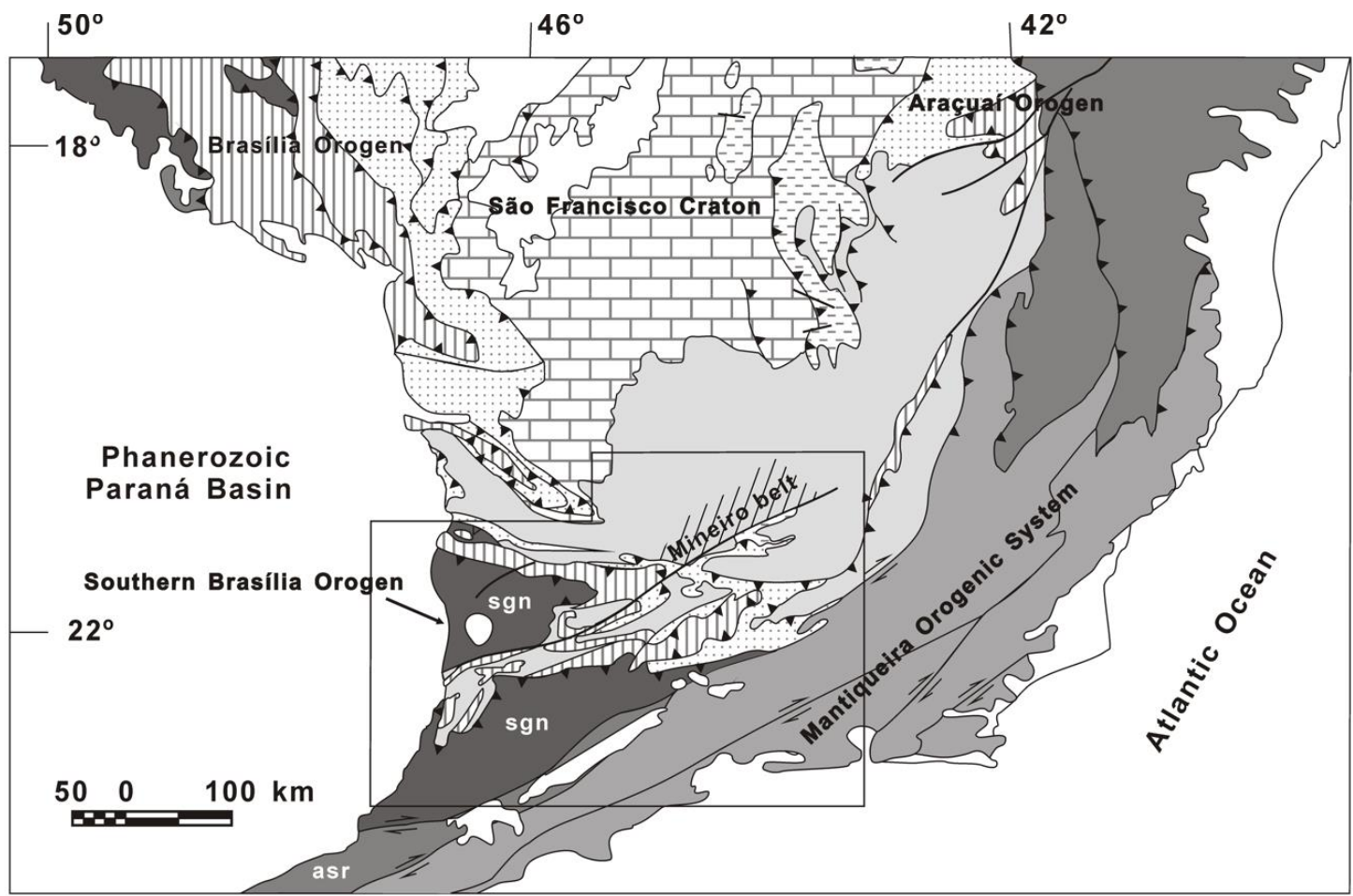

Phanerozoic

Cretaceous and Neogene covers:

Cretaceous alkaline intrusions; Paraná Basin

SÃO FRANCISCO CRATON

Ediacaran

I1 Carbonate platform

Statherian

Rift units

Archean-Paleoproterozoic

Granite-migmatite complexes and greenstone belts, mostly reworked
BRASILIA OROGEN

São Francisco Plate margin

Ediacaran

Passive continental margin
sequence
\#س
$\begin{aligned} & \text { Deep-water pelite and wacke } \\ & \text { sequences }\end{aligned}$

Paranapanema Plate margin

Ediacaran

Active continental margin complex (asr: Apiaí-São Roque magmatic arc)

Cryogenian-Ediacaran

Active continental margin complex

(sgn: Socorro-Guaxupé Nappe)
ARAÇUAÍ OROGEN

São Francisco Plate margin Ediacaran

Passive continental margin
sequence

sequences

Late Ediacaran

Active continental margin complex

Fig. 1. Tectonic map of the southern portion of the São Francisco craton and surrounding Neoproterozoic belts (adapted from Campos Neto et al., 2010) with location of Figure 2.

Archean and Paleoproterozoic migmatitic orthogneisses that represent the basement rocks of the nappe system outcrop in a tectonic window between the two domains of the Socorro-Guaxupé Nappe (Figs. 2 and 3). This window is approximately $300 \mathrm{~km}$ long and $15-75 \mathrm{~km}$ wide. The foliations exhibit two main orientations: NE-SW in the western portion and ENE-WSW in the central and eastern portions. These orthogneisses were strongly affected by deformation and metamorphism during the Neoproterozoic collisional event and are tectonically interlayered with supracrustal metasedimentary sequences. Orthogneisses also occur as tectonic slivers on tens to hundreds of meters scale within the metasedimentary sequence of the Andrelândia Nappe System (Fig. 2).

The western portion of the tectonic window is dominated by the Amparo and Serra Negra Complexes (Fig. 3). Published data from these complexes yield Archean igneous protolith crystallization ages between ca. 3.0 and 2.75 Ga (Fetter et al., 2001; Tassinari and Nutman, 2001). In 
the central and eastern segments of the window, the Pouso Alegre Complex orthogneisses overlie the metasedimentary sequence of the São Vicente Complex, which in turn overlies Archean basement rocks of the Heliodora Complex (Peternel, 2005; Trouw et al., 2008) (Fig. 3). Previous zircon U-Pb data from the Pouso Alegre Complex yield Paleoproterozoic igneous protolith crystallization ages between 2.16 and 2.08 Ga (ID-TIMS upper intercept - Fetter et al., 2001; Peternel et al., 2005; Campos Neto et al., 2011) (ion microprobe upper intercept - Zuquim et al., 2011) (Table 1). Sm/Nd data yield depleted mantle model ages ( $\left.T_{D M}\right)$ ranging from 2.51 to $2.14 \mathrm{Ga}$, associated with slightly negative to strongly positive $\varepsilon \mathrm{Nd}(\mathrm{t})$ values from -0.95 to +3.18 (Fetter et al., 2001; Campos Neto et al., 2011) (Table 1). These previous data suggest the occurrence of significant Paleoproterozoic continental crust generation events in the Pouso Alegre Complex.

The NE-SW trending Paleoproterozoic igneous suites and associated metasedimentary sequences of the Mineiro Belt are located in the southern tip of the São Francisco craton (Figs. 1 and 2). These units are related to a successive accretion of oceanic and continental arcs during the Paleoproterozoic (e.g., Teixeira et al., 2000, 2008, 2015; Noce et al., 2000; Ávila et al., 2010, 2014; Seixas et al., 2012, 2013). The main boundary between the Paleoproteozoic rocks of the Mineiro Belt and the Archean units of the São Francisco craton is the NE-SW trending Jeceaba-Bom Sucesso lineament (Campos and Carneiro, 2008) (Fig. 2). The igneous suites include non-deformed plutons of gabbroic to granitic composition and orthogneisses of trondhjemitic to granodioritic composition. The ages of the igneous suites range from 2.35 to $2.13 \mathrm{Ga}$ (Noce et al., 2000; Teixeira et al., 2000, 2008; Ávila et al., 2010; Seixas et al., 2012, 2013). Several bodies of juvenile rocks are recognized among these suites. The oldest juvenile suites described up to now are the Lagoa Dourada TTG suite (Seixas et al., 2012) and the Resende da Costa orthogneisses (Teixeira et al., 2015) (Fig. 2), which have crystallization ages of ca. $2.35 \mathrm{Ga}$ and $\mathrm{Nd} \mathrm{T}_{\mathrm{DM}}$ ranging from 2.4 to $2.5 \mathrm{Ga}$ and from 2.3 to $2.5 \mathrm{Ga}$, respectively. The youngest episode of juvenile magmatism recognized within the Mineiro Belt is represented by the tonalites and diorites of the Alto Maranhão Suite (Fig. 2), which have crystallization ages of ca. 2.13 Ga and Nd T DM between 2.3 and 2.4 Ga (Seixas et al., 2013).

\section{Field relationships and petrography}

The Paleoproterozoic basement rocks of the southern Brasilia Orogen designated here as the Pouso Alegre Complex are composed mostly of amphibolite facies layered metatexitic tonalitic to granodioritic orthogneisses. These orthogneisses display a well-developed foliation, parallel to stromatic leucosomes that range in thickness from millimeters to centimeters (Figs. 4a, b). The leucosomes are locally tightly folded with axial planes parallel to the main foliations (Figs. 4c, d). 
Peritectic hornblende occurs locally associated with leucosome patches and dilation zones (Figs. 4 e, f). The centimeter- to tens of meters-scale compositional layering is mostly parallel to the main foliation (Fig. 5a). The layering is most likely a result of reorientation and parallelization of previous igneous cross-cutting relationships due to deformation and development of the foliation. Sharp contacts between different lithotypes (Fig. 5b) and structures resembling deformed igneous dykes (Fig. 5c) were locally recognized. Mafic rocks occur as layers and boudins of centimeter to tens of meters scale (Figs. $5 \mathrm{~d}$, e) within the tonalitic and granodioritic gneisses.

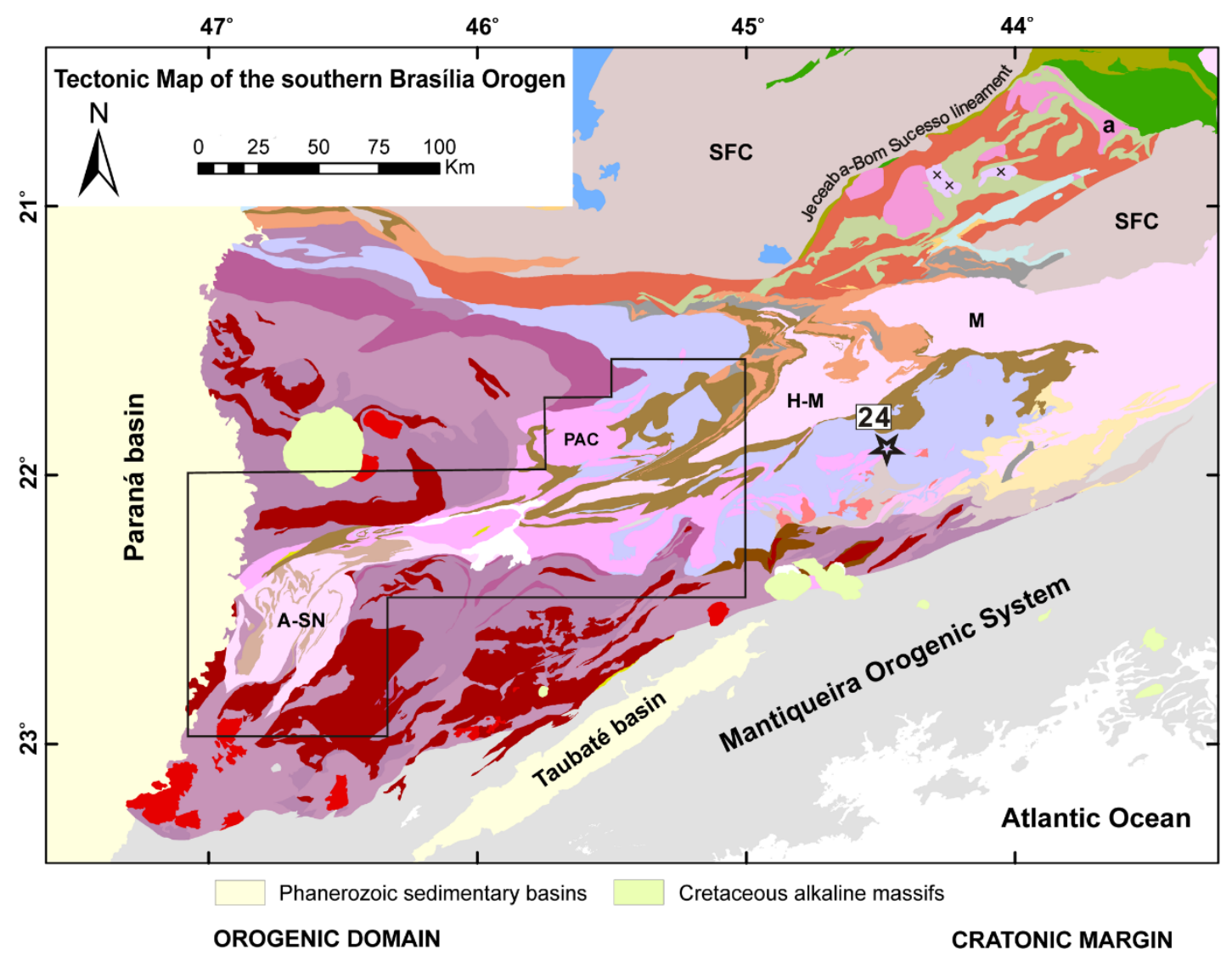

Active Margin Domain

Neoproterozoic accretionary prism and fore-arc basin

Leucogranites

Andrelândia Nappe System

Alagoa and Rio Preto Migmatites

Neoproterozoic arc domain

Socorro - Guaxupé Nappe

Post tectonic and anorogenic granitoids

Orogenic and late orogenic granitoids

Orthogneiss metatexite Unit

Paragneiss metatexite Unit

Orthogneiss diatexite Unit

Granulite Unit
Passive Margin Domain

Unknown age - Itapira Group

Neoproterozoic flysch sequence

Neoproterozoic psamo-pelite nappe systems

Carrancas $\square$ Lima Duarte

Mesoproterozoic

$\square$ São João del Rei and Carandaí sequences

Paleoproterozoic

Immature metasedimentary sequence São Vicente Complex

Orhogneisses - Pouso Alegre Complex (PAC)

Archean

Orthogneisses and migmatites

(A-SN Amparo-Serra Negra,

H-M Heliodora-Minduri, M Mantiqueira)
Neoproterozoic carbonate platform Paleoproterozoic (Rhyacian-Siderian) Mineiro Belt

2.13-2.17 Ga igneous suites (a - Alto Maranhão suite)

2.2-2.35 Ga supracrustal sequences

$x \times 2.35 \mathrm{Ga}$ igneous suites (Lagoa Dourada e Resende da Costa) Undivided granitoids

Paleoproterozoic

Minas Supergroup

Archean

Rio das Velhas Supergroup

Granite-gneiss complexes (SFC)

Fig. 2. Geological map of the southern Brasília Orogen with location of the studied area (modified from Campos Neto et al., 2011; Trouw et al., 2013; Teixeira et al., 2015) and location of the sample 24. 


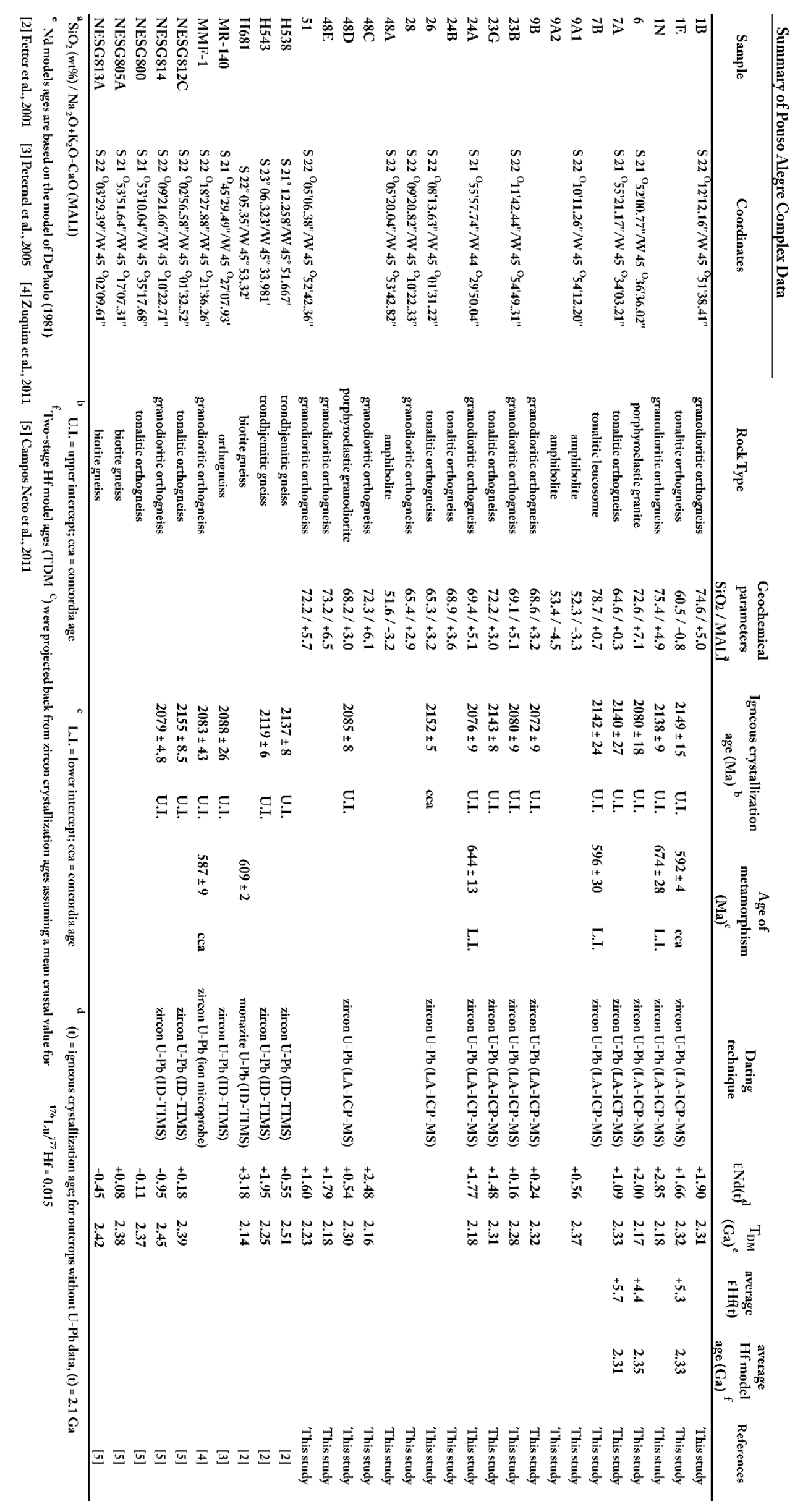

Table 1. Summary of Pouso Alegre Complex data. 


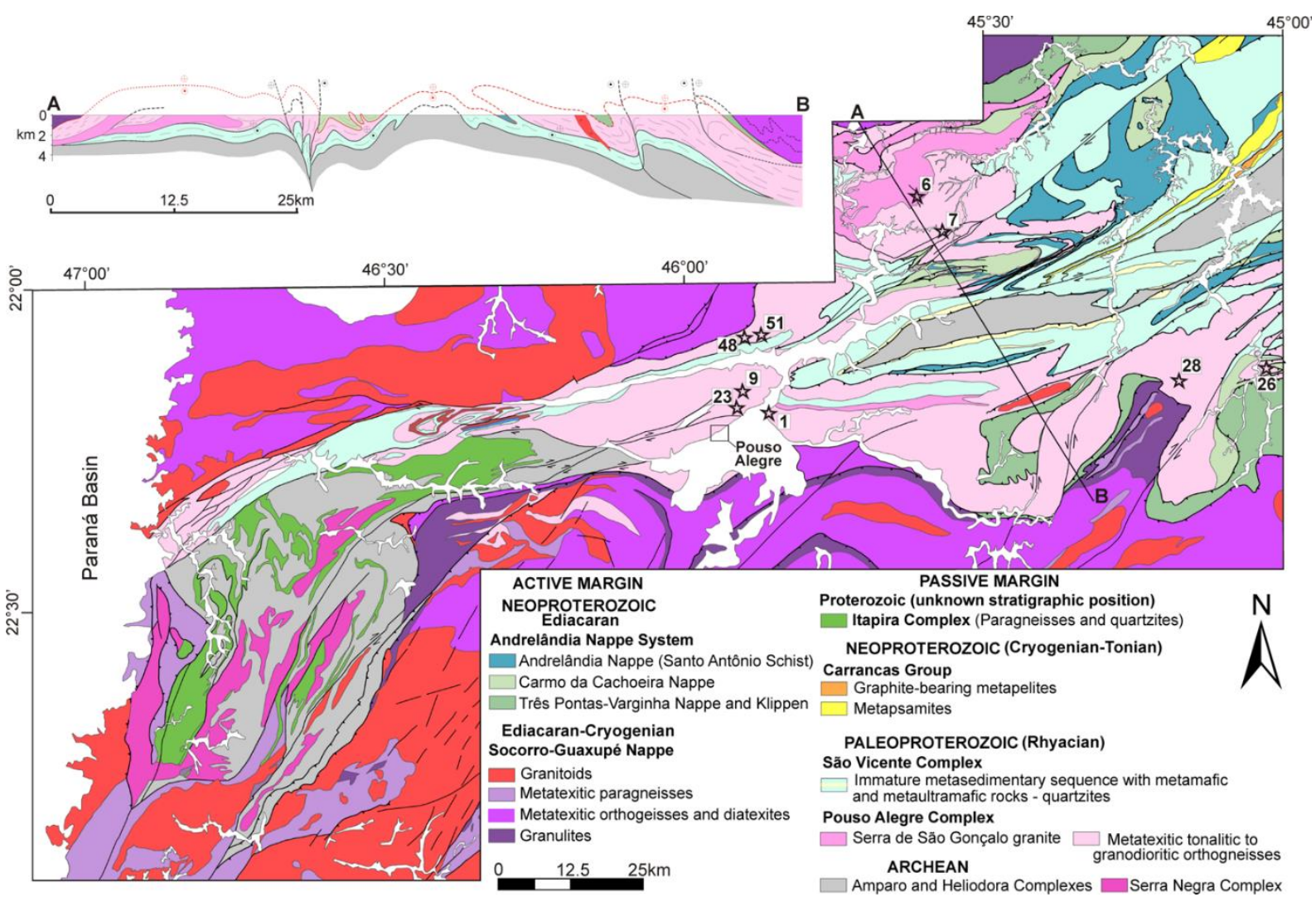

Fig. 3. Geological map of the studied area (compiled and modified from Perrota, 1991; Morais, 1999a,b; Peternel, 2005; Trouw et al., 2008) with location of the analyzed samples. Schematic cross-section from NW to SE is oriented along the line A-B.

Rocks of tonalitic composition are mainly medium-grained dark-gray biotite gneisses and biotite-hornblende gneisses, usually with garnet and epidote/zoisite. The color index of these rocks varies from approximately 15 to $25 \%$. Hornblende occurs as prismatic crystals up to $7 \mathrm{~mm}$ length, aligned with the foliation and partially replaced by biotite. Garnet is present as fine-grained, inclusionfree crystals and locally as inclusion-rich syn-kinematic crystals of up to $5 \mathrm{~mm}$ diameter. Epidote/zoisite is commonly associated with biotite-rich layers that surround plagioclase and hornblende grains. Granoblastic plagioclase is locally altered to sericite+zoisite+carbonate. Plagioclase grains in the tonalitic leucosomes frequently show anti-perthitic exsolution lamellae. Quartz mostly occurs as finegrained recrystallized aggregates. Coarser-grained quartz grains are elongated and have undulatory extinction. Fine-grained subeuhedral to euhedral titanite grains are common, frequently associated with garnet-rich layers. Other common accessory minerals include opaque minerals, apatite, allanite and zircon.

Granodioritic rocks are predominantly fine- to medium-grained, light gray biotite gneisses and minor amphibole-biotite gneisses, with a color index of approximately 7 to $12 \%$. Biotite-hornblende porphyroclastic granodiorite with plagioclase and K-feldspar porphyroclasts up to $3 \mathrm{~cm}$ in size occur 
locally and have a color index close to $15 \%$. Leucosomes are K-feldspar-rich and of granodioritic to granitic composition. Aligned biotite crystals up to $1 \mathrm{~mm}$ in size define the foliation. When present, amphibole occurs as sub-euhedral, bluish-green crystals up to $1.5 \mathrm{~mm}$ long associated with biotite. Fine-grained plagioclase has a granoblastic texture. Coarser-grained plagioclase grains up to $4 \mathrm{~mm}$ in size are common in leucosomes and frequently show anti-perthitic exsolution textures. Locally, plagioclase grains are partially altered to sericite. K-feldspar is mainly twinned microcline with local perthitic exsolution lamellae. Myrmekite intergrowths surrounding K-feldspar grains are common. Quartz is mostly fine-grained as a result of dynamic recrystallization. Coarser-grained quartz grains up to $2 \mathrm{~mm}$ are elongated and show undulatory extinction. Allanite is a frequent accessory mineral and occurs as sub-euhedral to euhedral fine-grained crystals, usually with rims replaced by epidote/zoisite. Other common accessory minerals are apatite, titanite, garnet, opaque minerals and zircon.

Mafic rocks that occur as layers and boudins (Fig. 5d, e) are fine- to medium-grained biotitehornblende gneisses of quartz dioritic composition and amphibolites. The color index of these rocks varies from approximately 40 to $70 \%$. Hornblende is the main mafic mineral and occurs as subeuhedral grains up to $2 \mathrm{~mm}$, aligned with the foliation and partially replaced by biotite. Clinopyroxene has local occurrence and is partially to totally replaced by hornblende \pm zoisite. Plagioclase display fine-grained granoblastic textures and is locally altered to sericite \pm zoisite. Quartz frequently occurs as fine-grained aggregates as a result of recrystallization. Coarser-grained quartz grains are elongated and have strong undulatory extinction. Common accessory minerals are apatite, titanite and chlorite.

Centimeter- to decimeter-scale leucogranite dykes cross-cutting the main foliation of the gneisses are common (Fig. 5e). These dikes are especially abundant in the outcrops near the town of Pouso Alegre (Fig. 3). The main lithotype is a coarse- to very coarse-grained leucogranite with plagioclase and perthitic K-feldspar megacrysts within a recrystallized quartzo-feldspathic matrix. Common accessory minerals are garnet, tourmaline, biotite and chlorite. Tourmaline crystals up to 5 $\mathrm{cm}$ long occur locally. Minor fine-grained leucogranite with garnet and muscovite also occurs. The contrasting compositions and textures compared to the stromatic leucosomes and the cross-cutting relationships suggest that these dykes were generated by partial melting of lower stratigraphic levels and intruded into the orthogneisses of the Pouso Alegre Complex. The source of these leucogranite dykes was most likely the metasedimentary rocks that occur underneath the gneiss complex (see crosssection in Fig. 3).

A coarse-grained porphyroclastic granite body in the northern portion of the study area was named the Serra de São Gonçalo Granite by Perrota (1991) (Figs. 3 and 5f). The rock is a biotite granite with a color index of approximately $5-7 \%$. The porphyroclastic texture is defined by coarse-grained microcline and plagioclase of up to 3-4 $\mathrm{cm}$ within a recrystallized quartzo-feldspathic matrix with a fine- to medium-grained granoblastic texture. Coarse-grained feldspar crystals are deformed and 
elongated parallel to the foliation. Microcline frequently shows perthitic exsolution lamellae, and the occurrence of myrmekite intergrowths associated with microcline rims is common. Quartz is mostly fine-grained as a result of dynamic recrystallization. Coarser-grained quartz grains are elongated and have strong undulatory extinction. Lepidoblastic layers of biotite \pm epidote/zoisite up to $2 \mathrm{~mm}$ thick surround the coarse-grained feldspar grains and define the foliation. Common accessory minerals include apatite, titanite, zircon, garnet and allanite.
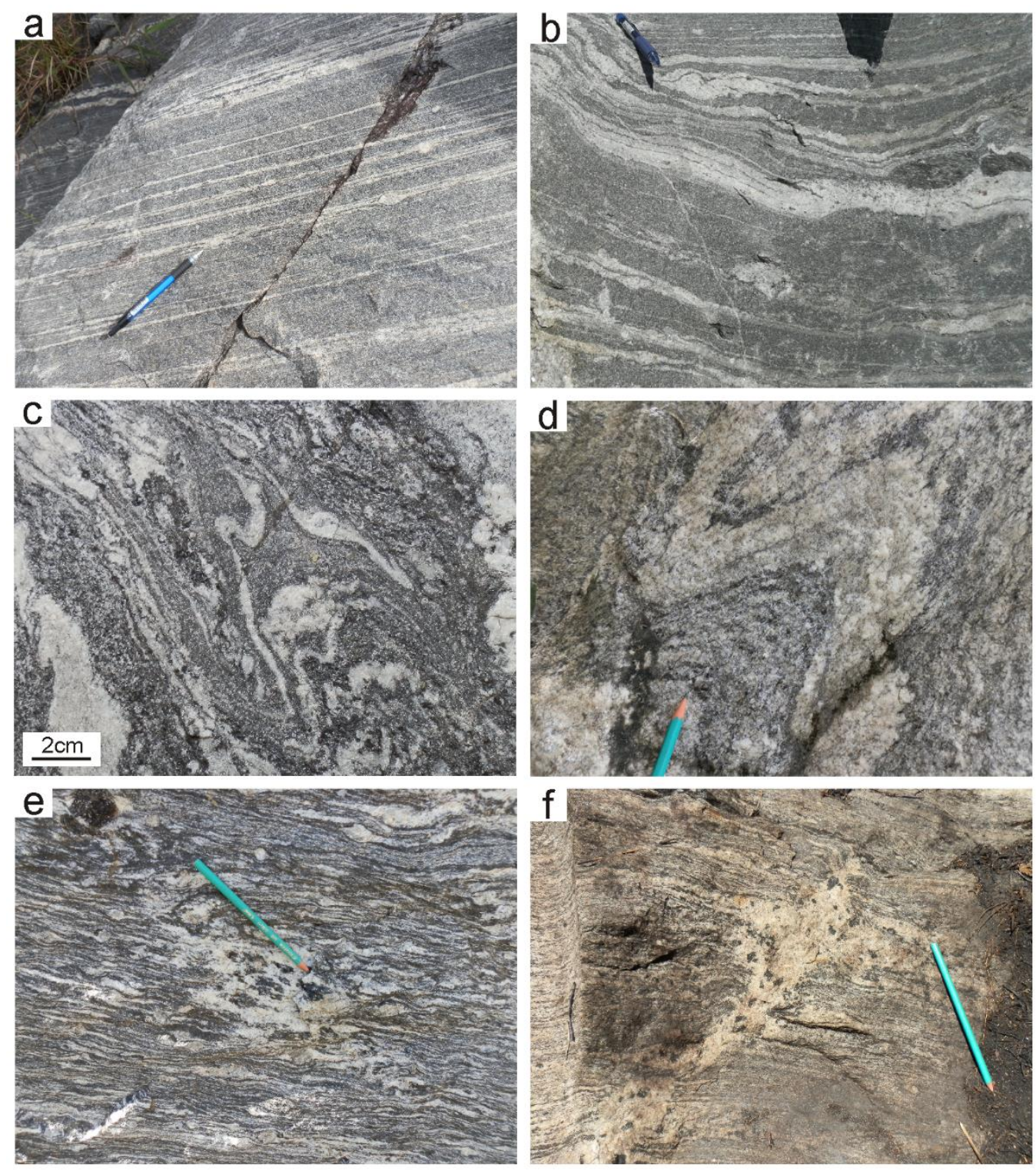

Fig. 4. Field aspects of Pouso Alegre Complex rocks. (a.b) Metatexitic granodioritic orthogneisses with millimeterto centimeter-scale stromatic leucosomes parallel to the main folation (outcrops 1 and 23, respectively). (c,d) Metatexitic tonalitic orthogneisses with tightly folded leucosomes with axial plan parallel to the main foliation (outcrops 1 and 7, respectively). (e) Leucosome patch with peritectic hornblende in porphyroclastic granodioritic orthogneiss (outcrop 48). (f) Leucosome with peritectic hornblende crystals up to $2 \mathrm{~cm}$ accumulated in a dilation zone (outcrop 28). 

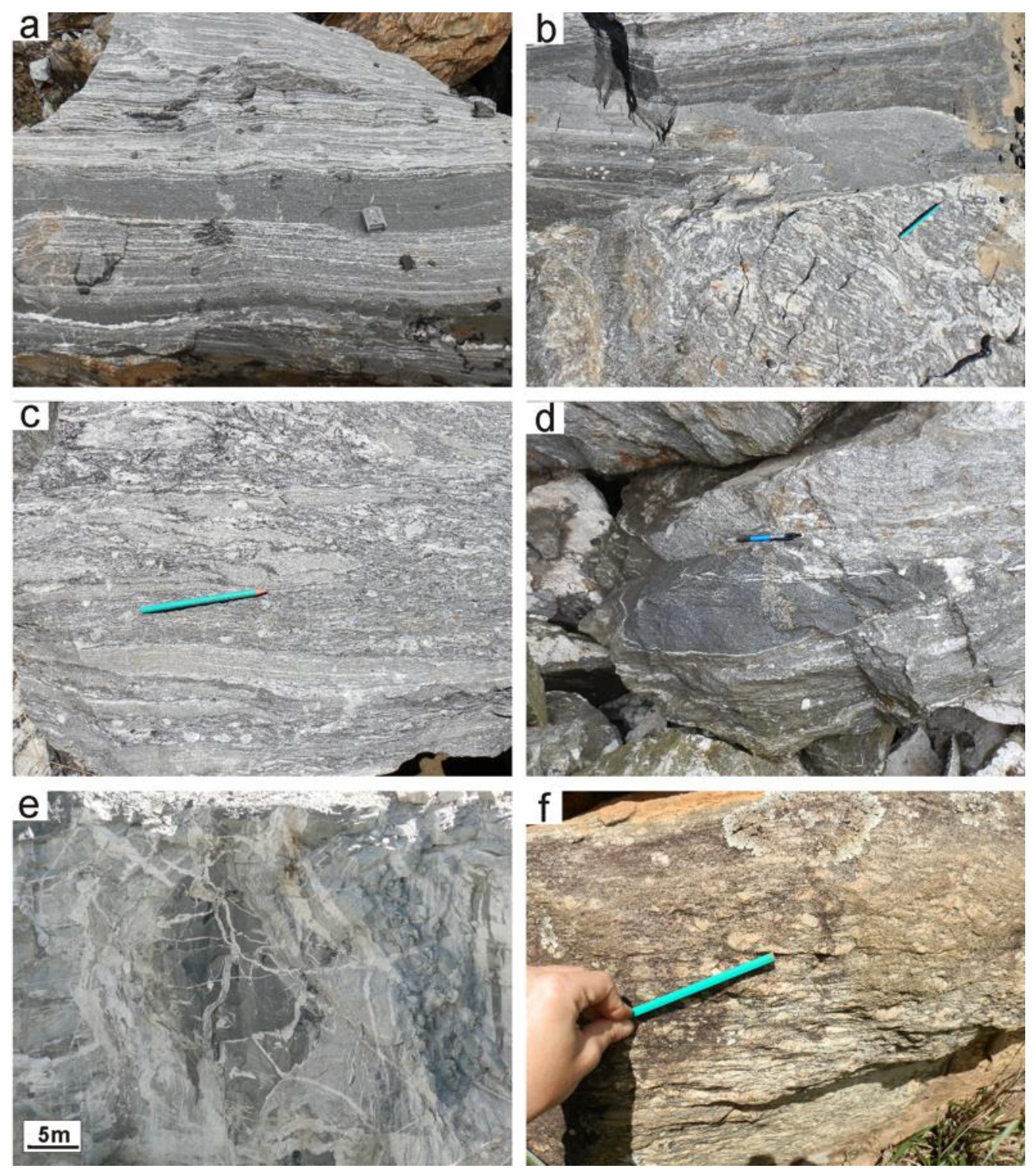

Fig. 5. Field aspects of Pouso Alegre Comples rocks. (a) Compositional layering parallel to the main foliation and to stromatic leucosomes (outcrop 9). (b) Sharp contact between coarse-grained granodioritic orthogneiss and fine-grained granodioritic orthogneiss (outcrop 48). (c) Fine-grained approximately $5 \mathrm{~cm}$ thick granodioritic layers within coarse-grained granodioritic orthogneiss in a structure interpreted as deformed igneous dykes (outcrop 48). (d) Centimeter-scale mafic boudin within tonalitic orthogneiss. Leucosome accumulation in the neck of the boudin (outcrop 1). (e) Tens of meters-scale mafic boudin within orthogneisses. Centimeters- to meter-scale leucogranite dykes cross-cutting the main foliation and the boudin (outcrop 23). (f) Serra de São Gonçalo porphyroclastic granite (outcrop 6).

\section{Analytical methods}

Samples were collected at the sites shown in Figures 2 and 3 (for sample coordinates see Table 1). For whole-rock geochemical analyses, unweathered samples were crushed in a steel jaw-crusher and subsequently in an agate mill. Major element compositions of twenty-one samples were obtained by $\mathrm{x}$-ray fluorescence (XRF) spectrometry after lithium metaborate/tetraborate fusion. Part of the 
analyses were carried out at the Geoanalitica Core Research Center, Universidade de São Paulo, following the methods described in Mori et al. (1999) and part at Acme Analytical Laboratories, Vancouver. Trace element concentrations, including rare earth elements (REE), of eighteen samples were obtained at the Geoanalitica Core Research Center, Universidade de São Paulo, by inductively coupled mass spectrometry (ICP-MS) using a Perkin Elmer Plasma Quadrupole MS Elan 6100DRC, after dissolution of the samples by acid $\left(\mathrm{HF}+\mathrm{HNO}_{3}\right)$ in Parr bombs for 5 days at 200ㄷ (see Navarro et al., 2002,2008 for further details). The results of the whole-rock geochemical analyses are shown in Online Supplementary Table S1.

A subset of fourteen samples was selected for $\mathrm{Nd}$ analyses. The $\mathrm{Nd}$ isotopic compositions of nine samples were determined using a Neptune multi-collector ICP-MS at the Geochronological Research Center (CPGeo) of the Universidade de São Paulo. The same powders used for whole-rock elemental analyses were dissolved in acid, and the elements of interest were separated in ionexchange columns following the procedures described in Sato et al. (1995). During the period of analyses, the JNdi standard (Geological Survey of Japan; Tanaka et al., $2000 ;{ }^{143} \mathrm{Nd} /{ }^{144} \mathrm{Nd}=0.512115 \pm$ 0.000007 ) yielded an average ${ }^{143} \mathrm{Nd} /{ }^{144} \mathrm{Nd}$ value of $0.512102 \pm 0.000006(1 \sigma) . \mathrm{Nd}$ isotopic analyses of five samples were carried out by thermal ionization mass spectrometry using a Finnigan MAT 262 at the Geochronological Laboratory of the Universidade de Brasília. These analyses followed the methods described by Gioia and Pimentel (2000). Uncertainties for ${ }^{143} \mathrm{Nd} /{ }^{144} \mathrm{Nd}$ are assumed to be better than $\pm 0.005 \%$ based on repeated analyses of the USGS standards BHVO-1 and BCR-1. The Nd isotopic ratios of all analyzed samples were normalized to a ${ }^{146} \mathrm{Nd} /{ }^{144} \mathrm{Nd}$ ratio of 0.7219 . The ${ }^{147} \mathrm{Sm} /{ }^{144} \mathrm{Nd}$ ratios were calculated from the concentrations determined by ICP-MS. The results of the Nd isotopic analyses are shown in Online Supplementary Table S2.

$\mathrm{U}-\mathrm{Pb}$ analyses of zircon grains from eleven samples were obtained by laser ablation (LA)-ICPMS. Zircon grains were separated from the crushed samples using standard heavy-mineral separation techniques including a disk grinder, Wilfley table, Frantz ${ }^{\mathrm{TM}}$ isodynamic magnetic separator and heavy liquids (bromoform and methylene iodide). The grains were handpicked under a binocular microscope, mounted in epoxy resin discs and polished to half width to expose the internal structures. Cathodoluminescence $(\mathrm{CL})$ images of the grains were obtained with a scanning electron microscope (SEM). Seven samples (1N, 9B, 23B, 23G, 24A, 26 and 48D) were analyzed the Department of Geology, The University of Kansas, using a Thermo Scientific Element2 ICP-MS attached to a Photon Machines Analyte.G2 $193 \mathrm{~nm}$ ArF excimer laser ablation system. The laser was used to ablate $20 \mu \mathrm{m}$ circular spots and was set to $2.2 \mathrm{~J} \mathrm{~cm}^{-2}$ fluency at a $10 \mathrm{~Hz}$ repetition rate. The ablated material was carried to the ICP in He gas. Elemental fractionation, downhole fractionation and calibration drift were corrected by bracketing measurements of unknowns with the GJ1 reference material (Jackson et al., 2004) and data reduction using the VizualAge data reduction scheme (Petrus and Kamber, 2011) for 
the IOLITE software package (Paton et al., 2011). During the course of the analyses, the secondary standard Plešovice (Sláma et al., 2008) yielded a weighted mean ${ }^{206} \mathrm{~Pb} /{ }^{238} \mathrm{U}$ date of $339.1 \pm 0.8(2 \sigma)$ ( $n=56 ; M S W D=1.4$ ), well within $1 \%$ of the $337.13 \pm 0.37$ Ma age determined by TIMS (Sláma et al., 2008). Four additional samples (1E, 6, 7A, 7B) were analyzed at the CPGeo using a Thermo Scientific Neptune multi-collector ICP-MS attached to a Photon Machines Analyte.193 nm ArF laser ablation system. The laser was used to ablate circular spots of $32 \mu \mathrm{m}$ at a repetition rate of $6 \mathrm{~Hz}$, and He was used as the carrier gas. The GJ1 reference material was used as the primary standard, and corrections were made using an in-house spreadsheet. The data from these four samples were corrected for common lead based on ${ }^{204} \mathrm{~Pb}$ and the model of Stacey and Kramers (1975). Concordia plots, concordia ages and weighted mean U-Pb ages for all data were derived using Isoplot (Ludwig, 2003). Intercepts were calculated using model 1 fitting and are quoted at $95 \%$ confidence level. The results of the U-Pb analyses are shown in Online Supplementary Table S3.

In-situ zircon Lu-Hf analyses were carried out on three samples (1E, 6, 7A) using a Thermo Scientific Neptune multi-collector ICP-MS attached to a Photon Machines Analyte.193 nm ArF laser ablation system at the CPGeo. The analyses were performed on the same internal zircon domains dated by the U-Pb technique. The laser spot used was $47 \mu \mathrm{m}$ in diameter, with an ablation time of 60 $\mathrm{s}$, a repetition rate of $7 \mathrm{~Hz}$ and $\mathrm{He}$ as the carrier gas (Sato et al., 2009). The isotopes ${ }^{172} \mathrm{Yb},{ }^{173} \mathrm{Yb},{ }^{175} \mathrm{Lu}$, ${ }^{177} \mathrm{Hf},{ }^{178} \mathrm{Hf},{ }^{179} \mathrm{Hf},{ }^{180} \mathrm{Hf}$ and ${ }^{176}(\mathrm{Hf}+\mathrm{Yb}+\mathrm{Lu})$ were collected simultaneously. ${ }^{176} \mathrm{Hf} /{ }^{177} \mathrm{Hf}$ ratios were normalized to ${ }^{179} \mathrm{Hf} /{ }^{177} \mathrm{Hf}=0.7325$. The calculation of ${ }^{176} \mathrm{Lu} /{ }^{177} \mathrm{Hf}$ was based on the ${ }^{176} \mathrm{Lu} /{ }^{175} \mathrm{Lu}$ ratio of 0.02669. Mass bias corrections of Lu-Hf isotopic ratios were conducted by applying the variations of the GJ1 standard. The calculations of $\varepsilon \mathrm{Hf}$ values were conducted based on the ${ }^{176} \mathrm{Lu}$ decay constant of $1.867 \times 10^{-11} \mathrm{a}^{-1}$ (Söderlund et al., 2004) and the present-day chondritic ratios of ${ }^{176} \mathrm{Hf} /{ }^{177} \mathrm{Hf}=0.282772$ and ${ }^{176} \mathrm{Lu} /{ }^{177} \mathrm{Hf}=0.0332$ (Blichert-Toft and Albarède, 1997). Two-stage model ages $\left(\mathrm{T}_{\mathrm{DM}}{ }^{\mathrm{C}}\right.$ ) were projected back from zircon crystallization ages, assuming a mean crustal value for ${ }^{176} \mathrm{Lu} /{ }^{177} \mathrm{Hf}=0.015$ (e.g., Griffin et al., 2002; Goodge and Vervoort, 2006). The present-day depleted mantle ratios of ${ }^{176} \mathrm{Hf} /{ }^{177} \mathrm{Hf}=0.283225$ and ${ }^{176} \mathrm{Lu} /{ }^{177} \mathrm{Hf}=0.038512$ (Vervoort and Blichert-Toft, 1997) were adopted. The results of the Lu-Hf analyses are shown in Online Supplementary Table S4.

\section{Zircon U-Pb geochronology}

\subsection{Rocks with crystallization ages from 2.14 to $2.15 \mathrm{Ga}$}

\subsubsection{Sample 1N (granodioritic orthogneiss)}

Outcrop 1 comprises strongly foliated and layered metatexitic orthogneisses with granodioritic and tonalitic meter-scale layers. Two samples were taken from this outcrop, one from a granodioritic 
layer (sample $1 \mathrm{~N}$ ) and another from a tonalitic one (sample $1 \mathrm{E}$ ). Sample $1 \mathrm{~N}$ is a fine- to mediumgrained, light-gray amphibole-biotite gneiss of granodioritic composition with up to $5 \mathrm{~mm}$ thick stromatic leucosomes (Fig. 4a). The analyzed zircon grains are ca. 100 to $200 \mu \mathrm{m}$ long. Two main populations of zircon grains were identified (Fig. 6a). The first is constituted by grains with aspect ratios from 1.5:1 to 2:1 with well-defined fine-scale oscillatory zoning and narrow (10-20 $\mu \mathrm{m})$, dark rims visible in $C L$ images. The second population comprises grains with aspect ratios from 2:1 to 3:1 that show oscillatory and/or sector zoning in $\mathrm{CL}$ images. Sixty-four zircon spots were analyzed from this sample. No correlation between the different shape and CL populations and dates was found. In general, the $\mathrm{Th} / \mathrm{U}$ ratios vary from 0.17 to 0.47 . Just two analyzed rims yield lower Th/U ratios of 0.04 and 0.13 , which correspond to the most discordant analyses. All of the analyzed spots fall on a discordia line with an upper intercept at $2137.5 \pm 8.8 \mathrm{Ma}$ and a poorly defined lower intercept at $674 \pm 28 \mathrm{Ma}$ (MSWD=1.20) (Fig. 7a). The upper intercept is interpreted as the crystallization age of the igneous protolith and the lower intercept as an approximate age of metamorphism.

\subsubsection{Sample 1E (tonalitic orthogneiss)}

Sample $1 \mathrm{E}$ is a medium-grained, dark-gray garnet-biotite-hornblende gneiss of tonalitic composition with up to $5 \mathrm{~mm}$ thick stromatic leucosomes. Based on the external morphologies, two main populations of zircon grains are recognized. The first population consists of euhedral to subhedral prismatic, approximately 100 to $300 \mu \mathrm{m}$ long grains with aspect ratios of ca. 3:1. The second population comprises subhedral grains with ovoid morphology, ca. 50 to $200 \mu \mathrm{m}$ long with aspect ratios of ca. 2:1. Both populations show oscillatory zoned cores and homogeneous recrystallized rims in the CL images (Fig. 6b). Twenty-six zircon spots were analyzed from this sample, twelve from cores and fourteen from recrystallized rims. The Th/U ratios of the cores vary from 0.23 to 0.59 , whereas the ratios of the rims are considerably lower, from $<0.01$ to 0.02 . The cores yield Paleoproterozoic dates and the rims Neoproterozoic dates. The two age populations together define a discordia line with an upper intercept at $2149 \pm 15 \mathrm{Ma}$ and a lower intercept at $589.6 \pm 7.2 \mathrm{Ma}$ (MSWD=0.42) (Fig. 7b). The Neoproterozic group by itself yields a concordia age of 592.4 $\pm 3.9 \mathrm{Ma}$ (MSWD=0.76) (Fig. 7b - inset) within error of the lower intercept of the discordia line. The upper intercept is interpreted as the crystallization age of the igneous protolith and the date obtained from the rims as the age of metamorphism. 


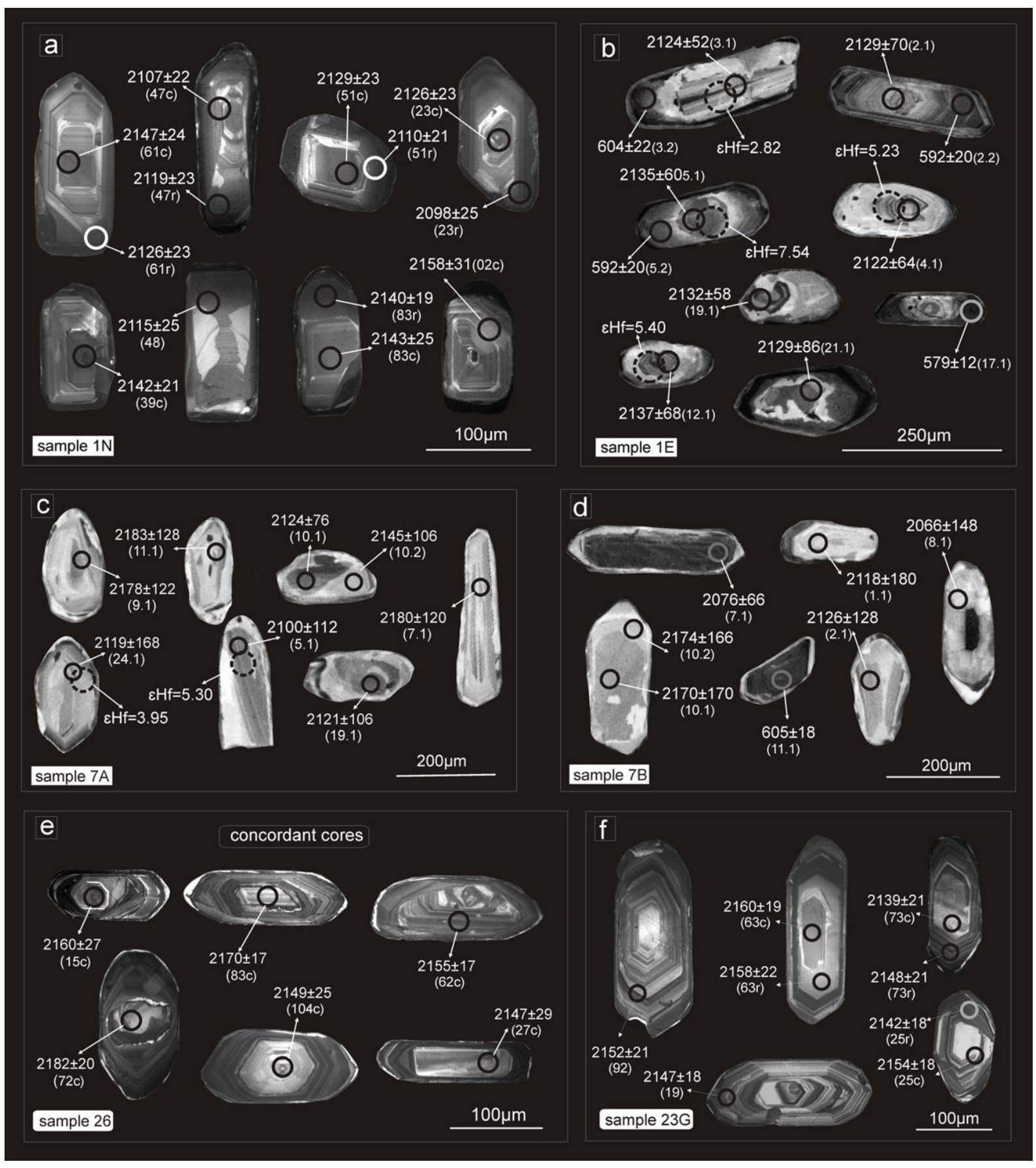

Fig. 6. Representative cathodoluminescence $(\mathrm{CL})$ images with analyzed spots indicated by open circles (grain numbers within parentheses). $\mathrm{U}-\mathrm{Pb}$ results are indicated as ${ }^{206} \mathrm{~Pb} /{ }^{238} \mathrm{U}$ dates for Neoproterozoic domains and as ${ }^{207} \mathrm{~Pb} /{ }^{206} \mathrm{~Pb}$ dates for Paleoproterozoic domains. $2 \sigma$ errors. Lu-Hf spot analyses are indicated by dashed circles. (a) Zircons from sample $1 \mathrm{~N}$ display oscillatory and/or sector zoned cores and narrow dark rims. (b) Sample $1 \mathrm{E}$ zircons show resorbed oscillatory zoned Paleoproterozoic cores and broad Neoproterozoic recrystallized rims. (c) Zircon grains from sample 7A are bright and display poorly-defined oscillatory and/or sector zoning. (d) Most of the zircons from leucosome 7B are CL-bright with sector zoning or are unzoned. Dark grains also occur and one of these yields the only Neoproterozoic date from this sample. (e) Zircons from the sample 26 display welldefined core-mantle structures with oscillatory zoned or unzoned cores truncated by oscillatory zoned rims. Just the cores yield concordant dates. All the rims yield discordant dates with a large spread towards Neoproterozoic lead-loss (Fig. 7e). (f) Zircons from sample 23G show well-defined fine-scale oscillatory zoning. Local resorption zones occur on zircon rims. 


\subsubsection{Samples 7A and 7B (tonalitic orthogneiss and leucosome)}

Sample 7A is a medium- to coarse-grained amphibole-biotite gneiss of tonalitic composition with 1 to $10 \mathrm{~mm}$ thick stromatic leucosomes. Based on the external morphology, two populations of zircon grains were recognized. The first comprises subhedral, approximately 100 to $200 \mu \mathrm{m}$ long, ovoid grains with aspect ratios of ca. 2:1. The second consists of subhedral to euhedral ca. 200 to $400 \mu \mathrm{m}$ long prismatic grains with aspect ratios of 4:1 to 5:1. Both populations are CL-bright and display poorly defined oscillatory or chaotic zoning (Fig. 6c). Twenty-six zircon spots were analyzed. There is no correlation between the morphological populations and dates. The Th/U ratios of the analyzed spots vary from 0.22 to 0.44 . All of the analyzed spots fall on a discordia line with an upper intercept at 2140 $\pm 27 \mathrm{Ma}$ (MSWD=0.19) (Fig. 7c) interpreted as the crystallization age of the igneous protolith.

Sample $7 B$ is a tonalitic leucosome collected from within the $7 A$ tonalitic gneiss. As in the gneiss, two populations of zircon grains were recognized. The first population consists of prismatic, 200 to $400 \mu \mathrm{m}$ long grains, and the second comprises ovoid, 100 to $200 \mu \mathrm{m}$ long grains. Most of the grains are CL-bright, and some display sector zoning. Unzoned dark grains also occur (Fig. 6d). Thirteen zircon spots were analyzed. The Th/U ratios vary from 0.18 to 0.56 , the only exception being a small, CL-dark grain with a Th/U ratio lower than 0.01 that is the only one to yield a Neoproterozoic date. All of the analyzed spots define a discordia line with an upper intercept at $2141 \pm 24 \mathrm{Ma}$ and a lower intercept at $596 \pm 30 \mathrm{Ma}(\mathrm{MSWD}=0.48)$ (Fig. 7d). The upper intercept is, within error, equal to the upper intercept obtained from sample 7A and is most likely related to zircon grains inherited from the host gneiss. The upper intercept is interpreted as the crystallization age of the igneous protolith and the lower intercept as the age of metamorphism. Combined data from both samples yield a pooled upper intercept at $2144 \pm 18 \mathrm{Ma}$ and a lower intercept at $596 \pm 30 \mathrm{Ma}(\mathrm{n}=39 ; \mathrm{MSWD}=0.28)$.

\subsubsection{Sample 26 (tonalitic orthogneiss)}

Sample 26 is a fine- to medium-grained, dark-gray biotite gneiss of tonalitic composition with up to $1 \mathrm{~cm}$ thick stromatic leucosomes. The zircon grains are approximately 100 to $175 \mu \mathrm{m}$ long with aspect ratios from 2:1 to 3:1. Most of the grains display oscillatory zoned or homogeneous cores, truncated by well-developed oscillatory zoned overgrowths (Fig. 6e). All analyzed overgrowths are discordant, with a large spread towards younger ages as a result of Pb loss (Fig. 7e). Eight cores yield a concordia age of $2152.0 \pm 5.4 \mathrm{Ma}$ (Fig. 7e - inset). This concordia age is most likely related to the crystallization of the igneous protolith. One concordant spot yield a slightly older ${ }^{207} \mathrm{~Pb} /{ }^{206} \mathrm{~Pb}$ date of $2181 \pm 27 \mathrm{Ma}$ that could be related to inheritance, but it is within error of the obtained concordia age. Another core yield a significantly higher ${ }^{207} \mathrm{~Pb} /{ }^{206} \mathrm{~Pb}$ date of $2581 \pm 17 \mathrm{Ma}$, but it is highly discordant and therefore unreliable. 

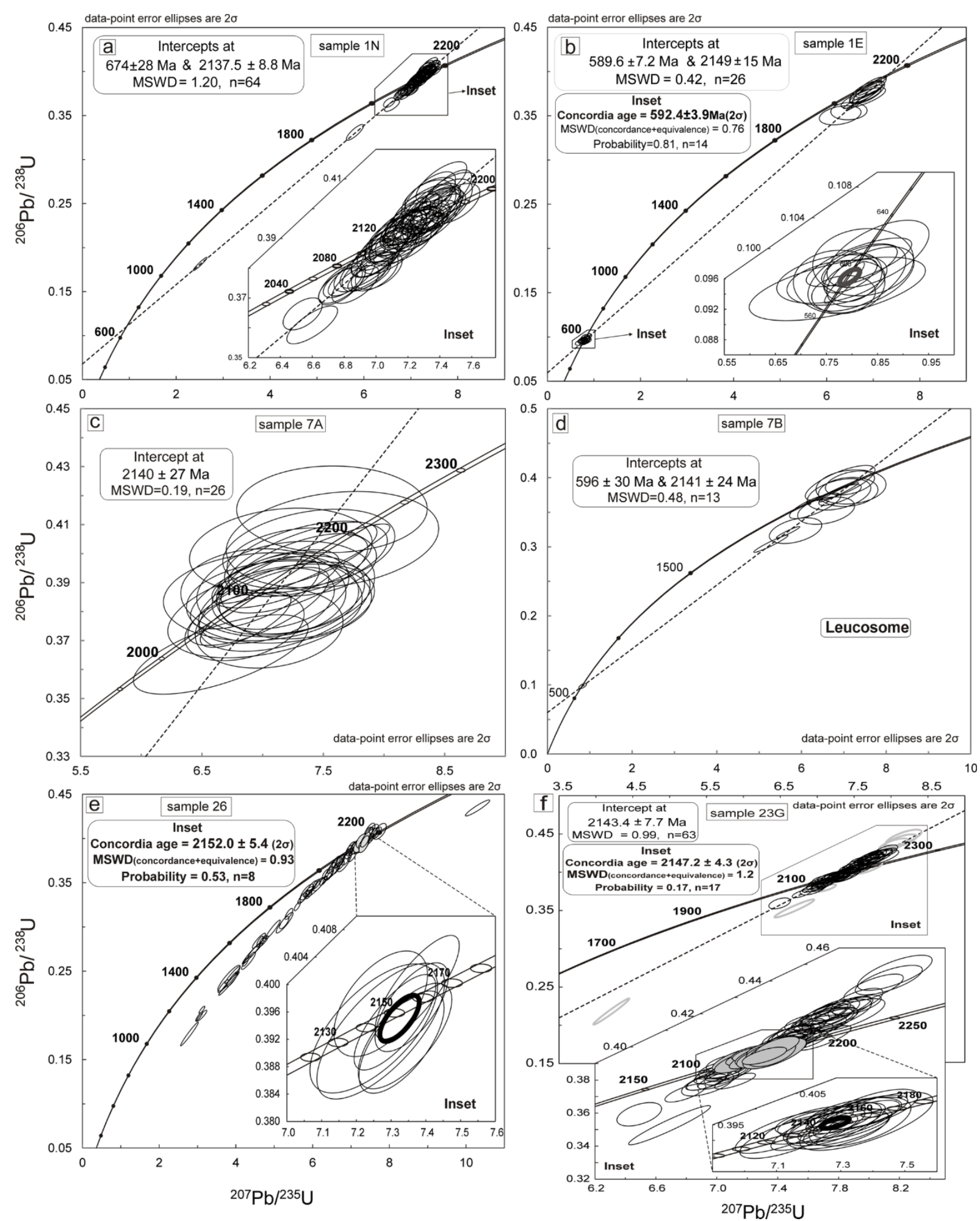

Fig. 7. Concordia diagrams for zircon U-Pb LA-ICP-MS analyses. Intercepts are quoted at $95 \%$ confidence level. (a) Sample $1 \mathrm{~N}$ - Intercepts at $674 \pm 27 \mathrm{Ma}$ and $2137.5 \pm 8.8 \mathrm{Ma}(\mathrm{n}=64$; MSWD =1.20). Inset shows a detail in the upper intercept. (b) Sample 1E - Intercepts at 589.6 $\pm 7.2 \mathrm{Ma}$ and $2149 \pm 15 \mathrm{Ma}(\mathrm{n}=26$; MSWD $=0.42)$. Inset displays a concordia age calculated from the Neoproterozoic dates. Concordia age $=592.4 \pm 3.9 \mathrm{Ma}(2 \sigma)(n=14$; MSWD of concordance \& equivalence $=0.76$; probability $=0.81$ ). (c) Sample 7A - Upper intercept at $2140 \pm 27$ $\mathrm{Ma}(\mathrm{n}=26 ; \mathrm{MSWD}=0.19)$. (d) Sample 7B - Intercepts at $596 \pm 30 \mathrm{Ma}$ and $2141 \pm 24 \mathrm{Ma}(\mathrm{n}=13 ; \mathrm{MSWD}=0.48)$. (e) Sample 26 - Inset shows a concordia age calculated with concordant analyses (gray filled ellipses). Concordia age $=2152.0 \pm 5.4 \mathrm{Ma}(2 \sigma)(n=8 ;$ MSWD of concordance \& equivalence $=0.93 ;$ probability $=0.53)$. (f) Sample $23 \mathrm{G}-$ Gray open ellipses excluded from intercept calculation. Upper intercept at $2143.4 \pm 7.7 \mathrm{Ma}(n=63 ; \mathrm{MSWD}$ $=0.99)$. Inset displays a concordia age calculated with concordant analyses (gray filled ellipses). Concordia age $=$ $2147.2 \pm 4.3 \mathrm{Ma}(2 \sigma)(\mathrm{n}=17 ; \mathrm{MSWD}$ of concordance \& equivalence $=1.2 ;$ probability $=0.17)$. 


\subsubsection{Sample 23G (tonalitic orthogneiss)}

Sample 23G is a fine-grained biotite gneiss of tonalitic composition with up to $5 \mathrm{~mm}$ thick stromatic leucosomes. Most of the zircon grains are euhedral and bipyramidal, approximately 100 to $300 \mu \mathrm{m}$ long with aspect ratios from 2:1 to 3:1. The CL images display well-defined fine-scale oscillatory zoning locally truncated by resorption zones (Fig. 6f). Seventy zircon spots were analyzed. The Th/U ratios generally vary from 0.07 to 0.37 , with just two spots yielding lower values of ca. 0.01 . The resorption zones yield dates that are within error equal to the dates obtained from the oscillatory zoned domains. Excluding seven spots that are strongly reversely discordant or have a common lead component, the remaining sixty-three spots fall on a discordia line with an upper intercept at 2143.4 $\pm 7.7 \mathrm{Ma}$ (MSWD=0.99) (Fig. 7f). Seventeen concordant spots yield a concordia age of $2147.2 \pm 4.3 \mathrm{Ma}$ (Fig. $7 f$ - inset) that is within error identical to the upper intercept date. Reverse discordant analyses therefore did not lead to bias in the upper intercept calculation. These dates are interpreted as the crystallization age of the igneous protolith.

\subsection{Rocks with crystallization ages from 2.07 to $2.08 \mathrm{Ga}$}

\subsubsection{Sample 9B (granodioritic orthogneiss)}

Sample $9 B$ is a fine-grained hornblende-biotite gneiss of granodioritic composition with 1 to 5 $\mathrm{mm}$ thick stromatic leucosomes. Two morphological populations of zircon grains were recognized (Fig. $8 a)$, the first are 150 to $200 \mu \mathrm{m}$ long grains with aspect ratios of ca. 2:1. Zircons of the second population are 150 to $400 \mu \mathrm{m}$ long with aspect ratios of 3:1 to 4:1. The grains from both populations show cores with fine- to wide-scale oscillatory zoning or sector zoning in the $\mathrm{CL}$ images. Bright and homogeneous rims are 5 to $60 \mu \mathrm{m}$ wide. Fifty-six spots on cores and eighteen spots on rims were analyzed. The Th/U ratios of the cores vary from 0.10 to 0.56 , whereas the ratios of the rims range from $<0.01$ to 0.02 . Excluding two analyses, the remaining core spots define a discordia line with an upper intercept at $2072.1 \pm 8.6 \mathrm{Ma}$ (MSWD=1.17) (Fig. 9a), interpreted as the crystallization age of the igneous protolith. The data from the rims show a considerable spread along the concordia line, with analyses less than $2 \%$ discordant yielding ${ }^{206} \mathrm{~Pb} /{ }^{238} \mathrm{U}$ dates between 581 and $657 \mathrm{Ma}$ (Fig. 9b). It is not possible to calculate a reliable weighted average age because of the large spread, but the data show that the metamorphic event took place in the Neoproterozoic. 


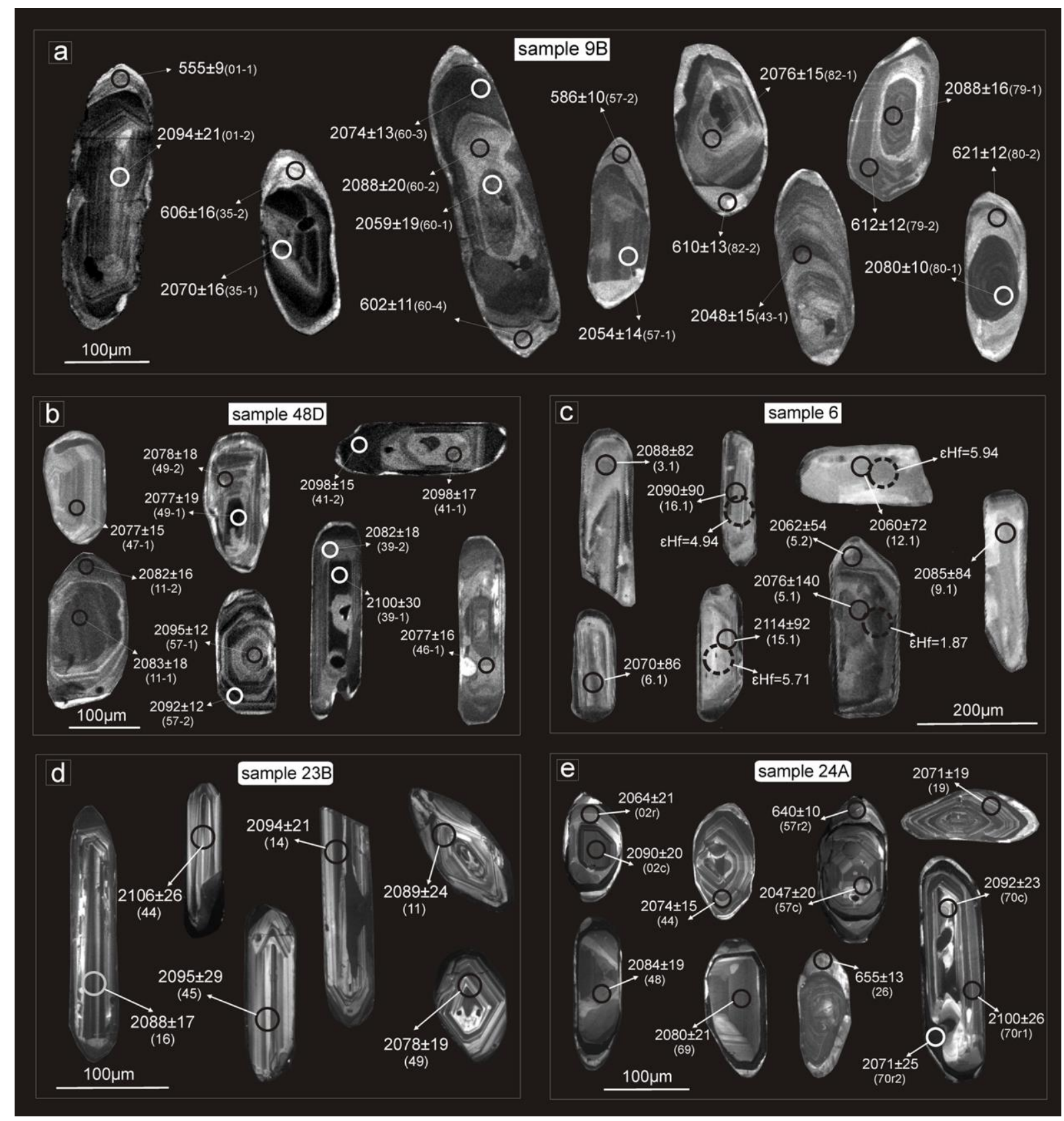

Fig. 8. Representative cathodoluminescence $(C L)$ images with analyzed spots indicated by open circles (grain numbers within parenthesis). U-Pb results are shown as ${ }^{206} \mathrm{~Pb} /{ }^{238} \mathrm{U}$ dates for Neoproterozoic domains and as ${ }^{207} \mathrm{~Pb} /{ }^{206} \mathrm{~Pb}$ dates for Paleoproterozoic domains. $2 \sigma$ errors. Lu-Hf spot analyses are indicated by dashed circles. (a) Zircons from sample 9B display Paleoproterozoic oscillatory zoned cores and Neoproterozoic rims. (b) Zircons from sample 48D show well-developed oscillatory zoning and local resorption zones around inclusions. (c) Most zircon grains from sample 6 are bright and show poorly-developed oscillatory zoning. (d) Sample 23B present elongated and short prismatic grains. Both populations display well-developed oscillatory zoning and narrow dark rims. (e) Zircons from sample 24 present oscillatory and/or sector zoned cores and narrow bright rims. Resorption zones around inclusions are common. The cores yield Paleoproterozoic dates and the rims Neoproterozoic dates. 

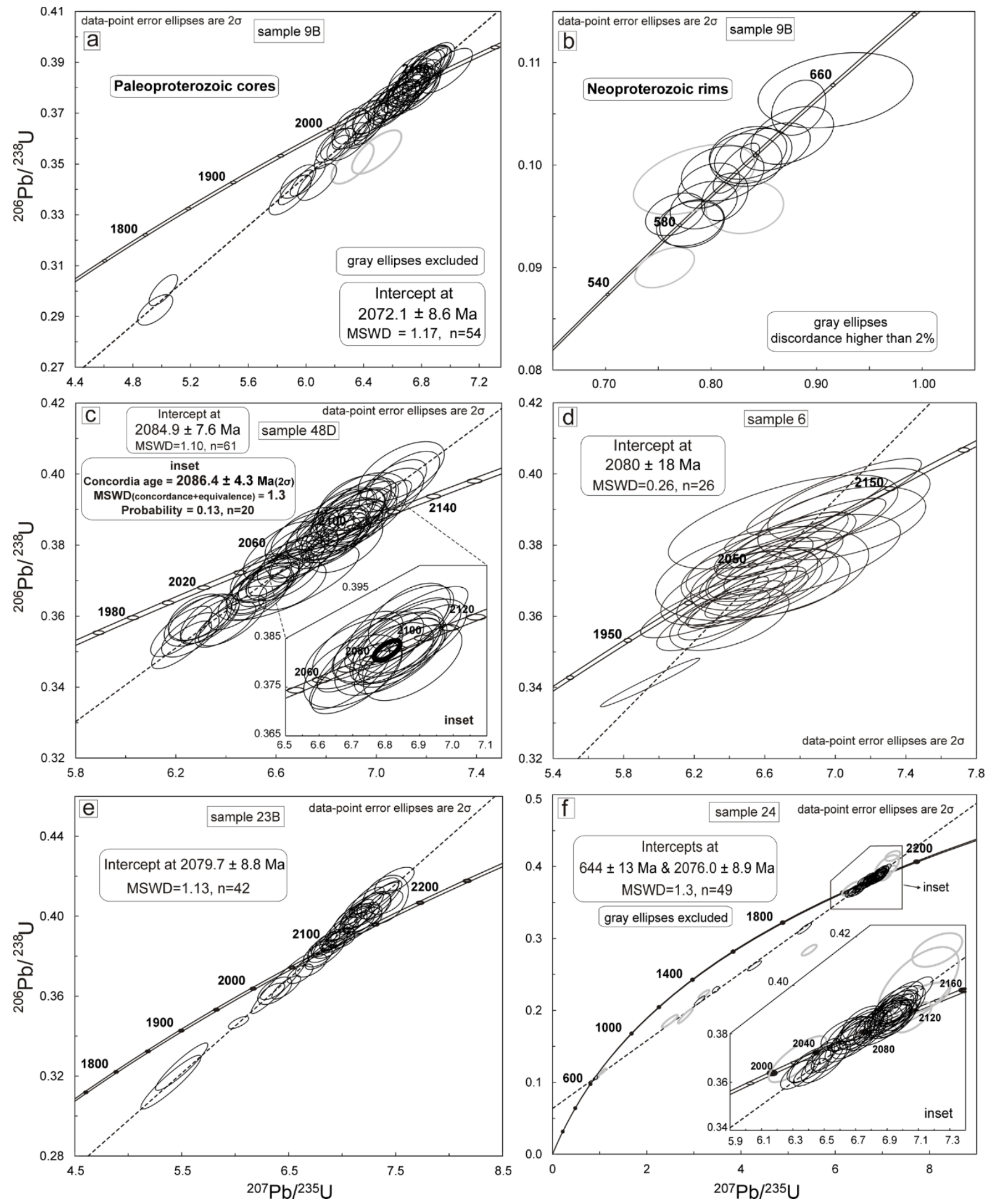

Fig. 9. Concordia diagrams for LA-ICP-MS U-Pb analyses of zircon. Intercepts are quoted at 95\% confidence level. (a) Sample 9B - Paleoproterozoic cores. Gray ellipses excluded from intercept calculation. Upper intercept at 2072.1 \pm 8.6 Ma ( $n=54 ;$ MSWD = 1.17). (b) Sample 9B - Neoproterozoic rims. Gray ellipses = discordance higher than 2\%. (c) Sample 48D - Upper intercept at 2084.9 $\pm 7.6 \mathrm{Ma}(\mathrm{n}=61 ; \mathrm{MSWD}=1.10)$. Inset shows concordia age calculated with concordant analyses. Concordia age $=2086.4 \pm 4.3 \mathrm{Ma}(2 \sigma)(n=20 ; \mathrm{MSWD}$ of concordance \& equivalence $=1.3$; probability =0.13). (d) Sample 6 - Upper intercept at $2080 \pm 18 \mathrm{Ma}(\mathrm{n}=26 ; \mathrm{MSWD}=0.26)$. (e) Sample 23B - Upper intercept at 2079.7 $\pm 8.8 \mathrm{Ma}(\mathrm{n}=42$; MSWD =1.13). (f) Sample $24-$ Gray ellipses excluded from intercept calculation. Intercepts at $644 \pm 13 \mathrm{Ma}$ and $2076.0 \pm 8.9 \mathrm{Ma}(\mathrm{n}=49 ; \mathrm{MSWD}=1.3)$. 


\subsubsection{Sample 48D (porphyroclastic granodiorite)}

Sample 48D is a porphyroclastic biotite-hornblende granodiorite. Two morphological zircon populations were recognized, the first population is 100 to $200 \mu \mathrm{m}$ long with aspect ratios of ca. 2:1. The other consists of 200 to $300 \mu \mathrm{m}$ long grains with aspect ratios from 3:1 to 4:1. Both populations show oscillatory zoning in the CL images (Fig. 8b) with resorption zones around inclusions. Sixty-one zircon spots were analyzed and no correlation was observed between the morphological populations and dates. The Th/U ratios range from 0.24 to 0.64 . All of the analyses fall on a discordia line with an upper intercept at $2084.9 \pm 7.6 \mathrm{Ma}$ (MSWD=1.10) (Fig. 9c). Concordant analyses yield a within error identical concordia age of $2086.4 \pm 4.3 \mathrm{Ma}$ (Fig. 9c - inset). These dates are interpreted as the crystallization age of the granodiorite.

\subsubsection{Sample 6 (porphyroclastic granite)}

Sample 6 is a porphyroclastic biotite granite collected within the Serra de São Gonçalo granite unit. The zircon grains from this sample are 100 to $350 \mu \mathrm{m}$ long with aspect ratios from 2.5:1 to 4:1. Most of the grains are CL-bright and do not show growth zoning in the $\mathrm{CL}$ images (Fig. 8c). Some of the grains have poorly-defined oscillatory zoning. Twenty-six zircon spots were analyzed. The Th/U ratios vary from 0.33 to 0.71 . All of the analyzed spots fall on a discordia line with an upper intercept at 2080 $\pm 18 \mathrm{Ma}(\mathrm{MSWD}=0.26)$ (Fig. 9d) interpreted as the crystallization age of the granite.

\subsubsection{Sample 23B (granodioritic orthogneiss)}

Sample 23B is a fine-grained biotite gneiss of granodioritic composition with up to $1 \mathrm{~cm}$ thick stromatic leucosomes. Two morphological populations of zircon grains were identified, the first consists of elongated, approximately 100 to $300 \mu \mathrm{m}$ long grains with aspect ratios from 4:1 to 5:1. The second population comprises stubby grains, 100 to $150 \mu \mathrm{m}$ long, with aspect ratios from 1:1 to 2:1. Both populations show well-defined oscillatory zoning in the CL images (Fig. 8d) and forty-two spots were analyzed. The Th/U ratios range in general from 0.29 to 1.74 , just one recrystallized rim yield a lower ratio of 0.01 . There is no correlation between the different zircon populations and dates. All of the analyzed spots define a discordia line with an upper intercept at 2079.7 $\pm 8.8 \mathrm{Ma}$ (MSWD=1.13) (Fig. 9e) interpreted as the crystallization age of the igneous protolith. 


\subsubsection{Sample 24A (granodioritic orthogneiss)}

Sample 24A is a fine- to medium-grained biotite gneiss of granodioritic composition that was collected in a basement slice within the metasedimentary rocks of the Andrelândia nappe system. Two main morphological populations of zircon grains were recognized, one consists of 100 to $150 \mu \mathrm{m}$ long grains with aspect ratios of ca. 2:1. The other population comprises 150 to $300 \mu \mathrm{m}$ long grains with aspect ratios between $3: 1$ and 4:1. Both populations display oscillatory and/or sector zoning in the $\mathrm{CL}$ images (Fig. 8e) and show local resorption zones on rims. Most of the grains have CL-bright unzoned 5 to $30 \mu \mathrm{m}$ thick rims. Sixty zircon spots were analyzed and no systematic difference between the dates obtained from the morphological populations was observed. The zircon cores yield Paleoproterozoic dates, and the bright rims yield Neoproterozoic dates. Some analyses spread between the Paleoproterozoic and the Neoproterozoic groups and most likely represent analyses overlapping both age domains and therefore mixed ages. The Th/U ratios of the zircon cores generally vary from 0.10 to 0.82 , whereas the $\mathrm{Th} / \mathrm{U}$ ratios of the rims are lower, ranging from 0.01 to 0.05 . Excluding eleven spots, the remaining forty-nine analyses define a discordia line with an upper intercept at $2076.0 \pm 8.9$ and a lower intercept at $644 \pm 13 \mathrm{Ma}$ (MSWD=1.3) (Fig. 9f). The upper intercept is interpreted as the crystallization age of the igneous protolith and the lower intercept as an approximation of the age of Neoproterozoic metamorphism.

\section{6. $\mathrm{Nd}$ and $\mathrm{Hf}$ isotopes}

Fourteen whole-rock samples were analyzed for $\mathrm{Nd}$ isotopes, and the results are shown in Table 2. The initial $\varepsilon N d_{(t)}$ was calculated based on the crystallization ages obtained by U-Pb dating. For samples without $\mathrm{U}-\mathrm{Pb}$ analyses, the $\varepsilon \mathrm{Nd}_{(\mathrm{t})}$ was calculated based on the age of a dated sample from the same outcrop. If there was not a dated sample from the same outcrop, the $\varepsilon \mathrm{Nd}_{(\mathrm{t})}$ was determined for $2.1 \mathrm{Ga}$. Depleted mantle model ages ( $\left.\mathrm{T}_{\mathrm{DM}}\right)$ were calculated based on the model of DePaolo (1981), which is considered to be more suitable for tonalitic crust generated in arc settings (Dickin, 2005) than the Goldstein (1984) model.

Even though the analyzed samples show a wide range of ${ }^{147} \mathrm{Sm} /{ }^{144} \mathrm{Nd}$ values from 0.09 to 0.15 , which is expected because of the range in $\mathrm{SiO}_{2}$ from 52 to $75 \mathrm{wt} \%$, the calculated model ages and initial $\varepsilon N d_{(t)}$ values show little variation (Figs. 10a, b). The samples characterized by 2.08 Ga crystallization age, hereafter called the $2.08 \mathrm{Ga}$ suite, have ${ }^{147} \mathrm{Sm} /{ }^{144} \mathrm{Nd}$ ratios from 0.09 to 0.11 whereas the samples characterized by 2.15 Ga crystallization age, hereafter called 2.15 Ga suite, show higher values between 0.12 and 0.15 (Fig. 10a). The $T_{D M}$ ages of thirteen analyzed samples vary from 2.16 to $2.33 \mathrm{Ga}$, which, associated with the U-Pb ages, represent crustal residence times ranging from 40 to $240 \mathrm{Ma}$. The $2.08 \mathrm{Ga}$ suite yields $\mathrm{T}_{\mathrm{DM}}$ ages from 2.17 to $2.32 \mathrm{Ga}$ and the older suite shows a similar range from 
2.18 to $2.33 \mathrm{Ga}$ (Fig. 10a). The only mafic sample analyzed yields a slightly older $\mathrm{T}_{\mathrm{DM}}$ age of $2.37 \mathrm{Ga}$, but the lack of crystallization age constraints from mafic samples precludes a reliable estimate of crustal residence time for this sample. All samples yield positive initial $\varepsilon N d_{(t)}$ values, ranging from +0.16 to +2.85 (Fig. 10b). The $2.08 \mathrm{Ga}$ suite shows the lowest initial $\varepsilon N d_{(t)}$ values, which range from +0.16 to +2.00 , with a mean of $+0.94(n=5)$. The initial $\varepsilon N d_{(t)}$ values of the older suite vary between +1.09 to +2.85 with a mean of $+1.77(n=4)$. These results provide evidence of a juvenile character for the analyzed samples.
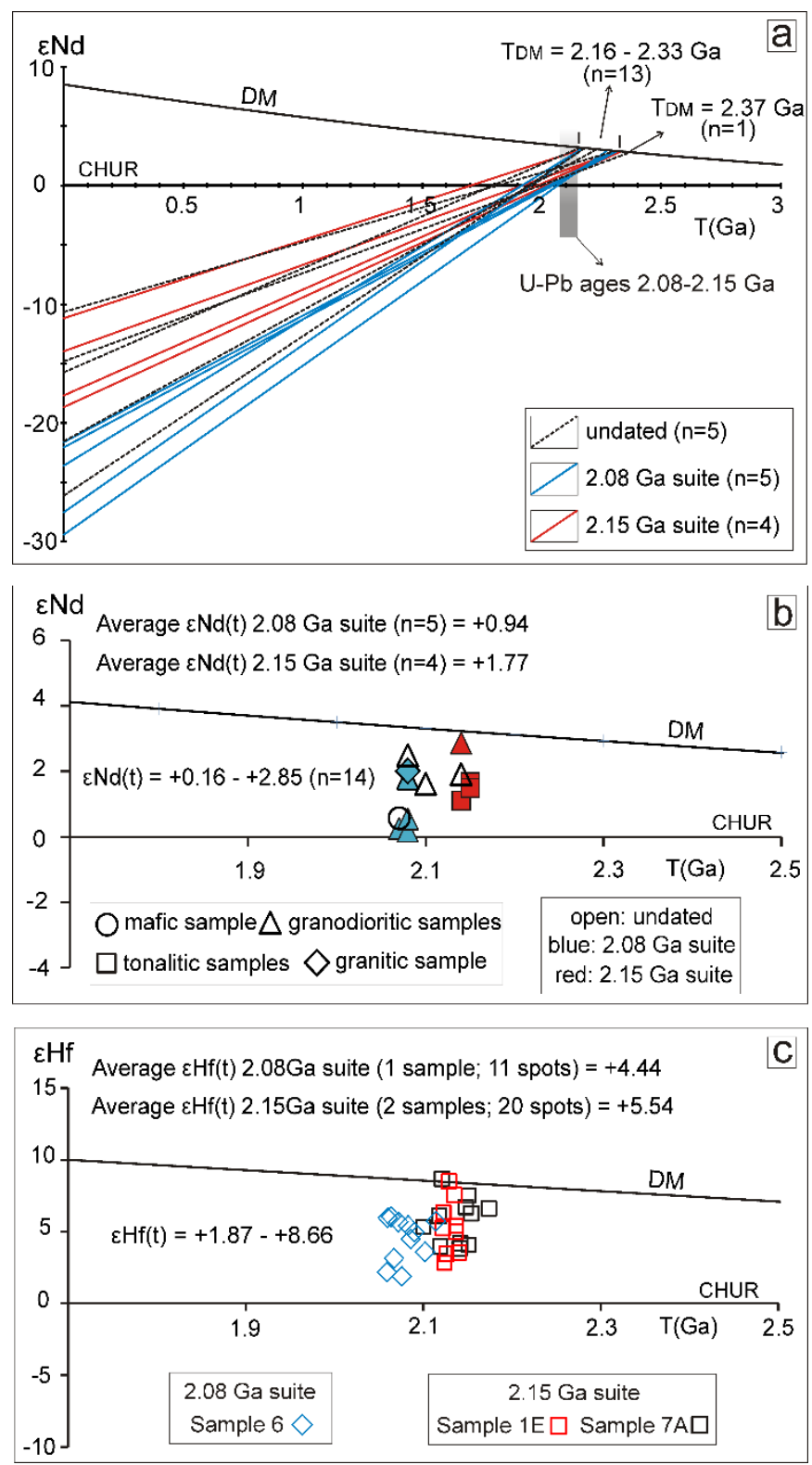

Fig. 10. (a) Nd evolution diagram for Pouso Alegre Complex samples. The isotopic evolution line is for the DePaolo (1981) depleted mantle model. (b) $\varepsilon N d_{(t)}$ versus crystallization ages diagram for Pouso Alegre Complex samples. (c) $\varepsilon \mathrm{Hf}_{(\mathrm{t})}$ versus age diagram for Pouso Alegre samples, plotted at the corresponding U-Pb ages of each analyzed spot. Depleted mantle line calculated for the model proposed by Vervoort and Blichert-Toft (1997). 
Lu-Hf analyses were conducted in zircon grains from three samples (samples $1 \mathrm{E}, 6,7 \mathrm{~A}$ ). The Lu-Hf analytical spots were positioned in the same internal domain of the zircons than previously acquired $\mathrm{U}-\mathrm{Pb}$ analytical spots. The calculations of model ages and initial $\varepsilon \mathrm{Hf}_{(\mathrm{t})}$ were based on individual ${ }^{207} \mathrm{~Pb} /{ }^{206} \mathrm{~Pb}$ dates. Two-stage model ages $\left(\mathrm{T}_{\mathrm{DM}}{ }^{\mathrm{C}}\right)$ were projected back from zircon crystallization ages assuming a mean crustal value for ${ }^{176} \mathrm{Lu} /{ }^{177} \mathrm{Hf}=0.015$ (e.g., Griffin et al., 2002; Goodge and Vervoort, 2006). Sample 6 is the biotite granite from the Serra de São Gonçalo Granite giving an upper intercept age of $2080 \pm 18 \mathrm{Ma}$. The analyzed zircon grains give $\varepsilon \mathrm{Hf}_{(\mathrm{t})}$ values that range from +1.87 to +6.02 (Fig. 10c) with a mean of $+4.44 \pm 1.53(1 S D)$. Two-stage $\mathrm{Hf}$ model ages of these zircons vary from 2.24 to $2.51 \mathrm{Ga}$ with a mean of $2.35 \pm 0.10 \mathrm{Ga}$ (1SD). Sample $1 \mathrm{E}$ is the garnet-biotite-hornblende orthogneiss

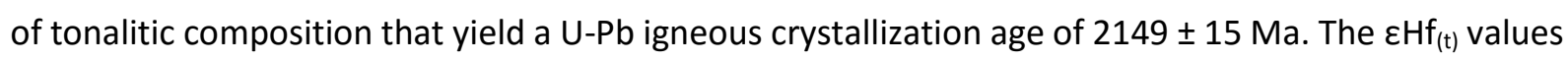
obtained from this sample range from +2.82 to +8.47 with a mean of $+5.30 \pm 1.91$ (1SD) that yield $\mathrm{Hf}$ model ages between 2.13 and 2.49 Ga with a mean of $2.33 \pm 0.12$ Ga (1SD). Sample 7A is the amphibole-biotite orthogneiss of tonalitic composition with an igneous crystallization age of $2140 \pm 27$ Ma. The obtained $\varepsilon \mathrm{Hf}_{(\mathrm{t})}$ values are between +3.80 and +8.66 with a mean of $+5.73 \pm 1.61$ (1SD) that yield $\mathrm{Hf}$ model ages of 2.11 to $2.44 \mathrm{Ga}$ with a mean of $2.31 \pm 0.10 \mathrm{Ga}$ (1SD). All analyzed zircon grains gave positive $\varepsilon \mathrm{Hf}_{(\mathrm{t})}$ values (Fig. 10c). Average two-stage $\mathrm{Hf}$ model ages associated with the crystallization age of each sample indicate crustal residence times ranging from approximately 170 to $270 \mathrm{Ma}$. The $\mathrm{Hf}$ isotope data are in good agreement with the $\mathrm{Nd}$ isotope data, and both indicate a juvenile character of the analyzed samples.

\section{Whole-rock geochemistry}

The analyzed samples show a wide range of $\mathrm{SiO}_{2}$ contents from 52 to $76 \mathrm{wt} \%$. There is a composition gap between the mafic samples with $\mathrm{SiO}_{2}$ values around 52 to $53 \mathrm{wt} \%$ and the tonalitic, granodioritic and granitic samples that show a continuous range of $\mathrm{SiO}_{2}$ contents between 61 and 76 wt\% (Fig. 11). $\mathrm{Al}_{2} \mathrm{O}_{3}, \mathrm{CaO}, \mathrm{MgO}, \mathrm{FeO}_{\mathrm{t}}$ and $\mathrm{TiO}_{2}$ contents show negative correlations with increasing $\mathrm{SiO}_{2}$, whereas $\mathrm{Na}_{2} \mathrm{O}$ and $\mathrm{K}_{2} \mathrm{O}$ contents have positive correlations (Fig. 11). Tonalitic samples have $\mathrm{SiO}_{2}$ contents that range from 61 to $72 \mathrm{wt} \%$ and higher $\mathrm{Al}_{2} \mathrm{O}_{3}, \mathrm{Na}_{2} \mathrm{O}, \mathrm{MgO}$ and lower $\mathrm{K}_{2} \mathrm{O}, \mathrm{FeO}_{\mathrm{t}}$ and $\mathrm{TiO}_{2}$ contents at the same $\mathrm{SiO}_{2}$ value than granodioritic and granitic samples (Fig. 11). The granodioritic and granitic rocks are characterized by low MgO contents between $<0.01$ and $0.88 \mathrm{wt} \%$. The $2.15 \mathrm{Ga}$ suite comprises tonalites and granodiorites that show a wide range of $\mathrm{SiO}_{2}$ contents from 61 to $75 \mathrm{wt} \%$. On the other hand, the $2.08 \mathrm{Ga}$ suite are granodiorites and granites that show little variation in $\mathrm{SiO}_{2}$ contents from 68 to $73 \mathrm{wt} \%$ and significantly higher $\mathrm{K}_{2} \mathrm{O}$ contents (3.1 - $5.0 \mathrm{wt} \%$ ) (Fig. 11). 


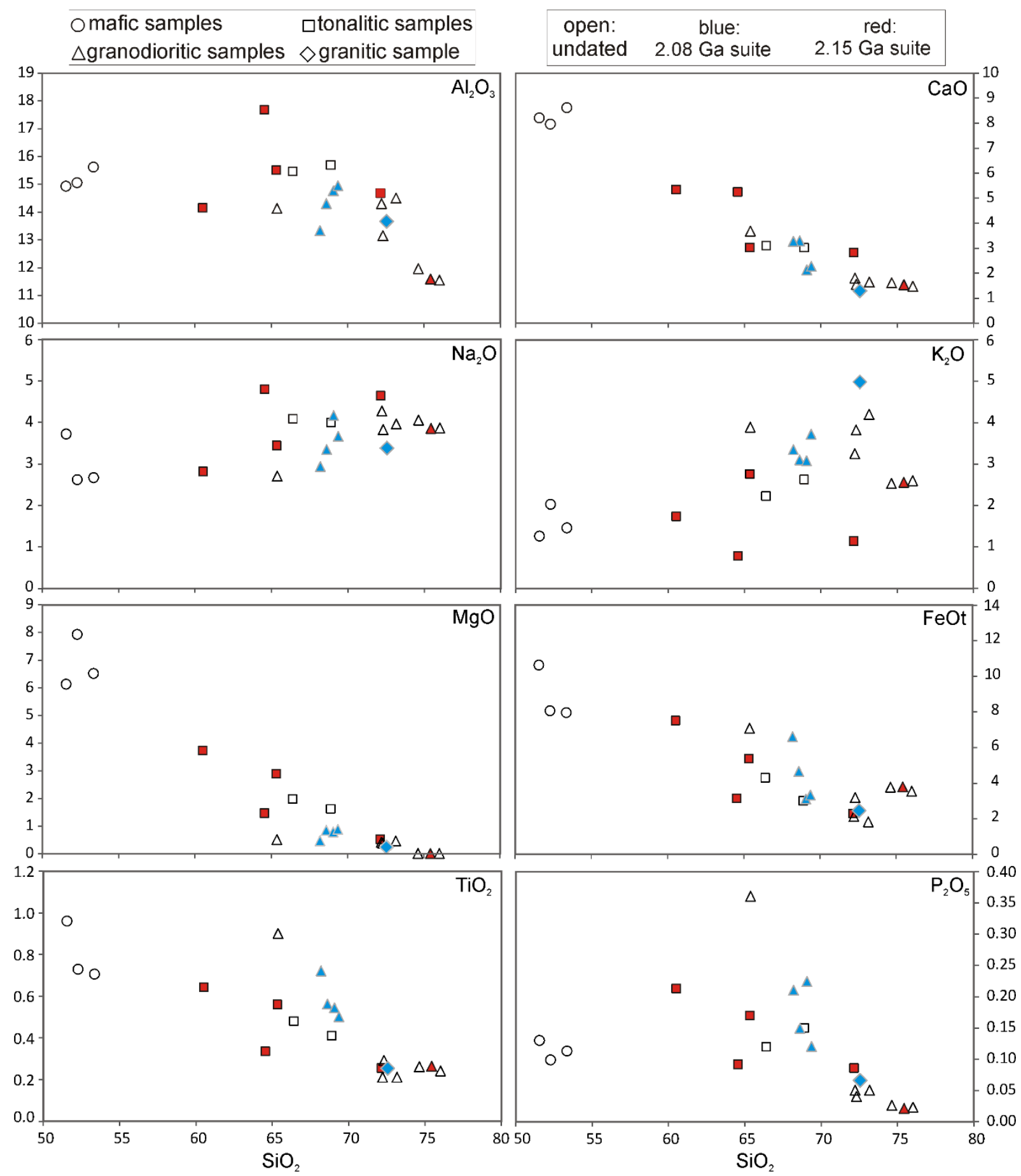

Fig. 11. Harker-type diagrams ( $\mathrm{SiO}_{2}$ vs. major elements) for Pouso Alegre Complex samples.

According to the $\mathrm{FeO}_{\mathrm{t}} /\left(\mathrm{FeO}_{\mathrm{t}}+\mathrm{MgO}\right)$ vs. $\mathrm{SiO}_{2}$ diagram (Frost et al., 2001) (Fig. 12a), all mafic and tonalitic samples are magnesian and fall in the cordilleran granitoids field. Granodioritic samples are both magnesian and ferroan. All granodioritic samples, except the samples 28 and 48D, plot within or close to the cordilleran granitoids field. The granitic sample is ferroan and falls in the cordilleran granitoids field. At a given $\mathrm{SiO}_{2}$ value samples of the $2.08 \mathrm{Ga}$ suite have higher $\mathrm{FeO}_{\mathrm{t}} /\left(\mathrm{FeO}_{\mathrm{t}}+\mathrm{MgO}\right)$ ratios than samples from the older group. In agreement with the $\mathrm{Na}_{2} \mathrm{O}+\mathrm{K}_{2} \mathrm{O}-\mathrm{CaO}$ (MALI) vs. $\mathrm{SiO}_{2}$ 
diagram (Frost et al., 2001), the mafic, tonalitic and granodioritic rocks are calcic and calc-alkalic (Fig. 12b). The granitic sample plots in the alkali-calcic field near the boundary with the calc-alkali field. All samples plot in the cordilleran granitoids field. Samples of the $2.15 \mathrm{Ga}$ suite are calcic to calc-alkalic and samples of the $2.08 \mathrm{Ga}$ suite are calcic to alkali-calcic. In the A / NK vs. A / CNK diagram (Fig. 12c) the mafic rocks are classified as metaluminous, the tonalitic and granodioritic samples are metaluminous to slightly peraluminous, and the granitic sample is slightly peraluminous. Tonalitic, granodioritic and granitic samples fall within or close to the continental arc and island arc granitoids fields of Maniar and Piccoli (1989) (Fig. 12C). The 2.15 Ga suite shows a larger spread of A / CNK ratios and higher average $\mathrm{A} / \mathrm{NK}$ ratio.
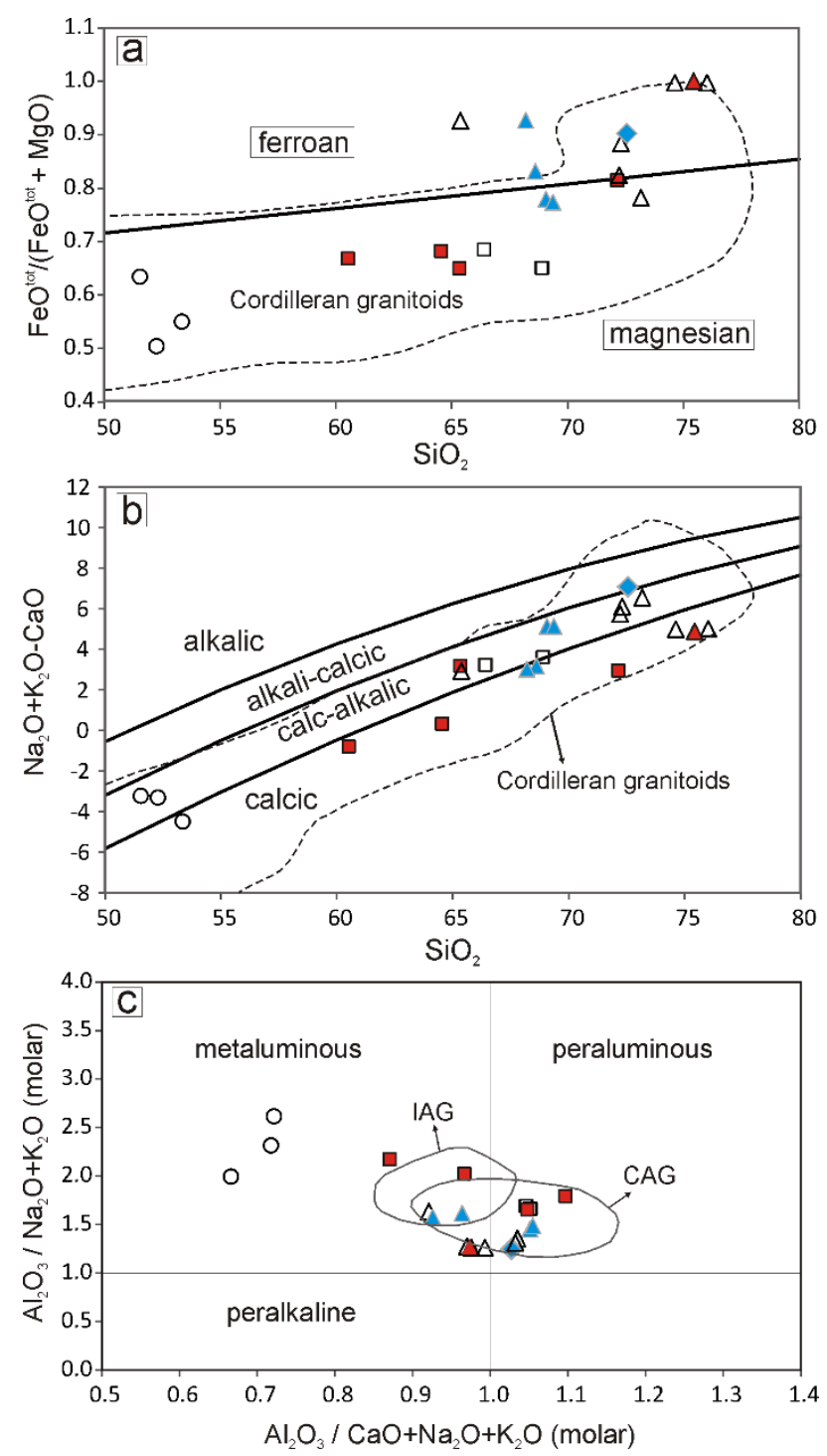

Fig. 12. (a) $\mathrm{FeO}^{\text {tot }} /\left(\mathrm{FeO}^{\text {tot }}+\mathrm{MgO}\right)$ vs. $\mathrm{SiO}_{2}$ diagram with the boundary between ferroan and magnesian plutons as well as the composition field of cordilleran granites from Frost et al. (2001). (b) $\mathrm{Na}_{2} \mathrm{O}+\mathrm{K}_{2} \mathrm{O}-\mathrm{CaO}$ (MALI index) vs. $\mathrm{SiO}_{2}$ diagram with ranges of alkali, alkali-calcic, calc-alkalic and calcic rock series as well as the composition field of cordilleran granites from Frost et al. (2001). (c) $\mathrm{Al}_{2} \mathrm{O}_{3} / \mathrm{Na}_{2} \mathrm{O}+\mathrm{K}_{2} \mathrm{O}$ (molar) vs. $\mathrm{CaO}+\mathrm{Na}_{2} \mathrm{O}+\mathrm{K}_{2} \mathrm{O}$ (molar) diagram (Shand's index) with composition fields of island arc granitoids (IAG) and continental arc granitoids (CAG) from Maniar and Piccoli (1989). Symbols as in Fig. 11. 
Primitive mantle normalized multielement diagrams are shown in Figure 13. All of the analyzed samples are characterized by LILE ( $\mathrm{Rb}, \mathrm{Ba}, \mathrm{K}, \mathrm{Pb}, \mathrm{Sr}), \mathrm{U}$, Th and LREE-enriched compositions. All samples show negative $\mathrm{Nb}, \mathrm{P}, \mathrm{Ti}$ and positive $\mathrm{Pb}$ anomalies. The negative anomalies, especially $\mathrm{P}$ and $\mathrm{Ti}$, are more pronounced in the granodioritic and granitic samples. The only granodioritic sample from the $2.15 \mathrm{Ga}$ suite is characterized by higher heavy rare earths (HREE) contents than the granodioritic and granitic samples from the younger suite (Fig. 13). In general terms, the trace element patterns that are observed in the primitive mantle normalized multielement diagrams resemble subduction-related patterns of modern arcs (Fig. 13).
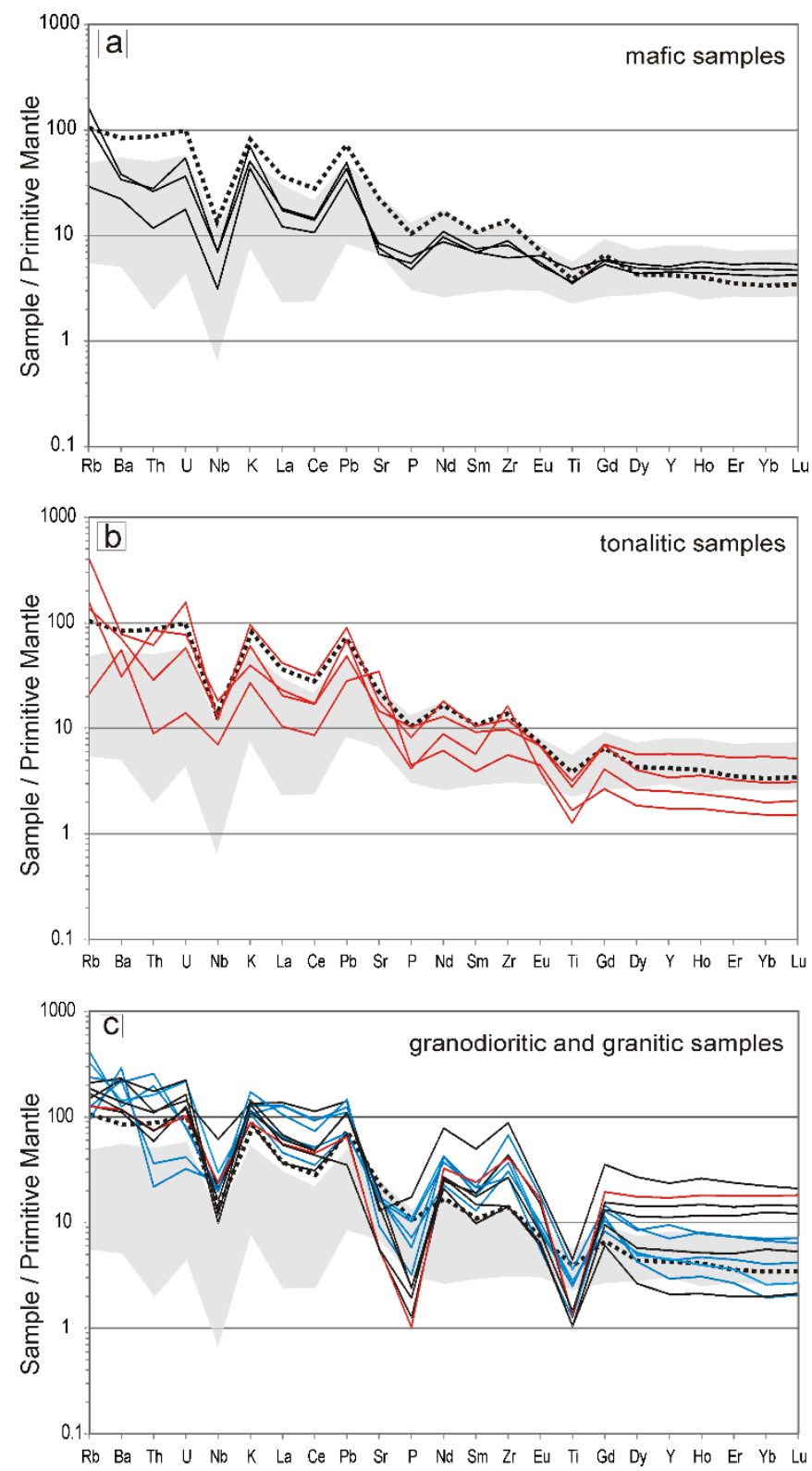

Fig. 13. Primitive mantle normalized multielement diagrams. Primitive mantle values from McDonough and Sun (1995). The gray shading represents the field of modern island arcs (between 75 percentile and 25 percentile) and the dotted line represents the median for the Andean continental arc margin (from Korsch et al., 2011). Black lines: undated; red lines: 2.15 Ga suite; blue lines: 2.08 Ga suite. (a) Mafic samples. (b) Tonalitic samples. (c) Granodioritic and granitic samples. 

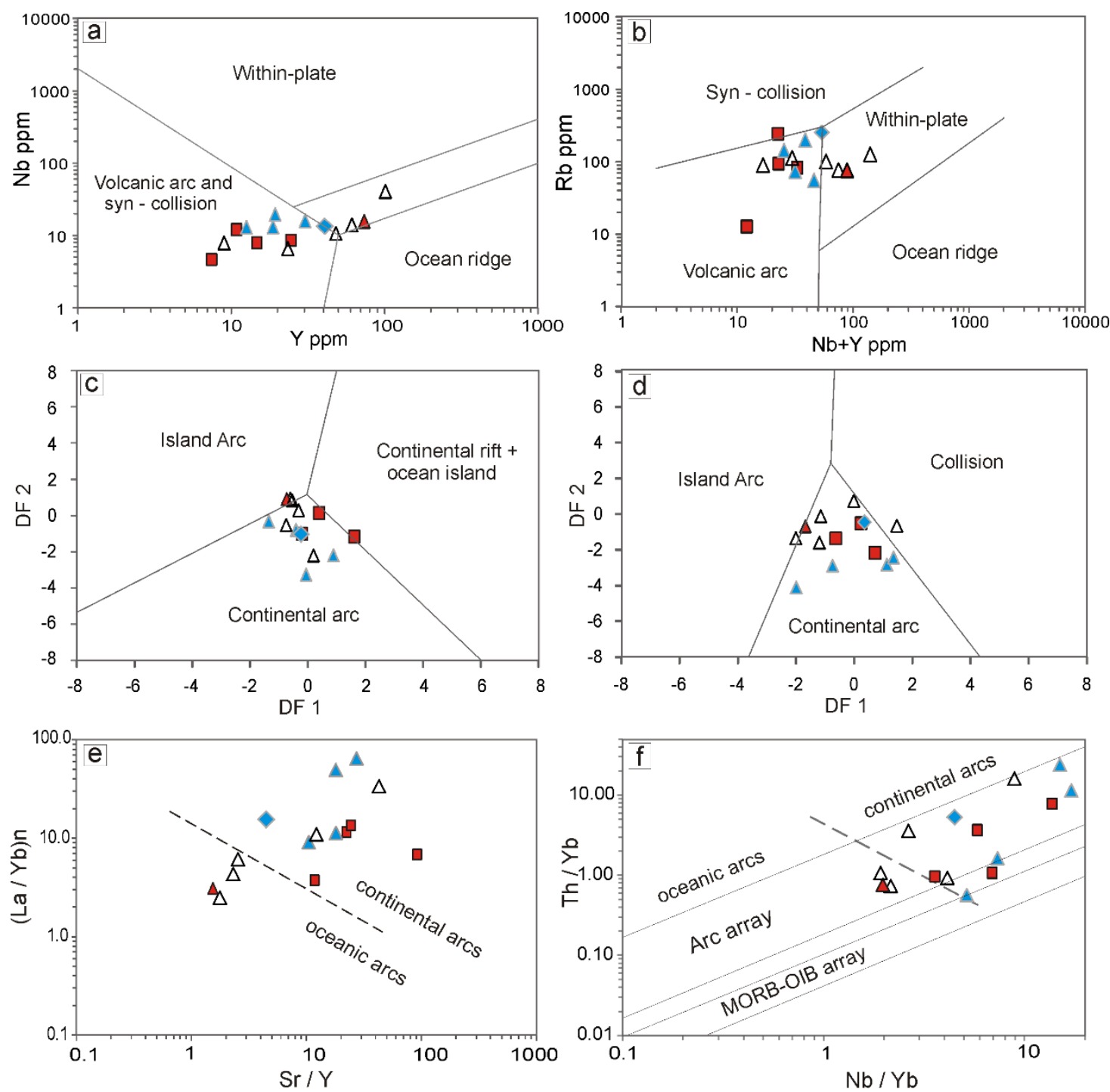

Fig. 14. Tectonic discrimination diagrams. (a) Nb vs. Y tectonic discrimination diagram of Pearce et al. (1984). (b) $\mathrm{Rb}$ vs $\mathrm{Nb}+\mathrm{Y}$ tectonic discrimination diagram of Pearce et al. (1984). (c) Discrimination diagram for acid rocks based on In-transformed ratios of immobile trace elements of Verma et al. (2013) (IA-CA-CR+OI). DF1 $=(-5.21 \mathrm{x}$ $\ln (\mathrm{La} / \mathrm{Yb}))+(6.62 \times \ln (\mathrm{Ce} / \mathrm{Yb}))+(-3.63 \times \ln (\mathrm{Sm} / \mathrm{Yb}))+(1.69 \times \ln (\mathrm{Nb} / \mathrm{Yb}))+(0.33 \times \ln (\mathrm{Th} / \mathrm{Yb}))+(1.56 \times \ln (\mathrm{Y} / \mathrm{Yb}))+$ $(-0.49 \times \ln (\mathrm{Zr} / \mathrm{Yb}))-9.61 ; \mathrm{DF} 2=(-3.72 \times \ln (\mathrm{La} / \mathrm{Yb}))+(4.79 \times \ln (\mathrm{Ce} / \mathrm{Yb}))+(-2.68 \times \ln (\mathrm{Sm} / \mathrm{Yb}))+(0.16 \times \ln (\mathrm{Nb} / \mathrm{Yb}))+$ $(-0.50 \times \ln (\mathrm{Th} / \mathrm{Yb}))+(1.04 \times \ln (\mathrm{Y} / \mathrm{Yb}))+(-0.34 \times \ln (\mathrm{Zr} / \mathrm{Yb}))-4.93$. (d) Discrimination diagram for acid rocks based on In-transformed ratios of immobile trace elements of Verma et al. (2013) (IA-CA-Col). DF1= (-0.047 x In(La/Yb)) $+(1.08 \times \ln (\mathrm{Ce} / \mathrm{Yb}))+(-0.96 \times \ln (\mathrm{Sm} / \mathrm{Yb}))+(0.84 \times \ln (\mathrm{Nb} / \mathrm{Yb}))+(0.59 \times \ln (\mathrm{Th} / \mathrm{Yb}))+(-0.88 \times \ln (\mathrm{Zr} / \mathrm{Yb}))-0.73 ; \mathrm{DF} 2$ $=(-4.07 \times \ln (\mathrm{La} / \mathrm{Yb}))+(4.74 \times \ln (\mathrm{Ce} / \mathrm{Yb}))+(-0.077 \times \ln (\mathrm{Sm} / \mathrm{Yb}))+(-0.23 \times \ln (\mathrm{Nb} / \mathrm{Yb}))+(0.77 \times \ln (\mathrm{Th} / \mathrm{Yb}))+(-2.49$ $\mathrm{x} \ln (\mathrm{Zr} / \mathrm{Yb}))+$ 5.10. (e) (La / Yb)n vs. Sr / Y diagram with the boundary between felsic igneous rocks from continental arcs and oceanic arcs adapted from Condie and Kröner (2013). (f) Th / Yb vs. Nb / Yb diagram proposed by Pearce and Peate (1995), with the boundary between felsic igneous rocks from oceanic and continental arcs adapted from Condie and Kröner (2013). Symbols as in Fig. 11. 
On the discrimination diagrams of Pearce et al. (1984) (Fig. 14a,b), most of the samples plot in the volcanic arc-related fields. Just a few granodioritic samples, including the only granodioritic sample from the $2.15 \mathrm{Ga}$ suite, plot in the within-plate fields. In two discrimination diagrams for acidic rocks based on immobile elements of Verma et al. (2013) (Figs. 14c,d), almost all samples plot within or close to the continental arc fields. Figure $14 \mathrm{e}$ is a (La / Yb)n vs. Sr / Y diagram, with the boundary between felsic igneous rocks from continental and oceanic arcs adapted from Condie and Kröner (2013). In this diagram, the tonalitic and granitic samples plot in the continental arc field. Six granodioritic samples fall in the continental arc field and four in the island arc field. All samples from the 2.08 Ga suite fall in the continental arc field and just one granodioritic sample of the $2.15 \mathrm{Ga}$ suite falls in the oceanic arc field. This diagram also shows that the average ( $\mathrm{La} / \mathrm{Yb}) \mathrm{n}$ of $2.08 \mathrm{Ga}$ suite is higher than the average value of the older suite. Figure $14 \mathrm{f}$ is the Th / Yb vs. $\mathrm{Nb} / \mathrm{Yb}$ diagram proposed by Pearce and Peate (1995), with the boundary between felsic igneous rocks from oceanic and continental arcs adapted from Condie and Kröner (2013). All samples, except one granodioritic sample from the 2.08 Ga suite and one tonalitic sample from the 2.15 Ga suite, fall on the arc array, and most of the samples fall in the continental arc field. Only three samples of granodioritic composition, including one from the 2.15 Ga suite, plot in the oceanic arc field.

\section{Discussion}

\subsection{Regional implications}

The Neoproterozoic suture between the São Francisco and the Paranapanema paleocontinents is located by some authors on top of the Andrelândia Nappe System (e.g. Trouw et al., 2013) and by others below this nappe system (e.g. Campos Neto et al., 2011). In both scenarios, the Pouso Alegre Complex would represent part of the lower São Francisco plate onto which the Neoproterozoic nappes were transported (Figs. 2 and 3). This part of the plate was strongly reworked during the Neoproterozoic collisional event. As a result, the Pouso Alegre Complex is now tectonically overlying the São Vicente Complex supracrustal sequence and Archean basement rocks (Heliodora Complex) (Fig. 3). Also, tectonic slivers of the Pouso Alegre Complex were transported into the overlying Andrelândia Nappe System (Fig. 2).

Geochronological and isotope data presented in this study strongly suggest that the Pouso Alegre Complex comprises two magmatic suites, one at $2.15 \mathrm{Ga}$ and the other at 2.08Ga (Figs. 7 and 9), both associated with juvenile $\mathrm{Nd}$ and $\mathrm{Hf}$ signatures (Fig. 10). The existence of other suites cannot be excluded, and datasets covering larger areas are necessary to confirm the hypothesis suggested by this study. The distinction between rocks of these suites in the field is not straightforward as this is a strongly deformed, layered complex with several closely interlayered lithotypes (Figs. 5a-e) and 
without continuous exposures. The discrimination of the two magmatic suites is thus mostly based on geochronological and isotope data. The only exception is the homogeneous Serra de São Gonçalo granite (Fig. 5f) that is represented as a different unit (Fig. 3) related to the 2.08 Ga suite.

In the Mineiro Belt area, within the southern São Francisco craton, a series of igneous suites with juvenile signatures have been recognized (Figs. 2 and 3) (Online Supplementary Table S5). The ages of these juvenile suites range from 2.35 to 2.13 Ga (e.g. Seixas et al., 2012, 2013; Teixeira et al., 2015) and they have been associated with a successive accretion of oceanic and continental arcs to the southern border of the São Francisco paleo-continent during the Paleoproterozoic. Based on the tectonic setting associated with geochronological and isotope data, the Pouso Alegre Complex is interpreted as the southernmost and youngest part of this Paleoproterozoic arc system, which was deeply reworked during the Neoproterozoic event related to the southern Brasília Orogen development.

\subsection{A major Paleoproterozoic continental crust generation event}

The data presented here, together with previous data (Fetter et al., 2001; Campos Neto et al., 2011) (Table 1), suggest an important period of continental crust generation recorded by the Pouso Alegre Complex in the basement of the southern Brasília Orogen. Two groups of crystallization ages were recognized in this study at $2078.7 \pm 6.7 \mathrm{Ma}$ and $2146.7 \pm 6.6 \mathrm{Ma}$ (weighted averages for the groups). These $\mathrm{U}-\mathrm{Pb}$ ages are associated with positive $\varepsilon N \mathrm{Nd}_{(\mathrm{t})}$ values of up to +2.85 and $\mathrm{T}_{\mathrm{DM}}$ model ages between 2.16 to $2.37 \mathrm{Ga}$ (Table 1). The zircon $\mathrm{Hf}$ isotope data are in good agreement with the wholerock $\mathrm{Nd}$ data, and all analyzed zircon grains yield positive $\varepsilon \mathrm{Hf}_{(\mathrm{t})}$ values from +1.9 to +8.7 (Fig. 10). These data associated with the absence of inheritance of older zircon are strong evidence of the juvenile character of the analyzed samples.

Recent models for the growth of continental crust based on $\mathrm{Hf}$ and $\mathrm{O}$ isotopes (Belousova et al., 2010; Dhuime et al., 2012) show a continuous growth process at variable rates. These models calculate that between 60 to $75 \%$ of the volume of the continental crust was separated from the mantle before $2.5 \mathrm{Ga}$. After that, crustal reworking processes have predominated. However, the distribution of zircon ages from juvenile rocks seems to be episodic with main peaks at ca. 2.7, 1.9 and 1.2 Ga (Condie, 1998, Condie and Aster, 2010). These peaks have been interpreted as periods of high preservation potential most likely related to periods of supercontinent assembly (Hawkesworth et al., 2009, 2013; Condie and Aster, 2010).

Reliable crust preservation models depend on accurate models for the age distribution of juvenile rocks. Non-representative sampling of the juvenile rock record can lead to distorted crust 
preservation models. The juvenile rocks investigated in this study have crystallization ages between 2.15 and $2.08 \mathrm{Ga}$. This age interval is situated between two major global peaks of juvenile crust preservation (Condie, 1998; Condie and Aster, 2010) at 2.7 and $1.9 \mathrm{Ga}$. Therefore, these rocks were generated in a period considered to have relatively low preservation rates of juvenile rocks on a global scale, but seems to be an important period of continental crust generation and preservation in South America and West Africa (e.g. Abouchami et al., 2000; Teixeira et al., 2015).

The fact that these rocks were strongly reworked by the Neoproterozoic orogeny adds a complicating factor that could be the reason why they had previously not been recognized, in contrast to the juvenile rocks from the cratonic area (Mineiro Belt). The data presented in this contribution considerably increase the area and the time interval of Paleoproterozoic continental crust generation events at the southern portion of the São Francisco paleo-continent. This study also supports the importance of the recognition of reworked juvenile rocks to better constrain models of continental crust generation and preservation. Together, the rocks of the Pouso Alegre Complex and the juvenile suites of the Mineiro Belt represent a major continental crust generation event with crystallization ages ranging from 2.35 to $2.08 \mathrm{Ga}$ and $\mathrm{T}_{\mathrm{DM}}$ ages from 2.5 to $2.2 \mathrm{Ga}$.

\subsection{Inferences on the tectonic setting}

Understanding the tectonic settings of crust generation during the Paleoproterozoic is crucial to understand the differences between Archean and Proterozoic crustal growth processes and to constrain the beginning of modern-style plate tectonics. The end of the Archean represents an important change in crustal growth processes and marks the end of the most productive period of crust generation and preservation in Earth's history (e.g. Hawkesworth et al., 2010; Kamber, 2015). It is likely that before the late Archean, the main sites of continental crust generation were represented by oceanic plateaus and oceanic arcs (Nair and Chacko, 2008; Condie and Kröner, 2013). After the Archean, the oceanic crust became thinner and more subductable. As a result, oceanic arcs would be less prone to accrete to continental margins, suggesting a change in the setting of continental crust generation and preservation after the end of the Archean from oceanic arcs and plateaus to continental arcs (Condie and Kröner, 2013).

In the case of reworked crust, where the primary relationships between the lithotypes have been erased, geochemical fingerprinting is the main tool to discriminate the tectonic setting. Even high-grade metamorphic rocks with evidence of partial melting can retain their geochemical signatures if significant melt extraction did not occur (e.g. Cioffi et al., 2012). The major element signatures of the Pouso Alegre Complex rocks are characteristic of subduction-related batholiths (Figs. 11 and 12). As shown in the primitive mantle normalized multielement diagrams (Fig. 13), the rocks of the Pouso 
Alegre Complex have trace element patterns similar to rocks generated in arc settings, a fact reinforced by the $\mathrm{Nd}$ and $\mathrm{Hf}$ juvenile signatures. The Pouso Alegre Complex lithotypes have high concentrations of $\mathrm{Rb}, \mathrm{Ba}, \mathrm{Th}, \mathrm{U}$ and low $\mathrm{Nb} / \mathrm{La}$ ratios, which are characteristic of subduction zone magmas. These signatures are a result of enrichment of fluid-mobile elements over fluid-immobile elements generated by an influx of fluids from the subducting slab in the mantle wedge (e.g. Rudnick and Fountain, 1995; Plank, 2005). The trace element discrimination diagrams (Figs. 14a-d) also indicate a subductionrelated environment for most of the analyzed samples.

Assuming a subduction setting, the next step is to discriminate between an oceanic or continental setting. In the Pouso Alegre Complex, felsic lithotypes clearly predominate over mafic lithotypes. Large volumes of felsic igneous rocks are common in continental arcs but are minor constituents of oceanic arcs (Best, 2003). The incompatible element enrichment of the granodioritic and granitic samples are significantly above the oceanic arc field and more akin to continental arcs (Fig. 13c). Almost all analyzed samples plot in the continental arc fields of the discrimination diagrams of Verma et al. (2013) (Figs. 14c, d). In the (La / Yb)n vs. Sr / Y and the Th / Yb vs. Nb / Yb diagrams, with the boundaries between felsic igneous rocks from continental arcs and oceanic arcs adapted from Condie and Kröner (2013), most of the samples fall in the continental arc fields (Figs. 14e, f). These results are all evidence of continental arc geochemical signatures in the rocks of the Pouso Alegre Complex.

A complicating factor in the distinction between oceanic and continental arcs is the fact that oceanic arcs can accrete to continents and then evolve into continental arcs (e.g. Draut et al., 2002, 2009; Condie and Kröner, 2013). During the accretion, the arcs become thicker, which creates the necessary conditions for the arc roots to start to melt and generate calc-alkaline batholiths with continental arc fingerprints. Lee et al. (2007) proposed a multi-stage model for the North America Cordillera with oceanic arc development, subsequent accretion and ending with continental arc magmatism. Assuming this model applies to the rocks of the Pouso Alegre Complex, they could be generated in a continental arc emplaced at the southern edge of the São Francisco paleo-continent or in an evolved oceanic arc accreted to the southern border of the São Francisco paleo-continent. In the second scenario, the felsic magmas were most likely generated after the accreted arc had become thicker and evolved into a continental arc, which could explain the large volume of felsic rocks and their continental arc geochemical signatures.

The 2.08 Ga suite comprises granodiorites and granites whereas more primitive compositions as tonalites predominate in the $2.15 \mathrm{Ga}$ suite. Figure 15 shows a comparison of average compositions of the two suites normalized to upper continental crust (Rudnick and Gao, 2003). Regarding to major elements the younger suite is enriched in $\mathrm{K}_{2} \mathrm{O}, \mathrm{TiO}_{2}, \mathrm{P}_{2} \mathrm{O}_{5}$ and depleted in $\mathrm{CaO}, \mathrm{MgO}, \mathrm{FeO}_{\mathrm{t}}$ compared to the older suite. Concerning trace elements the younger suite is enriched in $\mathrm{Rb}, \mathrm{Zr}, \mathrm{Nb}, \mathrm{Ba}, \mathrm{LREE}, \mathrm{Th}$ 
and have higher $\mathrm{Gd} / \mathrm{Yb}$ ratios. The average $\varepsilon \mathrm{Nd}$ and $\varepsilon \mathrm{Hf}$ of the $2.08 \mathrm{Ga}$ suite are slightly lower than the older suite (Figs. 10b, c). All these characteristics are similar to the ones used to differentiate the western and eastern Peninsular Ranges batholiths (e.g. Lee et al., 2007) in the North American Cordillera. The western batholiths are associated to an accreted arc and the eastern batholiths to a continental arc stage.

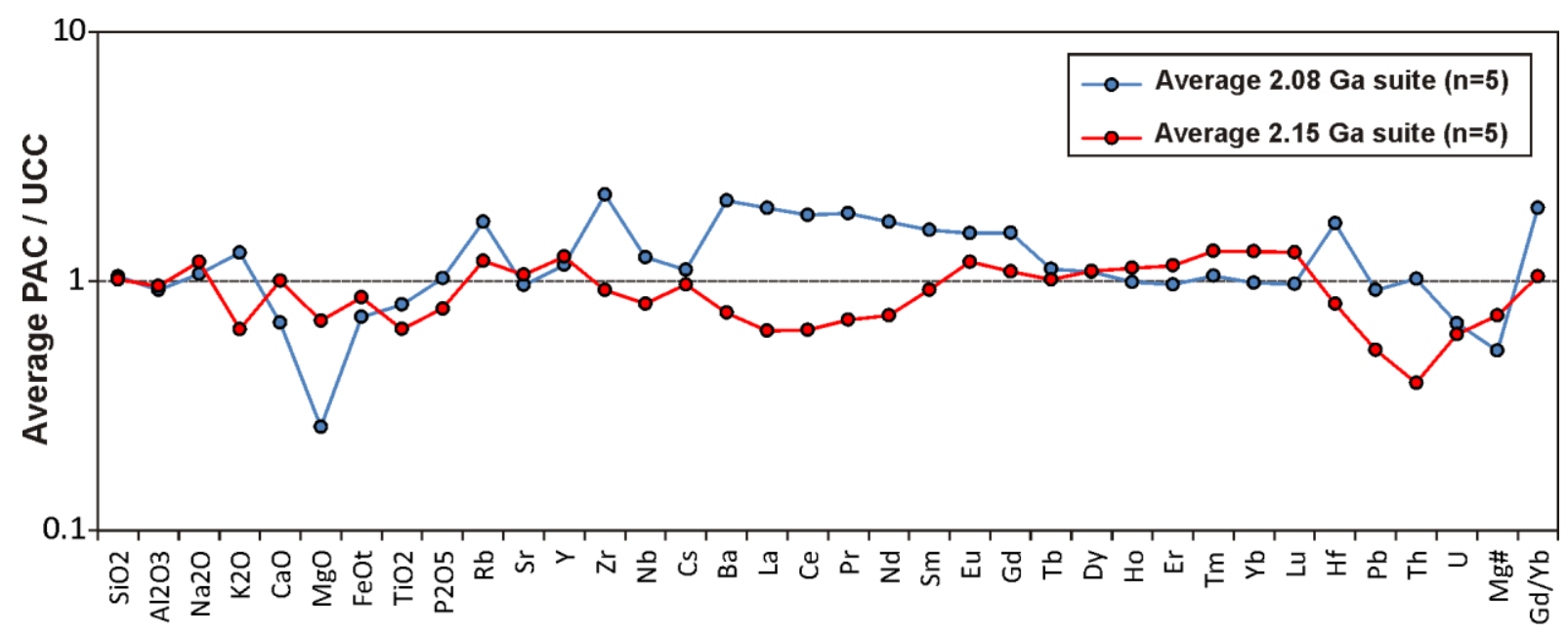

Fig. 15. Average compositions of the Pouso Alegre Complex suites normalized to the upper continental crust (Rudnick and Gao, 2003).

The main challenge in applying the Peninsular Ranges batholiths model for the Pouso Alegre Complex is the absence of preserved paleogeographic evidence. As discussed in chapter 8.1, these rocks were strongly reworked during the Neoproterozoic orogeny and therefore do not preserve their original paleogeographic and tectonic position. The Peninsular Ranges batholiths are clearly divided into two distinct geographical domains. Therefore, other possible processes such as the reworking of the more primitive 2.15 Ga rock suite to generate the $2.08 \mathrm{Ga}$ suite cannot be excluded. However, the zircon data from the $2.08 \mathrm{Ga}$ suite (Fig. 9) do not suggest inheritance from the $2.15 \mathrm{Ga}$ suite. Another possibility is that these distinct paleogeographic domains have not yet been recognized in the Pouso Alegre Complex and future studies with larger datasets are therefore highly encouraged.

\section{Conclusions}

The data presented in this study lead to the following conclusions:

- The Pouso Alegre Complex represents part of the lower São Francisco paleo-plate onto which the southern Brasília Orogen Neoproterozoic nappes were transported. The complex was strongly reworked during these processes. 
- The lenses of Paleoproterozoic orthogneisses within the Andrelândia Nappe System are tectonic slivers of the Pouso Alegre Complex transported into the nappe stack.

- Two crystallization age groups are recognized in the Pouso Alegre Complex at $2.15 \mathrm{Ga}$ (weighted average of $2146.7 \pm 6.6 \mathrm{Ma} ; 6$ samples; MSWD = 1.9) and $2.08 \mathrm{Ga}$ (weighted average of $2078.7 \pm 6.7$ $\mathrm{Ma} ; 5$ samples; MSWD = 1.4). Both suites show Nd and Hf juvenile isotopic signatures.

- The analyzed samples have arc-related geochemical signatures, and most of the samples show continental arc affinities. These characteristics associated with the predominance of felsic rocks suggest an active continental margin or an evolved accreted oceanic arc as the tectonic setting for the generation of the Pouso Alegre Complex rocks.

- The Pouso Alegre Complex is the southernmost and youngest recognized part of an arc complex emplaced at the southern edge of the São Francisco paleo-continent during the Paleoproterozoic. This was completely reworked at ca. $600 \mathrm{Ma}$ by the collisional event related to the southern Brasília Orogen, and its cratonic counterpart is represented by the rocks of the Mineiro Belt.

- The rocks of Pouso Alegre Complex and the juvenile suites of the Mineiro belt together represent a major Paleoproterozoic continental crust generation event at the southern edge of the São Francisco paleo-continent between 2.35 and $2.08 \mathrm{Ga}$.

\section{Acknowledgements}

This research was supported by FAPESP (grant 2013/13530-8). C.R. Cioffi is thankful to CAPES and FAPESP for the PhD scholarships. Renato Moraes is acknowledged for his help during field work, Josh Feldman for assistance with SEM image acquisition and Vasco Loios for support during zircon separation. Careful review by Bernard Bingen greatly improved the manuscript. Editorial handling by Randall Parrish is appreciated.

\section{References}

Abouchami, W., Boher, M., Michard, A., Albarède, F., 1990. A major 2.1Ga event of mafic magmatism in West Africa - an early stage of crustal accretion. Journal of Geophysical Research: Solid Earth 95, 17605-17629.

Ávila, C.A., Teixeira, W., Cordani, U.G., Moura, C.A.V., Pereira, R.M., 2010. Rhyacian (2.23-2.20 Ga) juvenile accretion in the Southern São Francisco craton, Brazil: Geochemical and isotopic evidence from the Serrinha magmatic suite, Mineiro belt. Journal of South American Earth Sciences 29, 464-482. 
Ávila, C.A., Teixeira, W., Bongiolo, E.M., Dussin, I.A., Vieira, T.A.T., 2014. Rhyacian evolution of subvolcanic and metasedimentary rocks of the Southern segment of the Mineiro belt, São Francisco Craton, Brazil. Precambrian Research 243, 221-251.

Belousova, E.A., Kostitsyn, Y.A., Griffin, W.L., Begg, G.C., O’Reilly, S.Y., Pearson, N.J., 2010. The growth of continental crust: Constraints from zircon Hf-isotopes data. Lithos 119, 457-466.

Best, M.G., 2003. Igneous and metamorphic petrology. Blackwell Publishing, Oxford (2003) (729pp.).

Blichert-Toft, J., Albarède, F., 1997. The Lu-Hf isotope geochemistry of chondrites and the evolution of the mantle-crust system. Earth and Planetary Science Letters 148, 243-258.

Brito Neves, B.B., Campos Neto, M.C., Fuck, R.A., 1999. From Rodinia to western Gondwana: an approach to the Brasiliano-pan African cycle and orogenic collage. Episodes 22, 155-166.

Campos, J.C.S., Carneiro, M.A., 2008. Neoarchean and Paleoproterozoic granitoids marginal to the Jeceaba-Bom Sucesso lineament (SE border of the southern São Francisco craton): Genesis and tectonic evolution. Journal of South American Earth Sciences 26, 463-484.

Campos Neto, M.C., 2000. Orogenic Systems from southwestern Gondwana: an approach to Brasiliano-Pan African Cycle and orogenic collage in southeastern Brazil. In: Cordani, U.G., Milani, E.J., Thomaz Filho, A., Campos, D.A. (Eds.), Tectonic Evolution of South America. 31th International Geological Congress. Rio de Janeiro, Brazil, pp. 335-365.

Campos Neto, M.C., Caby, R., 1999. Neoproterozoic high-pressure metamorphism and tectonic constraint from the nappe system south of the São Francisco Craton, southeast Brazil. Precambrian Research 97, 3-26.

Campos Neto, M.C., Caby, R., 2000. Lower crust extrusion and terrane accretion in the Neoproterozoic nappes of southeast Brazil. Tectonics 19, 669-687.

Campos Neto, M.C., Basei, M.A.S., Vlach, S.R.F., Caby, R., Szábo, G., Vasconcelos, P., 2004. Migração de orógenos e superposição de orogêneses: um esboço da colagem Brasiliana no sul do cráton do São Francisco, SE - Brasil. Revista do Instituto de Geociências - USP. Geologia USP Série Científica 4, 13-40.

Campos Neto, M.C., Cioffi, C.R., Moraes, R., Motta, R.G., Siga Jr., O., Basei, M.A.S., 2010. Structural and metamorphic control on the exhumation of high-P granulites: The Carvalhos Klippe example, from the oriental Andrelândia Nappe System, southern portion of the Brasília Orogen, Brazil. Precambrian Research 180, 125-142. 
Campos Neto, M.C., Basei, M.A.S., Janasi, V.A., Moraes, R., 2011. Orogen migration and tectonic setting of the Andrelândia Nappe System: An Ediacaran western Gondwana collage, south São Francisco craton. Journal of South American Earth Sciences 32, 393-406.

Cioffi, C.R., Campos Neto, M.C., Rocha, B.C., Moraes, R., Henrique-Pinto, R., 2012. Geochemical signatures of metasedimentary rocks of high-pressure granulite facies and their relation with partial melting: Carvalhos Klippe, Southern Brasília Belt, Brazil. Journal of South American Earth Sciences 40, 63-76.

Condie, K.C., 1998. Episodic continental growth and supercontinents: a mantle avalanche connection? Earth and Planetary Sciences Letters 163, 97-108.

Condie, K.C., 2000. Episodic crustal growth models: afterthoughts and extensions. Tectonophysics 322, 153-162.

Condie, K.C., Aster, R.C., 2010. Episodic zircon age spectra of orogenic granitoids: The supercontinent connection and continental growth. Precambrian Research 180, 227-236.

Condie, K.C., Kröner, A., 2013. The building blocks of continental crust: Evidence for a major change in the tectonic setting of continental growth at the end of the Archean. Gondwana Research 23, 394-402. Dardenne, M.A., 2000. The Brasília Fold Belt. In: Cordani, U.G., Milani, E.J., Thomaz Filho, A., Campos, D.A. (Eds.), Tectonic Evolution of South America. 31th International Geological Congress. Rio de Janeiro, Brazil, pp. 231-263.

DePaolo, D.J., 1981. Neodymium isotopes in the Colorado Front Range and crust-mantle evolution in the Proterozoic. Nature 291, 193-196.

Dhuime, B., Hawkesworth, C., Cawood, P.A., Storey, C.D., 2012. A change in the geodynamic of Continental Growth 3 Billion Years Ago. Science 335, 1334-1336.

Dickin, A.P., 1995. Radiogenic Isotope Geology. Cambridge University Press, Cambridge (2005) 471pp.

Draut, A.E., Clift, P.D., Hannigan, R.E., Layne, G., Shimizu, N., 2002. A model for continental crust genesis by arc accretion: rare earth element evidence from the Irish Caledonides. Earth and Planetary Science Letters 203, 861-877.

Draut, A.E., Clift, P.D., Amato, J.M., Blusztajn, J., Schouten, H., 2009. Arc-continent collision and the formation of continental crust: a new geochemical and isotopic record from the Ordovician Tyrone Igneous Complex, Ireland. Journal of the Geological Society of London 166, 485-500.

Fetter, A.H., Hackspacker, P.C., Ebert, H.D., Dantas, E.L., Costa, A.C.D., 2001. New Sm/Nd and U/Pb geochronological constraints on the Archean to Neoproterozoic evolution of the Amparo basement 
complex of the central Ribeira belt, southeastern Brazil. 3rd South American Symposium on Isotope Geology (Extended Abstracts, CD-ROM).

Frost, B.R., Barnes, C.G., Collins, W.J., Arculus, R.J., Ellis, D.J., Frost, C.D., 2001. A geochemical classification for granitic rocks. Journal of Petrology 42, 2033-2048.

Gioia, S.M.C.L., Pimentel, M.M., 2000. The Sm-Nd method in the geochronology laboratory of the University of Brasília. Anais da Academia Brasileira de Ciências 72, 219-245.

Goldstein, S.L., O'Nions, R.K., Hamilton, P.J., 1984. A Sm-Nd isotopic study of atmospheric dusts and particulates from major river systems. Earth and Planetary Science Letters 70, 221-236.

Goodge, J.W., Vervoort, J.D., 2006. Origin of Mesoproterozoic A-type granites in Laurentia: Hf isotope evidence. Earth and Planetary Science Letters 243, 711-731.

Griffin, W.L., Wang, X., Jackson, S.E., Pearson, N.J., O'Reilly, S.Y., Xu, X., Zhou, X., 2002. Zircon chemistry and magma mixing, SE China: In-situ analysis of $\mathrm{Hf}$ isotopes, Tonglu and Pingtan igneous complexes. Lithos 61, 237-169.

Hawkesworth, C., Cawood, P.A., Kemp, T., Storey, C.D., Dhuime, B., 2009. A matter of preservation. Science 323, 49-50.

Hawkesworth, C., Dhuime, B., Pietranik, A.B., Cawood, P.A., Kemp, A.I.S., Storey, C.D., 2010. The generation and evolution of the continental crust. Journal of the Geological Society of London 167, 229-248.

Hawkesworth, C., Cawood, P.A., Dhuime, B., 2013. Continental growth and the crustal record. Tectonophysics 609, 651-660.

Jackson, S.E., Pearson, N.J., Griffin, W.L., Belousova, E.A., 2004. The application of laser ablationinductively coupled plasma-mass spectrometry to in-situ U-Pb zircon geochronology. Chemical Geology 211, 47-69.

Jayananda, M., Moyen, J.-F., Martin, H., Peucat, J.-J., Auvray, B., Mahabaleswar, B., 2000. Late Archean (2550-2520) juvenile magmatism in the Eastern Dharwar craton, southern India: constraints from geochronology, Nd-Sr isotopes and whole-rock geochemistry. Precambrian Research 99, 225-254.

Kamber, B.S., 2015. The evolving nature of terrestrial crust from the Hadean, through the Archean, into the Proterozoic. Precambrian Research 258, 48-82.

Korsch, R.J., Kositcin, N., Champion, D.C., 2011. Australian island arcs through time: Geodynamic implications for the Archean and Proterozoic. Gondwana Research 19, 716-734. 
Lee, C.-T.A., Morton, D.M., Kistler, R.W., Baird, A.K., 2007. Petrology and tectonics of Phanerozoic continent formation: From island arcs to accretion and continental arc magmatism. Earth and Planetary Sciences Letters 263, 370-387.

Ludwig, K.R., 2003. Isoplot/Ex 3.00: A geochronological toolkit for Microsoft Excel. Berkeley Geochronology Center Special Publication, 4.

Maniar, P.D., Piccoli, P.M., 1989. Tectonic discrimination of granitoids. Geological Society of America Bulletin 101, 635-643.

Martins, L., Vlach, S.R.F., Janasi, V.A., 2009. Reaction microtextures of monazite: correlation between chemical and age domains in the Nazaré Paulista migmatite, SE Brazil. Chemical Geology 261, 271-285.

McDonough, W.F., Sun, S.S., 1995. The composition of the earth. Chemical Geology 120, 223-253.

Morais, S.N., 1999a. Programa Levantamentos Geológicos Básicos do Brasil: Integração Geológica da Folha Campinas . (Escala) 1:250.000 SF-23-Y-A. Estados de São Paulo e Minas Gerais (Nota Explicativa) - São Paulo - CPRM (26pp.).

Morais, S.N., 1999b. Programa Levantamentos Geológicos Básicos do Brasil: Integração Geológica da Folha Guaratinguetá. (Escala) 1:250.000 SF-23-Y-B. Estados de São Paulo e Minas Gerais (Nota Explicativa) - São Paulo - CPRM (28pp.).

Mori, P.E., Reeves, S., Correia, C.T., Haukka, M., 1999. Development of a fused glass disc XRF facility and comparison with the pressed powder pellet technique at Instituto de Geociências, Universidade de São Paulo. Revista brasileira de Geociências 29, 441-446.

Nair, R., Chacko, T., 2008. Role of oceanic plateaus in the initiation of subduction and origin of continental crust. Geology 36, 583-586.

Navarro, M.S., Ulbrich, H.H., Andrade, S., Janasi, V.A., 2002. Adaptation of ICP-OES routine determination techniques for the analysis of rare earth elements by chromatographic separation in geological materials: Tests with reference materials and granitic rocks. Journal of Alloy and Compounds $344,40-45$.

Navarro, M.S., Andrade, S., Ulbrich, H., Gomes, C.B., Girardi, V.A.V., 2008. The direct determination of rare Earth elements in basaltic and related rocks using ICP-MS: Testisng the efficiency of microwave oven sample decomposition procedures. Geostandards and Geoanalytical Research 32, 167-180.

Noce, C.M., Teixeira, W., Quéméneur, J.J.G., Martins, V.T.S., Bolzachini, E., 2000. Isotopic signatures of Paleoproterozoic granitoids from the Southern São Francisco Craton and implications for the evolution of the Transamazonian Orogeny. Journal of South American Earth Sciences 13, 225-239. 
Paton, C., Hellstrom, J., Paul, B., Woodhead, J., Hergt, J., 2011. Iolite:Freeware for the visualisation and processing of mass spectrometry data. Journal of Analytical Atomic Spectrometry 26, 2508-2518.

Pearce, J.A., Harris, N.B.W., Tindle, A.G., 1984. Trace element discrimination diagrams for the tectonic interpretation of granitic rocks. Journal of Petrology 25, 956-983.

Pearce, J.A., Peate, D.W., 1995. Tectonic implications of the composition of volcanic arc magmas. Annual Review of Earth and Planetary Sciences 23, 251-285.

Perrota, M.M., 1991. A Faixa Alto Rio Grande na região de São Gonçalo do Sapucaí, MG. Unpublished Master's dissertation, IGc-USP, (158pp.).

Peternel, R., 2005. A zona de superposição entre as Faixas Brasília e Ribeira na região entre Caxambu e Pedralva, sul de Minas Gerais. Unpublished PhD Thesis. Instituto de Geociências - UFRJ, (257pp.).

Peternel, R., Trouw, R.A.J., Schimitt, R.S., 2005. Interferência entre duas faixas móveis Neoproterozóicas: o caso das faixas Brasília e Ribeira no sudeste do Brasil. Revista Brasileira de Geociências 35, 297-310.

Petrus, J.A., Kamber, B.S., 2012. VizualAge: A Novel Approach to Laser Ablation ICP-MS U-Pb Geochronology Data Reduction. Geostandards and Geoanalytical Research 36, 247-270.

Plank, T., 2005. Constraints from thorium/lanthanum on sediment recycling at subduction zones and the evolution of the continents. Journal of Petrology 46, 921-944.

Reno, B.L., Brown, M., Kobayashi, K., Nakamura, E., Piccoli, P.M., Trouw, R.A.J., 2009. Eclogite-highpressure granulite metamorphism records early collision in West Gondwana: new data from Southern Brasília Belt, Brazil. Journal of the Geological Society of London 166, 1013-1032.

Rino, S., Komiya, T., Windley, B.F., Katayama, I., Motoki, A., Hirata, T., 2004. Major episodic increases of continental crustal growth determined from zircon ages of river sands: Implications for mantle overturns in the early Precambrian. Physics of Earth and Planetary Interiors 146, 369-394.

Rudnick, R.L., Fountain, D.M., 1995. Nature and compostion of the continental crust: a lower crustal perspective. Reviews of Geophysics 33, 267-309.

Rudnick, R.L., Gao, S., 2003. Composition of the Continental Crust. In: Rudnick, R.L., (Ed.), The Crust, Treatise on Geochemistry vol.3, pp. 1-64.

Sato, K., Tassinari, C.C.G., Kawashita, K., Petronilho, L., 1995. O método geocronológico Sm-Nd no IG/USP e suas aplicações. Anais da Academia Brasileira de Ciências 67, 315-336. 
Seixas, L.A.R., David, J., Stevenson, R., 2012. Geochemistry, Nd isotopes and U-Pb geochronology of a 2350 Ma TTG suite, Minas Gerais, Brazil: Implications for the crustal evolution of the southern São Francisco craton. Precambrian Research 196-197, 61-80.

Seixas, L.A.R., Bardintzeff, J-M., Stevenson, R., Bonin, B., 2013. Petrology of the high -Mg tonalites and dioritic enclaves of the ca. 2130 Ma Alto Maranhão suite: Evidence for a major juvenile crustal addition event during the Rhyacian orogenesis, Mineiro Belt, southeast Brazil. Precambrian Research 238, 1841.

Sláma, J., Košler, J., Condon, D.J., Crowley, J.L., Gerdes, A., Hanchar, J.M., Horstwood, S.A., Morris, G.A., Nasdala, L., Norberg, N., Schaltegger, U., Schoene, B., Tubrett, M.N., Whitehouse, M.J., 2008. Plešovice zircon - A new natural reference material for $\mathrm{U}-\mathrm{Pb}$ and $\mathrm{Hf}$ isotopic microanalysis. Chemical Geology 249, 1-35.

Söderlund, U., Patchett, P.J., Vervoort, J.D., Isachsen, C.E., 2004. The ${ }^{176}$ Lu decay constant determined by $\mathrm{Lu}-\mathrm{Hf}$ and $\mathrm{U}-\mathrm{Pb}$ isotope systematics of Precambrian mafic intrusions. Earth and Planetary Sciences Letters 219, 311-324.

Stacey, J.S., Kramers, J.D., 1975. Approximation of terrestrial lead isotope evolution by two-stage model. Earth and Planetary Science Letters 26, 207-221.

Tanaka, T; Togashi, S., Kamioka, H., Amakawa, H., Kagami, H., Hamamoto, T., Yuhara, M., Orihashi, Y., Yoneda, S., Shimizu, H., Kunimaru, T., Takahashi, K., Yanagi, T., Nakano, T., Fujimaki, H., Shinjo, R., Asahara, Y., Tanimizu, M., Dragusanu, C., 2000. JNdi-1: a neodymium isotopic reference in consistency with LaJolla neodymium. Chemical Geology 168, 279-281.

Tassinari, C.C.G., Nutman, A.P., Archean and Proterozoic multiple tectonothermal events recorded by gneisses in the Amparo region, São Paulo state, Brazil. 3rd South American Symposium on Isotope Geology (Extended Abstracts, CD-ROM).

Taylor, S.R., McLennan, S.M., 1985. The Continental Crust: Its composition and Evolution. Blackwell Publishing, London (1985) (312 pp.).

Teixeira, W., Sabatè, P., Barbosa, J., Noce, C.M., Carneiro, M.A., 2000. Archean and Paleoproterozoic evolution of the São Francisco Craton, Brazil. In: Cordani, U.G., Milani, E.J., Thomaz Filho, A., Campos, D.A. (Eds.), Tectonic Evolution of South America. 31th International Geological Congress. Rio de Janeiro, Brazil, pp. 101-137.

Teixeira, W., Ávila, C.A., Nunes, L.C., 2008. Nd-Sr isotopic geochemistry and U-Pb geochronology of the Fé Granitic Gneiss and Lajeado Granodiorite: Implications for Paleoproterozoic evolution of the Mineiro Belt, Southern São Francisco Craton, Brazil. Geologia USP série científica 8, 53-74. 
Teixeira, W., Ávila, C.A., Dussin, I.A., Corrêa Neto, A.V., Bongiolo, E.M., Santos, J.O., Barbosa, N.S., 2015. A juvenile accretion episode (2.35-2.32 Ga) in the Mineiro Belt and its role to the Minas accretionary orogeny: Zircon U-Pb-Hf and geochemical evidences. Precambrian Research 256, 148-169.

Trouw, R.A.J., Heilbron, M., Ribeiro, A., Paciullo, F., Valeriano, C.M., Almeida, J.C.H., Tupinambá, M., Andreis, R.R., 2000. The central segment of Ribeira belt. In: Cordani, U.G., Milani, E.J., Thomaz Filho, A., Campos, D.A. (Eds.), Tectonic Evolution of South America. 31th International Geological Congress. Rio de Janeiro, Brazil, pp. 287-310.

Trouw, R.A.J., Nunes, R.P.M., Castro, E.M.O., Trouw, C.C., Matos, G.C., 2008. Nota explicativa das Folhas Varginha (SF.23-V-D-VI) e Itajubá (SF.23-Y-B-III). Programa Geologia do Brasil. Contrato CPRMUFRJ Nº67/PR/05. (99pp).

Trouw, R.A.J., Peternel, R., Ribeiro, A., Heilbron, M., Vinagre, R., Duffles, P., Trouw, C.C., Fontainha, M., Kussama, H.H., 2013. A new interpretation for the interference zone between the southern Brasília belt and the central Ribeira belt, SE Brazil. Journal of South American Earth Sciences 48, 43-57.

Valeriano, C.M., Machado, N., Simonetti, A., Valladares, C.S., Seer, H.J., Simões, L.S.A., 2004. U-Pb geochronology of the Southern Brasília belt (SE-Brazil): sedimentary provenance, Neoproterozoic orogeny, and assembly of West Gondwana. Precambrian Research 130, 27-55.

Verma, S.P., Pandarinath, K., Verma, S.K., Agrawal, S., 2013. Fifteen new discriminant-function-based multi-dimension robust diagrams for acid rocks and their applications to Precambrian rocks. Lithos 168-169, 113-123.

Vervoort, J.D., Blichert-Toft, J., 1999. Evolution of the depleted mantle: Hf isotopic evidence from juvenile rocks through time. Geochimica et Cosmochimica Acta 63, 533-556.

Zuquim, M.P.S., Trouw, R.A.J., Trouw, C.C., Tohver, E., 2011. Structural evolution and U-Pb SHRIMP zircon ages of the Neoproterozoic Maria da Fé shear zone, central Ribeira Belt - SE Brazil. Journal of South American Earth Sciences 31, 199-213. 


\section{ANEXO II}

(Tectonic significance of the Meso- to Neoarchean complexes in the basement of the southern Brasilia Orogen) 


\title{
ANEXO II \\ Artigo submetido para revista Precambrian Research
}

\section{Tectonic significance of the Meso- to Neoarchean complexes in the basement of the southern Brasília Orogen}

\author{
Caue Rodrigues Cioffi ${ }^{a . b} ;$ Mario da Costa Campos Neto ${ }^{a}$ Andreas Möller ${ }^{b}$; Brenda Chung Rocha ${ }^{a, b}$ \\ anstituto de Geociências, Universidade de São Paulo, São Paulo, SP, Brazil. \\ ${ }^{b}$ Department of Geology, The University of Kansas, Lawrence, KS, USA
}

\begin{abstract}
Most evidence for growth history of the São Francisco paleocontinent is hidden within the Neoproterozoic orogens that surround the São Francisco Craton. The basement complexes within these orogens can give us important clues about the continental growth processes. This study investigates the Meso- to Neoarchean complexes in the southern Brasilia Orogen basement by a combination of zircon $\mathrm{U}-\mathrm{Pb}$ geochronology and $\mathrm{Hf}$ isotopes, as well as whole-rock geochemistry and $\mathrm{Nd}$ isotopes. This new data is used to discuss the Archean evolution of these complexes and their role in the São Francisco paleocontinent assembly.
\end{abstract}

A well-defined period of Mesoarchean TTG-type magmatism between 3.00 and $2.96 \mathrm{Ga}$ is identified. These samples yield mostly positive $\varepsilon_{\mathrm{Hf}}(\mathrm{t})$ between -0.4 and +4.7 associated with two-stage model ages between 3.0 and $3.3 \mathrm{Ga}$. Whole-rock Nd analyses yield $\mathrm{T}_{\mathrm{DM}}$ ages from 3.2 to $3.4 \mathrm{Ga}$. These results suggest juvenile sources with participation of slightly older crust, which is in agreement with zircon inheritance at ca. 3.19 Ga. An additional period of Neoarchean high-K granitoid magmatism at ca. 2.76 $\mathrm{Ga}$ is interpreted to mark the transition from TTG-type to high-K granitoid magmatism in the area. This Neoarchean magmatism is associated with less radiogenic signatures, with negative $\varepsilon \mathrm{Hf}_{(\mathrm{t})}$ between 0.6 and -7.1 and $\varepsilon \mathrm{Nd}_{(\mathrm{t})}$ of -2.5 . However, the source of this high- $\mathrm{K}$ granitoid is still undefined.

The studied Archean complexes are separated from the Archean crust of the southern São Francisco craton by the Paleoproterozoic Pouso Alegre Complex / Mineiro Belt arc system. Published data from the Archean crust within the southern São Francisco craton have crystallization ages ranging from ca. 
3.22 to $2.72 \mathrm{Ga}$, with a gap between ca. 3.20 and $2.93 \mathrm{Ga}$. Therefore, the data presented here indicate that the Archean complexes in the basement of the southern Brasilia Orogen are exotic to the São Francisco Craton Archean crust because they show crystallization ages within the "magmatic gap". Based on the geological setting and geochronological data, we propose that the Archean complexes in the basement of the southern Brasilia Orogen are Archean microcontinents that were accreted to the southern São Francisco paleocontinent. The timing of accretion is not well constrained, but most likely occurring during the Paleoproterozoic after $2.08 \mathrm{Ga}$.

\section{Introduction}

There is strong evidence that the São Francisco paleocontinent grew, during the Paleoproterozoic, between ca. 2.35 and 2.08 Ga (e.g. Teixeira et al., 2015). The main growth mechanisms include new crust generation in arc-settings (e.g. Barbosa et al., 2015; Cioffi et al., 2016) and accretion of older crustal segments (e.g. Heilbron et al., 2010). These Paleoproterozoic accretionary systems were located on the edges of the growing landmasses, surrounding Archean continental centers. As a result, large parts of these systems were deeply reworked during the Neoproterozoic collisional events and are now part of the basement of these marginal orogenic systems (e.g. Fuck et al., 2010; Silva et al., 2015; Cioffi et al., 2016). Therefore, these basement complexes are the key to constrain the timing and mechanisms of growth of the São Francisco paleocontinent.

The basement of the southern Brasília Orogen comprises two main tectonic domains: (1) a juvenile arc-related Paleoproterozoic domain (the orthogneisses of the Pouso Alegre Complex and associated metasedimentary rocks of the São Vicente Complex), and (2) an Archean domain (the Amparo, Serra Negra, Heliodora-Minduri and Mantiqueira complexes) (Fig. 1). The Paleoproterozoic domain has been subject of recent geochronological, isotopic and geochemical studies (e.g. Cioffi et al., 2016; Westin et al., 2016). This domain has been interpreted as part of the cratonic Mineiro Belt arc system (e.g. Ávila et al., 2010; Seixas et al., 2013; Teixeira et al., 2015) deeply reworked during the Neoproterozoic orogenic events (Cioffi et al., 2016). However, the role of the Archean complexes in the assembly of the São Francisco paleocontinent is still enigmatic.

In this contribution we use a combination of U-Pb zircon in-situ techniques (LA-ICP-MS), zircon $\mathrm{Hf}$ isotopes, whole-rock $\mathrm{Nd}$ isotopes and whole-rock geochemistry to constrain the tectonic evolution of the Archean complexes in the basement of the southern Brasilia Orogen. With these new data we discuss the Archean evolution of these crustal segments and how they possibly became amalgamated to the southern São Francisco paleocontinent. This gives some clues on how these poorly understood Archean crustal segments were involved in the São Francisco paleocontinent assembly. 


\section{Geological setting}

The Neoproterozoic Brasília Orogen (Dardenne, 2000) surrounds the western and southern edges of the São Francisco craton and has been interpreted as a product of an Ediacaran collision between the active margin of the Paranapanema plate and the passive margin of the São Francisco paleocontinent (Brito Neves et al., 1999; Campos Neto, 2000; Trouw et al., 2000). The southern part of the orogen comprises a thick-skinned nappe stack with southwest-dipping tectonic wedge and transport towards east-northeast (Campos Neto and Caby, 1999, Campos Neto et al., 2011; Trouw et al., 2000, 2013). Two main tectonic domains are identified within this nappe system (Fig. 1): (1) an active margin domain related to the Paranapanema plate, consisting of a magmatic arc unit (the Socorro-Guaxupé Nappe) (Campos Neto and Caby, 2000; Janasi, 2002) and active margin-related metasedimentary units (the Andrelândia Nappe System) (Campos Neto et al., 2010, 2011) and (2) a passive margin domain related to the São Francisco paleocontinent that comprises basement orthogneisses (Fetter et al., 2001; Cioffi et al., 2016) and passive margin-related metasedimentary units (the São Vicente Complex and the Carrancas and Lima Duarte nappes) (Rocha, 2011; Westin and Campos Neto, 2013; Westin et al., 2016).

The basement orthogneisses can be divided into two main tectonic units: (1) the Paleoproterozoic Pouso Alegre Complex (Cioffi et al., 2016) and (2) the Archean complexes (the Amparo, Serra Negra, Heliodora-Minduri and Mantiqueira complexes) (Fetter et al., 2001; Tassinari and Nutman, 2001; Peternel, 2005) (Fig. 1). The Pouso Alegre Complex orthogneisses have igneous crystallization ages between 2.15 and $2.08 \mathrm{Ga}$ associated with juvenile $\mathrm{Nd}$ and $\mathrm{Hf}$ signatures (Fetter et al., 2001; Campos Neto et al., 2011; Cioffi et al., 2016). The Pouso Alegre Complex has been interpreted as a continuation of the cratonic Paleoproterozoic Mineiro Belt arc system underneath the southern Brasília Orogen (Cioffi et al., 2016). Assuming this hypothesis, the Archean complexes in the basement of the southern Brasília Orogen are separated from the São Francisco craton Archean crust by this, at least 350 km long, NE-SW trending arc complex (Fig. 1). 


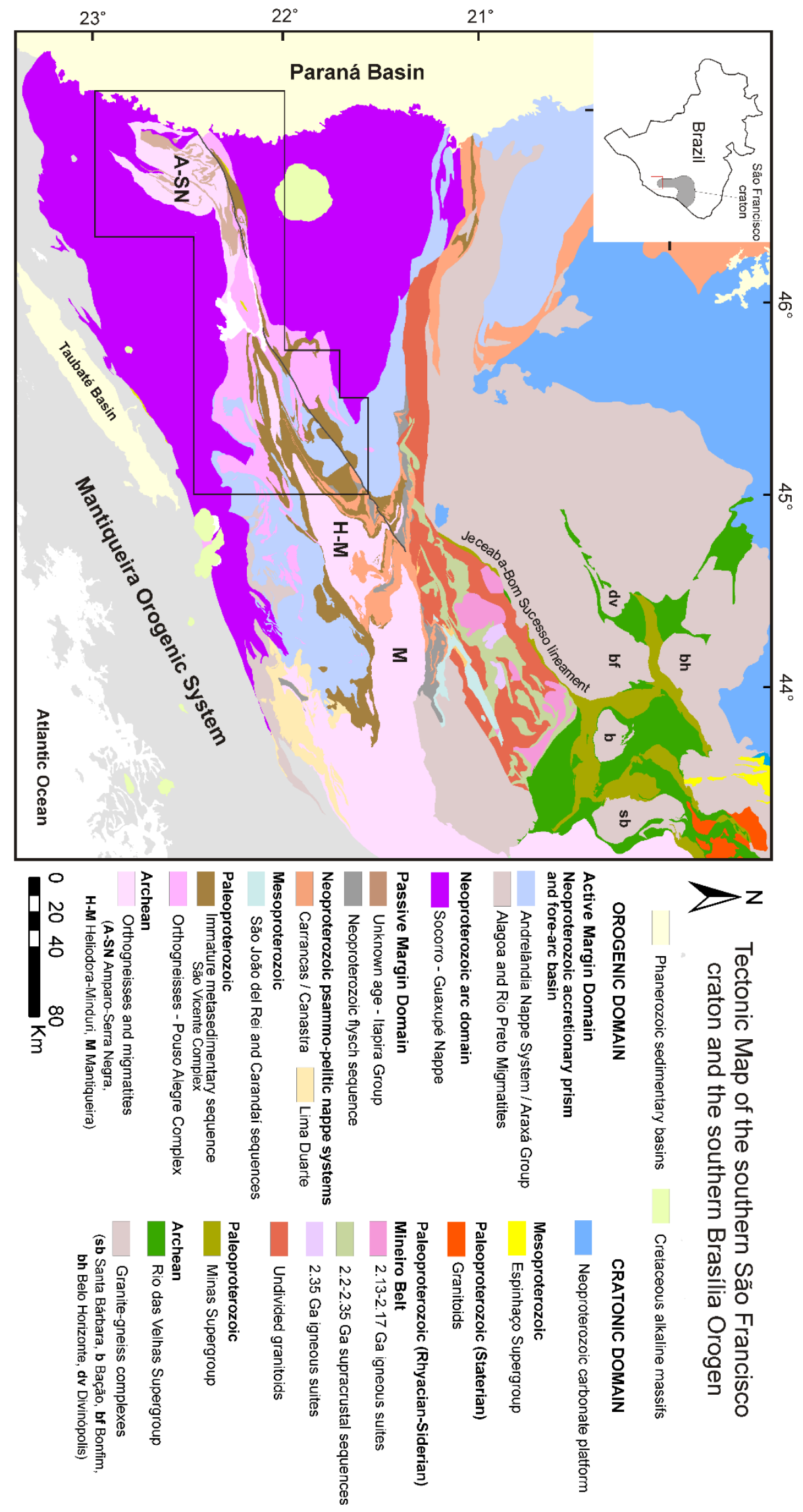

Figure 1. Tectonic map of the southern São Francisco craton and southern Brasilia Orogen with location of the studied area. 
Published data from the Archean complexes in the southern São Francisco craton show U-Pb zircon crystallization ages spanning from ca. 3.22 to $2.72 \mathrm{Ga}$ with a gap between ca. 3.20 and $2.93 \mathrm{Ga}$ (e.g. Lana et al., 2013; Farina et al., 2015). Previous data from the Archean complexes in the basement of the southern Brasília Orogen are very scarce but indicate igneous crystallization ages between 3.02 and 2.75 Ga with $\mathrm{T}_{\mathrm{DM}}$ ages from 3.3 to 3.0 Ga (Fetter et al., 2001; Tassinari and Nutman, 2001; Peternel, 2005; Santos, 2014). Tassinari and Nutman (2001) suggest reworking at ca. 2.0 Ga based on ion microprobe analyses of few zircon grains from a migmatite neosome. Despite of the very small dataset, these previous data suggest that the Archean complexes in the basement of the southern Brasilia Orogen are exotic to the São Francisco craton Archean crust, as they have crystallization ages within the São Francisco craton “magmatic gap”.

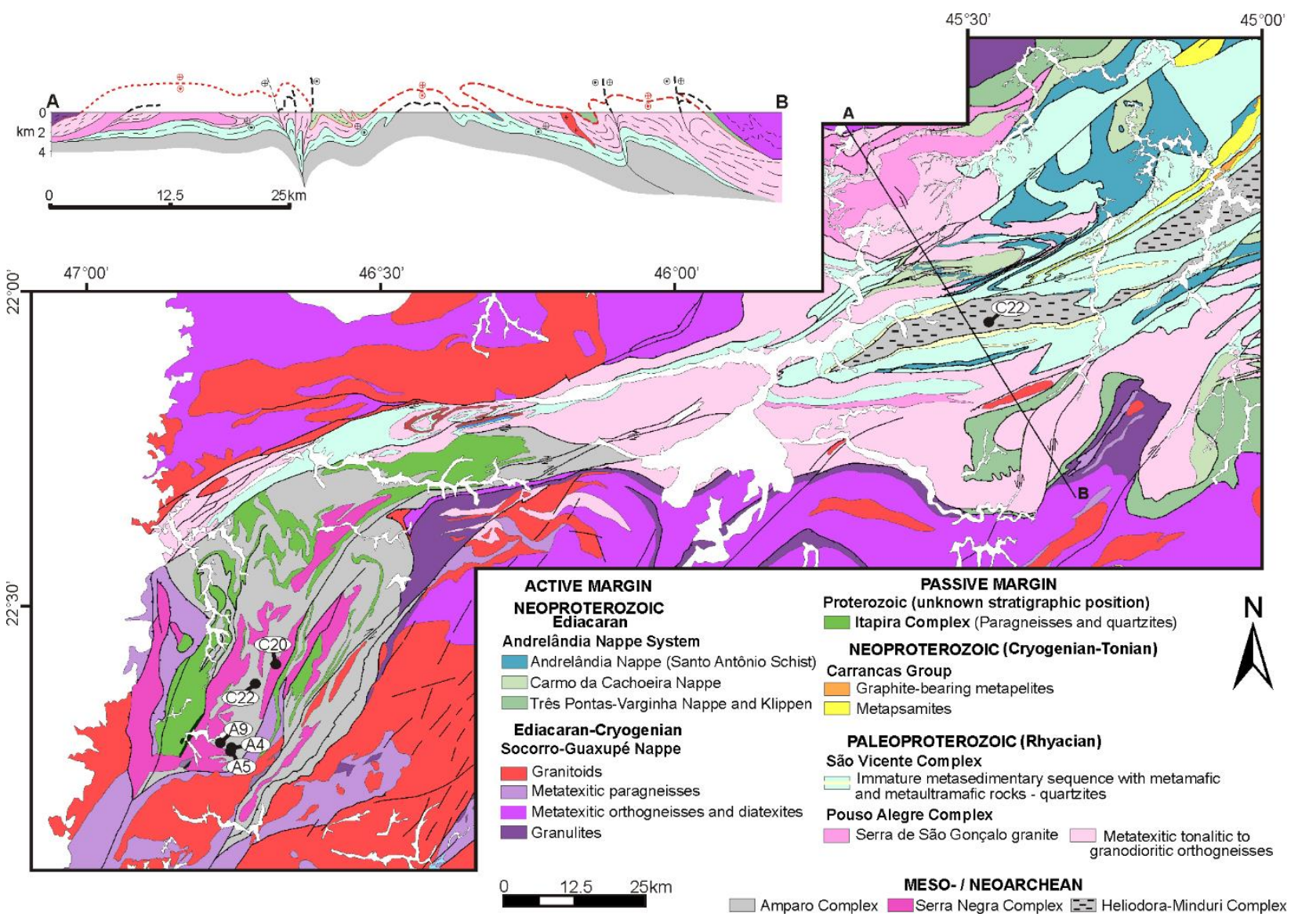

Figure 2. Geological map of the studied area (compiled and modified from Perrotta, 1991; Morais, 1999a, b; Peternel, 2005; Trouw et al., 2008; Cioffi et al., 2016) with location of the analyzed samples. Schematic crosssection from NW to SE is oriented along the line A-B. 


\section{Sample description}

Representative samples of three Archean complexes in the basement of the southern Brasilia Orogen (the Amparo, Serra Negra and Heliodora-Minduri complexes) were selected for analyses (Fig. 2) (Table S1). The Amparo Complex (Ebert, 1968) is located in the western part of the southern Brasília Orogen (Figs. 1 and 2) and mainly consists of layered migmatitic orthogneisses of tonalitic to granitic compositions with centimeter- to meter-scale amphibolite layers parallel to the main foliation (Fig. 3a). The Amparo Complex tonalitic rocks (samples A4, A9I, A9K) are medium-grained, dark-gray, migmatitic biotite-hornblende ortrhogneisses (Fig. 3b) with a color index of ca. 12-15\%. Peritectic hornblende crystals up to $2 \mathrm{~cm}$ length are common within tonalitic leucosomes (Fig. 3b). Common accessory minerals of tonalitic samples include chlorite, titanite, apatite, opaque minerals, zircon and allanite. Amparo Complex granodioritic rocks (samples A5, A9B) are fine- to medium-grained migmatitic biotite orthogneisses with a color index of ca. 5-7\%. Common accessory minerals of granodioritic samples are chlorite, titanite, apatite, allanite and zircon. Granitic rocks (sample C22) are pinkish-gray, fine- to medium-grained, migmatitic biotite orthogneisses with a color index of ca. 5\% (Fig. 3c). Common accessory minerals of granitic samples are: chlorite, allanite, opaque minerals, epidote, apatite and zircon.

The Serra Negra Complex occurs in the western portion of the southern Brasília Orogen in close association with the Amparo Complex (Fig. 2). The main lithotype is a homogeneous medium-grained, gray, biotite orthogneiss of granodioritic composition with a color index between 5-7\% (sample C20). Accessory minerals include titanite, apatite, allanite, amphibole, epidote, opaque minerals and zircon. The relationships between the Amparo and Serra Negra complexes are not well understood. However, because of the more complex deformation patterns observed in the Amparo Complex, the Serra Negra Complex has been considered intrusive into the Amparo Complex (Campos Neto et al., 2011). The Heliodora-Minduri Complex is located in the central and eastern portions of the southern Brasília Orogen (Figs. 1 and 2). The main lithotype is a light-gray, fine- to medium-grained, biotite orthogneiss of trondhjemitic composition, with a color index of ca. $5 \%$ (sample C37). Common accessory minerals are apatite, epidote and zircon. 

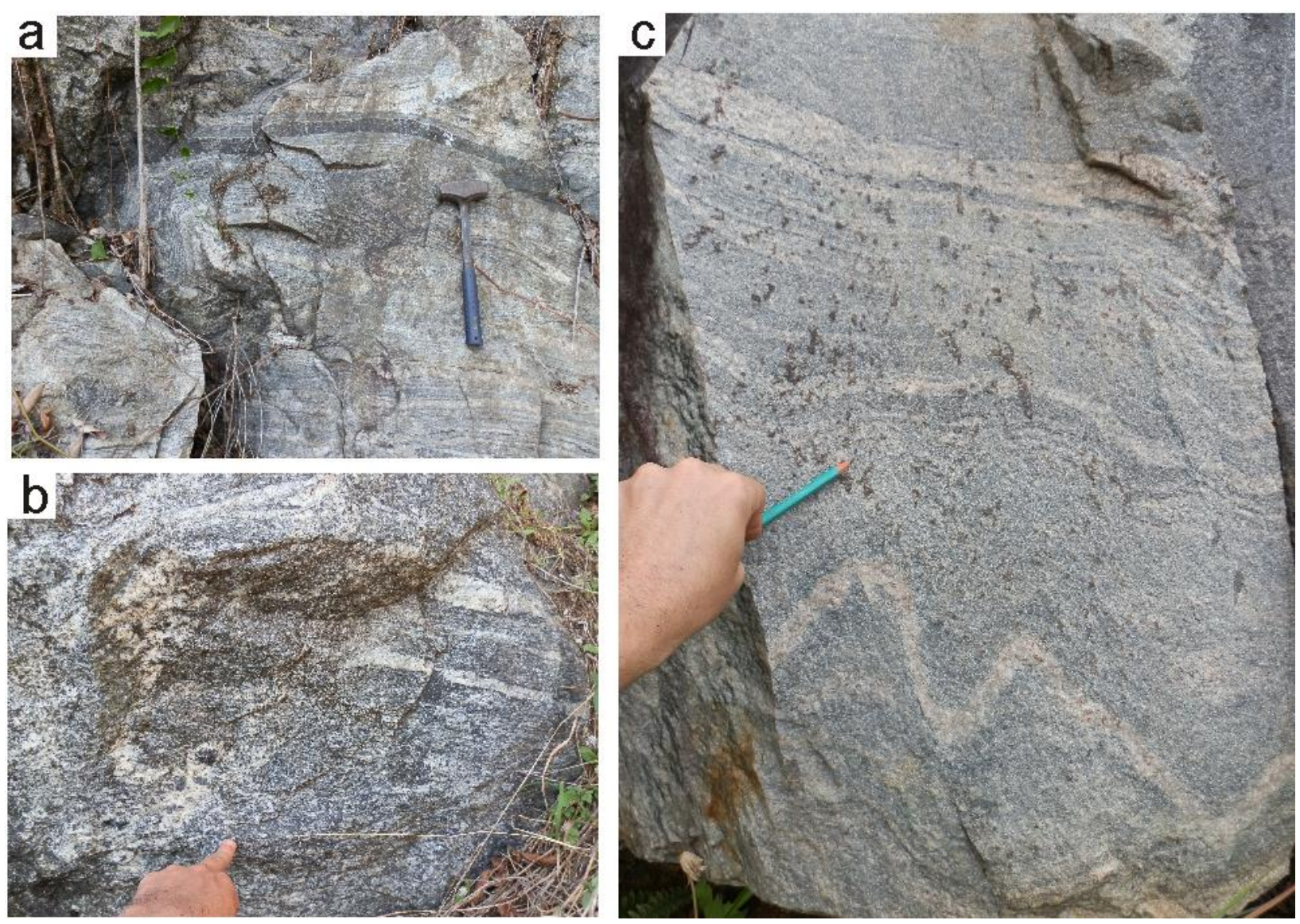

Figure 3. Field aspects of Amparo Complex rocks. (a) Layered migmatitic orthogneisses with $1-5 \mathrm{~cm}$ thick stromatic leucosomes and amphibolite layers parallel to the main foliation. Note the complex folding patterns visible on the left side of the photo. (b) Dark-gray biotite-hornblende migmatitic orthogneiss of tonalitic composition (sample A9I) with up to $2 \mathrm{~cm}$ large peritetic hornblende crystals within leucosomes. (c) Pinkish-gray migmatitic biotite orthogneiss of granitic composition.

\section{Analytical methods}

Samples were collected at the sites shown in Figure 2. A data summary including coordinates of sampling sites is presented in Table S1. For U-Pb analyses, zircon grains were extracted from crushed whole-rock samples using heavy-mineral separation techniques that include a disk mill, Wilfley table, Frantz $^{\mathrm{TM}}$ isodynamic magnetic separator and heavy liquids (bromoform and methylene iodide). Zircon grains were then handpicked, mounted in epoxy resin discs and polished to half width. Cathodoluminescence (CL) images of four samples (A9I, A9K, C20, C37) were obtained using a scanning electron microscope (SEM) at the Microscopy and Analytical Imaging Laboratory (MAI), The University of Kansas. CL images of sample C22 were acquired with a SEM at the Geochronological Research Center 
(CPGeo) of the Universidade de São Paulo. U-Pb analyses of all samples were obtained by laser ablation-inductively coupled plasma-mass spectrometry (LA-ICP-MS). Four samples (A9I, A9K, C20, C37) were analyzed at Department of Geology, The University of Kansas, using a Thermo Scientific Element2 ICP-MS attached to a Photon Machines Analyte.G2 $193 \mathrm{~nm}$ ArF excimer laser ablation system. The laser was used to ablate $20 \mu \mathrm{m}$ circular spots and was set to $2.2 \mathrm{~J} \mathrm{~cm}^{-2}$ fluency at a $10 \mathrm{~Hz}$ repetition rate. The ablated material was carried to the ICP in He gas. Elemental fractionation, downhole fractionation and calibration drift were corrected by bracketing measurements of unknowns with the GJ1 reference material (Jackson et al., 2004) and data reduction using the VizualAge data reduction scheme (Petrus and Kamber, 2011) for the IOLITE software package (Paton et al., 2011). The analyses were performed in two analytical sessions. During the first one (samples A9I, A9K, C37), the secondary standard Plešovice (Sláma et al., 2008) yielded a weighted mean ${ }^{206} \mathrm{~Pb} /{ }^{238} \mathrm{U}$ date of $336.1 \pm$ 1.0 Ma $(2 \sigma)(n=24 ; M S W D=0.96)$, in good agreement with the age determined by TIMS ( $337.13 \pm 0.37$ Ma; Sláma et al., 2008). During the second analytical session (sample C20) the secondary standard Plešovice yielded a weighted mean ${ }^{206} \mathrm{~Pb} / 238 \mathrm{U}$ date of $342.1 \pm 2.4 \mathrm{Ma}(2 \sigma)(\mathrm{n}=11 ; \mathrm{MSWD}=2.9)$. Sample C22 was analyzed at CPGeo-USP using a Thermo Scientific Neptune multi-collector ICP-MS attached to a Photon Machines Analyte.193 nm ArF laser ablation system. The laser was used to ablate $32 \mu \mathrm{m}$ circular spots at a repetition rate of $6 \mathrm{~Hz}$, and $\mathrm{He}$ was used as the carrier gas. The GJ1 reference material was used as the primary standard, and corrections were made using an in-house spreadsheet. The data from this sample were corrected for common lead based on ${ }^{204} \mathrm{~Pb}$ and the model of Stacey and Kramers (1975). Concordia plots and weighted mean U-Pb dates were derived using Isoplot (Ludwig, 2003). The $\mathrm{U}-\mathrm{Pb}$ data is shown in Online Supplementary Table S2.

Zircon Lu-Hf analyses were performed on four samples (A9K, C20, C22, C37). The analyses were carried out at the CPGeo-USP using a Neptune multi-collector ICP-MS attached to a Photon Machines Analyte.193 nm ArF laser ablation system. The laser was used to ablate $47 \mu \mathrm{m}$ circular spots that were placed on the same internal domains dated by U-Pb technique. The isotopes ${ }^{172} \mathrm{Yb},{ }^{173} \mathrm{Yb},{ }^{175} \mathrm{Lu},{ }^{177} \mathrm{Hf}$, ${ }^{178} \mathrm{Hf},{ }^{179} \mathrm{Hf},{ }^{180} \mathrm{Hf}$ and ${ }^{176}(\mathrm{Hf}+\mathrm{Yb}+\mathrm{Lu})$ were collected simultaneously. ${ }^{176} \mathrm{Hf} /{ }^{177} \mathrm{Hf}$ ratios were normalized to ${ }^{179} \mathrm{Hf} /{ }^{177} \mathrm{Hf}=0.7325$. The calculation of ${ }^{176} \mathrm{Lu} /{ }^{177} \mathrm{Hf}$ was based on the ${ }^{176} \mathrm{Lu} /{ }^{175} \mathrm{Lu}$ ratio of 0.02669 . Mass bias corrections of Lu-Hf isotopic ratios were conducted by applying the variations of the GJ1 standard. The calculations of $\varepsilon \mathrm{Hf}$ values were conducted based on the ${ }^{176} \mathrm{Lu}$ decay constant of $1.867 \mathrm{x}$ $10^{-11} \mathrm{a}^{-1}$ (Söderlund et al., 2004) and the present-day chondritic ratios of ${ }^{176} \mathrm{Hf} /{ }^{177} \mathrm{Hf}=0.282772$ and ${ }^{176} \mathrm{Lu} /{ }^{177} \mathrm{Hf}=0.0332$ (Blichert-Toft and Albarède, 1997). The present-day depleted mantle ratios of ${ }^{176} \mathrm{Hf} /{ }^{177} \mathrm{Hf}=0.283225$ and ${ }^{176} \mathrm{Lu} /{ }^{177} \mathrm{Hf}=0.038512$ (Vervoort and Blichert-Toft, 1999) were adopted. The results of the Lu-Hf analyses are shown in Online Supplementary Table S3.

For whole-rock geochemical analyses, unweathered samples were crushed in a steel-jaw crusher and then ground to powder with an agate mill. Major element compositions of eight whole- 
rock samples were determined by $\mathrm{x}$-ray fluorescence (XRF) spectrometry after lithium metaborate/tetraborate fusion. Four analyses (A9I, A9K, C20, C22) were carried out the Geoanalitica Core Research Center, Universidade de São Paulo, following the protocol described in Mori et al. (1999) and four samples (A4, A5, A9B, C37) were analyzed at the ACME Analytical Laboratories, Vancouver. For trace element analyses the powdered samples were dissolved by acid $\left(\mathrm{HF}+\mathrm{HNO}_{3}\right)$ in Parr bombs for five days. Trace element concentrations of seven samples were acquired by inductively coupled plasma mass spectrometry (ICP-MS) using a Perkin Elmer Plasma Quadrupole MS Elan 6100DRC at the Geoanalitica Core Research Center, Universidade de São Paulo (see Navarro et al., 2002, 2008 for further details). The results of whole-rock geochemical analyses are shown Online Supplementary Table S4.

Five whole-rock samples were selected for $\mathrm{Nd}$ isotopic analyses. The $\mathrm{Nd}$ isotopic compositions of four samples (A9I, A9K, C20, C22) were determined using a Neptune multi-collector ICP-MS at the Geochronological Research Center (CPGeo) of the Universidade de São Paulo. The powdered samples were dissolved in acid and the elements of interest were separated in ion exchange columns following the protocol described in Sato et al. (1995). During the period of analyses, the JNdi standard (Geological Survey of Japan; Tanaka et al., $2000 ;{ }^{143} \mathrm{Nd} /{ }^{144} \mathrm{Nd}=0.512115 \pm 0.000007$ ) yielded an average ${ }^{143} \mathrm{Nd} /{ }^{144} \mathrm{Nd}$ value of $0.512097 \pm 0.000005(1 \sigma)$. One sample (C37) was analyzed by thermal ionization mass spectrometry using a Finnigan MAT 262 at the Geochronological Laboratory of the Universidade de Brasília, following the protocol described by Gioia and Pimentel (2000). Uncertainties for ${ }^{143} \mathrm{Nd} /{ }^{144} \mathrm{Nd}$ are assumed to be better than $\pm 0.005 \%$ based on repeated analyses of the USGS standards BHVO-1 and BCR-1. The Nd isotopic ratios of all analyzed samples were normalized to a ${ }^{146} \mathrm{Nd} /{ }^{144} \mathrm{Nd}$ ratio of 0.7219 . The ${ }^{147} \mathrm{Sm} /{ }^{144} \mathrm{Nd}$ ratios were calculated from the concentrations determined by ICPMS. The results of the Nd isotopic analyses are shown in Online Supplementary Table S5.

\section{Whole-rock geochemistry}

Regarding major element concentrations, tonalitic samples from the Amparo Complex have the lowest $\mathrm{SiO}_{2}$ contents among the analyzed samples, ranging from 63 to $68 \mathrm{wt} \%$ (Fig. 4). The granodioritic samples from the Amparo and Serra Negra complexes and the trondhjemitic sample from the Heliodora-Minduri Complex have $\mathrm{SiO}_{2}$ contents that are intermediate between the tonalitic and granitic samples, ranging from 70 to $73 \mathrm{wt} \%$. The Amparo Complex granitic sample shows the highest $\mathrm{SiO}_{2}$ concentration of $74 \mathrm{wt} \%$. There is a well-defined negative correlation between increasing $\mathrm{SiO}_{2}$ and $\mathrm{CaO}, \mathrm{MgO}, \mathrm{FeO}_{\mathrm{t}}, \mathrm{TiO}_{2}$ contents (Fig. 4). In general, $\mathrm{Na}_{2} \mathrm{O}$ and $\mathrm{K}_{2} \mathrm{O}$ contents show no variation with increasing $\mathrm{SiO}_{2}$. The exception is the granitic sample from the Amparo Complex that show a considerably higher $\mathrm{K}_{2} \mathrm{O}$ concentration, outside the main trend (Fig. 4). 


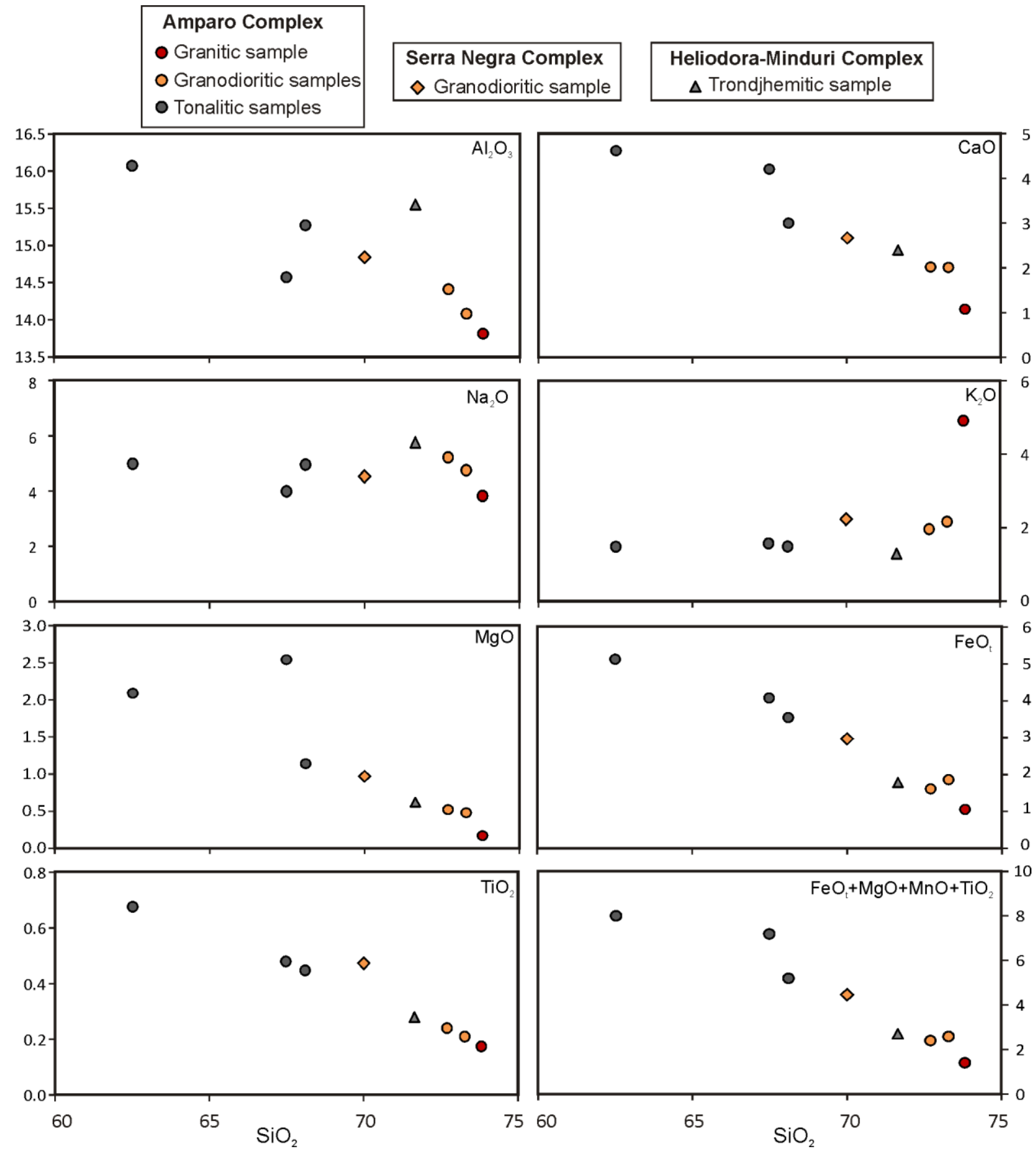

Figure 4. Harker-type diagrams ( $\mathrm{SiO}_{2}$ vs. major elements) for the analyzed samples.

According to the $\mathrm{Na}_{2} \mathrm{O}+\mathrm{K}_{2} \mathrm{O}-\mathrm{CaO}$ (MALI) vs. $\mathrm{SiO}_{2}$ diagram proposed by Frost et al. (2001), with the exception of the granitic sample from the Amparo Complex, samples are calcic to calc-alkalic and plot within the TTG field of Laurent et al. (2014) (Fig. 5a). The Amparo Complex granitic sample is classified as alkali-calcic and plots within the biotite granites field (Fig. $5 \mathrm{a}$ ). On the $\mathrm{A} / \mathrm{CNK}$ vs. $\mathrm{K}_{2} \mathrm{O} / \mathrm{Na}_{2} \mathrm{O}$ 
diagram (Fig. 5b), the Amparo Complex granitic sample falls in the biotite granites field with a $\mathrm{K}_{2} \mathrm{O} / \mathrm{Na}_{2} \mathrm{O}$ ratio of 1.3. All other samples plot within the TTG field with $\mathrm{K}_{2} \mathrm{O} / \mathrm{Na}_{2} \mathrm{O}$ ratios between 0.2 and 0.5. On the normative Ab-An-Or triangle (O'Connor, 1965) (Fig. 5c) all samples fall in the TTG field of Moyen and Martin (2012), with the exception of the Amparo Complex granitic sample. Figure $5 \mathrm{~d}$ is the recently proposed ternary diagram for classification of late-Archean granitoids of Laurent et al., (2014). In this diagram, the Amparo Complex granitic sample falls in the biotite-, two-mica granites field and all the other samples plot in the TTG field.
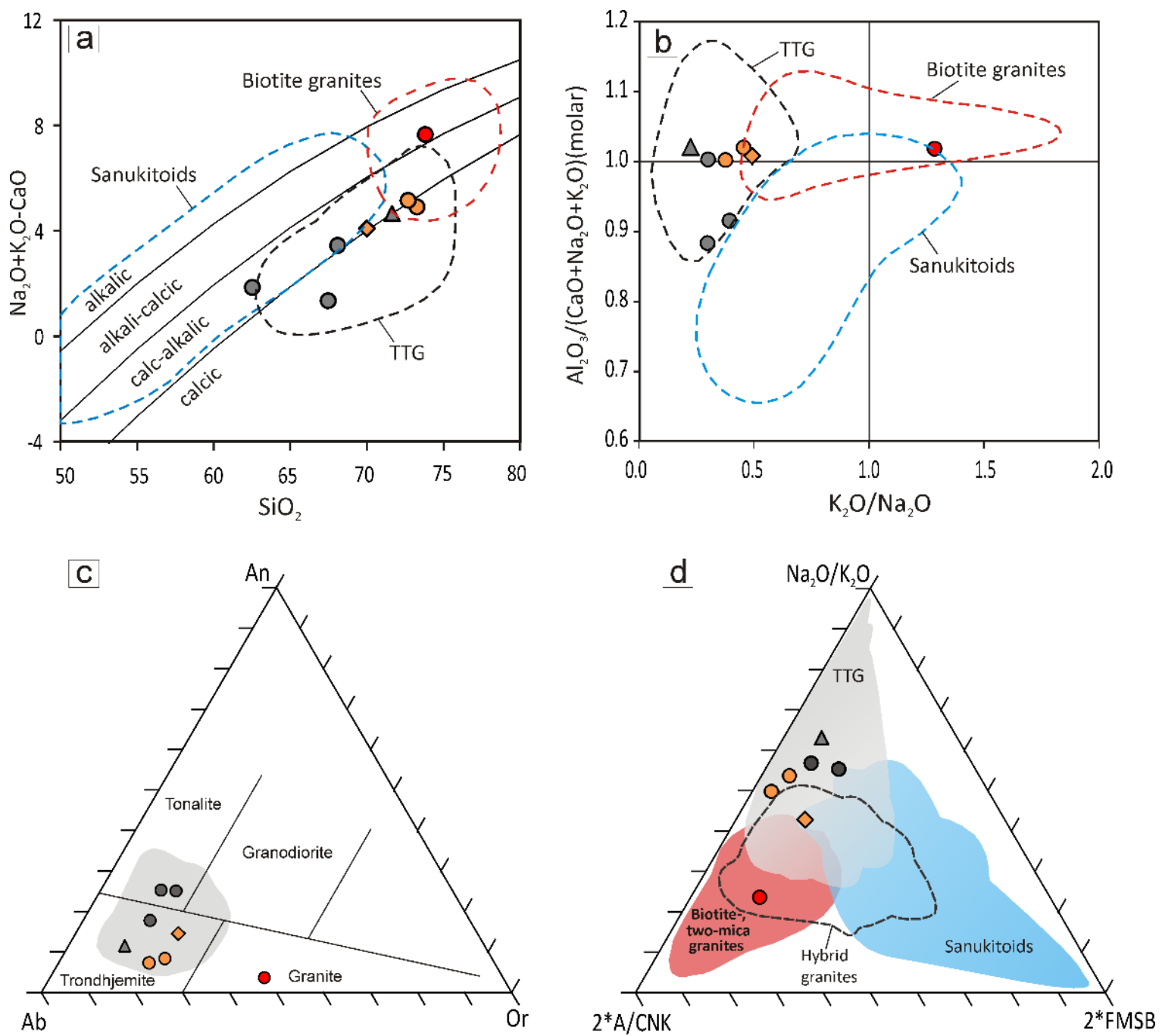

Figure 5. (a) $\mathrm{Na}_{2} \mathrm{O}+\mathrm{K}_{2} \mathrm{O}-\mathrm{CaO}$ (MALI) vs. $\mathrm{SiO}_{2}$ diagram proposed by Frost et al. (2001) with the TTG, sanukitoids and biotite granites fields from Laurent et al. (2014), (b) $\mathrm{Al}_{2} \mathrm{O}_{3} /\left(\mathrm{CaO}+\mathrm{Na}_{2} \mathrm{O}+\mathrm{K}_{2} \mathrm{O}\right.$ ) (molar) vs. $\mathrm{K}_{2} \mathrm{O} / \mathrm{Na} 2 \mathrm{O}$ diagram with TTG, sanukitoids and biotite granites fields from Laurent et al. (2014), (c) Normative Ab-An-Or triangle (O'Connor, 1965) with the TTG field of Moyen and Martin (2012), (d) Ternary classification diagram for late-Archean granitoids proposed by Laurent et al., (2014): 2 x A/CNK (molar $\left.\mathrm{Al}_{2} \mathrm{O}_{3} / \mathrm{CaO}+\mathrm{Na}_{2} \mathrm{O}+\mathrm{K}_{2} \mathrm{O}\right) ; 2$ x ( $\mathrm{FeO}_{\mathrm{t}}+\mathrm{MgO}$ ) wt\% $\mathrm{x}$ $(\mathrm{S} r+\mathrm{Ba}) \mathrm{wt} \%(=\mathrm{FSMB})$. 

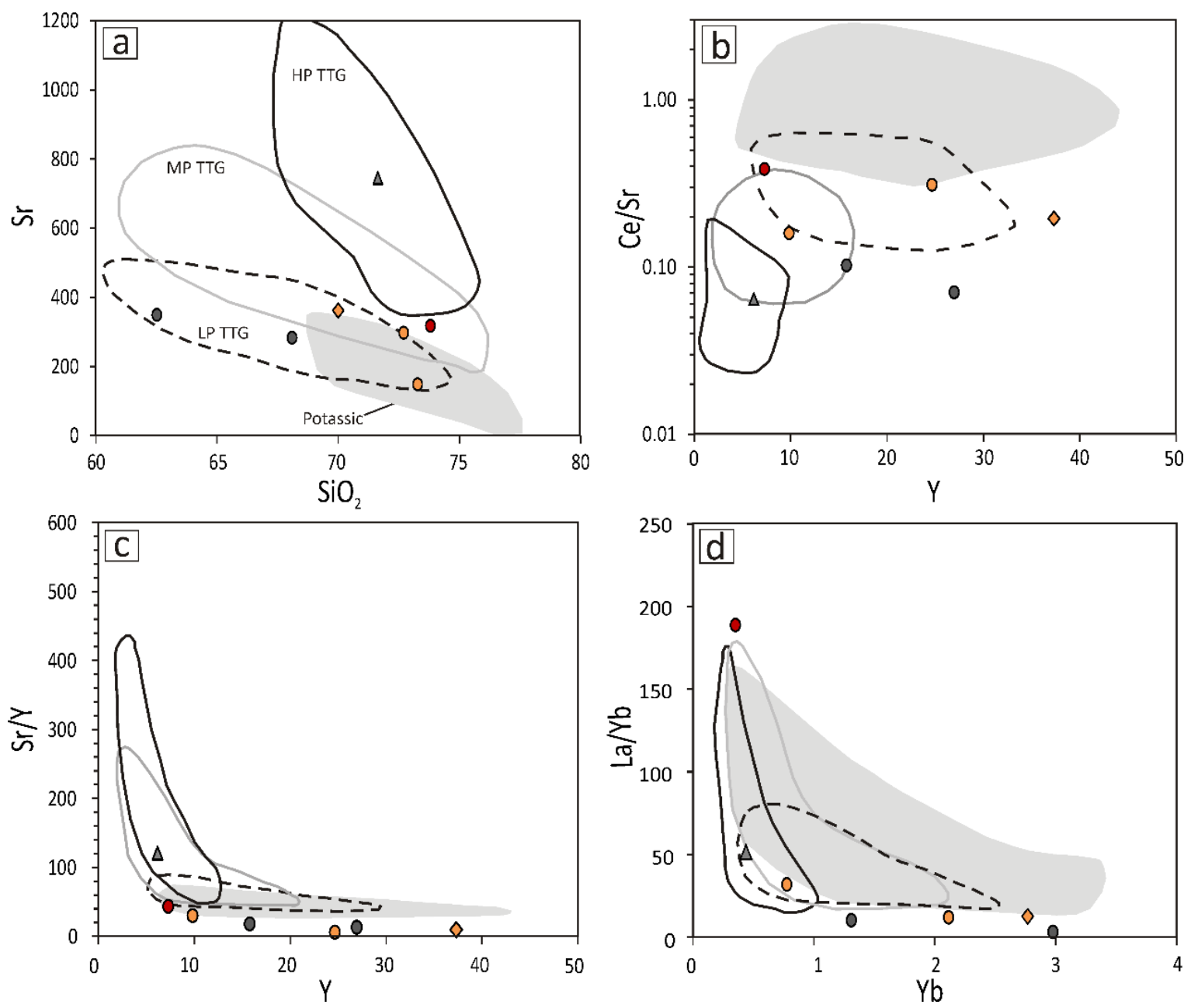

Figure 6. Binary trace element diagrams with fields of the three TTG groups and the potassic group of Moyen (2011): high-pressure TTG group (HP TTG); medium-pressure TTG group (MP TTG); low-pressure TTG group (LP TTG). (a) Sr vs. $\mathrm{SiO}_{2}$, (b) Ce / Sr vs. Y, (c) Sr / Y vs. Y; La / Yb vs. Yb.

Figure 6 shows binary trace element diagrams with fields of the three different TTG groups and the potassic group from Moyen (2011). Because of the low Sr concentrations and high $Y$ and $\mathrm{Yb}$ contents the Amparo Complex tonalitic and granodioritic samples and the Serra Negra granodioritic sample plot within or close to the low-pressure TTG fields. The Heliodora Complex trondhjemitic sample has a high $\mathrm{Sr}$ concentration and low $\mathrm{Y}$ and $\mathrm{Yb}$ contents and thus falls in the high-pressure TTG fields. The Amparo Complex granitic sample has low $\mathrm{Sr}, \mathrm{Y}$ and $\mathrm{Yb}$ concentrations and high La/Yb ratio and tends to plot close to the potassic field. 

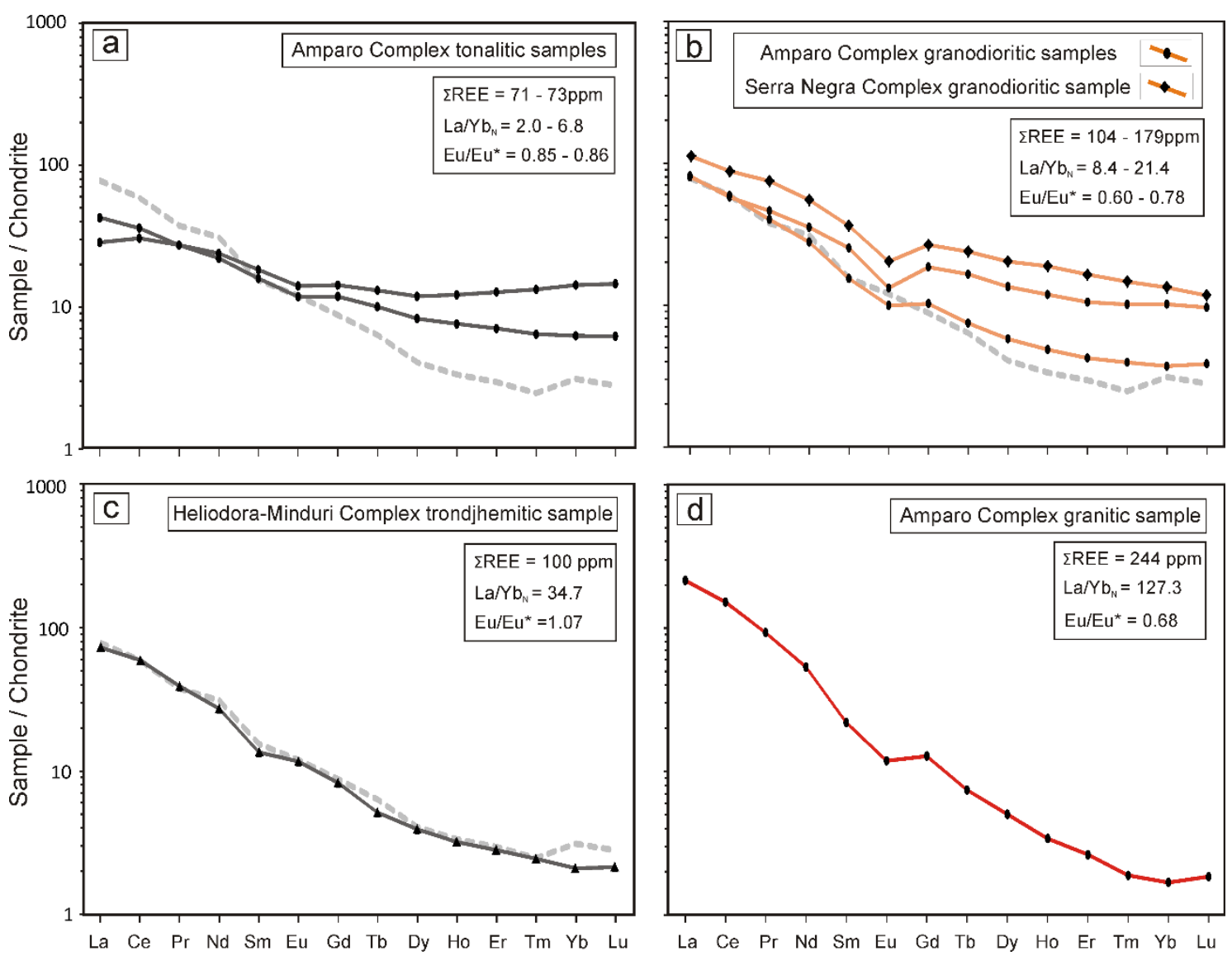

Figure 7. Chondrite normalized rare earth element (REE) diagrams. Chondrite values from Boynton (1983). The gray dotted line represents the average TTG composition of the Limpopo Belt and Pietersburg Block from Laurent et al. (2014). (a) Amparo Complex tonalitic samples, (b) Amparo and Serra Negra complexes granodioritic samples, (c) Heliodora-Minduri Complex trondhjemitic sample, (d) Amparo Complex granitic sample.

Regarding rare earth element (REE) concentrations, the Amparo Complex tonalitic samples have the lowest light rare earth element (LREE) concentrations and $\mathrm{La} / \mathrm{Yb}_{\mathrm{N}}$ ratios among the analyzed samples (Fig. 7a). The heavy rare earth element (HREE) concentrations of these samples are considerably higher than the average TTG from the Pietersburg block and central Limpopo Belt from Laurent et al. (2014) (Fig. 7a). The Amparo and Serra Negra complexes granodioritic samples (Fig. 7b) have LREE concentrations that are similar or a little higher than the average TTG of Laurent et al. (2014). These samples are different from the average TTG because their higher HREE contents and moderate negative Eu anomalies. The Heliodora Complex trondjhemitic sample has a strongly fractionated REE pattern with slightly positive Eu anomaly that is very similar to the average TTG of Laurent et al. (2014) (Fig 7c). The Amparo Complex granitic sample is characterized by the highest total REE element concentration and $\mathrm{La} / \mathrm{Yb}_{\mathrm{N}}$ ratio, associated with a moderately negative Eu anomaly (Fig. 7d). 


\section{Zircon U-Pb Geochronology}

\subsection{Sample A9I (tonalitic migmatite) (Amparo Complex)}

Sample A9I is a medium-grained, dark-gray migmatitic biotite-hornblende orthogneiss of tonalitic composition (Fig. 3b). Based on external morphologies, two distinct zircon populations are recognized. The first comprises euhedral to subhedral, 100-150 $\mu \mathrm{m}$ long stubby grains, with aspect ratios of 1.5:1 to 2:1. The second population consists of elongated grains with aspect ratios of ca. 4:1. Both populations display well-defined oscillatory zoned cores and narrow $(5-20 \mu \mathrm{m})$ bright rims visible in $\mathrm{CL}$ images. Some stubby grains also show sector zoning (Fig. 8a). The Th/U ratios vary from 0.14 to 0.73 and no correlation between morphological populations and $\mathrm{Th} / \mathrm{U}$ ratios and dates are recognized. Seventy spots were analyzed and excluding four analyses that show a common lead component, the remaining sixty-six spots define a discordia line with an upper intercept at 3002.4 $\pm 9.7 \mathrm{Ma}$ (MSWD = 1.2) (Fig. 9a). This date is interpreted as the crystallization age of the igneous protolith.

\subsection{Sample A9K (tonalitic migmatite) (Amparo Complex)}

Sample A9K is a fine- to medium-grained gray migmatitic biotite orthogneiss with a small amount of hornblende (ca. 2-3 vol. \%). Two distinct morphological zircon populations are recognized. One comprises ca. 100-175 $\mu \mathrm{m}$ long, oval grains with aspect ratios of approximately 1.5:1 and the other is constituted by ca. $175-200 \mu \mathrm{m}$ long grains with aspect ratios of approximately $2.5: 1$ to $3: 1$. Both populations show well-defined oscillatory zoning and narrow $(1-10 \mu \mathrm{m})$ bright rims in CL images (Fig. 8b). In general, Th/U ratios vary from 0.21 to 0.66 and just two discordant spots yield lower values of 0.06 and 0.11 . No correlation between distinct morphological populations and $\mathrm{Th} / \mathrm{U}$ ratios and dates is observed. Excluding just one spot, that show a different lead-loss trend, the remaining fifty-nine spots fall on a discordia line with an upper intercept at 3000.9 $\pm 8.7 \mathrm{Ma}$ (MSWD=1.05) (Fig. 9b) that is interpreted as the igneous crystallization age of the protolith. 


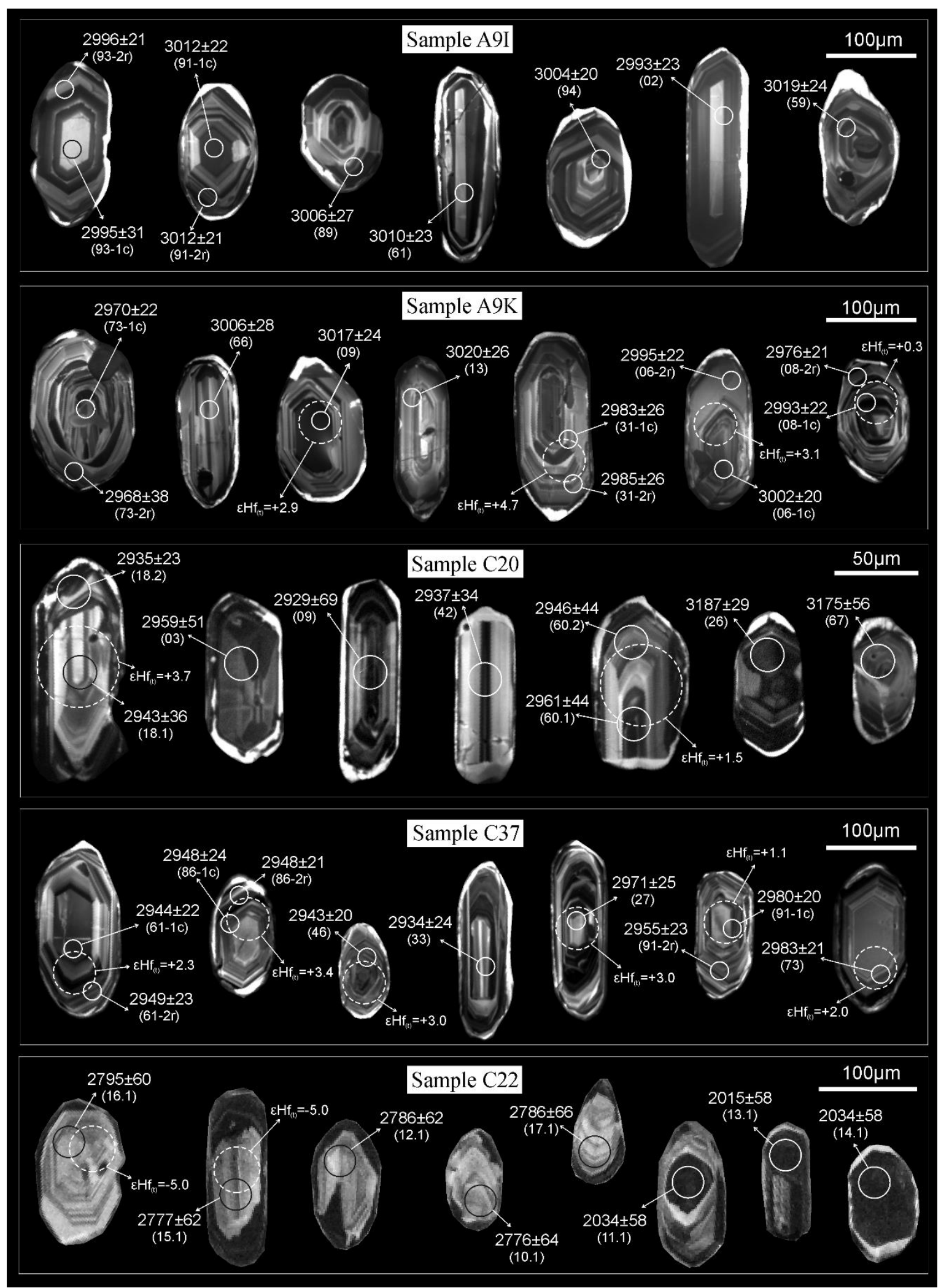

Figure 8. Representative cathodoluminescence $(C L)$ images of zircon grains with analyzed spots indicated by open circles (grain numbers within parenthesis). U-Pb results are shown as ${ }^{207} \mathrm{~Pb} /{ }^{206} \mathrm{~Pb}$ dates, with $2 \sigma$ errors. Lu-Hf analyses spots are indicated by dashed circles. 


\subsection{Sample C20 (granodioritic orthogneiss) (Serra Negra Complex)}

Sample C20 is a medium-grained biotite orthogneiss of granodioritic composition. Two distinct morphological populations are recognized. The first is constituted by ca. 100-150 $\mu \mathrm{m}$ long grains with aspect ratios of ca. 2:1 to 3:1 and the second comprises ca. 75 to $100 \mu \mathrm{m}$ long, stubby grains with aspect ratios of ca. 1.5:1 to 2:1. Both populations display oscillatory and/or sector zoned cores and narrow $(5-10 \mu \mathrm{m}$ ) bright rims in $\mathrm{CL}$ images (Fig. 8c). In general, the Th/U ratios of the first population vary from 0.11 to 0.95 with just two spots yielding lower values. The U-Pb analyses of grains from the first population show a large spread towards a Neoproterozoic date (lead-loss or mixing of age components) and forty-two analyzed spots define a discordia line with an upper intercept at $2962 \pm 11$ $\mathrm{Ma}$ and a lower intercept at $613 \pm 13 \mathrm{Ma}$ (MSWD=1.02) (Fig. 9c). The upper intercept is interpreted as the crystallization age of the igneous protolith and the lower intercept as the age of metamorphism. The five grains of the second population have Th/ $U$ ratios between 0.33 and 0.56 and yield older ${ }^{207} \mathrm{~Pb} /{ }^{206} \mathrm{~Pb}$ dates with a weighted mean of $3190 \pm 14 \mathrm{Ma}$ (MSWD=0.36; $\mathrm{n}=5$ ) (Fig. 9c), interpreted as inheritance.

\subsection{Sample C37 (trondhjemitic orthogneiss) (Heliodora Complex)}

Sample C37 is a fine- to medium-grained leucocratic biotite orthogneiss of trondhjemitic composition. External morphology divides the zircon grains into two main populations, one made of ca. 100-200 $\mu \mathrm{m}$ long oval grains with aspect ratios of ca. 2:1 and the other of elongate ca. 150-200 $\mu \mathrm{m}$ long grains with aspect ratios of 3:1 to 4:1. In CL images both populations show oscillatory zoned cores and narrow $(<5 \mu \mathrm{m})$ bright rims (Fig. $8 \mathrm{~d}$ ). No correlation between morphological populations and dates and $\mathrm{Th} / \mathrm{U}$ ratios is observed. Th/U ratios vary, in general, from 0.06 to 0.68 with just one discordant spot yielding a lower value of 0.02 . Seventy-three zircon spots were analyzed. Excluding nine spots that have a common-lead component or a different trend of lead-loss, the remaining sixty-four analyses define a discordia line with upper intercept at $2957 \pm 14$ Ma (MSWD=1.2) (Fig. 9d). This date is interpreted as the crystallization age of the igneous protolith.

\subsection{Sample C22 (granitic migmatite) (Amparo Complex)}

Sample C22 is a fine- to medium-grained pinkish-gray migmatitic biotite-chlorite orthogneiss of granitic composition (Fig. 3c). Zircon grains from this sample are subhedral ca. 100-175 $\mu \mathrm{m}$ long with aspect ratios from ca. 2:1 to 3:1. Most of the grains have oscillatory-zoned CL-bright cores and CL-dark rims (Fig. 8e). The least discordant analyses on these bright cores yield a weighted mean ${ }^{207} \mathrm{~Pb} /{ }^{206} \mathrm{~Pb}$ date of $2759 \pm 13 \mathrm{Ma}(\mathrm{n}=21 ; \mathrm{MSWD}=1.16)$ (Fig. 10). One spot on a CL-dark rim and two spots on CL- 
dark cores yield Paleoproterozoic dates with a weighted mean ${ }^{207} \mathrm{~Pb} /{ }^{206} \mathrm{~Pb}$ date of $2028 \pm 33 \mathrm{Ma}(\mathrm{n}=3$; MSWD=0.15) (Figs. 8e and 10). The Th/U ratios of the Paleoproterozoic domains (Th/U $=0.11-0.14$ ) are lower than those from the $\mathrm{CL}-$ bright Archean domains $(\mathrm{Th} / \mathrm{U}=0.43-1.37)$. The Archean date is interpreted as the crystallization age of the granitic igneous protolith. The dataset from the Paleoproterozoic zircon domains is very small. However, the relatively low discordance of these analyses associated with different internal textures and $T h / U$ ratios than those from Archean domains could suggest reworking around ca. $2.0 \mathrm{Ga}$. Few analyses spread between the two populations and can be the result of either lead-loss or mixing of different domains.
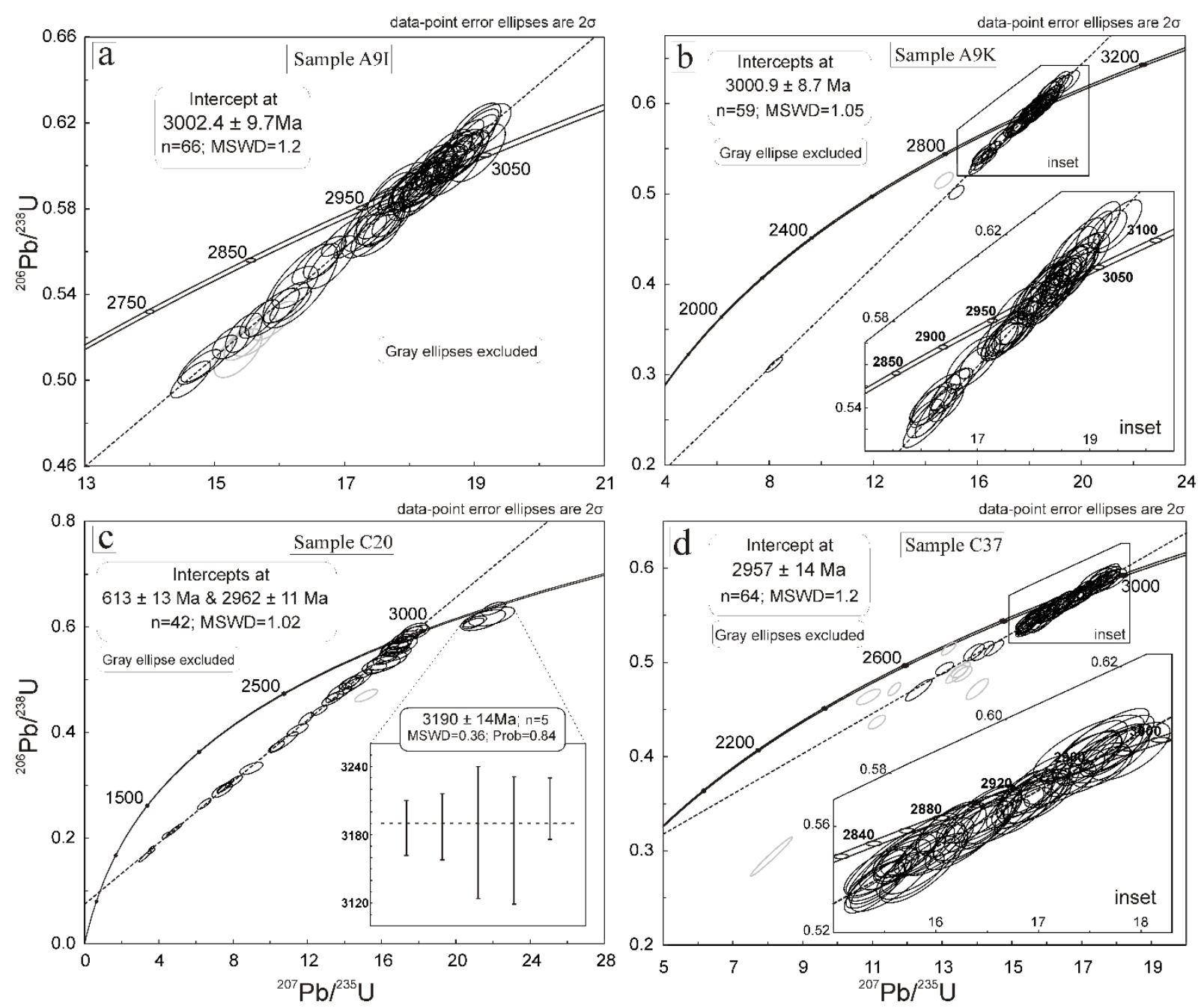

Figure 9. Concordia diagrams for zircon U-Pb LA-ICP-MS analyses. Error ellipses are $2 \sigma$. Intercepts are quoted at 95\% confidence level. (a) Sample A9l (Amparo Complex) - Upper intercept at 3002.4 $\pm 9.7 \mathrm{Ma}(\mathrm{n}=66$; MSWD = 1.2), (b) Sample A9K (Amparo Complex) - Upper intercept at 3000.9 $\pm 8.7 \mathrm{Ma}(\mathrm{n}=59 ; \mathrm{MSWD}=1.05)$, (c) Sample C20 (Serra Negra Complex) - Intercepts at $613 \pm 13 \mathrm{Ma}$ and $2962 \pm 11 \mathrm{Ma}(\mathrm{n}=42 ; \mathrm{MSWD}=1.02$ ), (d) Sample C37 (Heliodora-Minduri Complex) - Upper intercept at $2957 \pm 14 \mathrm{Ma}(\mathrm{n}=64 ;$ MSWD $=1.2$ ). 


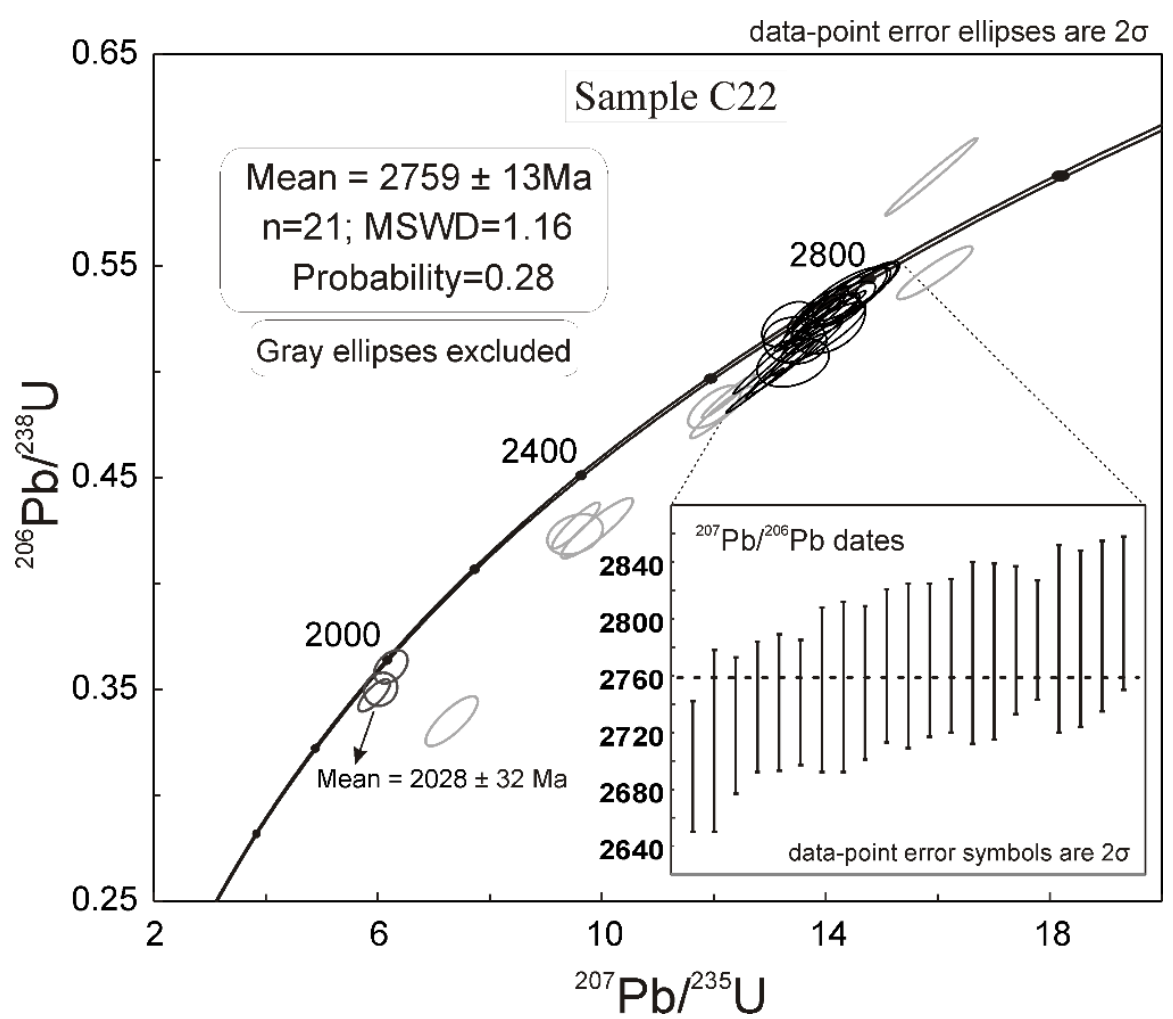

Figure 10. Concordia diagram for zircon U-Pb LA-ICP-MS analyses of sample C22 (Amparo Complex). Error ellipses are $2 \sigma$. The main zircon population yields a weighted mean ${ }^{207} \mathrm{~Pb} /{ }^{206} \mathrm{~Pb}$ date of $2759 \pm 13 \mathrm{Ma}(\mathrm{n}=21 ; \mathrm{MSWD}=$ 1.16; Probability $=0.28$ ). Three slightly discordant grains yield a weighted mean ${ }^{207} \mathrm{~Pb} /{ }^{206} \mathrm{~Pb}$ date of $2028 \pm 33 \mathrm{Ma}$ $(n=3 ; M S W D=0.15)$.

\section{Zircon $\mathrm{Hf}$ and whole-rock $\mathrm{Nd}$ isotopes}

Zircon Lu-Hf analyses were carried out in four samples (A9K, C20, C22, C37) (Fig. 11). Three of these samples are Mesoarchean orthogneisses with TTG affinities from the Amparo, Serra Negra and Heliodora-Minduri complexes (samples A9K, C20 and C37). These samples have igneous protolith crystallization ages between ca. 2.96 and $3.00 \mathrm{Ga}$ (Fig. 9) and their zircon grains yield $\varepsilon \mathrm{Hf}_{(\mathrm{t})}$ values that are slightly negative to moderate positive ranging between -0.4 and +4.7 (Fig. 11). Two-stage model ages $\left(T_{D M}{ }^{C}\right)$, projected back from zircon crystallization ages assuming a mean crustal value for ${ }^{176} \mathrm{Lu} /{ }^{177} \mathrm{Hf}=0.015$ (e.g., Griffin et al., 2002), are between 3.0 to $3.3 \mathrm{Ga}$. Inherited zircon grains from the Serra Negra Complex sample (C20) that yield U-Pb dates of ca. $3.19 \mathrm{Ga}$ (Fig. 9c) have positive $\varepsilon_{\mathrm{Hf}}(\mathrm{t})$ values between +3.4 and +4.0 (Fig. 11). The Amparo Complex granitic sample (C22) yields a Neoarchean igneous protolith crystallization age of ca. $2.76 \mathrm{Ga}$ (Fig. 10). The analyzed zircon grains from this sample have a large spread of $\varepsilon \mathrm{Hf}_{(t)}$ values, but most of the grains yield negative values between -0.6 to -7.1 with just one spot yielding a positive value of +2.3 (Fig. 11). 


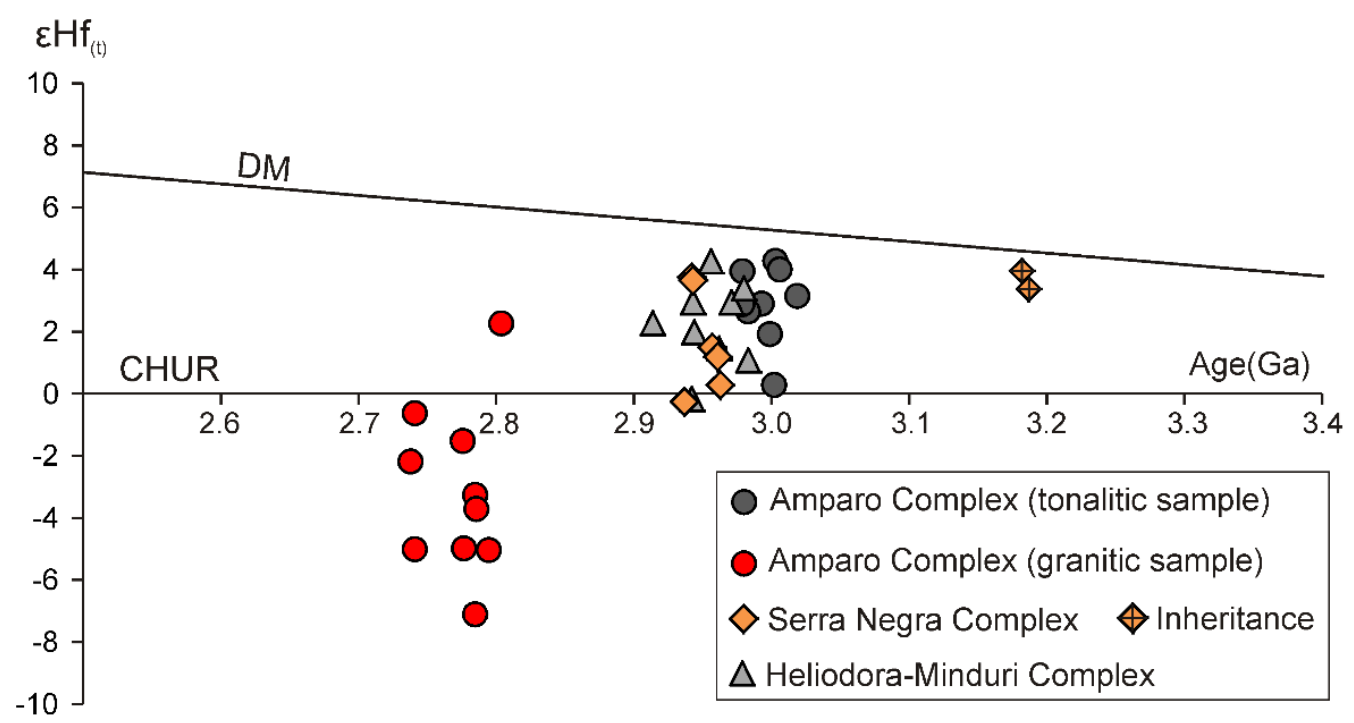

Figure 11. $\varepsilon \mathrm{Hf}_{(\mathrm{t})}$ versus age diagram for all analyzed samples, plotted at the corresponding $\mathrm{U}-\mathrm{Pb}$ ages of each analyzed spot. Depleted mantle line calculated for the model proposed by Vervoort and Blichert-Toft (1999).

Whole-rock Sm-Nd analyses were performed in five samples (A9K, A9I, C20, C22 and C37). Four of these samples are Mesoarchean (2.96 - 3.00 Ga) orthogneisses with TTG affinities from the Amparo, Serra Negra and Heliodora-Minduri complexes (samples A9K, A9I, C20 and C37). These Mesoarchean samples yield slightly negative $\varepsilon \mathrm{Nd}_{(\mathrm{t})}$ values between -1.2 to -2.5 . $\mathrm{Nd}$ model ages based on the depleted mantle model of DePaolo (1981) range from 3.2 to 3.4 Ga (Fig. 12). The Neoarchean (2.76 Ga) granitic sample of the Amparo Complex yields a $\varepsilon N d_{(t)}$ value of -2.5 that overlaps the $\mathrm{Nd}$ evolution lines of the Amparo Complex tonalitic samples (Fig. 12).

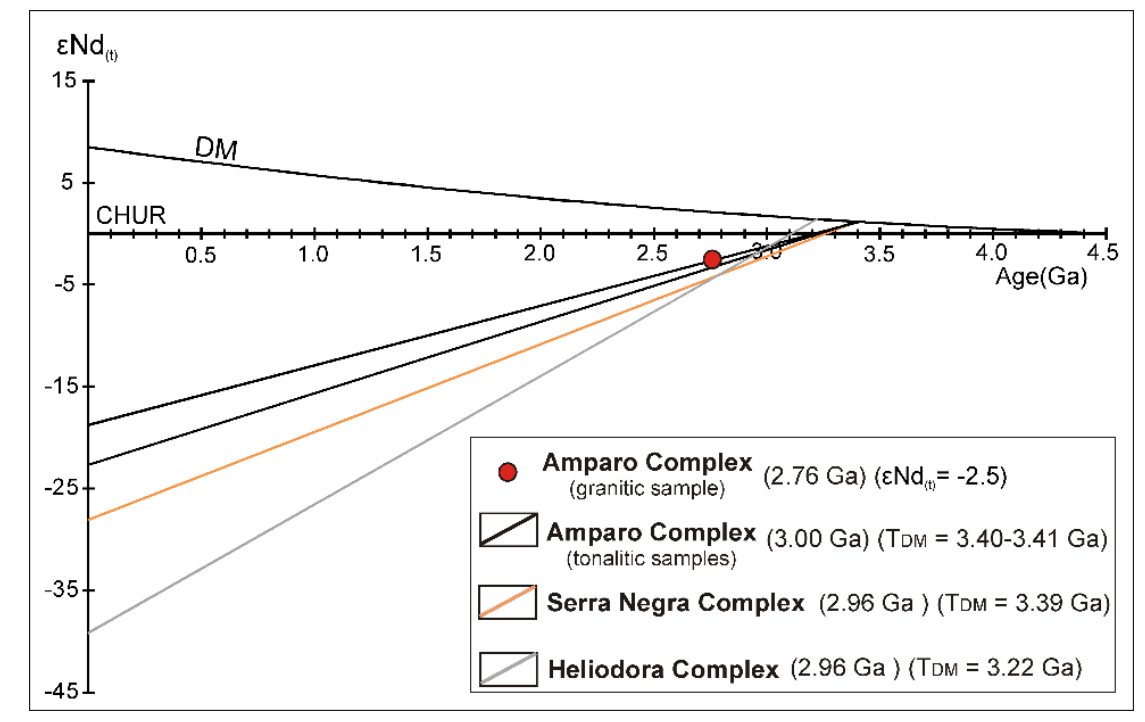

Figure 12. Nd evolution diagram for analyzed samples. The isotopic evolution line is for the DePaolo (1981) depleted mantle model. 


\section{Discussion}

\subsection{Are these Archean complexes accreted microcontinents?}

Cioffi et al. (2016) suggested that the orthogneisses in the basement of the southern Brasilia Orogen are part of the São Francisco paleo-plate reworked during the Neoproterozoic collisional events. The authors interpreted the Paleoproterozoic Pouso Alegre Complex as the orogenic counterpart of the Mineiro Belt arc system. Assuming these hypotheses are true, this at least $350 \mathrm{~km}$ long, NE-SW arc system is separating the Archean complexes in the basement of the southern Brasília Orogen from the São Francisco craton Archean crust (Fig. 1). Most of the original tectonic scenario was overprinted by the Neoproterozoic orogenic events. These events were responsible for major tectonic transport towards east-northeast, that is most likely the reason why part of these Archean complexes, especially in the central part of the orogen, are located underneath the Paleoproterozoic Pouso Alegre Complex (Figs. 1 and 2).

The new $\mathrm{U}-\mathrm{Pb}$ data presented in this study indicate a well-defined period of Mesoarchean igneous crystallization ages between 3.00 and $2.96 \mathrm{Ga}$ in the Amparo, Serra Negra and HeliodoraMinduri TTG-type orthogneisses (Fig. 9). An additional period of Neoarchean high-K magmatism at ca. 2.76 Ga is also observed in the Amparo Complex (Fig. 10). Four main periods of magmatism are recognized in the Archean crust at the southern São Francisco craton (e.g., Teixeira et al., 2000; Lana et al., 2013; Farina et al., 2015). These are the following: (1) Santa Barbara magmatic event (ca. 3230 - 3200 Ma) (2) Rio das Velhas I (ca. 2930 - 2850 Ma), (3) Rio das Velhas II (ca. 2800 - 2760 Ma) and (4) Mamona (ca. 2760-2680 Ma). Therefore, the Mesoarchean igneous crystallization ages presented in this study lie within the southern São Francisco craton "magmatic gap" (Fig. 13) and suggest that the Archean complexes in the basement of the southern Brasilia Orogen are exotic to the Archean crust of the southern São Francisco craton.

Based on the geological context and U-Pb data, we suggest that the Archean complexes in the basement of the southern Brasília Orogen are Archean microcontinents accreted to the southern edge of the São Francisco paleocontinent. The timing of accretion is not well constrained, but most likely occurring after the development of the Pouso Alegre Complex arc-related suites between 2.15 and $2.08 \mathrm{Ga}$. The only direct evidence about the timing of accretion are three slightly discordant $\mathrm{U}-\mathrm{Pb}$ analyses from the Amparo Complex granitic sample (sample C22; for details see section 6.5) that yield Paleoproterozoic dates with a mean ${ }^{207} \mathrm{~Pb} /{ }^{206} \mathrm{~Pb}$ date of $2028 \pm 33 \mathrm{Ma}$. Reworking at ca. $2.0 \mathrm{Ga}$ is also suggested by Tassinari and Nutmann (2001), based on ion microprobe analyses of zircon grains from an Amparo Complex migmatite neosome. We support that future studies focused on the timing of this hypothetical Paleoproterozoic accretionary event would be of great value for the regional geology understanding. 


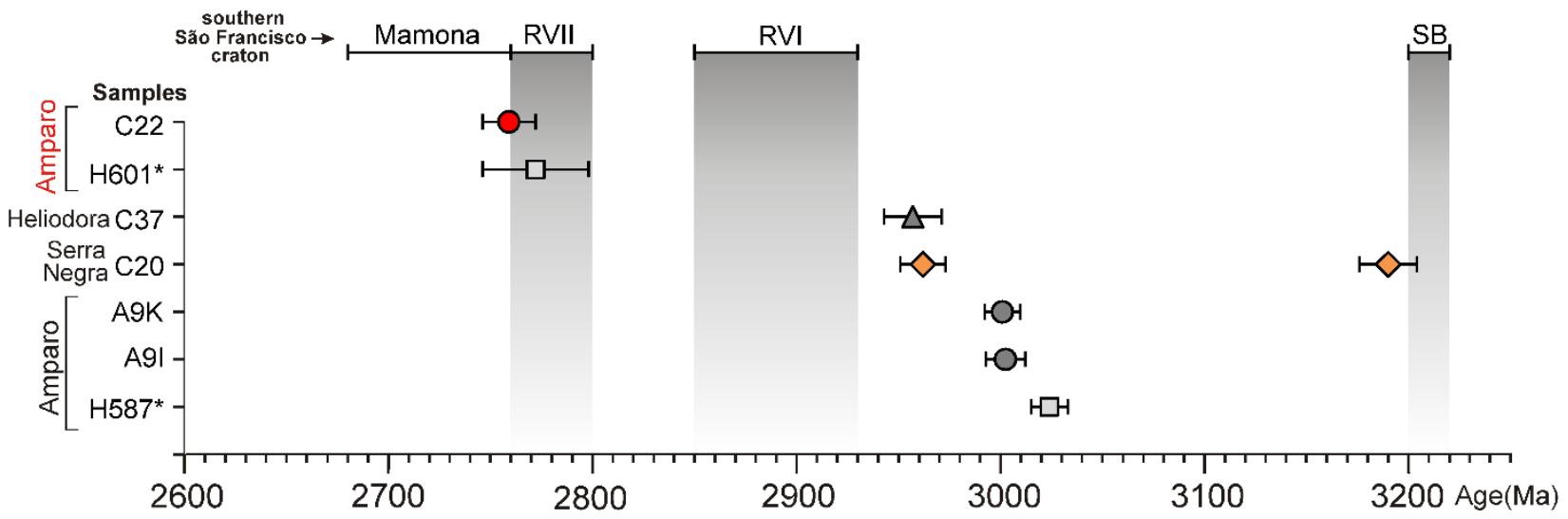

Figure 13. U-Pb zircon ages of the Archean complexes in the basement of the southern Brasília Orogen. Samples marked with asterisk are from Fetter et al. (2001). All remaining samples are from this study. Age intervals of magmatic events in the southern São Francisco craton are from Lana et al. (2013) and Farina et al. (2015) (RVI = Rio das Velhas I; RVII = Rio das Velhas II; SB = Santa Barbara).

An alternative model could be that these Archean Complexes were part of the basement of the Paranapanema block accreted during the Neoproterozoic collision. However, at least until now, there is no evidence that supports this hypothesis. There is no evidence of Archean crust in the basement nuclei within the Paranapanema block domains (e.g. Siga Jr. et al., 2011), most of the block basement consists of ca. 2.2 Ga orthogneisses. Additionally, the central and eastern Archean complexes are located too far northeast from the Paranapanema domain to be correlated with it (Fig. 2).

\subsection{Pre-accretion evolution}

According to the whole-rock major element signatures, especially $\mathrm{Na}$ and $\mathrm{K}$ concentrations, the Mesoarchean rocks analyzed in this study have TTG affinities (i.e. low $\mathrm{K}_{2} \mathrm{O} / \mathrm{Na}_{2} \mathrm{O}$ ratios between 0.2 and 0.5 ). These sample do not show K- or Na-enrichment during differentiation (Fig. 4), another characteristic trait of TTG-type suites. On the diagrams of Figure 5, these samples always plot within the TTG fields. The tonalitic samples of the Amparo Complex most likely represent less differentiated TTG compositions as they have lower $\mathrm{SiO}_{2}(63-68 \mathrm{wt} \%)$ and higher $\mathrm{FeO}_{\mathrm{t}}+\mathrm{MgO}+\mathrm{MnO}+\mathrm{TiO}_{2}(5.2-$ 8.0 wt\%) (Fig. 4) than typical TTG compositions and always contain hornblende. Trace element signatures of tonalitic and granodioritic samples of the Amparo and Serra Negra complexes resemble those of low-pressure TTG's of Moyen (2011) (Fig. 6). These rocks are different from the typical high- 
pressure TTG's because of their low Sr and high Y and HREE concentrations. On the other hand, the Heliodora-Complex trondjhemitic sample shows trace element signatures that are very similar to highpressure TTG's (Figs. 6 and 7).

The whole-rock geochemical signatures associated with the geochronological data indicate a main period of TTG-type magmatism in these Archean complexes between 3.00 and $2.96 \mathrm{Ga}$. Zircon Hf analyses of these TTG-type Mesoarchean samples yield mostly positive $\varepsilon \mathrm{Hf}_{(t)}$ values between -0.4 and +4.7 (Fig. 11) associated with two-stage $\mathrm{Hf}$ model ages between 3.0 and 3.3 Ga. Whole-rock Nd data yield slightly negative $\varepsilon \mathrm{Nd}_{(\mathrm{t})}$ values between -1.2 and -2.5 associated with $\mathrm{Nd}$ model ages from 3.2 to 3.4 Ga (Fig. 12). These results suggest juvenile crust formation with participation of slightly older crust. This interpretation is in good agreement with the zircon inheritance of ca. 3.19 Ga found in the Serra Negra Complex sample (Fig. 9c).

A high-K Neoarchean magmatic event is indicated by the Amparo Complex granitic sample that yields an igneous crystallization age of ca. $2.76 \mathrm{Ga}$. This sample has a $\mathrm{K}_{2} \mathrm{O}$ content of $4.9 \mathrm{wt} \%$, that is much higher than the TTG-type samples (Fig. 4) and falls within the late-Archean biotite granite fields of Laurent et al., (2014) (Fig. 5d). Fetter et al., (2001) and Santos (2014) obtained similar igneous crystallization ages of ca. $2.77 \mathrm{Ga}$ from orthogneisses of the Amparo and Heliodora-Minduri complexes, respectively. These data indicate that the Archean complexes in the basement of the southern Brasília Orogen underwent a prolonged evolution from Meso- to Neoarchean.

Zircon $\mathrm{Hf}$ analyses of this Neoarchean granitic sample show a large spread and yield mostly negative $\varepsilon \mathrm{Hf}_{(\mathrm{t})}$ values between -0.6 and -7.1, with just one spot yielding a positive value (Fig. 11). Whole-rock $\mathrm{Nd}$ analysis of this sample yields a slightly negative $\varepsilon N d_{(t)}$ value of -2.5 , that overlaps the $\mathrm{Nd}$ evolution lines of tonalitic samples from the Amparo Complex (Fig. 12). These less radiogenic signatures could suggest that reworking of the Mesoarchean suites was a major mechanism for the generation of the high-K Neoarchean suite. However, as pointed out by Laurent and Zeh (2015), Hf isotope-age arrays of Archean zircon populations should be interpreted with caution because they can provide ambiguous evidence about the source. Therefore, without a better understanding of the zircon inheritance from this Neoarchean suite, the involvement of crust older than 3.0 Ga or even juvenile inputs cannot be ruled out.

A Neoarchean transition from TTG's to high-K granitoids has been recognized in several cratonic areas around the globe including the Superior Province, Amazonian craton, Kaapvaal craton, Pilbara craton, North China craton, São Francisco craton, among others (e.g. Romano et al., 2013; Laurent et al., 2014; Farina et al., 2015). Our dataset clearly demonstrates the existence of this transition at ca. $2.76 \mathrm{Ga}$ in the Archean complexes in the basement of the southern Brasília Orogen. Romano et al., (2013) and Farina et al., (2015) suggested that the high-K magmatism between 2.75 - 
2.72 Ga in the southern São Francisco craton area was responsible for the stabilization of the crust and cratonization. If we assume this hypothesis for the Archean complexes in the basement of the southern Brasilia Orogen, we can argue that this Archean crust was thick and these complexes represent Archean microcontinents that were later accreted to the São Francisco paleocontinent, most likely during the Paleoproterozoic.

\section{Conclusions}

The data provided in this study lead to the following conclusions:

- The Archean complexes in the basement of the southern Brasilia Orogen show a well-defined period of Mesoarchean TTG-type magmatism between 3.00 and $2.96 \mathrm{Ga}$.

- This age interval is within the southern São Francisco craton "magmatic gap" and indicates that these complexes are exotic to the Archean crust found within the São Francisco craton tectonic boundaries.

- The complexes are separated from the Archean crust of the São Francisco by the Paleoproterozoic Pouso Alegre Complex - Mineiro Belt arc system and most likely represent Archean microcontinents accreted to the São Francisco paleocontinent after $2.08 \mathrm{Ga}$.

- The pre-accretion evolution includes Mesoarchean (ca. 3.00 - 2.96 Ga) TTG-type magmatism followed by Neoarchean (ca. $2.76 \mathrm{Ga}$ ) high-K granitoid magmatism.

- The TTG-type Mesoarchean magmatism is mostly juvenile with involvement of slightly older crust.

- The Neoarchean high-K granitoid magmatism shows less radiogenic $\mathrm{Hf}$ and $\mathrm{Nd}$ signatures, however the sources of magmatism are still undefined.

\section{Acknowledgements}

This research was supported by FAPESP (grant 2013/13530-8). C.R. Cioffi is thankful to CAPES and FAPESP for the PhD scholarships. Rafael Bittencourt Lima and Renato Moraes are acknowledged for their help during field work, Heather Shinogle for assistance with SEM image acquisition and Vasco Loios for support during zircon separation. 


\section{References}

Ávila, C.A., Teixeira, W., Cordani, U.G., Moura, C.A.V., Pereira, R.M., 2010. Rhyacian (2.23-2.20 Ga) juvenile accretion in the Southern São Francisco craton, Brazil: Geochemical and isotopic evidence from the Serrinha magmatic suite, Mineiro belt. Journal of South American Earth Sciences 29, 464-482.

Barbosa, N.S, Teixeira, W., Ávila, C.A., Montecinos, P.M., Bongiolo, E.M., 2015. 2.17 - 2.10 Ga plutonic episodes in the Mineiro belt, São Francisco Craton, Brazil: U-Pb ages, geochemical constraints and tectonics. Precambrian Research 270, 204-225.

Blichert-Toft, J., Albarède, F., 1997. The Lu-Hf isotope geochemistry of chondrites and the evolution of the mantle-crust system. Earth and Planetary Science Letters 148, 243-258.

Boynton, W. V. (1983). Cosmochemistry of the rare earth elements. Geochemistry of the rare earth elements: meteorite studies. In: P. Henderson (Ed.), Rare Earth Element Geochemistry, Elsevier (1984), pp. 63-114

Brito Neves, B.B., Campos Neto, M.C., Fuck, R.A., 1999. From Rodinia to western Gondwana: an approach to the Brasiliano-pan African cycle and orogenic collage. Episodes 22, 155-166.

Campos Neto, M.C., 2000. Orogenic Systems from southwestern Gondwana: an approach to Brasiliano-Pan African Cycle and orogenic collage in southeastern Brazil. In: Cordani, U.G., Milani, E.J., Thomaz Filho, A., Campos, D.A. (Eds.), Tectonic Evolution of South America. 31th International Geological Congress. Rio de Janeiro, Brazil, pp. 335-365.

Campos Neto, M.C., Caby, R., 1999. Neoproterozoic high-pressure metamorphism and tectonic constraint from the nappe system south of the São Francisco Craton, southeast Brazil. Precambrian Research 97, 3-26.

Campos Neto, M.C., Caby, R., 2000. Lower crust extrusion and terrane accretion in the Neoproterozoic nappes of southeast Brazil. Tectonics 19, 669-687.

Campos Neto, M.C., Cioffi, C.R., Moraes, R., Motta, R.G., Siga Jr., O., Basei, M.A.S., 2010. Structural and metamorphic control on the exhumation of high-P granulites: The Carvalhos Klippe example, from the oriental Andrelândia Nappe System, southern portion of the Brasília Orogen, Brazil. Precambrian Research 180, 125-142.

Campos Neto, M.C., Basei, M.A.S., Janasi, V.A., Moraes, R., 2011. Orogen migration and tectonic setting of the Andrelândia Nappe System: An Ediacaran western Gondwana collage, south São Francisco craton. Journal of South American Earth Sciences 32, 393-406. 
Cioffi, C.R., Campos Neto, M.C., Möller, A., Rocha, B.C., 2016. Paleoproterozoic continental crust generation events at 2.15 and $2.08 \mathrm{Ga}$ in the basement of the southern Brasilia Orogen, SE Brazil. Precambrian Research 275, 176-196.

Dardenne, M.A., 2000. The Brasília Fold Belt. In: Cordani, U.G., Milani, E.J., Thomaz Filho, A., Campos, D.A. (Eds.), Tectonic Evolution of South America. 31th International Geological Congress. Rio de Janeiro, Brazil, pp. 231-263.

DePaolo, D.J., 1981. Neodymium isotopes in the Colorado Front Range and crust-mantle evolution in the Proterozoic. Nature 291, 193-196.

Ebert, H., 1968. Ocorrências de Fácies Granulíticas no Sul de Minas Gerais e áreas adjacentes. Em dependências da estruturas orogênica: hipóteses sobre sua origem. Anais da Acadêmia Brasileira de Ciências 40, 215-229.

Farina, F., Capucine, A., Lana, C., 2015. The Neoarchean transition between medium- and high-K granitoids: Clues from the southern São Francisco Craton (Brazil). Precambrian Research 266, 375-394.

Fetter, A.H., Hackspacker, P.C., Ebert, H.D., Dantas, E.L., Costa, A.C.D., 2001. New Sm/Nd and U/Pb geochronological constraints on the Archean to Neoproterozoic evolution of the Amparo basement complex of the central Ribeira belt, southeastern Brazil. 3rd South American Symposium on Isotope Geology (Extended Abstracts, CD-ROM).

Frost, B.R., Barnes, C.G., Collins, W.J., Arculus, R.J., Ellis, D.J., Frost, C.D., 2001. A geochemical classification for granitic rocks. Journal of Petrology 42, 2033-2048.

Fuck, R.A., Dantas, E.L., Pimentel, M.M., Botelho, N.F., Armstrong, R., Laux, J.H., Junges, S.L., Soares, J.E., Praxedes, I.G., 2014. Paleoproterozoic crust formation and reworking events in the Tocantins Province, central Brazil: A contribution for Atlantica supercontinent reconstruction. Precambrian Research 244, 53-74.

Janasi, V., 2002. Elemental and Sr-Nd isotope geochemistry of two Neoproterozoic mangerite suites in SE Brazil: implications for the origin of the mangerite-charnockite-granite series. Precambrian Research 119, 301-327.

Gioia, S.M.C.L., Pimentel, M.M., 2000. The Sm-Nd method in the geochronology laboratory of the University of Brasília. Anais da Academia Brasileira de Ciências 72, 219-245.

Griffin, W.L., Wang, X., Jackson, S.E., Pearson, N.J., O'Reilly, S.Y., Xu, X., Zhou, X., 2002. Zircon chemistry and magma mixing, SE China: In-situ analysis of Hf isotopes, Tonglu and Pingtan igneous complexes. Lithos 61, 237-169. 
Heilbron, M., Duarte, B.P., Valeriano, C.M., Simonetti, A., Machado, N., Nogueira, J.R., 2010. Evolution of reworked Paleoproterozoic basement rocks within the Ribeira belt (Neoproterozoic), SE Brazil, based on U-Pb geochronology: Implications for paleogeographic reconstructions of the São FranciscoCongo paleocontinent. Precambrian Research 178, 136-148.

Jackson, S.E., Pearson, N.J., Griffin, W.L., Belousova, E.A., 2004. The application of laser ablationinductively coupled plasma-mass spectrometry to in-situ U-Pb zircon geochronology. Chemical Geology 211, 47-69.

Laurent, O., Martin, H., Moyen, J.F., Doucelance, R., 2014. The diversity and evolution of late-Archean granitoids: Evidence for the onset of "modern style" plate tectonics between 3.0 and $2.5 \mathrm{Ga}$. Lithos 205, 208-235.

Laurent, O., Zeh, A., 2015. A linear Hf isotope-age array despite different granitoid sources and complex Archean geodynamics: Example from the Pietersburg block (South Africa). Earth and Planetary Science Letters $430,326-338$.

Lana, C., Alkmin, F.F., Armstrong, R., Scholz, R., Romano, R., Nalini Jr., H.A., 2013. The ancestry and magmatic evolution of the Archaean TTG rocks of the Quadrilátero Ferrifero province, southeast Brazil. Precambrian Research 231, 157-173.

Ludwig, K.R., 2003. Isoplot/Ex 3.00: A geochronological toolkit for Microsoft Excel. Berkeley Geochronology Center Special Publication, 4.

Morais, S.N., 1999a. Programa Levantamentos Geológicos Básicos do Brasil: Integração Geológica da Folha Campinas. (Escala) 1:250.000 SF-23-Y-A. Estados de São Paulo e Minas Gerais (Nota Explicativa) - São Paulo - CPRM (26pp.).

Morais, S.N., 1999b. Programa Levantamentos Geológicos Básicos do Brasil: Integração Geológica da Folha Guaratinguetá. (Escala) 1:250.000 SF-23-Y-B. Estados de São Paulo e Minas Gerais (Nota Explicativa) - São Paulo - CPRM (28pp.).

Mori, P.E., Reeves, S., Correia, C.T., Haukka, M., 1999. Development of a fused glass disc XRF facility and comparison with the pressed powder pellet technique at Instituto de Geociências, Universidade de São Paulo. Revista brasileira de Geociências 29, 441-446.

Moyen, J.-F., 2011. The composite Archean grey gneisses: Petrological significance, and evidence for a non-unique tectonic setting for Archean crustal growth. Lithos 123, 21-36.

Moyen, J.-F., Martin, H., 2012. Forty years of TTG research. Lithos 148, 312-336. 
Navarro, M.S., Ulbrich, H.H., Andrade, S., Janasi, V.A., 2002. Adaptation of ICP-OES routine determination techniques for the analysis of rare earth elements by chromatographic separation in geological materials: Tests with reference materials and granitic rocks. Journal of Alloy and Compounds $344,40-45$.

Navarro, M.S., Andrade, S., Ulbrich, H., Gomes, C.B., Girardi, V.A.V., 2008. The direct determination of rare Earth elements in basaltic and related rocks using ICP-MS: Testing the efficiency of microwave oven sample decomposition procedures. Geostandards and Geoanalytical Research 32, 167-180.

O'Connor, J.T., 1965. A classification for quartz-rich igneous rocks based on feldspar ratios. U.S. Geological Survey Professional Paper 525, 79-84.

Paton, C., Hellstrom, J., Paul, B., Woodhead, J., Hergt, J., 2011. lolite:Freeware for the visualisation and processing of mass spectrometry data. Journal of Analytical Atomic Spectrometry 26, 2508-2518.

Perrota, M.M., 1991. A Faixa Alto Rio Grande na região de São Gonçalo do Sapucaí, MG. Unpublished Master's dissertation, IGc-USP, (158pp.).

Peternel, R., 2005. A zona de superposição entre as Faixas Brasília e Ribeira na região entre Caxambu e Pedralva, sul de Minas Gerais. Unpublished PhD Thesis. Instituto de Geociências - UFRJ, (257pp.).

Petrus, J.A., Kamber, B.S., 2012. VizualAge: A Novel Approach to Laser Ablation ICP-MS U-Pb Geochronology Data Reduction. Geostandards and Geoanalytical Research 36, 247-270.

Rocha, B.C. 2011. Evolução metamórfica dos metassedimentos da Nappe Lima Duarte e rochas associadas do Complexo Mantiqueira. Unpublished Master's dissertation, IGc-USP, (201pp.).

Romano, R., Lana, C., Alkmim, F.F., Stevens, G., Armstrong, R., 2013. Stabilization of the Southern portion of the São Francisco craton, SE Brazil, through a long-lived period of potassic magmatism. Precambrian Research 224, 143-159.

Santos, C.A., 2014. Geologia, petrografia e geocronologia dos gnaisses e rochas associadas na região entre Carrancas, Minduri e Luminárias (MG). Unpublished Master's dissertation, IGc-USP, (57pp.).

Sato, K., Tassinari, C.C.G., Kawashita, K., Petronilho, L., 1995. O método geocronológico Sm-Nd no IG/USP e suas aplicações. Anais da Academia Brasileira de Ciências 67, 315-336.

Seixas, L.A.R., Bardintzeff, J-M., Stevenson, R., Bonin, B., 2013. Petrology of the high -Mg tonalites and dioritic enclaves of the ca. 2130 Ma Alto Maranhão suite: Evidence for a major juvenile crustal addition event during the Rhyacian orogenesis, Mineiro Belt, southeast Brazil. Precambrian Research 238, 18 41. 
Siga Jr., O., Basei, M.A.S., Sato, K., Passarelli, C.R., Nutman, A., McReath, I., Prazeres Filho, H.J., 2011. Calymmian (1.50-1.45Ga) magmatic records in Votuverava and Perau sequences, south-southeastern Brazil: Zircon ages and Nd-Sr isotopic geochemistry. Journal of South American Earth Sciences 32, 301308.

Silva, L.C., Pedrosa-Soares, P., Armstrong, R., Pinto, C.P., Magalhães, J.T.R., Pinheiro, M.A.P., Santos, G.G., Disclosing the Paleoarchean to Ediacaran history of the São Francisco craton basement: The Porteirinha domain (northern Araçuai orogen, Brazil), Journal of South American Earth Sciences (2015), http://dx.doi.org/10.1016/i.jsames.2015.12.002.

Sláma, J., Košler, J., Condon, D.J., Crowley, J.L., Gerdes, A., Hanchar, J.M., Horstwood, S.A., Morris, G.A., Nasdala, L., Norberg, N., Schaltegger, U., Schoene, B., Tubrett, M.N., Whitehouse, M.J., 2008. Plešovice zircon - A new natural reference material for $\mathrm{U}-\mathrm{Pb}$ and $\mathrm{Hf}$ isotopic microanalysis. Chemical Geology 249, 1-35.

Söderlund, U., Patchett, P.J., Vervoort, J.D., Isachsen, C.E., 2004. The ${ }^{176} \mathrm{Lu}$ decay constant determined by Lu-Hf and U-Pb isotope systematics of Precambrian mafic intrusions. Earth and Planetary Sciences Letters $219,311-324$.

Stacey, J.S., Kramers, J.D., 1975. Approximation of terrestrial lead isotope evolution by two-stage model. Earth and Planetary Science Letters 26, 207-221.

Tanaka, T; Togashi, S., Kamioka, H., Amakawa, H., Kagami, H., Hamamoto, T., Yuhara, M., Orihashi, Y., Yoneda, S., Shimizu, H., Kunimaru, T., Takahashi, K., Yanagi, T., Nakano, T., Fujimaki, H., Shinjo, R., Asahara, Y., Tanimizu, M., Dragusanu, C., 2000. JNdi-1: a neodymium isotopic reference in consistency with LaJolla neodymium. Chemical Geology 168, 279-281.

Tassinari, C.C.G., Nutman, A.P., Archean and Proterozoic multiple tectonothermal events recorded by gneisses in the Amparo region, São Paulo state, Brazil. 3rd South American Symposium on Isotope Geology (Extended Abstracts, CD-ROM).

Teixeira, W., Sabatè, P., Barbosa, J., Noce, C.M., Carneiro, M.A., 2000. Archean and Paleoproterozoic evolution of the São Francisco Craton, Brazil. In: Cordani, U.G., Milani, E.J., Thomaz Filho, A., Campos, D.A. (Eds.), Tectonic Evolution of South America. 31th International Geological Congress. Rio de Janeiro, Brazil, pp. 101-137.

Teixeira, W., Ávila, C.A., Dussin, I.A., Corrêa Neto, A.V., Bongiolo, E.M., Santos, J.O., Barbosa, N.S., 2015. A juvenile accretion episode (2.35-2.32 Ga) in the Mineiro Belt and its role to the Minas accretionary orogeny: Zircon U-Pb-Hf and geochemical evidences. Precambrian Research 256, 148-169. 
Trouw, R.A.J., Heilbron, M., Ribeiro, A., Paciullo, F., Valeriano, C.M., Almeida, J.C.H., Tupinambá, M., Andreis, R.R., 2000. The central segment of Ribeira belt. In: Cordani, U.G., Milani, E.J., Thomaz Filho, A., Campos, D.A. (Eds.), Tectonic Evolution of South America. 31th International Geological Congress. Rio de Janeiro, Brazil, pp. 287-310.

Trouw, R.A.J., Nunes, R.P.M., Castro, E.M.O., Trouw, C.C., Matos, G.C., 2008. Nota explicativa das Folhas Varginha (SF.23-V-D-VI) e Itajubá (SF.23-Y-B-III). Programa Geologia do Brasil. Contrato CPRMUFRJ N067/PR/05. (99pp).

Trouw, R.A.J., Peternel, R., Ribeiro, A., Heilbron, M., Vinagre, R., Duffles, P., Trouw, C.C., Fontainha, M., Kussama, H.H., 2013. A new interpretation for the interference zone between the southern Brasília belt and the central Ribeira belt, SE Brazil. Journal of South American Earth Sciences 48, 43-57.

Vervoort, J.D., Blichert-Toft, J., 1999. Evolution of the depleted mantle: Hf isotopic evidence from juvenile rocks through time. Geochimica et Cosmochimica Acta 63, 533-556.

Westin, A., Campos Neto, M.C., 2013. Provenance and tectonic setting of the external nappe of the Southern Brasília Orogen. Journal of South American Earth Sciences 48, 220-239.

Westin, A., Campos Neto, M.C., Hawkesworth, C., Cawood, P., Dhuime, B., Delavault, H., A Paleoproterozoic intra-arc basin associated with a juvenile source in the southern Brasília Orogen: using $\mathrm{U}-\mathrm{Pb}$ ages and $\mathrm{Hf}-\mathrm{Nd}$ isotopic analyses in provenance studies of complexes areas. Precambrian Research 276, 178-193. 
Supplementary Table S1. Data summary.

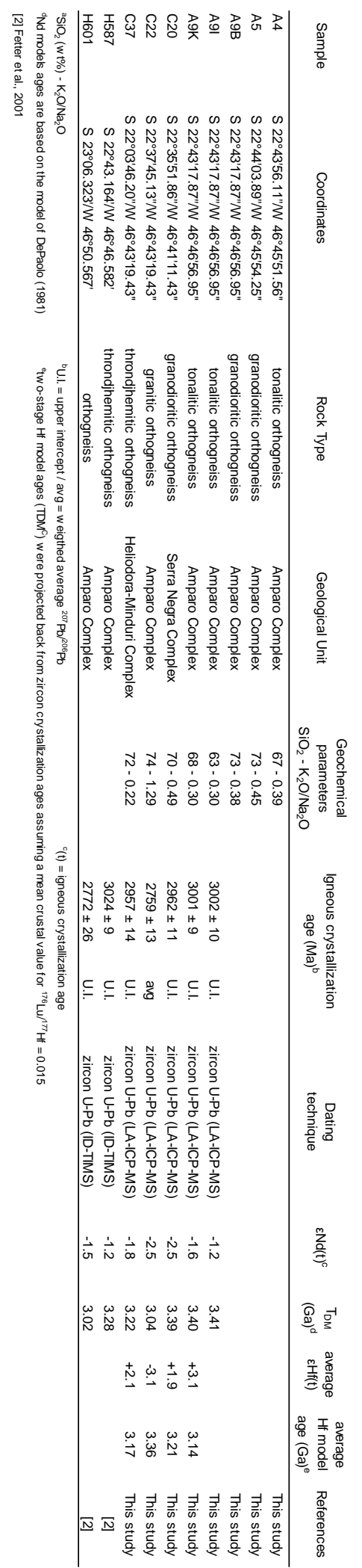




\section{ANEXO III}

(Dados de geoquímica de rocha-total) 


\begin{tabular}{|c|c|c|c|c|c|c|c|c|c|c|c|c|c|c|c|}
\hline Amostra & $1 \mathrm{~A}$ & $1 \mathrm{~B}$ & $1 \mathrm{E}$ & $1 \mathrm{~N}$ & 6 & $7 A$ & 9A1 & 9A2 & $9 B$ & $23 B$ & $23 G$ & $24 A$ & $24 B$ & 26 & 28 \\
\hline $\mathrm{SiO}_{2}$ & 76.02 & 74.63 & 60.52 & 75.44 & 72.56 & 64.55 & 52.29 & 53.36 & 68.61 & 69.07 & 72.15 & 69.37 & 68.90 & 65.34 & 65.38 \\
\hline $\mathrm{TiO}_{2}$ & 0.24 & 0.26 & 0.64 & 0.26 & 0.25 & 0.34 & 0.73 & 0.71 & 0.56 & 0.54 & 0.26 & 0.50 & 0.41 & 0.56 & 0.90 \\
\hline $\mathrm{Al}_{2} \mathrm{O}_{3}$ & 11.55 & 11.96 & 14.15 & 11.59 & 13.66 & 17.68 & 15.06 & 15.62 & 14.30 & 14.77 & 14.68 & 14.95 & 15.69 & 15.51 & 14.13 \\
\hline $\mathrm{Fe}_{2} \mathrm{O}_{3}$ & 3.55 & 3.77 & 8.34 & 3.79 & 2.46 & 3.50 & 8.96 & 8.84 & 4.65 & 3.10 & 2.54 & 3.33 & 3.35 & 5.96 & 7.07 \\
\hline MnO & 0.08 & 0.09 & 0.20 & 0.09 & 0.03 & 0.05 & 0.13 & 0.08 & 0.07 & 0.06 & 0.05 & 0.04 & 0.05 & 0.08 & 0.11 \\
\hline $\mathrm{MgO}$ & $<0.01$ & $<0.01$ & 3.73 & $<0.01$ & 0.24 & 1.47 & 7.93 & 6.52 & 0.85 & 0.79 & 0.52 & 0.88 & 1.62 & 2.89 & 0.51 \\
\hline $\mathrm{CaO}$ & 1.47 & 1.61 & 5.35 & 1.54 & 1.29 & 5.25 & 7.96 & 8.62 & 3.29 & 2.13 & 2.83 & 2.27 & 3.02 & 3.02 & 3.68 \\
\hline $\mathrm{Na}_{2} \mathrm{O}$ & 3.86 & 4.05 & 2.82 & 3.85 & 3.38 & 4.80 & 2.62 & 2.67 & 3.34 & 4.16 & 4.64 & 3.66 & 4.00 & 3.44 & 2.70 \\
\hline $\mathrm{K}_{2} \mathrm{O}$ & 2.60 & 2.53 & 1.74 & 2.56 & 4.98 & 0.78 & 2.03 & 1.46 & 3.10 & 3.08 & 1.14 & 3.72 & 2.63 & 2.76 & 3.89 \\
\hline $\mathrm{P}_{2} \mathrm{O}_{5}$ & 0.02 & 0.03 & 0.21 & 0.02 & 0.07 & 0.09 & 0.10 & 0.11 & 0.15 & 0.22 & 0.09 & 0.12 & 0.15 & 0.17 & 0.36 \\
\hline Loi & 0.30 & 0.20 & 1.14 & 0.12 & 0.42 & 0.60 & 1.25 & 1.07 & 0.52 & 0.88 & 0.60 & 0.95 & 0.70 & 0.87 & 0.75 \\
\hline Total & 99.70 & 99.12 & 98.84 & 99.26 & 99.34 & 99.11 & 99.06 & 99.06 & 99.44 & 98.81 & 99.49 & 99.79 & 100.52 & 100.60 & 99.48 \\
\hline $\mathbf{R b}$ & & 76 & 82 & 76 & 254 & 13 & 98 & 67 & 74 & 200 & 94 & 143 & & 242 & 126 \\
\hline $\mathrm{Sr}$ & & 109 & 291 & 114 & 183 & 688 & 153 & 132 & 342 & 351 & 243 & 345 & & 359 & 259 \\
\hline $\mathbf{Y}$ & & 61.4 & 24.6 & 73.8 & 40.8 & 7.47 & 19.4 & 20.6 & 18.8 & 19.4 & 10.9 & 12.6 & & 14.7 & 101 \\
\hline $\mathrm{Zr}$ & & 459 & 102 & 429 & 278 & 58.7 & 94.4 & 85.0 & 321 & 453 & 172 & 387 & & 127 & 929 \\
\hline $\mathrm{Nb}$ & & 14.0 & 8.56 & 15.6 & 13.3 & 4.63 & 4.68 & 4.56 & 13.1 & 19.5 & 12.0 & 12.9 & & 7.88 & 40.5 \\
\hline Cs & & 2.63 & 8.41 & 2.46 & 3.02 & 0.49 & 6.82 & 5.82 & 3.30 & 14.1 & 6.48 & 6.18 & & 5.92 & 2.28 \\
\hline $\mathrm{Ba}$ & & 734 & 467 & 779 & 826 & 366 & 255 & 224 & 1453 & 941 & 204 & 1410 & & 515 & 1533 \\
\hline La & & 23.7 & 13.3 & 36.1 & 68.1 & 6.75 & 11.4 & 11.7 & 29.7 & 83.2 & 14.9 & 82.1 & & 27.0 & 88.5 \\
\hline $\mathrm{Ce}$ & & 52.0 & 28.4 & 76.1 & 123.2 & 14.4 & 23.8 & 24.4 & 58.7 & 158 & 28.6 & 154.1 & & 52.8 & 189.5 \\
\hline Pr & & 7.55 & 4.00 & 9.80 & 15.9 & 1.94 & 2.99 & 3.46 & 7.11 & 16.3 & 3.05 & 16.0 & & 6.05 & 24.0 \\
\hline $\mathrm{Nd}$ & & 31.0 & 16.2 & 40.7 & 52.5 & 7.72 & 12.2 & 13.6 & 28.4 & 53.6 & 11.1 & 52.5 & & 22.6 & 98.0 \\
\hline Sm & & 7.72 & 3.74 & 9.78 & 8.71 & 1.59 & 2.79 & 3.04 & 5.26 & 7.56 & 2.32 & 7.49 & & 4.25 & 20.22 \\
\hline Eu & & 2.32 & 1.06 & 2.57 & 0.86 & 0.69 & 0.82 & 0.86 & 1.54 & 1.36 & 0.61 & 1.27 & & 1.05 & 3.12 \\
\hline Gd & & 8.46 & 3.84 & 10.6 & 7.00 & 1.45 & 2.93 & 3.15 & 4.50 & 5.70 & 2.23 & 6.16 & & 3.75 & 19.3 \\
\hline Tb & & 1.53 & 0.63 & 1.87 & 1.00 & 0.21 & 0.48 & 0.53 & 0.61 & 0.63 & 0.33 & 0.60 & & 0.50 & 3.03 \\
\hline Dy & & 9.66 & 3.82 & 11.9 & 5.69 & 1.25 & 2.98 & 3.32 & 3.48 & 3.30 & 1.76 & 2.87 & & 2.72 & 18.2 \\
\hline Ho & & 2.21 & 0.84 & 2.69 & 1.17 & 0.26 & 0.67 & 0.75 & 0.70 & 0.59 & 0.36 & 0.46 & & 0.53 & 3.91 \\
\hline $\mathrm{Er}$ & & 6.16 & 2.31 & 7.88 & 3.20 & 0.70 & 1.91 & 2.08 & 1.95 & 1.58 & 0.97 & 1.17 & & 1.42 & 10.4 \\
\hline $\mathrm{Tm}$ & & 0.96 & 0.35 & 1.18 & 0.47 & 0.10 & 0.28 & 0.32 & 0.27 & 0.21 & 0.14 & 0.15 & & 0.21 & 1.54 \\
\hline $\mathrm{Yb}$ & & 6.46 & 2.38 & 7.90 & 2.97 & 0.67 & 1.89 & 2.12 & 1.78 & 1.14 & 0.87 & 0.86 & & 1.35 & 9.78 \\
\hline Lu & & 0.97 & 0.35 & 1.22 & 0.43 & 0.10 & 0.29 & 0.32 & 0.28 & 0.18 & 0.14 & 0.14 & & 0.21 & 1.42 \\
\hline Hf & & 9.79 & 2.79 & 10.0 & 6.98 & 1.39 & 2.38 & 2.43 & 6.87 & 9.18 & 3.98 & 8.81 & & 3.28 & 19.4 \\
\hline $\mathrm{Pb}$ & & 10.3 & 7.25 & 9.73 & 22.0 & 4.22 & 6.45 & 7.37 & 10.5 & 16.6 & 10.3 & 18.6 & & 13.5 & 21.2 \\
\hline Th & & 4.70 & 2.29 & 5.94 & 15.7 & 0.71 & 2.08 & 2.22 & 2.89 & 12.9 & 6.72 & 20.4 & & 4.89 & 8.99 \\
\hline U & & 2.56 & 1.18 & 2.08 & 1.7 & 0.28 & 0.73 & 1.10 & 0.85 & 4.41 & 1.57 & 1.59 & & 3.16 & 2.90 \\
\hline
\end{tabular}




\begin{tabular}{|c|c|c|c|c|c|c|c|c|c|c|c|c|c|c|}
\hline Amostra & $48 \mathrm{~A}$ & 48B & $48 \mathrm{C}$ & 48D & $48 \mathrm{E}$ & $51 \mathrm{~A}$ & A4 & A5 & A9B & A9I & A9K & $\mathrm{C} 20$ & $\mathrm{C22}$ & C37 \\
\hline $\mathrm{SiO}_{2}$ & 51.56 & 66.41 & 72.31 & 68.20 & 73.17 & 72.23 & 67.48 & 73.28 & 72.70 & 62.52 & 68.10 & 70.00 & 73.81 & 71.64 \\
\hline $\mathrm{TiO}_{2}$ & 0.96 & 0.48 & 0.29 & 0.72 & 0.21 & 0.21 & 0.48 & 0.21 & 0.24 & 0.68 & 0.45 & 0.47 & 0.18 & 0.28 \\
\hline $\mathrm{Al}_{2} \mathrm{O}_{3}$ & 14.93 & 15.46 & 13.15 & 13.33 & 14.50 & 14.30 & 14.57 & 14.08 & 14.41 & 16.07 & 15.27 & 14.84 & 13.81 & 15.55 \\
\hline $\mathrm{Fe}_{2} \mathrm{O}_{3}$ & 11.80 & 4.78 & 3.19 & 6.61 & 1.83 & 2.13 & 4.53 & 2.07 & 1.79 & 5.70 & 3.94 & 3.30 & 1.17 & 1.98 \\
\hline MnO & 0.22 & 0.10 & 0.04 & 0.08 & 0.03 & 0.04 & 0.08 & 0.04 & 0.03 & 0.10 & 0.06 & 0.05 & 0.02 & 0.02 \\
\hline $\mathrm{MgO}$ & 6.13 & 1.98 & 0.38 & 0.47 & 0.46 & 0.41 & 2.54 & 0.48 & 0.52 & 2.09 & 1.14 & 0.97 & 0.17 & 0.62 \\
\hline $\mathrm{CaO}$ & 8.21 & 3.10 & 1.55 & 3.27 & 1.64 & 1.80 & 4.21 & 2.01 & 2.02 & 4.62 & 3.00 & 2.67 & 1.08 & 2.40 \\
\hline $\mathrm{Na}_{2} \mathrm{O}$ & 3.72 & 4.09 & 3.82 & 2.93 & 3.96 & 4.27 & 3.99 & 4.75 & 5.22 & 4.98 & 4.96 & 4.53 & 3.82 & 5.76 \\
\hline $\mathrm{K}_{2} \mathrm{O}$ & 1.26 & 2.23 & 3.82 & 3.35 & 4.20 & 3.25 & 1.57 & 2.16 & 1.96 & 1.48 & 1.49 & 2.23 & 4.91 & 1.29 \\
\hline $\mathrm{P}_{2} \mathrm{O}_{5}$ & 0.13 & 0.12 & 0.04 & 0.21 & 0.05 & 0.05 & 0.08 & 0.08 & 0.07 & 0.16 & 0.12 & 0.14 & 0.04 & 0.09 \\
\hline Loi & 0.90 & 0.88 & 1.06 & 0.55 & 0.51 & 0.63 & 0.95 & 0.73 & 0.82 & 0.60 & 0.50 & 0.57 & 0.44 & 0.63 \\
\hline Total & 99.82 & 99.63 & 99.65 & 99.72 & 100.56 & 99.32 & 100.48 & 99.89 & 99.78 & 98.99 & 99.03 & 99.77 & 99.44 & 100.3 \\
\hline $\mathbf{R b}$ & 18 & & 100 & 55 & 89 & 112 & & 86.9 & 72.2 & 60.9 & 82.8 & 69.1 & 103 & 19.5 \\
\hline $\mathrm{Sr}$ & 168 & & 112 & 321 & 388 & 288 & & 149 & 297 & 350 & 283 & 361 & 317 & 745 \\
\hline Y & 21.9 & & 48.3 & 30.4 & 9.00 & 23.4 & & 24.7 & 9.84 & 27.0 & 15.8 & 37.3 & 7.29 & 6.18 \\
\hline $\mathrm{Zr}$ & 64.5 & & 281 & 707 & 149 & 149 & & 147 & 143 & 163 & 133 & 210 & 143 & 132 \\
\hline $\mathrm{Nb}$ & 2.05 & & 10.6 & 16.0 & 7.82 & 6.53 & & 18.3 & 6.27 & 12.5 & 10.8 & 14.0 & 7.42 & 2.33 \\
\hline Cs & 0.44 & & 1.78 & 0.58 & 0.65 & 3.48 & & 2.40 & 1.67 & 1.48 & 1.56 & 2.44 & 0.49 & 0.10 \\
\hline $\mathrm{Ba}$ & 147 & & 771 & 1937 & 1488 & 915 & & 232 & 400 & 301 & 280 & 525 & 1658 & 447 \\
\hline La & 7.86 & & 35.3 & 41.5 & 43.8 & 39.9 & & 25.0 & 24.6 & 8.84 & 13.2 & 34.6 & 66.5 & 22.5 \\
\hline $\mathrm{Ce}$ & 17.9 & & 73.0 & 86.7 & 80.8 & 80.1 & & 46.2 & 47.4 & 24.7 & 29.0 & 70.5 & 122 & 47.8 \\
\hline $\mathrm{Pr}$ & 2.43 & & 8.66 & 11.0 & 8.06 & 9.06 & & 5.59 & 4.88 & 3.33 & 3.33 & 9.07 & 11.3 & 4.76 \\
\hline Nd & 10.9 & & 33.7 & 46.6 & 26.3 & 33.0 & & 21.1 & 16.6 & 14.3 & 13.2 & 32.9 & 32.0 & 16.3 \\
\hline Sm & 2.83 & & 7.13 & 8.72 & 3.97 & 6.02 & & 4.91 & 2.98 & 3.57 & 3.09 & 7.01 & 4.27 & 2.64 \\
\hline Eu & 0.99 & & 1.23 & 2.75 & 0.94 & 1.00 & & 0.97 & 0.73 & 1.03 & 0.87 & 1.48 & 0.87 & 0.86 \\
\hline Gd & 3.21 & & 7.20 & 7.91 & 3.30 & 5.18 & & 4.78 & 2.64 & 3.70 & 3.07 & 6.85 & 3.32 & 2.14 \\
\hline Tb & 0.58 & & 1.24 & 1.07 & 0.35 & 0.70 & & 0.78 & 0.35 & 0.62 & 0.48 & 1.13 & 0.35 & 0.24 \\
\hline Dy & 3.62 & & 7.68 & 5.92 & 1.78 & 3.87 & & 4.32 & 1.85 & 3.82 & 2.66 & 6.49 & 1.62 & 1.27 \\
\hline Ho & 0.84 & & 1.74 & 1.20 & 0.32 & 0.77 & & 0.85 & 0.35 & 0.88 & 0.54 & 1.34 & 0.24 & 0.23 \\
\hline $\mathrm{Er}$ & 2.33 & & 5.04 & 3.23 & 0.87 & 2.23 & & 2.19 & 0.89 & 2.68 & 1.48 & 3.45 & 0.55 & 0.59 \\
\hline Tm & 0.36 & & 0.82 & 0.47 & 0.13 & 0.35 & & 0.33 & 0.13 & 0.43 & 0.21 & 0.47 & 0.06 & 0.08 \\
\hline $\mathrm{Yb}$ & 2.41 & & 5.53 & 3.09 & 0.88 & 2.46 & & 2.11 & 0.78 & 2.98 & 1.31 & 2.77 & 0.35 & 0.44 \\
\hline Lu & 0.36 & & 0.82 & 0.48 & 0.14 & 0.36 & & 0.31 & 0.12 & 0.47 & 0.20 & 0.37 & 0.06 & 0.07 \\
\hline $\mathrm{Hf}$ & 1.86 & & 7.53 & 13.3 & 4.02 & 4.27 & & 4.15 & 4.03 & 3.91 & 3.33 & 5.46 & 3.85 & 2.98 \\
\hline $\mathrm{Pb}$ & 5.09 & & 5.28 & 10.6 & 16.3 & 16.6 & & 13.6 & 22.0 & 11.1 & 12.1 & 11.7 & 30.3 & 12.3 \\
\hline Th & 0.93 & & 5.85 & 1.74 & 13.9 & 8.71 & & 8.30 & 8.51 & 2.03 & 3.67 & 8.80 & 22.2 & 3.17 \\
\hline U & 0.36 & & 2.42 & 0.66 & 4.55 & 3.31 & & 2.82 & 0.92 & 1.34 & 1.07 & 1.33 & 0.54 & 0.17 \\
\hline
\end{tabular}




\section{ANEXO IV}

(Dados de isótopos de neodímio em rocha-total) 


\begin{tabular}{lccccccc}
\hline Amostra & $\mathbf{S m}(\mathbf{p p m})$ & $\mathbf{N d}(\mathbf{p p m})$ & ${ }^{147} \mathbf{S m} /{ }^{144} \mathbf{N d}$ & ${ }^{143} \mathbf{N d} /{ }^{144} \mathbf{N d} \pm \mathbf{2 S E}$ & $\mathbf{T}_{\mathrm{DM}}(\mathbf{G a})$ & $\mathbf{t}(\mathbf{M a})$ & $\boldsymbol{\varepsilon N d}_{(\mathbf{t})}$ \\
\hline 1B & 7.72 & 31.0 & 0.1507 & $0.512092 \pm 5$ & 2.31 & 2140 & +1.90 \\
1E & 3.74 & 16.2 & 0.1397 & $0.511922 \pm 7$ & 2.32 & 2150 & +1.66 \\
1N & 9.78 & 40.7 & 0.1453 & $0.512064 \pm 6$ & 2.18 & 2140 & +2.85 \\
6 & 8.71 & 52.5 & 0.1003 & $0.511429 \pm 5$ & 2.17 & 2080 & +2.00 \\
7A & 1.59 & 7.72 & 0.1243 & $0.511681 \pm 8$ & 2.33 & 2140 & +1.09 \\
9A1 & 2.79 & 12.2 & 0.1385 & $0.511879 \pm 6$ & 2.37 & 2070 & +0.56 \\
9B & 5.26 & 28.4 & 0.1123 & $0.511508 \pm 8$ & 2.32 & 2070 & +0.24 \\
23B & 7.56 & 53.6 & 0.0853 & $0.511131 \pm 7$ & 2.28 & 2080 & +0.16 \\
23G & 2.32 & 11.1 & 0.1269 & $0.511732 \pm 10$ & 2.31 & 2150 & +1.48 \\
24A & 7.49 & 52.5 & 0.0863 & $0.511227 \pm 21$ & 2.18 & 2080 & +1.77 \\
48D & 8.72 & 46.6 & 0.1132 & $0.511530 \pm 6$ & 2.30 & 2080 & +0.54 \\
48C & 7.13 & 33.7 & 0.1280 & $0.511831 \pm 17$ & 2.16 & 2080 & +2.48 \\
48E & 3.97 & 26.3 & 0.0915 & $0.511299 \pm 6$ & 2.18 & 2080 & +1.79 \\
51 & 6.02 & 33.0 & 0.1103 & $0.511534 \pm 2$ & 2.23 & 2100 & +1.60 \\
A9I & 3.57 & 14.3 & 0.1509 & $0.511676 \pm 7$ & 3.41 & 3000 & -1.22 \\
A9K & 3.09 & 13.2 & 0.1416 & $0.511474 \pm 9$ & 3.40 & 3000 & -1.60 \\
C37 & 2.64 & 16.3 & 0.0978 & $0.510630 \pm 29$ & 3.22 & 2960 & -1.85 \\
C20 & 7.01 & 32.9 & 0.1291 & $0.511199 \pm 6$ & 3.39 & 2960 & -2.54 \\
C22 & 4.27 & 32.0 & 0.0807 & $0.510414 \pm 7$ & 3.04 & 2760 & -2.55 \\
& & & & & &
\end{tabular}




\section{ANEXO V}

(Dados U-Pb LA-ICP-MS em zircão) 


\begin{tabular}{|c|c|c|c|c|c|c|c|c|c|c|c|c|c|c|}
\hline \multirow[b]{2}{*}{ Spot } & \multirow[b]{2}{*}{$\mathrm{U}(\mathrm{ppm})$} & \multirow[b]{2}{*}{$\mathrm{Th}(\mathrm{ppm})$} & \multirow[b]{2}{*}{ Th/U } & \multicolumn{6}{|l|}{ Ratios } & \multicolumn{5}{|l|}{ Ages (Ma) } \\
\hline & & & & ${ }^{206} \mathrm{~Pb} /{ }^{238} \mathrm{U}$ & $\pm 2 \mathrm{SE}$ & ${ }^{207} \mathrm{~Pb} /{ }^{235} \mathrm{U}$ & \pm 2 SE & ${ }^{207} \mathrm{~Pb} /{ }^{206} \mathrm{~Pb}$ & $\pm 2 \mathrm{SE}$ & ${ }^{206} \mathrm{~Pb} /{ }^{238} \mathrm{U}$ & $\pm 2 \mathrm{SE}$ & ${ }^{207} \mathrm{~Pb} /{ }^{206} \mathrm{~Pb}$ & $\pm 2 \mathrm{SE}$ & Discordance (\% \\
\hline \multicolumn{15}{|c|}{ Sample $\mathbf{1 N}$} \\
\hline $02 c$ & 55.8 & 13.5 & 0.24 & 0.3882 & 0.0055 & 7.1500 & 0.1600 & 0.1345 & 0.0024 & 2113 & 25 & 2158 & 31 & -2.1 \\
\hline $03 c$ & 88.0 & 24.8 & 0.28 & 0.3926 & 0.0058 & 7.2300 & 0.1500 & 0.1331 & 0.0020 & 2134 & 27 & 2134 & 26 & 0.0 \\
\hline $03 r$ & 190.0 & 48.8 & 0.26 & 0.3926 & 0.0060 & 7.1300 & 0.1300 & 0.1317 & 0.0018 & 2137 & 27 & 2120 & 24 & 0.8 \\
\hline $04 c$ & 66.0 & 16.3 & 0.25 & 0.3972 & 0.0070 & 7.3500 & 0.1500 & 0.1345 & 0.0021 & 2154 & 32 & 2152 & 28 & 0.1 \\
\hline $04 r$ & 721.0 & 26.3 & 0.04 & 0.1814 & 0.0062 & 2.5100 & 0.1200 & 0.1004 & 0.0018 & 1073 & 34 & 1635 & 32 & -52.4 \\
\hline $05 c$ & 71.4 & 16.9 & 0.24 & 0.3909 & 0.0056 & 7.1300 & 0.1400 & 0.1328 & 0.0020 & 2129 & 27 & 2130 & 27 & 0.0 \\
\hline $06 c$ & 67.2 & 17.0 & 0.25 & 0.3886 & 0.0053 & 7.1000 & 0.1400 & 0.1322 & 0.0022 & 2115 & 25 & 2124 & 29 & -0.4 \\
\hline $09 r$ & 471.0 & 62.8 & 0.13 & 0.3309 & 0.0073 & 5.8100 & 0.1500 & 0.1279 & 0.0019 & 1841 & 35 & 2069 & 27 & -12.4 \\
\hline $09 c$ & 53.2 & 12.1 & 0.23 & 0.4015 & 0.0070 & 7.4200 & 0.1500 & 0.1348 & 0.0023 & 2174 & 32 & 2159 & 31 & 0.7 \\
\hline $12 \mathrm{c}$ & 84.5 & 25.7 & 0.30 & 0.3928 & 0.0049 & 7.1740 & 0.1200 & 0.1327 & 0.0018 & 2135 & 23 & 2139 & 23 & -0.2 \\
\hline $15 c$ & 72.7 & 22.0 & 0.30 & 0.4029 & 0.0056 & 7.3200 & 0.1300 & 0.1317 & 0.0020 & 2185 & 25 & 2121 & 27 & 2.9 \\
\hline $17 \mathrm{c}$ & 106.5 & 28.2 & 0.26 & 0.3895 & 0.0060 & 7.0790 & 0.1200 & 0.1314 & 0.0019 & 2119 & 28 & 2113 & 25 & 0.3 \\
\hline $16 \mathrm{c}$ & 93.6 & 30.6 & 0.33 & 0.3997 & 0.0065 & 7.3500 & 0.1500 & 0.1338 & 0.0019 & 2167 & 30 & 2145 & 25 & 1.0 \\
\hline $19 r$ & 121.8 & 30.9 & 0.25 & 0.3861 & 0.0065 & 7.0900 & 0.1500 & 0.1324 & 0.0023 & 2103 & 30 & 2129 & 30 & -1.2 \\
\hline $21 c$ & 62.9 & 18.7 & 0.30 & 0.3940 & 0.0053 & 7.2000 & 0.1300 & 0.1326 & 0.0018 & 2141 & 24 & 2130 & 24 & 0.5 \\
\hline 22 & 92.7 & 25.7 & 0.28 & 0.3832 & 0.0051 & 6.9900 & 0.1200 & 0.1334 & 0.0016 & 2090 & 24 & 2140 & 22 & -2.4 \\
\hline $23 c$ & 105.2 & 34.0 & 0.32 & 0.3840 & 0.0056 & 6.9940 & 0.1200 & 0.1323 & 0.0018 & 2094 & 26 & 2126 & 23 & -1.5 \\
\hline $23 r$ & 140.1 & 38.2 & 0.27 & 0.3647 & 0.0044 & 6.5400 & 0.1000 & 0.1299 & 0.0018 & 2004 & 21 & 2098 & 25 & -4.7 \\
\hline $26 c$ & 99.0 & 28.9 & 0.29 & 0.4049 & 0.0062 & 7.3400 & 0.1300 & 0.1315 & 0.0018 & 2193 & 28 & 2122 & 23 & 3.2 \\
\hline $28 \mathrm{c}$ & 74.4 & 21.9 & 0.29 & 0.3792 & 0.0051 & 7.0170 & 0.1200 & 0.1345 & 0.0018 & 2071 & 24 & 2154 & 24 & -4.0 \\
\hline $29 r$ & 103.6 & 31.3 & 0.30 & 0.3974 & 0.0045 & 7.3600 & 0.1200 & 0.1345 & 0.0017 & 2156 & 20 & 2154 & 22 & 0.1 \\
\hline $29 c$ & 63.0 & 15.7 & 0.25 & 0.4048 & 0.0047 & 7.3400 & 0.1300 & 0.1327 & 0.0018 & 2190 & 22 & 2133 & 25 & 2.6 \\
\hline 30 & 59.2 & 15.0 & 0.25 & 0.3789 & 0.0053 & 6.9920 & 0.1200 & 0.1326 & 0.0020 & 2076 & 24 & 2138 & 25 & -3.0 \\
\hline 31 & 137.5 & 44.6 & 0.32 & 0.3896 & 0.0043 & 7.1050 & 0.1100 & 0.1324 & 0.0016 & 2120 & 20 & 2130 & 21 & -0.5 \\
\hline 32 & 82.6 & 19.9 & 0.24 & 0.3747 & 0.0057 & 6.7870 & 0.1200 & 0.1305 & 0.0019 & 2050 & 27 & 2103 & 26 & -2.6 \\
\hline 33 & 50.4 & 14.7 & 0.29 & 0.4000 & 0.0053 & 7.3900 & 0.1400 & 0.1337 & 0.0020 & 2168 & 24 & 2150 & 27 & 0.8 \\
\hline 34 & 70.1 & 21.3 & 0.30 & 0.3984 & 0.0054 & 7.2690 & 0.1200 & 0.1318 & 0.0019 & 2161 & 25 & 2121 & 25 & 1.9 \\
\hline $35 c$ & 275.0 & 128.1 & 0.47 & 0.3958 & 0.0065 & 7.1960 & 0.1200 & 0.1317 & 0.0015 & 2152 & 31 & 2119 & 21 & 1.5 \\
\hline 36 & 36.6 & 8.9 & 0.24 & 0.3940 & 0.0048 & 7.2200 & 0.1400 & 0.1341 & 0.0019 & 2140 & 22 & 2152 & 25 & -0.6 \\
\hline 37 & 100.7 & 27.3 & 0.27 & 0.4009 & 0.0063 & 7.3200 & 0.1700 & 0.1327 & 0.0023 & 2172 & 29 & 2141 & 32 & 1.4 \\
\hline $39 c$ & 101.6 & 33.6 & 0.33 & 0.3983 & 0.0055 & 7.3700 & 0.1400 & 0.1333 & 0.0017 & 2160 & 25 & 2142 & 21 & 0.8 \\
\hline 40 & 212.1 & 56.7 & 0.27 & 0.4090 & 0.0056 & 7.4100 & 0.1300 & 0.1330 & 0.0017 & 2209 & 26 & 2139 & 23 & 3.2 \\
\hline 41 & 78.6 & 26.0 & 0.33 & 0.3954 & 0.0046 & 7.2600 & 0.1200 & 0.1325 & 0.0017 & 2147 & 21 & 2130 & 22 & 0.8 \\
\hline $43 c$ & 77.8 & 12.9 & 0.17 & 0.3818 & 0.0069 & 6.9700 & 0.1600 & 0.1318 & 0.0018 & 2083 & 32 & 2119 & 24 & -1.7 \\
\hline $43 r$ & 108.1 & 25.7 & 0.24 & 0.3884 & 0.0054 & 7.0770 & 0.1200 & 0.1323 & 0.0017 & 2114 & 25 & 2134 & 21 & -0.9 \\
\hline $45 c$ & 76.6 & 24.3 & 0.32 & 0.3869 & 0.0061 & 7.0400 & 0.1300 & 0.1305 & 0.0018 & 2107 & 28 & 2109 & 24 & -0.1 \\
\hline $47 c$ & 90.5 & 26.3 & 0.29 & 0.3745 & 0.0051 & 6.7860 & 0.1200 & 0.1304 & 0.0017 & 2050 & 24 & 2107 & 22 & -2.8 \\
\hline $47 r$ & 134.9 & 35.1 & 0.26 & 0.3770 & 0.0051 & 6.8470 & 0.1200 & 0.1316 & 0.0017 & 2061 & 24 & 2119 & 23 & -2.8 \\
\hline 48 & 69.1 & 17.8 & 0.26 & 0.3960 & 0.0053 & 7.2200 & 0.1300 & 0.1316 & 0.0019 & 2150 & 25 & 2115 & 25 & 1.6 \\
\hline $50 \mathrm{r}$ & 45.0 & 9.1 & 0.20 & 0.3994 & 0.0071 & 7.3300 & 0.1400 & 0.1329 & 0.0020 & 2165 & 33 & 2135 & 27 & 1.4 \\
\hline $51 \mathrm{c}$ & 64.9 & 18.2 & 0.28 & 0.3991 & 0.0055 & 7.2490 & 0.1200 & 0.1322 & 0.0018 & 2164 & 25 & 2129 & 23 & 1.6 \\
\hline $51 r$ & 143.0 & 42.4 & 0.30 & 0.3752 & 0.0041 & 6.7920 & 0.1000 & 0.1307 & 0.0015 & 2053 & 19 & 2110 & 21 & -2.8 \\
\hline 52 & 75.7 & 20.1 & 0.27 & 0.3931 & 0.0055 & 7.1710 & 0.1200 & 0.1322 & 0.0019 & 2136 & 25 & 2124 & 24 & 0.6 \\
\hline 55 & 66.1 & 18.6 & 0.28 & 0.3947 & 0.0050 & 7.2490 & 0.1200 & 0.1331 & 0.0018 & 2144 & 23 & 2139 & 23 & 0.2 \\
\hline
\end{tabular}




\begin{tabular}{|c|c|c|c|c|c|c|c|c|c|c|c|c|c|c|}
\hline 57 & 86.6 & 26.6 & 0.31 & 0.3977 & 0.0043 & 7.3130 & 0.1200 & 0.1339 & 0.0017 & 2158 & 20 & 2155 & 21 & 0.1 \\
\hline 58 & 68.2 & 21.2 & 0.31 & 0.4013 & 0.0048 & 7.3880 & 0.1300 & 0.1336 & 0.0016 & 2175 & 22 & 2143 & 21 & 1.5 \\
\hline $61 c$ & 81.8 & 28.7 & 0.35 & 0.4064 & 0.0048 & 7.4700 & 0.1300 & 0.1335 & 0.0019 & 2198 & 22 & 2147 & 24 & 2.3 \\
\hline $61 r$ & 157.8 & 37.0 & 0.23 & 0.3784 & 0.0050 & 6.9340 & 0.1200 & 0.1321 & 0.0018 & 2068 & 24 & 2126 & 23 & -2.8 \\
\hline 63 & 62.1 & 16.6 & 0.27 & 0.3924 & 0.0053 & 7.2640 & 0.1300 & 0.1332 & 0.0017 & 2133 & 24 & 2138 & 22 & -0.2 \\
\hline $65 r$ & 179.0 & 37.2 & 0.21 & 0.3826 & 0.0046 & 7.0140 & 0.1100 & 0.1324 & 0.0015 & 2087 & 22 & 2129 & 20 & -2.0 \\
\hline 68 & 59.4 & 14.3 & 0.24 & 0.3790 & 0.0056 & 6.9200 & 0.1500 & 0.1320 & 0.0021 & 2070 & 26 & 2120 & 28 & -2.4 \\
\hline 71 & 58.7 & 16.4 & 0.28 & 0.3946 & 0.0047 & 7.2700 & 0.1300 & 0.1335 & 0.0020 & 2144 & 22 & 2141 & 26 & 0.1 \\
\hline 72 & 69.4 & 17.4 & 0.25 & 0.3965 & 0.0043 & 7.3060 & 0.1300 & 0.1333 & 0.0018 & 2155 & 20 & 2146 & 24 & 0.4 \\
\hline 74 & 75.8 & 20.5 & 0.27 & 0.3924 & 0.0048 & 7.2300 & 0.1300 & 0.1325 & 0.0017 & 2133 & 22 & 2128 & 23 & 0.2 \\
\hline 76 & 70.9 & 20.5 & 0.29 & 0.3945 & 0.0054 & 7.3020 & 0.1200 & 0.1331 & 0.0019 & 2146 & 25 & 2135 & 24 & 0.5 \\
\hline $77 c$ & 83.9 & 25.6 & 0.30 & 0.3746 & 0.0052 & 6.8710 & 0.1200 & 0.1324 & 0.0018 & 2050 & 24 & 2126 & 24 & -3.7 \\
\hline $77 r$ & 80.2 & 20.6 & 0.26 & 0.3873 & 0.0052 & 7.1070 & 0.1200 & 0.1324 & 0.0020 & 2109 & 24 & 2132 & 25 & -1.1 \\
\hline $78 r$ & 90.3 & 25.6 & 0.28 & 0.4049 & 0.0067 & 7.4400 & 0.1300 & 0.1330 & 0.0018 & 2190 & 31 & 2134 & 23 & 2.6 \\
\hline $78 c$ & 105.2 & 37.5 & 0.36 & 0.3936 & 0.0048 & 7.1820 & 0.1100 & 0.1323 & 0.0017 & 2139 & 22 & 2135 & 21 & 0.2 \\
\hline 80 & 68.2 & 18.7 & 0.27 & 0.3884 & 0.0041 & 7.1410 & 0.1200 & 0.1326 & 0.0020 & 2115 & 19 & 2131 & 26 & -0.8 \\
\hline 81 & 80.2 & 28.3 & 0.35 & 0.3610 & 0.0052 & 6.6000 & 0.1300 & 0.1317 & 0.0017 & 1986 & 24 & 2120 & 23 & -6.7 \\
\hline $83 c$ & 75.1 & 23.3 & 0.31 & 0.4018 & 0.0055 & 7.4920 & 0.1300 & 0.1335 & 0.0019 & 2176 & 25 & 2143 & 25 & 1.5 \\
\hline $83 r$ & 182.0 & 46.3 & 0.25 & 0.3774 & 0.0040 & 6.9580 & 0.1100 & 0.1333 & 0.0015 & 2063 & 19 & 2140 & 19 & -3.7 \\
\hline \multirow[t]{2}{*}{85} & 78.3 & 24.8 & 0.32 & 0.4001 & 0.0056 & 7.3770 & 0.1200 & 0.1340 & 0.0017 & 2168 & 26 & 2150 & 21 & 0.8 \\
\hline & & & & Ratios & & & & & & Ages (Ma) & & & & \\
\hline Spot & $\mathrm{U}(\mathrm{ppm})$ & Th(ppm) & $\mathrm{Th} / \mathrm{U}$ & ${ }^{206} \mathrm{~Pb} /{ }^{238} \mathrm{U}$ & $\pm 2 \mathrm{SE}$ & ${ }^{207} \mathrm{~Pb} /{ }^{235} \mathrm{U}$ & $\pm 2 \mathrm{SE}$ & ${ }^{207} \mathrm{~Pb} /{ }^{206} \mathrm{~Pb}$ & $\pm 2 \mathrm{SE}$ & ${ }^{206} \mathrm{~Pb} /{ }^{238} \mathrm{U}$ & $\pm 2 \mathrm{SE}$ & ${ }^{207} \mathrm{~Pb} /{ }^{206} \mathrm{~Pb}$ & $\pm 2 \mathrm{SE}$ & Discordance $(\%)^{\mathrm{a}}$ \\
\hline
\end{tabular}

\begin{tabular}{|c|c|c|c|c|c|c|c|c|c|c|c|c|c|c|}
\hline \multicolumn{15}{|c|}{ Sample 1E } \\
\hline 17.1 & 648.1 & 1.5 & $<0.01$ & 0.0940 & 0.0020 & 0.7835 & 0.0510 & 0.0605 & 0.0040 & 579 & 12 & 620 & 144 & -7.1 \\
\hline 18.1 & 159.5 & 3.3 & 0.02 & 0.0947 & 0.0034 & 0.7713 & 0.1410 & 0.0591 & 0.0116 & 583 & 20 & 570 & 428 & 2.2 \\
\hline 1.1 & 1785.9 & 4.7 & $<0.01$ & 0.0955 & 0.0022 & 0.7852 & 0.0320 & 0.0596 & 0.0020 & 588 & 14 & 589 & 74 & -0.2 \\
\hline 14.1 & 350.7 & $<0.1$ & $<0.01$ & 0.0955 & 0.0024 & 0.7686 & 0.0784 & 0.0584 & 0.0062 & 588 & 14 & 545 & 228 & 7.3 \\
\hline 7.1 & 261.8 & 1.2 & $<0.01$ & 0.0956 & 0.0034 & 0.7748 & 0.0732 & 0.0588 & 0.0058 & 589 & 20 & 559 & 212 & 5.1 \\
\hline 20.1 & 466.0 & 3.0 & $<0.01$ & 0.0960 & 0.0026 & 0.7606 & 0.0882 & 0.0575 & 0.0070 & 591 & 16 & 509 & 272 & 13.9 \\
\hline 2.2 & 292.1 & $<0.1$ & $<0.01$ & 0.0963 & 0.0032 & 0.8362 & 0.0698 & 0.0630 & 0.0054 & 592 & 20 & 708 & 186 & -19.6 \\
\hline 5.2 & 227.0 & 0.3 & $<0.01$ & 0.0962 & 0.0036 & 0.8097 & 0.0784 & 0.0610 & 0.0060 & 592 & 20 & 641 & 208 & -8.3 \\
\hline 6.1 & 531.1 & 1.8 & $<0.01$ & 0.0962 & 0.0026 & 0.8011 & 0.0470 & 0.0604 & 0.0034 & 592 & 16 & 617 & 118 & -4.2 \\
\hline 22.1 & 1014.1 & 11.2 & 0.01 & 0.0964 & 0.0018 & 0.7975 & 0.0422 & 0.0600 & 0.0032 & 593 & 10 & 604 & 112 & -1.9 \\
\hline 13.1 & 394.8 & 1.3 & $<0.01$ & 0.0978 & 0.0022 & 0.8146 & 0.0606 & 0.0604 & 0.0046 & 602 & 12 & 617 & 164 & -2.5 \\
\hline 3.2 & 348.3 & 0.5 & $<0.01$ & 0.0982 & 0.0036 & 0.8218 & 0.0806 & 0.0607 & 0.0064 & 604 & 22 & 629 & 228 & -4.1 \\
\hline 16.2 & 335.4 & 0.4 & $<0.01$ & 0.0982 & 0.0026 & 0.8137 & 0.0844 & 0.0601 & 0.0066 & 604 & 14 & 608 & 240 & -0.7 \\
\hline 10.1 & 280.8 & 1.1 & $<0.01$ & 0.0993 & 0.0036 & 0.8509 & 0.0816 & 0.0622 & 0.0064 & 610 & 22 & 679 & 222 & -11.3 \\
\hline 15.1 & 102.6 & 25.8 & 0.25 & 0.3505 & 0.0088 & 6.2900 & 0.3664 & 0.1302 & 0.0078 & 1937 & 42 & 2100 & 106 & -8.4 \\
\hline 21.1 & 114.3 & 26.5 & 0.23 & 0.3552 & 0.0080 & 6.4785 & 0.3188 & 0.1323 & 0.0064 & 1959 & 38 & 2129 & 86 & -8.7 \\
\hline 8.1 & 182.1 & 67.3 & 0.37 & 0.3670 & 0.0092 & 6.7377 & 0.2636 & 0.1332 & 0.0046 & 2015 & 44 & 2140 & 62 & -6.2 \\
\hline 16.1 & 300.3 & 152.6 & 0.51 & 0.3669 & 0.0072 & 6.6810 & 0.2640 & 0.1321 & 0.0050 & 2015 & 34 & 2126 & 66 & -5.5 \\
\hline 11.1 & 101.0 & 31.3 & 0.31 & 0.3702 & 0.0094 & 6.7867 & 0.3920 & 0.1330 & 0.0078 & 2030 & 44 & 2137 & 104 & -5.3 \\
\hline 12.1 & 252.9 & 149.7 & 0.59 & 0.3726 & 0.0072 & 6.8288 & 0.2764 & 0.1329 & 0.0052 & 2042 & 34 & 2137 & 68 & -4.7 \\
\hline 4.1 & 194.1 & 52.6 & 0.27 & 0.3763 & 0.0100 & 6.8387 & 0.2854 & 0.1318 & 0.0048 & 2059 & 46 & 2122 & 64 & -3.1 \\
\hline 19.1 & 296.8 & 123.3 & 0.42 & 0.3764 & 0.0068 & 6.8790 & 0.2420 & 0.1326 & 0.0044 & 2059 & 32 & 2132 & 58 & -3.5 \\
\hline 2.1 & 150.3 & 37.3 & 0.25 & 0.3766 & 0.0106 & 6.8696 & 0.3066 & 0.1323 & 0.0052 & 2061 & 50 & 2129 & 70 & -3.3 \\
\hline 5.1 & 184.1 & 60.9 & 0.33 & 0.3766 & 0.0096 & 6.8941 & 0.2784 & 0.1328 & 0.0048 & 2061 & 46 & 2135 & 62 & -3.6 \\
\hline
\end{tabular}




\begin{tabular}{|c|c|c|c|c|c|c|c|c|c|c|c|c|c|c|}
\hline 9.1 & 257.3 & 127.8 & 0.50 & 0.3823 & 0.0094 & 6.9503 & 0.2682 & 0.1318 & 0.0044 & 2087 & 44 & 2123 & 60 & -1.7 \\
\hline 3.1 & 382.4 & 208.1 & 0.54 & 0.3840 & 0.0088 & 6.9852 & 0.2498 & 0.1319 & 0.0040 & 2095 & 40 & 2124 & 52 & -1.4 \\
\hline \multirow[b]{2}{*}{ Spot } & \multirow[b]{2}{*}{$\mathrm{U}(\mathrm{ppm})$} & \multirow[b]{2}{*}{ Th(ppm) } & \multirow[b]{2}{*}{ Th/U } & \multicolumn{6}{|l|}{ Ratios } & \multicolumn{5}{|l|}{ Ages (Ma) } \\
\hline & & & & ${ }^{206} \mathrm{~Pb} /{ }^{238} \mathrm{U}$ & $\pm 2 \mathrm{SE}$ & ${ }^{207} \mathrm{~Pb} /{ }^{235} \mathrm{U}$ & $\pm 2 \mathrm{SE}$ & ${ }^{207} \mathrm{~Pb} /{ }^{206} \mathrm{~Pb}$ & $\pm 2 \mathrm{SE}$ & ${ }^{206} \mathrm{~Pb} /{ }^{238} \mathrm{U}$ & $\pm 2 \mathrm{SE}$ & ${ }^{207} \mathrm{~Pb} /{ }^{206} \mathrm{~Pb}$ & $\pm 2 \mathrm{SE}$ & Discordance (\%) \\
\hline \multicolumn{15}{|c|}{ Sample 7A } \\
\hline 13.1 & 100.5 & 36.9 & 0.37 & 0.3652 & 0.0112 & 6.6559 & 0.5886 & 0.1322 & 0.0122 & 2007 & 52 & 2127 & 162 & -6.0 \\
\hline 3.1 & 85.5 & 22.8 & 0.27 & 0.3742 & 0.0112 & 7.0538 & 0.4976 & 0.1367 & 0.0100 & 2049 & 52 & 2186 & 128 & -6.7 \\
\hline 6.1 & 125.4 & 49.8 & 0.40 & 0.3748 & 0.0096 & 6.8509 & 0.4014 & 0.1326 & 0.0078 & 2052 & 44 & 2132 & 102 & -3.9 \\
\hline 10.1 & 330.2 & 126.9 & 0.38 & 0.3772 & 0.0078 & 6.8601 & 0.3056 & 0.1319 & 0.0056 & 2063 & 36 & 2124 & 76 & -3.0 \\
\hline 23.1 & 61.5 & 16.5 & 0.27 & 0.3802 & 0.0132 & 7.0705 & 0.6960 & 0.1349 & 0.0138 & 2077 & 62 & 2163 & 180 & -4.1 \\
\hline 11.1 & 69.5 & 24.1 & 0.35 & 0.3817 & 0.0126 & 7.1810 & 0.5758 & 0.1364 & 0.0112 & 2084 & 58 & 2183 & 148 & -4.8 \\
\hline 12.1 & 90.8 & 25.2 & 0.28 & 0.3818 & 0.0110 & 6.9655 & 0.4746 & 0.1323 & 0.0092 & 2085 & 52 & 2129 & 124 & -2.1 \\
\hline 10.2 & 102.4 & 28.6 & 0.28 & 0.3820 & 0.0106 & 7.0317 & 0.4574 & 0.1335 & 0.0088 & 2086 & 50 & 2145 & 116 & -2.8 \\
\hline 25.1 & 87.5 & 25.6 & 0.29 & 0.3833 & 0.0116 & 7.1351 & 0.6232 & 0.1350 & 0.0120 & 2092 & 54 & 2164 & 156 & -3.4 \\
\hline 7.1 & 79.5 & 31.4 & 0.40 & 0.3843 & 0.0112 & 7.2196 & 0.4906 & 0.1362 & 0.0096 & 2096 & 52 & 2180 & 122 & -4.0 \\
\hline 24.1 & 84.2 & 23.4 & 0.28 & 0.3851 & 0.0124 & 6.9872 & 0.6574 & 0.1316 & 0.0130 & 2100 & 58 & 2119 & 168 & -0.9 \\
\hline 9.1 & 102.2 & 37.1 & 0.36 & 0.3858 & 0.0110 & 7.2414 & 0.4894 & 0.1361 & 0.0094 & 2103 & 52 & 2178 & 122 & -3.6 \\
\hline 5.1 & 150.2 & 66.7 & 0.44 & 0.3865 & 0.0102 & 6.9370 & 0.4346 & 0.1302 & 0.0084 & 2106 & 48 & 2100 & 112 & 0.3 \\
\hline 4.1 & 70.6 & 18.3 & 0.26 & 0.3865 & 0.0124 & 7.0062 & 0.5560 & 0.1315 & 0.0110 & 2107 & 58 & 2118 & 140 & -0.5 \\
\hline 8.1 & 86.6 & 23.1 & 0.27 & 0.3871 & 0.0108 & 7.1473 & 0.4608 & 0.1339 & 0.0088 & 2109 & 50 & 2150 & 116 & -1.9 \\
\hline 2.1 & 60.0 & 18.9 & 0.32 & 0.3881 & 0.0132 & 7.1906 & 0.5986 & 0.1344 & 0.0120 & 2114 & 60 & 2156 & 156 & -2.0 \\
\hline 19.1 & 258.5 & 59.0 & 0.23 & 0.3913 & 0.0082 & 7.1056 & 0.4282 & 0.1317 & 0.0080 & 2129 & 38 & 2121 & 106 & 0.4 \\
\hline 1.1 & 119.6 & 37.3 & 0.31 & 0.3932 & 0.0112 & 7.2620 & 0.4944 & 0.1340 & 0.0092 & 2138 & 52 & 2151 & 120 & -0.6 \\
\hline 14.1 & 80.9 & 27.2 & 0.34 & 0.3965 & 0.0112 & 7.3360 & 0.5830 & 0.1342 & 0.0114 & 2153 & 52 & 2154 & 150 & 0.0 \\
\hline 17.1 & 134.1 & 48.4 & 0.36 & 0.3971 & 0.0096 & 7.3228 & 0.5030 & 0.1338 & 0.0092 & 2155 & 44 & 2148 & 122 & 0.3 \\
\hline 15.1 & 62.9 & 17.8 & 0.28 & 0.3982 & 0.0106 & 7.3572 & 0.5482 & 0.1340 & 0.0102 & 2161 & 48 & 2151 & 134 & 0.5 \\
\hline 16.1 & 131.5 & 36.8 & 0.28 & 0.3991 & 0.0096 & 7.3311 & 0.4996 & 0.1332 & 0.0094 & 2165 & 44 & 2141 & 124 & 1.1 \\
\hline 20.1 & 92.6 & 23.6 & 0.25 & 0.4010 & 0.0120 & 7.1500 & 0.6148 & 0.1293 & 0.0114 & 2174 & 54 & 2089 & 156 & 3.9 \\
\hline 21.1 & 122.6 & 26.9 & 0.22 & 0.4016 & 0.0112 & 7.3807 & 0.5794 & 0.1333 & 0.0106 & 2176 & 52 & 2142 & 144 & 1.6 \\
\hline 22.1 & 76.7 & 21.5 & 0.28 & 0.4048 & 0.0136 & 7.5755 & 0.7152 & 0.1357 & 0.0132 & 2191 & 62 & 2174 & 172 & 0.8 \\
\hline 18.1 & 95.4 & 31.1 & 0.33 & 0.4153 & 0.0122 & 7.5711 & 0.6416 & 0.1322 & 0.0118 & 2239 & 56 & 2128 & 152 & 5.0 \\
\hline
\end{tabular}

$$
\text { Ratios } A \text { Ages (Ma) }
$$

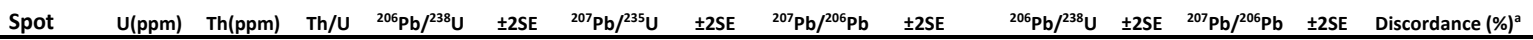
Sample 7B

\begin{tabular}{|c|c|c|c|c|c|c|c|c|c|c|c|c|c|}
\hline 11.1 & 402.3 & 3.0 & $<0.01$ & 0.0984 & 0.0030 & 0.8300 & 0.0732 & 0.0612 & 0.0058 & 605 & 18 & 646 & 210 \\
\hline 5.1 & 108.4 & 20.1 & 0.19 & 0.3044 & 0.0102 & 5.2767 & 0.3300 & 0.1257 & 0.0090 & 1713 & 50 & 2039 & 126 \\
\hline 7.1 & 501.7 & 122.0 & 0.24 & 0.3211 & 0.0068 & 5.6846 & 0.2262 & 0.1284 & 0.0048 & 1795 & 34 & 2076 & 66 \\
\hline 1.1 & 60.7 & 16.2 & 0.27 & 0.3234 & 0.0152 & 5.8608 & 0.5066 & 0.1315 & 0.0132 & 1806 & 74 & 2118 & 180 \\
\hline 10.1 & 85.5 & 38.7 & 0.45 & 0.3524 & 0.0162 & 6.5830 & 0.5504 & 0.1355 & 0.0132 & 1946 & 78 & 2170 & 170 \\
\hline 8.1 & 64.1 & 16.7 & 0.26 & 0.3592 & 0.0150 & 6.3233 & 0.4954 & 0.1277 & 0.0116 & 1978 & 72 & 2066 & 158 \\
\hline 6.2 & 93.3 & 16.6 & 0.18 & 0.3751 & 0.0124 & 6.9126 & 0.4110 & 0.1337 & 0.0084 & 2053 & 58 & 2147 & 112 \\
\hline 9.1 & 52.9 & 16.3 & 0.31 & 0.3760 & 0.0186 & 6.8887 & 0.6142 & 0.1329 & 0.0136 & 2057 & 86 & 2136 & 180 \\
\hline 3.1 & 79.1 & 44.2 & 0.56 & 0.3789 & 0.0114 & 6.8863 & 0.3784 & 0.1318 & 0.0082 & 2071 & 54 & 2122 & 112 \\
\hline 10.2 & 54.2 & 18.4 & 0.34 & 0.3795 & 0.0172 & 7.1042 & 0.5746 & 0.1358 & 0.0126 & 2074 & 80 & 2174 & 166 \\
\hline 4.1 & 42.5 & 16.4 & 0.39 & 0.3867 & 0.0202 & 7.1712 & 0.6758 & 0.1345 & 0.0150 & 2107 & 94 & 2158 & 194 \\
\hline 2.1 & 88.0 & 41.9 & 0.48 & 0.3924 & 0.0142 & 7.1460 & 0.4748 & 0.1321 & 0.0096 & 2134 & 66 & 2126 & 128 \\
\hline 6.1 & 40.2 & 8.8 & 0.22 & 0.3924 & 0.0208 & 6.9144 & 0.6730 & 0.1278 & 0.0142 & 2134 & 94 & 2068 & 190 \\
\hline
\end{tabular}




\begin{tabular}{|c|c|c|c|c|c|c|c|c|c|c|c|c|c|c|}
\hline \multirow[b]{2}{*}{ Spot } & \multirow[b]{2}{*}{$U($ ppm) } & \multirow[b]{2}{*}{$T h(p p m)$} & \multirow[b]{2}{*}{$T h / U$} & \multicolumn{6}{|l|}{ Ratios } & \multicolumn{5}{|l|}{ Ages (Ma) } \\
\hline & & & & ${ }^{206} \mathrm{~Pb} /{ }^{238} \mathrm{U}$ & $\pm 2 \mathrm{SE}$ & ${ }^{207} \mathrm{~Pb} /{ }^{235} \mathrm{U}$ & $\pm 2 \mathrm{SE}$ & ${ }^{207} \mathrm{~Pb} /{ }^{206} \mathrm{~Pb}$ & $\pm 2 \mathrm{SE}$ & ${ }^{206} \mathrm{~Pb} /{ }^{238} \mathrm{U}$ & $\pm 2 \mathrm{SE}$ & ${ }^{207} \mathrm{~Pb} /{ }^{206} \mathrm{~Pb}$ & $\pm 2 \mathrm{SE}$ & Discordance ( \\
\hline \multicolumn{15}{|c|}{ Sample 26} \\
\hline $44 r$ & 551.0 & 105.3 & 0.19 & 0.1790 & 0.0110 & 2.7900 & 0.1900 & 0.1146 & 0.0016 & 1054 & 61 & 1876 & 23 & -78.0 \\
\hline $101 \mathrm{r}$ & 485.0 & 108.1 & 0.22 & 0.1988 & 0.0044 & 3.0430 & 0.0760 & 0.1101 & 0.0012 & 1168 & 23 & 1800 & 20 & -54.1 \\
\hline 35 & 535.0 & 72.7 & 0.14 & 0.1996 & 0.0051 & 3.1100 & 0.1100 & 0.1136 & 0.0016 & 1172 & 27 & 1853 & 25 & -58.1 \\
\hline $83 r$ & 418.0 & 84.0 & 0.20 & 0.2063 & 0.0033 & 3.1150 & 0.0610 & 0.1100 & 0.0009 & 1209 & 18 & 1798 & 15 & -48.7 \\
\hline 39 & 433.0 & 71.0 & 0.16 & 0.2330 & 0.0060 & 3.6700 & 0.1100 & 0.1159 & 0.0014 & 1352 & 31 & 1890 & 22 & -39.8 \\
\hline 25 & 217.0 & 72.9 & 0.34 & 0.2420 & 0.0120 & 3.8200 & 0.2400 & 0.1123 & 0.0029 & 1389 & 62 & 1835 & 46 & -32.1 \\
\hline $82 r$ & 423.7 & 91.5 & 0.22 & 0.2360 & 0.0110 & 3.8200 & 0.2200 & 0.1143 & 0.0017 & 1361 & 58 & 1866 & 27 & -37.1 \\
\hline $31 r$ & 379.0 & 72.6 & 0.19 & 0.2411 & 0.0070 & 3.9100 & 0.1200 & 0.1163 & 0.0016 & 1390 & 37 & 1899 & 23 & -36.6 \\
\hline $68 \mathrm{r}$ & 397.0 & 38.4 & 0.10 & 0.2458 & 0.0080 & 3.9100 & 0.1600 & 0.1155 & 0.0015 & 1422 & 41 & 1884 & 23 & -32.5 \\
\hline 50 & 419.0 & 86.5 & 0.21 & 0.2603 & 0.0038 & 4.2520 & 0.0580 & 0.1180 & 0.0011 & 1496 & 20 & 1925 & 17 & -28.7 \\
\hline $15 r$ & 328.9 & 52.1 & 0.16 & 0.2618 & 0.0081 & 4.3300 & 0.1500 & 0.1194 & 0.0015 & 1496 & 41 & 1944 & 22 & -29.9 \\
\hline $98 r$ & 455.7 & 50.5 & 0.11 & 0.2700 & 0.0100 & 4.4100 & 0.2000 & 0.1171 & 0.0020 & 1537 & 52 & 1906 & 31 & -24.0 \\
\hline $67 r$ & 326.0 & 38.4 & 0.12 & 0.2749 & 0.0079 & 4.5200 & 0.1700 & 0.1195 & 0.0015 & 1563 & 41 & 1952 & 22 & -24.9 \\
\hline $27 r$ & 421.0 & 24.6 & 0.06 & 0.2843 & 0.0070 & 4.6000 & 0.1400 & 0.1190 & 0.0016 & 1615 & 36 & 1936 & 25 & -19.9 \\
\hline $42 r$ & 390.0 & 38.8 & 0.10 & 0.2834 & 0.0050 & 4.6230 & 0.0680 & 0.1189 & 0.0013 & 1614 & 26 & 1939 & 20 & -20.1 \\
\hline $73 r$ & 393.0 & 48.9 & 0.12 & 0.2855 & 0.0038 & 4.7120 & 0.0750 & 0.1198 & 0.0011 & 1618 & 19 & 1957 & 16 & -21.0 \\
\hline $104 r$ & 392.0 & 66.6 & 0.17 & 0.2837 & 0.0050 & 4.7240 & 0.0980 & 0.1216 & 0.0011 & 1609 & 25 & 1979 & 17 & -23.0 \\
\hline $69 r$ & 373.3 & 50.9 & 0.14 & 0.2970 & 0.0088 & 4.9600 & 0.1600 & 0.1228 & 0.0011 & 1673 & 44 & 1995 & 16 & -19.2 \\
\hline 54 & 284.0 & 38.7 & 0.14 & 0.3048 & 0.0057 & 5.2600 & 0.1000 & 0.1250 & 0.0016 & 1714 & 28 & 2035 & 24 & -18.7 \\
\hline 19 & 242.0 & 30.5 & 0.13 & 0.3048 & 0.0096 & 5.2700 & 0.1800 & 0.1262 & 0.0016 & 1711 & 47 & 2042 & 23 & -19.3 \\
\hline $40 r$ & 290.0 & 31.8 & 0.11 & 0.3147 & 0.0051 & 5.3820 & 0.0830 & 0.1237 & 0.0014 & 1766 & 26 & 2014 & 21 & -14.0 \\
\hline 95 & 312.0 & 41.8 & 0.13 & 0.3232 & 0.0040 & 5.6000 & 0.0650 & 0.1250 & 0.0010 & 1807 & 20 & 2028 & 15 & -12.2 \\
\hline $72 r$ & 203.0 & 26.2 & 0.13 & 0.3334 & 0.0042 & 5.7520 & 0.0670 & 0.1251 & 0.0010 & 1854 & 20 & 2033 & 15 & -9.7 \\
\hline $37 r$ & 263.0 & 40.0 & 0.15 & 0.3337 & 0.0062 & 5.7600 & 0.1200 & 0.1258 & 0.0014 & 1855 & 30 & 2039 & 18 & -9.9 \\
\hline 16 & 241.0 & 51.7 & 0.21 & 0.3394 & 0.0073 & 5.8500 & 0.1400 & 0.1267 & 0.0020 & 1882 & 35 & 2049 & 27 & -8.9 \\
\hline 94 & 245.0 & 33.4 & 0.14 & 0.3398 & 0.0047 & 5.8780 & 0.0980 & 0.1252 & 0.0011 & 1885 & 23 & 2032 & 16 & -7.8 \\
\hline $36 r$ & 247.0 & 29.3 & 0.12 & 0.3368 & 0.0041 & 5.8840 & 0.0780 & 0.1273 & 0.0015 & 1871 & 20 & 2064 & 20 & -10.3 \\
\hline 38 & 434.5 & 101.2 & 0.23 & 0.3446 & 0.0063 & 5.9800 & 0.1100 & 0.1269 & 0.0013 & 1908 & 30 & 2057 & 18 & -7.8 \\
\hline $61 \mathrm{r}$ & 259.9 & 34.1 & 0.13 & 0.3485 & 0.0044 & 6.0980 & 0.0800 & 0.1276 & 0.0012 & 1927 & 21 & 2065 & 16 & -7.2 \\
\hline $98 c$ & 255.3 & 53.0 & 0.21 & 0.3459 & 0.0095 & 6.1200 & 0.2100 & 0.1282 & 0.0014 & 1911 & 46 & 2070 & 19 & -8.3 \\
\hline $62 r$ & 235.0 & 48.8 & 0.21 & 0.3483 & 0.0062 & 6.1600 & 0.1100 & 0.1283 & 0.0015 & 1925 & 29 & 2081 & 21 & -8.1 \\
\hline 77 & 409.0 & 105.9 & 0.26 & 0.3522 & 0.0042 & 6.2860 & 0.0800 & 0.1302 & 0.0010 & 1944 & 20 & 2099 & 13 & -8.0 \\
\hline $52 r$ & 241.5 & 34.5 & 0.14 & 0.3603 & 0.0042 & 6.3540 & 0.0780 & 0.1275 & 0.0012 & 1983 & 20 & 2065 & 18 & -4.1 \\
\hline $48 r$ & 247.0 & 31.3 & 0.13 & 0.3595 & 0.0051 & 6.4180 & 0.0950 & 0.1293 & 0.0013 & 1987 & 25 & 2088 & 17 & -5.1 \\
\hline 3 & 312.6 & 13.5 & 0.04 & 0.3603 & 0.0063 & 6.4340 & 0.0970 & 0.1312 & 0.0016 & 1982 & 30 & 2116 & 20 & -6.8 \\
\hline $31 c$ & 247.0 & 63.8 & 0.26 & 0.3665 & 0.0051 & 6.4970 & 0.0880 & 0.1293 & 0.0012 & 2012 & 24 & 2087 & 16 & -3.7 \\
\hline $22 r$ & 102.7 & 26.9 & 0.26 & 0.3670 & 0.0110 & 6.5600 & 0.2000 & 0.1301 & 0.0019 & 2017 & 50 & 2099 & 24 & -4.1 \\
\hline $67 c$ & 249.0 & 182.0 & 0.73 & 0.3658 & 0.0054 & 6.6000 & 0.1000 & 0.1315 & 0.0013 & 2008 & 25 & 2116 & 17 & -5.4 \\
\hline 80 & 171.2 & 46.9 & 0.27 & 0.3733 & 0.0049 & 6.6010 & 0.0950 & 0.1281 & 0.0013 & 2044 & 23 & 2070 & 18 & -1.3 \\
\hline $11 r$ & 257.3 & 28.2 & 0.11 & 0.3733 & 0.0057 & 6.6320 & 0.0970 & 0.1290 & 0.0017 & 2044 & 27 & 2084 & 23 & -2.0 \\
\hline $44 c$ & 180.2 & 89.0 & 0.49 & 0.3746 & 0.0063 & 6.7100 & 0.1100 & 0.1305 & 0.0015 & 2053 & 30 & 2109 & 20 & -2.7 \\
\hline 81 & 77.0 & 28.2 & 0.37 & 0.3693 & 0.0041 & 6.7180 & 0.0880 & 0.1321 & 0.0011 & 2026 & 19 & 2127 & 15 & -5.0 \\
\hline $101 \mathrm{c}$ & 93.6 & 28.1 & 0.30 & 0.3750 & 0.0055 & 6.7300 & 0.0860 & 0.1314 & 0.0014 & 2052 & 26 & 2118 & 20 & -3.2 \\
\hline 55 & 212.0 & 47.2 & 0.22 & 0.3763 & 0.0052 & 6.8650 & 0.0880 & 0.1322 & 0.0013 & 2058 & 24 & 2125 & 17 & -3.3 \\
\hline
\end{tabular}




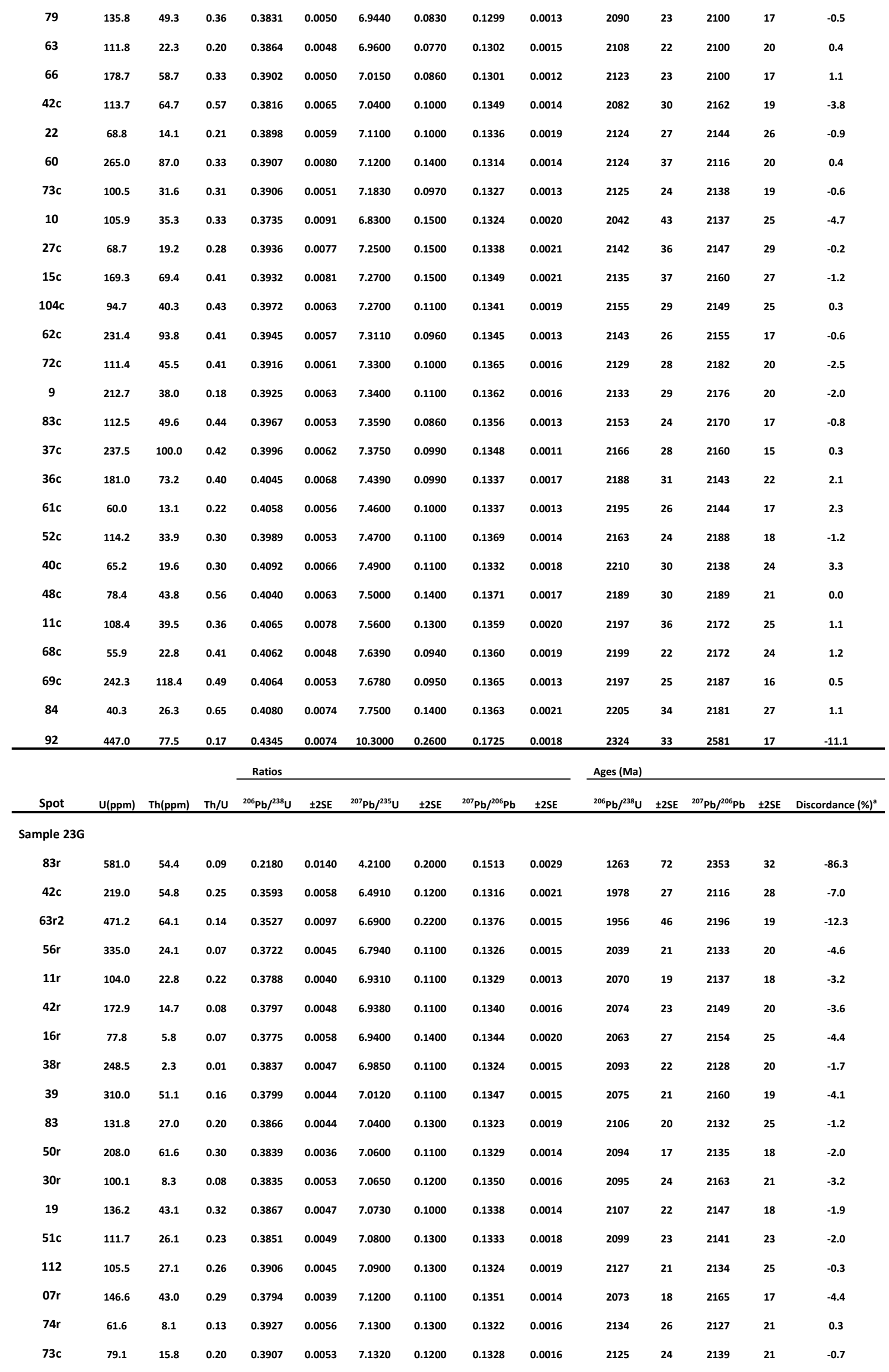




\begin{tabular}{|c|c|c|c|c|c|c|c|c|c|c|c|c|c|c|}
\hline 81 & 97.6 & 19.0 & 0.19 & 0.3938 & 0.0041 & 7.2060 & 0.1200 & 0.1330 & 0.0017 & 2142 & 20 & 2137 & 22 & 0.2 \\
\hline $25 r$ & 140.2 & 1.8 & 0.01 & 0.3965 & 0.0036 & 7.2180 & 0.1000 & 0.1333 & 0.0014 & 2152 & 17 & 2142 & 18 & 0.5 \\
\hline 1 & 200.0 & 62.1 & 0.31 & 0.3934 & 0.0054 & 7.2290 & 0.1200 & 0.1342 & 0.0014 & 2138 & 25 & 2154 & 18 & -0.7 \\
\hline 75 & 105.1 & 23.1 & 0.22 & 0.3960 & 0.0039 & 7.2500 & 0.1200 & 0.1340 & 0.0017 & 2153 & 18 & 2151 & 22 & 0.1 \\
\hline $57 c$ & 168.0 & 62.9 & 0.37 & 0.3952 & 0.0057 & 7.2800 & 0.1200 & 0.1346 & 0.0017 & 2149 & 27 & 2159 & 22 & -0.5 \\
\hline 92 & 156.1 & 35.0 & 0.22 & 0.3955 & 0.0053 & 7.2800 & 0.1300 & 0.1340 & 0.0016 & 2147 & 24 & 2152 & 21 & -0.2 \\
\hline $22 r$ & 57.7 & 4.9 & 0.08 & 0.3937 & 0.0053 & 7.2900 & 0.1300 & 0.1346 & 0.0019 & 2139 & 24 & 2155 & 24 & -0.7 \\
\hline $06 r$ & 203.3 & 64.5 & 0.32 & 0.3947 & 0.0043 & 7.3130 & 0.1200 & 0.1334 & 0.0014 & 2144 & 20 & 2146 & 17 & -0.1 \\
\hline $24 c$ & 126.8 & 27.7 & 0.22 & 0.3937 & 0.0043 & 7.3180 & 0.1100 & 0.1356 & 0.0015 & 2142 & 20 & 2170 & 19 & -1.3 \\
\hline $73 r$ & 124.7 & 30.3 & 0.24 & 0.3985 & 0.0042 & 7.3430 & 0.1200 & 0.1339 & 0.0017 & 2164 & 19 & 2148 & 21 & 0.7 \\
\hline $16 c 2$ & 201.5 & 60.2 & 0.30 & 0.3968 & 0.0049 & 7.3490 & 0.1100 & 0.1333 & 0.0015 & 2153 & 23 & 2146 & 20 & 0.3 \\
\hline 36 & 73.6 & 13.4 & 0.18 & 0.3983 & 0.0050 & 7.3500 & 0.1300 & 0.1342 & 0.0016 & 2166 & 23 & 2154 & 20 & 0.6 \\
\hline $05 c$ & 141.4 & 34.9 & 0.25 & 0.3960 & 0.0064 & 7.3600 & 0.1300 & 0.1350 & 0.0022 & 2150 & 29 & 2164 & 28 & -0.7 \\
\hline $44 r$ & 148.0 & 28.9 & 0.20 & 0.3961 & 0.0076 & 7.3800 & 0.1700 & 0.1356 & 0.0023 & 2155 & 36 & 2172 & 29 & -0.8 \\
\hline $24 r$ & 82.3 & 10.5 & 0.13 & 0.4000 & 0.0052 & 7.3950 & 0.1200 & 0.1347 & 0.0017 & 2168 & 24 & 2157 & 22 & 0.5 \\
\hline 77 & 180.7 & 52.3 & 0.29 & 0.4019 & 0.0040 & 7.4000 & 0.1200 & 0.1345 & 0.0016 & 2177 & 19 & 2155 & 21 & 1.0 \\
\hline $50 c$ & 112.0 & 34.5 & 0.31 & 0.4002 & 0.0049 & 7.4100 & 0.1300 & 0.1359 & 0.0018 & 2172 & 22 & 2175 & 24 & -0.1 \\
\hline $63 c$ & 143.6 & 43.0 & 0.30 & 0.4020 & 0.0057 & 7.4100 & 0.1300 & 0.1348 & 0.0015 & 2177 & 26 & 2160 & 19 & 0.8 \\
\hline 46 & 145.3 & 33.9 & 0.23 & 0.3988 & 0.0042 & 7.4300 & 0.1300 & 0.1361 & 0.0019 & 2163 & 19 & 2175 & 24 & -0.6 \\
\hline $03 r$ & 138.8 & 32.9 & 0.24 & 0.4046 & 0.0043 & 7.4640 & 0.1100 & 0.1337 & 0.0014 & 2190 & 20 & 2149 & 18 & 1.9 \\
\hline 106 & 121.6 & 30.2 & 0.25 & 0.4070 & 0.0052 & 7.4700 & 0.1400 & 0.1347 & 0.0017 & 2200 & 24 & 2157 & 23 & 2.0 \\
\hline $25 c$ & 109.2 & 27.0 & 0.25 & 0.4034 & 0.0036 & 7.4760 & 0.1000 & 0.1341 & 0.0014 & 2184 & 17 & 2154 & 18 & 1.4 \\
\hline $16 c$ & 94.1 & 16.6 & 0.18 & 0.4071 & 0.0047 & 7.4810 & 0.1200 & 0.1338 & 0.0016 & 2201 & 22 & 2146 & 21 & 2.5 \\
\hline 40 & 118.5 & 22.9 & 0.19 & 0.4063 & 0.0053 & 7.4900 & 0.1300 & 0.1344 & 0.0019 & 2204 & 26 & 2155 & 24 & 2.2 \\
\hline $62 r$ & 97.7 & 22.8 & 0.23 & 0.4085 & 0.0048 & 7.5200 & 0.1300 & 0.1338 & 0.0016 & 2207 & 22 & 2145 & 21 & 2.8 \\
\hline 41 & 89.4 & 20.6 & 0.23 & 0.4049 & 0.0052 & 7.5300 & 0.1300 & 0.1352 & 0.0018 & 2190 & 24 & 2174 & 23 & 0.7 \\
\hline $22 c$ & 74.1 & 19.9 & 0.27 & 0.4063 & 0.0042 & 7.5500 & 0.1100 & 0.1340 & 0.0015 & 2203 & 19 & 2150 & 19 & 2.4 \\
\hline 35 & 139.7 & 27.2 & 0.19 & 0.4115 & 0.0049 & 7.5560 & 0.1300 & 0.1339 & 0.0017 & 2221 & 22 & 2147 & 22 & 3.3 \\
\hline 90 & 82.0 & 16.5 & 0.20 & 0.4040 & 0.0050 & 7.5600 & 0.1400 & 0.1354 & 0.0018 & 2187 & 23 & 2171 & 24 & 0.7 \\
\hline $72 r$ & 164.7 & 29.1 & 0.18 & 0.4104 & 0.0047 & 7.5660 & 0.1200 & 0.1343 & 0.0014 & 2216 & 22 & 2155 & 18 & 2.8 \\
\hline $44 c$ & 111.0 & 25.1 & 0.23 & 0.4071 & 0.0059 & 7.5800 & 0.1500 & 0.1355 & 0.0017 & 2200 & 27 & 2170 & 22 & 1.4 \\
\hline $60 \mathrm{r}$ & 120.1 & 25.9 & 0.22 & 0.4147 & 0.0043 & 7.5940 & 0.1200 & 0.1346 & 0.0017 & 2236 & 20 & 2162 & 21 & 3.3 \\
\hline 37 & 86.9 & 21.5 & 0.25 & 0.4136 & 0.0047 & 7.6800 & 0.1400 & 0.1349 & 0.0018 & 2231 & 22 & 2167 & 24 & 2.9 \\
\hline 82 & 138.9 & 36.9 & 0.27 & 0.4140 & 0.0084 & 7.6800 & 0.2000 & 0.1337 & 0.0020 & 2232 & 38 & 2149 & 26 & 3.7 \\
\hline 23 & 88.8 & 21.9 & 0.25 & 0.4194 & 0.0057 & 7.6900 & 0.1400 & 0.1344 & 0.0016 & 2257 & 26 & 2158 & 20 & 4.4 \\
\hline $05 r$ & 89.5 & 9.5 & 0.11 & 0.4055 & 0.0061 & 7.7000 & 0.1500 & 0.1381 & 0.0016 & 2193 & 28 & 2201 & 20 & -0.4 \\
\hline 69 & 126.5 & 27.9 & 0.22 & 0.4186 & 0.0045 & 7.7020 & 0.1200 & 0.1343 & 0.0013 & 2253 & 20 & 2156 & 18 & 4.3 \\
\hline 110 & 175.7 & 50.1 & 0.29 & 0.4168 & 0.0057 & 7.7100 & 0.1800 & 0.1338 & 0.0022 & 2248 & 25 & 2150 & 29 & 4.4 \\
\hline $30 \mathrm{c} 2$ & 135.0 & 33.5 & 0.25 & 0.4206 & 0.0057 & 7.7200 & 0.1300 & 0.1345 & 0.0015 & 2265 & 26 & 2158 & 20 & 4.7 \\
\hline $51 r$ & 173.0 & 48.3 & 0.28 & 0.4182 & 0.0061 & 7.7200 & 0.1500 & 0.1339 & 0.0017 & 2251 & 28 & 2151 & 23 & 4.4 \\
\hline $56 c$ & 96.0 & 21.9 & 0.23 & 0.4161 & 0.0058 & 7.7300 & 0.1400 & 0.1354 & 0.0018 & 2242 & 26 & 2171 & 24 & 3.2 \\
\hline $66 c$ & 146.4 & 36.3 & 0.25 & 0.4173 & 0.0048 & 7.7420 & 0.1200 & 0.1345 & 0.0013 & 2250 & 22 & 2156 & 17 & 4.2 \\
\hline $30 c$ & 61.5 & 11.6 & 0.19 & 0.4190 & 0.0083 & 7.7600 & 0.2100 & 0.1340 & 0.0022 & 2254 & 38 & 2151 & 28 & 4.6 \\
\hline $63 r$ & 115.3 & 25.3 & 0.22 & 0.4222 & 0.0057 & 7.7800 & 0.1300 & 0.1345 & 0.0017 & 2269 & 26 & 2158 & 22 & 4.9 \\
\hline $57 r$ & 151.4 & 38.7 & 0.26 & 0.4235 & 0.0060 & 7.8300 & 0.1500 & 0.1345 & 0.0015 & 2275 & 27 & 2159 & 19 & 5.1 \\
\hline 29 & 65.2 & 13.7 & 0.21 & 0.4194 & 0.0081 & 7.8600 & 0.2000 & 0.1360 & 0.0023 & 2256 & 37 & 2177 & 29 & 3.5 \\
\hline $03 c$ & 110.1 & 25.2 & 0.23 & 0.4242 & 0.0050 & 7.8780 & 0.1200 & 0.1349 & 0.0016 & 2279 & 23 & 2162 & 20 & 5.1 \\
\hline $38 c$ & 75.7 & 15.3 & 0.20 & 0.4278 & 0.0064 & 7.9200 & 0.1400 & 0.1350 & 0.0018 & 2298 & 28 & 2163 & 23 & 5.9 \\
\hline \multicolumn{15}{|c|}{159} \\
\hline
\end{tabular}




\begin{tabular}{|c|c|c|c|c|c|c|c|c|c|c|c|c|c|c|}
\hline $66 r$ & 80.6 & 13.6 & 0.17 & 0.4254 & 0.0050 & 7.9210 & 0.1300 & 0.1360 & 0.0017 & 2286 & 22 & 2173 & 22 & 4.9 \\
\hline $72 \mathrm{c}$ & 113.8 & 22.9 & 0.20 & 0.4359 & 0.0068 & 8.0300 & 0.1600 & 0.1350 & 0.0020 & 2331 & 30 & 2168 & 24 & 7.0 \\
\hline 108 & 76.4 & 21.6 & 0.28 & 0.4406 & 0.0073 & 8.1300 & 0.1800 & 0.1349 & 0.0022 & 2351 & 32 & 2160 & 28 & 8.1 \\
\hline $60 c$ & 72.8 & 11.9 & 0.16 & 0.4450 & 0.0087 & 8.1700 & 0.2000 & 0.1357 & 0.0025 & 2371 & 39 & 2183 & 32 & 7.9 \\
\hline \multicolumn{10}{|c|}{ Ratios } & \multicolumn{5}{|l|}{ Ages (Ma) } \\
\hline Spot & $\mathrm{U}(\mathrm{ppm})$ & $T h(p p m)$ & $\mathrm{Th} / \mathrm{U}$ & ${ }^{206} \mathrm{~Pb} /{ }^{238} \mathrm{U}$ & $\pm 2 \mathrm{SE}$ & ${ }^{207} \mathrm{~Pb} /{ }^{235} \mathrm{U}$ & $\pm 2 \mathrm{SE}$ & ${ }^{207} \mathrm{~Pb} /{ }^{206} \mathrm{~Pb}$ & $\pm 2 \mathrm{SE}$ & ${ }^{206} \mathrm{~Pb} /{ }^{238} \mathrm{U}$ & $\pm 2 \mathrm{SE}$ & ${ }^{207} \mathrm{~Pb} /{ }^{206} \mathrm{~Pb}$ & $\pm 2 \mathrm{SE}$ & Discordance (\%) \\
\hline \multicolumn{15}{|l|}{ Sample 09B } \\
\hline 09B-01-1 & 33.1 & 0.6 & 0.02 & 0.0900 & 0.0016 & 0.7560 & 0.0230 & 0.0604 & 0.0015 & 555 & 9 & 616 & 55 & -10.9 \\
\hline 09B-57-2 & 30.7 & 0.3 & 0.01 & 0.0952 & 0.0017 & 0.7660 & 0.0230 & 0.0590 & 0.0015 & 586 & 10 & 566 & 54 & 3.4 \\
\hline 09B-58-3 & 25.3 & 0.1 & $<0.01$ & 0.0943 & 0.0018 & 0.7800 & 0.0260 & 0.0598 & 0.0018 & 582 & 10 & 592 & 69 & -1.7 \\
\hline 09B-32-2 & 19.3 & $<0.1$ & $<0.01$ & 0.0943 & 0.0019 & 0.7820 & 0.0250 & 0.0597 & 0.0018 & 581 & 11 & 587 & 62 & -1.1 \\
\hline 09B-35-2 & 12.5 & $<0.1$ & $<0.01$ & 0.0986 & 0.0028 & 0.7840 & 0.0460 & 0.0584 & 0.0031 & 606 & 16 & 520 & 120 & 14.2 \\
\hline 09B-21-2 & 25.1 & 0.1 & $<0.01$ & 0.0961 & 0.0018 & 0.7930 & 0.0260 & 0.0593 & 0.0017 & 591 & 11 & 594 & 66 & -0.5 \\
\hline 09B-60-4 & 22.5 & 0.2 & 0.01 & 0.0980 & 0.0018 & 0.7980 & 0.0240 & 0.0595 & 0.0016 & 602 & 11 & 590 & 60 & 2.0 \\
\hline 09B-82-2 & 11.3 & 0.1 & 0.01 & 0.0992 & 0.0021 & 0.8110 & 0.0320 & 0.0597 & 0.0023 & 610 & 13 & 582 & 81 & 4.6 \\
\hline 09B-02-2 & 47.9 & 0.2 & $<0.01$ & 0.0969 & 0.0018 & 0.8130 & 0.0180 & 0.0611 & 0.0013 & 596 & 11 & 644 & 44 & -8.1 \\
\hline 09B-79-2 & 270.0 & 0.9 & $<0.01$ & 0.0997 & 0.0020 & 0.8240 & 0.0180 & 0.0601 & 0.0007 & 612 & 12 & 602 & 26 & 1.7 \\
\hline 09B-25-3 & 18.8 & 0.1 & $<0.01$ & 0.0959 & 0.0021 & 0.8320 & 0.0300 & 0.0620 & 0.0022 & 590 & 12 & 670 & 77 & -13.6 \\
\hline 09B-74-2 & 20.5 & 0.1 & 0.01 & 0.1005 & 0.0021 & 0.8330 & 0.0280 & 0.0602 & 0.0021 & 618 & 12 & 594 & 74 & 3.9 \\
\hline 09B-80-2 & 17.2 & $<0.1$ & $<0.01$ & 0.1012 & 0.0021 & 0.8350 & 0.0300 & 0.0595 & 0.0019 & 621 & 12 & 569 & 69 & 8.4 \\
\hline 09B-73-2 & 16.5 & 0.1 & $<0.01$ & 0.1009 & 0.0022 & 0.8400 & 0.0300 & 0.0597 & 0.0020 & 620 & 13 & 591 & 73 & 4.7 \\
\hline 09B-91-3 & 33.1 & 0.2 & 0.01 & 0.1018 & 0.0018 & 0.8610 & 0.0260 & 0.0617 & 0.0016 & 625 & 11 & 647 & 59 & -3.6 \\
\hline 09B-08-2 & 20.6 & 0.2 & 0.01 & 0.1029 & 0.0022 & 0.8770 & 0.0320 & 0.0629 & 0.0021 & 631 & 13 & 677 & 72 & -7.3 \\
\hline 09B-78-3 & 30.7 & 0.1 & $<0.01$ & 0.1056 & 0.0021 & 0.8830 & 0.0210 & 0.0608 & 0.0014 & 647 & 12 & 630 & 50 & 2.6 \\
\hline 09B-91-2 & 5.9 & $<0.1$ & 0.01 & 0.1073 & 0.0030 & 0.9180 & 0.0600 & 0.0621 & 0.0039 & 657 & 17 & 630 & 120 & 4.1 \\
\hline 09B-92-2 & 28.8 & 6.1 & 0.21 & 0.2926 & 0.0049 & 4.9550 & 0.1000 & 0.1245 & 0.0016 & 1654 & 24 & 2018 & 22 & -22.0 \\
\hline 09B-47-1 & 186.0 & 65.6 & 0.35 & 0.3004 & 0.0050 & 5.0110 & 0.0810 & 0.1209 & 0.0010 & 1693 & 25 & 1968 & 15 & -16.2 \\
\hline 09B-02-1 & 63.1 & 26.4 & 0.42 & 0.3378 & 0.0064 & 5.8910 & 0.1200 & 0.1262 & 0.0016 & 1876 & 31 & 2043 & 22 & -8.9 \\
\hline 09B-21-1 & 180.0 & 101.1 & 0.56 & 0.3408 & 0.0056 & 5.9300 & 0.0990 & 0.1262 & 0.0008 & 1892 & 27 & 2046 & 11 & -8.1 \\
\hline 09B-25-1 & 57.3 & 27.8 & 0.48 & 0.3431 & 0.0054 & 5.9450 & 0.1000 & 0.1260 & 0.0012 & 1901 & 26 & 2044 & 16 & -7.5 \\
\hline 09B-47-3 & 288.0 & 29.6 & 0.10 & 0.3441 & 0.0055 & 6.0130 & 0.1000 & 0.1262 & 0.0008 & 1906 & 26 & 2045 & 12 & -7.3 \\
\hline 09B-25-2 & 94.1 & 20.7 & 0.22 & 0.3429 & 0.0059 & 6.0770 & 0.1100 & 0.1280 & 0.0012 & 1900 & 28 & 2069 & 17 & -8.9 \\
\hline 09B-96-3 & 122.8 & 21.3 & 0.17 & 0.3547 & 0.0054 & 6.1770 & 0.0980 & 0.1266 & 0.0008 & 1957 & 26 & 2053 & 11 & -4.9 \\
\hline 09B-74-1 & 77.9 & 31.1 & 0.40 & 0.3573 & 0.0054 & 6.1850 & 0.0940 & 0.1263 & 0.0009 & 1969 & 26 & 2046 & 13 & -3.9 \\
\hline 09B-83-2 & 107.5 & 32.8 & 0.31 & 0.3578 & 0.0051 & 6.2230 & 0.1000 & 0.1263 & 0.0010 & 1971 & 24 & 2045 & 14 & -3.8 \\
\hline 09B-60-1 & 40.4 & 12.2 & 0.30 & 0.3588 & 0.0061 & 6.2920 & 0.1200 & 0.1274 & 0.0013 & 1976 & 29 & 2059 & 19 & -4.2 \\
\hline 09B-96-1 & 30.6 & 10.9 & 0.36 & 0.3649 & 0.0058 & 6.3140 & 0.1000 & 0.1268 & 0.0013 & 2005 & 27 & 2051 & 18 & -2.3 \\
\hline 09B-43-1 & 54.8 & 24.8 & 0.45 & 0.3628 & 0.0058 & 6.3170 & 0.1100 & 0.1263 & 0.0011 & 1995 & 28 & 2048 & 15 & -2.7 \\
\hline 09B-01-2 & 33.3 & 15.3 & 0.46 & 0.3503 & 0.0066 & 6.3230 & 0.1200 & 0.1299 & 0.0015 & 1935 & 31 & 2094 & 21 & -8.2 \\
\hline 09B-75-1 & 35.1 & 11.9 & 0.34 & 0.3635 & 0.0061 & 6.3270 & 0.1200 & 0.1264 & 0.0015 & 1998 & 29 & 2046 & 21 & -2.4 \\
\hline 09B-92-1 & 425.0 & 144.9 & 0.34 & 0.3625 & 0.0052 & 6.4150 & 0.0950 & 0.1282 & 0.0005 & 1994 & 25 & 2073 & 7 & -3.9 \\
\hline 09B-16-1 & 46.1 & 18.5 & 0.40 & 0.3677 & 0.0060 & 6.4190 & 0.1200 & 0.1267 & 0.0015 & 2018 & 28 & 2056 & 20 & -1.9 \\
\hline 09B-69-1 & 123.8 & 48.8 & 0.39 & 0.3664 & 0.0059 & 6.4450 & 0.1000 & 0.1277 & 0.0010 & 2012 & 28 & 2066 & 14 & -2.7 \\
\hline 09B-57-1 & 76.9 & 35.3 & 0.46 & 0.3686 & 0.0057 & 6.4490 & 0.1000 & 0.1268 & 0.0011 & 2024 & 27 & 2054 & 14 & -1.5 \\
\hline 09B-80-1 & 268.0 & 80.8 & 0.30 & 0.3654 & 0.0065 & 6.4700 & 0.1100 & 0.1286 & 0.0007 & 2007 & 31 & 2080 & 10 & -3.7 \\
\hline 09B-06-2 & 57.7 & 16.1 & 0.28 & 0.3703 & 0.0068 & 6.4800 & 0.1300 & 0.1267 & 0.0015 & 2030 & 32 & 2055 & 21 & -1.2 \\
\hline 09B-91-1 & 56.1 & 11.9 & 0.21 & 0.3547 & 0.0070 & 6.4900 & 0.1400 & 0.1322 & 0.0017 & 1957 & 33 & 2125 & 22 & -8.6 \\
\hline
\end{tabular}




\begin{tabular}{|c|c|c|c|c|c|c|c|c|c|c|c|c|c|c|}
\hline 09B-96-2 & 55.3 & 19.7 & 0.36 & 0.3741 & 0.0057 & 6.5320 & 0.1000 & 0.1270 & 0.0010 & 2048 & 26 & 2057 & 14 & -0.4 \\
\hline 09B-50-1 & 59.9 & 28.1 & 0.47 & 0.3730 & 0.0060 & 6.5650 & 0.1100 & 0.1280 & 0.0010 & 2043 & 28 & 2071 & 14 & -1.4 \\
\hline 09B-65-1 & 149.0 & 71.8 & 0.48 & 0.3717 & 0.0055 & 6.5880 & 0.1000 & 0.1293 & 0.0008 & 2037 & 26 & 2092 & 11 & -2.7 \\
\hline 09B-60-3 & 105.9 & 35.4 & 0.33 & 0.3737 & 0.0060 & 6.5930 & 0.1000 & 0.1282 & 0.0009 & 2046 & 28 & 2074 & 13 & -1.4 \\
\hline 09B-08-1 & 74.7 & 29.0 & 0.39 & 0.3731 & 0.0073 & 6.6030 & 0.1300 & 0.1280 & 0.0012 & 2043 & 34 & 2073 & 18 & -1.5 \\
\hline 09B-83-1 & 42.1 & 20.5 & 0.49 & 0.3764 & 0.0059 & 6.6070 & 0.1100 & 0.1274 & 0.0011 & 2059 & 28 & 2062 & 15 & -0.1 \\
\hline 09B-16-2 & 33.2 & 9.0 & 0.27 & 0.3745 & 0.0057 & 6.6170 & 0.1200 & 0.1290 & 0.0014 & 2050 & 27 & 2081 & 19 & -1.5 \\
\hline 09B-65-3 & 64.2 & 13.3 & 0.21 & 0.3752 & 0.0062 & 6.6430 & 0.1200 & 0.1290 & 0.0013 & 2056 & 28 & 2083 & 18 & -1.3 \\
\hline 09B-94-1 & 70.7 & 37.4 & 0.53 & 0.3757 & 0.0056 & 6.6660 & 0.0990 & 0.1283 & 0.0009 & 2056 & 26 & 2076 & 12 & -1.0 \\
\hline 09B-14-2 & 90.6 & 14.0 & 0.15 & 0.3777 & 0.0061 & 6.6700 & 0.1200 & 0.1286 & 0.0011 & 2065 & 29 & 2078 & 15 & -0.6 \\
\hline 09B-79-1 & 103.5 & 35.3 & 0.34 & 0.3762 & 0.0058 & 6.6820 & 0.0970 & 0.1292 & 0.0012 & 2058 & 27 & 2088 & 16 & -1.5 \\
\hline 09B-94-2 & 45.3 & 17.1 & 0.38 & 0.3807 & 0.0056 & 6.6900 & 0.1100 & 0.1282 & 0.0012 & 2079 & 26 & 2072 & 16 & 0.3 \\
\hline 09B-18-1 & 53.8 & 20.8 & 0.39 & 0.3805 & 0.0064 & 6.7030 & 0.1100 & 0.1282 & 0.0012 & 2078 & 30 & 2073 & 17 & 0.2 \\
\hline 09B-47-2 & 58.6 & 21.1 & 0.36 & 0.3845 & 0.0065 & 6.7030 & 0.1100 & 0.1270 & 0.0012 & 2097 & 30 & 2055 & 16 & 2.0 \\
\hline 09B-60-2 & 33.4 & 10.3 & 0.31 & 0.3798 & 0.0062 & 6.7130 & 0.1200 & 0.1292 & 0.0015 & 2075 & 29 & 2088 & 20 & -0.6 \\
\hline 09B-33-2 & 105.6 & 17.2 & 0.16 & 0.3797 & 0.0053 & 6.7180 & 0.0980 & 0.1280 & 0.0008 & 2075 & 25 & 2071 & 11 & 0.2 \\
\hline 09B-35-1 & 39.8 & 11.1 & 0.28 & 0.3800 & 0.0062 & 6.7210 & 0.1100 & 0.1281 & 0.0012 & 2075 & 29 & 2070 & 16 & 0.2 \\
\hline 09B-56-1 & 85.0 & 35.2 & 0.41 & 0.3817 & 0.0057 & 6.7280 & 0.1000 & 0.1275 & 0.0009 & 2084 & 26 & 2065 & 13 & 0.9 \\
\hline 09B-06-1 & 145.3 & 74.7 & 0.51 & 0.3794 & 0.0071 & 6.7300 & 0.1400 & 0.1292 & 0.0019 & 2073 & 33 & 2084 & 27 & -0.5 \\
\hline 09B-65-2 & 41.9 & 11.8 & 0.28 & 0.3817 & 0.0059 & 6.7420 & 0.1100 & 0.1280 & 0.0013 & 2084 & 28 & 2071 & 19 & 0.6 \\
\hline 09B-94-3 & 62.3 & 13.8 & 0.22 & 0.3825 & 0.0058 & 6.7430 & 0.1100 & 0.1278 & 0.0009 & 2089 & 27 & 2068 & 12 & 1.0 \\
\hline $09 B-42-2$ & 38.1 & 8.4 & 0.22 & 0.3843 & 0.0093 & 6.7500 & 0.1900 & 0.1269 & 0.0013 & 2094 & 44 & 2058 & 18 & 1.7 \\
\hline 09B-58-2 & 47.6 & 17.2 & 0.36 & 0.3842 & 0.0059 & 6.7620 & 0.1100 & 0.1277 & 0.0012 & 2096 & 28 & 2067 & 17 & 1.4 \\
\hline 09B-18-2 & 62.2 & 24.7 & 0.40 & 0.3803 & 0.0059 & 6.7790 & 0.1100 & 0.1291 & 0.0010 & 2077 & 28 & 2087 & 14 & -0.5 \\
\hline 09B-18-3 & 103.2 & 35.5 & 0.34 & 0.3784 & 0.0060 & 6.7920 & 0.1100 & 0.1305 & 0.0010 & 2068 & 28 & 2105 & 14 & -1.8 \\
\hline 09B-14-1 & 77.4 & 36.5 & 0.47 & 0.3814 & 0.0058 & 6.8000 & 0.1100 & 0.1297 & 0.0011 & 2082 & 27 & 2094 & 15 & -0.6 \\
\hline 09B-33-1 & 51.1 & 25.3 & 0.50 & 0.3838 & 0.0059 & 6.8020 & 0.1100 & 0.1287 & 0.0012 & 2093 & 27 & 2080 & 16 & 0.6 \\
\hline 09B-56-2 & 69.9 & 25.2 & 0.36 & 0.3877 & 0.0059 & 6.8040 & 0.1100 & 0.1275 & 0.0011 & 2112 & 27 & 2062 & 15 & 2.4 \\
\hline 09B-82-1 & 39.6 & 18.7 & 0.47 & 0.3876 & 0.0060 & 6.8270 & 0.1100 & 0.1281 & 0.0011 & 2113 & 29 & 2076 & 15 & 1.8 \\
\hline 09B-58-1 & 74.5 & 32.2 & 0.43 & 0.3876 & 0.0073 & 6.8480 & 0.1300 & 0.1291 & 0.0012 & 2111 & 34 & 2090 & 18 & 1.0 \\
\hline $09 \mathrm{~B}-42-1$ & 49.4 & 22.7 & 0.46 & 0.3892 & 0.0062 & 6.8520 & 0.1200 & 0.1283 & 0.0012 & 2119 & 29 & 2074 & 16 & 2.1 \\
\hline 09B-78-2 & 43.1 & 16.4 & 0.38 & 0.3891 & 0.0058 & 6.8730 & 0.1100 & 0.1280 & 0.0009 & 2120 & 27 & 2069 & 12 & 2.4 \\
\hline 09B-73-1 & 54.6 & 19.1 & 0.35 & 0.3908 & 0.0057 & 6.9080 & 0.1000 & 0.1278 & 0.0010 & 2126 & 27 & 2068 & 13 & 2.7 \\
\hline \multirow[t]{2}{*}{ 09B-32-1 } & 53.4 & 19.7 & 0.37 & 0.3867 & 0.0072 & 6.9700 & 0.1500 & 0.1316 & 0.0016 & 2107 & 34 & 2118 & 21 & -0.5 \\
\hline & \multicolumn{9}{|c|}{ Ratios } & \multicolumn{5}{|l|}{ Ages (Ma) } \\
\hline Spot & $\mathrm{U}(\mathrm{ppm})$ & $\operatorname{Th}(\mathrm{ppm})$ & $\mathrm{Th} / \mathrm{U}$ & ${ }^{206} \mathrm{~Pb} /{ }^{238} \mathrm{U}$ & $\pm 2 \mathrm{SE}$ & ${ }^{207} \mathrm{~Pb} /{ }^{235} \mathrm{U}$ & $\pm 2 \mathrm{SE}$ & ${ }^{207} \mathrm{~Pb} /{ }^{206} \mathrm{~Pb}$ & $\pm 2 \mathrm{SE}$ & ${ }^{206} \mathrm{~Pb} /{ }^{238} \mathrm{U}$ & $\pm 2 \mathrm{SE}$ & ${ }^{207} \mathrm{~Pb} /{ }^{206} \mathrm{~Pb}$ & $\pm 2 \mathrm{SE}$ & Discordance (\%) \\
\hline \multicolumn{15}{|l|}{ Sample 48D } \\
\hline $84-2 r$ & 113.1 & 28.8 & 0.25 & 0.3557 & 0.0058 & 6.2220 & 0.1000 & 0.1275 & 0.0010 & 1961 & 27 & 2064 & 13 & -5.3 \\
\hline $65-1 c$ & 53.3 & 27.4 & 0.51 & 0.3519 & 0.0055 & 6.2230 & 0.0980 & 0.1290 & 0.0010 & 1944 & 26 & 2083 & 13 & -7.2 \\
\hline $85-2 r$ & 89.5 & 28.3 & 0.32 & 0.3547 & 0.0051 & 6.2580 & 0.0940 & 0.1277 & 0.0008 & 1957 & 24 & 2068 & 11 & -5.7 \\
\hline 54-1c & 41.1 & 15.7 & 0.38 & 0.3586 & 0.0058 & 6.2880 & 0.1100 & 0.1276 & 0.0012 & 1975 & 28 & 2064 & 17 & -4.5 \\
\hline $67-2 r$ & 42.5 & 18.1 & 0.43 & 0.3597 & 0.0053 & 6.2880 & 0.0970 & 0.1263 & 0.0012 & 1980 & 25 & 2047 & 17 & -3.4 \\
\hline $18-2 r$ & 112.0 & 45.7 & 0.41 & 0.3596 & 0.0054 & 6.3060 & 0.1100 & 0.1281 & 0.0012 & 1980 & 26 & 2070 & 17 & -4.5 \\
\hline $43-2 r$ & 108.9 & 37.2 & 0.34 & 0.3592 & 0.0056 & 6.3360 & 0.0960 & 0.1280 & 0.0009 & 1978 & 26 & 2069 & 13 & -4.6 \\
\hline $82-1 c$ & 274.0 & 175.0 & 0.64 & 0.3586 & 0.0053 & 6.3360 & 0.0960 & 0.1282 & 0.0007 & 1975 & 25 & 2074 & 9 & -5.0 \\
\hline $90-1 c$ & 70.8 & 39.6 & 0.56 & 0.3576 & 0.0052 & 6.3980 & 0.0990 & 0.1307 & 0.0008 & 1971 & 25 & 2107 & 10 & -6.9 \\
\hline 73-1c & 65.3 & 26.6 & 0.41 & 0.3587 & 0.0058 & 6.4250 & 0.1100 & 0.1296 & 0.0012 & 1975 & 28 & 2091 & 16 & -5.9 \\
\hline
\end{tabular}




\begin{tabular}{|c|c|c|c|c|c|c|c|c|c|c|c|c|c|c|}
\hline $92-2 r$ & 143.5 & 60.0 & 0.42 & 0.3623 & 0.0050 & 6.4470 & 0.0950 & 0.1286 & 0.0007 & 1994 & 23 & 2080 & 10 & -4.3 \\
\hline $73-2 c$ & 61.8 & 17.4 & 0.28 & 0.3653 & 0.0052 & 6.5260 & 0.1000 & 0.1296 & 0.0010 & 2007 & 25 & 2093 & 14 & -4.3 \\
\hline $93-1 c$ & 45.5 & 22.7 & 0.50 & 0.3672 & 0.0057 & 6.5350 & 0.1100 & 0.1287 & 0.0012 & 2016 & 27 & 2078 & 16 & -3.1 \\
\hline $46-2 r$ & 70.6 & 19.3 & 0.27 & 0.3708 & 0.0055 & 6.5400 & 0.1000 & 0.1283 & 0.0011 & 2033 & 26 & 2074 & 16 & -2.0 \\
\hline $68-2 r$ & 83.6 & 20.0 & 0.24 & 0.3672 & 0.0053 & 6.5430 & 0.0980 & 0.1291 & 0.0008 & 2016 & 25 & 2087 & 11 & -3.5 \\
\hline $11-2 r$ & 117.3 & 31.8 & 0.27 & 0.3684 & 0.0055 & 6.5470 & 0.1200 & 0.1289 & 0.0012 & 2023 & 26 & 2082 & 16 & -2.9 \\
\hline $92-3 r$ & 52.5 & 19.5 & 0.37 & 0.3694 & 0.0055 & 6.5670 & 0.1000 & 0.1289 & 0.0010 & 2026 & 26 & 2081 & 14 & -2.7 \\
\hline $70-2 c$ & 66.6 & 31.5 & 0.47 & 0.3704 & 0.0054 & 6.5720 & 0.1000 & 0.1291 & 0.0010 & 2031 & 26 & 2087 & 14 & -2.8 \\
\hline $49-2 r$ & 44.1 & 23.6 & 0.53 & 0.3728 & 0.0069 & 6.5840 & 0.1300 & 0.1286 & 0.0013 & 2045 & 33 & 2078 & 18 & -1.6 \\
\hline $89-1 c$ & 136.5 & 61.8 & 0.45 & 0.3723 & 0.0054 & 6.6040 & 0.0940 & 0.1290 & 0.0007 & 2043 & 25 & 2085 & 10 & -2.1 \\
\hline $37-1 c$ & 58.0 & 31.8 & 0.55 & 0.3784 & 0.0067 & 6.6160 & 0.1200 & 0.1277 & 0.0013 & 2068 & 31 & 2068 & 18 & 0.0 \\
\hline $57-2 r$ & 72.1 & 29.7 & 0.41 & 0.3717 & 0.0058 & 6.6160 & 0.1100 & 0.1295 & 0.0009 & 2037 & 27 & 2092 & 12 & -2.7 \\
\hline $05-1 c$ & 64.4 & 39.9 & 0.62 & 0.3712 & 0.0056 & 6.6260 & 0.1200 & 0.1292 & 0.0014 & 2035 & 26 & 2089 & 19 & -2.7 \\
\hline $39-1 c$ & 150.0 & 80.0 & 0.53 & 0.3694 & 0.0087 & 6.6500 & 0.2300 & 0.1305 & 0.0023 & 2025 & 41 & 2100 & 30 & -3.7 \\
\hline $22-1 c$ & 104.6 & 65.1 & 0.62 & 0.3754 & 0.0058 & 6.6600 & 0.1100 & 0.1285 & 0.0012 & 2054 & 27 & 2076 & 17 & -1.1 \\
\hline $96-1 c$ & 39.1 & 21.6 & 0.55 & 0.3685 & 0.0055 & 6.6650 & 0.1100 & 0.1307 & 0.0012 & 2022 & 26 & 2106 & 16 & -4.2 \\
\hline $84-1 c$ & 201.1 & 89.6 & 0.45 & 0.3771 & 0.0054 & 6.6910 & 0.0980 & 0.1287 & 0.0008 & 2064 & 25 & 2080 & 11 & -0.8 \\
\hline $21-1 c$ & 49.8 & 22.7 & 0.46 & 0.3783 & 0.0061 & 6.7010 & 0.1200 & 0.1287 & 0.0016 & 2068 & 28 & 2082 & 22 & -0.7 \\
\hline $22-2 r$ & 69.7 & 31.7 & 0.45 & 0.3819 & 0.0059 & 6.7030 & 0.1200 & 0.1279 & 0.0014 & 2085 & 28 & 2073 & 18 & 0.6 \\
\hline $64-1 c$ & 61.6 & 29.1 & 0.47 & 0.3769 & 0.0060 & 6.7110 & 0.1100 & 0.1299 & 0.0010 & 2061 & 28 & 2096 & 13 & -1.7 \\
\hline $47-1 c$ & 54.7 & 31.3 & 0.57 & 0.3835 & 0.0058 & 6.7150 & 0.1100 & 0.1286 & 0.0011 & 2092 & 27 & 2077 & 15 & 0.7 \\
\hline $46-1 c$ & 76.9 & 31.7 & 0.41 & 0.3833 & 0.0059 & 6.7770 & 0.1100 & 0.1284 & 0.0012 & 2091 & 28 & 2077 & 16 & 0.7 \\
\hline $49-1 c$ & 49.2 & 24.9 & 0.51 & 0.3837 & 0.0079 & 6.7900 & 0.1600 & 0.1283 & 0.0014 & 2100 & 37 & 2077 & 19 & 1.1 \\
\hline $11-1 c$ & 77.5 & 45.4 & 0.59 & 0.3808 & 0.0061 & 6.7940 & 0.1200 & 0.1288 & 0.0013 & 2079 & 28 & 2083 & 18 & -0.2 \\
\hline $08-2 r$ & 40.7 & 16.4 & 0.40 & 0.3829 & 0.0060 & 6.8100 & 0.1400 & 0.1287 & 0.0018 & 2089 & 28 & 2082 & 26 & 0.3 \\
\hline $41-2 r$ & 96.4 & 26.3 & 0.27 & 0.3832 & 0.0060 & 6.8260 & 0.1100 & 0.1302 & 0.0012 & 2091 & 28 & 2098 & 15 & -0.3 \\
\hline $92-1 c$ & 41.3 & 16.4 & 0.40 & 0.3821 & 0.0058 & 6.8350 & 0.1100 & 0.1292 & 0.0011 & 2086 & 27 & 2086 & 15 & 0.0 \\
\hline $57-1 c$ & 78.4 & 40.0 & 0.51 & 0.3842 & 0.0058 & 6.8360 & 0.1100 & 0.1299 & 0.0009 & 2095 & 27 & 2095 & 12 & 0.0 \\
\hline $43-1 c$ & 108.5 & 44.7 & 0.41 & 0.3807 & 0.0057 & 6.8400 & 0.1100 & 0.1307 & 0.0008 & 2079 & 27 & 2108 & 11 & -1.4 \\
\hline $90-2 r$ & 86.7 & 35.2 & 0.41 & 0.3825 & 0.0055 & 6.8400 & 0.1000 & 0.1294 & 0.0009 & 2090 & 26 & 2090 & 12 & 0.0 \\
\hline $26-1 c$ & 50.1 & 23.1 & 0.46 & 0.3877 & 0.0067 & 6.8420 & 0.1300 & 0.1266 & 0.0014 & 2111 & 31 & 2050 & 19 & 2.9 \\
\hline $03-1 c$ & 95.8 & 41.0 & 0.43 & 0.3871 & 0.0070 & 6.8600 & 0.1500 & 0.1288 & 0.0013 & 2108 & 32 & 2079 & 18 & 1.4 \\
\hline $65-2 r$ & 50.9 & 15.2 & 0.30 & 0.3894 & 0.0057 & 6.8690 & 0.1000 & 0.1284 & 0.0010 & 2121 & 27 & 2074 & 14 & 2.2 \\
\hline $74-2 r$ & 51.5 & 14.6 & 0.28 & 0.3839 & 0.0066 & 6.8760 & 0.1200 & 0.1302 & 0.0010 & 2094 & 31 & 2101 & 14 & -0.3 \\
\hline $95-1 c$ & 35.1 & 17.2 & 0.49 & 0.3801 & 0.0064 & 6.8790 & 0.1200 & 0.1308 & 0.0014 & 2076 & 30 & 2110 & 19 & -1.6 \\
\hline $39-2 r$ & 38.6 & 16.9 & 0.44 & 0.3855 & 0.0062 & 6.8800 & 0.1300 & 0.1290 & 0.0013 & 2101 & 29 & 2082 & 18 & 0.9 \\
\hline $08-1 c$ & 60.1 & 26.7 & 0.44 & 0.3884 & 0.0060 & 6.8860 & 0.1200 & 0.1283 & 0.0014 & 2117 & 28 & 2072 & 19 & 2.1 \\
\hline $67-1 c$ & 73.4 & 37.5 & 0.51 & 0.3849 & 0.0054 & 6.9030 & 0.1000 & 0.1303 & 0.0009 & 2099 & 25 & 2104 & 12 & -0.2 \\
\hline $18-1 c$ & 26.4 & 11.2 & 0.42 & 0.3880 & 0.0066 & 6.9100 & 0.1400 & 0.1290 & 0.0017 & 2118 & 30 & 2085 & 25 & 1.6 \\
\hline $70-1 c$ & 44.4 & 18.6 & 0.42 & 0.3898 & 0.0071 & 6.9100 & 0.1200 & 0.1289 & 0.0015 & 2121 & 33 & 2080 & 20 & 1.9 \\
\hline $85-1 c$ & 42.2 & 17.7 & 0.42 & 0.3862 & 0.0054 & 6.9130 & 0.1100 & 0.1299 & 0.0012 & 2105 & 25 & 2095 & 16 & 0.5 \\
\hline $54-3 r$ & 106.5 & 38.4 & 0.36 & 0.3884 & 0.0058 & 6.9140 & 0.1000 & 0.1292 & 0.0009 & 2115 & 27 & 2088 & 12 & 1.3 \\
\hline $68-1 c$ & 27.9 & 12.2 & 0.44 & 0.3919 & 0.0064 & 6.9150 & 0.1200 & 0.1288 & 0.0017 & 2131 & 30 & 2083 & 23 & 2.3 \\
\hline $41-1 c$ & 39.1 & 16.7 & 0.43 & 0.3909 & 0.0065 & 6.9320 & 0.1200 & 0.1300 & 0.0013 & 2129 & 31 & 2098 & 17 & 1.5 \\
\hline $37-2 r$ & 18.0 & 5.7 & 0.32 & 0.3906 & 0.0080 & 6.9400 & 0.1500 & 0.1298 & 0.0023 & 2127 & 37 & 2096 & 31 & 1.5 \\
\hline $82-2 r$ & 71.5 & 30.8 & 0.43 & 0.3910 & 0.0057 & 6.9670 & 0.1000 & 0.1297 & 0.0009 & 2127 & 26 & 2093 & 12 & 1.6 \\
\hline $82-3 r$ & 102.1 & 46.3 & 0.45 & 0.3905 & 0.0063 & 7.0060 & 0.1100 & 0.1303 & 0.0007 & 2124 & 29 & 2101 & 10 & 1.1 \\
\hline $96-2 r$ & 26.0 & 9.3 & 0.36 & 0.3937 & 0.0065 & 7.0420 & 0.1200 & 0.1292 & 0.0014 & 2139 & 30 & 2088 & 20 & 2.4 \\
\hline
\end{tabular}




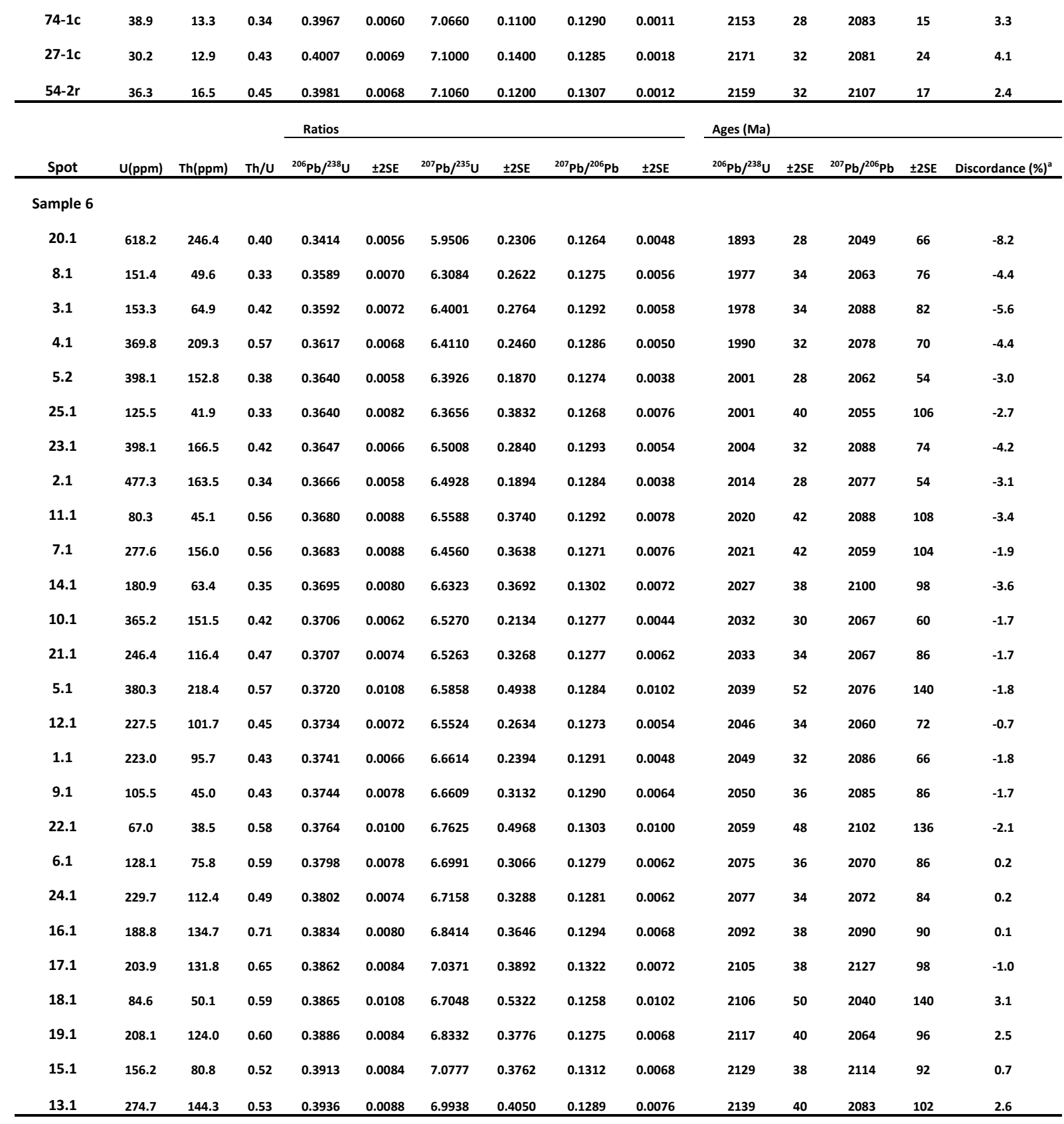

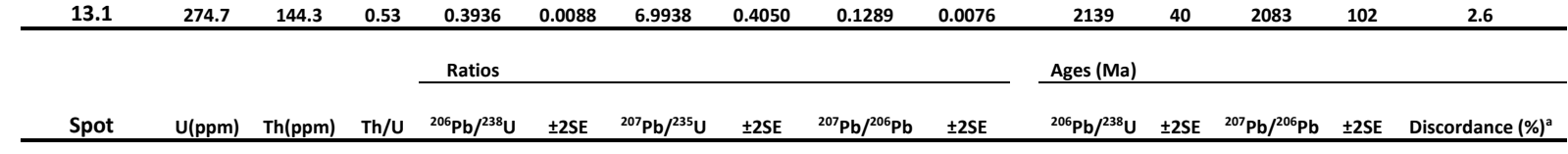
Sample 23B

\begin{tabular}{|c|c|c|c|c|c|c|c|c|c|c|c|c|c|c|}
\hline 55 & 48.8 & 23.9 & 0.49 & 0.3170 & 0.0110 & 5.4000 & 0.2300 & 0.1232 & 0.0021 & 1769 & 52 & 2004 & 30 & -13.3 \\
\hline 24 & 86.7 & 40.3 & 0.46 & 0.3247 & 0.0097 & 5.5000 & 0.2000 & 0.1202 & 0.0018 & 1813 & 48 & 1957 & 27 & -7.9 \\
\hline 27 & 504.0 & 5.1 & 0.01 & 0.3468 & 0.0025 & 6.0320 & 0.0780 & 0.1257 & 0.0011 & 1919 & 12 & 2038 & 15 & -6.2 \\
\hline 31 & 382.8 & 110.4 & 0.29 & 0.3624 & 0.0034 & 6.3490 & 0.0930 & 0.1263 & 0.0014 & 1993 & 16 & 2045 & 20 & -2.6 \\
\hline 4 & 22.1 & 20.9 & 0.95 & 0.3627 & 0.0056 & 6.3700 & 0.1300 & 0.1284 & 0.0022 & 1993 & 27 & 2070 & 30 & -3.9 \\
\hline 15 & 161.1 & 88.8 & 0.55 & 0.3660 & 0.0120 & 6.4200 & 0.2200 & 0.1281 & 0.0015 & 2005 & 56 & 2074 & 19 & -3.4 \\
\hline 2 & 161.9 & 107.0 & 0.66 & 0.3644 & 0.0048 & 6.4780 & 0.1100 & 0.1294 & 0.0014 & 2002 & 22 & 2096 & 19 & -4.7 \\
\hline 21 & 91.8 & 80.1 & 0.87 & 0.3712 & 0.0040 & 6.6070 & 0.0990 & 0.1293 & 0.0015 & 2035 & 19 & 2087 & 20 & -2.6 \\
\hline 85 & 99.8 & 102.0 & 1.02 & 0.3753 & 0.0047 & 6.7110 & 0.1200 & 0.1296 & 0.0019 & 2053 & 22 & 2091 & 27 & -1.9 \\
\hline 22 & 52.2 & 49.7 & 0.95 & 0.3803 & 0.0046 & 6.7720 & 0.1100 & 0.1294 & 0.0019 & 2077 & 22 & 2091 & 27 & -0.7 \\
\hline 54 & 76.1 & 57.4 & 0.75 & 0.3839 & 0.0036 & 6.8030 & 0.1000 & 0.1285 & 0.0015 & 2094 & 17 & 2075 & 21 & 0.9 \\
\hline 11 & 62.0 & 54.5 & 0.88 & 0.3824 & 0.0045 & 6.8110 & 0.1100 & 0.1292 & 0.0017 & 2089 & 21 & 2089 & 24 & 0.0 \\
\hline
\end{tabular}




\begin{tabular}{|c|c|c|c|c|c|c|c|c|c|c|c|c|c|c|}
\hline 9 & 668.0 & 335.0 & 0.50 & 0.3864 & 0.0049 & 6.8310 & 0.0980 & 0.1292 & 0.0013 & 2105 & 23 & 2086 & 17 & 0.9 \\
\hline 10 & 84.2 & 57.5 & 0.68 & 0.3811 & 0.0063 & 6.8400 & 0.1500 & 0.1320 & 0.0017 & 2080 & 29 & 2123 & 22 & -2.1 \\
\hline 16 & 279.0 & 485.0 & 1.74 & 0.3867 & 0.0045 & 6.8440 & 0.1100 & 0.1292 & 0.0012 & 2107 & 21 & 2088 & 17 & 0.9 \\
\hline 33 & 58.2 & 46.7 & 0.80 & 0.3856 & 0.0055 & 6.8900 & 0.1300 & 0.1295 & 0.0017 & 2101 & 25 & 2097 & 21 & 0.2 \\
\hline 49 & 88.5 & 114.8 & 1.30 & 0.3885 & 0.0045 & 6.9240 & 0.1100 & 0.1283 & 0.0014 & 2116 & 21 & 2078 & 19 & 1.8 \\
\hline 1 & 51.0 & 65.6 & 1.29 & 0.3879 & 0.0050 & 6.9600 & 0.1300 & 0.1299 & 0.0017 & 2116 & 24 & 2098 & 22 & 0.9 \\
\hline 41 & 67.2 & 65.2 & 0.97 & 0.3887 & 0.0045 & 6.9610 & 0.1200 & 0.1293 & 0.0013 & 2116 & 21 & 2089 & 18 & 1.3 \\
\hline 62 & 273.0 & 112.0 & 0.41 & 0.3897 & 0.0061 & 6.9800 & 0.1400 & 0.1293 & 0.0015 & 2127 & 27 & 2088 & 20 & 1.8 \\
\hline 20 & 65.1 & 50.2 & 0.77 & 0.3883 & 0.0035 & 6.9830 & 0.1100 & 0.1299 & 0.0018 & 2115 & 16 & 2095 & 24 & 0.9 \\
\hline 6 & 504.0 & 243.0 & 0.48 & 0.3934 & 0.0052 & 6.9960 & 0.1200 & 0.1298 & 0.0014 & 2138 & 24 & 2094 & 20 & 2.1 \\
\hline 38 & 85.5 & 73.2 & 0.86 & 0.3944 & 0.0058 & 7.0100 & 0.1400 & 0.1274 & 0.0015 & 2142 & 27 & 2060 & 21 & 3.8 \\
\hline 71 & 50.3 & 52.9 & 1.05 & 0.3997 & 0.0053 & 7.0900 & 0.1300 & 0.1291 & 0.0017 & 2167 & 24 & 2087 & 23 & 3.7 \\
\hline 46 & 158.3 & 123.0 & 0.78 & 0.3964 & 0.0044 & 7.0990 & 0.1100 & 0.1295 & 0.0014 & 2152 & 21 & 2091 & 19 & 2.8 \\
\hline 76 & 62.0 & 44.4 & 0.72 & 0.3995 & 0.0044 & 7.1330 & 0.1200 & 0.1296 & 0.0018 & 2169 & 20 & 2091 & 24 & 3.6 \\
\hline 14 & 162.9 & 170.0 & 1.04 & 0.3996 & 0.0097 & 7.1400 & 0.2000 & 0.1298 & 0.0016 & 2169 & 44 & 2094 & 21 & 3.5 \\
\hline 45 & 44.1 & 49.3 & 1.12 & 0.3999 & 0.0053 & 7.1400 & 0.1300 & 0.1295 & 0.0022 & 2171 & 24 & 2095 & 29 & 3.5 \\
\hline 77 & 146.5 & 91.3 & 0.62 & 0.4021 & 0.0052 & 7.1430 & 0.1200 & 0.1299 & 0.0015 & 2178 & 24 & 2094 & 20 & 3.9 \\
\hline 51 & 66.1 & 51.4 & 0.78 & 0.3966 & 0.0046 & 7.1560 & 0.1200 & 0.1308 & 0.0017 & 2152 & 21 & 2108 & 23 & 2.0 \\
\hline 65 & 190.0 & 195.0 & 1.03 & 0.3990 & 0.0110 & 7.1600 & 0.2400 & 0.1301 & 0.0026 & 2162 & 49 & 2094 & 35 & 3.1 \\
\hline 82 & 37.4 & 33.2 & 0.89 & 0.3990 & 0.0056 & 7.1900 & 0.1500 & 0.1318 & 0.0022 & 2172 & 25 & 2120 & 29 & 2.4 \\
\hline 87 & 28.7 & 25.1 & 0.87 & 0.3978 & 0.0055 & 7.1900 & 0.1500 & 0.1308 & 0.0024 & 2165 & 26 & 2111 & 32 & 2.5 \\
\hline 19 & 76.1 & 63.3 & 0.83 & 0.4009 & 0.0049 & 7.2040 & 0.1200 & 0.1308 & 0.0017 & 2172 & 23 & 2109 & 22 & 2.9 \\
\hline 32 & 74.1 & 63.8 & 0.86 & 0.4072 & 0.0060 & 7.2100 & 0.1500 & 0.1288 & 0.0016 & 2201 & 28 & 2082 & 22 & 5.4 \\
\hline 80 & 84.7 & 35.0 & 0.41 & 0.4057 & 0.0098 & 7.2900 & 0.2200 & 0.1298 & 0.0019 & 2192 & 45 & 2092 & 26 & 4.6 \\
\hline 40 & 23.2 & 23.4 & 1.01 & 0.4053 & 0.0055 & 7.3000 & 0.1300 & 0.1295 & 0.0023 & 2196 & 26 & 2089 & 31 & 4.9 \\
\hline 79 & 81.5 & 86.7 & 1.06 & 0.4093 & 0.0081 & 7.3000 & 0.1900 & 0.1301 & 0.0022 & 2210 & 37 & 2098 & 30 & 5.1 \\
\hline 37 & 54.9 & 40.5 & 0.74 & 0.4091 & 0.0064 & 7.3200 & 0.1700 & 0.1282 & 0.0022 & 2209 & 30 & 2078 & 31 & 5.9 \\
\hline 72 & 22.3 & 13.7 & 0.61 & 0.4084 & 0.0099 & 7.4000 & 0.1800 & 0.1322 & 0.0040 & 2205 & 46 & 2123 & 54 & 3.7 \\
\hline 17 & 36.1 & 35.2 & 0.97 & 0.4070 & 0.0049 & 7.4100 & 0.1300 & 0.1324 & 0.0019 & 2200 & 22 & 2127 & 25 & 3.3 \\
\hline 44 & 46.0 & 52.2 & 1.13 & 0.4178 & 0.0055 & 7.4900 & 0.1500 & 0.1304 & 0.0019 & 2250 & 25 & 2106 & 26 & 6.4 \\
\hline \multicolumn{10}{|c|}{ Ratios } & \multicolumn{5}{|l|}{ Ages (Ma) } \\
\hline Spot & $\mathrm{U}(\mathrm{ppm})$ & Th(ppm) & $\mathrm{Th} / \mathrm{U}$ & ${ }^{206} \mathrm{~Pb} /{ }^{238} \mathrm{U}$ & $\pm 2 \mathrm{SE}$ & ${ }^{207} \mathrm{~Pb} /{ }^{235} \mathrm{U}$ & $\pm 2 \mathrm{SE}$ & ${ }^{207} \mathrm{~Pb} /{ }^{206} \mathrm{~Pb}$ & $\pm 2 \mathrm{SE}$ & ${ }^{206} \mathrm{~Pb} /{ }^{238} \mathrm{U}$ & \pm 2 SE & ${ }^{207} \mathrm{~Pb} /{ }^{206} \mathrm{~Pb}$ & $\pm 2 \mathrm{SE}$ & Discordance (\%) \\
\hline \multicolumn{15}{|c|}{ Sample $24 A$} \\
\hline $57 \mathrm{r} 2$ & 75.7 & 1.2 & 0.02 & 0.1043 & 0.0017 & 0.8780 & 0.0150 & 0.0618 & 0.0011 & 640 & 10 & 663 & 39 & -3.7 \\
\hline $30 r$ & 81.3 & 1.3 & 0.02 & 0.1065 & 0.0022 & 0.9250 & 0.0270 & 0.0629 & 0.0020 & 652 & 13 & 708 & 64 & -8.6 \\
\hline $26 r$ & 60.7 & 0.7 & 0.01 & 0.1067 & 0.0021 & 0.9490 & 0.0320 & 0.0661 & 0.0019 & 655 & 13 & 788 & 62 & -20.3 \\
\hline $57 r 1$ & 95.0 & 1.4 & 0.01 & 0.1152 & 0.0034 & 1.0680 & 0.0570 & 0.0668 & 0.0019 & 702 & 19 & 827 & 58 & -17.8 \\
\hline $65 r$ & 197.9 & 9.6 & 0.05 & 0.1851 & 0.0072 & 2.4900 & 0.1400 & 0.0952 & 0.0028 & 1098 & 39 & 1534 & 58 & -39.7 \\
\hline $11 \mathrm{r}$ & 843.0 & 96.1 & 0.11 & 0.1923 & 0.0084 & 2.8200 & 0.1300 & 0.1065 & 0.0015 & 1131 & 45 & 1743 & 26 & -54.1 \\
\hline $27 r$ & 256.2 & 12.0 & 0.05 & 0.2136 & 0.0054 & 3.1230 & 0.0930 & 0.1057 & 0.0015 & 1246 & 29 & 1728 & 26 & -38.7 \\
\hline $32 \mathrm{r}$ & 136.7 & 27.9 & 0.20 & 0.2224 & 0.0048 & 3.2160 & 0.0960 & 0.1053 & 0.0016 & 1294 & 25 & 1716 & 29 & -32.6 \\
\hline $40 r$ & 336.9 & 71.4 & 0.21 & 0.2289 & 0.0036 & 3.4660 & 0.0610 & 0.1112 & 0.0013 & 1328 & 19 & 1822 & 23 & -37.2 \\
\hline $47 r$ & 261.8 & 24.5 & 0.09 & 0.2619 & 0.0056 & 4.2900 & 0.1200 & 0.1193 & 0.0014 & 1498 & 29 & 1947 & 21 & -30.0 \\
\hline $50 \mathrm{r}$ & 522.3 & 248.0 & 0.47 & 0.3137 & 0.0063 & 5.3500 & 0.1200 & 0.1243 & 0.0012 & 1757 & 31 & 2018 & 17 & -14.9 \\
\hline $50 \mathrm{c}$ & 193.0 & 37.6 & 0.19 & 0.2838 & 0.0062 & 5.4500 & 0.1300 & 0.1338 & 0.0016 & 1609 & 31 & 2148 & 21 & -33.5 \\
\hline 51 & 193.0 & 53.2 & 0.28 & 0.3631 & 0.0049 & 6.3280 & 0.0870 & 0.1261 & 0.0014 & 1996 & 23 & 2042 & 19 & -2.3 \\
\hline 64 & 199.0 & 79.4 & 0.40 & 0.3695 & 0.0078 & 6.3300 & 0.1500 & 0.1259 & 0.0017 & 2025 & 37 & 2038 & 24 & -0.6 \\
\hline
\end{tabular}




\begin{tabular}{|c|c|c|c|c|c|c|c|c|c|c|c|c|c|c|}
\hline $57 c$ & 91.6 & 33.2 & 0.36 & 0.366 & 0.0052 & 6.3750 & 0.0800 & 0.1263 & 0.0014 & 2012 & 24 & 2047 & 20 & -1.7 \\
\hline 13 & 138.7 & 50.6 & 0.36 & 0.3673 & 0.006 & 6.4100 & 0.1200 & 0.1276 & 0.0016 & 2016 & 28 & 2063 & 22 & -2.3 \\
\hline 19 & 239.0 & 67.1 & 0.28 & 0.3641 & 0.0047 & 6.4150 & 0.0910 & 0.1279 & 0.0013 & 2001 & 22 & 2071 & 19 & -3.5 \\
\hline 59 & 251.0 & 69.2 & 0.28 & 0.3699 & 0.0052 & 6.4730 & 0.0760 & 0.1274 & 0.0014 & 2028 & 24 & 2062 & 19 & -1.7 \\
\hline 70r2 & 171.0 & 16.8 & 0.10 & 0.3683 & 0.0069 & 6.5000 & 0.1200 & 0.1282 & 0.0018 & 2019 & 32 & 2071 & 25 & -2.6 \\
\hline 40 & 172.8 & 49.2 & 0.28 & 0.3727 & 0.0044 & 6.5140 & 0.0720 & 0.1273 & 0.0012 & 2041 & 21 & 2059 & 17 & -0.9 \\
\hline 44 & 197.0 & 55.4 & 0.28 & 0.3703 & 0.0046 & 6.5180 & 0.0830 & 0.1282 & 0.0011 & 2030 & 22 & 2074 & 15 & -2.2 \\
\hline 25 & 121.1 & 32.8 & 0.27 & 0.3705 & 0.0053 & 6.5500 & 0.0970 & 0.1288 & 0.0015 & 2031 & 25 & 2081 & 21 & -2.5 \\
\hline $02 r$ & 97.2 & 27.1 & 0.28 & 0.3757 & 0.0061 & 6.6400 & 0.1100 & 0.1275 & 0.0015 & 2055 & 29 & 2064 & 21 & -0.4 \\
\hline 27 & 148.2 & 52.2 & 0.35 & 0.3794 & 0.0054 & 6.6400 & 0.1000 & 0.1277 & 0.0015 & 2073 & 25 & 2064 & 20 & 0.4 \\
\hline 75 & 420.0 & 129.9 & 0.31 & 0.3801 & 0.0058 & 6.6500 & 0.1400 & 0.1274 & 0.0022 & 2076 & 27 & 2058 & 30 & 0.9 \\
\hline $32 c$ & 342.0 & 175.1 & 0.51 & 0.3804 & 0.0054 & 6.6810 & 0.0850 & 0.1279 & 0.0013 & 2080 & 26 & 2068 & 18 & 0.6 \\
\hline $70 c$ & 120.0 & 46.3 & 0.39 & 0.3785 & 0.0056 & 6.6900 & 0.1200 & 0.1295 & 0.0018 & 2068 & 26 & 2092 & 23 & -1.2 \\
\hline 10 & 100.8 & 50.5 & 0.50 & 0.3783 & 0.007 & 6.7000 & 0.1300 & 0.1285 & 0.0018 & 2066 & 33 & 2079 & 23 & -0.6 \\
\hline 14 & 116.2 & 51.9 & 0.45 & 0.3803 & 0.0056 & 6.7110 & 0.0950 & 0.1287 & 0.0016 & 2079 & 27 & 2090 & 22 & -0.5 \\
\hline $37 r$ & 145.7 & 36.8 & 0.25 & 0.3795 & 0.0049 & 6.7280 & 0.0740 & 0.1287 & 0.0012 & 2076 & 22 & 2080 & 16 & -0.2 \\
\hline 81 & 132.7 & 59.6 & 0.45 & 0.3837 & 0.0056 & 6.7400 & 0.1100 & 0.1285 & 0.0017 & 2092 & 26 & 2076 & 23 & 0.8 \\
\hline 89 & 66.6 & 32.0 & 0.48 & 0.3845 & 0.0057 & 6.7500 & 0.1100 & 0.1282 & 0.0020 & 2100 & 27 & 2072 & 26 & 1.3 \\
\hline 88 & 118.6 & 57.0 & 0.48 & 0.3827 & 0.0058 & 6.7600 & 0.1400 & 0.1282 & 0.0020 & 2088 & 27 & 2074 & 27 & 0.7 \\
\hline $60 \mathrm{r}$ & 86.4 & 27.4 & 0.32 & 0.381 & 0.0065 & 6.7700 & 0.1100 & 0.1292 & 0.0017 & 2086 & 31 & 2086 & 23 & 0.0 \\
\hline $03 c$ & 131.4 & 63.5 & 0.48 & 0.3821 & 0.0052 & 6.7990 & 0.0860 & 0.1302 & 0.0015 & 2085 & 24 & 2102 & 19 & -0.8 \\
\hline 20 & 78.3 & 28.3 & 0.36 & 0.3848 & 0.0052 & 6.8500 & 0.1200 & 0.1288 & 0.0019 & 2101 & 24 & 2090 & 27 & 0.5 \\
\hline 68 & 42.7 & 18.3 & 0.43 & 0.3845 & 0.0077 & 6.8700 & 0.1500 & 0.1307 & 0.0023 & 2100 & 35 & 2105 & 31 & -0.2 \\
\hline 17 & 58.8 & 22.1 & 0.38 & 0.387 & 0.0054 & 6.8900 & 0.1100 & 0.1305 & 0.0017 & 2112 & 24 & 2101 & 23 & 0.5 \\
\hline 37 & 266.6 & 88.9 & 0.33 & 0.3908 & 0.0044 & 6.9040 & 0.0790 & 0.1288 & 0.0011 & 2128 & 21 & 2083 & 16 & 2.1 \\
\hline 08c & 55.5 & 20.6 & 0.37 & 0.3855 & 0.0061 & 6.9100 & 0.1100 & 0.1310 & 0.0019 & 2101 & 28 & 2110 & 26 & -0.4 \\
\hline $02 c$ & 119.2 & 39.6 & 0.33 & 0.388 & 0.0054 & 6.9100 & 0.1100 & 0.1286 & 0.0015 & 2112 & 25 & 2090 & 20 & 1.0 \\
\hline 82 & 154.7 & 78.2 & 0.51 & 0.3868 & 0.0061 & 6.9100 & 0.1300 & 0.1303 & 0.0017 & 2107 & 28 & 2100 & 23 & 0.3 \\
\hline 53 & 118.6 & 44.9 & 0.38 & 0.3883 & 0.0057 & 6.9150 & 0.0970 & 0.1302 & 0.0013 & 2114 & 26 & 2102 & 18 & 0.6 \\
\hline 49 & 53.3 & 15.2 & 0.28 & 0.3859 & 0.0064 & 6.9400 & 0.1200 & 0.1311 & 0.0020 & 2103 & 30 & 2115 & 26 & -0.6 \\
\hline $08 \mathrm{r}$ & 93.4 & 29.1 & 0.31 & 0.3854 & 0.0056 & 6.9450 & 0.0920 & 0.1304 & 0.0018 & 2097 & 25 & 2099 & 24 & -0.1 \\
\hline 79 & 67.0 & 19.0 & 0.28 & 0.3907 & 0.0061 & 6.9500 & 0.1200 & 0.1295 & 0.0018 & 2131 & 27 & 2091 & 24 & 1.9 \\
\hline 47c & 130.7 & 39.3 & 0.30 & 0.3865 & 0.0054 & 6.9520 & 0.0880 & 0.1307 & 0.0013 & 2106 & 25 & 2105 & 18 & 0.0 \\
\hline 48 & 72.8 & 23.9 & 0.33 & 0.3904 & 0.005 & 6.9530 & 0.0950 & 0.1289 & 0.0014 & 2126 & 24 & 2084 & 19 & 2.0 \\
\hline $16 \mathrm{c}$ & 92.3 & 40.5 & 0.44 & 0.3911 & 0.0058 & 6.9600 & 0.1100 & 0.1302 & 0.0016 & 2127 & 27 & 2100 & 21 & 1.3 \\
\hline 11c & 133.6 & 49.5 & 0.37 & 0.3902 & 0.0093 & 6.9600 & 0.1400 & 0.1304 & 0.0021 & 2121 & 43 & 2103 & 27 & 0.8 \\
\hline 69 & 107.5 & 57.0 & 0.53 & 0.3934 & 0.0052 & 6.9600 & 0.1100 & 0.1287 & 0.0015 & 2140 & 23 & 2080 & 21 & 2.8 \\
\hline 52 & 69.6 & 23.3 & 0.33 & 0.3912 & 0.0054 & 6.9700 & 0.0920 & 0.1308 & 0.0016 & 2128 & 25 & 2110 & 21 & 0.8 \\
\hline 60 & 141.5 & 62.2 & 0.44 & 0.3878 & 0.0053 & 6.9770 & 0.0940 & 0.1306 & 0.0016 & 2112 & 24 & 2103 & 21 & 0.4 \\
\hline 21c & 78.6 & 28.1 & 0.36 & 0.3898 & 0.0056 & 6.9800 & 0.1100 & 0.1312 & 0.0016 & 2121 & 26 & 2116 & 22 & 0.2 \\
\hline $21 r$ & 49.3 & 13.9 & 0.28 & 0.3919 & 0.0066 & 7.0100 & 0.1100 & 0.1305 & 0.0017 & 2130 & 30 & 2100 & 23 & 1.4 \\
\hline 55 & 212.2 & 173.7 & 0.82 & 0.3868 & 0.0051 & 7.0680 & 0.0940 & 0.1325 & 0.0013 & 2107 & 24 & 2133 & 17 & -1.2 \\
\hline 56 & 102.4 & 40.7 & 0.40 & 0.3977 & 0.0048 & 7.0900 & 0.0830 & 0.1302 & 0.0012 & 2158 & 22 & 2100 & 16 & 2.7 \\
\hline 87 & 11.6 & 1.5 & 0.13 & 0.4 & 0.013 & 7.1000 & 0.2100 & 0.1308 & 0.0035 & 2163 & 59 & 2109 & 47 & 2.5 \\
\hline 70r1 & 118.3 & 50.9 & 0.43 & 0.3945 & 0.0055 & 7.1200 & 0.1500 & 0.1305 & 0.0019 & 2143 & 25 & 2100 & 26 & 2.0 \\
\hline 71 & 44.0 & 17.0 & 0.39 & 0.4147 & 0.0057 & 7.2200 & 0.1300 & 0.1275 & 0.0018 & 2235 & 26 & 2066 & 26 & .6 \\
\hline
\end{tabular}




\begin{tabular}{|c|c|c|c|c|c|c|c|c|c|c|c|c|c|c|}
\hline \multirow[b]{2}{*}{ Spot } & \multirow[b]{2}{*}{$U(\mathrm{ppm})$} & \multirow[b]{2}{*}{ Th(ppm) } & \multirow[b]{2}{*}{$\mathrm{Th} / \mathrm{U}$} & \multicolumn{6}{|l|}{ Ratios } & \multicolumn{5}{|l|}{ Ages (Ma) } \\
\hline & & & & ${ }^{206} \mathrm{~Pb} /{ }^{238} \mathrm{U}$ & \pm 2 SE & ${ }^{207} \mathrm{~Pb} /{ }^{235} \mathrm{U}$ & \pm 2 SE & ${ }^{207} \mathrm{~Pb} /{ }^{206} \mathrm{~Pb}$ & $\pm 2 \mathrm{SE}$ & ${ }^{206} \mathrm{~Pb} /{ }^{238} \mathrm{U}$ & $\pm 2 \mathrm{SE}$ & ${ }^{207} \mathrm{~Pb} /{ }^{206} \mathrm{~Pb}$ & $\pm 2 \mathrm{SE}$ & Discordance (\% \\
\hline \multicolumn{15}{|c|}{ sample A9I } \\
\hline 84 & 134.0 & 23.6 & 0.18 & 0.5004 & 0.0070 & 14.6300 & 0.2500 & 0.2120 & 0.0030 & 2615 & 30 & 2920 & 23 & -11.7 \\
\hline 25 & 304.9 & 132.0 & 0.43 & 0.5127 & 0.0093 & 15.3600 & 0.3000 & 0.2182 & 0.0037 & 2666 & 40 & 2968 & 28 & -11.3 \\
\hline 45 & 286.5 & 160.3 & 0.56 & 0.5068 & 0.0062 & 14.7900 & 0.2500 & 0.2109 & 0.0029 & 2645 & 26 & 2911 & 22 & -10.1 \\
\hline $52-1 c$ & 116.5 & 44.9 & 0.39 & 0.5211 & 0.0080 & 15.6100 & 0.2800 & 0.2188 & 0.0035 & 2703 & 34 & 2973 & 25 & -10.0 \\
\hline 38 & 295.0 & 214.0 & 0.73 & 0.5167 & 0.0060 & 15.4300 & 0.2300 & 0.2157 & 0.0029 & 2684 & 25 & 2950 & 22 & -9.9 \\
\hline 22 & 98.7 & 22.8 & 0.23 & 0.5096 & 0.0094 & 14.8900 & 0.3700 & 0.2103 & 0.0033 & 2653 & 40 & 2905 & 26 & -9.5 \\
\hline 42 & 213.9 & 88.7 & 0.41 & 0.5176 & 0.0062 & 15.2500 & 0.2300 & 0.2127 & 0.0033 & 2688 & 27 & 2929 & 26 & -9.0 \\
\hline $78-2 r$ & 252.0 & 135.3 & 0.54 & 0.5278 & 0.0074 & 15.9200 & 0.2800 & 0.2196 & 0.0031 & 2735 & 30 & 2977 & 23 & -8.8 \\
\hline 34 & 97.7 & 20.6 & 0.21 & 0.5222 & 0.0075 & 15.4500 & 0.2300 & 0.2149 & 0.0034 & 2707 & 32 & 2945 & 25 & -8.8 \\
\hline $87-2 r$ & 94.6 & 17.0 & 0.18 & 0.5286 & 0.0073 & 15.6900 & 0.2500 & 0.2152 & 0.0030 & 2734 & 31 & 2944 & 22 & -7.7 \\
\hline 88 & 90.5 & 12.9 & 0.14 & 0.5352 & 0.0066 & 16.1700 & 0.2600 & 0.2184 & 0.0030 & 2763 & 28 & 2971 & 21 & -7.5 \\
\hline $26-2 r$ & 195.1 & 78.9 & 0.40 & 0.5362 & 0.0078 & 16.1000 & 0.2800 & 0.2177 & 0.0031 & 2766 & 33 & 2965 & 24 & -7.2 \\
\hline 58 & 190.0 & 95.0 & 0.50 & 0.5317 & 0.0092 & 15.8900 & 0.3400 & 0.2150 & 0.0035 & 2753 & 40 & 2941 & 27 & -6.8 \\
\hline $56-2 r$ & 165.6 & 60.1 & 0.36 & 0.5434 & 0.0080 & 16.2400 & 0.2900 & 0.2179 & 0.0033 & 2796 & 33 & 2964 & 24 & -6.0 \\
\hline $43-2 r$ & 72.2 & 10.8 & 0.15 & 0.5440 & 0.0160 & 16.3200 & 0.4700 & 0.2158 & 0.0054 & 2798 & 65 & 2944 & 40 & -5.2 \\
\hline 37 & 184.1 & 93.6 & 0.51 & 0.5555 & 0.0067 & 16.6500 & 0.2300 & 0.2183 & 0.0030 & 2847 & 28 & 2967 & 22 & -4.2 \\
\hline $44-1 c$ & 100.7 & 41.5 & 0.41 & 0.5551 & 0.0100 & 16.8100 & 0.3100 & 0.2179 & 0.0037 & 2850 & 41 & 2965 & 27 & -4.0 \\
\hline 71 & 51.7 & 18.4 & 0.36 & 0.5559 & 0.0092 & 16.6100 & 0.3400 & 0.2165 & 0.0032 & 2847 & 38 & 2953 & 24 & -3.7 \\
\hline 32 & 281.0 & 191.0 & 0.68 & 0.5676 & 0.0080 & 17.4800 & 0.3100 & 0.2227 & 0.0037 & 2902 & 32 & 3005 & 28 & -3.5 \\
\hline $55-1 c$ & 116.2 & 58.4 & 0.50 & 0.5731 & 0.0084 & 17.6100 & 0.3300 & 0.2252 & 0.0035 & 2920 & 34 & 3017 & 25 & -3.3 \\
\hline 2 & 92.3 & 29.3 & 0.32 & 0.5691 & 0.0073 & 17.3200 & 0.2700 & 0.2219 & 0.0032 & 2903 & 30 & 2993 & 23 & -3.1 \\
\hline 4 & 50.4 & 11.0 & 0.22 & 0.5731 & 0.0082 & 17.5400 & 0.3200 & 0.2237 & 0.0040 & 2919 & 34 & 3006 & 28 & -3.0 \\
\hline 20 & 69.9 & 19.3 & 0.28 & 0.5727 & 0.0086 & 17.6000 & 0.2600 & 0.2234 & 0.0030 & 2918 & 35 & 3004 & 22 & -2.9 \\
\hline $93-1 c$ & 47.0 & 11.1 & 0.24 & 0.5730 & 0.0130 & 17.4300 & 0.3900 & 0.2218 & 0.0043 & 2917 & 54 & 2995 & 31 & -2.7 \\
\hline 41 & 210.5 & 120.0 & 0.57 & 0.5755 & 0.0071 & 17.7200 & 0.2400 & 0.2236 & 0.0029 & 2929 & 29 & 3005 & 21 & -2.6 \\
\hline $78-1 c$ & 157.7 & 46.1 & 0.29 & 0.5671 & 0.0076 & 17.0000 & 0.2900 & 0.2175 & 0.0028 & 2895 & 31 & 2961 & 21 & -2.3 \\
\hline $26-1 c$ & 61.8 & 14.4 & 0.23 & 0.5740 & 0.0140 & 17.4400 & 0.4900 & 0.2187 & 0.0033 & 2921 & 55 & 2973 & 25 & -1.8 \\
\hline 92 & 80.4 & 27.6 & 0.34 & 0.5781 & 0.0099 & 17.5500 & 0.3000 & 0.2209 & 0.0035 & 2945 & 39 & 2986 & 26 & -1.4 \\
\hline 51 & 95.5 & 41.1 & 0.43 & 0.5852 & 0.0087 & 18.0200 & 0.2800 & 0.2241 & 0.0033 & 2968 & 35 & 3008 & 23 & -1.3 \\
\hline 46 & 92.0 & 35.9 & 0.39 & 0.5920 & 0.0091 & 18.3100 & 0.3500 & 0.2264 & 0.0035 & 2996 & 37 & 3025 & 25 & -1.0 \\
\hline $87-1 c$ & 82.0 & 23.9 & 0.29 & 0.5890 & 0.0110 & 18.2000 & 0.3600 & 0.2239 & 0.0035 & 2982 & 45 & 3009 & 24 & -0.9 \\
\hline 6 & 69.8 & 26.6 & 0.38 & 0.5966 & 0.0085 & 18.6900 & 0.3100 & 0.2277 & 0.0030 & 3014 & 34 & 3038 & 22 & -0.8 \\
\hline 29 & 105.7 & 31.8 & 0.30 & 0.5920 & 0.0110 & 18.3200 & 0.3800 & 0.2265 & 0.0038 & 3002 & 46 & 3025 & 27 & -0.8 \\
\hline $56-1 c$ & 83.0 & 22.7 & 0.27 & 0.5924 & 0.0090 & 18.2300 & 0.3000 & 0.2253 & 0.0034 & 2997 & 36 & 3017 & 24 & -0.7 \\
\hline 12 & 137.0 & 39.2 & 0.29 & 0.5921 & 0.0076 & 18.3000 & 0.2700 & 0.2245 & 0.0030 & 2997 & 31 & 3015 & 22 & -0.6 \\
\hline 57 & 145.7 & 64.5 & 0.44 & 0.5877 & 0.0075 & 17.9000 & 0.2800 & 0.2220 & 0.0032 & 2979 & 30 & 2995 & 23 & -0.5 \\
\hline $55-2 r$ & 298.0 & 139.8 & 0.47 & 0.5872 & 0.0077 & 17.8700 & 0.2900 & 0.2213 & 0.0029 & 2977 & 31 & 2990 & 21 & -0.4 \\
\hline 85 & 68.0 & 17.4 & 0.26 & 0.5869 & 0.0082 & 17.9300 & 0.3300 & 0.2214 & 0.0033 & 2980 & 33 & 2989 & 24 & -0.3 \\
\hline 13 & 95.8 & 40.5 & 0.42 & 0.5884 & 0.0083 & 17.9800 & 0.2500 & 0.2216 & 0.0032 & 2981 & 34 & 2990 & 23 & -0.3 \\
\hline $62-2 r$ & 220.7 & 106.5 & 0.48 & 0.5924 & 0.0071 & 18.1900 & 0.2400 & 0.2237 & 0.0032 & 2998 & 29 & 3007 & 24 & -0.3 \\
\hline 28 & 123.7 & 57.3 & 0.46 & 0.5886 & 0.0073 & 18.0200 & 0.2700 & 0.2216 & 0.0031 & 2982 & 30 & 2990 & 22 & -0.3 \\
\hline $62-1 c$ & 138.4 & 54.3 & 0.39 & 0.5893 & 0.0100 & 17.8100 & 0.3700 & 0.2215 & 0.0035 & 2984 & 42 & 2992 & 25 & -0.3 \\
\hline 48 & 125.8 & 51.2 & 0.41 & 0.5956 & 0.0073 & 18.4300 & 0.2700 & 0.2252 & 0.0030 & 3011 & 29 & 3017 & 22 & -0.2 \\
\hline 76 & 69.9 & 14.8 & 0.21 & 0.5927 & 0.0091 & 18.1400 & 0.3400 & 0.2235 & 0.0033 & 2999 & 37 & 3004 & 24 & -0.2 \\
\hline
\end{tabular}




\begin{tabular}{|c|c|c|c|c|c|c|c|c|c|c|c|c|c|}
\hline $93-2 r$ & 170.0 & 52.5 & 0.31 & 0.5916 & 0.0075 & 18.0600 & 0.2600 & 0.2217 & 0.0029 & 2994 & 30 & 2996 & 21 \\
\hline $65-1 c$ & 100.5 & 37.7 & 0.38 & 0.5912 & 0.0090 & 18.2100 & 0.3100 & 0.2221 & 0.0032 & 2996 & 37 & 2996 & 22 \\
\hline 94 & 117.6 & 41.1 & 0.35 & 0.5939 & 0.0069 & 18.3400 & 0.2800 & 0.2231 & 0.0028 & 3004 & 28 & 3004 & 20 \\
\hline $43-1 c$ & 82 & 35.6 & 0.44 & 0.6060 & 0.0110 & 19.0500 & 0.3500 & 0.2287 & 0.0038 & 3052 & 43 & 3048 & 26 \\
\hline 64 & 74.7 & 23.1 & 0.31 & 0.6019 & 0.0079 & 18.6900 & 0.2600 & 0.2269 & 0.0030 & 3036 & 32 & 3029 & 22 \\
\hline 1 & 67.2 & 20.9 & 0.31 & 0.5994 & 0.0078 & 18.4700 & 0.3100 & 0.2249 & 0.0031 & 3026 & 32 & 3017 & 22 \\
\hline 79 & 103.7 & 51.9 & 0.50 & 0.6000 & 0.0081 & 18.5400 & 0.2900 & 0.2253 & 0.0031 & 3028 & 33 & 3017 & 22 \\
\hline 80 & 180.0 & 80.9 & 0.45 & 0.5883 & 0.0071 & 17.7700 & 0.2600 & 0.2188 & 0.0031 & 2982 & 29 & 2970 & 23 \\
\hline 81 & 202.6 & 61.0 & 0.30 & 0.5999 & 0.0073 & 18.3900 & 0.2500 & 0.2240 & 0.0029 & 3032 & 30 & 3010 & 21 \\
\hline 50 & 89.4 & 27.2 & 0.30 & 0.5977 & 0.0073 & 18.3900 & 0.2900 & 0.2220 & 0.0031 & 3019 & 30 & 2997 & 22 \\
\hline 86 & 64.1 & 27.9 & 0.44 & 0.6055 & 0.0092 & 18.8500 & 0.3100 & 0.2269 & 0.0034 & 3051 & 37 & 3028 & 24 \\
\hline 60 & 76.3 & 25.9 & 0.34 & 0.5994 & 0.0085 & 18.3100 & 0.3000 & 0.2229 & 0.0035 & 3026 & 34 & 3000 & 25 \\
\hline $65-2 r$ & 249.0 & 84.2 & 0.34 & 0.5997 & 0.0081 & 18.4200 & 0.2600 & 0.2228 & 0.0033 & 3027 & 33 & 2999 & 24 \\
\hline 23 & 129.2 & 35.3 & 0.27 & 0.6050 & 0.0088 & 18.8300 & 0.3200 & 0.2261 & 0.0034 & 3053 & 35 & 3022 & 24 \\
\hline $44-2 r$ & 295.0 & 136.6 & 0.46 & 0.6011 & 0.0075 & 18.5300 & 0.2700 & 0.2228 & 0.0032 & 3033 & 30 & 3001 & 24 \\
\hline 61 & 108.7 & 52.0 & 0.48 & 0.6036 & 0.0089 & 18.7500 & 0.3100 & 0.2243 & 0.0033 & 3043 & 36 & 3010 & 23 \\
\hline $91-1 c$ & 105.4 & 40.8 & 0.39 & 0.6046 & 0.0093 & 18.6100 & 0.3000 & 0.2241 & 0.0031 & 3046 & 37 & 3012 & 22 \\
\hline 18 & 111.4 & 43.2 & 0.39 & 0.6051 & 0.0084 & 18.7600 & 0.2900 & 0.2243 & 0.0031 & 3049 & 34 & 3010 & 22 \\
\hline 70 & 144.5 & 65.1 & 0.45 & 0.6066 & 0.0085 & 18.7600 & 0.3100 & 0.2246 & 0.0033 & 3055 & 34 & 3012 & 23 \\
\hline $91-2 r$ & 172 & 66.9 & 0.39 & 0.6080 & 0.0130 & 18.8700 & 0.3900 & 0.2246 & 0.0030 & 3057 & 51 & 3012 & 21 \\
\hline 82 & 138.5 & 56.9 & 0.41 & 0.6047 & 0.0080 & 18.6100 & 0.3000 & 0.2227 & 0.0028 & 3048 & 32 & 2999 & 20 \\
\hline $52-2 r$ & 123.0 & 42.4 & 0.34 & 0.6104 & 0.0091 & 18.7800 & 0.3000 & 0.2247 & 0.0031 & 3074 & 36 & 3013 & 22 \\
\hline 9 & 107.9 & 42.1 & 0.39 & 0.6049 & 0.0099 & 18.5700 & 0.3200 & 0.2205 & 0.0032 & 3048 & 40 & 2983 & 24 \\
\hline 59 & 171 & 56.8 & 0.33 & 0.6178 & 0.0093 & 19.0200 & 0.3200 & 0.2256 & 0.0034 & 3100 & 37 & 3019 & 24 \\
\hline 68 & 114 & 43.0 & 0.38 & 0.6142 & 0.0100 & 18.9600 & 0.3400 & 0.2235 & 0.0033 & 3085 & 42 & 3004 & 24 \\
\hline 89 & 82 & 21.6 & 0.26 & 0.6182 & 0.0088 & 19.1500 & 0.3400 & 0.2238 & 0.0038 & 3108 & 37 & 3006 & 27 \\
\hline
\end{tabular}

\begin{tabular}{|c|c|c|c|c|c|c|c|c|c|c|c|c|c|c|}
\hline $24-2 r$ & 87.0 & 16.8 & 0.19 & 0.3108 & 0.0068 & 8.2000 & 0.2600 & 0.1990 & 0.0039 & 1743 & 34 & 2814 & 32 & -61.4 \\
\hline $24-1 c$ & 155.7 & 46.7 & 0.30 & 0.5015 & 0.0062 & 15.2000 & 0.2400 & 0.2195 & 0.0032 & 2620 & 26 & 2975 & 24 & -13.5 \\
\hline 91 & 162.0 & 58.2 & 0.36 & 0.5350 & 0.0110 & 16.1600 & 0.3900 & 0.2197 & 0.0031 & 2760 & 48 & 2977 & 23 & -7.9 \\
\hline 55 & 104.6 & 31.3 & 0.30 & 0.5149 & 0.0072 & 14.7200 & 0.2900 & 0.2072 & 0.0036 & 2676 & 31 & 2885 & 29 & -7.8 \\
\hline $46-2 r$ & 209.5 & 127.8 & 0.61 & 0.5350 & 0.0073 & 16.0800 & 0.2700 & 0.2182 & 0.0032 & 2761 & 31 & 2971 & 22 & -7.6 \\
\hline 86 & 104.1 & 26.9 & 0.26 & 0.5388 & 0.0100 & 16.2600 & 0.3000 & 0.2182 & 0.0029 & 2776 & 42 & 2968 & 22 & -6.9 \\
\hline 16 & 121.5 & 63.1 & 0.52 & 0.5422 & 0.0070 & 16.4500 & 0.2500 & 0.2192 & 0.0031 & 2792 & 29 & 2973 & 23 & -6.5 \\
\hline $36-1 c$ & 180.8 & 70.7 & 0.39 & 0.5415 & 0.0068 & 16.1300 & 0.2700 & 0.2162 & 0.0029 & 2789 & 29 & 2953 & 22 & -5.9 \\
\hline 34 & 101.8 & 34.6 & 0.34 & 0.5479 & 0.0085 & 16.5300 & 0.2800 & 0.2185 & 0.0028 & 2814 & 35 & 2971 & 20 & -5.6 \\
\hline $47-2 r$ & 154.1 & 9.9 & 0.06 & 0.5486 & 0.0079 & 16.5400 & 0.3100 & 0.2180 & 0.0030 & 2818 & 33 & 2964 & 22 & -5.2 \\
\hline $95-2 r$ & 172.0 & 18.3 & 0.11 & 0.5413 & 0.0085 & 16.1800 & 0.3000 & 0.2127 & 0.0030 & 2787 & 36 & 2925 & 23 & -5.0 \\
\hline 56 & 75.5 & 26.1 & 0.35 & 0.5438 & 0.0096 & 16.2700 & 0.3500 & 0.2153 & 0.0036 & 2807 & 38 & 2945 & 26 & -4.9 \\
\hline $73-1 c$ & 86.0 & 35.2 & 0.41 & 0.5573 & 0.0086 & 16.8200 & 0.2800 & 0.2187 & 0.0030 & 2854 & 36 & 2970 & 22 & -4.1 \\
\hline $73-2 r$ & 121.2 & 25.3 & 0.21 & 0.5610 & 0.0100 & 16.9300 & 0.3900 & 0.2188 & 0.0042 & 2867 & 43 & 2968 & 31 & -3.5 \\
\hline $08-2 r$ & 141.8 & 57.0 & 0.40 & 0.5628 & 0.0076 & 17.0100 & 0.2700 & 0.2191 & 0.0030 & 2881 & 31 & 2976 & 21 & -3.3 \\
\hline $06-1 c$ & 266.0 & 136.5 & 0.51 & 0.5711 & 0.0069 & 17.5000 & 0.2600 & 0.2226 & 0.0029 & 2911 & 28 & 3002 & 20 & -3.1 \\
\hline 10 & 113.8 & 36.4 & 0.32 & 0.5742 & 0.0071 & 17.6200 & 0.2900 & 0.2223 & 0.0032 & 2928 & 30 & 3000 & 23 & -2.5 \\
\hline
\end{tabular}




\begin{tabular}{|c|c|c|c|c|c|c|c|c|c|c|c|c|c|c|}
\hline $08-1 c$ & 229.0 & 103.0 & 0.45 & 0.5731 & 0.0091 & 17.5200 & 0.3100 & 0.2217 & 0.0030 & 2923 & 36 & 2993 & 22 & -2.4 \\
\hline 81 & 174.9 & 67.9 & 0.39 & 0.5706 & 0.0072 & 17.4000 & 0.2700 & 0.2199 & 0.0029 & 2909 & 29 & 2978 & 21 & -2.4 \\
\hline 78 & 62.1 & 20.3 & 0.33 & 0.5750 & 0.0100 & 17.5400 & 0.3800 & 0.2215 & 0.0032 & 2926 & 41 & 2992 & 23 & -2.3 \\
\hline 11 & 72.3 & 24.3 & 0.34 & 0.5724 & 0.0070 & 17.3600 & 0.2900 & 0.2202 & 0.0031 & 2917 & 29 & 2981 & 23 & -2.2 \\
\hline 27 & 95.7 & 24.1 & 0.25 & 0.5744 & 0.0075 & 17.6100 & 0.3300 & 0.2215 & 0.0033 & 2929 & 30 & 2993 & 23 & -2.2 \\
\hline 49 & 193.0 & 68.7 & 0.36 & 0.5778 & 0.0095 & 17.7200 & 0.3400 & 0.2230 & 0.0034 & 2938 & 39 & 3002 & 23 & -2.2 \\
\hline $06-2 r$ & 80.6 & 20.9 & 0.26 & 0.5771 & 0.0064 & 17.6400 & 0.2600 & 0.2222 & 0.0031 & 2936 & 26 & 2995 & 22 & -2.0 \\
\hline 87 & 97.7 & 26.7 & 0.27 & 0.5803 & 0.0090 & 17.7500 & 0.2800 & 0.2224 & 0.0032 & 2952 & 37 & 2998 & 22 & -1.6 \\
\hline 30 & 132.0 & 86.7 & 0.66 & 0.5865 & 0.0074 & 18.0800 & 0.2900 & 0.2240 & 0.0032 & 2974 & 30 & 3008 & 23 & -1.1 \\
\hline 41 & 108.6 & 43.5 & 0.40 & 0.5893 & 0.0088 & 18.0900 & 0.3100 & 0.2245 & 0.0035 & 2989 & 36 & 3013 & 25 & -0.8 \\
\hline 54 & 87.8 & 42.6 & 0.49 & 0.5917 & 0.0079 & 18.3100 & 0.3000 & 0.2243 & 0.0034 & 2995 & 32 & 3016 & 25 & -0.7 \\
\hline 22 & 85.4 & 22.6 & 0.26 & 0.5934 & 0.0089 & 18.4100 & 0.2900 & 0.2255 & 0.0032 & 3001 & 36 & 3019 & 23 & 0.6 \\
\hline 57 & 176.0 & 77.4 & 0.44 & 0.5916 & 0.0083 & 18.2300 & 0.3300 & 0.2237 & 0.0029 & 2994 & 33 & 3006 & 21 & -0.4 \\
\hline 79 & 64.6 & 23.9 & 0.37 & 0.5910 & 0.0110 & 18.2400 & 0.3500 & 0.2230 & 0.0033 & 2992 & 43 & 3000 & 24 & -0.3 \\
\hline 59 & 115.4 & 54.0 & 0.47 & 0.5963 & 0.0090 & 18.4800 & 0.2900 & 0.2245 & 0.0031 & 3013 & 36 & 3015 & 22 & -0.1 \\
\hline 84 & 59.8 & 24.3 & 0.41 & 0.5906 & 0.0098 & 18.2400 & 0.3000 & 0.2211 & 0.0036 & 2990 & 39 & 2989 & 25 & 0.0 \\
\hline 64 & 66.7 & 15.6 & 0.23 & 0.5946 & 0.0100 & 18.1400 & 0.3000 & 0.2232 & 0.0033 & 3006 & 41 & 3004 & 23 & 0.1 \\
\hline $95-1 c$ & 171.0 & 35.9 & 0.21 & 0.5800 & 0.0130 & 17.6300 & 0.3900 & 0.2175 & 0.0039 & 2962 & 50 & 2959 & 29 & 0.1 \\
\hline 63 & 188.5 & 84.0 & 0.45 & 0.5882 & 0.0079 & 17.9000 & 0.2600 & 0.2200 & 0.0031 & 2984 & 32 & 2979 & 22 & 0.2 \\
\hline $77-2 r$ & 50.9 & 19.0 & 0.37 & 0.5940 & 0.0110 & 18.2200 & 0.3400 & 0.2225 & 0.0037 & 3004 & 43 & 2997 & 27 & 0.2 \\
\hline 68 & 111.5 & 37.2 & 0.33 & 0.5966 & 0.0081 & 18.4600 & 0.2600 & 0.2241 & 0.0031 & 3018 & 32 & 3010 & 22 & 0.3 \\
\hline 9 & 100.0 & 40.0 & 0.40 & 0.5996 & 0.0100 & 18.6500 & 0.3600 & 0.2247 & 0.0032 & 3026 & 41 & 3017 & 24 & 0.3 \\
\hline $36-2 r$ & 280.2 & 135.1 & 0.48 & 0.5990 & 0.0084 & 18.5000 & 0.2900 & 0.2246 & 0.0034 & 3025 & 34 & 3012 & 24 & 0.4 \\
\hline $31-2 r$ & 105.7 & 30.2 & 0.29 & 0.5931 & 0.0100 & 18.1300 & 0.3300 & 0.2210 & 0.0037 & 3000 & 41 & 2985 & 26 & 0.5 \\
\hline 23 & 48.0 & 11.6 & 0.24 & 0.6034 & 0.0100 & 18.6500 & 0.3500 & 0.2263 & 0.0041 & 3042 & 41 & 3022 & 29 & 0.7 \\
\hline $31-1 c$ & 132.9 & 32.7 & 0.25 & 0.5938 & 0.0099 & 18.1000 & 0.3600 & 0.2205 & 0.0035 & 3003 & 40 & 2983 & 26 & 0.7 \\
\hline 60 & 135.4 & 48.3 & 0.36 & 0.6026 & 0.0098 & 18.5700 & 0.3200 & 0.2248 & 0.0032 & 3038 & 39 & 3016 & 23 & 0.7 \\
\hline 3 & 52.8 & 23.6 & 0.45 & 0.6005 & 0.0082 & 18.6100 & 0.2700 & 0.2244 & 0.0037 & 3034 & 32 & 3009 & 26 & 0.8 \\
\hline 67 & 83.4 & 23.7 & 0.28 & 0.5993 & 0.0091 & 18.4900 & 0.3100 & 0.2221 & 0.0034 & 3025 & 37 & 2999 & 24 & 0.9 \\
\hline 90 & 212.5 & 108.5 & 0.51 & 0.5988 & 0.0084 & 18.5200 & 0.2600 & 0.2225 & 0.0029 & 3024 & 34 & 2998 & 21 & 0.9 \\
\hline $77-1 c$ & 81.9 & 29.2 & 0.36 & 0.6051 & 0.0074 & 18.7600 & 0.3200 & 0.2248 & 0.0032 & 3049 & 30 & 3016 & 23 & 1.1 \\
\hline 85 & 177.9 & 56.4 & 0.32 & 0.5940 & 0.0110 & 18.2000 & 0.3800 & 0.2199 & 0.0031 & 3014 & 44 & 2979 & 23 & 1.2 \\
\hline 48 & 282.0 & 129.0 & 0.46 & 0.5994 & 0.0088 & 18.3200 & 0.3000 & 0.2211 & 0.0034 & 3025 & 35 & 2986 & 25 & 1.3 \\
\hline 13 & 26.8 & 7.6 & 0.28 & 0.6097 & 0.0094 & 18.9100 & 0.3600 & 0.2259 & 0.0036 & 3067 & 38 & 3020 & 26 & 1.5 \\
\hline $12-2 r$ & 63.6 & 13.3 & 0.21 & 0.6080 & 0.0130 & 18.6900 & 0.3900 & 0.2253 & 0.0042 & 3068 & 51 & 3016 & 30 & 1.7 \\
\hline $12-1 c$ & 233.0 & 130.0 & 0.56 & 0.6093 & 0.0091 & 18.8100 & 0.3200 & 0.2247 & 0.0029 & 3069 & 36 & 3014 & 20 & 1.8 \\
\hline 94 & 140.0 & 48.8 & 0.35 & 0.6045 & 0.0084 & 18.6200 & 0.2900 & 0.2221 & 0.0030 & 3050 & 33 & 2995 & 22 & 1.8 \\
\hline 52 & 276.7 & 148.1 & 0.54 & 0.6069 & 0.0078 & 18.8100 & 0.2900 & 0.2226 & 0.0033 & 3056 & 31 & 2997 & 24 & 1.9 \\
\hline 66 & 199.0 & 115.0 & 0.58 & 0.6120 & 0.0130 & 18.7900 & 0.4000 & 0.2239 & 0.0039 & 3076 & 51 & 3006 & 28 & 2.3 \\
\hline $46-1 c$ & 119.0 & 48.4 & 0.41 & 0.6140 & 0.0140 & 18.8500 & 0.4500 & 0.2234 & 0.0030 & 3083 & 55 & 3003 & 22 & 2.6 \\
\hline 5 & 46.4 & 23.4 & 0.50 & 0.6241 & 0.0100 & 19.4900 & 0.3600 & 0.2286 & 0.0034 & 3124 & 41 & 3041 & 24 & 2.7 \\
\hline $47-1 c$ & 119.4 & 50.9 & 0.43 & 0.6224 & 0.0074 & 19.3200 & 0.2800 & 0.2259 & 0.0032 & 3119 & 29 & 3022 & 23 & 3.1 \\
\hline 21 & 96.5 & 28.4 & 0.29 & 0.6232 & 0.0100 & 19.1500 & 0.3200 & 0.2239 & 0.0033 & 3121 & 41 & 3012 & 24 & 3.5 \\
\hline
\end{tabular}

Ratios Ages (Ma)

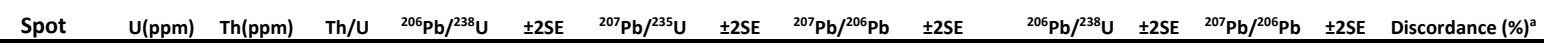
sample C20 


\begin{tabular}{|c|c|c|c|c|c|c|c|c|c|c|c|c|c|c|}
\hline 48 & 279.0 & 72.0 & 0.26 & 0.1659 & 0.0089 & 3.2600 & 0.2700 & 0.1452 & 0.0055 & 987 & 49 & 2294 & 67 & -132.4 \\
\hline 34.1 & 584.0 & 176.5 & 0.30 & 0.1764 & 0.0045 & 3.5900 & 0.1600 & 0.1468 & 0.0050 & 1047 & 24 & 2301 & 56 & -119.8 \\
\hline 19 & 531.0 & 148.3 & 0.28 & 0.1816 & 0.0037 & 3.6200 & 0.1300 & 0.1453 & 0.0024 & 1075 & 20 & 2289 & 27 & -112.9 \\
\hline 38 & 459.0 & 74.2 & 0.16 & 0.2055 & 0.0050 & 4.3900 & 0.1700 & 0.1585 & 0.0044 & 1204 & 27 & 2433 & 47 & -102.1 \\
\hline 13.2 & 420.0 & 116.3 & 0.28 & 0.2160 & 0.0100 & 4.8400 & 0.3500 & 0.1595 & 0.0046 & 1255 & 55 & 2432 & 50 & -93.8 \\
\hline 59.1 & 398.0 & 52.0 & 0.13 & 0.2654 & 0.0083 & 6.4500 & 0.3000 & 0.1763 & 0.0048 & 1515 & 42 & 2612 & 46 & -72.4 \\
\hline 69 & 316.0 & 145.0 & 0.46 & 0.2910 & 0.0110 & 7.4100 & 0.4500 & 0.1839 & 0.0077 & 1646 & 53 & 2680 & 71 & -62.8 \\
\hline 34.2 & 280.0 & 54.3 & 0.19 & 0.2970 & 0.0087 & 7.5400 & 0.3300 & 0.1850 & 0.0042 & 1673 & 43 & 2700 & 38 & -61.4 \\
\hline 13.1 & 288.0 & 113.6 & 0.39 & 0.2990 & 0.0110 & 7.5900 & 0.3700 & 0.1848 & 0.0026 & 1681 & 55 & 2697 & 23 & -60.4 \\
\hline 50 & 433.0 & 25.9 & 0.06 & 0.3075 & 0.0092 & 8.0500 & 0.3700 & 0.1898 & 0.0051 & 1726 & 46 & 2738 & 44 & -58.6 \\
\hline 68 & 311.0 & 151.0 & 0.49 & 0.3324 & 0.0094 & 8.9800 & 0.5100 & 0.1947 & 0.0081 & 1848 & 45 & 2776 & 70 & -50.2 \\
\hline 32.2 & 286.0 & 74.3 & 0.26 & 0.3736 & 0.0082 & 10.3400 & 0.3500 & 0.2023 & 0.0043 & 2049 & 38 & 2836 & 35 & -38.4 \\
\hline 77 & 304.0 & 148.8 & 0.49 & 0.3820 & 0.0160 & 10.7300 & 0.6300 & 0.2001 & 0.0051 & 2072 & 76 & 2816 & 41 & -35.9 \\
\hline 62 & 414.0 & 46.5 & 0.11 & 0.4053 & 0.0095 & 11.4800 & 0.4600 & 0.2065 & 0.0058 & 2191 & 43 & 2866 & 46 & -30.8 \\
\hline 22 & 262.0 & 72.8 & 0.28 & 0.4264 & 0.0098 & 11.9300 & 0.3200 & 0.2024 & 0.0038 & 2288 & 44 & 2846 & 31 & -24.4 \\
\hline 40.1 & 185.1 & 90.5 & 0.49 & 0.4704 & 0.0096 & 15.1700 & 0.5000 & 0.2350 & 0.0049 & 2482 & 42 & 3077 & 33 & -24.0 \\
\hline 21 & 224.7 & 116.1 & 0.52 & 0.4416 & 0.0078 & 12.6500 & 0.3400 & 0.2082 & 0.0032 & 2360 & 35 & 2889 & 25 & -22.4 \\
\hline 15 & 173.0 & 91.8 & 0.53 & 0.4659 & 0.0071 & 13.3200 & 0.2700 & 0.2074 & 0.0029 & 2465 & 31 & 2889 & 23 & -17.2 \\
\hline 41.1 & 248.1 & 103.8 & 0.42 & 0.4650 & 0.0110 & 13.3700 & 0.4800 & 0.2081 & 0.0047 & 2460 & 47 & 2880 & 36 & -17.1 \\
\hline 32.1 & 263.0 & 84.8 & 0.32 & 0.4780 & 0.0130 & 13.7500 & 0.5300 & 0.2072 & 0.0056 & 2517 & 56 & 2873 & 43 & -14.1 \\
\hline 41.2 & 235.0 & 78.7 & 0.33 & 0.4890 & 0.0130 & 14.3500 & 0.5500 & 0.2113 & 0.0044 & 2567 & 56 & 2909 & 34 & -13.3 \\
\hline 59.2 & 268.0 & 118.5 & 0.44 & 0.4939 & 0.0098 & 14.2500 & 0.4400 & 0.2101 & 0.0044 & 2585 & 42 & 2902 & 34 & -12.3 \\
\hline 20 & 162.0 & 67.8 & 0.42 & 0.4970 & 0.0098 & 14.3800 & 0.4200 & 0.2103 & 0.0041 & 2598 & 42 & 2903 & 31 & -11.7 \\
\hline 36 & 231.0 & 79.0 & 0.34 & 0.5010 & 0.0150 & 14.7700 & 0.5700 & 0.2112 & 0.0055 & 2628 & 65 & 2922 & 44 & -11.2 \\
\hline 18.2 & 128.5 & 25.6 & 0.20 & 0.5112 & 0.0072 & 15.0400 & 0.3500 & 0.2144 & 0.0030 & 2660 & 31 & 2935 & 23 & -10.3 \\
\hline 40.2 & 173.6 & 1.0 & 0.01 & 0.5211 & 0.0087 & 15.6700 & 0.4900 & 0.2187 & 0.0052 & 2702 & 37 & 2965 & 39 & -9.7 \\
\hline 9 & 96.1 & 35.8 & 0.37 & 0.5290 & 0.0130 & 15.9800 & 0.8400 & 0.2155 & 0.0091 & 2733 & 53 & 2929 & 69 & -7.2 \\
\hline 10 & 131.1 & 25.3 & 0.19 & 0.5360 & 0.0140 & 16.2900 & 0.8700 & 0.2185 & 0.0096 & 2761 & 57 & 2946 & 71 & -6.7 \\
\hline 1 & 97.6 & 35.5 & 0.36 & 0.5410 & 0.0100 & 16.2200 & 0.5500 & 0.2167 & 0.0055 & 2785 & 43 & 2949 & 41 & -5.9 \\
\hline 3 & 203.0 & 78.4 & 0.39 & 0.5490 & 0.0110 & 16.7700 & 0.6700 & 0.2194 & 0.0069 & 2824 & 48 & 2959 & 51 & -4.8 \\
\hline 29 & 211.0 & 201.0 & 0.95 & 0.5480 & 0.0120 & 16.3900 & 0.5400 & 0.2167 & 0.0049 & 2826 & 49 & 2951 & 36 & -4.4 \\
\hline 16.2 & 201.1 & 96.1 & 0.48 & 0.6069 & 0.0083 & 20.9400 & 0.4700 & 0.2506 & 0.0037 & 3056 & 33 & 3186 & 24 & -4.3 \\
\hline 6.1 & 105.7 & 93.1 & 0.88 & 0.5541 & 0.0074 & 16.4100 & 0.4200 & 0.2168 & 0.0038 & 2841 & 31 & 2950 & 29 & -3.8 \\
\hline 26 & 201.1 & 112.1 & 0.56 & 0.6104 & 0.0086 & 21.0200 & 0.5200 & 0.2515 & 0.0046 & 3070 & 35 & 3187 & 29 & -3.8 \\
\hline 7 & 66.8 & 32.8 & 0.49 & 0.6130 & 0.0160 & 21.4600 & 0.9900 & 0.2535 & 0.0092 & 3076 & 63 & 3182 & 58 & -3.4 \\
\hline 60.1 & 118.8 & 96.6 & 0.81 & 0.5608 & 0.0093 & 16.8800 & 0.5200 & 0.2190 & 0.0060 & 2868 & 38 & 2961 & 44 & -3.2 \\
\hline 18.1 & 81.9 & 55.6 & 0.68 & 0.5612 & 0.0098 & 16.8400 & 0.5100 & 0.2153 & 0.0047 & 2870 & 40 & 2943 & 36 & -2.5 \\
\hline 60.2 & 80.1 & 34.1 & 0.43 & 0.5610 & 0.0110 & 16.7000 & 0.5800 & 0.2155 & 0.0059 & 2873 & 43 & 2946 & 44 & -2.5 \\
\hline 52.2 & 62.8 & 30.1 & 0.48 & 0.5640 & 0.0150 & 16.9400 & 0.8000 & 0.2194 & 0.0091 & 2881 & 60 & 2953 & 66 & -2.5 \\
\hline 8.2 & 96.8 & 58.1 & 0.60 & 0.5666 & 0.0074 & 16.9700 & 0.5100 & 0.2181 & 0.0053 & 2892 & 30 & 2960 & 40 & -2.4 \\
\hline 67 & 89.2 & 39.8 & 0.45 & 0.6200 & 0.0150 & 21.9400 & 1.0000 & 0.2510 & 0.0090 & 3108 & 60 & 3175 & 56 & -2.2 \\
\hline 46 & 91.3 & 49.2 & 0.54 & 0.5705 & 0.0099 & 17.0700 & 0.5100 & 0.2184 & 0.0049 & 2908 & 40 & 2963 & 36 & -1.9 \\
\hline 16.1 & 101.7 & 33.8 & 0.33 & 0.6350 & 0.0100 & 22.0100 & 0.5300 & 0.2534 & 0.0042 & 3172 & 40 & 3203 & 27 & -1.0 \\
\hline 8.1 & 80.1 & 67.9 & 0.85 & 0.5781 & 0.0070 & 17.2000 & 0.3400 & 0.2153 & 0.0029 & 2940 & 29 & 2942 & 21 & -0.1 \\
\hline 42 & 45.0 & 29.8 & 0.66 & 0.5807 & 0.0100 & 17.2500 & 0.5500 & 0.2154 & 0.0046 & 2954 & 42 & 2937 & 34 & 0.6 \\
\hline 52.1 & 54.8 & 31.2 & 0.57 & 0.5900 & 0.0110 & 17.8500 & 0.5900 & 0.2188 & 0.0059 & 2987 & 43 & 2957 & 43 & 1.0 \\
\hline 58 & 100.5 & 69.5 & 0.69 & 0.5860 & 0.0120 & 17.5100 & 0.5700 & 0.2158 & 0.0050 & 2971 & 47 & 2938 & 38 & 1.1 \\
\hline 61 & 97.3 & 79.8 & 0.82 & 0.5940 & 0.0110 & 17.7700 & 0.5700 & 0.2187 & 0.0057 & 3010 & 43 & 2959 & 42 & 1.7 \\
\hline \multicolumn{15}{|c|}{169} \\
\hline
\end{tabular}




\begin{tabular}{|c|c|c|c|c|c|c|c|c|c|c|c|c|c|c|}
\hline \multirow[b]{2}{*}{ Spot } & \multirow[b]{2}{*}{$\mathrm{U}(\mathrm{ppm})$} & \multirow[b]{2}{*}{ Th(ppm) } & \multirow[b]{2}{*}{ Th/U } & \multicolumn{2}{|l|}{ Ratios } & \multicolumn{9}{|c|}{ Ages (Ma) } \\
\hline & & & & ${ }^{206} \mathrm{~Pb} /{ }^{238} \mathrm{U}$ & $\pm 2 \mathrm{SE}$ & ${ }^{207} \mathrm{~Pb} /{ }^{235} \mathrm{U}$ & $\pm 2 \mathrm{SE}$ & ${ }^{207} \mathrm{~Pb} /{ }^{206} \mathrm{~Pb}$ & \pm 2 SE & ${ }^{206} \mathrm{~Pb} /{ }^{238} \mathrm{U}$ & $\pm 2 \mathrm{SE}$ & ${ }^{207} \mathrm{~Pb} /{ }^{206} \mathrm{~Pb}$ & $\pm 2 \mathrm{SE}$ & Discordance (\%) \\
\hline \multicolumn{15}{|c|}{ sample C37 } \\
\hline $01-1$ & 105.4 & 39.3 & 0.37 & 0.5898 & 0.0073 & 17.7600 & 0.2800 & 0.2180 & 0.0031 & 2987 & 30 & 2964 & 23 & 0.8 \\
\hline $64-2 r$ & 242.0 & 70.0 & 0.29 & 0.2940 & 0.0170 & 8.1100 & 0.4900 & 0.2011 & 0.0027 & 1658 & 86 & 2835 & 21 & -71.0 \\
\hline $05-2 r$ & 79.3 & 20.8 & 0.26 & 0.4717 & 0.0090 & 14.0100 & 0.2600 & 0.2123 & 0.0031 & 2488 & 39 & 2925 & 23 & -17.6 \\
\hline $23-2 r$ & 216.0 & 34.0 & 0.16 & 0.4366 & 0.0059 & 11.1300 & 0.2000 & 0.1855 & 0.0028 & 2338 & 27 & 2700 & 25 & -15.5 \\
\hline $65-1 c$ & 165.0 & 46.0 & 0.28 & 0.4877 & 0.0066 & 13.5800 & 0.2300 & 0.2024 & 0.0031 & 2560 & 29 & 2850 & 24 & -11.3 \\
\hline $49-1 c$ & 465.0 & 56.0 & 0.12 & 0.4705 & 0.0094 & 12.3300 & 0.3100 & 0.1927 & 0.0031 & 2485 & 41 & 2764 & 27 & -11.2 \\
\hline $57-2 r$ & 174.0 & 25.1 & 0.14 & 0.4892 & 0.0092 & 13.4600 & 0.2900 & 0.2019 & 0.0029 & 2565 & 40 & 2839 & 23 & -10.7 \\
\hline $37-1 c$ & 139.0 & 53.3 & 0.38 & 0.4904 & 0.0053 & 13.4900 & 0.1900 & 0.2013 & 0.0029 & 2572 & 23 & 2837 & 23 & -10.3 \\
\hline $94-1 c$ & 106.8 & 53.2 & 0.50 & 0.5149 & 0.0067 & 14.4900 & 0.2300 & 0.2036 & 0.0028 & 2676 & 29 & 2857 & 22 & -6.8 \\
\hline $29-2 r$ & 399.8 & 30.9 & 0.08 & 0.4935 & 0.0055 & 13.0700 & 0.2100 & 0.1921 & 0.0028 & 2585 & 24 & 2758 & 24 & -6.7 \\
\hline $42-2 r$ & 143.0 & 31.6 & 0.22 & 0.5122 & 0.0083 & 14.1600 & 0.2700 & 0.2004 & 0.0030 & 2664 & 35 & 2829 & 25 & -6.2 \\
\hline $65-2 r$ & 257.9 & 4.2 & 0.02 & 0.4716 & 0.0056 & 11.6300 & 0.1500 & 0.1790 & 0.0023 & 2490 & 24 & 2643 & 21 & -6.1 \\
\hline $85-1 r$ & 83.0 & 12.9 & 0.16 & 0.5108 & 0.0073 & 13.9100 & 0.2400 & 0.1967 & 0.0031 & 2659 & 31 & 2800 & 26 & -5.3 \\
\hline $23-1 c$ & 93.8 & 38.2 & 0.41 & 0.5418 & 0.0075 & 15.7500 & 0.2700 & 0.2124 & 0.0033 & 2789 & 31 & 2924 & 26 & -4.8 \\
\hline $53-1$ & 177.4 & 97.6 & 0.55 & 0.5384 & 0.0075 & 15.4400 & 0.2600 & 0.2101 & 0.0028 & 2776 & 31 & 2905 & 22 & -4.6 \\
\hline $33-1 c$ & 177.0 & 62.8 & 0.35 & 0.5455 & 0.0089 & 15.8500 & 0.3100 & 0.2136 & 0.0032 & 2805 & 37 & 2934 & 24 & -4.6 \\
\hline $40-1 c$ & 261.0 & 70.2 & 0.27 & 0.5372 & 0.0080 & 15.4000 & 0.2400 & 0.2076 & 0.0027 & 2770 & 34 & 2891 & 23 & -4.4 \\
\hline $15-1 c$ & 60.9 & 19.2 & 0.32 & 0.5393 & 0.0092 & 15.5600 & 0.3200 & 0.2090 & 0.0031 & 2778 & 38 & 2899 & 25 & -4.4 \\
\hline $97-2 r$ & 74.8 & 18.6 & 0.25 & 0.4634 & 0.0067 & 10.8900 & 0.2800 & 0.1705 & 0.0035 & 2459 & 29 & 2565 & 34 & -4.3 \\
\hline $17-1 c$ & 315.0 & 58.5 & 0.19 & 0.5460 & 0.0120 & 15.8800 & 0.3500 & 0.2114 & 0.0038 & 2807 & 49 & 2917 & 30 & -3.9 \\
\hline $58-2 r$ & 159.0 & 68.1 & 0.43 & 0.5393 & 0.0060 & 15.4200 & 0.2300 & 0.2077 & 0.0027 & 2782 & 26 & 2888 & 21 & -3.8 \\
\hline $35-1 c$ & 134.0 & 65.0 & 0.49 & 0.5495 & 0.0065 & 16.0100 & 0.2500 & 0.2124 & 0.0029 & 2822 & 27 & 2929 & 21 & -3.8 \\
\hline $49-2 r$ & 174.8 & 10.8 & 0.06 & 0.5452 & 0.0055 & 15.6100 & 0.1800 & 0.2101 & 0.0026 & 2804 & 23 & 2907 & 20 & -3.7 \\
\hline $57-1 c$ & 146.0 & 80.0 & 0.55 & 0.5559 & 0.0100 & 16.3000 & 0.3300 & 0.2161 & 0.0032 & 2848 & 42 & 2951 & 24 & -3.6 \\
\hline $69-1 c$ & 397.0 & 133.0 & 0.34 & 0.5480 & 0.0058 & 15.6800 & 0.2200 & 0.2104 & 0.0028 & 2816 & 24 & 2911 & 21 & -3.4 \\
\hline $45-1$ & 69.2 & 17.3 & 0.25 & 0.5426 & 0.0071 & 15.4100 & 0.2500 & 0.2072 & 0.0030 & 2793 & 30 & 2886 & 23 & -3.3 \\
\hline $05-1 c$ & 111.2 & 10.0 & 0.09 & 0.5401 & 0.0076 & 15.4600 & 0.2500 & 0.2060 & 0.0028 & 2783 & 32 & 2872 & 22 & -3.2 \\
\hline $62-1 c$ & 42.4 & 9.5 & 0.22 & 0.5493 & 0.0070 & 15.7400 & 0.2900 & 0.2109 & 0.0033 & 2821 & 29 & 2910 & 26 & -3.2 \\
\hline $22-1 c$ & 109.8 & 33.3 & 0.30 & 0.5526 & 0.0088 & 16.0000 & 0.3000 & 0.2115 & 0.0033 & 2835 & 36 & 2918 & 26 & -2.9 \\
\hline $52-1 c$ & 144.0 & 72.2 & 0.50 & 0.5609 & 0.0076 & 16.5800 & 0.2700 & 0.2160 & 0.0027 & 2869 & 31 & 2952 & 20 & -2.9 \\
\hline $58-1 c$ & 136.4 & 62.0 & 0.45 & 0.5444 & 0.0067 & 15.5400 & 0.2300 & 0.2073 & 0.0028 & 2804 & 28 & 2883 & 22 & -2.8 \\
\hline $41-1 c$ & 91.4 & 39.7 & 0.43 & 0.5494 & 0.0063 & 15.7300 & 0.2200 & 0.2098 & 0.0029 & 2825 & 26 & 2902 & 22 & -2.7 \\
\hline $11-1 c$ & 36.5 & 10.1 & 0.28 & 0.5590 & 0.0097 & 16.3800 & 0.3300 & 0.2152 & 0.0034 & 2865 & 41 & 2942 & 25 & -2.7 \\
\hline $55-1$ & 130.4 & 42.5 & 0.33 & 0.5490 & 0.0130 & 15.6700 & 0.4300 & 0.2094 & 0.0031 & 2827 & 53 & 2901 & 25 & -2.6 \\
\hline $08-1$ & 165.8 & 94.6 & 0.57 & 0.5659 & 0.0072 & 16.8500 & 0.2300 & 0.2177 & 0.0029 & 2890 & 30 & 2962 & 21 & -2.5 \\
\hline $19-1 c$ & 171.0 & 41.0 & 0.24 & 0.5516 & 0.0081 & 15.9400 & 0.2800 & 0.2091 & 0.0030 & 2831 & 33 & 2899 & 24 & -2.4 \\
\hline $47-1$ & 192.4 & 123.7 & 0.64 & 0.5610 & 0.0070 & 16.4600 & 0.2300 & 0.2142 & 0.0028 & 2870 & 29 & 2936 & 21 & -2.3 \\
\hline $78-2 r$ & 95.4 & 8.2 & 0.09 & 0.5501 & 0.0088 & 15.7900 & 0.3200 & 0.2072 & 0.0032 & 2824 & 37 & 2885 & 26 & -2.2 \\
\hline $42-1 c$ & 179.5 & 65.3 & 0.36 & 0.5610 & 0.0120 & 16.3900 & 0.3400 & 0.2135 & 0.0034 & 2869 & 48 & 2930 & 26 & -2.1 \\
\hline $59-1 c$ & 204.1 & 65.3 & 0.32 & 0.5466 & 0.0097 & 15.4900 & 0.3000 & 0.2060 & 0.0026 & 2815 & 39 & 2873 & 20 & -2.1 \\
\hline
\end{tabular}




\begin{tabular}{|c|c|c|c|c|c|c|c|c|c|c|c|c|c|c|}
\hline 24-01 & 102.5 & 25.1 & 0.24 & 0.5586 & 0.0081 & 16.1600 & 0.2700 & 0.2103 & 0.0034 & 2860 & 33 & 2912 & 26 & -1.8 \\
\hline $08-2$ & 123.6 & 54.3 & 0.44 & 0.5700 & 0.0070 & 16.9900 & 0.2700 & 0.2161 & 0.0031 & 2907 & 29 & 2953 & 24 & -1.6 \\
\hline $97-1 c$ & 103.7 & 21.9 & 0.21 & 0.5596 & 0.0080 & 16.1200 & 0.2600 & 0.2102 & 0.0029 & 2863 & 33 & 2906 & 22 & -1.5 \\
\hline $11-2 r$ & 197.0 & 12.2 & 0.06 & 0.5645 & 0.0090 & 16.6600 & 0.3200 & 0.2128 & 0.0035 & 2884 & 37 & 2925 & 26 & -1.4 \\
\hline $102-1 c$ & 117.7 & 44.1 & 0.37 & 0.5627 & 0.0074 & 16.3500 & 0.2800 & 0.2114 & 0.0030 & 2877 & 31 & 2917 & 23 & -1.4 \\
\hline 29-1c & 111.1 & 7.0 & 0.06 & 0.5634 & 0.0079 & 16.4600 & 0.3100 & 0.2121 & 0.0031 & 2883 & 32 & 2922 & 23 & -1.4 \\
\hline $22-2 r$ & 132.0 & 42.2 & 0.32 & 0.5698 & 0.0086 & 16.9000 & 0.2900 & 0.2151 & 0.0032 & 2905 & 35 & 2943 & 24 & -1.3 \\
\hline $90-1 c$ & 109.9 & 39.8 & 0.36 & 0.5680 & 0.0075 & 16.8100 & 0.2600 & 0.2136 & 0.0031 & 2902 & 30 & 2938 & 23 & -1.2 \\
\hline $50-1 c$ & 92.5 & 25.2 & 0.27 & 0.5623 & 0.0096 & 16.4600 & 0.3100 & 0.2112 & 0.0031 & 2880 & 41 & 2914 & 24 & -1.2 \\
\hline 63-1 & 209.0 & 142.0 & 0.68 & 0.5755 & 0.0069 & 17.1300 & 0.2200 & 0.2178 & 0.0029 & 2929 & 28 & 2963 & 21 & -1.2 \\
\hline $94-2 r$ & 1064.0 & 230.5 & 0.22 & 0.5146 & 0.0056 & 13.1900 & 0.1700 & 0.1864 & 0.0022 & 2678 & 23 & 2709 & 20 & -1.2 \\
\hline $17-2 r$ & 82.6 & 12.1 & 0.15 & 0.5712 & 0.0083 & 16.9500 & 0.2900 & 0.2154 & 0.0032 & 2911 & 34 & 2944 & 24 & -1.1 \\
\hline $78-1 c$ & 114.3 & 58.3 & 0.51 & 0.5663 & 0.0072 & 16.5400 & 0.2400 & 0.2126 & 0.0032 & 2892 & 30 & 2924 & 24 & -1.1 \\
\hline $61-1 c$ & 100.9 & 33.7 & 0.33 & 0.5722 & 0.0076 & 16.8800 & 0.2400 & 0.2152 & 0.0030 & 2916 & 31 & 2944 & 22 & -1.0 \\
\hline $86-2 r$ & 130.7 & 23.1 & 0.18 & 0.5729 & 0.0068 & 16.8800 & 0.2200 & 0.2157 & 0.0028 & 2921 & 27 & 2948 & 21 & -0.9 \\
\hline $46-1$ & 224.7 & 119.6 & 0.53 & 0.5726 & 0.0077 & 16.9800 & 0.2700 & 0.2151 & 0.0026 & 2917 & 31 & 2943 & 20 & -0.9 \\
\hline $61-2 r$ & 131.4 & 26.6 & 0.20 & 0.5734 & 0.0068 & 17.0200 & 0.2200 & 0.2160 & 0.0030 & 2924 & 27 & 2949 & 23 & -0.9 \\
\hline 73-1 & 109.1 & 41.9 & 0.38 & 0.5825 & 0.0063 & 17.6200 & 0.2400 & 0.2205 & 0.0029 & 2958 & 26 & 2983 & 21 & -0.8 \\
\hline $99-1 c$ & 114.2 & 34.2 & 0.30 & 0.5801 & 0.0071 & 17.3500 & 0.2400 & 0.2183 & 0.0030 & 2948 & 29 & 2970 & 21 & -0.7 \\
\hline 64-1c & 158.7 & 53.1 & 0.33 & 0.5752 & 0.0094 & 16.9800 & 0.2800 & 0.2155 & 0.0030 & 2928 & 39 & 2946 & 23 & -0.6 \\
\hline 25-1 & 129.6 & 56.6 & 0.44 & 0.5769 & 0.0070 & 17.1900 & 0.3000 & 0.2164 & 0.0038 & 2935 & 29 & 2951 & 28 & -0.5 \\
\hline $16-1 c$ & 77.5 & 20.6 & 0.27 & 0.5818 & 0.0079 & 17.5100 & 0.3100 & 0.2178 & 0.0031 & 2955 & 32 & 2962 & 23 & -0.2 \\
\hline 27-1 & 65.5 & 19.9 & 0.30 & 0.5864 & 0.0082 & 17.6900 & 0.3200 & 0.2184 & 0.0034 & 2973 & 33 & 2971 & 25 & 0.1 \\
\hline 03-1c & 134.3 & 61.1 & 0.45 & 0.5883 & 0.0089 & 17.8900 & 0.3200 & 0.2195 & 0.0035 & 2981 & 36 & 2978 & 26 & 0.1 \\
\hline 91-1c & 105.0 & 40.5 & 0.39 & 0.5892 & 0.0076 & 17.7700 & 0.2700 & 0.2200 & 0.0027 & 2985 & 31 & 2980 & 20 & 0.2 \\
\hline $50-2 r$ & 115.4 & 45.0 & 0.39 & 0.5880 & 0.0075 & 17.7100 & 0.2500 & 0.2194 & 0.0028 & 2980 & 31 & 2975 & 20 & 0.2 \\
\hline $89-1 c$ & 107.3 & 49.9 & 0.47 & 0.5848 & 0.0076 & 17.5000 & 0.2600 & 0.2173 & 0.0028 & 2967 & 31 & 2961 & 21 & 0.2 \\
\hline $86-1 c$ & 118.2 & 46.1 & 0.39 & 0.5880 & 0.0097 & 17.5000 & 0.3000 & 0.2158 & 0.0032 & 2979 & 39 & 2948 & 24 & 1.0 \\
\hline $103-1 c$ & 171.0 & 35.1 & 0.21 & 0.5862 & 0.0082 & 17.4000 & 0.3100 & 0.2155 & 0.0029 & 2977 & 32 & 2946 & 22 & 1.0 \\
\hline 09-1c & 167.0 & 69.5 & 0.42 & 0.5901 & 0.0096 & 17.7100 & 0.3400 & 0.2170 & 0.0030 & 2988 & 39 & 2956 & 23 & 1.1 \\
\hline 82-1 & 102.2 & 41.1 & 0.40 & 0.5877 & 0.0065 & 17.4900 & 0.2600 & 0.2154 & 0.0029 & 2982 & 26 & 2946 & 22 & 1.2 \\
\hline $91-2 r$ & 94.4 & 37.7 & 0.40 & 0.5937 & 0.0088 & 17.6600 & 0.3400 & 0.2163 & 0.0030 & 3003 & 36 & 2955 & 23 & 1.6 \\
\hline $03-2 r$ & 131.8 & 65.2 & 0.49 & 0.5897 & 0.0100 & 17.4900 & 0.4400 & 0.2125 & 0.0040 & 2987 & 41 & 2922 & 30 & 2.2 \\
\hline
\end{tabular}

$\begin{array}{clllllllllllll}\text { Spot } \quad \mathrm{U}(\mathrm{ppm}) & \mathrm{Th}(\mathrm{ppm}) & \mathrm{Th} / \mathrm{U} & { }^{206} \mathrm{~Pb} /{ }^{238} \mathrm{U} & \pm 2 \mathrm{SE} & { }^{207} \mathrm{~Pb} /{ }^{235} \mathrm{U} & \pm 2 \mathrm{SE} & { }^{207} \mathrm{~Pb} /{ }^{206} \mathrm{~Pb} & \pm 2 \mathrm{SE} & { }^{206} \mathrm{~Pb} /{ }^{238} \mathrm{U} & \pm 2 \mathrm{SE} & { }^{207} \mathrm{~Pb} /{ }^{206} \mathrm{~Pb} & \pm 2 \mathrm{SE} & \mathrm{Discordance}(\%)^{\mathrm{a}}\end{array}$ sample C22

\begin{tabular}{|c|c|c|c|c|c|c|c|c|c|c|c|c|c|c|}
\hline 32.1 & 71.5 & 24.8 & 0.35 & 0.3349 & 0.0096 & 7.3199 & 0.3802 & 0.1585 & 0.0076 & 1862 & 46 & 2440 & 76 & -31.0 \\
\hline 16.2 & 142.0 & 66.5 & 0.47 & 0.4261 & 0.0116 & 9.9160 & 0.5242 & 0.1688 & 0.0088 & 2288 & 52 & 2545 & 84 & -11.2 \\
\hline 33.1 & 167.3 & 118.2 & 0.71 & 0.4529 & 0.0086 & 11.2814 & 0.3506 & 0.1807 & 0.0064 & 2408 & 40 & 2659 & 62 & -10.4 \\
\hline 20.1 & 178.6 & 14.8 & 0.08 & 0.4232 & 0.0078 & 9.5234 & 0.4044 & 0.1632 & 0.0060 & 2275 & 36 & 2489 & 58 & -9.4 \\
\hline 22.1 & 627.5 & 427.2 & 0.68 & 0.4274 & 0.0088 & 9.5396 & 0.3466 & 0.1619 & 0.0048 & 2294 & 40 & 2475 & 50 & -7.9 \\
\hline 29.1 & 396.4 & 252.9 & 0.64 & 0.4809 & 0.0100 & 12.1303 & 0.4492 & 0.1830 & 0.0058 & 2531 & 44 & 2680 & 54 & -5.9 \\
\hline 7.1 & 184.4 & 166.3 & 0.90 & 0.4911 & 0.0086 & 12.7345 & 0.4210 & 0.1881 & 0.0054 & 2575 & 38 & 2725 & 48 & -5.8 \\
\hline 11.1 & 730.2 & 80.7 & 0.11 & 0.3500 & 0.0064 & 6.0520 & 0.2420 & 0.1254 & 0.0042 & 1934 & 30 & 2035 & 58 & -5.2 \\
\hline 19.1 & 299.3 & 332.7 & 1.11 & 0.5044 & 0.0094 & 13.4134 & 0.5262 & 0.1929 & 0.0064 & 2633 & 40 & 2767 & 54 & -5.1 \\
\hline 23.1 & 284.2 & 368.1 & 1.30 & 0.5012 & 0.0112 & 13.1962 & 0.5050 & 0.1910 & 0.0066 & 2619 & 50 & 2750 & 58 & -5.0 \\
\hline
\end{tabular}




\begin{tabular}{|c|c|c|c|c|c|c|c|c|c|c|c|c|c|c|}
\hline 13.1 & 972.5 & 110.6 & 0.11 & 0.3471 & 0.0062 & 5.9361 & 0.2312 & 0.1240 & 0.0040 & 1921 & 30 & 2015 & 58 & -4.9 \\
\hline 27.1 & 243.7 & 185.8 & 0.76 & 0.5039 & 0.0114 & 13.3077 & 0.5292 & 0.1915 & 0.0064 & 2631 & 48 & 2755 & 54 & -4.7 \\
\hline 5.1 & 214.3 & 175.7 & 0.82 & 0.4835 & 0.0082 & 12.0113 & 0.3834 & 0.1802 & 0.0048 & 2543 & 36 & 2654 & 44 & -4.4 \\
\hline 6.1 & 165.7 & 107.8 & 0.65 & 0.4884 & 0.0084 & 12.2595 & 0.3858 & 0.1821 & 0.0050 & 2564 & 36 & 2672 & 50 & -4.2 \\
\hline 9.1 & 144.4 & 141.7 & 0.98 & 0.5114 & 0.0106 & 13.6565 & 0.5206 & 0.1937 & 0.0064 & 2663 & 44 & 2774 & 54 & -4.2 \\
\hline 1.1 & 105.3 & 28.7 & 0.27 & 0.5468 & 0.0102 & 15.9461 & 0.5516 & 0.2115 & 0.0062 & 2812 & 42 & 2917 & 48 & -3.7 \\
\hline 17.1 & 137.3 & 102.4 & 0.75 & 0.5188 & 0.0116 & 13.9616 & 0.6144 & 0.1952 & 0.0078 & 2694 & 50 & 2786 & 66 & -3.4 \\
\hline 30.1 & 108.3 & 88.6 & 0.82 & 0.5052 & 0.0128 & 13.0135 & 0.5426 & 0.1868 & 0.0072 & 2636 & 56 & 2714 & 64 & -3.0 \\
\hline 25.1 & 313.7 & 325.6 & 1.04 & 0.5225 & 0.0114 & 14.0466 & 0.5354 & 0.1950 & 0.0062 & 2710 & 48 & 2785 & 52 & -2.8 \\
\hline 14.1 & 1170.2 & 160.9 & 0.14 & 0.3606 & 0.0064 & 6.2346 & 0.2440 & 0.1254 & 0.0040 & 1985 & 30 & 2034 & 58 & -2.5 \\
\hline 3.1 & 213.7 & 134.8 & 0.63 & 0.5148 & 0.0090 & 13.4486 & 0.4600 & 0.1895 & 0.0056 & 2677 & 38 & 2738 & 46 & -2.3 \\
\hline 28.1 & 315.1 & 168.1 & 0.53 & 0.5229 & 0.0118 & 13.9428 & 0.5412 & 0.1934 & 0.0064 & 2711 & 50 & 2771 & 54 & -2.2 \\
\hline 18.1 & 296.0 & 134.5 & 0.45 & 0.5232 & 0.0100 & 13.9131 & 0.5452 & 0.1928 & 0.0068 & 2713 & 42 & 2767 & 58 & -2.0 \\
\hline 8.1 & 307.0 & 299.8 & 0.98 & 0.5277 & 0.0086 & 14.1862 & 0.4326 & 0.1950 & 0.0050 & 2732 & 36 & 2785 & 42 & -1.9 \\
\hline 10.1 & 187.6 & 143.7 & 0.77 & 0.5288 & 0.0114 & 14.1426 & 0.6068 & 0.1940 & 0.0076 & 2736 & 48 & 2776 & 64 & -1.5 \\
\hline 21.1 & 163.8 & 142.5 & 0.87 & 0.5363 & 0.0122 & 14.5847 & 0.5636 & 0.1972 & 0.0064 & 2768 & 50 & 2804 & 54 & -1.3 \\
\hline 24.1 & 494.5 & 260.3 & 0.53 & 0.5226 & 0.0106 & 13.6839 & 0.4888 & 0.1899 & 0.0056 & 2710 & 46 & 2741 & 48 & -1.1 \\
\hline 12.1 & 224.1 & 199.8 & 0.89 & 0.5352 & 0.0116 & 14.3988 & 0.6234 & 0.1951 & 0.0074 & 2763 & 50 & 2786 & 62 & -0.8 \\
\hline 16.1 & 220.8 & 243.0 & 1.10 & 0.5381 & 0.0114 & 14.5613 & 0.6194 & 0.1963 & 0.0074 & 2775 & 48 & 2795 & 60 & -0.7 \\
\hline 31.1 & 293.2 & 124.9 & 0.43 & 0.5290 & 0.0130 & 13.9458 & 0.5756 & 0.1912 & 0.0072 & 2737 & 56 & 2752 & 60 & -0.5 \\
\hline 15.1 & 240.0 & 328.4 & 1.37 & 0.5353 & 0.0116 & 14.3289 & 0.6256 & 0.1941 & 0.0074 & 2764 & 48 & 2777 & 62 & -0.5 \\
\hline 2.1 & 153.7 & 129.4 & 0.84 & 0.5297 & 0.0088 & 13.8649 & 0.4458 & 0.1899 & 0.0052 & 2740 & 38 & 2741 & 44 & 0.0 \\
\hline 4.1 & 269.3 & 172.5 & 0.64 & 0.5226 & 0.0086 & 13.3150 & 0.3732 & 0.1848 & 0.0048 & 2710 & 36 & 2696 & 46 & 0.5 \\
\hline 26.1 & 108.8 & 64.6 & 0.59 & 0.5922 & 0.0150 & 15.8839 & 0.6726 & 0.1945 & 0.0076 & 2998 & 60 & 2781 & 64 & 7.2 \\
\hline
\end{tabular}

Ratios $\quad$ Ages (Ma)

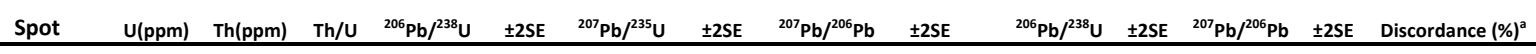

sample 1(0)

\begin{tabular}{|c|c|c|c|c|c|c|c|c|c|c|c|c|c|c|}
\hline 1 & 6270 & 124 & 0.02 & 0.0988 & 0.0015 & 0.8120 & 0.0160 & 0.0595 & 0.0008 & 607.4 & 8.6 & 589 & 26 & 3.0 \\
\hline 5 & 6400 & 106 & 0.02 & 0.0949 & 0.0022 & 0.7950 & 0.0200 & 0.0607 & 0.0013 & 584 & 13 & 626 & 48 & -7.2 \\
\hline 7.1 & 4400 & 277 & 0.06 & 0.1013 & 0.003 & 0.8430 & 0.0280 & 0.0603 & 0.0007 & 621 & 18 & 609 & 24 & 1.9 \\
\hline 7.2 & 4790 & 75 & 0.02 & 0.1001 & 0.0017 & 0.8400 & 0.0180 & 0.0602 & 0.0008 & 614.6 & 9.9 & 606 & 27 & 1.4 \\
\hline 7.3 & 4810 & 71 & 0.01 & 0.0903 & 0.0015 & 0.7610 & 0.0190 & 0.0612 & 0.0009 & 556.9 & 8.7 & 642 & 31 & -15.3 \\
\hline 15 & 4750 & 92 & 0.02 & 0.0995 & 0.0016 & 0.8260 & 0.0190 & 0.0602 & 0.0009 & 612.2 & 9 & 605 & 32 & 1.2 \\
\hline 14 & 4920 & 91 & 0.02 & 0.1008 & 0.0019 & 0.8300 & 0.0220 & 0.0597 & 0.0011 & 621 & 11 & 586 & 39 & 5.6 \\
\hline 8 & 6610 & 103 & 0.02 & 0.0968 & 0.0017 & 0.8030 & 0.0190 & 0.0601 & 0.0010 & 595.8 & 10 & 612 & 36 & -2.7 \\
\hline 4 & 4280 & 80 & 0.02 & 0.0984 & 0.0013 & 0.8190 & 0.0150 & 0.0602 & 0.0007 & 605.6 & 7.5 & 610 & 26 & -0.7 \\
\hline 2 & 4010 & 53 & 0.01 & 0.0962 & 0.0035 & 0.8060 & 0.0310 & 0.0606 & 0.0009 & 594 & 21 & 625 & 32 & -5.2 \\
\hline 19 & 3550 & 52 & 0.01 & 0.0993 & 0.0019 & 0.8300 & 0.0240 & 0.0598 & 0.0011 & 610 & 11 & 589 & 40 & 3.4 \\
\hline 25 & 1873 & 23 & 0.01 & 0.1043 & 0.0017 & 0.8670 & 0.0170 & 0.0600 & 0.0007 & 639.3 & 9.6 & 599 & 25 & 6.3 \\
\hline 30.2 & 5680 & 88 & 0.02 & 0.0919 & 0.0024 & 0.7660 & 0.0250 & 0.0607 & 0.0011 & 567 & 14 & 622 & 40 & -9.7 \\
\hline 30.1 & 3720 & 59 & 0.02 & 0.0956 & 0.0028 & 0.7960 & 0.0250 & 0.0603 & 0.0009 & 588 & 16 & 611 & 32 & -3.9 \\
\hline 26 & 5080 & 89 & 0.02 & 0.0994 & 0.0017 & 0.8210 & 0.0170 & 0.0600 & 0.0008 & 611 & 9.7 & 597 & 28 & 2.3 \\
\hline 22 & 4330 & 84 & 0.02 & 0.1022 & 0.002 & 0.8440 & 0.0200 & 0.0598 & 0.0009 & 627 & 11 & 586 & 33 & 6.5 \\
\hline 33 & 3890 & 59 & 0.02 & 0.0966 & 0.0014 & 0.7980 & 0.0160 & 0.0602 & 0.0008 & 594.1 & 8.4 & 606 & 30 & -2.0 \\
\hline
\end{tabular}




\begin{tabular}{|c|c|c|c|c|c|c|c|c|c|c|c|c|c|c|}
\hline 35 & 6020 & 110 & 0.02 & 0.0990 & 0.0019 & 0.8160 & 0.0200 & 0.0599 & 0.0009 & 609 & 11 & 598 & 32 & 1.8 \\
\hline 38 & 6690 & 133 & 0.02 & 0.0991 & 0.0012 & 0.8150 & 0.0150 & 0.0594 & 0.0007 & 609.3 & 7 & 582 & 26 & 4.5 \\
\hline 43 & 5980 & 118 & 0.02 & 0.0997 & 0.0012 & 0.8220 & 0.0150 & 0.0599 & 0.0007 & 612.6 & 7 & 595 & 26 & 2.9 \\
\hline 46 & 6820 & 119 & 0.02 & 0.1002 & 0.0013 & 0.8260 & 0.0160 & 0.0600 & 0.0007 & 615.4 & 7.4 & 598 & 26 & 2.8 \\
\hline 44 & 3140 & 44 & 0.01 & 0.0999 & 0.0019 & 0.8210 & 0.0190 & 0.0604 & 0.0012 & 614 & 11 & 620 & 40 & -1.0 \\
\hline 50 & 5890 & 98 & 0.02 & 0.0987 & 0.0015 & 0.8200 & 0.0210 & 0.0603 & 0.0010 & 606.5 & 9 & 607 & 36 & -0.1 \\
\hline 61 & 4700 & 71 & 0.02 & 0.0978 & 0.0014 & 0.8040 & 0.0180 & 0.0598 & 0.0011 & 601.5 & 8.5 & 594 & 40 & 1.2 \\
\hline 55 & 5820 & 118 & 0.02 & 0.0985 & 0.0012 & 0.8120 & 0.0170 & 0.0597 & 0.0008 & 605.3 & 7 & 587 & 30 & 3.0 \\
\hline 62 & 5230 & 106 & 0.02 & 0.0921 & 0.002 & 0.7690 & 0.0210 & 0.0608 & 0.0007 & 568 & 12 & 628 & 26 & -10.6 \\
\hline 68 & 5170 & 79 & 0.02 & 0.1017 & 0.0013 & 0.8410 & 0.0170 & 0.0596 & 0.0008 & 624.5 & 7.8 & 587 & 27 & 6.0 \\
\hline 69 & 5870 & 140 & 0.02 & 0.0991 & 0.0024 & 0.8270 & 0.0250 & 0.0602 & 0.0017 & 612 & 13 & 602 & 60 & 1.6 \\
\hline 67 & 6090 & 128 & 0.02 & 0.0999 & 0.0012 & 0.8250 & 0.0180 & 0.0596 & 0.0009 & 614.6 & 7.2 & 588 & 31 & 4.3 \\
\hline 65 & 5950 & 125 & 0.02 & 0.0993 & 0.0013 & 0.8200 & 0.0180 & 0.0594 & 0.0007 & 610.4 & 7.4 & 578 & 26 & 5.3 \\
\hline
\end{tabular}

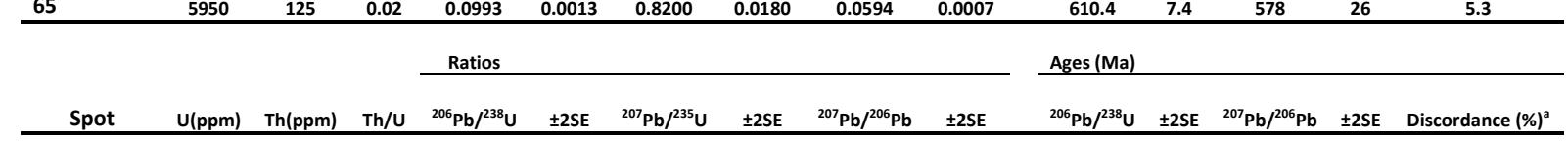

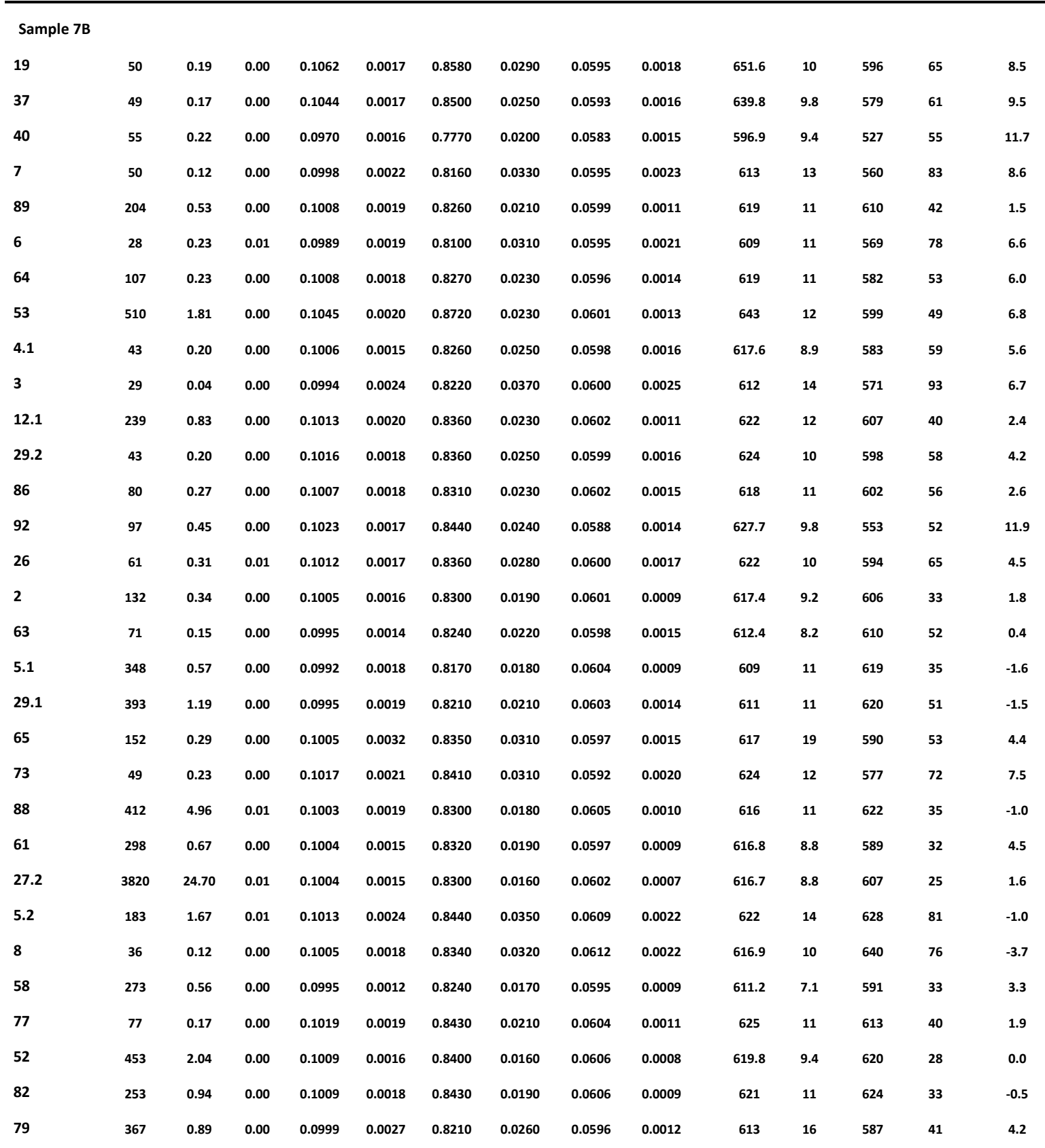




\begin{tabular}{|c|c|c|c|c|c|c|c|c|c|c|c|c|c|c|}
\hline 47 & 50 & 0.24 & 0.00 & 0.0989 & 0.0019 & 0.8240 & 0.0260 & 0.0600 & 0.0018 & 608 & 11 & 610 & 66 & -0.3 \\
\hline 49.2 & 778 & 1.43 & 0.00 & 0.1010 & 0.0019 & 0.8430 & 0.0170 & 0.0601 & 0.0010 & 620 & 11 & 614 & 38 & 1.0 \\
\hline 83 & 160 & 0.43 & 0.00 & 0.1014 & 0.0016 & 0.8480 & 0.0190 & 0.0593 & 0.0009 & 622.4 & 9.2 & 591 & 39 & 5.0 \\
\hline 22 & 96 & 1.88 & 0.02 & 0.1003 & 0.0013 & 0.8400 & 0.0250 & 0.0609 & 0.0016 & 617.2 & 7.6 & 619 & 58 & -0.3 \\
\hline 4.2 & 405 & 1.12 & 0.00 & 0.0984 & 0.0016 & 0.8150 & 0.0210 & 0.0595 & 0.0009 & 605.2 & 9.4 & 600 & 36 & 0.9 \\
\hline 51.2 & 153 & 0.40 & 0.00 & 0.1001 & 0.0032 & 0.8360 & 0.0290 & 0.0602 & 0.0015 & 615 & 19 & 600 & 53 & 2.4 \\
\hline 46 & 349 & 1.30 & 0.00 & 0.1008 & 0.0015 & 0.8410 & 0.0170 & 0.0605 & 0.0008 & 619.3 & 8.8 & 619 & 29 & 0.0 \\
\hline 17.2 & 1838 & 9.80 & 0.01 & 0.0988 & 0.0014 & 0.8220 & 0.0170 & 0.0607 & 0.0009 & 607.3 & 8.2 & 623 & 31 & -2.6 \\
\hline 11 & 192 & 0.35 & 0.00 & 0.1014 & 0.0016 & 0.8460 & 0.0190 & 0.0609 & 0.0011 & 622.7 & 9.6 & 632 & 39 & -1.5 \\
\hline 85 & 47 & 0.19 & 0.00 & 0.0974 & 0.0019 & 0.8020 & 0.0260 & 0.0597 & 0.0017 & 599 & 11 & 579 & 63 & 3.3 \\
\hline 68 & 442 & 1.10 & 0.00 & 0.0973 & 0.0020 & 0.8090 & 0.0270 & 0.0603 & 0.0016 & 598 & 12 & 611 & 56 & -2.2 \\
\hline 33 & 66 & 0.14 & 0.00 & 0.1016 & 0.0016 & 0.8520 & 0.0230 & 0.0610 & 0.0016 & 623.7 & 9.5 & 623 & 54 & 0.1 \\
\hline 50 & 660 & 3.38 & 0.01 & 0.1011 & 0.0026 & 0.8530 & 0.0210 & 0.0623 & 0.0015 & 620 & 15 & 674 & 51 & -8.7 \\
\hline 14 & 49 & 0.29 & 0.01 & 0.0997 & 0.0024 & 0.8310 & 0.0320 & 0.0595 & 0.0021 & 612 & 14 & 568 & 80 & 7.2 \\
\hline 18 & 175 & 3.65 & 0.02 & 0.1011 & 0.0015 & 0.8500 & 0.0180 & 0.0615 & 0.0011 & 620.6 & 8.6 & 654 & 39 & -5.4 \\
\hline 55 & 461 & 8.10 & 0.02 & 0.1010 & 0.0024 & 0.8540 & 0.0270 & 0.0622 & 0.0010 & 620 & 14 & 679 & 34 & -9.5 \\
\hline 69 & 134 & 0.24 & 0.00 & 0.1012 & 0.0016 & 0.8490 & 0.0190 & 0.0610 & 0.0010 & 622.4 & 9.9 & 631 & 36 & -1.4 \\
\hline 51.1 & 531 & 2.01 & 0.00 & 0.0974 & 0.0014 & 0.8220 & 0.0170 & 0.0602 & 0.0007 & 599.2 & 8.5 & 608 & 24 & -1.5 \\
\hline 66 & 171 & 14.00 & 0.08 & 0.0870 & 0.0013 & 0.7160 & 0.0160 & 0.0601 & 0.0010 & 537.7 & 7.7 & 600 & 35 & -11.6 \\
\hline 48 & 51 & 0.24 & 0.00 & 0.0976 & 0.0031 & 0.8250 & 0.0410 & 0.0622 & 0.0026 & 600 & 18 & 685 & 89 & -14.2 \\
\hline 49.1 & 162 & 0.41 & 0.00 & 0.0949 & 0.0013 & 0.8040 & 0.0210 & 0.0608 & 0.0011 & 584.3 & 7.7 & 626 & 40 & -7.1 \\
\hline 42 & 363 & 2.59 & 0.01 & 0.0989 & 0.0014 & 0.8560 & 0.0170 & 0.0627 & 0.0008 & 607.8 & 7.9 & 694 & 27 & -14.2 \\
\hline 54 & 660 & 5.20 & 0.01 & 0.1006 & 0.0018 & 0.8970 & 0.0190 & 0.0638 & 0.0012 & 618 & 11 & 731 & 41 & -18.3 \\
\hline 57 & 340 & 1.42 & 0.00 & 0.1031 & 0.0015 & 0.9350 & 0.0280 & 0.0652 & 0.0015 & 632.3 & 8.7 & 767 & 46 & -21.3 \\
\hline 27.1 & 722 & 3.48 & 0.00 & 0.1069 & 0.0022 & 0.9830 & 0.0300 & 0.0661 & 0.0013 & 655 & 13 & 807 & 41 & -23.2 \\
\hline 75 & 670 & 6.18 & 0.01 & 0.1025 & 0.0030 & 0.9970 & 0.0260 & 0.0700 & 0.0018 & 629 & 17 & 929 & 50 & -47.7 \\
\hline 43 & 691 & 4.53 & 0.01 & 0.1046 & 0.0015 & 1.0230 & 0.0220 & 0.0707 & 0.0013 & 641.1 & 9 & 944 & 37 & -47.2 \\
\hline 12.2 & 702 & 7.81 & 0.01 & 0.0949 & 0.0017 & 0.9720 & 0.0240 & 0.0738 & 0.0019 & 584.6 & 10 & 1054 & 51 & -80.3 \\
\hline 67 & 729 & 9.21 & 0.01 & 0.0948 & 0.0017 & 1.0450 & 0.0280 & 0.0795 & 0.0018 & 585 & 11 & 1184 & 48 & -102.4 \\
\hline 71 & 225 & 2.08 & 0.01 & 0.1056 & 0.0013 & 1.2870 & 0.0490 & 0.0879 & 0.0029 & 647.2 & 7.8 & 1364 & 62 & -110.8 \\
\hline 17.1 & 516 & 4.09 & 0.01 & 0.1147 & 0.0031 & 1.7560 & 0.0960 & 0.1080 & 0.0045 & 699 & 18 & 1751 & 80 & -150.5 \\
\hline 84 & 61 & 6.18 & 0.10 & 0.2980 & 0.0160 & 5.2600 & 0.3400 & 0.1254 & 0.0020 & 1677 & 79 & 2029 & 28 & -21.0 \\
\hline 24 & 165 & 38.70 & 0.23 & 0.3087 & 0.0054 & 5.3500 & 0.1400 & 0.1260 & 0.0020 & 1733 & 26 & 2037 & 28 & -17.5 \\
\hline 35.2 & 16 & 2.24 & 0.14 & 0.3229 & 0.0080 & 5.5700 & 0.2300 & 0.1253 & 0.0032 & 1802 & 39 & 2034 & 45 & -12.9 \\
\hline 1 & 25 & 5.70 & 0.22 & 0.3667 & 0.0070 & 6.6100 & 0.1700 & 0.1320 & 0.0025 & 2012 & 33 & 2122 & 34 & -5.5 \\
\hline 44 & 98 & 29.70 & 0.30 & 0.3666 & 0.0051 & 6.6540 & 0.1200 & 0.1317 & 0.0013 & 2013 & 24 & 2121 & 17 & -5.4 \\
\hline 16.2 & 28 & 6.05 & 0.22 & 0.3820 & 0.0060 & 6.8100 & 0.1600 & 0.1295 & 0.0022 & 2084 & 28 & 2101 & 29 & -0.8 \\
\hline 35.1 & 60 & 24.98 & 0.42 & 0.3772 & 0.0049 & 6.9300 & 0.1300 & 0.1333 & 0.0018 & 2063 & 23 & 2145 & 22 & -4.0 \\
\hline 16.1 & 80 & 29.50 & 0.37 & 0.3851 & 0.0054 & 6.9400 & 0.1300 & 0.1318 & 0.0017 & 2099 & 25 & 2126 & 23 & -1.3 \\
\hline 41 & 23 & 5.37 & 0.23 & 0.3912 & 0.0072 & 7.0300 & 0.1700 & 0.1309 & 0.0021 & 2130 & 33 & 2112 & 27 & 0.8 \\
\hline \multirow[t]{2}{*}{25} & 49 & 21.90 & 0.45 & 0.3894 & 0.0058 & 7.1200 & 0.1600 & 0.1323 & 0.0021 & 2119 & 27 & 2123 & 27 & -0.2 \\
\hline & \multicolumn{9}{|c|}{ Ratios } & \multicolumn{5}{|l|}{ Ages (Ma) } \\
\hline Spot & $\mathrm{U}(\mathrm{ppm})$ & Th(ppm) & $\mathrm{Th} / \mathrm{U}$ & ${ }^{206} \mathrm{~Pb} /{ }^{238} \mathrm{U}$ & $\pm 2 \mathrm{SE}$ & ${ }^{207} \mathrm{~Pb} /{ }^{235} \mathrm{U}$ & $\pm 2 \mathrm{SE}$ & ${ }^{207} \mathrm{~Pb} /{ }^{206} \mathrm{~Pb}$ & $\pm 2 \mathrm{SE}$ & ${ }^{206} \mathrm{~Pb} /{ }^{238} \mathrm{U}$ & $\pm 2 \mathrm{SE}$ & ${ }^{207} \mathrm{~Pb} /{ }^{206} \mathrm{~Pb}$ & $\pm 2 \mathrm{SE}$ & Discordance (\%) \\
\hline \multicolumn{15}{|c|}{ sample 9C } \\
\hline 104 & 316 & 0.66 & 0.00 & 0.1042 & 0.0014 & 0.8560 & 0.0150 & 0.0594 & 0.0009 & 639 & 7.9 & 588 & 31 & 8.0 \\
\hline 16.2 & 392 & 0.65 & 0.00 & 0.1074 & 0.0017 & 0.8870 & 0.0210 & 0.0603 & 0.0009 & 657.4 & 9.9 & 613 & 32 & 6.8 \\
\hline 65 & 898 & 3.24 & 0.00 & 0.1009 & 0.0022 & 0.8380 & 0.0190 & 0.0602 & 0.0008 & 623 & 13 & 615 & 32 & 1.3 \\
\hline
\end{tabular}




\begin{tabular}{|c|c|c|c|c|c|c|c|c|c|c|c|c|c|c|}
\hline 93 & 736 & 0.78 & 0.00 & 0.1027 & 0.0021 & 0.8550 & 0.0230 & 0.0609 & 0.0011 & 630 & 12 & 630 & 38 & 0.0 \\
\hline 18 & 760 & 1.45 & 0.00 & 0.0983 & 0.0020 & 0.8120 & 0.0240 & 0.0600 & 0.0013 & 604 & 12 & 606 & 45 & -0.3 \\
\hline 2.2 & 367 & 1.33 & 0.00 & 0.0989 & 0.0016 & 0.8170 & 0.0220 & 0.0596 & 0.0012 & 609 & 9.1 & 591 & 41 & 3.0 \\
\hline 20.2 & 2450 & 15.40 & 0.01 & 0.1000 & 0.0024 & 0.8280 & 0.0220 & 0.0609 & 0.0014 & 614 & 14 & 625 & 49 & -1.8 \\
\hline 24.2 & 2130 & 2.95 & 0.00 & 0.1008 & 0.0017 & 0.8400 & 0.0190 & 0.0608 & 0.0010 & 620.3 & 10 & 635 & 32 & -2.4 \\
\hline 45.3 & 622 & 1.09 & 0.00 & 0.0991 & 0.0014 & 0.8210 & 0.0150 & 0.0604 & 0.0007 & 609.1 & 8.5 & 616 & 24 & -1.1 \\
\hline 81.2 & 656 & 3.64 & 0.01 & 0.0986 & 0.0018 & 0.8180 & 0.0180 & 0.0600 & 0.0007 & 606 & 11 & 603 & 23 & 0.5 \\
\hline 73.2 & 1860 & 9.06 & 0.00 & 0.0997 & 0.0020 & 0.8310 & 0.0190 & 0.0609 & 0.0006 & 613 & 12 & 638 & 22 & -4.1 \\
\hline 31.2 & 3150 & 14.84 & 0.00 & 0.0997 & 0.0027 & 0.8330 & 0.0270 & 0.0615 & 0.0015 & 613 & 16 & 648 & 54 & -5.7 \\
\hline 69 & 2501 & 7.90 & 0.00 & 0.1008 & 0.0018 & 0.8410 & 0.0170 & 0.0603 & 0.0007 & 619 & 10 & 612 & 25 & 1.1 \\
\hline 47 & 663 & 1.39 & 0.00 & 0.1001 & 0.0014 & 0.8330 & 0.0160 & 0.0608 & 0.0006 & 614.8 & 8.3 & 630 & 22 & -2.5 \\
\hline 10 & 2542 & 15.15 & 0.006 & 0.0997 & 0.0015 & 0.8330 & 0.0160 & 0.0606 & 0.0009 & 612.5 & 8.8 & 624 & 30 & -1.9 \\
\hline 54.2 & 618 & 0.85 & 0.001 & 0.1009 & 0.0011 & 0.8470 & 0.0150 & 0.0605 & 0.0008 & 619.7 & 6.3 & 622 & 27 & -0.4 \\
\hline 88.2 & 1830 & 12.51 & 0.007 & 0.1007 & 0.0023 & 0.8450 & 0.0200 & 0.0606 & 0.0006 & 619 & 14 & 625 & 22 & -1.0 \\
\hline 54.1 & 398 & 1.31 & 0.003 & 0.0996 & 0.0032 & 0.8370 & 0.0300 & 0.0617 & 0.0010 & 612 & 19 & 661 & 35 & -8.0 \\
\hline 98 & 2280 & 13.27 & 0.01 & 0.1002 & 0.0028 & 0.8410 & 0.0230 & 0.0614 & 0.0006 & 615 & 17 & 652 & 22 & -6.0 \\
\hline 15 & 1092 & 6.86 & 0.01 & 0.0989 & 0.0015 & 0.8300 & 0.0170 & 0.0611 & 0.0009 & 607.8 & 9 & 639 & 30 & -5.1 \\
\hline 1 & 714 & 10.70 & 0.01 & 0.1013 & 0.0018 & 0.8590 & 0.0180 & 0.0616 & 0.0009 & 622 & 11 & 658 & 31 & -5.8 \\
\hline 74.2 & 1565 & 19.40 & 0.01 & 0.1068 & 0.0016 & 0.9220 & 0.0170 & 0.0622 & 0.0006 & 654.1 & 9.2 & 678 & 22 & -3.7 \\
\hline 58.2 & 1504 & 6.12 & 0.00 & 0.1017 & 0.0012 & 0.8660 & 0.0150 & 0.0619 & 0.0005 & 624.4 & 7.3 & 669 & 17 & -7.1 \\
\hline 62 & 993 & 5.80 & 0.01 & 0.0916 & 0.0023 & 0.7620 & 0.0200 & 0.0600 & 0.0007 & 565 & 14 & 606 & 24 & -7.3 \\
\hline 34 & 1220 & 5.73 & 0.00 & 0.0722 & 0.0081 & 0.6070 & 0.0690 & 0.0614 & 0.0010 & 446 & 49 & 647 & 35 & -45.1 \\
\hline 28.2 & 971 & 3.31 & 0.00 & 0.0881 & 0.0016 & 0.7510 & 0.0200 & 0.0615 & 0.0013 & 546.8 & 9.8 & 652 & 46 & -19.2 \\
\hline 31.3 & 1710 & 11.20 & 0.01 & 0.0893 & 0.0037 & 0.7660 & 0.0310 & 0.0628 & 0.0010 & 551 & 22 & 697 & 35 & -26.5 \\
\hline 12 & 827 & 3.34 & 0.00 & 0.0924 & 0.0021 & 0.8060 & 0.0210 & 0.0636 & 0.0009 & 569 & 12 & 724 & 30 & -27.2 \\
\hline 5.2 & 1298 & 16.80 & 0.01 & 0.1096 & 0.0021 & 1.0170 & 0.0240 & 0.0683 & 0.0012 & 670 & 12 & 875 & 37 & -30.6 \\
\hline 38.2 & 2055 & 8.57 & 0.00 & 0.0709 & 0.0038 & 0.5890 & 0.0300 & 0.0602 & 0.0010 & 441 & 23 & 612 & 37 & -38.8 \\
\hline 45.2 & 405 & 0.98 & 0.002 & 0.0768 & 0.0035 & 0.6600 & 0.0340 & 0.0627 & 0.0009 & 476 & 21 & 697 & 32 & -46.4 \\
\hline 41 & 663 & 12.80 & 0.019 & 0.0735 & 0.0029 & 0.6250 & 0.0240 & 0.0613 & 0.0007 & 457 & 18 & 651 & 25 & -42.5 \\
\hline 100 & 885 & 27.90 & 0.032 & 0.0879 & 0.0044 & 0.7790 & 0.0350 & 0.0649 & 0.0010 & 542 & 26 & 772 & 31 & -42.4 \\
\hline 85 & 1078 & 12.00 & 0.01 & 0.0683 & 0.0045 & 0.5690 & 0.0370 & 0.0604 & 0.0007 & 425 & 27 & 618 & 25 & -45.4 \\
\hline 21 & 956 & 14.30 & 0.01 & 0.0592 & 0.0037 & 0.4970 & 0.0310 & 0.0614 & 0.0011 & 370 & 23 & 655 & 39 & -77.0 \\
\hline 113 & 2110 & 10.58 & 0.01 & 0.0669 & 0.0035 & 0.5760 & 0.0310 & 0.0621 & 0.0006 & 417 & 21 & 674 & 20 & -61.6 \\
\hline 59 & 996 & 40.30 & 0.04 & 0.0779 & 0.0017 & 0.7090 & 0.0170 & 0.0667 & 0.0012 & 483 & 10 & 827 & 39 & -71.2 \\
\hline 102 & 2140 & 2.83 & 0.00 & 0.0385 & 0.0053 & 0.3270 & 0.0450 & 0.0615 & 0.0006 & 245 & 33 & 656 & 20 & -167.8 \\
\hline 38.1 & 1561 & 5.48 & 0.00 & 0.0420 & 0.0030 & 0.3590 & 0.0260 & 0.0624 & 0.0009 & 265 & 18 & 691 & 29 & -160.8 \\
\hline 50 & 1176 & 11.40 & 0.01 & 0.0426 & 0.0009 & 0.3662 & 0.0088 & 0.0620 & 0.0007 & 268.9 & 5.4 & 684 & 25 & -154.4 \\
\hline 43 & 1770 & 9.28 & 0.01 & 0.0703 & 0.0015 & 0.6680 & 0.0150 & 0.0692 & 0.0008 & 438.1 & 9 & 903 & 25 & -106.1 \\
\hline 27 & 1117 & 39.30 & 0.04 & 0.0445 & 0.0039 & 0.3950 & 0.0310 & 0.0662 & 0.0014 & 280 & 24 & 811 & 44 & -189.6 \\
\hline 56 & 1620 & 65.90 & 0.04 & 0.0592 & 0.0032 & 0.5830 & 0.0270 & 0.0715 & 0.0012 & 372 & 20 & 976 & 33 & -162.4 \\
\hline 48 & 3000 & 92.30 & 0.03 & 0.0157 & 0.0007 & 0.1420 & 0.0064 & 0.0663 & 0.0008 & 100.2 & 4.3 & 813 & 25 & -711.4 \\
\hline 9 & 1530 & 142.00 & 0.09 & 0.0623 & 0.0031 & 0.7050 & 0.0400 & 0.0864 & 0.0030 & 389 & 19 & 1332 & 66 & -242.4 \\
\hline 92 & 2770 & 8.14 & 0.00 & 0.0187 & 0.0010 & 0.1775 & 0.0082 & 0.0703 & 0.0012 & 119.5 & 6.4 & 933 & 35 & -680.8 \\
\hline 67 & 2150 & 91.10 & 0.04 & 0.0177 & 0.0004 & 0.2093 & 0.0090 & 0.0864 & 0.0025 & 112.8 & 2.8 & 1332 & 57 & -1080.9 \\
\hline 20.1 & 3600 & 381.00 & 0.11 & 0.1137 & 0.0028 & 1.2400 & 0.0450 & 0.0791 & 0.0015 & 694 & 16 & 1167 & 38 & -68.2 \\
\hline 64.2 & 697 & 25.10 & 0.04 & 0.1092 & 0.0018 & 1.3810 & 0.0590 & 0.0926 & 0.0041 & 667.7 & 10 & 1456 & 88 & -118.1 \\
\hline 19.2 & 2630 & 157.90 & 0.06 & 0.0375 & 0.0011 & 1.4670 & 0.0450 & 0.2867 & 0.0067 & 237.5 & 6.6 & 3398 & 36 & -1330.7 \\
\hline 31.1 & 2370 & 234.00 & 0.10 & 0.1223 & 0.0056 & 1.5360 & 0.0670 & 0.0911 & 0.0012 & 742 & 32 & 1458 & 27 & -96.5 \\
\hline
\end{tabular}




\begin{tabular}{|c|c|c|c|c|c|c|c|c|c|c|c|c|c|c|}
\hline 68.2 & 758 & 31.80 & 0.04 & 0.1067 & 0.0072 & 1.5800 & 0.1100 & 0.1056 & 0.0012 & 656 & 42 & 1724 & 22 & -162.8 \\
\hline 45.1 & 922 & 46.30 & 0.05 & 0.1298 & 0.0037 & 1.5820 & 0.0760 & 0.0880 & 0.0020 & 786 & 21 & 1387 & 44 & -76.5 \\
\hline 81.1 & 3580 & 50.00 & 0.01 & 0.1346 & 0.0050 & 1.6560 & 0.0940 & 0.0909 & 0.0023 & 812 & 28 & 1426 & 49 & -75.6 \\
\hline 88.1 & 1890 & 140.00 & 0.07 & 0.1383 & 0.0073 & 1.7500 & 0.1100 & 0.0910 & 0.0012 & 832 & 41 & 1448 & 25 & -74.0 \\
\hline 19.1 & 1724 & 50.60 & 0.03 & 0.1617 & 0.0047 & 2.0490 & 0.0740 & 0.0925 & 0.0018 & 971 & 25 & 1473 & 36 & -51.7 \\
\hline 64.1 & 1641 & 35.60 & 0.02 & 0.1417 & 0.0052 & 2.1200 & 0.1100 & 0.1079 & 0.0023 & 856 & 30 & 1757 & 39 & -105.3 \\
\hline 73.1 & 1514 & 43.50 & 0.03 & 0.1926 & 0.0078 & 2.8300 & 0.1200 & 0.1078 & 0.0014 & 1133 & 42 & 1767 & 24 & -56.0 \\
\hline 5.1 & 1682 & 55.60 & 0.03 & 0.2023 & 0.0051 & 2.8740 & 0.0960 & 0.1030 & 0.0019 & 1187 & 27 & 1675 & 34 & -41.1 \\
\hline 97.2 & 1610 & 72.30 & 0.04 & 0.2011 & 0.0045 & 3.0390 & 0.0710 & 0.1099 & 0.0013 & 1181 & 24 & 1795 & 21 & -52.0 \\
\hline 16.1 & 1740 & 454.00 & 0.26 & 0.1788 & 0.0096 & 3.1400 & 0.1700 & 0.1281 & 0.0019 & 1055 & 52 & 2069 & 27 & -96.1 \\
\hline 74.1 & 370 & 57.80 & 0.16 & 0.2797 & 0.0070 & 4.5400 & 0.1500 & 0.1162 & 0.0014 & 1588 & 35 & 1898 & 22 & -19.5 \\
\hline 28.1 & 269 & 120.90 & 0.45 & 0.3151 & 0.0046 & 5.5300 & 0.1300 & 0.1278 & 0.0022 & 1765 & 22 & 2066 & 29 & -17.1 \\
\hline 97.1 & 152 & 32.82 & 0.22 & 0.3184 & 0.0049 & 5.6260 & 0.1000 & 0.1280 & 0.0011 & 1781 & 24 & 2071 & 16 & -16.3 \\
\hline 44 & 172 & 51.10 & 0.30 & 0.3550 & 0.0053 & 6.3020 & 0.1200 & 0.1289 & 0.0013 & 1958 & 25 & 2083 & 18 & -6.4 \\
\hline 90 & 292 & 152.00 & 0.52 & 0.3680 & 0.0069 & 6.5300 & 0.1500 & 0.1289 & 0.0011 & 2018 & 32 & 2082 & 14 & -3.2 \\
\hline 39 & 79 & 21.07 & 0.27 & 0.3720 & 0.0052 & 6.5700 & 0.1300 & 0.1289 & 0.0016 & 2038 & 24 & 2080 & 22 & -2.1 \\
\hline 61 & 984 & 420.00 & 0.43 & 0.3742 & 0.0052 & 6.5970 & 0.1100 & 0.1277 & 0.0010 & 2051 & 25 & 2065 & 13 & -0.7 \\
\hline 55 & 104 & 31.12 & 0.30 & 0.3818 & 0.0052 & 6.7420 & 0.1200 & 0.1285 & 0.0015 & 2087 & 24 & 2079 & 21 & 0.4 \\
\hline 58.1 & 136 & 49.10 & 0.36 & 0.3831 & 0.0046 & 6.7700 & 0.1100 & 0.1286 & 0.0012 & 2090 & 21 & 2077 & 16 & 0.6 \\
\hline 108 & 200 & 64.60 & 0.32 & 0.3812 & 0.0049 & 6.8000 & 0.1200 & 0.1297 & 0.0010 & 2083 & 22 & 2093 & 14 & -0.5 \\
\hline 24.1 & 424 & 132.50 & 0.31 & 0.3900 & 0.0060 & 6.8600 & 0.1500 & 0.1279 & 0.0019 & 2122 & 28 & 2072 & 28 & 2.4 \\
\hline 2.1 & 258 & 59.00 & 0.23 & 0.3845 & 0.0098 & 6.8700 & 0.2100 & 0.1302 & 0.0017 & 2099 & 47 & 2099 & 24 & 0.0 \\
\hline 75 & 301 & 198.00 & 0.66 & 0.3835 & 0.0045 & 6.9170 & 0.1100 & 0.1312 & 0.0011 & 2092 & 21 & 2117 & 15 & -1.2 \\
\hline 60 & 147 & 44.20 & 0.30 & 0.3919 & 0.0050 & 6.9260 & 0.1200 & 0.1292 & 0.0015 & 2131 & 23 & 2085 & 20 & 2.2 \\
\hline 13 & 71 & 28.6 & 0.40 & 0.3933 & 0.0052 & 6.9300 & 0.1500 & 0.1277 & 0.0016 & 2137 & 24 & 2063 & 23 & 3.5 \\
\hline 68.1 & 217 & 43.3 & 0.20 & 0.3957 & 0.0048 & 6.9660 & 0.1200 & 0.1271 & 0.0011 & 2148 & 22 & 2059 & 15 & 4.1 \\
\hline 78 & 385 & 148.7 & 0.39 & 0.3848 & 0.0070 & 7.0100 & 0.1700 & 0.1332 & 0.0020 & 2103 & 34 & 2142 & 27 & -1.9 \\
\hline 23 & 136 & 50.2 & 0.37 & 0.3963 & 0.0073 & 7.0600 & 0.1900 & 0.1289 & 0.0025 & 2155 & 33 & 2079 & 35 & 3.5 \\
\hline 111 & 185 & 71.5 & 0.39 & 0.3988 & 0.0042 & 7.2730 & 0.1200 & 0.1313 & 0.0012 & 2163 & 19 & 2113 & 17 & 2.3 \\
\hline
\end{tabular}

${ }^{\mathrm{a} D i s c o r d a n c e}(\%)=(1-(207 \mathrm{~Pb} / 206 \mathrm{~Pb}$ Age $/ 206 \mathrm{~Pb} / 238 \mathrm{U}$ Age $)) * 100$ 


\section{ANEXO VI}

(Dados de isótopos de háfnio em zircão) 


\begin{tabular}{|c|c|c|c|c|c|c|c|c|}
\hline Spot & ${ }^{176} \mathrm{Hf} /{ }^{177} \mathrm{Hf}$ & $\pm 2 S E$ & ${ }^{176} \mathrm{Lu} /{ }^{177} \mathrm{Hf}$ & $\pm 2 S E$ & ${ }^{207} \mathrm{~Pb} /{ }^{206} \mathrm{~Pb}$ age $(\mathrm{t})(\mathrm{Ma})$ & ${ }^{176} H f / / 177 H f(t)$ & $\varepsilon H f(t)$ & $T_{D M^{c}}(M a)$ \\
\hline \multicolumn{9}{|c|}{ Sample $1 E$} \\
\hline 16.1 & 0.281581 & 0.000043 & 0.001391 & 0.000022 & 2126 & 0.281525 & 3.44 & 2448 \\
\hline 3.1 & 0.281668 & 0.000045 & 0.003938 & 0.000088 & 2124 & 0.281508 & 2.82 & 2486 \\
\hline 4.1 & 0.281605 & 0.000024 & 0.000690 & 0.000014 & 2122 & 0.281577 & 5.23 & 2330 \\
\hline 5.1 & 0.281679 & 0.000035 & 0.001109 & 0.000029 & 2135 & 0.281634 & 7.54 & 2192 \\
\hline 8.1 & 0.281571 & 0.000033 & 0.001306 & 0.000036 & 2140 & 0.281518 & 3.52 & 2454 \\
\hline 9.1 & 0.281638 & 0.000031 & 0.000752 & 0.000010 & 2123 & 0.281608 & 6.32 & 2261 \\
\hline 11.1 & 0.281633 & 0.000039 & 0.001785 & 0.000026 & 2137 & 0.281561 & 4.97 & 2358 \\
\hline 12.1 & 0.281599 & 0.000031 & 0.000653 & 0.000008 & 2137 & 0.281572 & 5.40 & 2331 \\
\hline 21.1 & 0.281708 & 0.000037 & 0.001082 & 0.000035 & 2129 & 0.281666 & 8.47 & 2127 \\
\hline Spot & ${ }^{176} \mathrm{Hf} /{ }^{177} \mathrm{Hf}$ & $\pm 2 S E$ & ${ }^{176} \mathrm{Lu} /{ }^{177} \mathrm{Hf}$ & $\pm 2 S E$ & ${ }^{207} \mathrm{~Pb} /{ }^{206} \mathrm{~Pb}$ age $(\mathrm{t})(\mathrm{Ma})$ & ${ }^{176} H f /{ }^{177} H f(t)$ & $\varepsilon H f(t)$ & $T_{D M^{c}}(M a)$ \\
\hline \multicolumn{9}{|c|}{ Sample 6} \\
\hline 1.1 & 0.281608 & 0.000025 & 0.000732 & 0.000015 & 2086 & 0.281579 & 4.47 & 2352 \\
\hline 24.1 & 0.281644 & 0.000030 & 0.000567 & 0.000002 & 2072 & 0.281622 & 5.65 & 2265 \\
\hline 12.1 & 0.281665 & 0.000036 & 0.000704 & 0.000011 & 2060 & 0.281637 & 5.94 & 2237 \\
\hline 15.1 & 0.281627 & 0.000027 & 0.000767 & 0.000007 & 2114 & 0.281596 & 5.71 & 2293 \\
\hline 16.1 & 0.281625 & 0.000028 & 0.000879 & 0.000021 & 2090 & 0.281590 & 4.94 & 2324 \\
\hline 19.1 & 0.281684 & 0.000023 & 0.001197 & 0.000019 & 2064 & 0.281637 & 6.02 & 2235 \\
\hline 22.1 & 0.281591 & 0.000031 & 0.001187 & 0.000012 & 2102 & 0.281544 & 3.58 & 2421 \\
\hline 21.1 & 0.281588 & 0.000023 & 0.000885 & 0.000022 & 2067 & 0.281554 & 3.12 & 2423 \\
\hline 13.1 & 0.281637 & 0.000030 & 0.000728 & 0.000019 & 2083 & 0.281608 & 5.42 & 2288 \\
\hline 5.1 & 0.281539 & 0.000021 & 0.000674 & 0.000018 & 2076 & 0.281513 & 1.87 & 2510 \\
\hline 7.1 & 0.281553 & 0.000027 & 0.000528 & 0.000006 & 2059 & 0.281532 & 2.17 & 2478 \\
\hline Spot & ${ }^{176} \mathrm{Hf} /{ }^{177} \mathrm{Hf}$ & $\pm 2 S E$ & ${ }^{176} \mathrm{Lu} /{ }^{177} \mathrm{Hf}$ & $\pm 2 S E$ & ${ }^{207} \mathrm{~Pb} /{ }^{206} \mathrm{~Pb}$ age $(\mathrm{t})(\mathrm{Ma})$ & ${ }^{176} H f /{ }^{177} H f(t)$ & $\varepsilon H f(t)$ & $T_{D M^{c}}(M a)$ \\
\hline \multicolumn{9}{|c|}{ Sample $7 A$} \\
\hline 4.1 & 0.281622 & 0.000028 & 0.000465 & 0.000003 & 2118 & 0.281603 & 6.06 & 2274 \\
\hline 5.1 & 0.281654 & 0.000032 & 0.001509 & 0.000067 & 2100 & 0.281594 & 5.30 & 2309 \\
\hline 1.1 & 0.281553 & 0.000025 & 0.000661 & 0.000009 & 2151 & 0.281526 & 4.06 & 2428 \\
\hline 15.1 & 0.281656 & 0.000031 & 0.000815 & 0.000026 & 2151 & 0.281623 & 7.50 & 2206 \\
\hline 17.1 & 0.281630 & 0.000029 & 0.000693 & 0.000008 & 2148 & 0.281602 & 6.68 & 2257 \\
\hline 19.1 & 0.281692 & 0.000039 & 0.000436 & 0.000024 & 2121 & 0.281675 & 8.66 & 2109 \\
\hline 22.1 & 0.281604 & 0.000032 & 0.000532 & 0.000005 & 2174 & 0.281582 & 6.58 & 2283 \\
\hline 21.1 & 0.281550 & 0.000028 & 0.000379 & 0.000003 & 2142 & 0.281535 & 4.18 & 2413 \\
\hline 24.1 & 0.281563 & 0.000035 & 0.000497 & 0.000006 & 2119 & 0.281543 & 3.95 & 2410 \\
\hline 16.1 & 0.281552 & 0.000028 & 0.000673 & 0.000004 & 2141 & 0.281525 & 3.80 & 2436 \\
\hline 14.1 & 0.281620 & 0.000035 & 0.000850 & 0.000020 & 2154 & 0.281586 & 6.25 & 2289 \\
\hline
\end{tabular}

\begin{tabular}{ccccccccc}
\hline Spot & ${ }^{176} \mathrm{Hf} /{ }^{177} \mathrm{Hf}$ & $\mathbf{\pm 2 S E}$ & ${ }^{176} \mathrm{Lu} /{ }^{177} \mathrm{Hf}$ & $\mathbf{\pm 2 S E}$ & ${ }^{207} \mathrm{~Pb} /{ }^{206} \mathrm{~Pb}$ age $(t)(\mathrm{Ma})$ & ${ }^{176} \mathrm{Hf} /{ }^{177} \mathrm{Hf}(\mathrm{t})$ & $\varepsilon \mathrm{Hf}(\mathrm{t})$ & $\mathrm{T}_{\mathrm{DM}}{ }^{\mathrm{C}}(\mathrm{Ma})$ \\
\hline sample A9K & & & & & & & & \\
9 & 0.280997 & 0.000036 & 0.001159 & 0.000025 & 3017 & 0.280929 & 2.89 & 3163
\end{tabular}




$\begin{array}{ccccccccc}8 & 0.280920 & 0.000039 & 0.000830 & 0.000021 & 2993 & 0.280872 & 0.28 & 3312 \\ 6 & 0.281021 & 0.000035 & 0.001287 & 0.000036 & 3002 & 0.280946 & 3.15 & 3135 \\ 22 & 0.280951 & 0.000034 & 0.000523 & 0.000008 & 3019 & 0.280921 & 2.64 & 3181 \\ 31 & 0.281072 & 0.000042 & 0.001191 & 0.000009 & 2983 & 0.281003 & 4.73 & 3020 \\ 46 & 0.281037 & 0.000031 & 0.001035 & 0.000022 & 3003 & 0.280977 & 4.27 & 3064 \\ 57 & 0.281058 & 0.000040 & 0.001563 & 0.000040 & 3006 & 0.280968 & 3.99 & 3084 \\ 63 & 0.281070 & 0.000051 & 0.001501 & 0.000014 & 2979 & 0.280984 & 3.94 & 3067 \\ 67 & 0.280966 & 0.000037 & 0.000895 & 0.000019 & 2999 & 0.280914 & 1.92 & 3212 \\ 85 & 0.281013 & 0.000029 & 0.001022 & 0.000010 & 2979 & 0.280954 & 2.88 & 3135\end{array}$

\begin{tabular}{|c|c|c|c|c|c|c|c|c|}
\hline Spot & ${ }^{176} \mathrm{Hf} /{ }^{177} \mathrm{Hf}$ & $\pm 2 \mathrm{SE}$ & ${ }^{176} \mathrm{Lu} /{ }^{177} \mathrm{Hf}$ & $\pm 2 \mathrm{SE}$ & ${ }^{207} \mathrm{~Pb} /{ }^{206} \mathrm{~Pb}$ age $(\mathrm{t})(\mathrm{Ma})$ & ${ }^{176} \mathrm{Hf} /{ }^{177} \mathrm{Hf}(\mathrm{t})$ & $\varepsilon H f(t)$ & $\mathrm{T}_{\mathrm{DM}}{ }^{\mathrm{C}}(\mathrm{Ma})$ \\
\hline \multicolumn{9}{|c|}{ sample C20 } \\
\hline 8 & 0.281123 & 0.000029 & 0.002133 & 0.000014 & 2942 & 0.281003 & 3.74 & 3052 \\
\hline 7 & 0.280901 & 0.000035 & 0.000825 & 0.000020 & 3182 & 0.280851 & 3.95 & 3221 \\
\hline 18 & 0.281081 & 0.000032 & 0.001448 & 0.000027 & 2943 & 0.280999 & 3.65 & 3058 \\
\hline 26 & 0.280918 & 0.000034 & 0.001421 & 0.000016 & 3187 & 0.280831 & 3.38 & 3262 \\
\hline 46 & 0.280981 & 0.000042 & 0.001885 & 0.000051 & 2963 & 0.280874 & -0.36 & 3330 \\
\hline 52 & 0.280976 & 0.000032 & 0.001420 & 0.000034 & 2957 & 0.280895 & 0.28 & 3285 \\
\hline 60 & 0.281006 & 0.000032 & 0.001393 & 0.000012 & 2961 & 0.280927 & 1.49 & 3210 \\
\hline 42 & 0.281023 & 0.000037 & 0.001577 & 0.000026 & 2937 & 0.280934 & 1.19 & 3211 \\
\hline 20 & 0.280978 & 0.000029 & 0.001123 & 0.000004 & 2903 & 0.280916 & -0.26 & 3278 \\
\hline
\end{tabular}

\begin{tabular}{|c|c|c|c|c|c|c|c|c|}
\hline Spot & ${ }^{176} \mathrm{Hf} /{ }^{177} \mathrm{Hf}$ & $\pm 2 \mathrm{SE}$ & ${ }^{176} \mathrm{Lu} /{ }^{177} \mathrm{Hf}$ & $\pm 2 \mathrm{SE}$ & ${ }^{207} \mathrm{~Pb} /{ }^{206} \mathrm{~Pb}$ age $(\mathrm{t})(\mathrm{Ma})$ & ${ }^{176} \mathrm{Hf} /{ }^{177} \mathrm{Hf}(\mathrm{t})$ & $\varepsilon H f(t)$ & $\mathrm{T}_{\mathrm{DM}}{ }^{\mathrm{C}}(\mathrm{Ma})$ \\
\hline \multicolumn{9}{|c|}{ sample C37 } \\
\hline 9 & 0.281047 & 0.000038 & 0.000687 & 0.000024 & 2956 & 0.281008 & 4.27 & 3028 \\
\hline 16 & 0.280949 & 0.000031 & 0.000413 & 0.000004 & 2962 & 0.280925 & 1.46 & 3213 \\
\hline 11 & 0.280912 & 0.000043 & 0.000339 & 0.000007 & 2942 & 0.280893 & -0.16 & 3302 \\
\hline 27 & 0.281003 & 0.000046 & 0.000737 & 0.000007 & 2971 & 0.280961 & 2.95 & 3124 \\
\hline 46 & 0.281018 & 0.000034 & 0.000676 & 0.000004 & 2943 & 0.280980 & 2.95 & 3103 \\
\hline 50 & 0.280966 & 0.000032 & 0.000631 & 0.000006 & 2914 & 0.280931 & 0.53 & 3236 \\
\hline 61 & 0.281019 & 0.000041 & 0.001036 & 0.000003 & 2944 & 0.280960 & 2.28 & 3147 \\
\hline 73 & 0.280953 & 0.000029 & 0.000473 & 0.000005 & 2983 & 0.280926 & 1.98 & 3196 \\
\hline 91 & 0.280932 & 0.000031 & 0.000505 & 0.000005 & 2980 & 0.280903 & 1.07 & 3252 \\
\hline 86 & 0.281017 & 0.000023 & 0.000508 & 0.000006 & 2948 & 0.280989 & 3.39 & 3079 \\
\hline Spot & ${ }^{176} \mathrm{Hf} /{ }^{177} \mathrm{Hf}$ & $\pm 2 \mathrm{SE}$ & ${ }^{176} \mathrm{Lu} /{ }^{177} \mathrm{Hf}$ & $\pm 2 \mathrm{SE}$ & ${ }^{207} \mathrm{~Pb} / 206 \mathrm{~Pb}$ age $(\mathrm{t})(\mathrm{Ma})$ & ${ }^{176} \mathrm{Hf} /{ }^{177} \mathrm{Hf}(t)$ & $\varepsilon H f(t)$ & $\mathrm{T}_{\mathrm{DM}}{ }^{\mathrm{C}}(\mathrm{Ma})$ \\
\hline \multicolumn{9}{|c|}{ sample C22 } \\
\hline 16.1 & 0.280903 & 0.000039 & 0.000948 & 0.000007 & 2795 & 0.280852 & -5.04 & 3500 \\
\hline 15.1 & 0.280910 & 0.000036 & 0.000845 & 0.000013 & 2777 & 0.280865 & -4.99 & 3483 \\
\hline 10.1 & 0.280987 & 0.000028 & 0.000458 & 0.000014 & 2776 & 0.280963 & -1.53 & 3262 \\
\hline 25.1 & 0.280967 & 0.000028 & 0.001094 & 0.000025 & 2785 & 0.280908 & -3.26 & 3379 \\
\hline 24.1 & 0.280953 & 0.000032 & 0.001249 & 0.000004 & 2741 & 0.280888 & -5.01 & 3457 \\
\hline 8.1 & 0.280850 & 0.000041 & 0.000929 & 0.000012 & 2785 & 0.280800 & -7.11 & 3624 \\
\hline 12.1 & 0.280939 & 0.000034 & 0.000833 & 0.000008 & 2786 & 0.280895 & -3.72 & 3410 \\
\hline 2.1 & 0.281067 & 0.000032 & 0.001075 & 0.000008 & 2741 & 0.281011 & -0.63 & 3178 \\
\hline 3.1 & 0.281003 & 0.000028 & 0.000644 & 0.000012 & 2738 & 0.280969 & -2.19 & 3276 \\
\hline 21.1 & 0.281118 & 0.000033 & 0.001236 & 0.000028 & 2804 & 0.281051 & 2.26 & 3041 \\
\hline
\end{tabular}




\section{ANEXO VII}

(Dados U-Pb LA-ICP-MS em titanita) 


\begin{tabular}{|c|c|c|c|c|c|c|c|}
\hline \multirow[b]{2}{*}{ Spot } & \multirow[b]{2}{*}{$\mathrm{Pb}(\mathrm{ppm})$} & \multirow[b]{2}{*}{$T h(p p m)$} & \multirow[b]{2}{*}{$U(\mathrm{ppm})$} & \multicolumn{2}{|l|}{ Ratios } & \multirow[b]{2}{*}{${ }^{207} \mathrm{~Pb} /{ }^{206} \mathrm{~Pb}$} & \multirow[b]{2}{*}{ $\pm 2 \mathrm{SE}$} \\
\hline & & & & ${ }^{206} \mathrm{~Pb} /{ }^{238} \mathrm{U}$ & $\pm 2 \mathrm{SE}$ & & \\
\hline \multicolumn{8}{|l|}{ sample 1D } \\
\hline 1D-4-01 & 15.8 & 3.1 & 46 & 0.1352 & 0.0024 & 0.1950 & 0.0043 \\
\hline 1D-4-02 & 8.8 & 3.7 & 95 & 0.1081 & 0.0018 & 0.0974 & 0.0014 \\
\hline 1D-4-03 & 5.9 & 8.1 & 28 & 0.1164 & 0.0020 & 0.1319 & 0.0025 \\
\hline 1D-4-04 & 5.6 & 7.4 & 27 & 0.1163 & 0.0021 & 0.1311 & 0.0026 \\
\hline 1D-14-01 & 5.9 & 9.7 & 42 & 0.1139 & 0.0024 & 0.1038 & 0.0020 \\
\hline 1D-15-01 & 8.5 & 22.8 & 99 & 0.1056 & 0.0019 & 0.0782 & 0.0016 \\
\hline 1D-15-02 & 5.1 & 2.6 & 24 & 0.1148 & 0.0024 & 0.1469 & 0.0032 \\
\hline 1D-16-01 & 7.9 & 19.1 & 115 & 0.1020 & 0.0016 & 0.0755 & 0.0011 \\
\hline 1D-18-01 & 9.9 & 32.3 & 265 & 0.1022 & 0.0019 & 0.0606 & 0.0010 \\
\hline 1D-19-01 & 7.3 & 14.8 & 64 & 0.1070 & 0.0019 & 0.0922 & 0.0018 \\
\hline 1D-19-02 & 13.1 & 42.7 & 149 & 0.1023 & 0.0018 & 0.0740 & 0.0013 \\
\hline 1D-19.2-01 & 11.5 & 32.2 & 168 & 0.1065 & 0.0020 & 0.0700 & 0.0011 \\
\hline 1D-19.2-02 & 8.6 & 23.2 & 110 & 0.1084 & 0.0019 & 0.0738 & 0.0013 \\
\hline 1D-19.2-03 & 7.9 & 17.1 & 109 & 0.1065 & 0.0019 & 0.0753 & 0.0013 \\
\hline 1D-19.2-04 & 8.8 & 22.0 & 108 & 0.1070 & 0.0019 & 0.0769 & 0.0013 \\
\hline 1D-19.2-05 & 6.7 & 12.7 & 92 & 0.1058 & 0.0019 & 0.0772 & 0.0013 \\
\hline 1D-23-01 & 6.3 & 11.6 & 39 & 0.1065 & 0.0019 & 0.1130 & 0.0023 \\
\hline 1D-23-02 & 5.2 & 2.9 & 20 & 0.1214 & 0.0024 & 0.1628 & 0.0036 \\
\hline 1D-23-03 & 5.8 & 4.4 & 24 & 0.1229 & 0.0022 & 0.1502 & 0.0034 \\
\hline 1D-26-01 & 6.9 & 9.0 & 28 & 0.1184 & 0.0023 & 0.1446 & 0.0030 \\
\hline 1D-26-02 & 5.5 & 2.6 & 22 & 0.1206 & 0.0024 & 0.1616 & 0.0035 \\
\hline 1D-26-03 & 6.6 & 8.5 & 34 & 0.1134 & 0.0023 & 0.1288 & 0.0025 \\
\hline 1D-28-01 & 15.8 & 1.8 & 24 & 0.1678 & 0.0038 & 0.2845 & 0.0087 \\
\hline 1D-28-02 & 8.4 & 14.1 & 109 & 0.1039 & 0.0024 & 0.0835 & 0.0025 \\
\hline 1D-29-01 & 4.8 & 1.6 & 16 & 0.1233 & 0.0025 & 0.1908 & 0.0043 \\
\hline 1D-29-02 & 5.5 & 7.2 & 79 & 0.1021 & 0.0018 & 0.0833 & 0.0014 \\
\hline 1D-29-03 & 5.5 & 4.9 & 44 & 0.1105 & 0.0022 & 0.1088 & 0.0022 \\
\hline 1D-30-01 & 9.5 & 17.0 & 65 & 0.1120 & 0.0019 & 0.1037 & 0.0017 \\
\hline 1D-30-02 & 18.6 & 75.9 & 290 & 0.1026 & 0.0020 & 0.0614 & 0.0010 \\
\hline 1D-31-01 & 6.5 & 7.0 & 33 & 0.1152 & 0.0024 & 0.1303 & 0.0031 \\
\hline 1D-31-02 & 7.0 & 12.4 & 41 & 0.1143 & 0.0024 & 0.1119 & 0.0024 \\
\hline 1D-31-03 & 7.7 & 17.3 & 78 & 0.1017 & 0.0021 & 0.0856 & 0.0016 \\
\hline 1D-32-01 & 19.0 & 73.4 & 267 & 0.1027 & 0.0023 & 0.0626 & 0.0012 \\
\hline 1D-32-02 & 20.0 & 96.8 & 294 & 0.1024 & 0.0018 & 0.0594 & 0.0010 \\
\hline 1D-32-03 & 21.6 & 94.9 & 364 & 0.0967 & 0.0017 & 0.0595 & 0.0008 \\
\hline 1D-37-01 & 6.5 & 13.5 & 43 & 0.1067 & 0.0019 & 0.1020 & 0.0020 \\
\hline 1D-38-01 & 11.3 & 0.8 & 10 & 0.1974 & 0.0040 & 0.3628 & 0.0068 \\
\hline 1D-46-01 & 18.9 & 2.0 & 14 & 0.2217 & 0.0071 & 0.4280 & 0.0120 \\
\hline \multirow[t]{2}{*}{ 1D-46-02 } & 6.4 & 10.9 & 65 & 0.1087 & 0.0020 & 0.0891 & 0.0016 \\
\hline & & & & Ratios & & & \\
\hline Spot & $\mathrm{Pb}(\mathrm{ppm})$ & Th(ppm) & $U($ ppm) & ${ }^{206} \mathrm{~Pb} /{ }^{238} \mathrm{U}$ & $\pm 2 \mathrm{SE}$ & ${ }^{207} \mathrm{~Pb} /{ }^{206} \mathrm{~Pb}$ & $\pm 2 \mathrm{SE}$ \\
\hline \multicolumn{8}{|l|}{ Sample 1E } \\
\hline $1 \mathrm{E}-1-02$ & 6.5 & 12.4 & 71 & 0.1081 & 0.0020 & 0.0868 & 0.0016 \\
\hline $1 E-1-03$ & 5.6 & 2.9 & 86 & 0.1080 & 0.0023 & 0.0846 & 0.0022 \\
\hline
\end{tabular}




\begin{tabular}{|c|c|c|c|c|c|c|c|}
\hline $1 E-2-01$ & 17.1 & 26.8 & 60 & 0.1246 & 0.0021 & 0.1550 & 0.0027 \\
\hline $1 E-2-02$ & 24.9 & 46.1 & 66 & 0.3457 & 0.0061 & 0.1111 & 0.0016 \\
\hline $1 E-2-03$ & 7.3 & 16.8 & 119 & 0.1055 & 0.0018 & 0.0725 & 0.0013 \\
\hline $1 E-4-01$ & 4.8 & 2.3 & 28 & 0.1136 & 0.0021 & 0.1293 & 0.0029 \\
\hline $1 E-4-02$ & 11.0 & 13.5 & 44 & 0.1234 & 0.0022 & 0.1490 & 0.0028 \\
\hline $1 E-5-01$ & 15.6 & 18.9 & 80 & 0.1142 & 0.0020 & 0.1322 & 0.0025 \\
\hline $1 E-5-02$ & 13.7 & 19.1 & 83 & 0.1130 & 0.0020 & 0.1201 & 0.0026 \\
\hline $1 E-5-03$ & 9.6 & 12.5 & 25 & 0.1345 & 0.0027 & 0.1894 & 0.0037 \\
\hline $1 E-8-01$ & 12.6 & 16.9 & 42 & 0.1238 & 0.0022 & 0.1670 & 0.0033 \\
\hline $1 E-8-02$ & 5.2 & 5.6 & 157 & 0.0998 & 0.0019 & 0.0681 & 0.0012 \\
\hline $1 E-9-01$ & 14.1 & 14.7 & 59 & 0.1205 & 0.0025 & 0.1532 & 0.0030 \\
\hline $1 E-9-02$ & 4.7 & 2.3 & 28 & 0.1146 & 0.0021 & 0.1362 & 0.0029 \\
\hline $1 E-9-03$ & 4.6 & 2.0 & 66 & 0.1087 & 0.0019 & 0.0887 & 0.0018 \\
\hline $1 \mathrm{E}-10-01$ & 13.3 & 14.9 & 62 & 0.1217 & 0.0021 & 0.1411 & 0.0023 \\
\hline $1 \mathrm{E}-10-02$ & 14.7 & 16.6 & 102 & 0.1153 & 0.0019 & 0.1146 & 0.0018 \\
\hline $1 E-10-03$ & 5.5 & 7.7 & 74 & 0.1074 & 0.0019 & 0.0840 & 0.0014 \\
\hline $1 \mathrm{E}-12-01$ & 10.4 & 18.1 & 66 & 0.1126 & 0.0020 & 0.1140 & 0.0024 \\
\hline $1 \mathrm{E}-12-02$ & 11.8 & 12.6 & 27 & 0.1410 & 0.0026 & 0.2196 & 0.0038 \\
\hline $1 \mathrm{E}-12-03$ & 11.9 & 41.3 & 172 & 0.1016 & 0.0019 & 0.0690 & 0.0012 \\
\hline $1 \mathrm{E}-12-04$ & 8.0 & 16.1 & 123 & 0.1086 & 0.0017 & 0.0750 & 0.0012 \\
\hline $1 \mathrm{E}-12-05$ & 13.3 & 18.2 & 60 & 0.1190 & 0.0022 & 0.1373 & 0.0020 \\
\hline $1 \mathrm{E}-12-06$ & 9.3 & 14.4 & 138 & 0.1017 & 0.0019 & 0.0804 & 0.0013 \\
\hline $1 \mathrm{E}-14-01$ & 5.9 & 8.2 & 59 & 0.1105 & 0.0022 & 0.0961 & 0.0019 \\
\hline $1 E-14-02$ & 6.5 & 11.5 & 52 & 0.1094 & 0.0020 & 0.0995 & 0.0020 \\
\hline $1 E-14-03$ & 9.0 & 8.4 & 170 & 0.1006 & 0.0017 & 0.0763 & 0.0015 \\
\hline $1 E-15-01$ & 5.8 & 4.1 & 39 & 0.1105 & 0.0022 & 0.1215 & 0.0025 \\
\hline $1 E-15-02$ & 20.8 & 24.4 & 157 & 0.1108 & 0.0019 & 0.1076 & 0.0016 \\
\hline $1 E-15-03$ & 22.8 & 17.3 & 112 & 0.1170 & 0.0022 & 0.1407 & 0.0020 \\
\hline $1 E-15-04$ & 7.0 & 5.8 & 51 & 0.1082 & 0.0020 & 0.1122 & 0.0019 \\
\hline $1 E-15.2-01$ & 7.6 & 14.6 & 118 & 0.1030 & 0.0018 & 0.0759 & 0.0012 \\
\hline $1 E-15.2-02$ & 7.5 & 4.7 & 109 & 0.1064 & 0.0018 & 0.0828 & 0.0024 \\
\hline $1 \mathrm{E}-18-01$ & 14.3 & 19.7 & 31 & 0.1388 & 0.0029 & 0.2060 & 0.0037 \\
\hline $1 \mathrm{E}-20-01$ & 13.2 & 18.1 & 44 & 0.1217 & 0.0023 & 0.1590 & 0.0026 \\
\hline $1 \mathrm{E}-20-03$ & 14.2 & 33.1 & 153 & 0.1036 & 0.0017 & 0.0815 & 0.0016 \\
\hline $1 E-20.2-01$ & 13.3 & 17.0 & 119 & 0.1091 & 0.0018 & 0.0975 & 0.0018 \\
\hline $1 E-20.2-02$ & 6.4 & 7.0 & 78 & 0.1095 & 0.0020 & 0.0862 & 0.0015 \\
\hline $1 E-23-01$ & 14.1 & 18.8 & 58 & 0.1169 & 0.0020 & 0.1446 & 0.0023 \\
\hline $1 E-23-02$ & 14.5 & 19.9 & 65 & 0.1159 & 0.0020 & 0.1379 & 0.0023 \\
\hline $1 E-23-03$ & 12.6 & 29.7 & 188 & 0.1018 & 0.0016 & 0.0747 & 0.0011 \\
\hline $1 E-23-04$ & 7.5 & 11.7 & 65 & 0.1077 & 0.0018 & 0.0987 & 0.0017 \\
\hline $1 \mathrm{E}-23-05$ & 6.3 & 7.6 & 52 & 0.1083 & 0.0019 & 0.1029 & 0.0016 \\
\hline $1 \mathrm{E}-24-01$ & 10.3 & 8.5 & 32 & 0.1310 & 0.0023 & 0.1775 & 0.0038 \\
\hline $1 \mathrm{E}-24-02$ & 4.8 & 1.6 & 49 & 0.3419 & 0.0074 & 0.1173 & 0.0022 \\
\hline \multirow[t]{2}{*}{$1 E-24-03$} & 6.2 & 5.4 & 47 & 0.1725 & 0.0033 & 0.1129 & 0.0019 \\
\hline & & & & Ratios & & & \\
\hline Spot & $\mathrm{Pb}(\mathrm{ppm})$ & Th(ppm) & $\mathrm{U}(\mathrm{ppm})$ & ${ }^{206} \mathrm{~Pb} /{ }^{238} \mathrm{U}$ & $\pm 2 \mathrm{SE}$ & ${ }^{207} \mathrm{~Pb} /{ }^{206} \mathrm{~Pb}$ & $\pm 2 \mathrm{SE}$ \\
\hline $9 B-5-01$ & 4.8 & 4.5 & 38 & 0.1071 & 0.0019 & 0.1088 & 0.0020 \\
\hline
\end{tabular}




\begin{tabular}{|c|c|c|c|c|c|c|c|}
\hline $9 B-5-02$ & 14.8 & 2.1 & 14 & 0.1847 & 0.0034 & 0.3814 & 0.0070 \\
\hline $9 B-5-03$ & 12.6 & 1.6 & 20 & 0.1473 & 0.0028 & 0.2980 & 0.0050 \\
\hline 9B-5-04 & 5.1 & 5.5 & 40 & 0.1088 & 0.0018 & 0.1098 & 0.0018 \\
\hline $9 B-5-05$ & 4.2 & 1.0 & 9 & 0.1349 & 0.0027 & 0.2432 & 0.0057 \\
\hline $9 B-5-06$ & 4.3 & 0.6 & 6 & 0.1547 & 0.0039 & 0.3024 & 0.0084 \\
\hline 9B-16-01 & 8.4 & 0.9 & 10 & 0.1623 & 0.0031 & 0.3308 & 0.0069 \\
\hline $9 B-16-02$ & 9.1 & 2.5 & 21 & 0.1356 & 0.0023 & 0.2262 & 0.0043 \\
\hline $9 B-16-03$ & 4.1 & 1.3 & 9 & 0.1355 & 0.0027 & 0.2434 & 0.0053 \\
\hline $9 B-16-04$ & 4.1 & 1.2 & 8 & 0.1390 & 0.0027 & 0.2592 & 0.0053 \\
\hline $9 B-25-01$ & 21.8 & 1.8 & 6 & 0.4082 & 0.0100 & 0.6020 & 0.0110 \\
\hline $9 B-25-02$ & 5.5 & 8.0 & 60 & 0.1030 & 0.0019 & 0.0891 & 0.0017 \\
\hline 9B-34-01 & 11.6 & 2.2 & 17 & 0.1554 & 0.0031 & 0.3106 & 0.0055 \\
\hline $9 B-34-02$ & 6.3 & 10.8 & 43 & 0.1109 & 0.0019 & 0.1035 & 0.0019 \\
\hline $9 B-34-03$ & 13.5 & 1.6 & 20 & 0.1531 & 0.0033 & 0.3071 & 0.0068 \\
\hline $9 B-42-01$ & 6.4 & 7.7 & 46 & 0.1074 & 0.0019 & 0.1120 & 0.0034 \\
\hline $9 B-55-01$ & 5.0 & 6.5 & 44 & 0.1038 & 0.0019 & 0.1012 & 0.0018 \\
\hline $9 B-55-02$ & 11.4 & 2.6 & 23 & 0.1377 & 0.0028 & 0.2575 & 0.0048 \\
\hline $9 B-55-03$ & 11.6 & 3.7 & 17 & 0.1526 & 0.0028 & 0.3095 & 0.0052 \\
\hline $9 B-55-04$ & 16.4 & 4.5 & 20 & 0.1630 & 0.0029 & 0.3407 & 0.0064 \\
\hline $9 B-55-05$ & 9.1 & 0.9 & 11 & 0.1684 & 0.0034 & 0.3519 & 0.0077 \\
\hline 9B-6-01 & 12.4 & 2.6 & 19 & 0.1529 & 0.0026 & 0.3087 & 0.0057 \\
\hline 9B-6-02 & 11.7 & 2.8 & 15 & 0.1606 & 0.0030 & 0.3320 & 0.0064 \\
\hline 9B-6-03 & 13.8 & 2.5 & 23 & 0.1456 & 0.0024 & 0.2916 & 0.0055 \\
\hline $9 B-6-04$ & 9.9 & 1.8 & 15 & 0.1505 & 0.0028 & 0.3024 & 0.0062 \\
\hline $9 B-12-01$ & 3.5 & 0.7 & 6 & 0.1407 & 0.0031 & 0.2724 & 0.0073 \\
\hline 9B-19-01 & 12.4 & 1.8 & 15 & 0.1640 & 0.0034 & 0.3408 & 0.0064 \\
\hline 9B-19-02 & 7.3 & 0.8 & 9 & 0.1663 & 0.0040 & 0.3567 & 0.0096 \\
\hline 9B-24-01 & 4.2 & 5.5 & 36 & 0.1059 & 0.0023 & 0.1046 & 0.0021 \\
\hline $9 B-24-02$ & 16.9 & 6.6 & 22 & 0.1611 & 0.0031 & 0.3234 & 0.0066 \\
\hline $9 B-24-03$ & 11.8 & 2.6 & 25 & 0.1387 & 0.0028 & 0.2566 & 0.0051 \\
\hline $9 B-24-04$ & 15.4 & 6.0 & 93 & 0.1096 & 0.0026 & 0.1441 & 0.0058 \\
\hline $9 B-28-01$ & 4.3 & 1.6 & 20 & 0.1175 & 0.0023 & 0.1602 & 0.0034 \\
\hline $9 B-28-02$ & 17.3 & 0.8 & 14 & 0.2046 & 0.0040 & 0.4431 & 0.0071 \\
\hline $9 B-28-03$ & 3.9 & 1.5 & 22 & 0.1142 & 0.0021 & 0.1436 & 0.0031 \\
\hline 9B-29-01 & 10.1 & 1.0 & 6 & 0.2424 & 0.0051 & 0.4930 & 0.0096 \\
\hline $9 B-29-02$ & 6.7 & 8.6 & 19 & 0.1204 & 0.0023 & 0.1932 & 0.0041 \\
\hline 9B-29-03 & 9.3 & 0.9 & 11 & 0.1726 & 0.0043 & 0.3772 & 0.0086 \\
\hline $9 B-29-04$ & 10.5 & 3.4 & 13 & 0.1641 & 0.0031 & 0.3546 & 0.0065 \\
\hline $9 B-29-06$ & 5.0 & 1.6 & 16 & 0.1270 & 0.0023 & 0.2014 & 0.0045 \\
\hline 9B-33-01 & 12.8 & 1.8 & 20 & 0.1546 & 0.0030 & 0.3168 & 0.0057 \\
\hline $9 B-33-02$ & 7.5 & 1.1 & 19 & 0.1343 & 0.0023 & 0.2497 & 0.0056 \\
\hline $9 B-33-03$ & 9.5 & 1.8 & 28 & 0.1266 & 0.0025 & 0.2248 & 0.0039 \\
\hline $9 B-33-04$ & 7.0 & 1.7 & 19 & 0.1295 & 0.0022 & 0.2335 & 0.0038 \\
\hline $9 B-41-01$ & 6.7 & 0.8 & 13 & 0.1479 & 0.0028 & 0.2854 & 0.0053 \\
\hline $9 B-41-02$ & 11.2 & 2.2 & 12 & 0.1811 & 0.0044 & 0.3895 & 0.0079 \\
\hline $9 B-41-03$ & 3.5 & 1.3 & 13 & 0.1230 & 0.0027 & 0.1892 & 0.0041 \\
\hline $9 B-45-01$ & 7.3 & 1.4 & 18 & 0.1365 & 0.0025 & 0.2553 & 0.0046 \\
\hline $9 B-45-02$ & 11.9 & 8.2 & 20 & 0.1451 & 0.0030 & 0.2823 & 0.0062 \\
\hline
\end{tabular}




$\begin{array}{lccccccc}\text { 9B-45-03 } & 8.7 & 2.6 & 19 & 0.1388 & 0.0026 & 0.2640 & 0.0079 \\ \text { 9B-57-01 } & 4.7 & 7.9 & 42 & 0.1041 & 0.0018 & 0.1009 & 0.0017 \\ \text { 9B-57-02 } & 12.6 & 4.4 & 17 & 0.1550 & 0.0028 & 0.3345 & 0.0054 \\ \text { 9B-57-03 } & 10.9 & 2.3 & 14 & 0.1657 & 0.0034 & 0.3497 & 0.0067 \\ \text { 9B-23-01 } & 12.0 & 2.3 & 18 & 0.1552 & 0.0035 & 0.3057 & 0.0075 \\ \text { 9B-23-02 } & 17.5 & 1.4 & 8 & 0.2817 & 0.0068 & 0.5400 & 0.0120\end{array}$




\section{ANEXO VIII}

(Dados de elementos traço em titanita) 


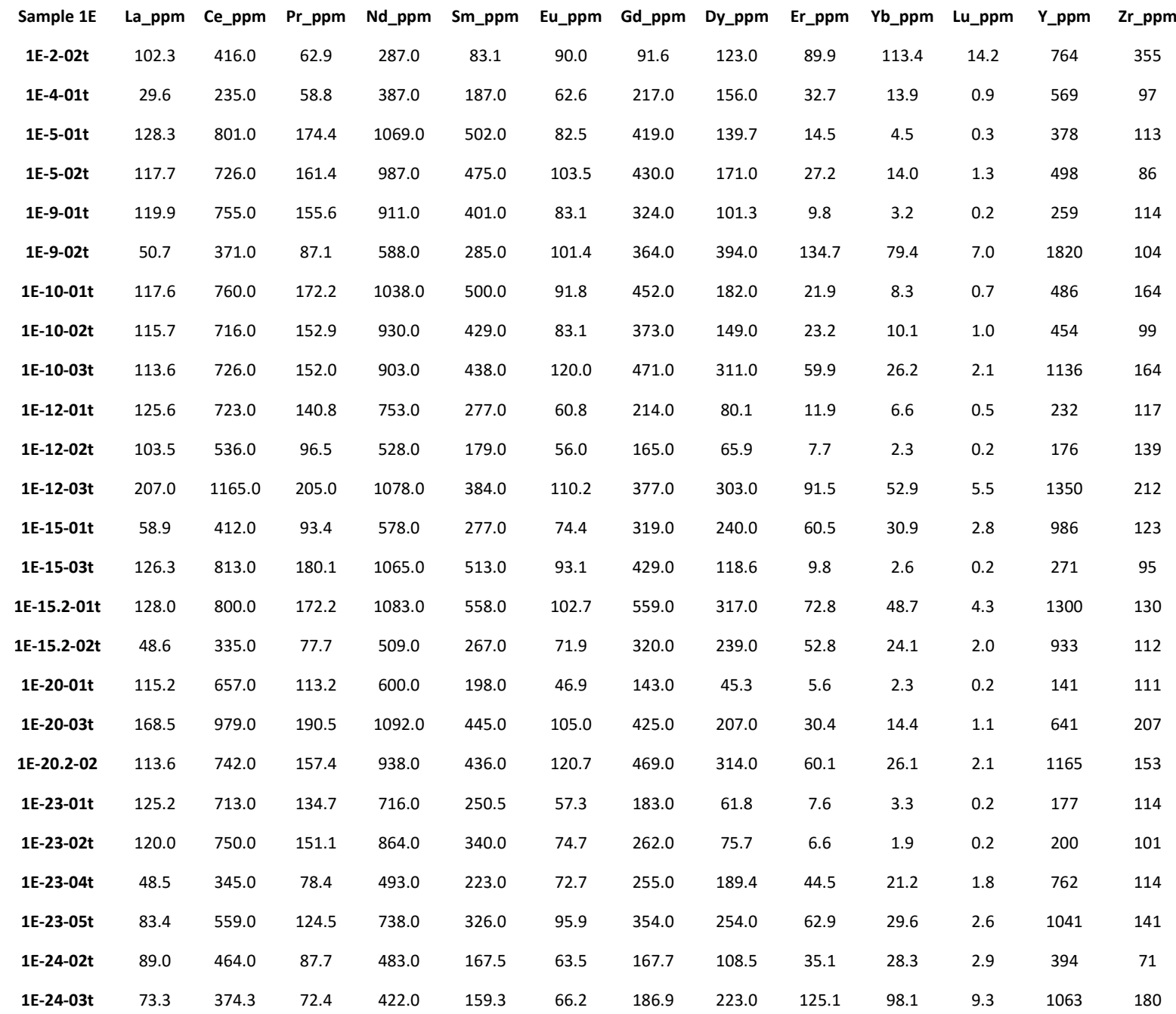

Sample 1D La_ppm Ce_ppm Pr_ppm Nd_ppm Sm_ppm Eu_ppm Gd_ppm Dy_ppm Er_ppm Yb_ppm Lu_ppm Y_ppm Zr_ppm

\begin{tabular}{|c|c|c|c|c|c|c|c|c|c|c|c|c|c|}
\hline 1D-4-01t & 15.9 & 104.5 & 24.2 & 160.0 & 71.4 & 27.9 & 78.7 & 57.6 & 17.3 & 14.3 & 1.7 & 209 & 37 \\
\hline 1D-14-01t & 127.1 & 555.0 & 90.8 & 460.0 & 137.0 & 65.6 & 145.0 & 176.0 & 111.0 & 119.8 & 15.0 & 990 & 167 \\
\hline $1 D-15-02 t$ & 90.0 & 475.0 & 89.1 & 504.0 & 174.0 & 59.5 & 183.0 & 214.0 & 119.5 & 105.0 & 12.0 & 1115 & 163 \\
\hline 1D-18-01t & 251.0 & 1095.0 & 161.3 & 746.0 & 204.0 & 96.0 & 175.0 & 193.0 & 102.0 & 91.1 & 10.8 & 977 & 249 \\
\hline 1D-19-02t & 259.0 & 1108.0 & 165.3 & 730.0 & 158.0 & 105.1 & 155.0 & 187.0 & 112.1 & 100.1 & 11.6 & 1075 & 533 \\
\hline 1D-19.2-01t & 202.0 & 916.0 & 144.8 & 679.0 & 172.0 & 101.2 & 167.0 & 209.0 & 126.9 & 121.6 & 15.2 & 1201 & 275 \\
\hline 1D-19.2-02t & 118.5 & 574.0 & 95.6 & 463.0 & 116.4 & 69.8 & 107.0 & 147.0 & 99.8 & 113.6 & 15.1 & 910 & 192 \\
\hline 1D-19.2-03t & 101.6 & 537.0 & 94.8 & 496.0 & 144.0 & 62.0 & 152.0 & 199.0 & 113.8 & 119.2 & 14.6 & 1090 & 168 \\
\hline $1 D-26-02 t$ & 133.6 & 598.0 & 94.8 & 488.0 & 145.0 & 75.0 & 165.0 & 218.0 & 122.0 & 122.0 & 15.3 & 1074 & 192 \\
\hline 1D-26-03t & 128.6 & 498.0 & 70.9 & 329.0 & 87.0 & 65.0 & 99.0 & 133.0 & 81.9 & 105.6 & 13.0 & 711 & 181 \\
\hline 1D-28-01t & 49.4 & 306.0 & 69.4 & 520.0 & 293.0 & 104.0 & 387.0 & 248.0 & 56.3 & 43.9 & 5.0 & 692 & 157 \\
\hline 1D-29-01t & 83.7 & 427.0 & 73.2 & 378.0 & 117.0 & 65.1 & 149.0 & 185.0 & 112.0 & 112.2 & 14.8 & 1013 & 153 \\
\hline 1D-29-02t & 23.8 & 169.7 & 37.8 & 235.0 & 84.8 & 43.4 & 117.0 & 152.0 & 91.3 & 94.2 & 12.5 & 811 & 106 \\
\hline 1D-30-01t & 111.9 & 419.0 & 59.4 & 271.0 & 68.9 & 50.8 & 65.9 & 43.7 & 19.0 & 30.8 & 4.0 & 233 & 216 \\
\hline
\end{tabular}




\begin{tabular}{|c|c|c|c|c|c|c|c|c|c|c|c|c|c|}
\hline 1D-30-02t & 261.0 & 900.0 & 140.0 & 744.0 & 202.0 & 59.6 & 230.0 & 261.0 & 141.0 & 133.0 & 17.1 & 1296 & 152 \\
\hline 1D-31-01t & 94.0 & 415.0 & 66.2 & 338.0 & 96.0 & 47.1 & 122.0 & 180.0 & 136.0 & 169.0 & 24.3 & 1096 & 156 \\
\hline 1D-32-02t & 394.0 & 1507.0 & 224.2 & 1068.0 & 291.0 & 100.0 & 356.0 & 462.0 & 263.0 & 245.0 & 28.0 & 2500 & 315 \\
\hline 1D-37-01t & 102.7 & 477.0 & 76.0 & 366.0 & 75.0 & 83.6 & 60.2 & 66.3 & 39.3 & 36.2 & 4.7 & 379 & 191 \\
\hline 1D-38-01t & 3.8 & 24.9 & 5.6 & 42.0 & 26.0 & 9.0 & 52.2 & 96.0 & 29.5 & 14.1 & 1.3 & 373 & 99 \\
\hline 1D-46-01t & 8.9 & 51.9 & 10.9 & 66.6 & 34.6 & 14.4 & 54.4 & 80.0 & 46.3 & 64.8 & 8.3 & 462 & 41 \\
\hline 1D-46-02t & 169.0 & 800.0 & 134.8 & 717.0 & 220.0 & 77.7 & 253.0 & 337.0 & 182.0 & 158.0 & 18.7 & 1568 & 232 \\
\hline Sample 9B & La_ppm & Ce_ppm & Pr_ppm & Nd_ppm & Sm_ppm & Eu_ppm & Gd_ppm & Dy_ppm & Er_ppm & Yb_ppm & Lu_ppm & Y_ppm & Zr_ppm \\
\hline $9 B-5-02 t$ & 80.5 & 523.0 & 131.3 & 903.0 & 338.0 & 87.2 & 277.0 & 174.0 & 72.3 & 81.5 & 10.4 & 692 & 106 \\
\hline 9B-5-04t & 89.9 & 539.0 & 120.8 & 775.0 & 277.0 & 159.0 & 325.0 & 385.0 & 240.0 & 234.0 & 31.8 & 2180 & 182 \\
\hline 9B-16-01t & 33.6 & 218.8 & 57.8 & 449.0 & 216.0 & 74.7 & 212.0 & 114.3 & 35.6 & 32.5 & 4.4 & 362 & 94 \\
\hline 9B-16-03t & 104.6 & 632.0 & 152.2 & 1046.0 & 437.0 & 162.9 & 504.0 & 607.0 & 327.0 & 268.0 & 34.2 & 2890 & 217 \\
\hline 9B-25-01t & 54.4 & 486.0 & 117.1 & 691.0 & 168.0 & 33.1 & 113.0 & 89.0 & 35.7 & 27.4 & 3.0 & 368 & 53 \\
\hline 9B-5-01t & 114.6 & 684.0 & 155.8 & 1069.0 & 415.0 & 162.0 & 468.0 & 573.0 & 339.0 & 297.0 & 36.0 & 2920 & 203 \\
\hline 9B-34-01t & 46.5 & 316.9 & 77.5 & 544.0 & 231.9 & 79.9 & 212.7 & 139.1 & 58.9 & 69.3 & 9.9 & 588 & 103 \\
\hline 9B-34-02t & 134.5 & 768.0 & 153.9 & 903.0 & 288.0 & 129.8 & 310.0 & 354.0 & 194.0 & 155.1 & 18.2 & 1805 & 173 \\
\hline 9B-42-01t & 125.2 & 780.0 & 169.1 & 1061.0 & 384.0 & 145.9 & 391.0 & 386.0 & 193.2 & 138.5 & 16.5 & 1701 & 192 \\
\hline 9B-55-03t & 35.5 & 248.1 & 65.1 & 486.0 & 234.0 & 79.7 & 218.0 & 100.6 & 15.5 & 8.1 & 0.7 & 234 & 90 \\
\hline 9B-6-01t & 70.1 & 418.0 & 104.1 & 737.0 & 290.0 & 90.7 & 252.0 & 122.4 & 25.1 & 15.6 & 1.9 & 338 & 115 \\
\hline 9B-6-03t & 68.2 & 411.0 & 102.7 & 727.0 & 289.0 & 89.8 & 269.0 & 139.5 & 29.0 & 14.5 & 1.6 & 384 & 116 \\
\hline 9B-24-03t & 50.7 & 352.0 & 89.6 & 645.0 & 344.0 & 115.0 & 302.0 & 126.0 & 18.7 & 6.2 & 0.6 & 284 & 92 \\
\hline 9B-19-01t & 39.1 & 283.0 & 68.5 & 523.0 & 266.0 & 91.0 & 242.0 & 115.0 & 24.5 & 18.2 & 2.5 & 302 & 97 \\
\hline 9B-28-01t & 67.1 & 473.0 & 114.7 & 810.0 & 319.0 & 96.9 & 254.0 & 119.0 & 23.2 & 11.5 & 1.2 & 282 & 83 \\
\hline 9B-28-03t & 82.9 & 612.0 & 154.7 & 993.0 & 341.0 & 61.9 & 237.0 & 135.0 & 50.5 & 49.9 & 6.9 & 491 & 75 \\
\hline 9B-29-01t & 30.0 & 224.5 & 61.2 & 447.0 & 213.6 & 71.9 & 223.0 & 168.7 & 54.4 & 30.9 & 3.3 & 538 & 89 \\
\hline 9B-29-02t & 183.0 & 610.0 & 90.6 & 453.0 & 128.6 & 39.5 & 124.9 & 113.4 & 51.0 & 49.7 & 7.2 & 489 & 88 \\
\hline 9B-33-02t & 69.8 & 472.0 & 117.4 & 819.0 & 320.0 & 101.1 & 261.0 & 177.5 & 95.2 & 117.2 & 16.6 & 866 & 106 \\
\hline 9B-41-01t & 38.6 & 259.9 & 64.2 & 468.0 & 232.0 & 80.8 & 232.0 & 139.0 & 41.6 & 40.2 & 5.4 & 417 & 97 \\
\hline 9B-41-03t & 38.1 & 250.0 & 63.7 & 451.0 & 214.0 & 78.0 & 215.0 & 114.0 & 21.3 & 9.1 & 0.8 & 276 & 93 \\
\hline $9 \mathrm{~B}-45-02 \mathrm{t}$ & 54.6 & 368.0 & 75.1 & 462.0 & 164.1 & 56.8 & 168.1 & 118.2 & 38.5 & 29.1 & 4.0 & 420 & 94 \\
\hline 9B-57-01t & 141.5 & 836.0 & 185.0 & 1168.0 & 424.0 & 128.5 & 476.0 & 522.0 & 222.0 & 142.2 & 14.8 & 2323 & 219 \\
\hline 9B-57-03t & 69.3 & 420.0 & 86.1 & 513.0 & 174.4 & 62.3 & 158.0 & 108.9 & 34.6 & 22.5 & 2.5 & 394 & 101 \\
\hline 9B-23-02t & 49.0 & 342.0 & 90.7 & 663.0 & 326.0 & 99.0 & 295.0 & 133.0 & 24.0 & 14.8 & 1.7 & 302 & 83 \\
\hline
\end{tabular}




\section{ANEXO IX}

(Análises representativas de química mineral por microssonda eletrônica) 


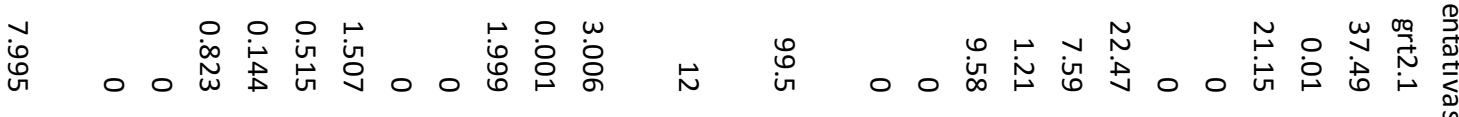

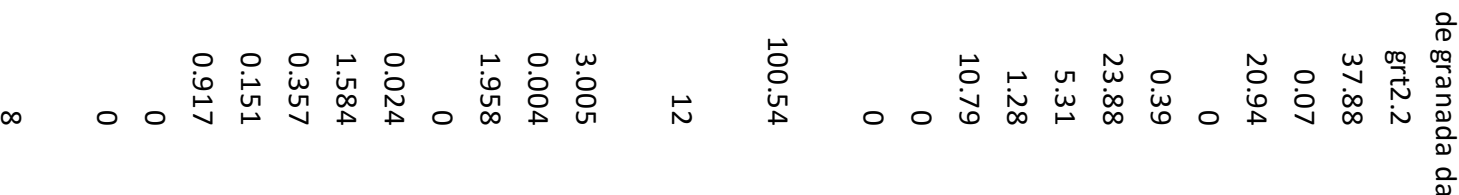

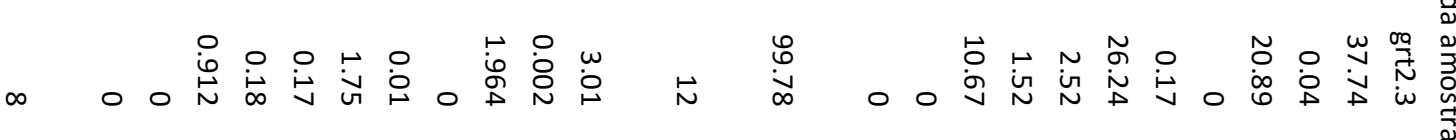

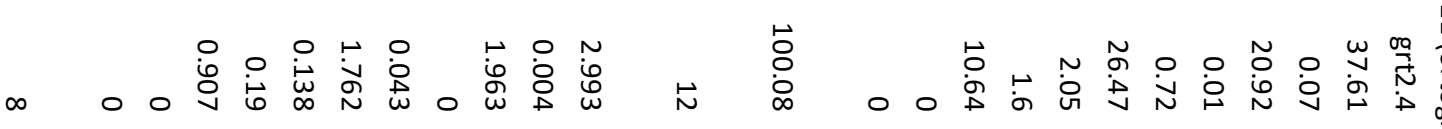

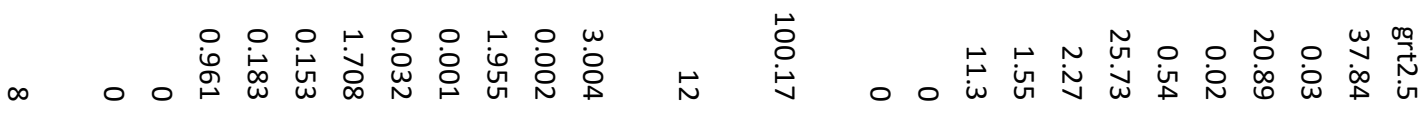

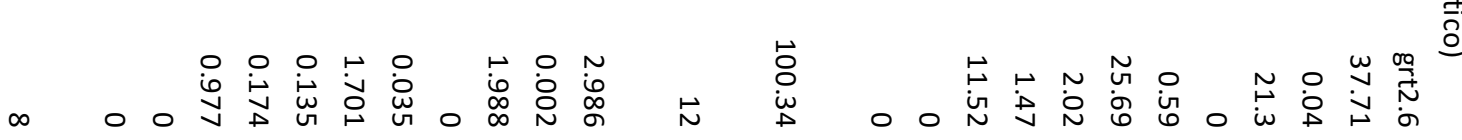

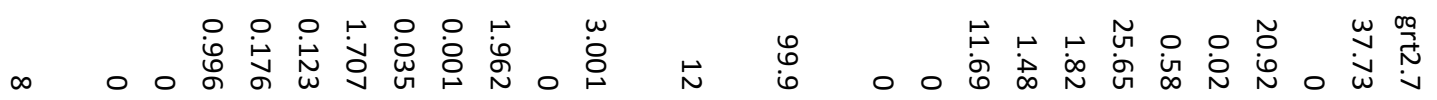

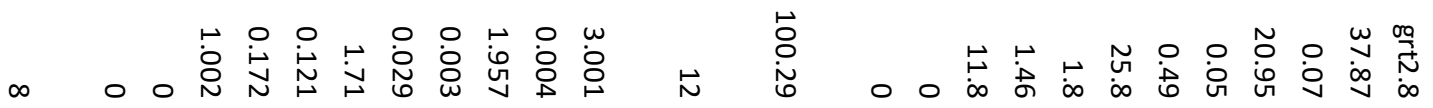

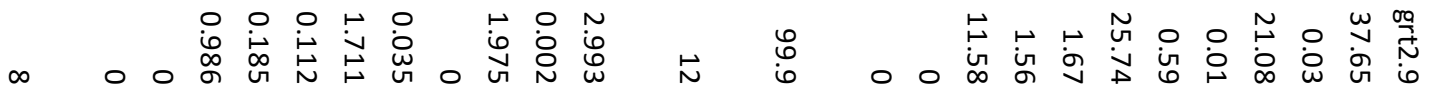

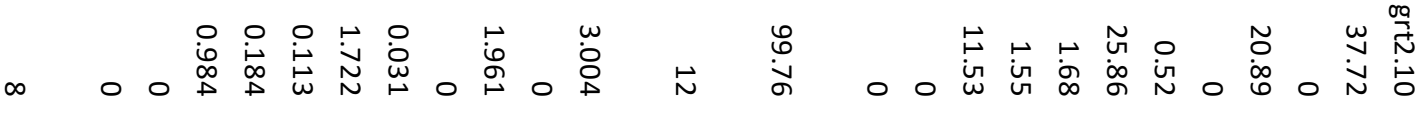

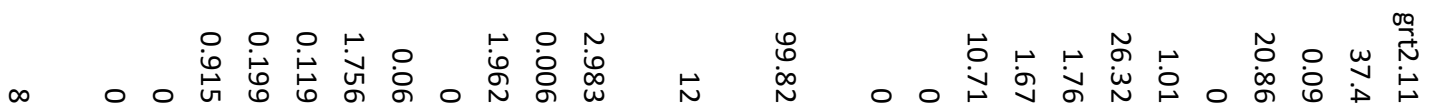

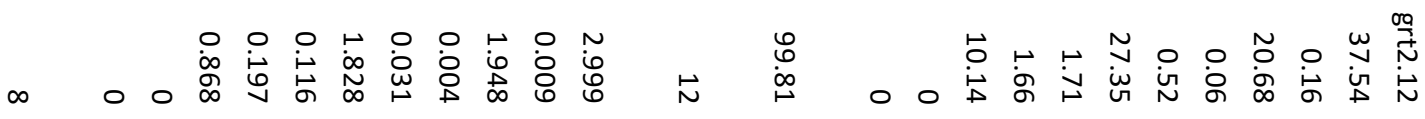

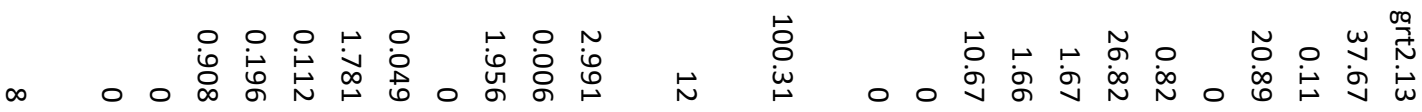

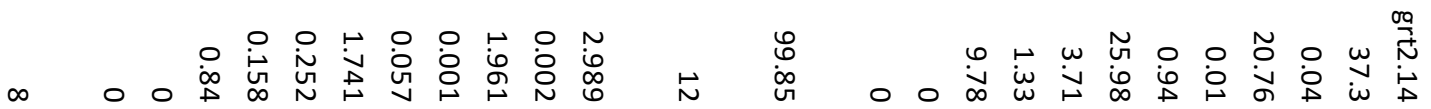

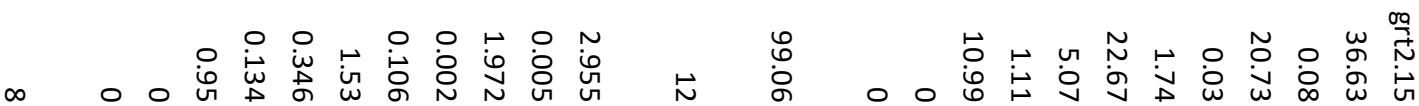




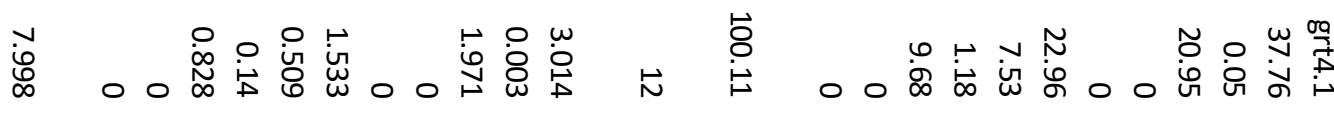
웅요

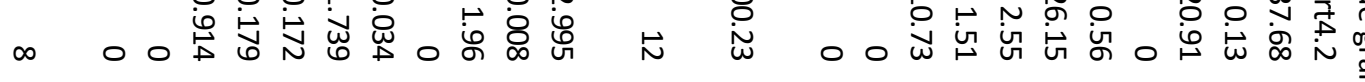

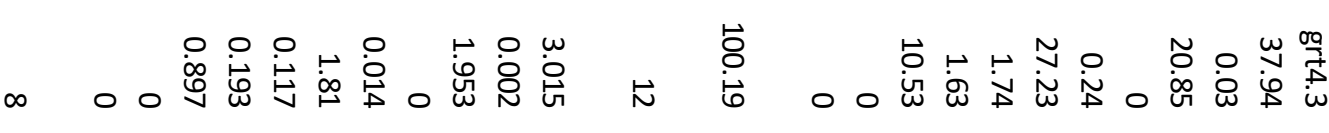

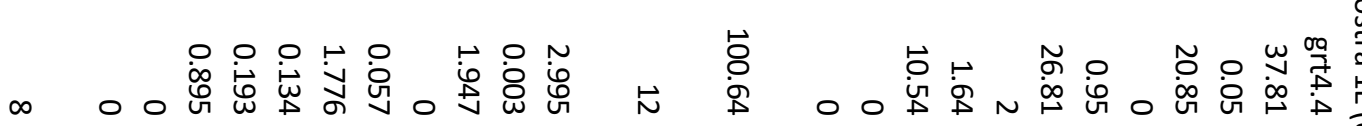

○

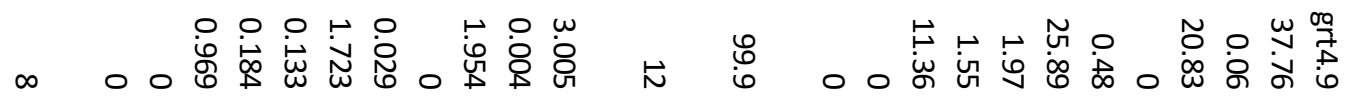

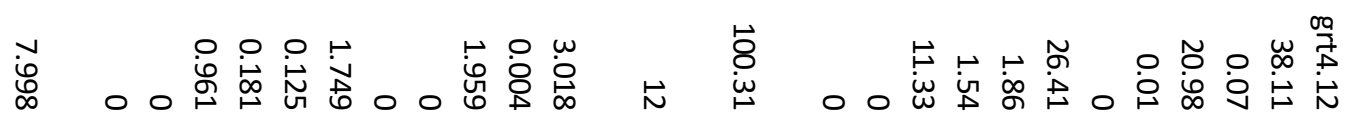

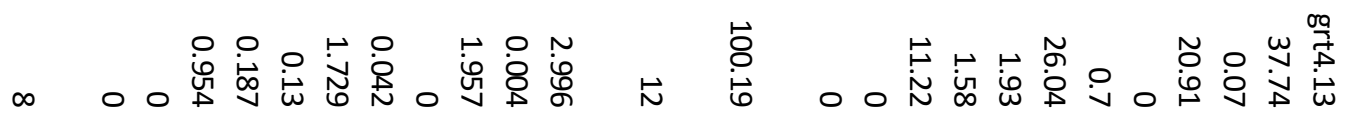

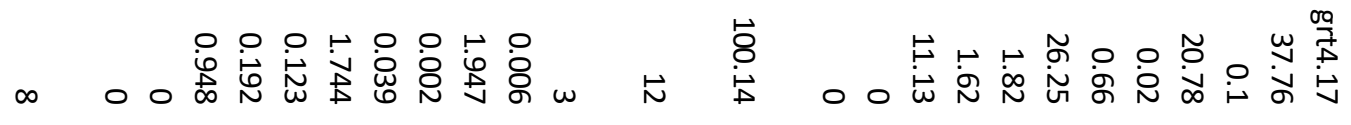

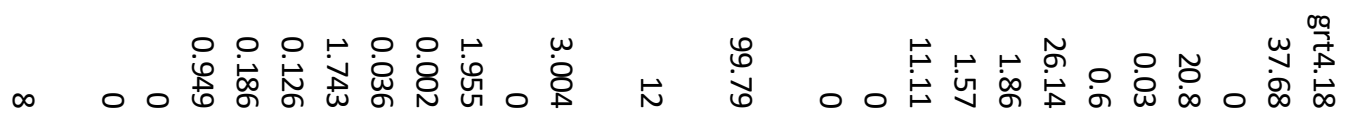

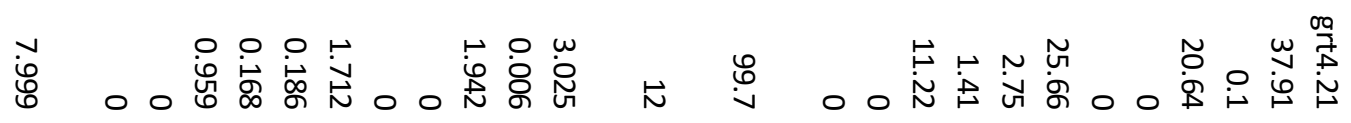

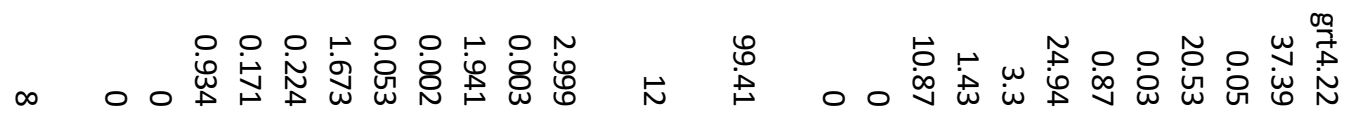

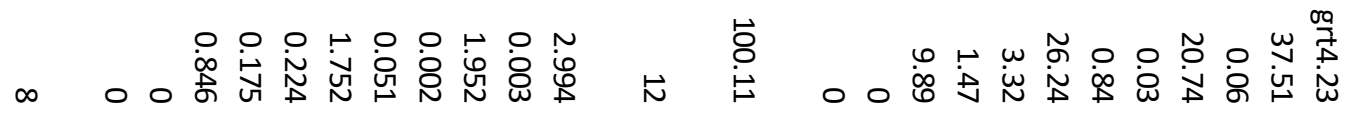

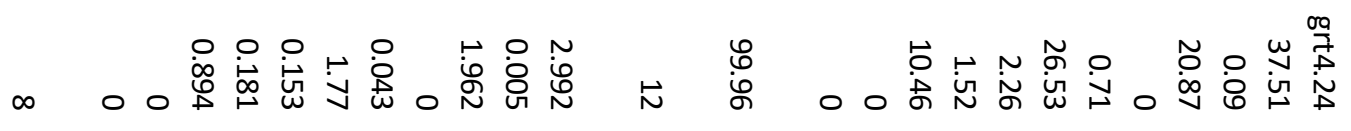

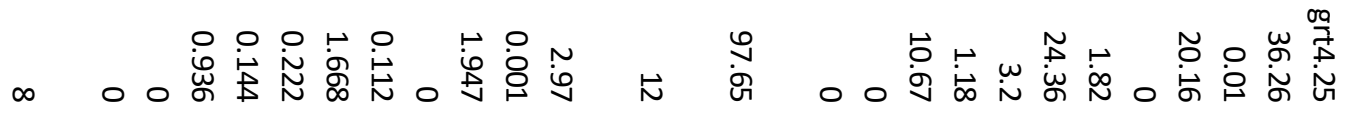




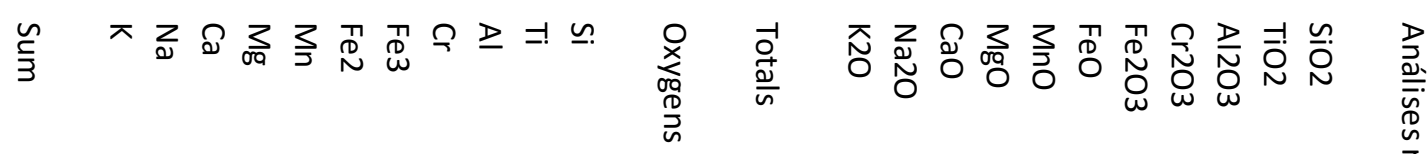

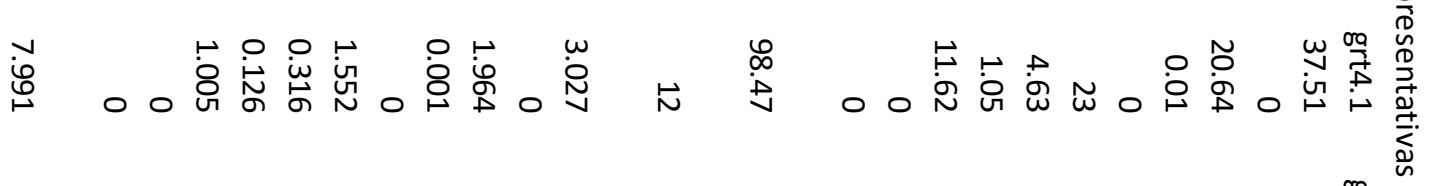

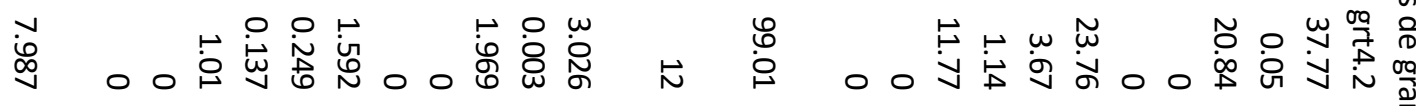

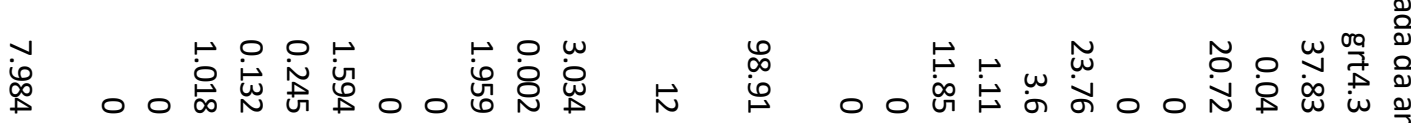

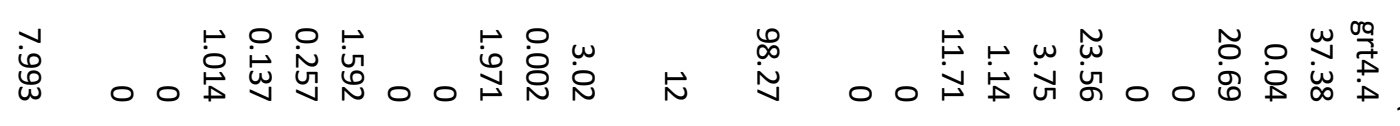

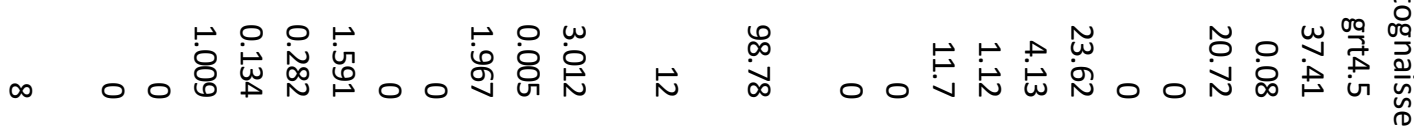

总

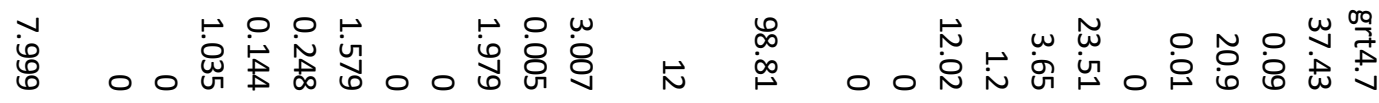

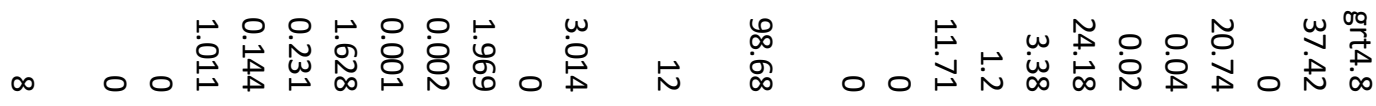

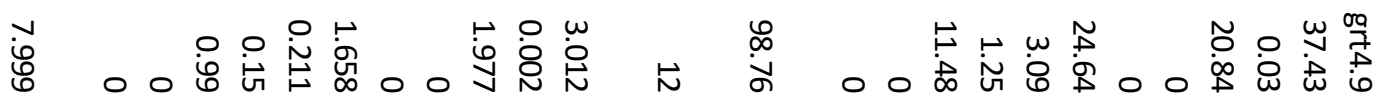

总

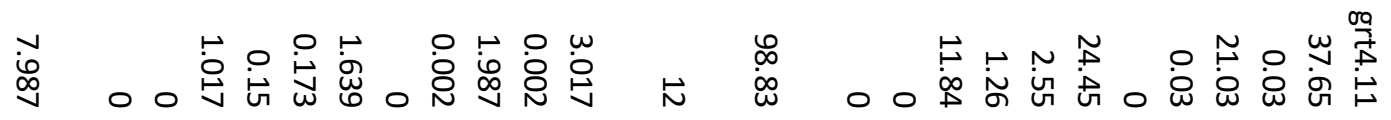

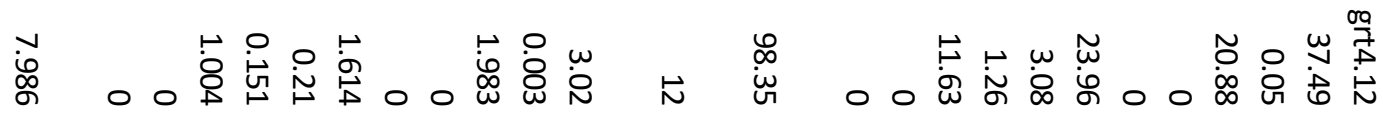

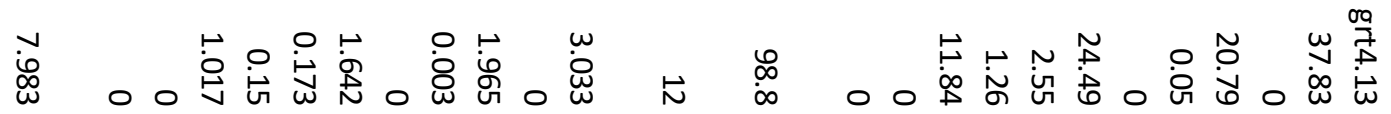

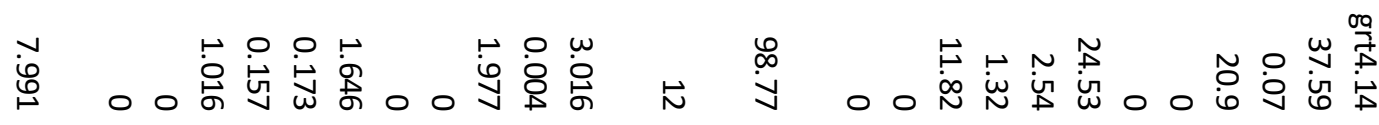




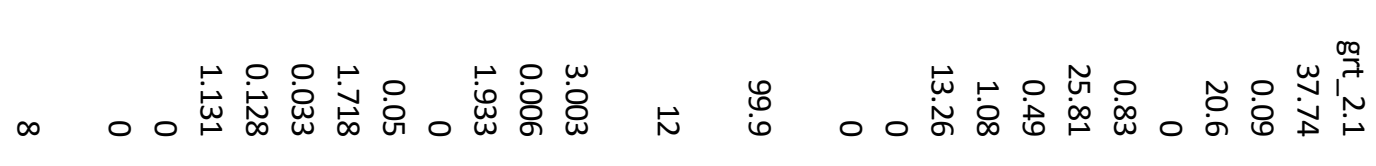

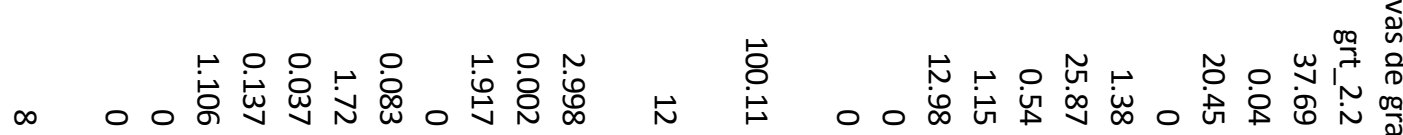

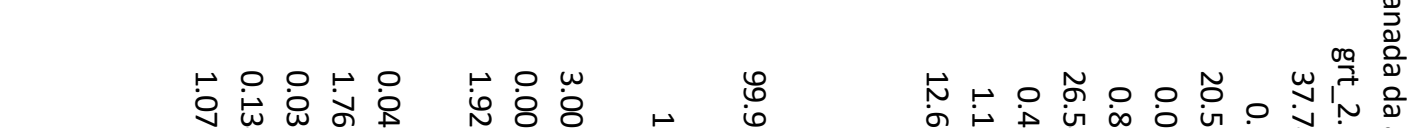

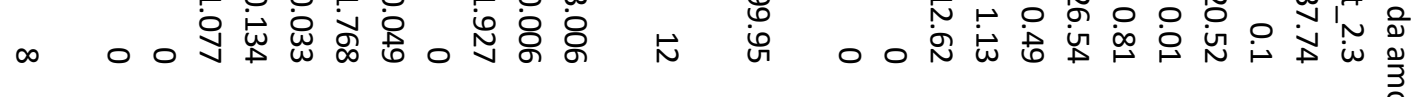

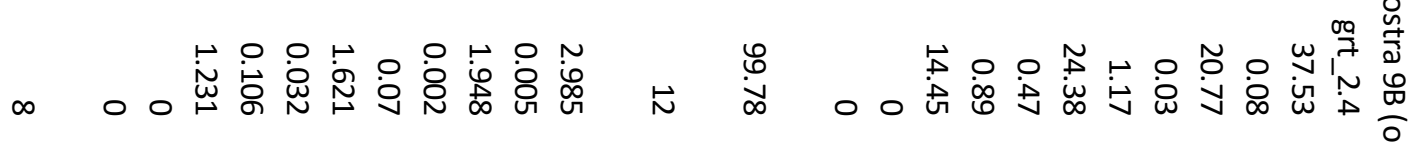

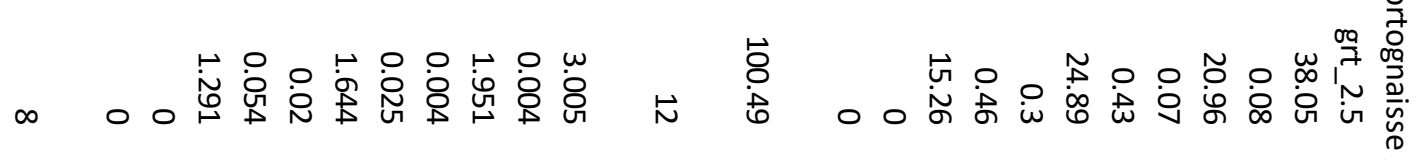

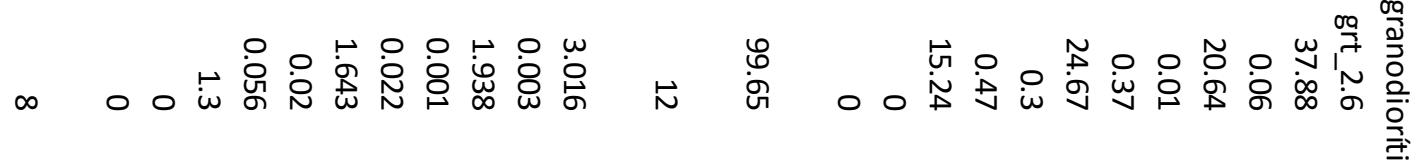

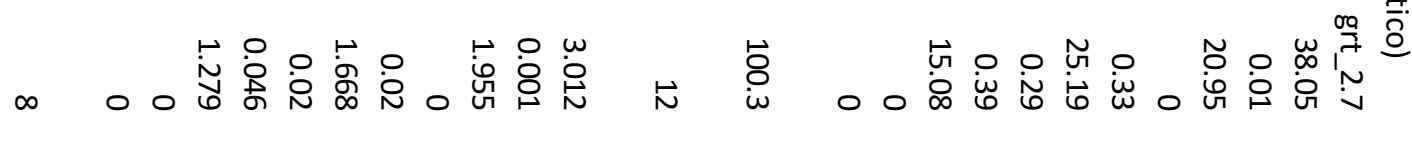

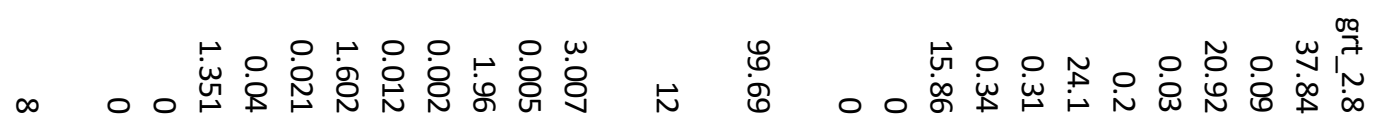

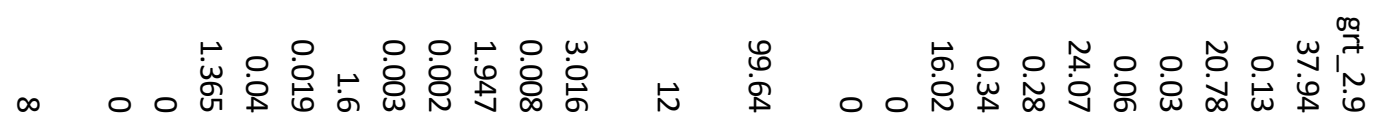

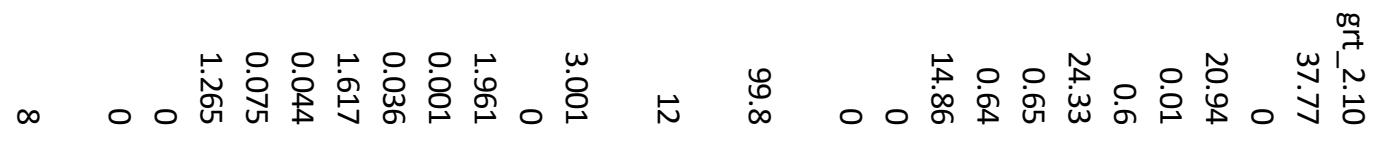

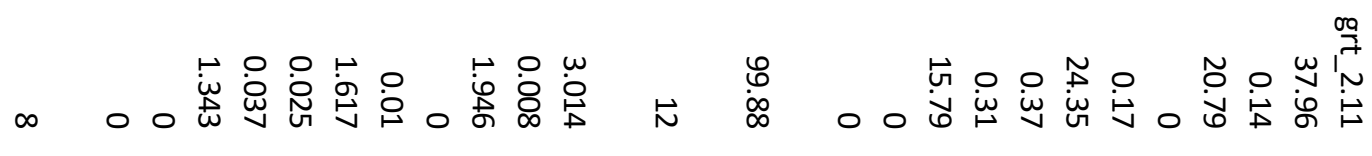

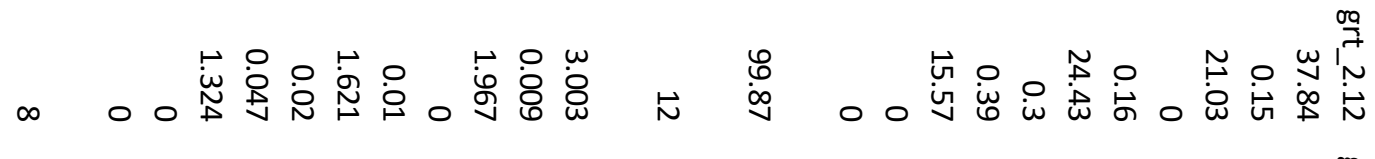

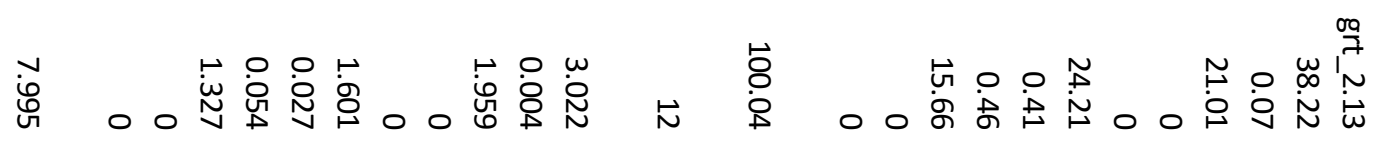

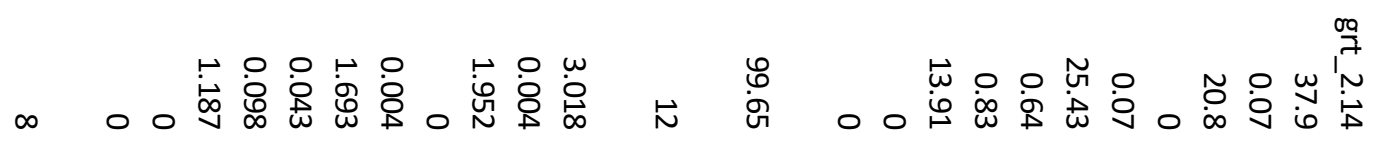

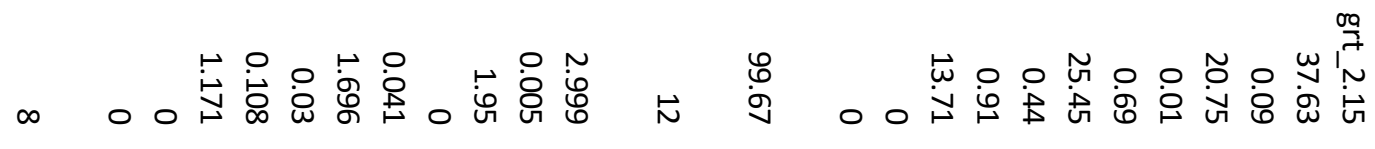




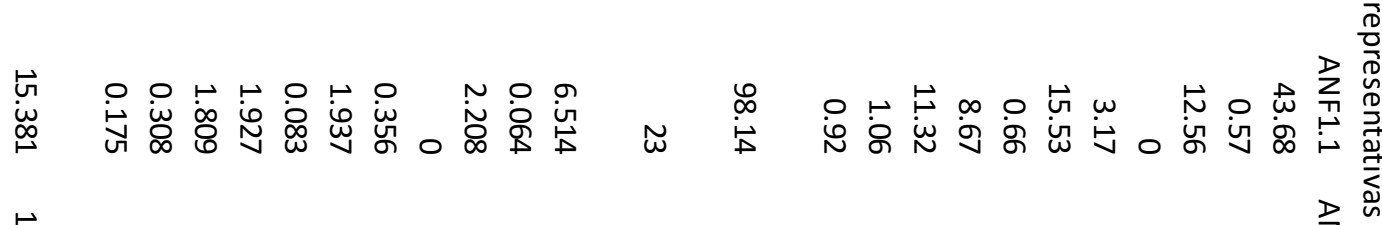

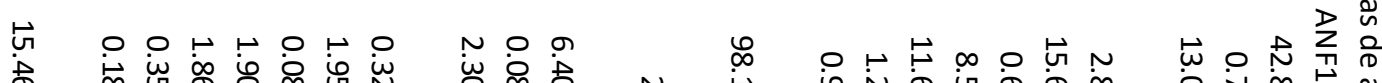

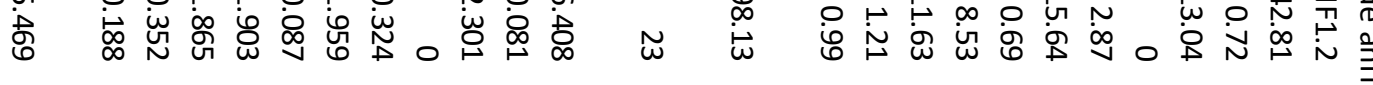

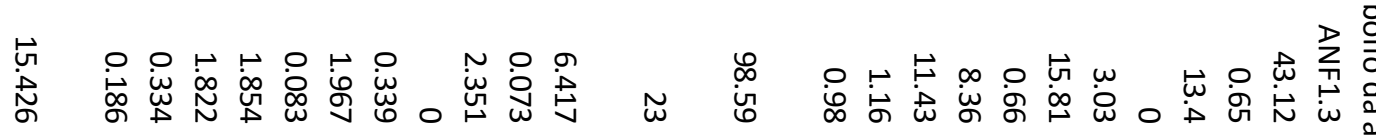

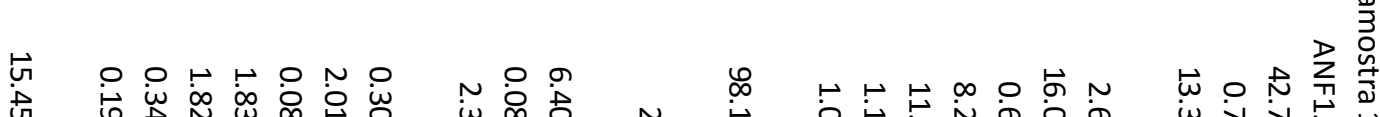

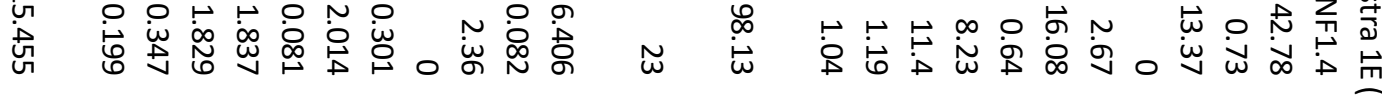

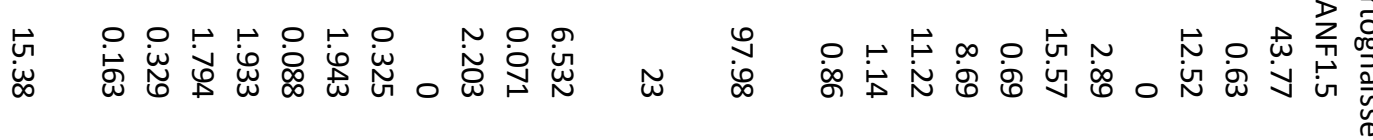

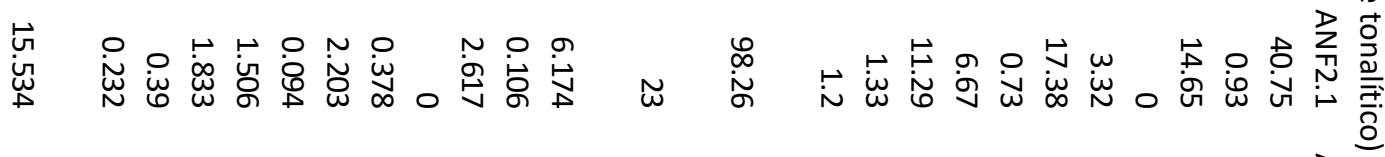

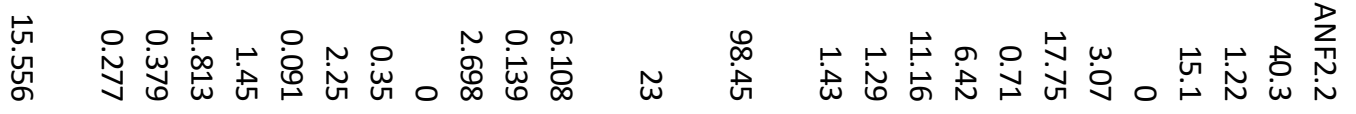

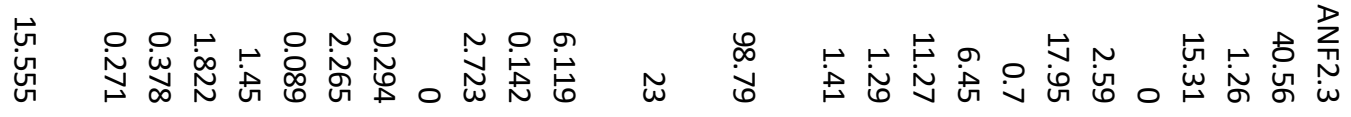

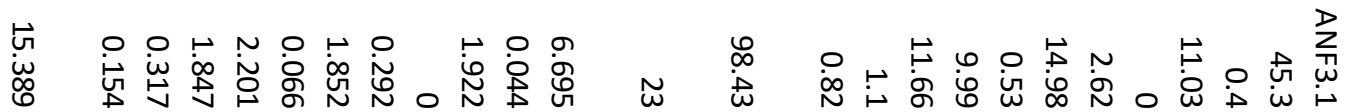

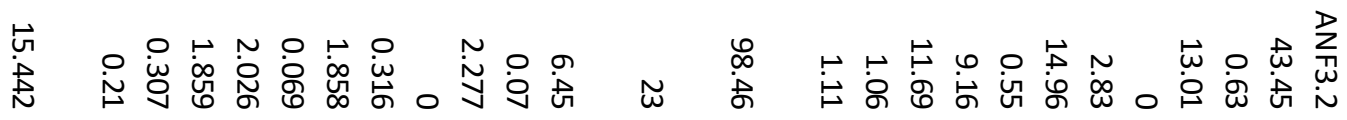

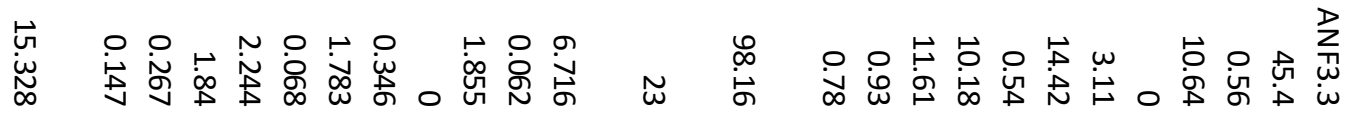

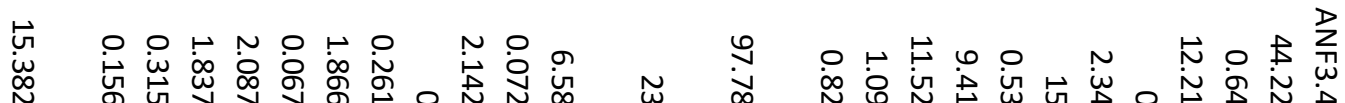

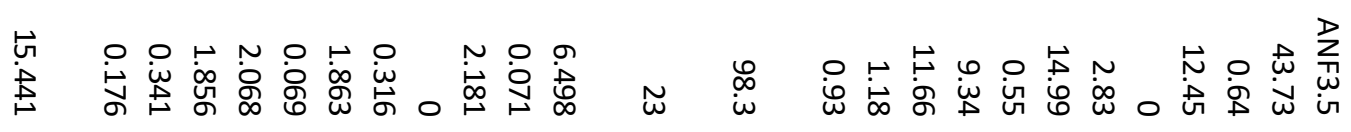

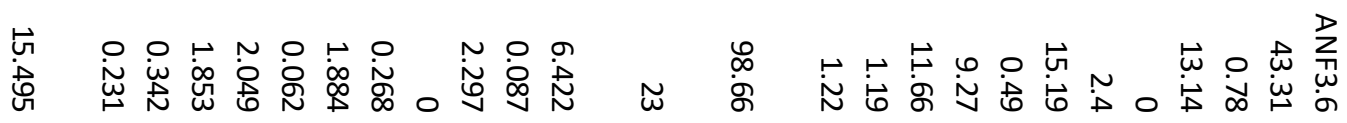

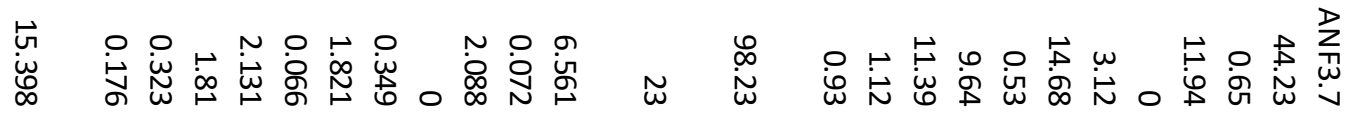




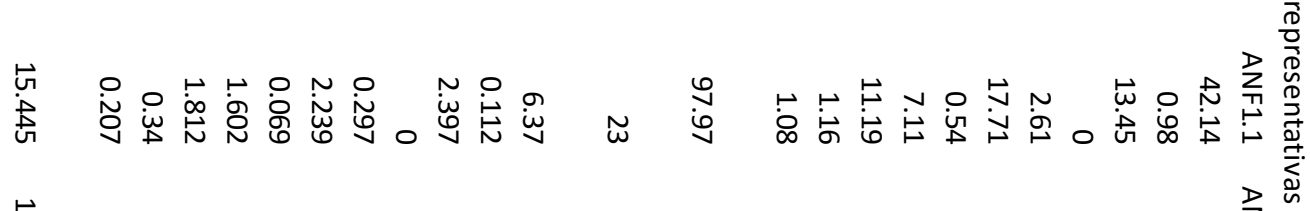

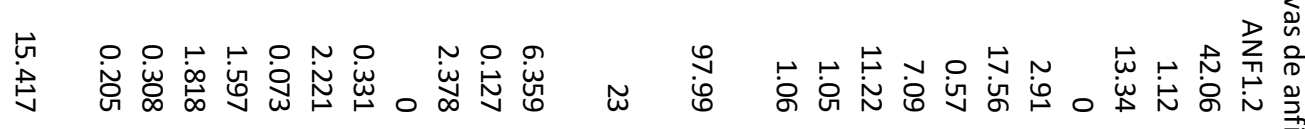

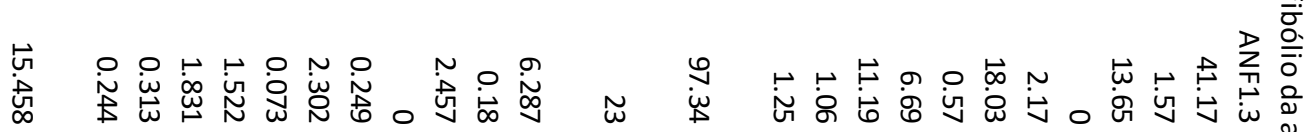

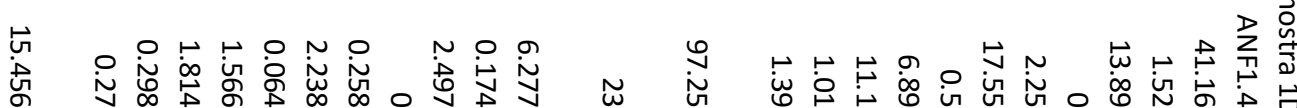

品 N

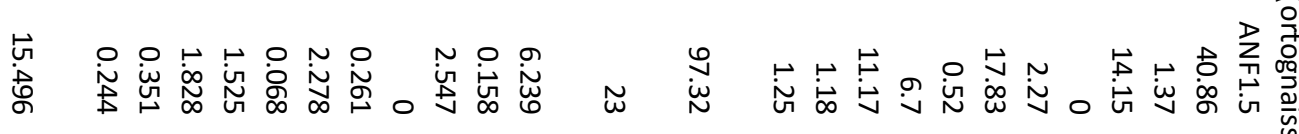

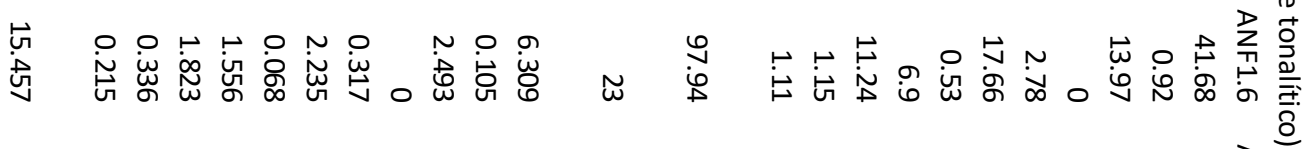

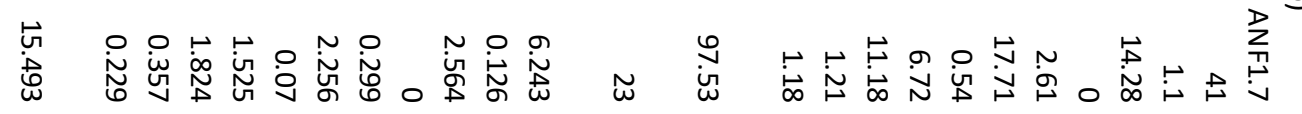

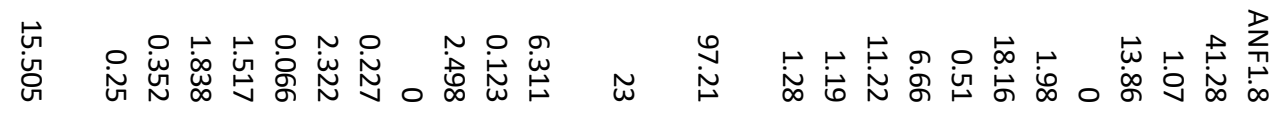

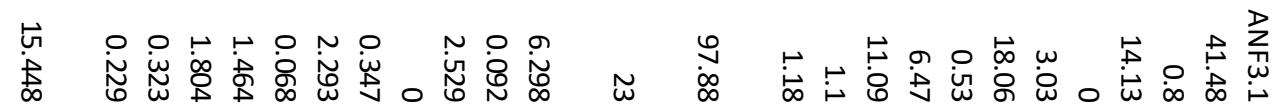

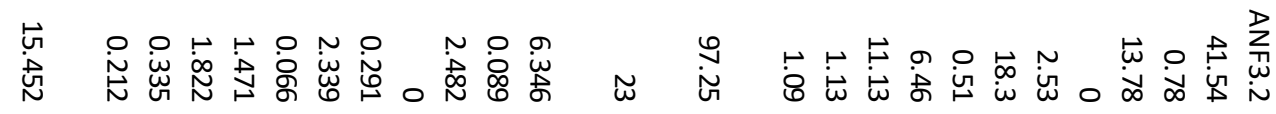

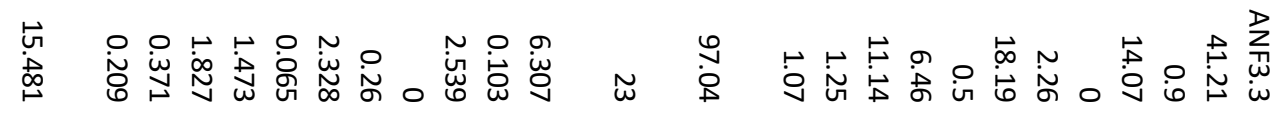

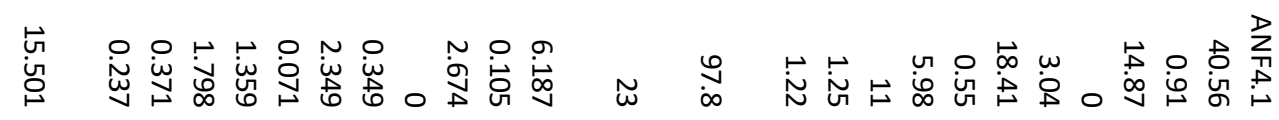

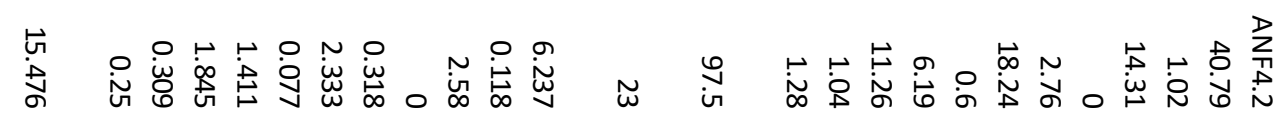

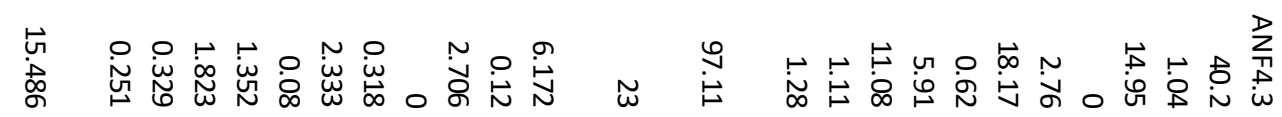

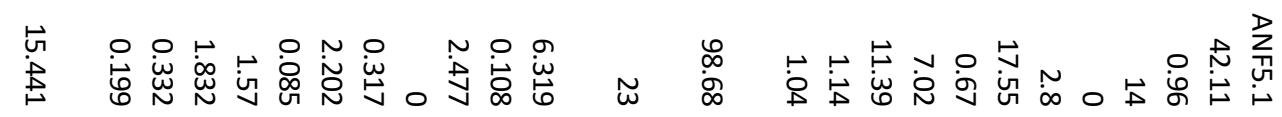

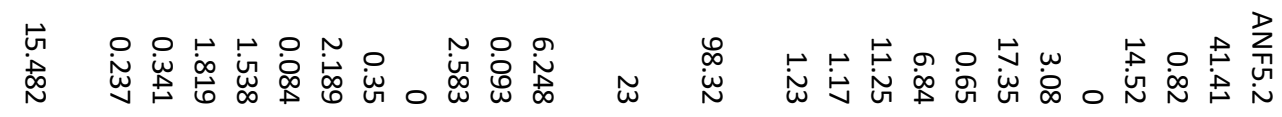




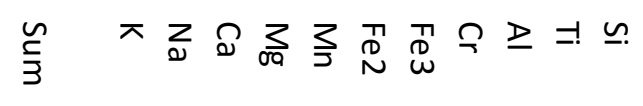

U

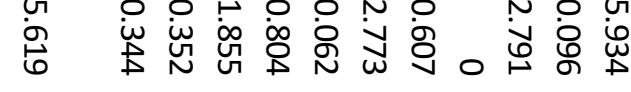

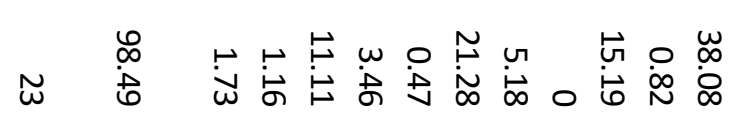

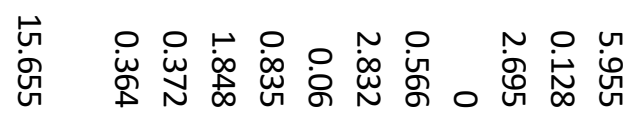
$\tilde{\omega}$

$\underset{\infty}{\infty}$

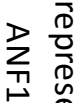

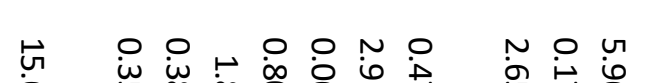

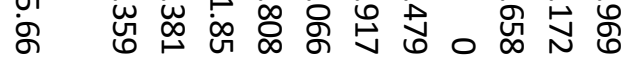

$\widetilde{\omega}$

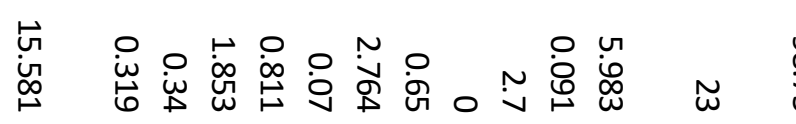

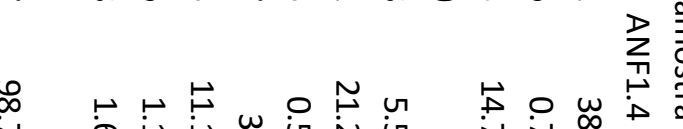

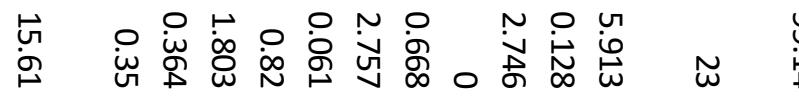

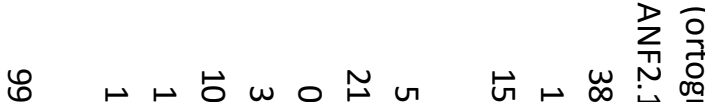

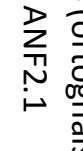

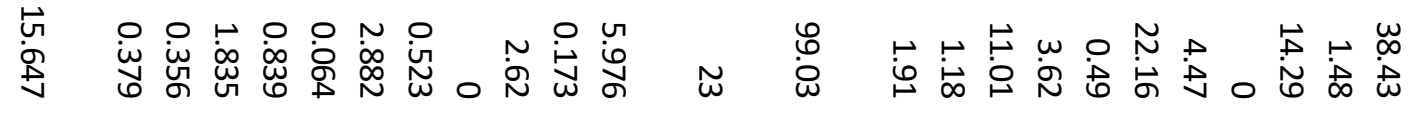

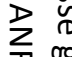

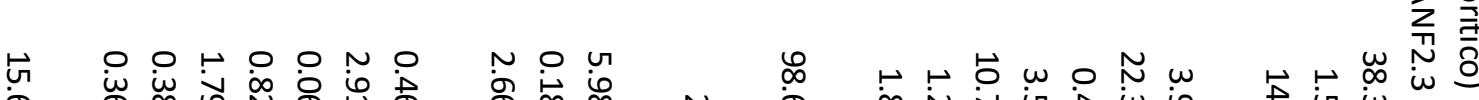

仙

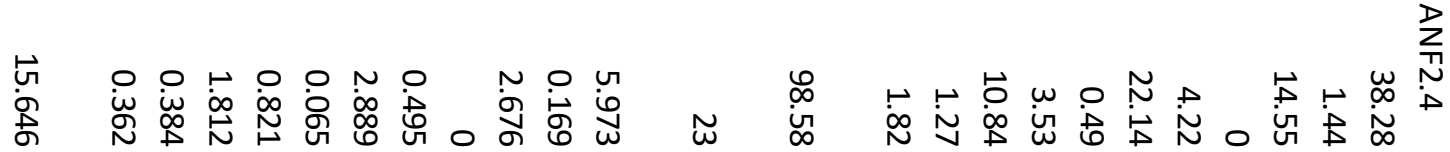

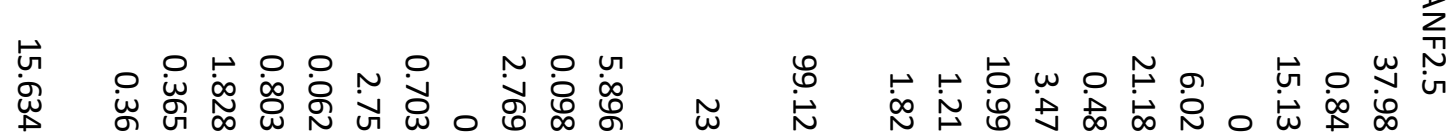

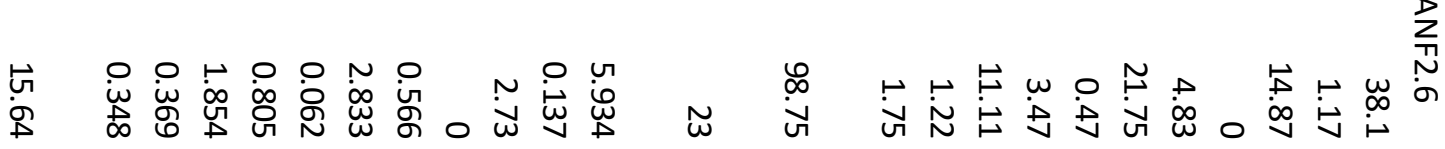

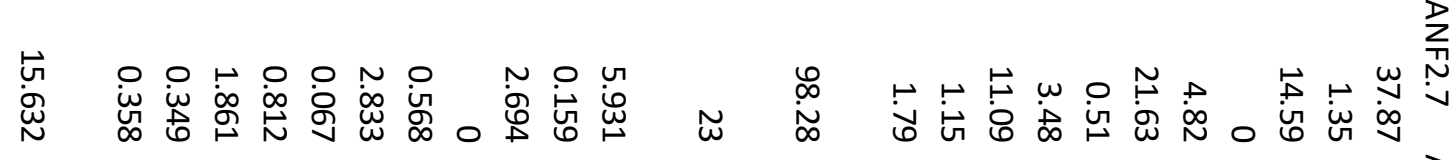

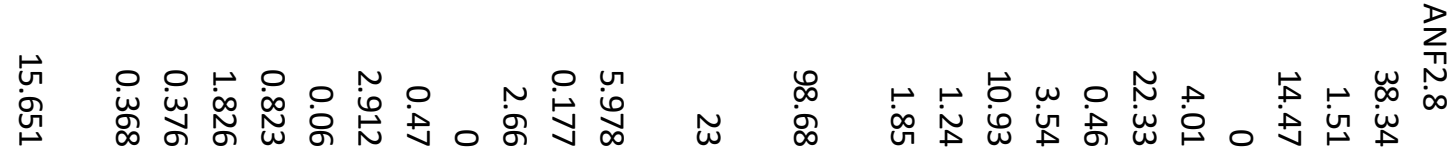

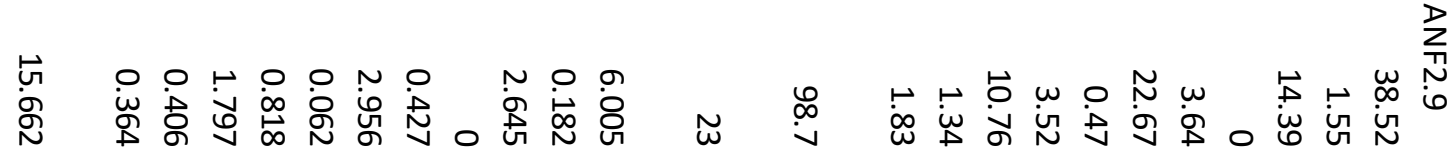

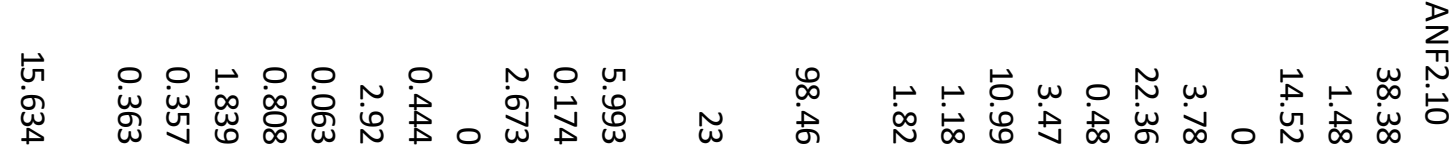




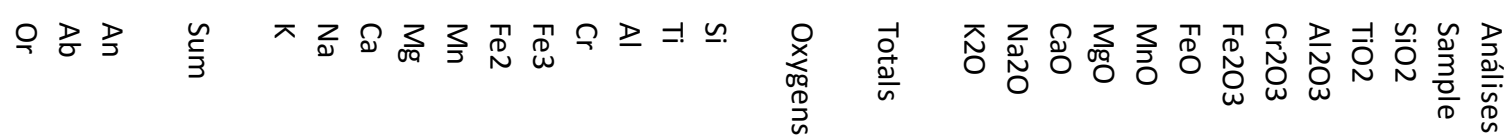

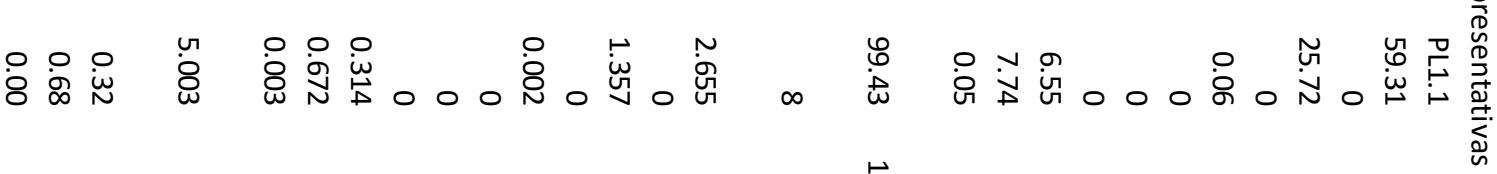

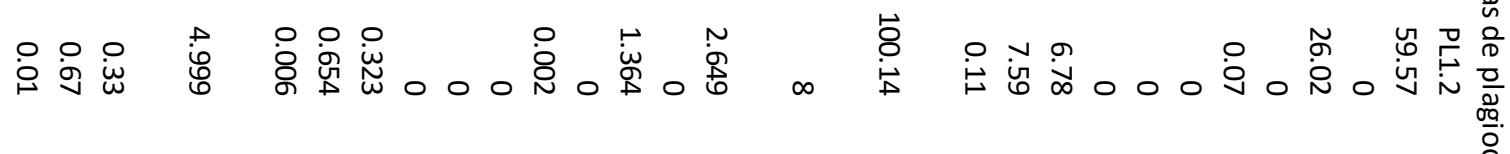

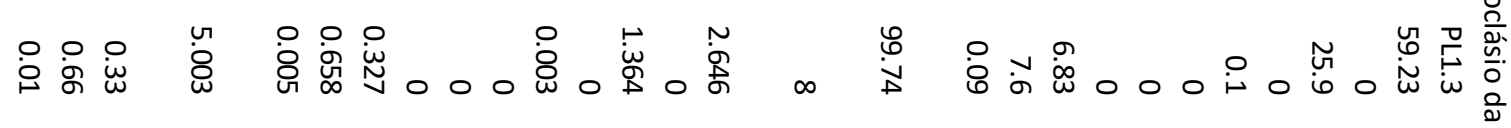

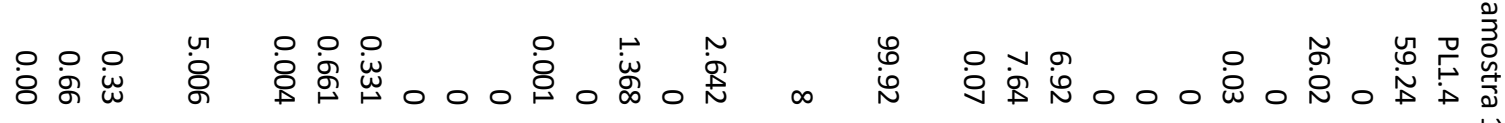

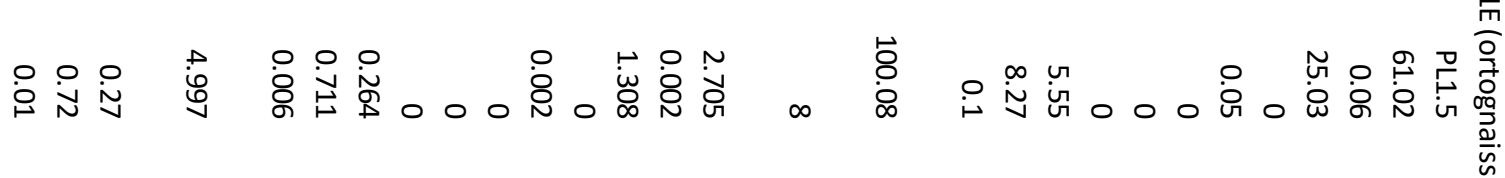

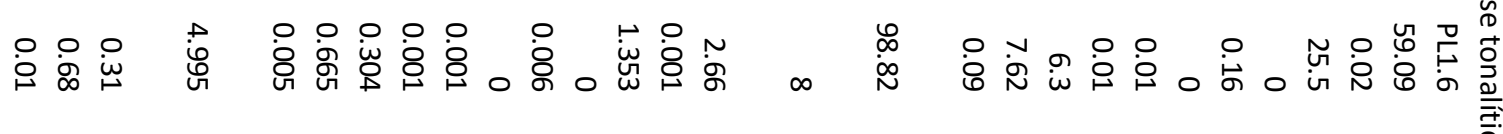

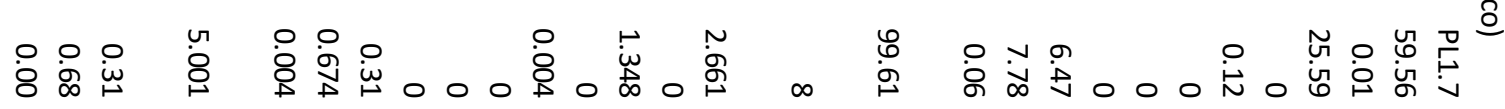

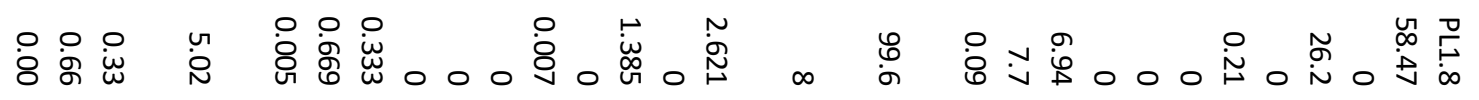

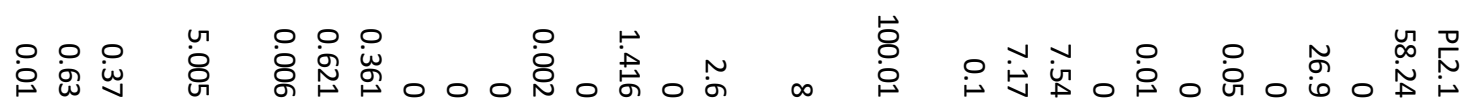

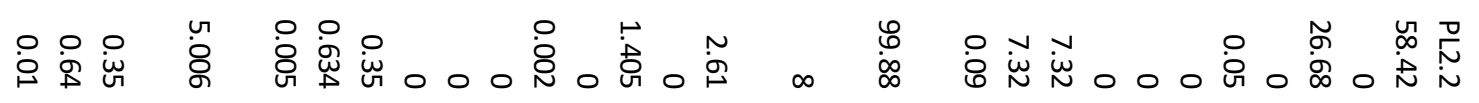

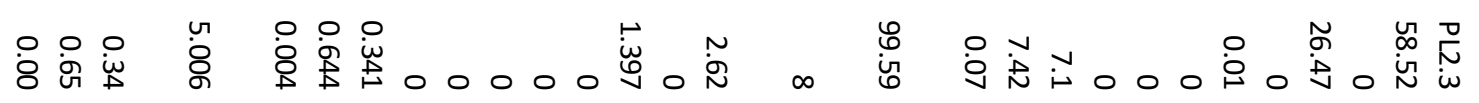

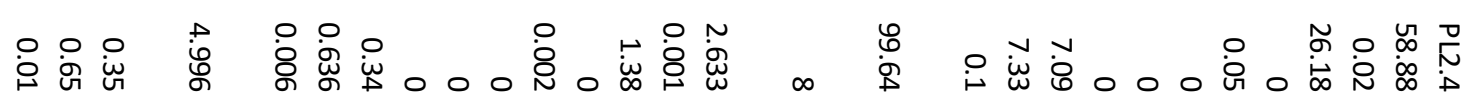

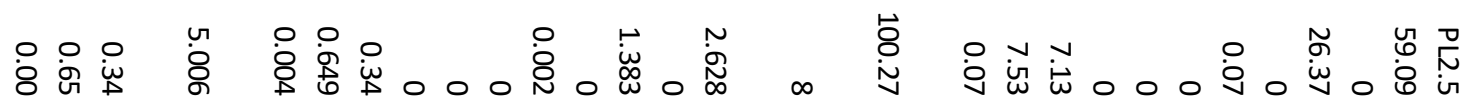

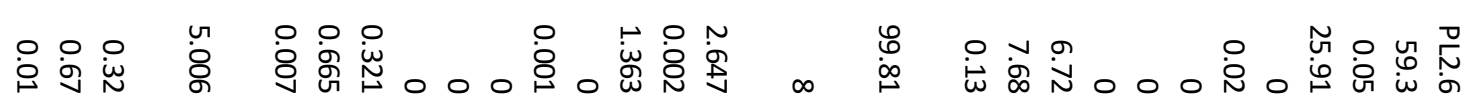




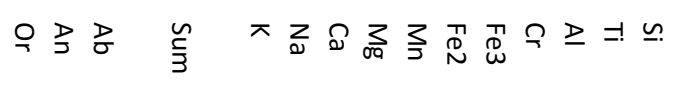

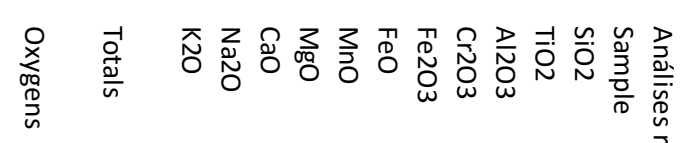

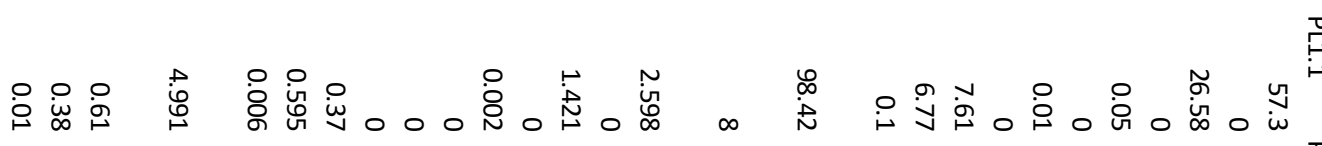

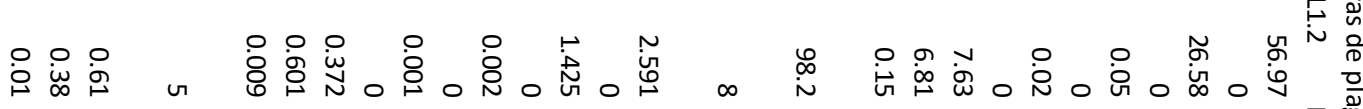

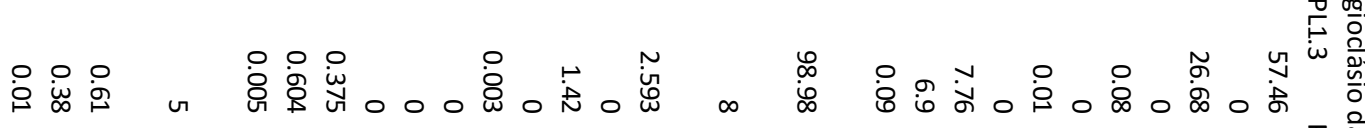

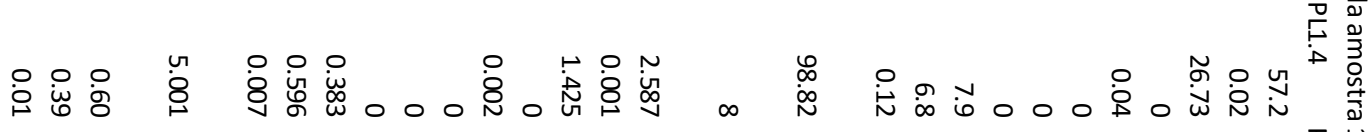

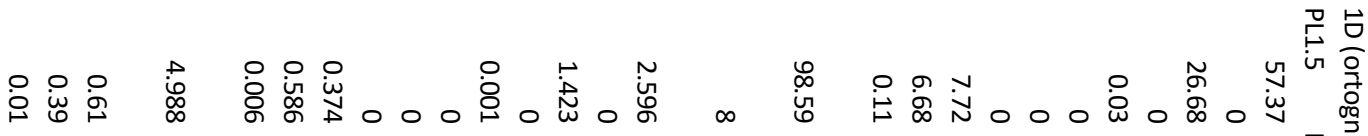

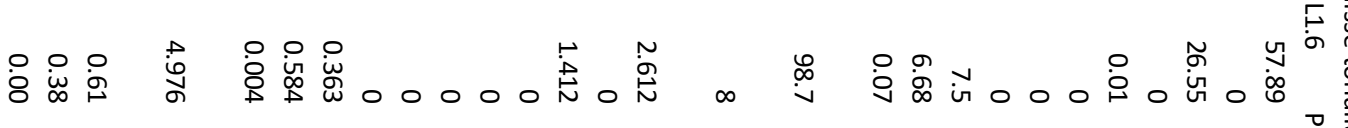

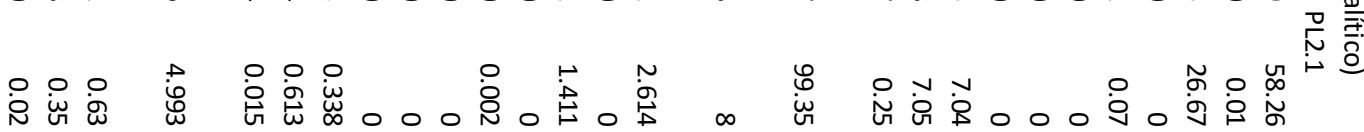

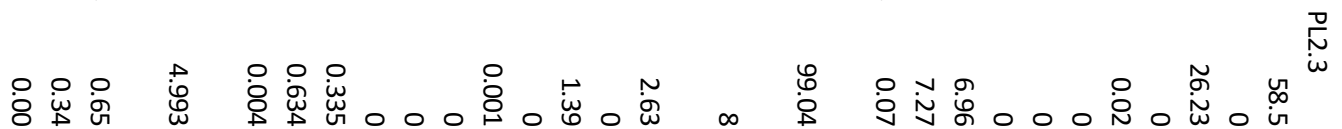

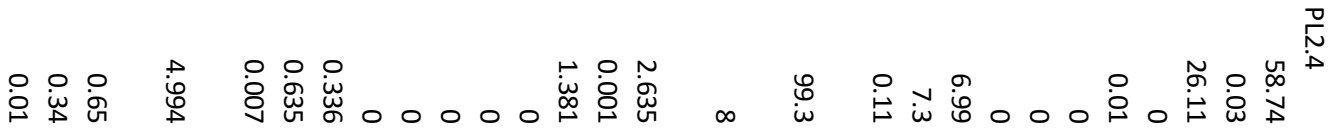

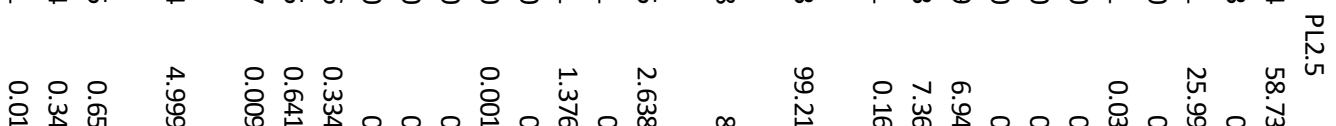

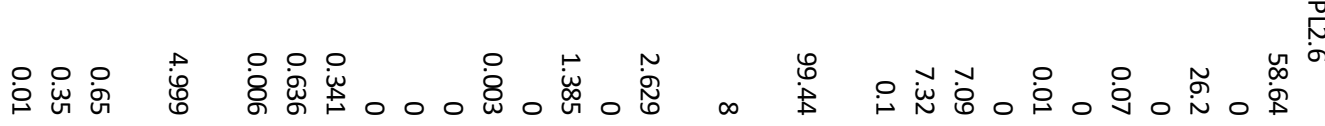

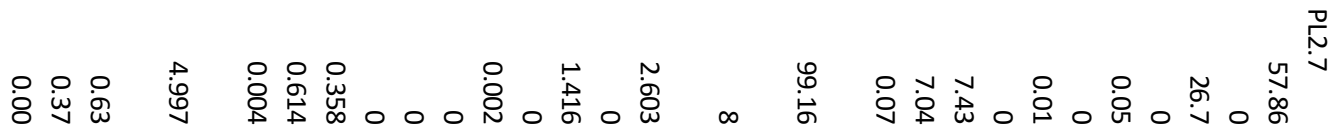

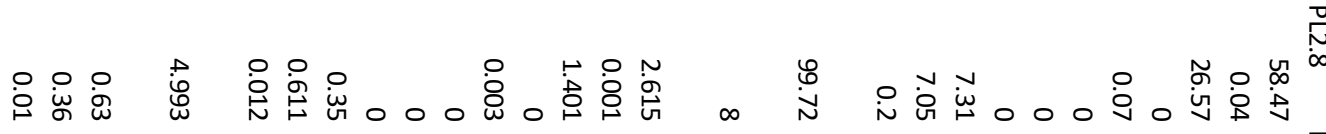

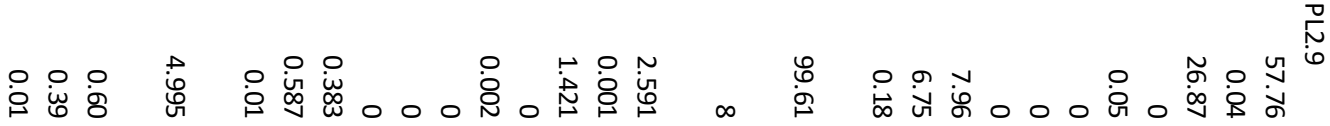

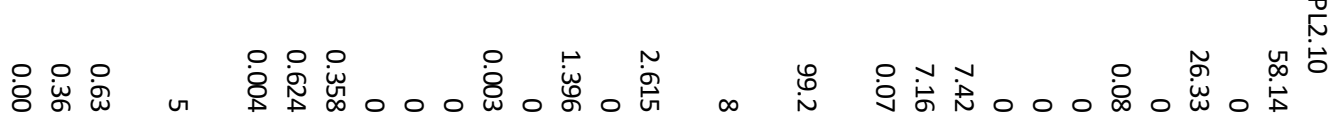

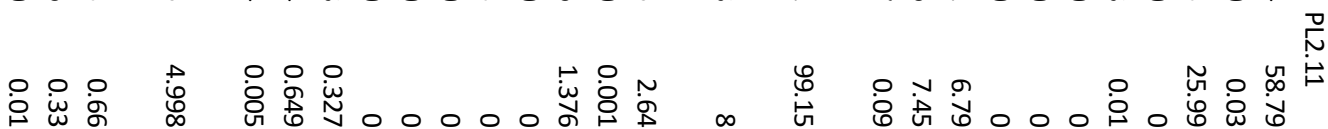




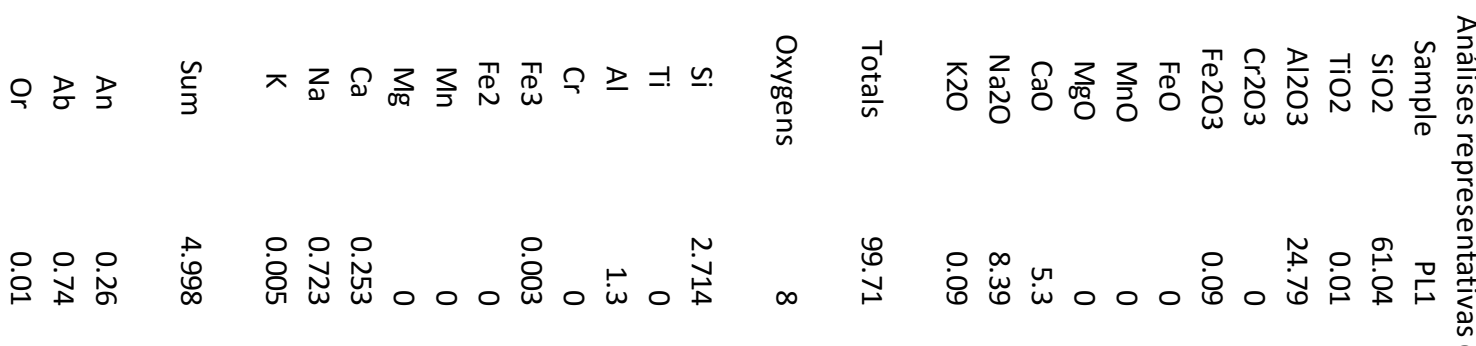

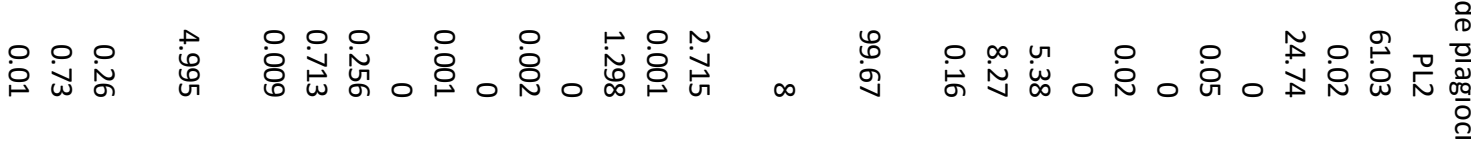

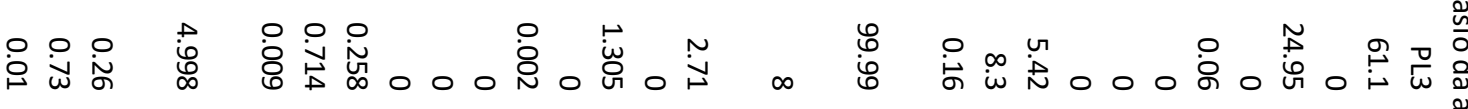

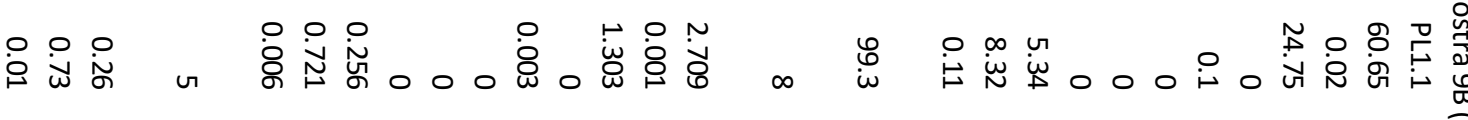

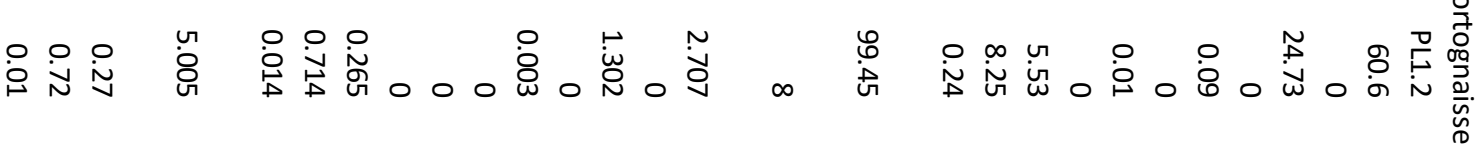

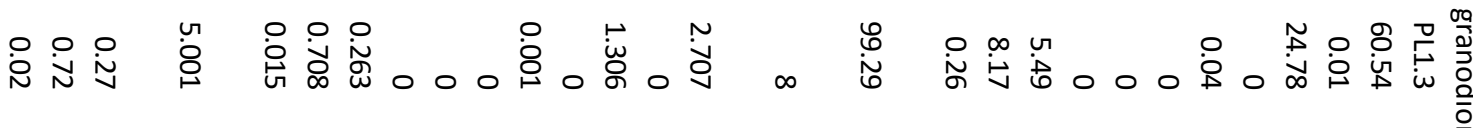

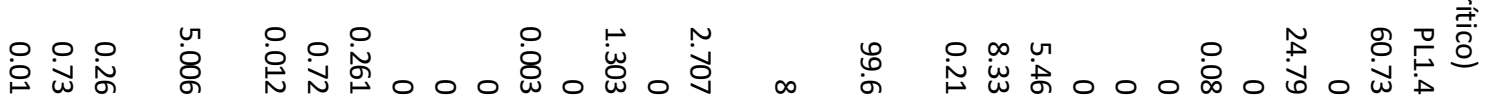

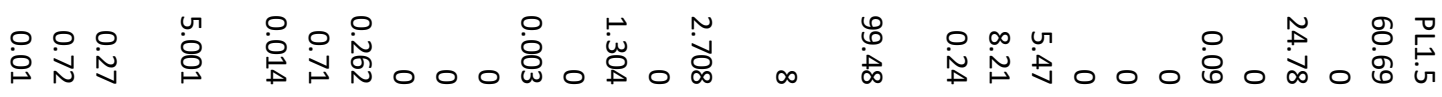

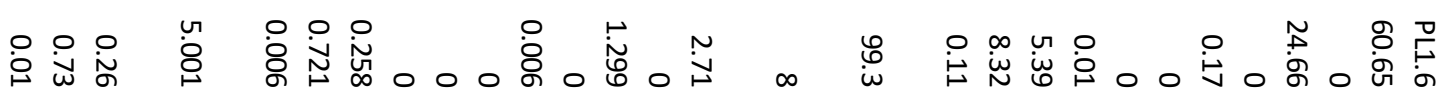

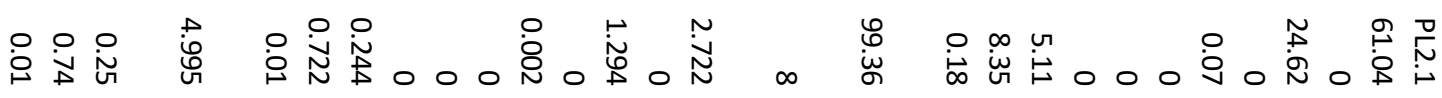

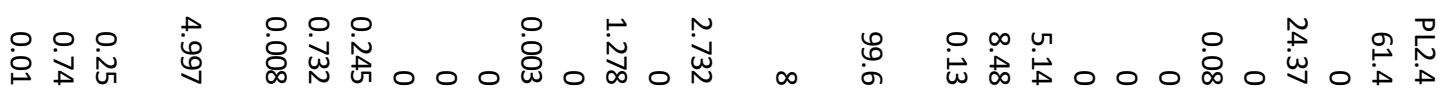

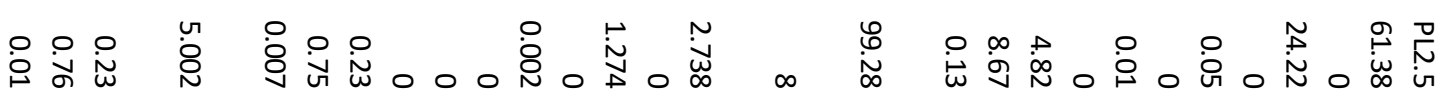

